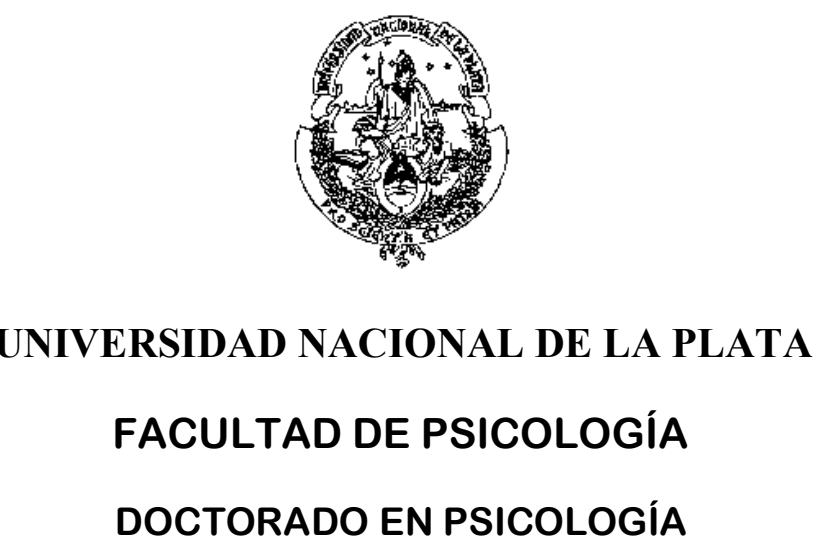

TESIS DOCTORAL

\title{
LAS CRÍTICAS DE POPPER Y GRÜNBAUM AL PSICOANÁLISIS: UN ABORDAJE EPISTEMOLÓGICO DE LA RACIONALIDAD FREUDIANA
}

Doctorando: Mg. MAXIMILIANO AZCONA

Director: Dr. ARIEL VIGUERA

Codirectora: Dra. ANA MARÍA TALAK 
A Julieta, por hacerme vivir la vida desde otro lugar 


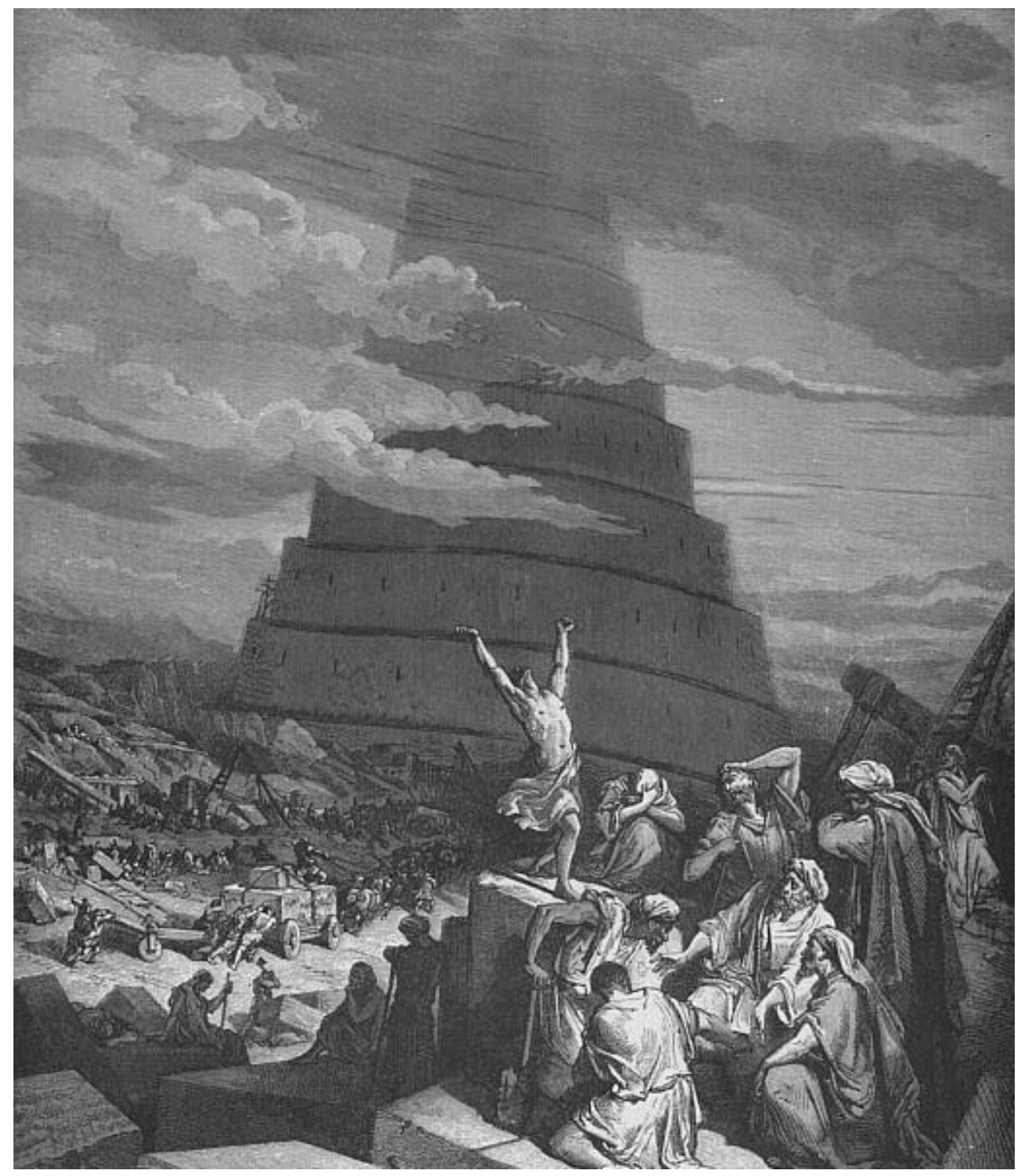

“La confusion des langues" - Gustave Doré (1865-1868)

[Public domain, via Wikimedia Commons] 


\section{ÍNDICE}

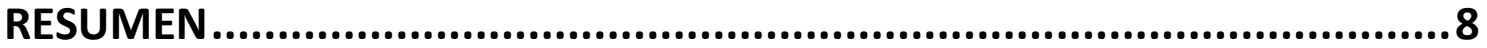

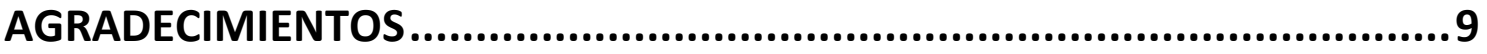

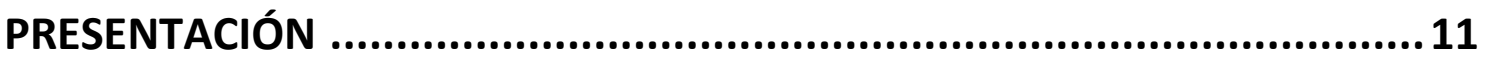

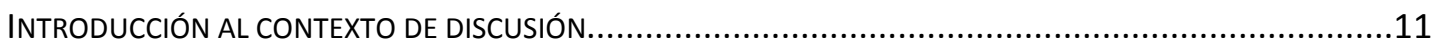

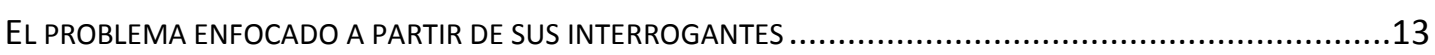

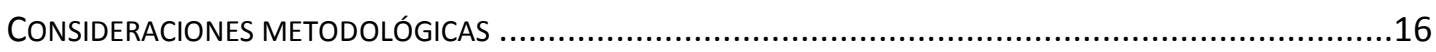

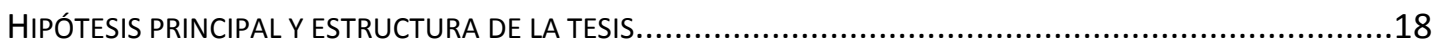

\section{PRIMERA PARTE. DEBATES SOBRE LA NATURALEZA DEL CONOCIMIENTO PSICOANALÍTICO Y SUS METODOLOGÍAS DE INVESTIGACIÓN:}

PANORAMA Y CARTOGRAFÍA.......................................................224

CAPÍTULO 1: DISCUSIONES SOBRE LA NATURALEZA DEL CONOCIMIENTO PSICOANALÍTICO .......................25

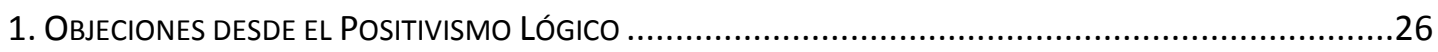

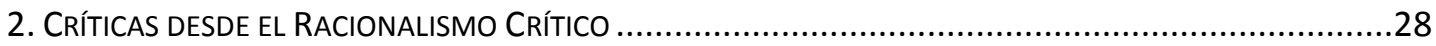

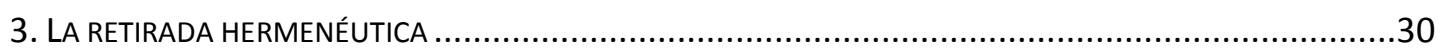

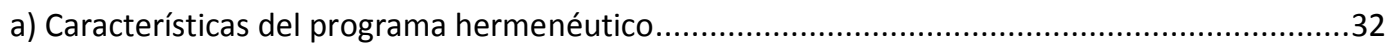

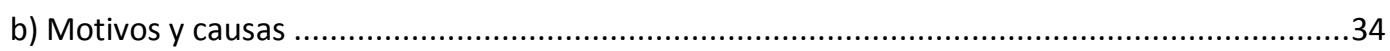

c) Conceptualización hermenéutica de la realidad, la verdad y la validación de hipótesis .............35

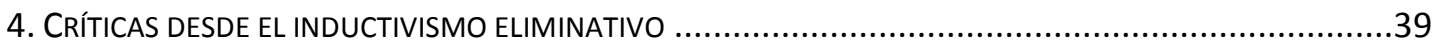

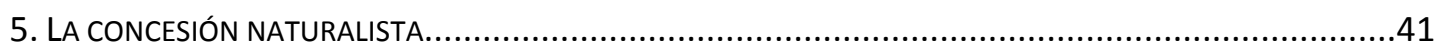

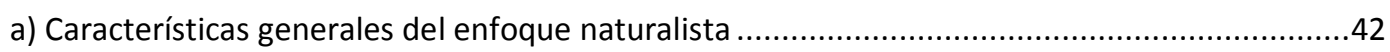

b) Algunos supuestos filosóficos subyacentes a la validación de hipótesis ....................................43

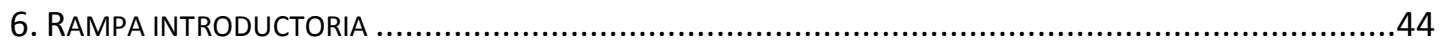

CAPÍTULO 2: DISCUSIONES SOBRE LA NATURALEZA DE LA INVESTIGACIÓN PSICOANALÍTICA....................46

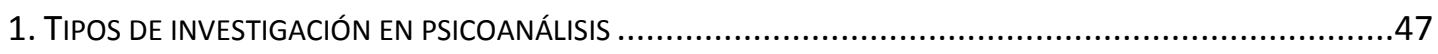



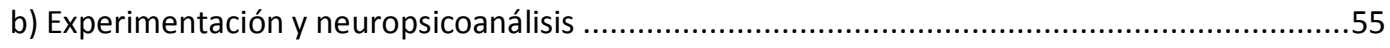

c) Las investigaciones sobre la efectividad del psicoanálisis ....................................................60

d) Las resistencias a la investigación empírica ...........................................................................64

e) La defensa del método clínico psicoanalítico para investigar ....................................................6

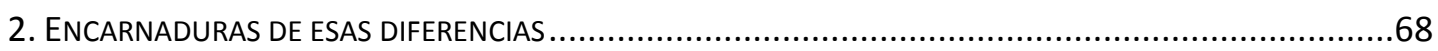

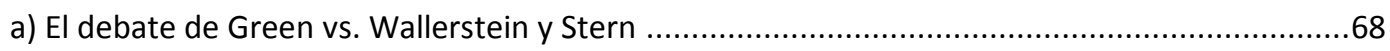

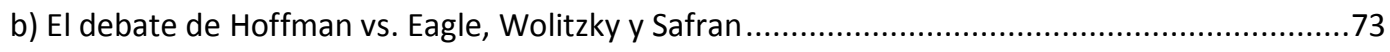

3. SíNTESIS, FOCALIZACIÓN E INGRESO AL TERRENO DE INDAGACIÓN ..............................................87 


\section{SEGUNDA PARTE. EL PSICOANÁLISIS DE KARL POPPER: UNA}

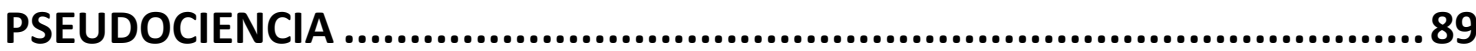

CAPÍTULO 3: EL FALSACIONISMO DE POPPER Y SU CRÍtICA AL PSICOANÁLISIS FREUDIANO. .....................90

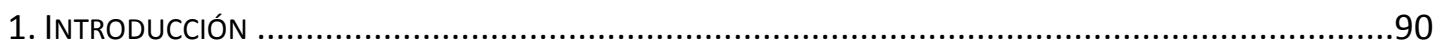

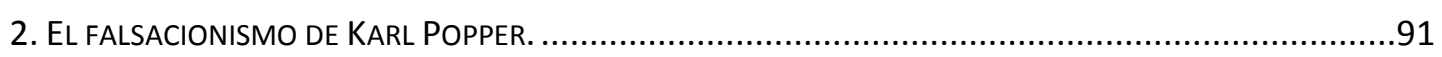

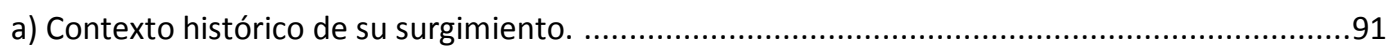

b) Las críticas al inductivismo y al criterio de demarcación positivistas ........................................94

c) El método de las conjeturas y refutaciones como criterio de demarcación ...............................99

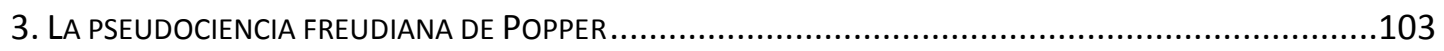

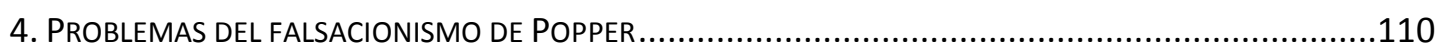

a) Las principales críticas recibidas y las réplicas de Popper. ..................................................110

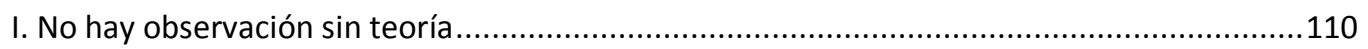

II. El papel de las hipótesis auxiliares en la contrastación....................................................114

III. El comportamiento de los científicos desde la óptica histórica .........................................120

b) La permanencia de los problemas de la inducción y la verosimilitud ......................................125

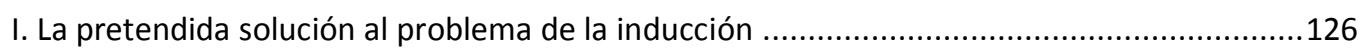

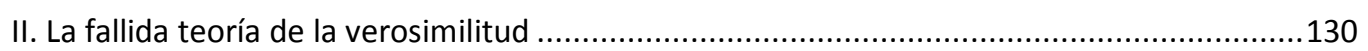

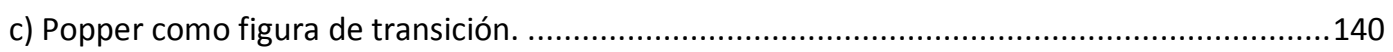

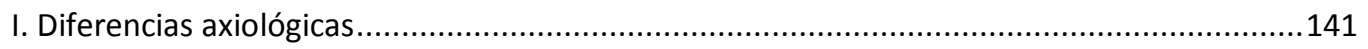

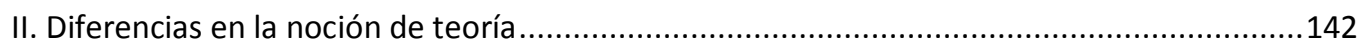

III. Entre el Empirismo Lógico y la "nueva” filosofía de la ciencia .............................................144

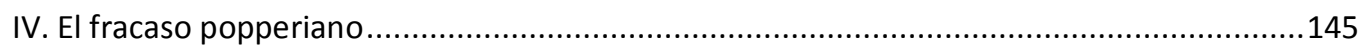

CAPÍTULO 4: ELEMENTOS PARA UNA RECONSTRUCCIÓN DEL PROCEDER FALIBILISTA DE FREUD ................147

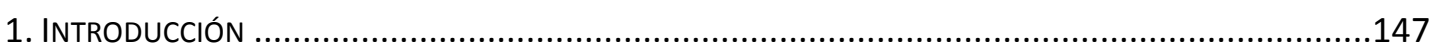

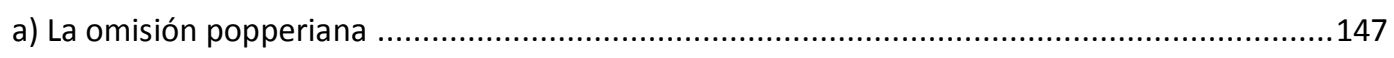

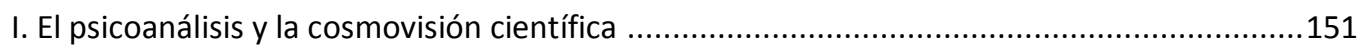

II. La tradición científico-filosófica de Freud: el lugar de la crítica ........................................154

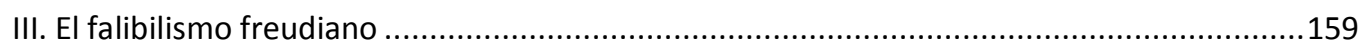

b) Los programas de investigación: una herramienta reconstructiva .........................................162

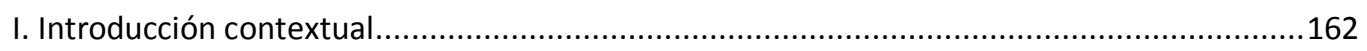

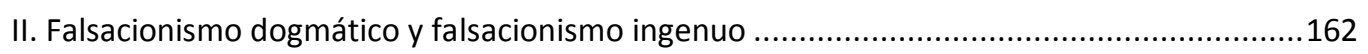

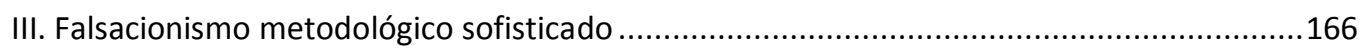

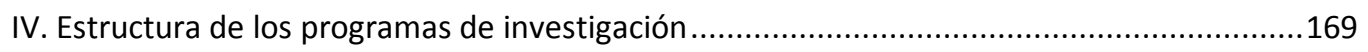

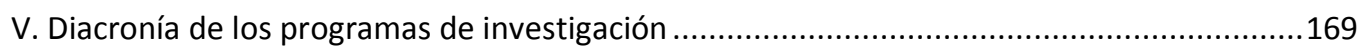

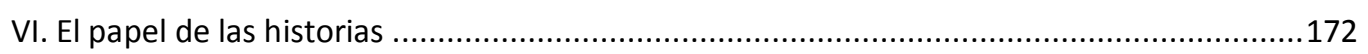

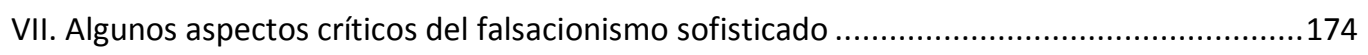

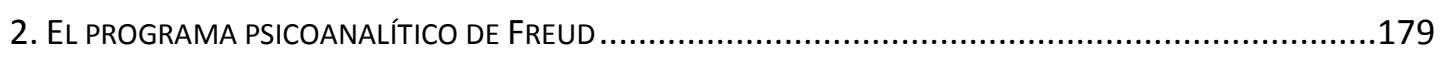

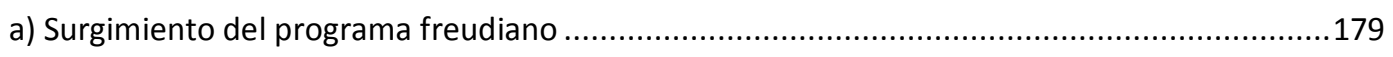

b) Identificación de algunos elementos del programa freudiano...............................................181

\section{CAPÍTULO 5: EL FALSACIONISMO SOFISTICADO DE FREUD: UNA RECONSTRUCCIÓN DE DOS EJEMPLOS DE}

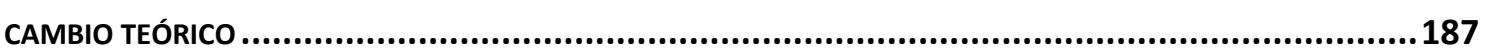

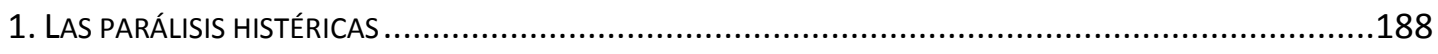

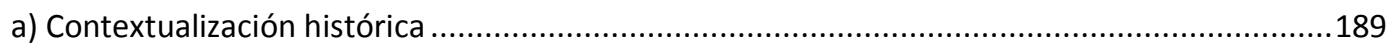

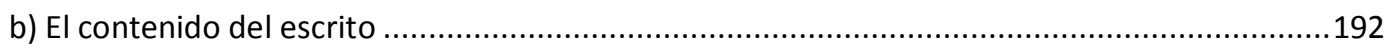

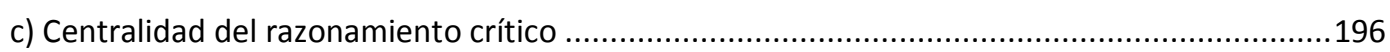




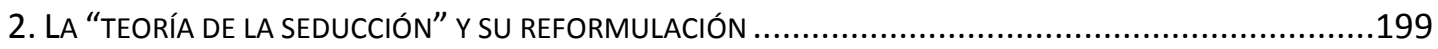
a) El cambio de hipótesis
.202
b) La célebre carta a Fließ y el proceder falsacionista en el cambio ST-FT ...............................203
c) La falsación sofisticada de Freud y la progresividad del programa en el cambio ST-FT............205

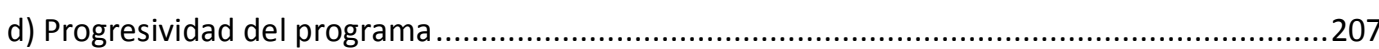
e) El cambio ST-FT, más allá de la contrastación empírica ....................................................210
I. Divergencias en la narrativa freudiana del cambio ST-FT ..............................................211
II. La relación original de Freud con ST y el peso de la crítica ............................................221
III. Otras explicaciones del tránsito ST-FT: el sobrepeso de la historia externa......................227

PRIMERA SÍNTESIS RETROSPECTIVA..............................................................233

1. AlgUNAS CONCLUSIONES PROVISORIAS A PARTIR DEL RECORRIDO REALIZADO ..............................233

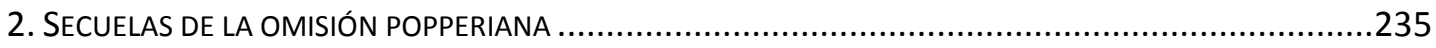

\section{TERCERA PARTE. EL PSICOANÁLISIS DE ADOLF GRÜNBAUM: UNA CIENCIA MAL FUNDAMENTADA ............................................................. 238}

CAPÍTULO 6: EL INDUCTIVISMO dE AdOLF GRÜNBAUM Y SU CRÍTICA AL PSICOANÁLISIS FREUDIANO .......239

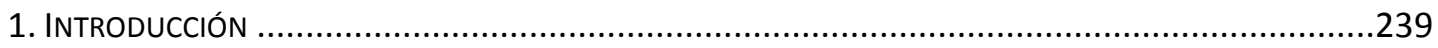

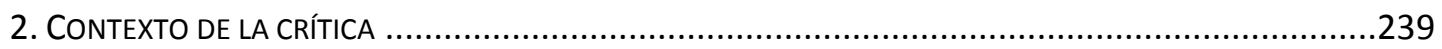

3. El ATAQUE DE GRÜNBAUM A LA TRADICIÓN HERMENÉUTICA.................................................241

a) La crítica a las ideas de Jürgen Habermas.......................................................................243

b) La crítica a las ideas de Paul Ricœur..............................................................................248

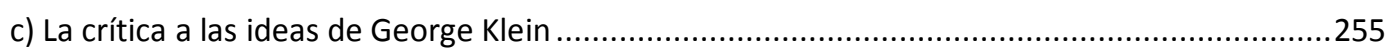

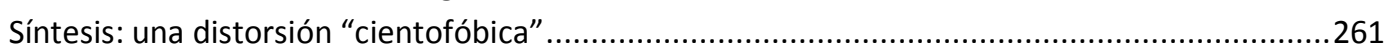

4. EL INDUCTIVISMO ELIMINATIVO COMO MODELO PARA EVALUAR LA RELEVANCIA CAUSAL ...................261

a) La falsabilidad de la teoría psicoanalítica: una vía para criticar el canon de Popper................261

b) El inductivismo eliminativo como criterio de demarcación................................................266

c) El enfoque de Stuart Mill y la inducción eliminativa .........................................................2270

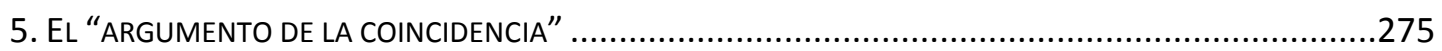

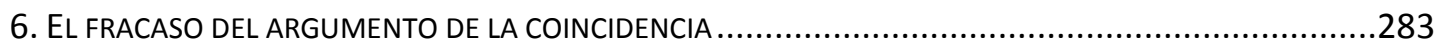

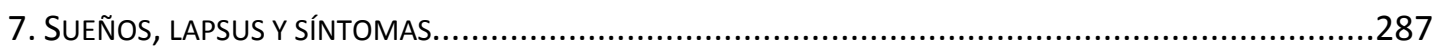

CAPÍTULO 7: ANÁLISIS CRÍTICO DE LA POSTURA DE GRÜNBAUM. ............................................295

1. RÉPLICAS INICIALES A LOS ARGUMENTOS DE GRÜNBAUM.....................................................295

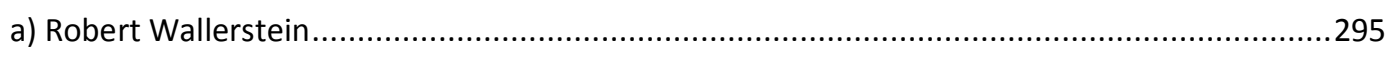

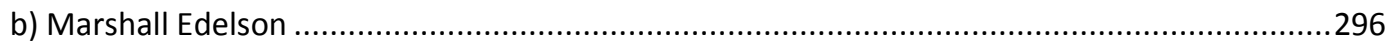

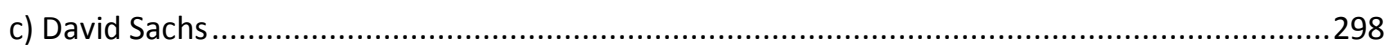

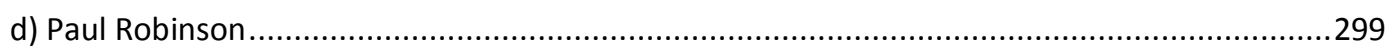

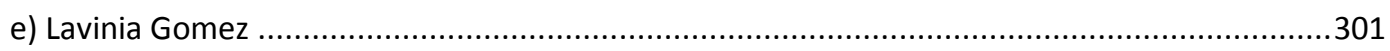

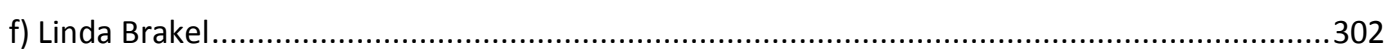

2. EL ARGUMENTO DE LA COINCIDENCIA: ¿UN REASEGURO IMPLÍCITO O UNA FICCIÓN APÓCRIFA?...........302

a) Los argumentos de la coincidencia de Freud y de Grünbaum ..............................................303

b) Una dificultad añadida: la traducción de «Wirklichkeit» ......................................................306

3. LA ASOCIACIÓN LIBRE: ¿UN MÉTODO DEFECTUOSO O UNA TÉCNICA INCOMPRENDIDA? ......................311

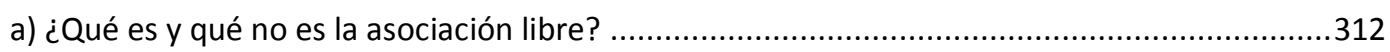

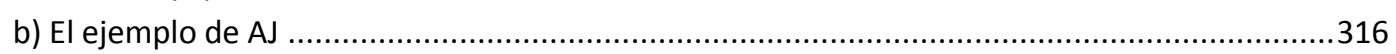




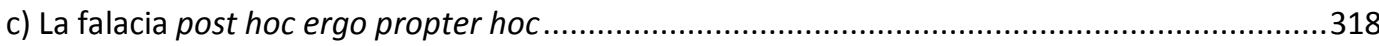

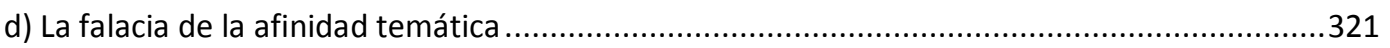

e) La pretensión de certeza y el rechazo de la inferencia a la mejor explicación..........................325

4. LAPSUS Y SUEÑOS: ¿PARÁSITOS EPISTÉMICOS O CONSILIENCIA DE LAS INDUCCIONES?.......................328

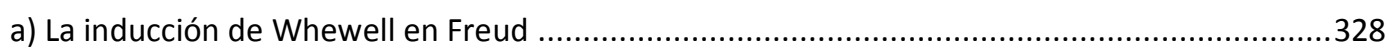

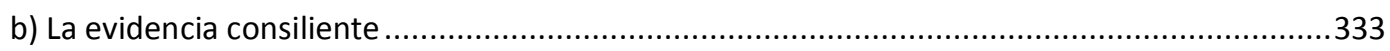

5. ¿DEPENDE LA VALIDACIÓN DEL CONOCIMIENTO PSICOANALÍTICO DE LA EFICACIA TERAPÉUTICA? ..........337

a) La evidencia probatoria que prescinde del éxito terapéutico ...............................................337

b) El éxito terapéutico no es el mejor indicio de validación etiológica .........................................341

c) Evidencia extraclínica contemporánea de la validación teórica .............................................344

d) La función de la metapsicología en la teoría clínica...........................................................347

6. ¿ES EL INDUCTIVISMO ELIMINATIVO UNA PROPUESTA UNIVERSALMENTE VÁLIDA Y PARTICULARMENTE

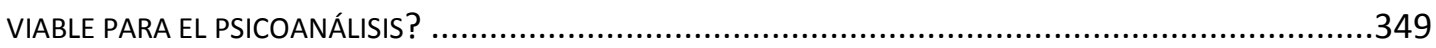

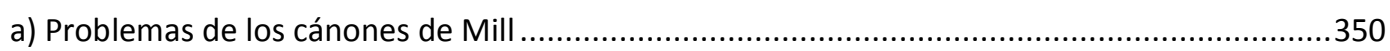

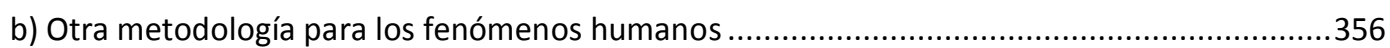

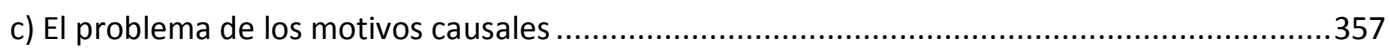

d) Problemas de la aplicabilidad del inductivismo eliminativo al psicoanálisis: presupuestos

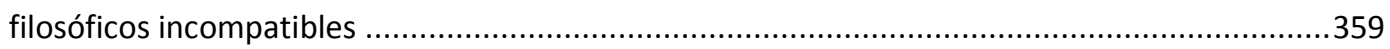

CAPÍTULO 8: UNA LECTURA DEL PROBLEMA METODOLÓGICO DE LA SUGESTIÓN EN PSICOANÁLISIS. .........370

1. ¿ES VÁLIDA LA ACUSACIÓN DE CONTAMINACIÓN EPISTÉMICA VÍA SUGESTIÓN? .............................370

a) Las objeciones de circularidad argumental y de adoctrinamiento ........................................370

b) Las objeciones de Grünbaum están mal fundamentadas ................................................374

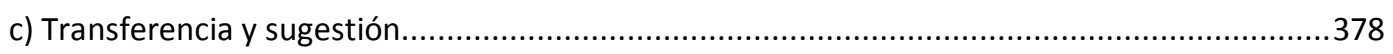

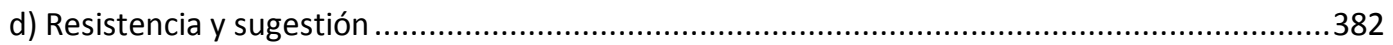

2. UNA REDEFINICIÓN DEL PROBLEMA DE LA SUGESTIÓN EN PSICOANÁLISIS: MINIMIZANDO EL EFECTO

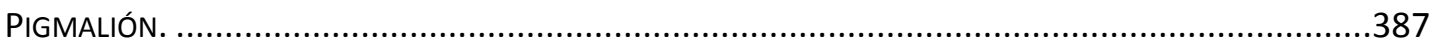

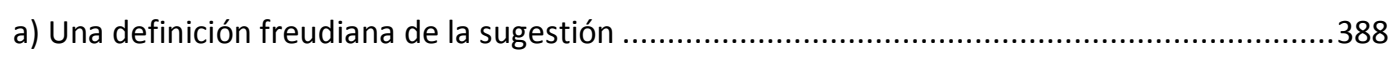

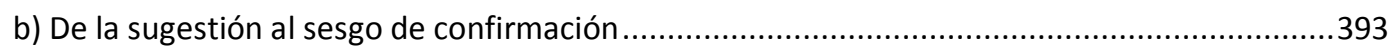

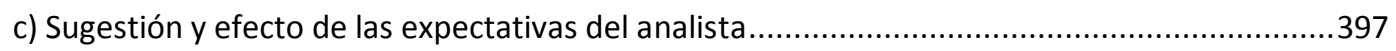

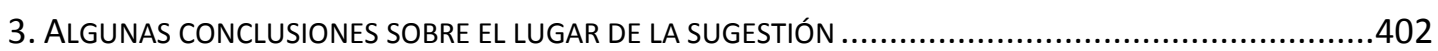

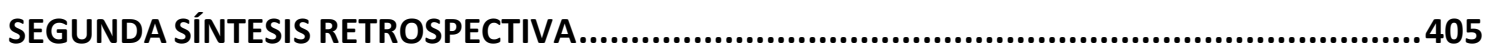

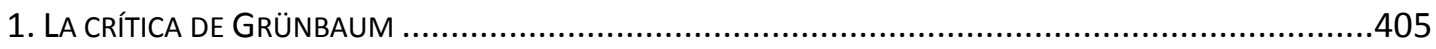

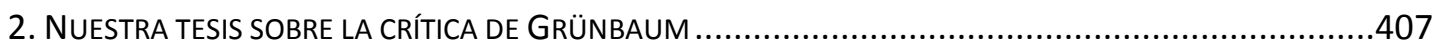

\section{CUARTA PARTE. DE LA RACIONALIDAD DE LA INDAGACIÓN}

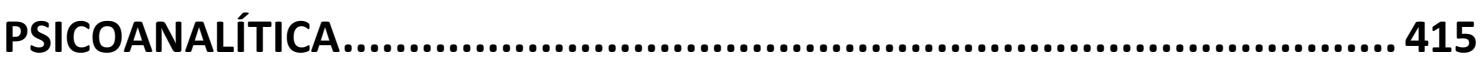

CAPÍTULO 9: ¿ES POSIBLE HACER DEL PROGRAMA FREUDIANO UNA FORMA DE HERMENÉUTICA?..........416

1. DESAVENENCIAS METODOLÓGICAS CON LA HERMENÉUTICA METÓDICA ...................................417

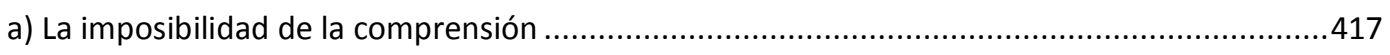

b. Límites de la metáfora exegética ...................................................................................425

c) La co-construcción de un saber hacer .........................................................................428

2. CONFLUENCIAS EPISTÉMICAS CON LA HERMENÉUTICA CONTEMPORÁNEA ...................................431

a) ¿Aporta la hermenéutica filosófica algo decisivo al psicoanálisis? ..........................................432

b) Una propuesta actual para el psicoanálisis: la hermenéutica analógica ................................438 
c) ¿Es entonces el psicoanálisis una antihermenéutica? .................................................443

d) La hermeneutización de la filosofía de la ciencia............................................................449

3. EL DEBATE SOBRE LAS CAUSAS Y LAS RAZONES EN PSICOANÁLISIS ..........................................453

a) ¿Es adecuada la crítica de Grünbaum a la lectura hermenéutica de la causalidad freudiana? 453

b) ¿Suponen las explicaciones freudianas una confusión inviable entre causas y motivos? ........458

c) ¿Sólo puede haber explicaciones causales por referencia a leyes en psicoanálisis? ...............469

4. ALGUNAS CONCLUSIONES SOBRE LA PROPUESTA DE HERMENEUTIZACIÓN DEL PSICOANÁLISIS...............476

CAPÍTULO 10: ASPECTOS LÓGICO-METODOLÓGICOS DE LA ELABORACIÓN TEÓRICA EN PSICOANÁLISIS.....481

1. LA ABDUCCIÓN Y LA INFERENCIA A LA MEJOR EXPLICACIÓN ...............................................483

a) La abducción de Peirce: una lógica del descubrimiento .................................................483

I. Del azar y el instinto a la analogía ........................................................................48

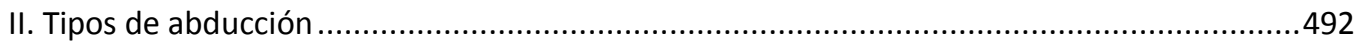

b) Abducción e inferencia a la mejor explicación ................................................................495

c) Anteponiendo la IME a los cánones de Mill ......................................................................505

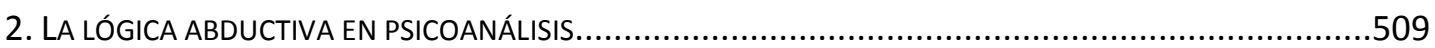

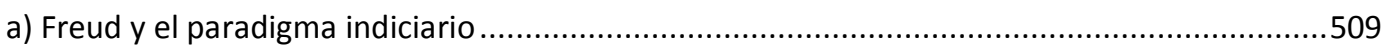

b) Colegir: alcances de la lógica abductiva en el método freudiano........................................515

I. Colegir, interpretar y construir: lógica de la indagación clínica .........................................516

II. Colegir y teorizar: la abducción en el contexto de producción metapsicológica ..................525

c) Vicisitudes de la preciosa conjunción para la investigación clínica ........................................533

3. ASPECTOS DE LA CONTRASTACIÓN CLÍNICA DE HIPÓTESIS ABDUCIDAS ........................................539

a) ¿Impide la materialidad significante, por su condición de tal, su evaluación empírica? ..........540

b) La interpretación clínica como conjetura evaluable: interrogantes al enfoque clásico ............542

c) El valor de los caracteres predesignados en la lógica práctica del analista ............................547

d) Alfredo Reik: ¿es una intervención necesariamente una formulación de la conjetura del analista?

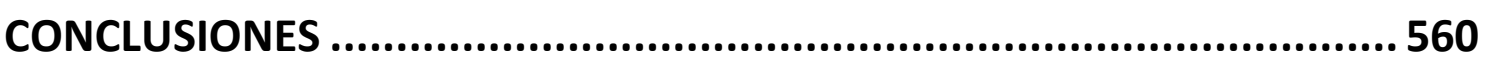

RETROSPECTIVA GENERAL...................................................................................560

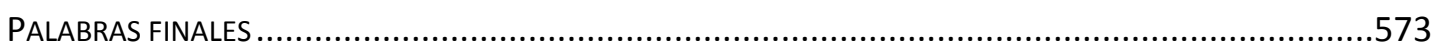

REFERENCIAS BIBLIOGRÁFICAS ................................................5 576 


\section{RESUMEN}

Esta tesis tiene por objetivo principal elucidar y sistematizar una serie de argumentos epistemológicos sobre la racionalidad de los fundamentos freudianos del psicoanálisis, asumiendo que han sido insuficientemente examinados en el ámbito local y atendiendo a las repercusiones que tales argumentos han tenido en diversas latitudes, tanto en los debates por el estatuto identitario de la disciplina como en las discusiones sobre su metodología de investigación.

Se efectúa un análisis teórico-crítico del hipotético-deductivismo de Karl Popper y del inductivismo eliminativo de Adolf Grünbaum, elucidando la viabilidad de sus propuestas y la pertinencia de su aplicabilidad al campo psicoanalítico. También se examinan los argumentos centrales de la tradición hermenéutica en psicoanálisis, sus transformaciones diacrónicas y sus consecuencias para la racionalidad del programa freudiano.

Se concluye que las objeciones principales de Popper y Grünbaum sobre el psicoanálisis resultan, por diversas razones, equivocadas; y también que las pretensiones de redefinición hermenéutica del psicoanálisis constituyen una orientación inviable e innecesaria para la racionalidad freudiana. Se propone recurrir a la filosofía contemporánea de la causación y a la metodología de Charles Peirce para elucidar los aspectos centrales de la génesis y evaluación de hipótesis en psicoanálisis, contribuyendo a una imagen racional de la lógica práctica del proceder clínico, susceptible de proyectarse en desarrollos metodológicos sobre la investigación clínica en psicoanálisis. 


\section{AGRADECIMIENTOS}

Este trabajo es fruto de un sinuoso y arduo trayecto que no podría haber sido recorrido sin el acompañamiento de varias personas, a las que quiero agradecer.

En primer lugar a mi director, Ariel Viguera, por hacerse cargo de guiar un emprendimiento que ya había comenzado y demostrar plena confianza en la labor que yo venía realizando. Pero, sobre todo, por su lectura atenta y por el invalorable carácter de sus observaciones, señalamientos y comentarios. Me resulta difícil expresar con palabras el apoyo transmitido por Ariel en cada una de sus intervenciones, cuyo admirable estilo de dirección trascendía ampliamente el estricto ámbito de los asuntos cognoscitivos de la tesis.

Agradezco también a mi codirectora, Ana Talak, por estar siempre dispuesta a escucharme y orientarme. Sus observaciones, sospechas y comentarios, han sido determinantes para afianzar el rumbo de algunas de mis ideas en esta tesis.

A Rocío Arauco le agradezco por ahorrarme varias penurias administrativas en el Doctorado en Psicología.

Quiero dar gracias a Carlos Escars, esté donde esté, por haberme recibido amablemente en los equipos que coordinaba y por acompañarme en los primeros trayectos de este itinerario.

A la Secretaría de Ciencia y Técnica de la Universidad Nacional de La Plata, por las Becas de Investigación que me fueron otorgadas; y a mis directores de beca, Héctor Lahitte y María José Sánchez Vazquez, por las oportunidades brindadas y por sus interlocuciones con mis primeras ideas sobre estos asuntos.

También va mi gratitud a Marta León, quien supo recibir hace más de diez años a un alumno de psicología con inquietudes un poco raras y guiarlo en sus primeras lecturas de aspectos epistemológicos del psicoanálisis. También le agradezco por tutelar cariñosamente mis primeros pasos en la enseñanza, en la materia de Epistemología y Metodología de la Investigación en Psicología; cátedra en la que sigo disfrutando del oficio de aprender transmitiendo, en esta Facultad. 
A los amigos y compañeros de pensamiento con los que he podido debatir y aprender en diversos contextos paraacadémicos, auténticos e invaluables.

Por último, quiero agradecer especialmente a mi familia. A mi vieja, por mostrarme cómo sobrenadar en los naufragios de la vida; a mi viejo, por haberme enseñado mucho más de lo que sabía y se proponía en vida. También a mi hermana Mariana, cuya absurda ausencia no podrá robarme nunca su sonrisa. A mi hermana Florencia, por el cariño devuelto con su genuina forma de ser.

A mi hermosa hija Julieta, a quien dedico esta tesis, le agradezco haberme cambiado la perspectiva de este viaje y, en consecuencia, de este trabajo de tesis. Quiero agradecer profundamente a Maite, por su constante aliento para que yo termine (de una buena vez) la escritura de las páginas que siguen: no sólo por el valioso tiempo dispensado, sino también porque sus prudentes cuestionamientos a los borradores devinieron, a veces sin que ella lo sospechase, en una interlocución tan saludable como insoslayable para la concreción de mis ideas. Con ella he discutido y revisado todos los temas, por lo que a sus aportes y sugerencias se deben buena parte de los aciertos que pudieran encontrarse en esta tesis. 


\section{PRESENTACIÓN}

\section{Introducción al contexto de discusión}

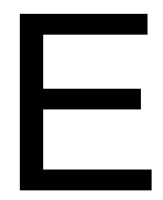

s sabido que las pretensiones de Freud por incluir al psicoanálisis entre las ciencias naturales de su época se vieron rápidamente cuestionadas $^{1}$. De allí en adelante se ha venido discutiendo, con curioso fervor, cuáles son los alcances del tipo de racionalidad inaugurado por Freud y qué posibilidades hay de que su creación pueda ser considerada una disciplina científica. Pretensión que ha sido objetada por una diversidad considerable de opiniones, provenientes de distintos dominios cognitivos. Entre las réplicas más recurrentes suelen mencionarse: a) las procedentes de la filosofía de la ciencia, b) las derivadas de otros enfoques psicológicos y c) las que provienen de algunas orientaciones internas al propio campo psicoanalítico. De las primeras cabe destacar a las críticas de Nagel (1959/1964), Popper (1963/1991), Grünbaum (1984) y Bunge (1985, 2006, 2010). Entre las segundas hallamos las detracciones de psicólogos de diversas orientaciones, entre las que suelen resaltar las de Skinner, (1956/1967); Cioffi (1970); Van Rillaer (1980/1985) y Eysenck (1985/2004). Por último, al interior del psicoanálisis también hay quienes han visto críticamente la relación cienciapsicoanálisis; p. ej. Ahumada, (1997b/1999), Fonagy (1982), Green (1991/1993), Lacan (1966/1992), Laplanche (1995/2001), Wallerstein (2000), entre muchos otros ${ }^{2}$.

\footnotetext{
${ }^{1}$ El propio Freud se lamentaba de ello: "Siempre sentí como grave injusticia que no se quisiese dispensar al psicoanálisis el mismo trato que a cualquier otra ciencia natural" (Freud, 1925b/2004: 54).

${ }^{2}$ Aunque no podemos obviar la existencia de algunas críticas más recientes al psicoanálisis (difíciles de ubicar en nuestra simplificada aproximación clasificatoria), como las encarnadas en El libro negro del Psicoanálisis (Mayer, 2005/2007) o en Freud: El crepúsculo de un ídolo (Onfray, 2010/2011), las desestimaremos debido a que sus estilos argumentativos parecieran guiarse más por afanes persuasivos que por pretensiones elucidatorias.
} 
A diferencia de lo que podría suceder con el desarrollo de otras disciplinas científicas en las que su legitimidad no resulta tan recurrentemente cuestionada, en el psicoanálisis pareciera ser que los problemas epistemológicos y metodológicos han sido un factor determinante para su evolución histórica. Si bien las objeciones a su cientificidad han sido recibidas de muy diversas formas en los ámbitos psicoanalíticos de distintas partes del mundo, han constituido un motor para la toma de posiciones sobre la naturaleza de la disciplina y sobre la forma de continuar desarrollándola. En ese sentido, podemos discriminar dos aspectos generales que servirán para enmarcar nuestro tema:

1) Existe cierto consenso general sobre la evolución histórica del campo psicoanalítico: a pesar de la pluralidad de orientaciones teóricas y su desarrollo interno, cabe la posibilidad de reencontrar al interior del psicoanálisis una oposición entre tradiciones naturalistas y tradiciones hermenéuticas (Strenger, 1991; Bleichmar y Leiberman, 1997; Buzzoni, 2001; Luyten et. al., 2006; Fusella, 2014; Ávila Espada y García de la Hoz, 2014; Erwin, 2015; Aguillaume, 2016). Éstas parecieran ser la cristalización de dos polos opuestos sobre un continuum de perspectivas disciplinares que conviven y evolucionan de manera diversificada. Sin embargo, desde un punto de vista epistemológico, si se consideran determinados criterios, entonces esa diversidad puede ser ubicada por referencia a uno u otro lado de los extremos de ese añejado binomio. Esto es así en la medida en que persisten, de manera transversal, una serie de problemas epistemológicos vinculados a la identidad disciplinar y a la metodología inherente; problemas cuyo despliegue se ha venido produciendo con similares características en el ámbito general de las ciencias sociales ${ }^{3}$ (Von Wright, 1971/1979; Mardones y Ursua, 1982; Velasco Gómez, 2000).

\footnotetext{
${ }^{3}$ Aunque con matices, este fenómeno histórico-epistemológico ha sido referido e historizado a partir de lo que dio en llamarse querella de los métodos: una contienda originada y bautizada en Alemania (Methodenstreit) cuya forma más "sistematizada y dramatizada" coincide con la época del nacimiento del psicoanálisis (Assoun, 1993/2003: 20). Von Wright (1971/1979) ha indagado sus raíces hasta distinguir una tradición galileana opuesta a una tradición aristotélica. Mardones y Ursua (1982), por su parte, plantean que esta controversia ha tenido una evolución histórica en tres fases: 1) el positivismo decimonónico frente a la tradición hermeneútica; 2) el racionalismo crítico frente a la teoría crítica (Popper vs Adorno) y 3 ) los enfoques alternativos vs. el modelo nomológico-deductivo. El conjunto de los debates epistemológicos que dieron origen a esta querella ha ido entreverándose con otros debates más amplios en materia de ontología, gnoseología y ética. Pareciera que estas controversias han tenido raíces más allá del suelo común en el que han planteado abiertamente sus debates. Considérese, por ejemplo,
} 
2) Por otro lado, el entramado de controversias que se desarrollan desde el siglo pasado sobre la identidad disciplinar del psicoanálisis pareciera haber desplazado su foco en las últimas décadas: el debate principal no parece ser el de definir esa naturaleza epistémica sino el de determinar cuáles son las formas legítimas de investigar en la disciplina. Como veremos, si se lo analiza con cierto detalle, el péndulo de esta controversia oscila entre posturas que se originan como respuesta a la controversia anterior: por un lado, los defensores de la exclusividad del método clínico tradicional de estudio de casos y, por otro lado, los promotores de la búsqueda y construcción de otros procedimientos para la producción y/o evaluación del conocimiento en psicoanálisis (Bernardi, 2015; Bornstein, 2001; Eagle y Wolitzky, 2011; Fonagy, 2003; Green, 1996; Jimenez, 2004; Leuzinger-Bohleber, 2015; Perron, 1999; Safran, 2010).

El conjunto de debates epistemológicos sobre la identidad de la disciplina y el conjunto de controversias metodológicas sobre el modo de investigar en este campo, se encuentran íntimamente relacionados. Las posturas argumentativas que podemos hallar al interior del psicoanálisis, parecieran encarnar posiciones argumentativas de una disputa más amplia por la legitimidad del conocimiento en las ciencias de lo humano.

\section{El problema enfocado a partir de sus interrogantes}

En virtud de este estado de cosas, la presente tesis propone un abordaje de las críticas que hicieran Karl Popper y Adolf Grünbaum a la fundamentación epistemológica y metodológica del psicoanálisis freudiano. Ambas posturas, por diversas razones que se mostrarán, han incidido significativamente en la evolución disciplinar de este campo y en los debates inherentes a la construcción de conocimiento dentro y fuera de la disciplina. Ambos autores

la descripción que supo hacer Charles Snow a mediados del siglo XX, destacando que la vida intelectual de la sociedad de occidente se estaba dividiendo cada vez más entre dos grupos extremos: las humanidades y las ciencias; separados por un abismo de incomprensión mutua (Snow, 1959/2000). Lo que problematizaremos para el ámbito del psicoanálisis pareciera ser la expresión de una problemática cultural mucho más abarcativa y profunda de lo que comúnmente se supone. 
constituyen referentes centrales de los dos principales enfoques sobre la fundamentación del conocimiento científico: deductivismo e inductivismo.

El hecho de haber seleccionado el nombre de tales filósofos para titular y vertebrar esta tesis podría alentar una expectativa equivocada sobre la misma, que es necesario desmontar de entrada. Considero, e intentaré mostrarlo durante el recorrido, que el tipo de problemas que ha propiciado la intervención crítica de ambos filósofos en el campo psicoanalítico permanece digno de consideración. Es decir que los nombres propios de estos y otros autores no serán más que puertas de ingreso a un terreno argumental delimitado por debates que, aquí en nuestro margen rioplatense, o bien han sido eludidos 0 bien insuficientemente conceptualizados.

Aunque afortunadamente existen desde las últimas décadas, en algunas orientaciones psicoanalíticas de nuestro margen, paulatinos intentos por explorar, desarrollar y problematizar el campo de la investigación en psicoanálisis y de sus fundamentos epistemológicos (Azaretto \& Ros, 2014; Bernardi, 2014; Cancina, 2008; Etchegoyen, 2001; Maldavsky y Liberman, 2004; Moreira, 2001; Pulice et. al., 2000; Rubistein, 2007; Umérez, 2007), las objeciones de Popper no han sido sistemáticamente respondidas como para que dejemos de sentirnos acechados, cada tanto, por el fantasma de la pseudociencia. $Y$ las objeciones de Grünbaum todavía son prácticamente desconocidas o escasamente abordadas, pese a constituir un conjunto argumental mucho más atendible. Por eso, esta tesis está destinada también a ofrecerle al lector interesado el acceso a una serie de debates y referencias poco conocidas en nuestro ámbito local.

Por factores socio-históricos diversos, creo que la reacción más frecuente de las cofradías psicoanalíticas de nuestro margen rioplatense ante este tipo de problemas ha sido evasiva; reacción que, como cualquier otra, conlleva consecuencias para la postura subsiguiente en las prácticas, a nivel colectivoinstitucional y académico-profesional. Consecuencias que se vuelven imperiosamente atendibles si consideramos la injerencia sumamente significativa que la teoría psicoanalítica ha tenido y tiene en la formación de los psicólogos argentinos (Courel \& Talak, 2001; Dagfal, 2014a, 2014b; Klappenbach, 2003). Persuadido de que es mejor un diálogo frontal que la evasión, en esta tesis voy a partir de una reconstrucción de los argumentos 
adversos de Popper y Grünbaum sobre el psicoanálisis para arribar a una reflexión crítica sobre el entramado de la racionalidad freudiana y su vigencia en los debates arriba mencionados.

Para operativizarlo, a continuación transcribo el problema en algunos interrogantes específicos. En lo que atañe a las objeciones epistemológicas en juego, el interrogante central que guiará nuestra indagación es el siguiente: ¿en qué medida son pertinentes las críticas a la fundamentación del método freudiano basadas tanto en el modelo hipotético-deductivo como en el modelo del inductivismo eliminativo? Considerando que Popper y Grünbaum han sido prolíficos representantes de tales enfoques epistemológicos con indudable vigencia, consideramos que responder a esa pregunta conllevará no sólo un análisis sistemático de sus objeciones sobre el psicoanálisis sino también un descenso a sus presupuestos filosóficos subyacentes. En virtud de que esos enfoques han desestimado históricamente el análisis epistemológico de lo que suele llamarse contexto de descubrimiento, podemos preguntarnos: ¿qué papel ocupan los aportes de la lógica del descubrimiento a la validación del conocimiento psicoanalítico?, ¿qué aportan las inferencias abductivas a la elucidación de la racionalidad freudiana? Además, en virtud de que los debates originados a partir de tales críticas epistemológicas están vinculados, de diversa manera, con la polémica sobre el estatuto identitario de la disciplina, hay algunos interrogantes que parecen salirnos al paso: ¿es necesaria una fundamentación del conocimiento psicoanalítico basada o bien en las premisas de la tradición hermenéutica o bien en el enfoque de las ciencias empíriconaturales?, ¿es posible concebir una identidad epistémica del psicoanálisis sin apoyarse exclusivamente a uno de tales extremos? Finalmente, por derivación de las preguntas anteriores, también intentaremos orientarnos por una última cuestión metodológica: ¿puede la racionalidad de la indagación clínica servir de base para el establecimiento del estudio de casos como única metodología psicoanalítica de investigación?, ¿se requiere, por el contrario, necesariamente de otras metodologías para arribar a una fundamentación racional del conocimiento psicoanalítico? Una intuición que guiará nuestro recorrido es que los interrogantes delimitados no pueden ser abordados aisladamente: han surgido de un entramado común de problemas epistemológicos y metodológicos, por lo que intentar contestar a cualquiera de ellos implicaría 
asumir (explícita o implícitamente) una respuesta para los demás asuntos involucrados.

\section{Consideraciones metodológicas}

Por tratarse de una investigación teórica de reflexión crítica, se hace necesaria la combinación de distintas fuentes de datos, originados desde diferentes orientaciones teóricas y campos de aplicación: en especial la filosofía de las ciencias sociales, la metodología de la investigación científica, la teoría psicoanalítica freudiana y la historia del psicoanálisis. Se privilegiará la sistemática reconstrucción de argumentos y posturas sobre las distintas dimensiones del problema, y la ponderación de las posibles respuestas a los interrogantes en juego mediante el uso crítico de inferencias y la construcción argumentativa.

Como voy a ocuparme de los debates indicados respecto de la racionalidad freudiana, creo conveniente explicitar primero una elección metodológica que me parece lícita pero que, en virtud de los atravesamientos hegemónicos en nuestros ámbitos institucionales, podría no serlo para muchos lectores psicoanalistas. Un supuesto de base que guiará mi investigación y del que podré dar cuenta durante la tesis es que las elaboraciones de Sigmund Freud y de Jacques Lacan deben verse como constituyendo dos programas de investigación claramente diferentes ${ }^{4}$; y no, como común e implícitamente se suele asumir en nuestras latitudes, dos propuestas que estarían en una suerte

\footnotetext{
${ }^{4}$ Este argumento es inmejorablemente desarrollado por Juan de la Cruz Argañaráz, quien analiza en clave lakatosiana las diferencias y semejanzas de ambos programas de investigación. Estoy convencido de la necesidad de insistir en esta idea, entre otras cosas porque "la arquitectura teórica del psicoanálisis freudiano intenta satisfacer los requerimientos de una ciencia natural de base empírico clínica; y la arquitectura teórica del psicoanálisis de Lacan intenta satisfacer los requerimientos del programa fenomenológico existencial y la 'filosofía del ser' heideggeriana" (Argañaráz, 2012: 89-90). Aunque pone el acento en otras premisas, Alfredo Eidelsztein (2015) defiende, desde una singular versión del lacanismo, la misma perspectiva de diferenciación explícita de las teorizaciones de ambos autores. A pesar de que no acuerdo con la exacerbación que hace Eidelsztein de los aspectos biologicistas o esencialistas de Freud, simplificando la complejidad de su obra, ni tampoco coincido con el galileanismo que él parece asumir para hacer pasar por necesaria la tendencia a la formalización matemática en psicoanálisis, no obstante acuerdo y celebro la conclusión a la que llega: no está justificado leer una continuidad natural, a priori, entre los desarrollos conceptuales de Lacan y los de Freud.
} 
de continuidad natural o de armonía conceptual que nos obligara a incluirlas necesariamente en una misma matriz argumental. Aunque la pujanza de la tradición podría hacer que alguien se lamente de que aquí no se aborden ambos programas en conjunto, estoy convencido de que no hay razones epistemológicas para reunir, a priori, la racionalidad freudiana con la racionalidad lacaniana. Reunirlas naturalmente supondría, además, una injusticia epistémica para con otras perspectivas psicoanalíticas (kleinianas, kohutianas, winnicottianas, etc.) que podrían considerarse en derecho de reclamar el mismo privilegio. Aunque siempre será injusto que cada región del saber psicoanalítico se tome a sí misma por patria, creo que el lector podrá convenir conmigo (quizás hacia el final de esta tesis) en que la obra de Freud sigue siendo una referencia ineludible para las principales controversias epistemológicas a las que voy a referirme.

Una aclaración idiomática resulta también oportuna. Aunque gran parte de las fuentes que voy a analizar no ha sido traducida al castellano, he decidido, para las veces que sea necesario hacer citas textuales, no realizarlas en su idioma original (casi siempre el inglés) sino efectuar la traducción correspondiente al castellano. Esto se aclarará en todos los casos y, para que el lector pueda remitirse fácilmente a la fuente cuando lo necesite, se mantendrá el texto original en nota al pie.

Para las citas y referencias voy a emplear el Manual de estilo de la Asociación Americana de Psicología (2010); porque, además de ser uno de los más frecuentemente utilizados en psicología, es con el que personalmente estoy más familiarizado.

Quiero resaltar dos características del espíritu de la indagación propuesta: en primer lugar, en virtud del tipo de problemática en juego, procederé explicitando y elucidando los aspectos filosófico-conceptuales plasmados en cada perspectiva que abordemos, conforme al espíritu general de la filosofía analítica de la ciencia. En segundo lugar, la lectura reconstructiva de argumentos y posturas se orientará por algunos rasgos inherentes del proceder psicoanalítico. Esto quiere decir que se intentarán abordar las posturas de los autores analizados como "textos (necesariamente) sintomáticos", susceptibles de ser deconstruidos, señalando contradicciones, omisiones, puntos oscuros, supuestos no asumidos, etc.; con la esperanza de que tal trabajo permitirá un 
acercamiento más cabal entre los procesos y productos teóricos que serán objeto de análisis.

La perspectiva general que adoptaré sobre la filosofía de la ciencia, que aquí entenderé como sinónimo de epistemología, es caracterizada cabalmente por Ulises Moulines, quien la define como

\footnotetext{
un tipo particular de teorización sobre teorizaciones [...] la filosofía de la ciencia es una interpretación de interpretaciones de la realidad; o bien, para ser un poco más precisos, la filosofía de la ciencia consiste en la construcción de marcos interpretativos filosóficos que nos permiten entender esos marcos interpretativos de la realidad que llamamos «teorías científicas» (Moulines, 1995: 110).
}

Aunque creo que la tarea de la filosofía de la ciencia trasciende la elucidación de la estructura de las teorías, alcanzando también a su utilización práctica, coincido en la ubicación que da Moulines a esta labor de construcción de metainterpretaciones: "dado que estas últimas [las interpretaciones científicas de primer nivel] son objetos culturales, está claro por qué podemos adscribir la filosofía de la ciencia a las ciencias de la cultura o humanidades" (ibíd. p. 113). Asumir cabalmente que la epistemología o filosofía de la ciencia es una disciplina más entre las ciencias de lo humano, puede contribuir al diálogo frontal y sin la presunción clásica sobre pedestales o escalonamientos de autoridad. Además, voy a entender en esta tesis que la labor epistemológica desarrollada desde el interior del psicoanálisis puede contribuir a su devenir en el campo cultural del siglo XXI de manera racional.

\section{Hipótesis principal y estructura de la tesis}

La hipótesis central que pretendo defender en esta tesis es la siguiente: la racionalidad clínica inaugurada por Freud resiste los embates de las críticas epistemológicas de Popper y Grünbaum y, al mismo tiempo, se resiste a ser redefinida en términos hermenéuticos. La complejidad de esta afirmación no podría basarse en un simple razonamiento: será el itinerario de la tesis lo que permitirá ir enlazando el entramado argumentativo para sustentarla. 
Además de la presente introducción, esta tesis consta de diez capítulos y la conclusión. Los capítulos están organizados en cuatro partes con autonomía relativa y una estructura argumental convergente.

La PRIMERA PARTE de la tesis está destinada a orientar el sentido de nuestros interrogantes, cartografiando algunas líneas centrales del complejo territorio al que referimos al inicio de esta presentación. El primer capítulo presenta un breve itinerario de las principales discusiones epistemológicas sobre el psicoanálisis, haciendo foco en la correlación que pareciera haber entre algunas críticas epistemológicas y las distintas formas de concebir la identidad disciplinar. Allí se muestra cómo las principales objeciones han contribuido, en diversos momentos y de diversa manera, a la evolución disciplinar: mientras que por un lado se encuentran aquellos que han asumido e intentado incorporar las diversas objeciones, abogando por una reformulación del psicoanálisis en términos naturalistas; por el otro lado, hay quienes han rechazado la viabilidad de esas críticas a condición de resituar al psicoanálisis por fuera de la órbita de las ciencias y de redefinirlo en términos hermenéuticos. En el segundo capítulo describo cómo el establecimiento de ambas tradiciones ha derivado en dos posturas diversas respecto al modo de desarrollar la investigación: por un lado, los que promueven la implementación de metodologías foráneas y el desarrollo de procedimientos propios para investigar en psicoanálisis $y$, por otro lado, aquellos que defienden la suficiencia del estudio de casos tradicional. El objetivo del capítulo no es otro que el de mostrar cómo, para ambas perspectivas, las objeciones epistemológicas siguen siendo ineludibles: mientras que algunos las adoptan para repensar y redefinir el modo de investigar en el siglo XXI de manera integrada con el resto de las ciencias, para otros esas críticas no se aplican al campo freudiano porque éste da origen a: o bien una hermenéutica o bien una disciplina sui generis, pero no a una ciencia. El panorama expuesto en esta primera parte nos permitirá localizar y justipreciar (quizás retroactivamente) el valor de los problemas que se abordan en las partes siguientes.

En la SEGUNDA PARTE de la tesis se evalúa la crítica de Popper a la teoría de Freud. Nuestra intención primera en esta parte será mostrar que Popper se equivocó al afirmar que la teoría de Freud no era falsable. Resulta evidente que para evaluar la crítica de Popper necesitamos primero presentarla con cierto 
detalle: intentaremos, en el tercer capítulo, considerar y sistematizar los aspectos centrales de su teoría epistemológica, destacando el contexto de su surgimiento y las características distintivas de su propuesta. Sólo así estaremos en condiciones de comprender la trama histórica y la tradición en la que se inscriben las objeciones que serán objeto de nuestro análisis. Pero también de ese modo podremos conocer, además de las virtudes del pensamiento popperiano, sus aspectos más discutibles. Por otro lado, no es menos evidente que para evaluar el valor asertivo de la objeción popperiana, necesitamos también explicitar algunos aspectos de la teoría y metodología freudiana; por lo que, en el cuarto capítulo, se exponen los rasgos centrales de la tradición crítica en la que Freud se formó y la perspectiva que tenía del conocimiento científico. A esas alturas, por razones que se mostrarán, habremos de adherir a la necesidad de trascender la perspectiva de Popper sobre la metodología de la ciencia; por lo cual presentaremos un enfoque alternativo: la propuesta de Imre Lakatos. A partir de allí, se mostrará la posibilidad de concebir los desarrollos teórico-metodológicos de Freud como un programa de investigación.

En virtud de esta reconstrucción, en el quinto capítulo podré mostrar cómo algunos ejemplos concretos de cambio teórico, en la diacronía de las ideas de Freud, se asemejan al proceder del falsacionismo sofisticado. Finalmente concluiremos, entre otras cosas, que el mote de pseudociencia dado por Popper al creador del psicoanálisis no se apoya en datos concretos ni se acerca a su proceder metodológico.

El sexto capítulo abre la TERCERA PARTE de la tesis presentando la postura de Grünbaum: su crítica de las pretensiones hermenéuticas, su caracterización del inductivismo eliminativo y las principales objeciones a la fundamentación freudiana del conocimiento psicoanalítico. Luego, en el séptimo capítulo, analizaré el modo en que están construidos esos argumentos, revisando sus premisas centrales y algunos de los supuestos filosóficos implícitamente asumidos. Intentaré elucidar el valor del bautizado por Grünbaum argumento de la coincidencia en la racionalidad freudiana, así como las relaciones entre eficacia terapéutica y validación teórica. Finalmente, pretenderé mostrar por qué las presunciones ecuménicas del inductivismo eliminativo, en tanto criterio para evaluar la relevancia causal, resultan 
inviables. En función del peso relativo que la acusación de contaminación sugestiva tiene en la crítica de Grünbaum a la validación de los datos clínicos, dedicaré el octavo capítulo a abordar este problema desde un punto de vista diferente y a los fines de desactivar la objeción. Por el recorrido realizado, concluiré la tercera parte de la tesis afirmando que planteamiento general de Grünbaum constituye una crítica epistemológica insatisfactoria.

La CUARTA PARTE de la tesis se ocupa de elucidar algunos aspectos centrales de la racionalidad del conocimiento clínico, cuyos alcances llegan hasta las discusiones sobre la identidad de la disciplina y sobre sus metodologías de investigación. En el noveno capítulo se exponen y revisan los argumentos generales de la propuesta de redefinir, total o parcialmente, la identidad epistemológica del psicoanálisis en términos hermenéuticos. Primero se examinan comparativamente las características y presupuestos del método interpretativo de Freud y del método de la hermenéutica metódica. En segundo lugar, en virtud de que esta última ha sido apenas un punto de partida de la tradición hermenéutica contemporánea, se exponen las transformaciones principales acaecidas en su interior durante el siglo $\mathrm{XX}$, analizando diferencialmente los principales aportes ontológicos y metodológicos que algunos han pretendido desembarcar en el campo psicoanalítico. Se analizan especialmente los aportes de la hermenéutica analógica, cuyos desarrollos recientes han venido a renovar la propuesta de redefinición hermenéutica del psicoanálisis; y también la propuesta de Jean Laplanche de considerar al psicoanálisis como una antihermenéutica, en abierta oposición al planteamiento de Paul Ricœur. Allí también se examina la tesis de la existencia de una hermeneutización de la filosofía de la ciencia, asumiendo que existe un conjunto de supuestos compartidos por las diversas formas contemporáneas de conocimiento científico y dilucidando cómo repercute esta perspectiva en las consideraciones identitarias del psicoanálisis. En tercer lugar, el capítulo aborda específicamente uno de los aspectos centrales de la controversia entre las perspectivas naturalistas y hermenéuticas en psicoanálisis: el tipo de entidades a las que se le otorga relevancia causal y su papel desempeñado en las explicaciones psicoanalíticas. Para ello se recupera la lectura que hiciese Grünbaum de la tradición hermenéutica, enfocando el problema de la distinción causas-razones y la postura asumida por Freud en torno a ello; y, finalmente, 
se exploran aspectos contemporáneos que intersectan algunos problemas del tópico de la explicación científica con el campo de los debates filosóficos sobre la causalidad, tales como las ventajas de la teoría contrafáctica de la causación y el vínculo entre causación y nomicidad; a los fines de indagar la posibilidad de concebir explicaciones genuinamente causales sobre fenómenos clínicos singulares e independientemente del modelo nomológico-deductivo.

El décimo capítulo finaliza nuestro recorrido atendiendo pormenorizadamente a ciertos aspectos lógico-metodológicos de la elaboración teórica en psicoanálisis. En primer lugar, asumiendo a esa altura las limitaciones del deductivismo popperiano y del inductivismo grünbaumiano, se indaga el papel que un tercer tipo de inferencia desempeña en la construcción del conocimiento: la abducción. Se presenta para ello el modelo de Charles Sanders Peirce y el modelo de la Inferencia a la Mejor Explicación, estableciendo una comparación y haciendo hincapié en algunos aspectos relativamente poco considerados. Seguido de ello, se examina el papel desempeñado por la lógica abductiva en psicoanálisis: primero se exponen los principales argumentos que han llevado a reconocer en el método freudiano una adherencia al paradigma indiciario y, luego, se elucida el rol desempañado por la abducción freudiana en el contexto de producción metapsicológica y en la lógica de indagación clínica. Una vez situados algunos elementos de la lógica abductiva del descubrimiento psicoanalítico, se pasan a considerar las posibilidades de poner a prueba el producto de esas invenciones en el contexto clínico del que han surgido: se analiza la tesis de la testeabilidad de la interpretación psicoanalítica y se propone complementarla con algunos aspectos de la lógica inductiva de Peirce que no han sido tenidos en cuenta por los autores que en nuestro campo han planteado esta articulación. Se elucida de este modo una parte de la racionalidad clínica, teniendo en cuenta la presencia combinada de diversos tipos de abducción y la puesta a prueba de conjeturas en el contexto clínico; y se lo ejemplifica con algunos fragmentos de casos clínicos freudianos.

Aunque cada una de las partes conforma una unidad en sí misma con un recorrido argumentativo propio, el entramado urdido converge en un mismo núcleo de aspectos problemáticos: las vicisitudes epistemológicas de la racionalidad freudiana. 
A pesar de la complejidad de los problemas abordados, confío en que el lector podrá acompañarme en la argumentación general. No obstante, debo reconocer que varios de los aspectos analizados durante la investigación permanecerán abiertos para futuras indagaciones y que ninguno de los argumentos esbozados se pretenderá conclusivo. Espero que, más allá de las encrucijadas, el recorrido efectuado nos lleve al lugar que nos hemos propuesto y que termine contribuyendo, de algún modo u otro, a las incursiones futuras por el terreno que nos convoca. 


\section{PRIMERA PARTE. Debates sobre la naturaleza del conocimiento psicoanalítico y sus metodologías de investigación: panorama y cartografía}

"La filosofía de la ciencia sin la historia de la ciencia es vacía; la historia de la ciencia sin la filosofía de la ciencia es ciega" (Imre Lakatos, La metodología de los programas de investigación científica, p. 134).

\footnotetext{
"La historia no es otra cosa que una constante interrogación de los tiempos pasados en nombre de los problemas y de las curiosidades -e incluso las inquietudes y las angustiasdel presente que nos rodea y nos asedia" (Fernand Braudel, El Mediterráneo. El espacio y la historia, p. 7).
} 


\section{CAPÍTULO 1: Discusiones sobre la naturaleza del conocimiento psicoanalítico}

sta parte de la tesis recorre una serie de problemas que convergen en torno a dos cuestiones fundamentales: el estatuto disciplinar del psicoanálisis y la naturaleza de sus metodologías de investigación. En este capítulo introductorio encuadraremos, desde una óptica histórica y de modo panorámico, ciertos aspectos centrales que permitirán contextualizar los diversos aspectos que iremos analizando en el resto de los capítulos.

Tal y como adelantamos en la presentación de la tesis, los debates epistemológicos sobre el psicoanálisis se presentan profundamente vinculados con el desarrollo histórico de sus principales tradiciones de investigación ${ }^{5}$. En virtud de ese entrelazamiento, reseñaré a continuación los hitos destacables de ese devenir. No voy a detenerme en el peculiar desarrollo que las distintas orientaciones teóricas han venido mostrando en el siglo XX y lo que va del XXI, sino que voy a mantenerme en un nivel de análisis que contemple la plataforma metateórica de debates sobre la naturaleza de la disciplina y sobre la naturaleza de su conocimiento, más allá de las subdivisiones internas que se han venido edificando sobre esa plataforma.

Debo advertir al lector que no pretendo afán alguno de exhaustividad histórica ni epistemológica, sino que espero poder representar los accidentes más sobresalientes del terreno en el que voy a transitar. Pienso que puede concebírselo como un proceso cartográfico cuya función no es reflejar el territorio sino brindar la potencialidad de facilitar el recorrido ${ }^{6}$. Voy a privilegiar,

\footnotetext{
${ }^{5}$ La noción de tradición suele referirse a la transmisión transgeneracional del conjunto de acervos constituyentes de una identidad cultural. Voy a utilizar el sentido metafórico que Larry Laudan le otorga para su análisis sobre el progreso de las ciencias: "...una tradición de investigación es un conjunto de supuestos generales acerca de las entidades y procesos de un ámbito de estudio, y acerca de los métodos apropiados que deben ser utilizados para investigar los problemas y construir las teorías de ese dominio" (Laudan, 1977/1986: 116).

${ }^{6}$ Asumiendo que "lo real-objetivo permanecerá siempre «no discernible» (Freud, 1937b/2004: 198), convendría recordar que "el mapa no es el territorio" (Korzybski, 1933/1994). En virtud de mi punto de vista, desestimo a priori la pretensión de ese tipo de mapa imposible que Jorge
} 
por lo tanto, una visión panorámica de amplias regiones; incluso de aquellas que, aunque no vayan a ser transitadas en la tesis, será necesario conocer y representar a los fines de una mejor orientación relativa.

\section{Objeciones desde el Positivismo Lógico}

La opinión adversa sobre el psicoanálisis que algunos como Skinner y Eysenck mantuvieron puede considerarse, por provenir de programas rivales al psicoanálisis (en sentido lakatosiano) con intereses particularmente contrarios, demasiado sesgada desde el origen. Diferente pareciera ser la perspectiva adoptada por ciertos representantes del Positivismo Lógico, que efectuaron algunos análisis parciales de determinados aspectos del psicoanálisis a partir de una concepción sintáctica de las teorías, que intentaban promover.

Podemos fijar un principio del debate abierto sobre la cientificidad del psicoanálisis en ocasión de un simposio celebrado en Nueva York en 1958, titulado Psicoanálisis, método científico y filosofía (Hook, 1959/1964). La cuestión central que allí se planteó fue: ¿es científica o no la teoría psicoanalítica? A pesar de que el Positivismo Lógico, en tanto perspectiva filosófica hegemónica hasta ese momento, ya había mostrado la endeblez de sus cimientos, todavía aportaba las principales claves de lectura para cualquier filosofía general o particular de la ciencia y por eso se impuso naturalmente como criterio de demarcación de lo científico. Gran parte de los filósofos de la ciencia allí congregados declararon que el psicoanálisis no podía considerarse una disciplina científica.

Ernest Nagel (1959/1964) representa bien esta línea de fuego al haber planteado dos tipos de objeciones: una relativa a la estructura lógica de la metapsicología psicoanalítica y otra inherente a la evidencia que permite fundamentar la teoría y a la metodología empleada para obtenerla. Algunas de las dificultades denunciadas respecto del primer tipo de objeción, son: a) que la teoría psicoanalítica no satisface los requisitos esenciales para ser capaz de

Luis Borges le adjudicó al rigor de la ciencia: un mapa que, desplegado, coincidía inútilmente con el imperio mismo que pretendía representar (Borges, 1998/1960). 
confirmación empírica; b) que las principales hipótesis metapsicológicas, junto con sus reglas de correspondencia, son ambiguas e imprecisas, por lo que su utilización termina basándose en decisiones arbitrarias; c) que la forma de implementación de metáforas en el lenguaje de la teoría psicoanalítica es demasiado vaga como para operacionalizar los conceptos de una manera unívoca, por lo que existe el riesgo de que cada analista complete esa falta de contenido con sus propias fantasías; d) que la teoría freudiana postula, a pesar de sus pretensiones futuras de reducción biológica, una variante del denominado fantasma en la máquina ${ }^{7}$.

El otro tipo de dificultades remite a diversos problemas metodológicos, tales como: a) que el encuadre de la sesión no permite determinar con precisión en qué medida los prejuicios del analista intervienen en las interpretaciones de los datos clínicos, pues su carácter privado impide la corroboración por parte de otros investigadores. b) En virtud de que el material clínico de un caso permite distintas interpretaciones coherentes, la coherencia no puede ser el único criterio para evaluar su verdad. c) Los resultados terapéuticos no son siempre exitosos, etc.

Aunque la filosofía de la ciencia del Positivismo Lógico puede considerarse un programa abandonado (Diez y Moulines, 1997; Suppe, 1979), no parece estar claro hasta qué punto este tipo de objeciones puede considerarse completamente inviable. De hecho, como tendremos oportunidad de ver, casi todas ellas reaparecen, aunque quizás no en los términos del Positivismo lógico, contempladas de un modo $\mathrm{u}$ otro en los debates futuros.

\footnotetext{
${ }^{7}$ Nagel asume, equivocadamente por cierto, que la concepción freudiana implicaría o tendría implícita la postura dualista de la denominada por Gilbert Ryle (1949/2005) doctrina oficial del dogma del fantasma en la máquina (expresiones con la que Ryle definió y rechazó al dualismo cartesiano). Décadas más tarde, Mario Bunge esbozará una crítica similar al psicoanálisis, a los fines de proclamar que la única psicología científica debe basarse en la Psicobiología: desde un enfoque monista, lo único que interesa es el vínculo del sistema nervioso central con el resto del cuerpo. Cualquier pretensión de cientificidad para lo psíquico debe basarse en la investigación de los procesos cerebrales. Desgraciadamente, Bunge desconoce que por ahí comenzó Freud y que el necesario abandono de ese camino lo condujo a forjar una nueva racionalidad de lo humano.
} 


\section{Críticas desde el Racionalismo Crítico}

Por razones no epistémicas, aunque las objeciones de Karl Popper al psicoanálisis fueron anteriores a las de Nagel, se difundieron más tardíamente ${ }^{8}$. Rechazando los criterios del Positivismo Lógico y proponiendo otros, el filósofo vienés expresó sin ambages que el requisito de falsabilidad está ausente en el psicoanálisis. Simultáneamente denunció que la teoría de Freud se basaba en el criterio inductivo-verificacionista, objeto predilecto de la denostación falsacionista. En los ojos de Popper, el psicoanálisis (junto al marxismo y la astrología) en lugar de disponerse a refutar sus enunciados hipotéticos, los confirma con pretendidas verificaciones; y es de allí que obtendría (basándose en la inducción enumerativa) las credenciales de cientificidad. Además, salvaguarda cualquier evidencia empírica refutatoria mediante la introducción de hipótesis auxiliares ad-hoc, lo cual implica una estrategia ilegítima para Popper y constituye el centro de su noción de pseudociencia: todo conjunto de enunciados que, independientemente de su racionalidad o verdad, evita dar lugar a meticulosas contrastaciones empíricas y/o carece de una clase no-vacía de falsadores potenciales.

La temprana crítica de Popper se consolidó como una de las principales objeciones al carácter científico del psicoanálisis y ha sido retomada por casi todos los filósofos o psicoanalistas que posteriormente se han referido al tema. Pese a su ubicuidad, dicha crítica no ha recibido siempre la misma valoración y aún en las últimas décadas persisten posturas antagónicas sobre su pertinencia. Algunos consideran que la "prueba de la falsabilidad" es inaplicable al psicoanálisis, porque analista y paciente no se hallan "en el mismo plano de

\footnotetext{
${ }^{8}$ La caracterización del psicoanálisis como una pseudociencia es efectuada originalmente por Popper en su célebre Logik der Forschung, cuya primera versión fue publicada en 1934 y en alemán. Sin embargo, su difusión se produjo mucho después, una vez que el autor abandonase Austria (justo antes de la invasión Nazi) y emigrara a Nueva Zelanda, lugar desde el que reescribiría el libro en inglés para publicarlo en 1959 con el título The Logic of Scientific Discovery. Pese a que esa segunda publicación es la que se ha vuelto sumamente conocida, no debemos olvidar que su versión original es anterior y que, por lo tanto, contiene las primeras objeciones epistemológicas al psicoanálisis. Estas circunstancias históricas han confluido, junto con otras, en un malentendido mayor: la atribución peyorativa del mote de "positivistas" a un vasto y difuso conjunto de perspectivas, entre las que se verían incluidos desde los Empiristas Lógicos hasta Popper. Aunque Popper comparte una serie considerable de presupuestos filosóficos con varios de los representantes del Positivismo Lógico, veremos en la parte siguiente de la tesis el modo en que ambas perspectivas difieren en sus aspectos centrales y por qué es incorrecto homologarlas.
} 
racionalidad" (Green, 1991/1993: 186); mientras que otros ${ }^{9}$ consideran que "es fecundo pensar la teoría en términos de falsación" (Laplanche, 1997/1998).

En nuestra región, por ejemplo, hallamos opiniones opuestas incluso entre epistemólogos que han adherido al espíritu de la propuesta popperiana: mientras que algunos, como Mario Bunge, acuerdan y redoblan la crítica de Popper al psicoanálisis (Bunge, 1977/1980: 127; 1985: 81-95; 2001: 232-237; 2006: 200-205; 2010: 44), otros, como Gregorio Klimovsky, la consideran infundada por desconocer o distorsionar el proceder del creador del psicoanálisis (cf. Klimovsky, 2009; en donde se compilan los trabajos del autor sobre el tema). No pareciera haber, sin embargo, trabajos sistemáticos que analicen estas críticas desde el interior del psicoanálisis. Considerando la vigencia del modelo hipotético-deductivo en nuestros días, los interrogantes por la factibilidad y el alcance de la crítica de Popper permanecen meritorios de consideración. A ello nos abocaremos en la segunda parte de la tesis.

Hoy podemos afirmar que esa imagen del psicoanálisis como una pseudociencia no se condice con el creciente número de investigaciones empíricas sobre las teorías y las técnicas en nuestro campo. Lo que voy a intentar mostrar es algo no suficientemente tenido en cuenta: que el proceder mismo de Freud, junto con las inconsistencias de la filosofía de Popper, ya eran suficientes para cuestionar esa acusación desde mucho antes de que las investigaciones empíricas de las últimas décadas fueran siquiera imaginadas. $\mathrm{O}$, lo que es otra forma de decirlo, que la racionalidad freudiana es una propuesta falibilista desde el principio e independientemente de los modos en que se haya recogido su legado.

\footnotetext{
${ }^{9}$ Jacques Lacan, por ejemplo, ya avanzada su enseñanza sostuvo: "el psicoanálisis debe ser tomado en serio, aún cuando no sea una ciencia [...] como lo ha mostrado abundantemente un llamado Karl Popper, es que no es una ciencia porque es irrefutable." (Lacan, 1977/1978: 1). [...la psychanalyse est à prendre au sérieux bien que ça ne soit pas une science [...] comme l'a montré surabondamment un nommé Karl Popper, c'est que ce n'est pas une science parce que c'est irréfutable.]
} 


\section{La retirada hermenéutica}

Ante críticas filosóficas como las anteriores gran parte de la comunidad psicoanalítica pareciera haber visto amenazado su estatus científico y haber asumido que el psicoanálisis debía ajustarse a los parámetros hegemónicos de la ciencia empírico-natural: organización sintácticamente unívoca de la teoría, cuantificación de las variables que se vinculan en los conceptos, corroboración empírica de las hipótesis (en poblaciones suficientemente grandes) con la mayor exactitud posible y determinación precisa de las condiciones de refutabilidad (lo que equivaldría a decir, para muchos, de cientificidad), a los fines de alcanzar explicaciones nomológico-subsuntivas basadas en leyes causales confirmadas. Todo esto bajo la suposición de que si no lograba consolidarse como una ciencia, entonces perdería su valor.

Hubo teóricos famosos que insistieron en consumar las pretensiones freudianas, asumiendo que el psicoanálisis es, pese a las críticas, una "ciencia natural de lo anímico"10 (Hartmann, 1927: 13). Legitimando a su propio verdugo, algunos analistas se vieron en la necesidad de clarificar las hipótesis metapsicológicas para que sorteasen el obstáculo epistemológico. La obra de David Rapaport (1960/1067) puede verse como un intento emblemático por dialogar sumisamente con la concepción heredada de las teorías. Allí se percibe un ensayo por mantener el entramado conceptual de la metapsicología, a la par de delimitar su contenido empírico en términos de variables controlables y de observación directa.

Paradójicamente, fueron los propios colaboradores de Rapaport, Merton Gill (1976), George Klein (1976a), Roy Schafer (1976), Donald Spence (1984) y Philip Holzman (1985), algunos de los que tomaron una dirección contraria: criticando la concepción biologizante de la metapsicología (fundamentalmente el supuesto de una energía psíquica), atribuyeron a Freud un malentendido cientificista y rescataron el método clínico con exclusivo hincapié en el significado idiosincrático de las experiencias singulares. Denunciaron en Freud una flagrante contradicción entre su manera de teorizar (metapsicología tendiente a buscar causas del comportamiento, dando respuestas a las

\footnotetext{
10 "Die Psychoanalyse, als Naturwissenschaft vom Seelischen..."
} 
preguntas por el "como") y su manera de proceder en la clínica (tendiente a buscar razones que permitan responder a preguntas sobre el "por qué" de la conducta). Esta contradicción habilitaba el desarrollo de un psicoanálisis hermenéutico, en tanto que su germen se hallaba en la obra del propio creador (aunque esa posición no fuera asumida por él). Por esta vía, el psicoanálisis quedaba ubicado en un ámbito diferente al de las ciencias naturales, puesto que privilegia el abordaje del sentido. Su metodología no debía, por lo tanto, emular los procedimientos naturalistas sino arribar a una fundamentación hermenéutica.

La versión hermenéutica o narrativa del psicoanálisis comenzó a esbozarse desde la década de 1960 y tuvo por puntapié inicial el desarrollo epistemológico de algunos filósofos como Jean Hyppolite (1965), Paul Ricœur (1969/2006) y Jürgen Habermas (1968/1990); que se apoyaron en las implicancias de la distinción entre ciencias de la naturaleza y ciencias del espíritu, sostenida por autores como Wilhelm Dilthey (1883/1949), Heinricht Rickert (1899/1943), Ernst Cassirer (1942/1973) y Robin Collingwood (1946/1952). Se dio lugar a una reformulación del programa original de Freud a los fines de dar respuestas legítimas a las demandas epistemológicas: se trató de un intento por ubicar al psicoanálisis fuera de la órbita de las discusiones sobre su cientificidad, aduciendo que es una disciplina exegética distinguible de las ciencias naturales a las que no debería aspirar a pertenecer. Coincidimos con Carlo Strenger en que

\begin{abstract}
La concepción hermenéutica del psicoanálisis es en gran parte un intento radical de invalidar las críticas metodológicas hechas contra el psicoanálisis. En lugar de tratar de responder a las acusaciones sobre la inverificabilidad de las proposiciones psicoanalíticas una por una, quieren descartarlas por irrelevantes ${ }^{11}$ (Strenger, 1991: 40).
\end{abstract}

De ahí que muchos consideran este movimiento no tanto como el efecto de nuevos desarrollos conceptuales sino como una verdadera huida a la hermenéutica (Blight, 1981). Va de suyo que esta posición ratifica,

\footnotetext{
11 "The hermeneuticist conception of psychoanalysis is to a large extent a radical attempt to invalidate methodological criticisms made against psychoanalysis. Instead of trying to answer charges about the unverifiability of psychoanalytic propositions one by one, they want to discard them as irrelevant".
} 
paradójicamente, las distinciones epistemológicas de la concepción tradicional de la ciencia.

\section{a) Características del programa hermenéutico}

La hermenéutica psicoanalítica ha hecho hincapié (aunque por vías distintas a la Ego Psychology ${ }^{12}$ ) en el yo y sus posibilidades de historizar una identidad narrativa, es decir de lograr una historia coherente de sí mismo. Desde esta perspectiva, la incoherencia de la propia historia es una fuente privilegiada de sufrimientos y es por eso que debe ser rectificada mediante el análisis, hasta constituirse en una identidad soportable en donde el sujeto se reconozca.

Según Paul Ricœur "el inconciente es un objeto, en el sentido de que está 'constituido' por el conjunto de las operaciones hermenéuticas que lo descifran. No existe de manera absoluta, sino relativa a la hermenéutica como método y como diálogo" (Ricœur, 1969/2006: 101). Esto impide, según él, que el psicoanálisis sea una ciencia de la observación del comportamiento: como los cambios de la conducta no valen como observables sino como significantes, no hay observación de hechos sino interpretación de una historia;

...de ahí en más, su objeto propio serán siempre efectos de sentido -síntomas, delirios, sueños ilusiones- que la psicología empírica sólo puede considerar como segmentos de conducta; [a diferencia de ello] para el analista, la conducta es un segmento de sentido. De ahí que su método esté mucho más cerca de las ciencias históricas que de las ciencias naturales [...] reconocer esto último es la única réplica válida contra el ataque de los lógicos, semánticos y metodólogos que cuestionan el carácter científico del psicoanálisis (ibíd.: 173; corchetes añadidos).

Como la técnica psicoanalítica se aparta de los afanes de control y progreso manipulativo propios de la técnica en ciencias naturales, la tarea del psicoanalista es homologable a la del historiador: ambas consisten en las sucesivas rectificaciones de relatos previos.

Para Jürgen Habermas, la visión hermenéutica del psicoanálisis es la que pone de relieve su naturaleza más específica: en tanto que aborda mediante el

${ }^{12}$ Suele verse en la Self Psychology, especialemnte en los trabajos de Kohut (1971/1996, 1977) y su insistencia en nociones como las de introspección, intuición y empatía, un primer buen puerto del desembarco posterior de la hermenéutica en terreno psicoanalítico (Holzman, 1985). 
lenguaje el problema de los sujetos que se engañan a sí mismos, se orienta por una vía crítico-reflexiva que lo diferencia del positivismo objetivante de las ciencias naturales (Habermas, 1968/1990).

Arriba mencionamos la denuncia que han hecho los hermenéuticos, postulando una contradicción freudiana entre sus maneras de teorizar y de concebir la práctica clínica. Esta postura no tuvo, sin embargo, la misma acogida por parte de todos. Podemos distinguir dos posturas respecto de esa contradicción freudiana: en primer lugar cabría hablar de un narrativismo extremo, consistente en rechazar todo elemento naturalista de la teorización de su creador. George Klein (1976a) ha representado bien esta perspectiva con su propuesta de efectuar una "teorectomía" que deje de lado la obsoleta metapsicología, a los fines de continuar desarrollando lo que debe ser una teoría clínico-hermenéutica. En sintonía con Klein, Roy Schafer (1976) ha planteado la necesidad de eliminar la dimensión "económica" o de considerarla como una mera narrativa entre otras que podrían esbozarse ${ }^{13}$. Tales posturas pueden ser diferenciadas de un narrativismo más moderado, en el que se inscriben aquellos que rescatan ciertos aspectos del freudismo no esencialmente hermenéuticos. Allí se ubicarían, por ejemplo, Ricœur y Habermas. El primero ha notado la mixtura del discurso freudiano planteando que "su descubrimiento se da a nivel de los efectos de sentido, pero sigue exponiéndolo en el lenguaje y en la conceptualización del energetismo de sus maestros de Viena y Berlín" (Ricœur, 1969/2006: 155). Esa mixtura no es, para Ricœur, un error categorial que debería ser rectificado sino que debería funcionar como base de una semántica del deseo, habilitando una redefinición del hombre a partir de una zona intermedia a naturaleza y cultura.

\footnotetext{
${ }^{13}$ Este planteamiento nos recuerda la "muerte a la psicología" que Georges Politzer (1928/1964) había propuesto antes, desde un enfoque fenomenológico que denostaba tanto las abstracciones especulativas como el realismo ontológico procedentes de la psicología tradicional y presentes en la perspectiva freudiana. Su crítica a la metapsicología mantiene significativos puntos en común a la de los hermenéuticos, aunque ambas hayan surgido en diferentes tradiciones, momentos y contextos geográficos. En nuestro ámbito rioplatense el pensamiento de Politzer ha sido tempranamente recepcionado por José Bleger (Viguera, 2012), dando lugar a una perspectiva relacional que consolidaron algunos como E. Pichon Rivière, H. Racker, W. y M. Baranger, y cuyos planteamientos llegan hasta nuestros días en los aportes de autores como I. Berenstein y J. Puget, entre otros (Bernardi, 2009). Algunos años después que Politzer pero con no menores consecuencias, en Francia se gestaría el planteamiento de separar el método de la doctrina freudiana, propugnado por Roland Dalbiez (1936/1948).
} 


\section{b) Motivos y causas}

Aunque no siempre suele mencionárselo, conviene resaltar los antecedentes que a mitad del siglo XX sentaron algunos filósofos analíticos que, interesándose por distintas razones en el psicoanálisis, denunciaron una equivocación freudiana sobre su propio trabajo: pese a sus afanes de explicar causalmente el vienés habría aportado una psicología motivacional (Flew, 1949; Maclntyre, 1958/2004; Peters, 1949; Toulmin, 1948). Estas primeras lecturas tuvieron su impacto al interior del psicoanálisis en algunos trabajos pioneros (Home, 1966; Rycroft, 1966; Klauber, 1968) que parecieran haber sido un aporte fundamental al núcleo duro del programa hermenéutico que se iría gestando. Una de las hipótesis centrales que se estaba consolidando es aquella que define a lo inconsciente como un conjunto de significados que guían la acción y que es susceptible de analizar lingüísticamente, dejando por fuera toda especulación sobre fuerzas y su correspondiente aproximación causal. Según este punto de vista, como el hombre es esencialmente un sujeto creador de significados, las modelizaciones naturalistas del funcionamiento psíquico (fuerzas, energías y mecanismos) son inapropiadas a su objeto y deben ser rechazadas. El psicoanálisis apunta así a comprender sentidos idiosincráticos y no a descubrir fuerzas universales.

Esa idea se apoya y refuerza la añejada distinción entre causas y motivos que muchos han aceptado para los estudios de lo humano ${ }^{14}$ y que, desde la década del sesenta, ha preponderado en esta perspectiva hermenéutica del psicoanálisis. Según esta perspectiva, a diferencia de las causas, los motivos son significados creados por los sujetos y susceptibles de ser modificados. Habermas sostuvo que en psicoanálisis se trata de un tipo distinto de causalidad:

con Hegel la podemos llamar, para distinguirla de la causalidad de la naturaleza, una causalidad de destino, puesto que la conexión causal entre escena inicial, defensa y síntoma no está fijada según leyes naturales en una invarianza de la

\footnotetext{
${ }^{14}$ Para Robert Wallerstein, por ejemplo, precisamente esto es lo que todas las perspectivas hermenéuticas tienen en común: "...la aceptación de la dicotomía declarada en el ámbito explicativo entre una psicología basada en razones y otra basada en causas" (Wallerstein, 1986/1987: 14).
} 
naturaleza, sino sólo espontáneamente en una invarianza de la biografía, representada por la compulsión a la repetición, pero soluble mediante la fuerza de la reflexión (Habermas, op. cit. p. 268).

En sintonía con esta idea, aunque con notas añadidas, Alfred Lorenzer afirma que "la comprensión psicoanalítica tiene que revelarse como procedimiento hermenéutico" (Lorenzer, 1970/1977: 121), es decir, sin apelar a explicaciones nomológicas.

\section{c) Conceptualización hermenéutica de la realidad, la verdad y la validación de hipótesis}

Como consecuencia de esa hipótesis central pareciera esbozarse el principal supuesto metodológico de la tradición hermenéutica: la investigación y práctica psicoanalíticas son posibles a condición de centrarse en el significado de las experiencias clínicas. El método de estudio de casos, tan utilizado tempranamente por Freud, se revaloriza como estrategia predilecta para la investigación (producción y justificación de las hipótesis psicoanalíticas); simultáneamente, los pretensión de utilizar procedimientos provenientes de las ciencias naturales es completamente desestimada.

Los parámetros generales adoptados para referir a la validación de hipótesis en esta tradición han sido sintetizados por Ricœur bajo la denominación de constelación confirmatoria (Ricœur, 1977/2009). Se trata del establecimiento interactivo de los criterios de coherencia, consistencia interna e inteligibilidad narrativa; es decir de la armonía de las partes con el todo en un marco de significación lingüística. Mediante esta forma de círculo hermenéutico la interpretación clínica recibe su validación: no por adecuación descriptiva a hechos de alguna realidad histórica ni por correspondencia con algún estado intrapsíquico, sino por consistencia interna de la narrativa lograda (Steele, 1979). Para Lorenzer, por ejemplo, el criterio de confiabilidad de la "comprensión escénica" a la que se llega en cada caso es una "vivencia de evidencia", debido al reconocimiento de sus consecuentes patrones de interacción singulares y prescindiendo de aspectos explicativos en su fundamentación (Lorenzer, 1970/1977: 109 y 104). El psicoanálisis hermenéutico apunta a lograr la coherencia de una verdad narrativa (Spence, 
1982) y la metapsicología freudiana puede ser entendida como un conjunto de reglas para volver a narrar historias de vida (Ricœur, 1985/2004) o como un mero sistema de referencia para los procesos de autorreflexión (Habermas op. cit. pp. 52-53); es decir como líneas argumentales que ayudan al analista a encontrar significado. La verdad narrativa es efecto del trabajo analítico y de un consenso (entre analista y analizante) sobre la historia que mejor explica el sentido de los síntomas. La configuración narrativa que se crea en un psicoanálisis no sólo configura nuestra visión del pasado sino que lo construye. De ese modo, si la interpretación propuesta es adoptada por el paciente para continuar su autorreflexión y superar las auto-distorsiones biográficas, entonces ella es correcta o verdadera. Varios autores pertenecientes a esta tradición hermenéutica no ven en este pluralismo interpretativo un problema (Goldberg, 1984; Gill, 1983). Irwin Hoffman, más recientemente, no duda en afirmar que la ambigüedad de los datos clínicos "en sí misma asegura la apertura de los 'datos' a la revisión crítica y a múltiples interpretaciones"15 (Hoffman, 2009: 1052). Mientras que para otros, por el contrario, esa ambigüedad y su pluralismo interpretativo derivado sí constituyen un obstáculo a la validación (Eagle 1984; Spence, 1982). Hay quienes abogan por una tercera postura intermedia a "la identidad que exige el univocismo y la diferencia que rescata el equivocismo" (Tubert-Oklander, 2013: 293). A mi modo de ver, las raíces filosóficas de ese pluralismo se insertan en el suelo relativista de la hermenéutica filosófica, la filosofía postestructuralista y la teoría literaria, constituyendo un tópico en sí mismo más allá del psicoanálisis.

En torno a esa noción de verdad narrativa pueden ser inferidos algunos supuestos ontológicos y epistemológicos generales: se trata de una perspectiva historicista que adopta una vertiente antirrealista epistemológica y, en algunos casos extremos, pareciera alcanzar algún grado de antirrealismo ontológico. Viderman, por ejemplo, sostiene que todo objeto de conocimiento (y por ende lo inconsciente) es una construcción del sujeto cognoscente y que el analista debe enunciar las fantasías inconscientes del analizante no para descubrir o reproducir hechos pasados sino para inventarlos (Viderman, 1970); lo cual

\footnotetext{
15 "The ambiguity in itself ensures the openness of the "data" to critical review and to multiple interpretations"
} 
supone que no sólo el conocimiento de las entidades en juego (en este caso parte de la realidad psíquica) sino también su modo de existencia, son dependientes del modo de representar del psicoanalista ${ }^{16}$. Por todo ello, las explicaciones psicoanalíticas son narrativas, en el sentido de que intentan reorganizar los hechos biográficos en un todo coherente.

Esa forma de entender el proceso de validación es aplicable al producto de las interpretaciones y construcciones en el contexto clínico, que aparecen puestas en primer plano. Menos importantes parecieran resultar los modelos e hipótesis nómicas de la metapsicología, por provenir de un naturalismo inaplicable al contexto de lo humano. El afán ideográfico deviene un punto central en esta tradición y cualquier desarrollo teórico universalizante es concebido como meramente instrumental (sin referencia a algo existente) y evaluado por su utilidad para propiciar la lectura y emergencia de lo singular. Así considerado el tema de la validez de la interpretación psicoanalítica, pareciera plantear similares problemas que el tema de la validez de las interpretaciones históricas o, incluso, literarias.

Los rasgos anteriores son apenas algunos aspectos centrales de lo que podemos considerar una tradición hermenéutica en psicoanálisis. Aunque con matices y particularidades, varios supuestos epistemológicos del núcleo de esa tradición han llegado hasta nuestros días en diversos enfoques teóricos. La insistencia que algunos desarrollos psicoanalíticos mantienen en aspectos relacionales, contextuales, ideográficos y humanísticos, hacen patente su relación con las primeras formulaciones hermenéuticas. Esto se aprecia, por ejemplo, en los desarrollos del denominado enfoque intersubjetivista (Storolow y Atwood, 2004) o del movimiento relacional (Mitchell, 2000). Ambas perspectivas defienden la necesidad de atender al contexto de las experiencias y significados que tienen lugar en lo intersubjetivo: el campo creado por la intersección de las subjetividades del paciente y del analista. Stephen Mitchell, por ejemplo, sostiene que "el conocimiento en nuestros días es considerado solo puede ser considerado- pluralista, no singular; contextual, no absoluto;

\footnotetext{
16 Jorge Luis Ahumada califica esta postura como "creacionismo verbal" (Ahumada, 1999b: 219) y califica el desembarco hermenéutico en terreno freudiano como una "irrupción en el psicoanálisis del nihilismo posmodernista" cuyo espíritu es "antiepistémico" (Ahumada, 1999a: 54-55).
} 
construido, no descubierto; cambiante y dinámico, no estático y eterno" ${ }^{17}$ (Mitchell, 1993b: 44). Es el contexto de interacción interpersonal lo que construye los fenómenos mentales, por lo que se rechaza de raíz cualquier consideración sobre una naturaleza independiente de las narrativas mismas. De ello se sigue que la situación psicoanalítica no se caracterice como descubriendo algo sino, por el contrario, en base en un trabajo de reconfiguración de los sistemas significativos del paciente. Mauricio Beuchot, creador de la hermenéutica analógico-icónica y promotor de su implementación en psicoanálisis, sintoniza con estos planteos:

es el poder de reconstruir la trama de una vida como una narración coherente lo que ayuda al analizado. Sus bloqueos y confusiones le impiden ver esa trama y el analista tiene que llevar a cabo la humilde y paciente labor de ir entretejiendo los cabos sueltos. (Beuchot, 1997/2009: 166).

En un trabajo reciente, Donna Orange reivindica la necesidad de adherir a la tradición hermenéutica y propone un basamento del trabajo clínico que denomina hermenéutica de la confianza: "el entendimiento dialógico, en una hermenéutica de la confianza, forma la respuesta hospitalaria al desconocido que sufre exigido por la ética de la responsabilidad infinita" (Orange, 2011/2013: 14).

En la tercera parte de la tesis expondré con mayor detalle las principales ideas de algunos referentes clave de esta tradición y, en la cuarta parte, retomaré críticamente las pretensiones de redefinir la identidad epistemológica del psicoanálisis en clave hermenéutica. Aunque considero que el empalme del perspectivismo posmodernista con la hermenéutica psicoanalítica de los últimos años nos lleva a una posición que multiplica las dificultades que originalmente se intentaban resolver, voy a intentar mostrar que la empresa es inviable desde un tiempo anterior: la redefinición hermenéutica del programa freudiano no puede hacerse sino a condición de, o bien soslayar aspectos esenciales y vigentes que no pueden ser digeridos por dicha tradición, o bien

17 "Knowledge in our day is considered — can only be considered - pluralistic, not singular; contextual, not absolute; constructed, not uncovered; changing and dynamic, not static and eternal". 
simplificar líneas argumentales de Freud para verlas como contradicciones a solventar.

\section{Críticas desde el inductivismo eliminativo}

Mientras que los desarrollos de la tradición hermenéutica alcanzaban su ápice de asimilación y reelaboración al interior del psicoanálisis, Adolf Grünbaum preparaba un socavamiento contundente de ese repliegue epistemológico. Existe cierto consenso en considerar las objeciones de Grünbaum $(1984,1993)^{18}$, como una crítica más sólida que las anteriores, a pesar de que provenga de una tradición naturalista. El conjunto de argumentos sistematizados por Grünbaum, junto con su minuciosa lectura de Freud y un escenario filosófico propenso, parecen haber contribuido a consolidar un desafío importante a la fundamentación del conocimiento psicoanalítico, no suficientemente asumido hasta hoy en día ${ }^{19}$.

Grünbaum considera lícitas las pretensiones freudianas de que el psicoanálisis sea una ciencia empírico-natural y por ello concluye la primera parte de su trabajo asegurando que la reconstrucción hermenéutica del psicoanálisis constituye una "exégesis mítica" de la concepción del creador del psicoanálisis, un giro ideológico que no tiene sustento en las bases psicoanalíticas y que conduce a un callejón sin salida. La hermenéutica psicoanalítica se basa en una tradición "científico-fóbica" que parte de una concepción anacrónica de las ciencias naturales, con binomios obsoletos (como causa-razón, nomotético-ideográfico, etc.).

Grünbaum considera que, adoptando los mismos estándares de cientificidad con los que Freud se manejaba (que distan mucho de la visión hermenéutica y se acercan a los criterios generales de cientificidad), se evidencian sus puntos

\footnotetext{
${ }^{18}$ La postura que Grünbaum asume en esos libros es fruto de un trabajo cuyo proceso puede atisbarse en la progresiva elaboración de algunos artículos precedentes (Grünbaum, 1977a, 1977b, 1978a, 1979a, 1979b, 1980, 1981, 1983a, 1983b, 1983c, 1983d).

${ }^{19}$ Considerando que la producción de Popper sobre el psicoanálisis asciende a no más de veinticinco páginas, y que Grünbaum ha escrito dos libros y decenas de artículos, resulta curiosa la disímil recepción que en nuestro margen rioplatense se ha hecho de ambos.
} 
endebles. Más específicamente: para Grünbaum las hipótesis psicoanalíticas no pueden ser probadas en la situación analítica, pues no satisfacen los cánones del inductivismo eliminativo ${ }^{20}$; como consecuencia nos topamos con una falta de confiabilidad de los datos clínicos y una insuficiencia del método basado en el estudio de casos individuales para fundamentar las inferencias causales. Como el valor de los datos clínicos no es probatorio y el tipo de argumentación que conecta la teoría con sus evidencias es deficiente, el psicoanálisis requeriría otro tipo de validación: extra-clínica.

Ahora bien, para dar crédito al punto de vista de las objeciones de Grünbaum deberíamos poder reconocer que se cumplen al menos dos condiciones mínimas: en primer lugar, que su reconstrucción del psicoanálisis freudiano no tergiversa (como la mayoría de los críticos ajenos a la disciplina) su contenido ni su espíritu en los aspectos esenciales. En segundo lugar, deberíamos poder acordar en que el criterio de demarcación que él propone para caracterizar y delimitar la actividad científica de otras no científicas es viable en general y, además, aplicable al dominio psicoanalítico en particular. A nuestro modo de ver, hasta hoy no parece haber una respuesta unívoca a estas consideraciones y ello constituye una de las razones por las que la crítica de Grünbaum permanece en una especie de stand by.

Las objeciones de Grünbaum son radicalmente distintas de las de Popper y, al mismo tiempo, permanecen actualmente como referencia ineludible a cualquier consideración epistemológica sobre el conocimiento psicoanalítico (Bernardi, 1994/1995; Coderch, 2006; Sachs, 1993/1996). La recepción que el psicoanálisis ha hecho de la crítica de Grünbaum tampoco es unívoca: mientras que para algunos constituye una argumentación ineludible que necesita ser respondida (Edelson, 1988; Erwin, 1993; Hanly, 1994; Wallerstein, 1986/1997), otros la consideran una objeción basada en una concepción de la metodología demasiado estrecha para captar la complejidad de la fundamentación freudiana del psicoanálisis (Ahumada, 1999; Brakel, 2015; Gomez, 2005; Green, 1991/1993). Más allá de tales diferencias, la crítica de este filósofo pareciera haber generado cierta preocupación en las comunidades

${ }^{20}$ Grünbaum denuncia firmemente las insuficiencias del criterio popperiano de demarcación y propone basarse en el arsenal de la tradición inductivista desprendida de Francis Bacon y Stuart Mill para la fundamentación de las hipótesis causales. 
analíticas, situación que ha sido descripta, no sin ironía, como "el síndrome Grünbaum" (Mitchell, 1998). Con esa expresión sarcástica Mitchell refiere a preocupación que algunas sociedades psicoanalíticas muestran por la elucidación racional de los fundamentos epistemológicos y la manera de investigar en la disciplina, profundizadas por el impacto que han tenido las consecuencias del análisis de Grünbaum sobre el denominado por él argumento de la coincidencia. Mitchell, como se vio, responde a ello como los hermenéuticos de la primera hora respondían a las demandas del empirismo lógico o del racionalismo crítico: evadiendo el problema (en su caso amparándose en una vertiente posmoderna del constructivismo radical). Aunque, como veremos en la tercera parte de la tesis, los argumentos de Grünbaum son inviables, coincidimos en que la perspectiva de respuesta de Mitchell constituye un peligro equivalente a las críticas que evade (Eagle \& Wakefield, 2004).

El peso de estas discusiones epistemológicas ha repercutido en los desarrollos metodológicos al interior de la disciplina, en tanto que ha servido de referencia para sentar posición respecto de cómo es necesario y conveniente producir conocimiento en psicoanálisis.

\section{La concesión naturalista}

Pero no ha sido el movimiento hermenéutico el único refugio donde los analistas buscaran resistir el asedio de las críticas epistemológicas mencionadas. Ha habido otra gran línea argumental que ha incorporado como válidas gran parte de esas objeciones y ha modificado, en una dirección opuesta a la hermenéutica, el rumbo del psicoanálisis. En cierto modo, los orígenes de esta tradición se remontan al propio Freud, quien intentó siempre ubicar su obra entre las ciencias de la naturaleza: el monismo naturalista del psicoanálisis está desde su creación e implicó toda una serie de valores epistémicos para la aplicación y el desarrollo del movimiento posterior a Freud.

Sin embargo, a partir de la sistematicidad de las críticas epistemológicas, sostener esa pretensión freudiana ha implicado una serie considerable de 
ajustes y redefiniciones de su empresa original. Hemos mencionado los esfuerzos tempranos de algunos analistas por reorganizar el entramado conceptual del psicoanálisis, corrigiendo sus contenidos metapsicológicos de manera tal que se operacionalicen en variables susceptibles de control y observación directa. Desde un punto de vista metateórico, los trabajos de Kline (1972/2014) y de Kolteniuk Krauze (1976) constituyen buenos ejemplos de interpretación epistemológica del psicoanálisis en clave naturalista. Mucho tiempo después, todavía hay analistas que ven en el psicoanálisis lo esencial de una ciencia natural:

lo que hace un psicoanalista con los datos que se derivan de la aplicación del método psicoanalítico no es diferente de lo que cualquier científico hace con sus datos. Un analista postula las mismas relaciones de causa-efecto con respecto a los datos psicoanalíticos que postula un físico, por ejemplo, con respecto a sus datos disponibles. ${ }^{21}$ (Brenner, 1982: 4).

\section{a) Características generales del enfoque naturalista}

Lo que nos permite agrupar y describir ciertos desarrollos bajo la nómina de una tradición naturalista es la presencia de un núcleo conceptual que contiene supuestos ligados a la visión hegemónica de ciencia y sus variaciones en cada momento histórico. Es la ferviente tentativa de sus afiliados por responder a las mencionadas demandas de legitimidad epistemológica, asimilando los cánones de cientificidad dominantes en cada época. En una primera oleada, a partir de las demandas del positivismo lógico, adoptando la noción de teoría como calculo axiomático interpretado y el criterio verificacionista del significado cognitivo. En una segunda oleada, a partir de los requerimientos del racionalismo crítico, asumiendo la necesidad de establecer claramente los falsadores potenciales y contrastar empíricamente las formulaciones metapsicológicas. Finalmente, desde la crítica de Grünbaum, incorporando las premisas del inductivismo eliminativo y la desestimación del encuadre analítico como contexto válido para la puesta a prueba. Aunque esto pueda verse como

\footnotetext{
21 "what a psychoanalyst does with the data which derive from applying the psychoanalytic method is no different from what any scientist does with his or her data. An analyst postulates the same cause-and-effect relationships with respect to psychoanalytic data as a physicist, for example, postulates with respect to the data available to him or her."
} 
una simplificación excesiva, no encuentro un rasgo distintivo mejor para describir el núcleo de lo que ha dado en llamarse tradición naturalista en psicoanálisis que su carácter concesivo a los parámetros de cientificidad de turno.

Como veremos en el próximo capítulo, los psicoanalistas partidarios de este enfoque han venido alentando la prevalencia de investigación empírica, bajo la suposición de que esa es la vía más conveniente para validar las hipótesis psicoanalíticas. En general, sostienen la necesidad de desarrollar el proceso contrastador ampliando la base empírica que prevé el dispositivo analítico tradicional, tendiendo a generar datos empíricos sólidos y afirmaciones probabilísticas, con métodos provenientes de otras disciplinas (Fonagy et al, 1999; Wallerstein, 1993; Masling y Bornstein, 1996). Para lograr satisfacer los requisitos de cientificidad, en las últimas décadas del siglo XX esta tradición ha privilegiado el uso de técnicas provenientes de las ciencias naturales o sociales con enfoque neopositivista: la experimentación o cuasi-experimentación, conjuntamente con la estadística inferencial; bajo la creencia de que éstas estrategias serían más apropiadas que el estudio de casos tradicional para arribar a una validación de las teorías psicoanalíticas.

\section{b) Algunos supuestos filosóficos subyacentes a la validación de hipótesis}

La consideración de esas demandas críticas ha llevado a plantear la necesidad ineludible de investigar empíricamente, en afán de hallar evidencias sistemáticas que den apoyo a las hipótesis metapsicológicas y a los productos del método psicoanalítico (Westen, 1998; Bornstein, 2005; Shedler, 2002; Blatt y Auerbach, 2003; Fonagy, 2003). Es notable cómo las preocupaciones de esta línea argumental tienden a privilegiar las formulaciones metapsicológicas, fundamentalmente la corrección de sus enunciados nómicos mediante datos empíricos extra-clínicos y teniendo en cuenta el diálogo con otras áreas del conocimiento. Desde que Grünbaum expusiera sus argumentos, muchos consideran imposible la puesta a prueba de las hipótesis clínicas en el dispositivo tradicional y consideran imprescindible desarrollar modelos de investigación experimental. En estos diseños, como es sabido, los participantes 
son aleatoriamente distribuidos (para evitar sesgos de selección) en grupos de experimentación y en grupos de control, apuntando a maximizar el control de las variables potencialmente perturbadoras y la manipulación de las variables independientes, para poder establecer conclusiones causales empíricamente fundadas. Los estudios de caso único $(\mathrm{N}=1)$ se consideran viables sólo en la medida en que se diseñen con un formato cuasi-experimental, aunque se los desestime en su potencialidad para justificar la generalización de los hallazgos.

Aunque casi nunca son explicitados, muchas de las investigaciones parten de supuestos fisicalistas 0 , al menos, elementaristas. Casi siempre se mantiene, respecto del conocimiento, alguna variante del realismo epistémico que deviene en la búsqueda de conocimiento objetivo de entidades inobservables; lo cual se suele apoyar en alguna variante del realismo ontológico: las entidades indagadas existen con independencia y anterioridad al sujeto cognoscente que se las representa. Aunque con matices, estos aspectos gnoseológicos y ontológicos, que muchas veces han sido catalogados de neopositivistas, suelen diferir de los compromisos asumidos por lo partidarios de la tradición hermenéutica, muchas veces definidos como posmodernistas.

\section{Rampa introductoria}

Hay quienes suelen ver en la dicotomía de enfoques naturalistas y hermenéuticos un binomio irreductible y radicalizado sobre la identidad disciplinar (Steiner, 2000). Así, las comunidades psicoanalíticas estarían escindidas entre: a) aquellos que entienden al psicoanálisis como una disciplina interpretativa concerniente a las humanidades y, b) aquellos que consideran que debería continuar desarrollándose en base a la matriz naturalista que rige las principales conceptualizaciones de las ciencias naturales o sociales. Como adelanté al principio, esas dos tradiciones son abstracciones extremas que no representan la compleja zona gris en la que pueden ubicarse un sin número de propuestas clínicas e investigativas de las diversas comunidades psicoanalíticas de todo el mundo; pese a lo cual constituyen organizadores conceptuales útiles para el tipo de abordaje propuesto. 
De la sintética presentación anterior se desprenden tres cuestiones que vale la pena subrayar: 1) en primer lugar, que las discusiones sobre la identidad epistémica del psicoanálisis no pueden separarse de los debates filosóficos que históricamente se han venido efectuando sobre su legitimidad. 2) Por otro lado, que no hay consenso respecto de la pertinencia de las principales críticas epistemológicas recibidas, lo cual en cierto modo justifica (o al menos habilita) una revisión pormenorizada de las mismas. 3) Finalmente, que la manera de recepcionar ${ }^{22}$ tales críticas epistemológicas se vincula no sólo con el modo de concebir la identidad epistémica de la disciplina sino también el modo de continuar desarrollándola; es decir, el modo de entender eso que se viene conceptualizando como metodología psicoanalítica de la investigación. De ello nos ocuparemos en el próximo capítulo.

22 En el sentido dado por la teoría de la comunicación literaria de Hans Robert Jauss (1979/1981) a la recepción: asimilación transformativa que impide definir la migración de ideas en términos de mera reproducción, copia fidedigna o neutralidad alguna. 


\title{
CAPÍTULO 2: Discusiones sobre la naturaleza de la investigación psicoanalítica
}

\begin{abstract}
Para el psicoanalista, en las circunstancias hoy reinantes, hay una tendencia afectiva peligrosísima: la ambición de obtener, con su nuevo y tan atacado instrumento, un logro convincente para los demás. (Freud, 1912a/2004: 114)
\end{abstract}

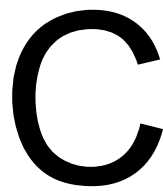

omo adelantamos en la presentación, el entramado de controversias que se desarrollan desde el siglo pasado sobre la identidad disciplinar del psicoanálisis pareciera haber variado su punto de foco: el principal debate en la actualidad no parece ser el de definir la naturaleza epistémica sino el de determinar cuáles son o deberían ser las formas legítimas de investigar en la disciplina. En realidad, si se lo analiza con cierto detalle, el péndulo de las controversias oscila entre posturas que se originan como respuesta al debate anterior $^{23}$.

En este capítulo, primero intentaremos sistematizar algunas taxonomías posibles para clasificar las formas de investigar en psicoanálisis; seguido de ello nos adentraremos en la evolución histórica y en algunos rasgos específicos que suelen asumir las investigaciones empíricas de procesos y resultados actualmente, así como la resistencia que presentan aquellos que defienden la exclusividad de la investigación clínica. En tercer lugar, ilustraremos cómo en la última década las posturas mencionadas han venido encarnándose en prestigiosos psicoanalistas, dando lugar a una apasionada serie de contiendas argumentativas.

\footnotetext{
${ }^{23}$ Me parece que el modelo desarrollado por Oscar Nudler (2004) para conceptualizar algunos aspectos de la evolución controversial en un campo determinado, sin caer en los extremos rupturistas o continuistas y atendiendo a procesos de refocalización, podría ser adecuado para una futura reconstrucción de este complejo panorama.
} 


\section{Tipos de investigación en psicoanálisis}

Ulrich Moser distinguió tempranamente, basándose en términos computacionales, las investigaciones psicoanalíticas "on-line" de las "off-line":

el terapeuta en la práctica psicoanalítica es [...] un investigador on-line [...]; esto por dos razones. Primero, el terapeuta, como parte de un sistema, elije al objeto que observa y lo va cambiando permanentemente y, segundo, debe operar "científicamente" en la situación del manejo terapéutico. El crea conocimientos. [...] pero la validez de su propio quehacer en este área queda supeditado a la certeza intuitiva, un fenómeno -hasta donde yo sé- al que la investigación psicoterapéutica no ha prestado aun atención ${ }^{24}{ }^{25}$ (Moser, 1989/1992: 183).

Mientras que la investigación "on-line" designa el trabajo que todo terapeuta realiza en el transcurso del tratamiento con el paciente, la investigación "off line" refiere al trabajo que se realiza en ausencia del paciente y con la aplicación de diferentes métodos a los materiales producidos en la sesión. Esa distinción se ha mantenido y hoy suele hablarse de investigación clínica e investigación extra-clínica. En nuestro país, David Liberman, de manera independiente y algunos años antes, había arribado a la misma diferenciación:

Existen dos formas de indagar en psicoanálisis: una es la indagación que se realiza con el paciente durante la tarea analítica (esta labor de investigación sabemos que sólo abarca un trecho relativamente corto) y la otra es la indagación del diálogo psicoanalítico en sesiones ya efectuadas. (Liberman, 1970: 78).

Roger Perrón, más recientemente, sostiene que desde mediados del siglo pasado podemos distinguir dos tipos de acciones referidas a la investigación en el campo del psicoanálisis: "aquellas donde prevalece una actitud clínica, y aquellas que hacen uso de procedimientos formales sistematizados" (Perron,

\footnotetext{
${ }^{24}$ The psychoanalytic therapist and practitioner is [...] an on-line scientist [...] This is the case for two reasons. First, therapies as a part of the system create the system they observe and change it continuously, and second, therapists must be "scientifically" active during the therapy situation. They produce knowledge. The validity of one's own action in this area is left to intuitive certainty, a phenomenon - as far as I know - to which psychotherapy research has not yet turned its attention".

${ }^{25}$ En la cuarta parte de la tesis volveremos nuestra atención, desde los desarrollos de Charles Peirce, a este fenómeno de la "certeza intuitiva"; así como a otros fenómenos inherentes a la lógica clínica y sus condiciones de validación.
} 
1999, p. 3). También Rubén Zukerfeld ha planteado, en sintonía con lo anterior, que podemos diferenciar la "investigación psicoanalítica" de la "investigación en psicoanálisis": mientras que la primera remite a la utilización del método psicoanalítico freudiano exclusivamente en la situación analítica, la segunda supone un conjunto diverso de problemas relativos a la realidad clínica, la situación analítica y la producción analítica (Zukerfeld, 2009).

Robert Wallerstein ha sido uno de los analistas que más empeño ha puesto por caracterizar el campo de la investigación off-line, delimitando algunas áreas posibles que trascienden de algún modo u otro el método clínico tradicional:

1. La investigación clínica sistemática de procesos y resultados con enfoque naturalista, mediante instrumentos y métodos de investigación especializados (como grabaciones, escalas y cuestionarios).

2. La investigación del desarrollo del infante, en cooperación con investigadores de psicología del desarrollo.

3. La investigación acerca del área de contacto entre el psicoanálisis y la biología, la medicina y la ciencia natural.

4. La investigación comparada en el área de intersección entre el psicoanálisis y las ciencias sociales, como la antropología, la sociología, la psicología clínica y social, etc.

5. La investigación de las aplicaciones del psicoanálisis a las humanidades, como la literatura, la crítica literaria, la biografía, la historia, el arte y la música. (Wallerstein, 1993).

A mi modo de ver, la clasificación más simple y consistente es la que plantean Leuzinger-Bohleber y Bürgin (2003), diferenciando tres grandes clases: investigación clínica, investigación conceptual e investigación empírica.

1) La investigación clínica se origina a partir de los problemas que plantea un sujeto y su trabajo analítico. El analista funciona, en un segundo momento, como investigador: no es durante el trabajo clínico que investiga sino a posteriori, elaborando el caso y teorizando a partir de él. Se trata del proceso de generación de insights y conocimientos, que permite contrastar los modelos teóricos con el material clínico.

2) La investigación conceptual se refiere al abordaje sistemático y metódico de los significados implícitos y explícitos de los conceptos psicoanalíticos, en sus usos clínicos y extra-clínicos. Supone el tratamiento de problemas relativos 
a la producción, evolución o implantación geográfica de conceptos, así como a la forma en la que los conceptos se vinculan con los referentes, con el nuevo conocimiento o con conceptos de otras disciplinas, etc. (cf. Dreher, 2000, 2005).

3) Finalmente, la investigación empírica engloba a la indagación extra-clínica de las teorías y modelos que han nacido en el contexto clínico, la investigación sobre la eficacia de los tratamientos, etc.

Marianne Leuzinger-Bohleber (2015: 11) ha retomado recientemente esta clasificación, esquematizando sus complejas relaciones en un diagrama que aquí reproducimos:

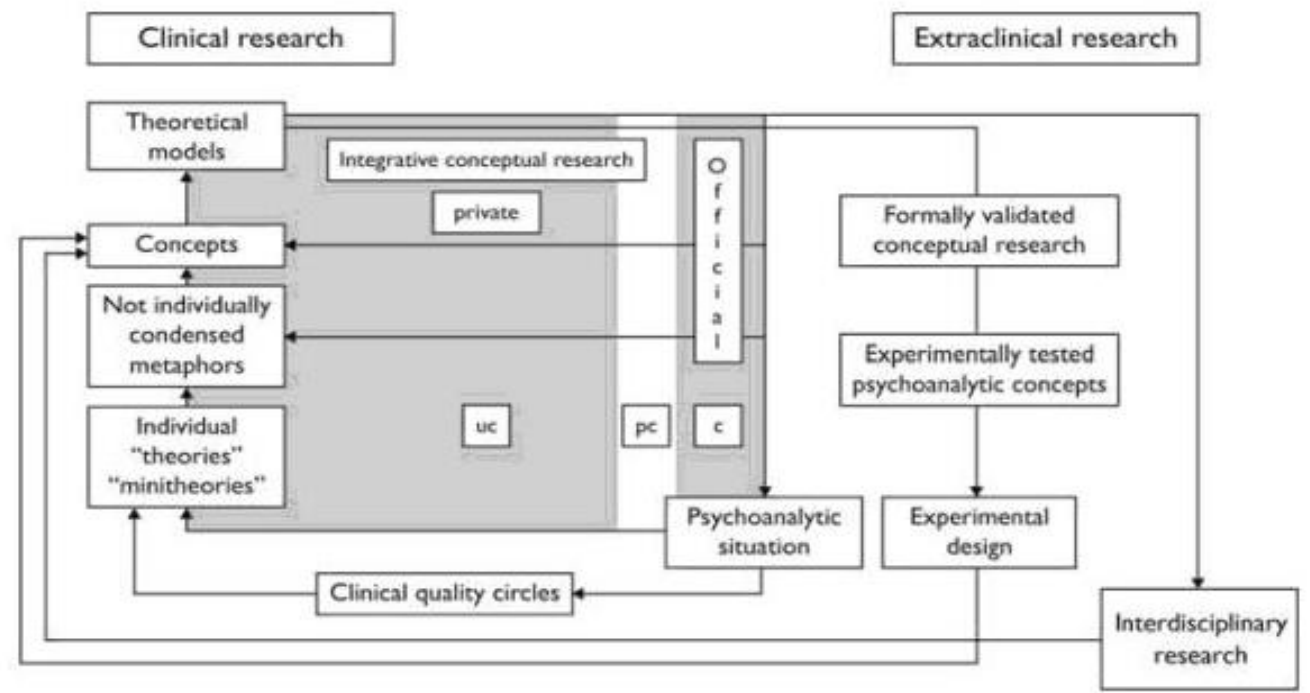

Figure 1: Different forms of research in psychoanalysis

Esta clasificación pareciera haberse impuesto con algún grado de consenso en la comunidad psicoanalítica internacional y es sobre ella que se diseñan actualmente investigaciones en psicoanálisis. La reciente versión de la Revisión a puertas abiertas de estudios de resultados y procesos en psicoanálisis (Leuzinger-Bohleber \& Kächele, 2015) profundiza esas mismas categorías a partir de los desarrollos efectuados en diversas partes del mundo, dando testimonio de ese consenso. El uso de esta taxonomía puede constatarse en el lugar que han venido alcanzando en algunas de las más importantes revistas psicoanalíticas, como el Journal of the American Psychoanalytic Association y el International Journal of Psychoanalysis. En nuestro margen rioplatense también podemos advertir que el tema de la investigación se ha venido discutiendo en diversos encuentros y 
presentaciones psicoanalíticas de las últimas décadas, utilizando algunas de esas nominaciones.

Más allá del consenso relativo de esa tripartición, las taxonomías reseñadas son apenas una muestra de las diversas maneras en las que se ha intentado organizar descriptivamente el campo de la investigación en psicoanálisis. Aún con la clasificación alcanzada, persisten dificultades inherentes a la exhaustividad y disjuntividad de las clases utilizadas.

Se ha dicho que las fronteras son las cicatrices de la historia. Pues bien, eso vale también para los confines de la investigación en psicoanálisis. Nos adentraremos ahora en uno de los aspectos posiblemente más controversiales de la investigación en este campo: el debate entre las investigaciones que priorizan el contexto psicoanalítico tradicional y las investigaciones que priorizan otros diseños y metodologías. Primero reseñaremos el surgimiento y caracterización de lo que ha dado en llamarse investigación empírica sistemática, analizando los principales argumentos que intentan promoverla. Seguido de ello, examinaremos las principales resistencias que este tipo de investigación ha suscitado en las comunidades analíticas $y$, finalmente, expondremos los argumentos que esbozan los defensores del método clínico tradicional para intentar descalificarla.

\section{a) Razones para la investigación empírica sistemática}

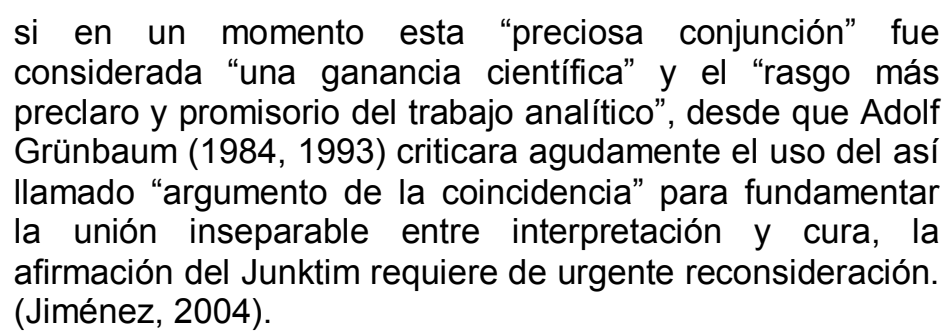

En las últimas décadas algunos sectores de la comunidad psicoanalítica se han visto en la necesidad de contrastar y complementar los conocimientos alcanzados por el método clínico tradicional con saberes que pueden surgir con otras metodologías de investigación, a los fines de contribuir a la credibilidad de la disciplina. Así, en 1998 la Asociación Internacional de Psicoanálisis creó un comité de investigación empírica (presidido inicialmente por Robert Wallerstein 
y luego por Peter Fonagy), que ha venido organizando encuentros, ofertando cursos y financiando proyectos de investigación (Lemlij, 2013).

Asumiendo las críticas epistemológicas a la validez de los conocimientos obtenidos mediante la investigación clínica, estos psicoanalistas han venido renovando sus votos naturalistas y se han orientado por la búsqueda de otros caminos para dar cuenta de nuestro campo de fenómenos. Así, se han propuesto diversos procedimientos, provenientes de diferentes disciplinas consolidadas, para enmendar las denunciadas carencias de objetivación y sistematización del procedimiento tradicional. Con la expresión de investigación empírica sistemática se suele referir a aquellas investigaciones que no se basan en la metodología tradicional de historiales clínicos ni en diseños experimentales o cuasi-experimentales, sino que constituyen una forma intermedia: aspiran a ser sistemáticas pero no a ser experimentales. Es decir, se orientan por una secuencia invariante de pasos en la que intervienen instrumentos específicos de recolección y/o análisis de datos, junto con criterios formalizados de evaluación, pero sin pretender la manipulación controlada de variables propia de los experimentos.

El desarrollo de esta área de investigación se comprende mejor si tenemos en cuenta que las críticas epistemológicas empalmaron, durante la década de los '80, con la retirada del Estado Benefactor; cuya seguridad social incluía, en algunos países europeos, la cobertura de tratamientos psicoanalíticos. Por esta época se iniciaron las demandas al psicoanálisis sobre su "eficacia terapéutica", a los fines de justificar el coste de los tratamientos, que ahora tenían que competir con otras formas consolidadas de abordajes psicoterapéuticos. Al mismo tiempo, la llegada de lo que ha dado en llamarse medicina basada en evidencias al campo de la salud mental, ha favorecido una toma de conciencia en ciertos sectores psicoanalíticos de que la investigación empírica sistemática es necesaria y de que prescindir de ella constituye una amenaza al porvenir del psicoanálisis como ciencia y como terapéutica (Bornstein, 2001; Fonagy, 2000; Gunderson y Gabbard, 1998; Kächele, 1992; Safran, 2001). Este tipo de exigencia, proveniente del exterior al movimiento psicoanalítico, contribuyó a las reorganizaciones de la IPA, por ejemplo. La publicación, en 1999, del Open Door Research Review, contenía las principales ideas directrices sobre qué respuesta dar a tales demandas. Veremos en 
seguida que la postura crítica de varios de sus miembros (como Green y Perron), derivó en la creación, en el 2001, del segundo subcomité de investigación conceptual, clínica, epistemológica e histórica, dando lugar a voces disidentes respecto de la investigación empírica que proponían los naturalistas para dar respuesta a las demandas externas.

La muestra más contundente de la incidencia fundamental que las críticas de Grünbaum han tenido en el desarrollo de estos debates lo constituye el hecho de que sus objeciones epistemológicas y metodológicas han sido internalizadas: mientras que inicialmente sus razonamientos contribuyeron a redefinir el campo de batalla en el que contendieron los psicoanalistas con sus adversarios externos, hoy en día es una parte misma de la comunidad psicoanalítica la que se empeña en responder de diversas maneras a esas demandas de validación, asumiéndolas como requisitos autoimpuestos.

Va de suyo que la tendencia a investigar empíricamente en psicoanálisis no nace con la crítica de Grünbaum ni de ningún otro filósofo, sino que ya había diseños de investigación consolidados y otros gestándose desde mucho antes. Sin embargo, como podremos analizar más adelante, la fuerza persuasiva de la crítica de Grünbaum parece tener la virtud de reunir algunos elementos significativos: no se trata sólo de la solidez de su argumentación crítica, sino también del interés que presenta su desestimación sagaz de la tendencia hermenéutica y de la crítica popperiana por igual, a la que luego se añade la promoción de validación extra-clínica de las teorías psicoanalíticas. Lo cierto es que una parte considerable de analistas pareciera haber encontrado en las objeciones de Grünbaum una forma de justificar la necesidad de llevar la investigación psicoanalítica más allá de lo que Freud hubiera imaginado.

La conclusión más importante que los analistas de orientación naturalista extrajeron de la crítica de Grünbaum, posiblemente sea la objeción al estudio de casos como metodología prínceps para la investigación psicoanalítica: "si el psicoanálisis tiene futuro como una empresa científica, es muy probable que no radica en el método de historia clínica, sino con otros diseños de prueba" ${ }^{26}$ (Grünbaum, 1988: 657). No son pocos los analistas que se hicieron eco de esta crítica. Peter Fonagy, quien se ha ocupado agudamente del tema, afirma que

\footnotetext{
26 "...if psychoanalysis is to have a future as a scientific enterprise, it very probably does not lie
} with the clinical case history method, but with other testing designs." 
Hay tres condiciones que deberían cumplirse para que la investigación clínica sea una metodología adecuada y pueda ser la única metodología aceptada en la construcción de teorías psicoanalíticas. Estas son: a) una conexión lógica estrecha entre la teoría y la práctica, b) un razonamiento deductivo apropiado en relación al material clínico, y c) el uso no ambiguo de términos ${ }^{27}$. (Fonagy, 1999: 13)

Fonagy considera que ninguna de esas tres condiciones se cumple y concluye que

El estudio de casos, en sí mismo, sin embargo, es insuficiente como método de investigación. Precisa ser complementado por otros procedimientos confirmatorios tales como la replicación, los estudios experimentales detallados y las investigaciones anatómicas, genéticas y neurofisiológicas ${ }^{28}$ (Fonagy, 1999: 20).

Helmut Thomä y Horst Kächele, en coincidencia con ello, piensan que ha habido una frecuente desestimación u omisión de los aspectos evaluativos de la teorización emergente en los estudios de caso:

Los analistas más influyentes mantienen una actitud de condescendencia hacia la investigación sistemática. Se sienten satisfechos con generar hipótesis dentro de la situación clínica. La diferencia entre el contexto de descubrimiento y el contexto de justificación parece ser desconocida para esos analistas que se contentan con la descripción de resúmenes de casos clínicos (Thomä y Kächele, 1999/2000: 102).

En ese sentido, para estos autores "debemos restringir la investigación psicoanalítica aludida en la tesis [freudiana] de la unión inseparable, en el sentido de que sus resultados pueden ser usados sólo para el descubrimiento y el desarrollo de hipótesis preliminares, y no para su verificación" (Thomä y Kächele, 1985/1989: 519; corchetes añadidos). Además, consideran que

es una exigencia muy ambiciosa querer unir la investigación psicoanalítica en la situación analítica (entendiendo por tal la obtención de nuevas hipótesis psicoanalíticas, que se debe distinguir estrictamente de la investigación para

\footnotetext{
27 "There are three conditions that should be met for clinical research to be an adequate sole methodology of psychoanalytic theory building. These are: (a) a close logical tie between theory and practice, (b) appropriate deductive reasoning in relation to clinical material and (c) the unambiguous use of terms."

28 "The case study by itself, however, is insufficient as a method of investigation. It needs to be supplemented by other confirmatory procedures such as replication, detailed experimental studies, anatomical, genetic and neurophysiological investigations."
} 
verificar tales hipótesis a través de terceros no comprometidos en el tratamiento) con los intereses curativos. Esta exigencia no podrá ser satisfecha, si el analista no distingue, en la teoría de la técnica, los siguientes componentes independientes: curación, obtención de nuevas hipótesis, prueba de las hipótesis, exactitud de las explicaciones y utilidad del conocimiento. (ibíd.).

En términos generales, los partidarios de la investigación empírica han venido sosteniendo la necesidad de utilizar los resultados de las investigaciones clínicas y conceptuales para desarrollar investigaciones extraclínicas, pues consideran que sólo en estas últimas radica la posibilidad de justificar los desarrollos teóricos del psicoanálisis.

Robert Wallerstein $(2001,2006)$ efectúa un análisis de la evolución de las investigaciones empíricas sobre procesos y resultados, caracterizando la existencia de diversas generaciones, que representan el espíritu predominante de este tipo de producciones en distintos momentos históricos. Se puede atisbar en esa descripción cómo el comienzo de estas investigaciones en la década de 1920, signado por las necesidades de determinar el grado de éxito terapéutico, procedía con criterios bastante inespecíficos y mediante rudimentarios informes estadísticos de estudios retrospectivos; pero también cómo fueron abriéndose paso, paulatinamente, estudios formales y sistemáticos en los que se combinaron los análisis de procesos con los análisis de resultados psicoterapéuticos, para culminar, desde 1970 en adelante, en la utilización de nuevas tecnologías para la recolección y análisis de los datos ${ }^{29}$; así como en la creación de métodos específicos para la investigación en el campo. Entre las metodologías más conocidas diseñadas para investigar empírica y sistemáticamente aspectos de la situación analítica, podemos mencionar el Método del Tema Central de Conflicto Relacional (CCRT) ideado por Lester Luborsky (1976, 1977, 1990), el método de las Estructuras Emocionales Fundamentales Repetitivas y Desadaptadas (FRAMES) de Dahl (1988, 1998), la teoría de los Códigos Múltiples de Wilma Bucci (1997), el Procedimiento de Evaluación Shedler-Westen (SWAP) de Jonathan Shedler y Drew Westen $(1998,1999)$, el método PQS de Enrico Jones (2000), el método

\footnotetext{
${ }^{29}$ Grabaciones de audio y video resultan las más frecuentes. Para una reseña y análisis crítico de las ventajas y desventajas de estos procedimientos, cf. "The Pro and Contra of Tape Recordings" (Kächele et. al., 2011: 12) y Wallerstein \& Sampson (1971).
} 
del Plan de Acción Latente del Terapeuta (TLAP), diseñado por Ávila-Espada y Mitjavila (2003); el Algoritmo David Liberman (ADL) desarrollado por Maldavsky (2004) y el Modelo de los Tres Niveles para la Observación de las Transformaciones del Paciente (3-LM), ideado por Ricardo Bernardi (2015). La variabilidad de problemas y procedimientos a los que estos métodos se aplican hace imposible establecer algún denominador común característico, más allá del mencionado hecho de que se sostiene la necesidad de ir más allá de la metodología basada exclusivamente en la indagación clínica on-line. Esto no supone necesariamente una completa desestimación del estudio de casos, pero sí la suposición de que es necesario trascenderlo, por ejemplo combinando la investigación clínica con un tratamiento sistemático de la información obtenida.

\section{b) Experimentación y neuropsicoanálisis}

Coincidimos con Leuzinger-Bohleber (2015) en que conviene diferenciar subtipos de investigación extraclínica a partir del diseño utilizado, ya que además de las mencionadas empíricas y sistemáticas, han ganado terreno las investigaciones experimentales e interdisciplinarias, con marcadas características propias.

En las últimas décadas ha habido un creciente número de investigaciones que demuestran la contrastabilidad de las hipótesis psicoanalíticas (tornando actualmente inviable la tesis popperiana de la pseudocientificidad del psicoanálisis ${ }^{30}$ ) y que arrojan significativa evidencia empírica a su favor (Bornstein y Masling, 1998a, 1998b; Fisher y Greenberg, 1996; Kline, 1972; Sarnoff, 1971; Shapiro \& Emde, 1995; Westen, 1999). En lo que va del siglo $\mathrm{XXI}$, el camino más promisorio en ese sentido pareciera ser, para algunos analistas, el de la relación del psicoanálisis con las neurociencias.

Eric Kandel, premio Nobel de Fisiología o Medicina en el 2000, ha sido uno de los promotores de la investigación psicoanalítica a partir de su relación con otras disciplinas, particularmente las neurociencias. Kandel ha afirmado que

\footnotetext{
${ }^{30}$ En la siguiente parte de esta tesis voy a intentar mostrar porqué la crítica de Popper resulta, por diversas razones, inviable desde su formulación inicial. Si esto fuera acertado, no necesitaríamos, por lo tanto, de la consolidada tradición de estudios experimentales en psicoanálisis para poder expedirnos sobre ella.
} 
El futuro del psicoanálisis, si es que tiene un futuro, está en el contexto de una psicología empírica, apoyada en técnicas de imagen, métodos de neuroanatomía, y genética humana. Engastado en las ciencias del conocimiento humano, las ideas del psicoanálisis pueden ser testeadas, y es así que esas ideas pueden tener su mayor impacto. ${ }^{31}$ (Kandel, 1998: 168).

Kandel considera que el psicoanálisis "sigue representando la visión más coherente e intelectualmente satisfactoria de la mente"32 (Kandel, 1999: 505) pero mantiene una opinión desfavorable sobre el método clínico: "como herramienta de investigación, este método concreto ha agotado su poder. Cien años después de su creación [...] es necesario reconocer que [...] no proporciona una base suficiente a la ciencia de la mente"33 (Kandel, 1999, 506). ¿No es acaso curioso que la visión más coherente e intelectualmente satisfactoria de la mente se haya basado en un procedimiento mágicamente agotado ${ }^{34}$

En el año 2000 fue fundada la Sociedad Internacional de Neuropsicoanálisis y creada la primera revista destinada a ello, llamada Neuro-Psychoanalysis. Mark Solms y Oliver Turnbull, pioneros en este intento de relación, consideran que los afanes investigativos de Freud se vieron limitados por el desarrollo tecnológico de su época, pero que

nosotros ahora tenemos métodos neurocientíficos que nos permiten estudiar la naturaleza dinámica de la mente para identificar la organización neuronal de su subestructura inconsciente [...] Freud, en nuestra opinión, habría considerado esto

\footnotetext{
31 "The future of psychoanalysis, if it is to have a future, is in the context of an empirical psychology, abetted by imaging techniques, neuroanatomical methods, and human genetics. Embedded in the sciences of human cognition, the ideas of psychoanalysis can be tested, and it is here that these ideas can have their greatest impact"

32 "psychoanalysis still represents the most coherent and intellectually satisfying view of the mind"

33 "as a research tool this particular method has exhausted much of its novel investigative power. One hundred years after its introduction [...] We must, at last, acknowledge that [...] is not a

sufficient basis for a science of mind"

${ }^{34}$ En la cuarta parte de la tesis, luego de haber contrariado las críticas que habrían producido el supuesto agotamiento del que nos habla Kandel, estaremos en mejores condiciones de exponer y argumentar nuestra postura al respecto.
} 
como un desarrollo completamente legítimo y bienvenido de su trabajo pionero. ${ }^{35}$

(Solms \& Turnbull, 2011: 135).

Estos autores manifiestan su acuerdo con la perspectiva freudiana del conocimiento como modelo de la realidad y afirman que "la neurociencia ofrece una segunda perspectiva de la 'cosa' incognoscible que denominamos aparato mental, la cosa que Freud intentó describir por primera vez en su metapsicología" ${ }^{36}$ (ibíd. p.137). Algunos de los principales méritos de este enfoque han sido la integración de tratamiento psicoanalítico a la investigación de pacientes neurológicos (Kaplan-Solms \& Solms, 2000/2005) ${ }^{37}$ y la corroboración empírica de la teoría freudiana de los sueños más allá del ámbito clínico (Solms, 2001).

A pesar de que son conocidas las dificultades que conlleva utilizar diseños experimentales para testear las hipótesis psicoanalíticas, por ejemplo los problemas de operacionalizar conceptos de carácter metafórico y sumamente polisémicos (Fonagy, 1982), en las últimas décadas eso ha sucedido de una manera considerable. Las investigaciones de Howard Shevrin (2000, 2002) sobre el procesamiento preconsciente e inconsciente de la información en la memoria y los sueños, constituyen un buen ejemplo de ello. Shevrin ha investigado durante más de 40 años en la intersección del psicoanálisis con las neurociencias y la psicología cognitiva, fundamentalmente buscando evidencia experimental de los conceptos freudianos. Asumiendo que diversos fenómenos

\footnotetext{
35 "we do now have neuroscientific methods that enable us to study the dynamic nature of the mind and to identify the neural organization of its unconscious substructure [...] Freud would, in our opinion, have considered this a welcome and wholly legitimate development of the work that he pioneered".

36 "neuroscience offers a second perspective on the unknowable 'thing' that we call the mental apparatus, the thing that Freud attempted to describe for the first time in his metapsychology".

${ }^{37}$ Así presentan la perspectiva de sus investigaciones estos autores: "Irónicamente, debemos el desarrollo de un procedimiento clínico para analizar la estructura profunda de la vida mental subjetiva al hecho de que Freud abandonó los métodos neurocientíficos de investigación, cuando se dio cuenta de que estos eran incapaces de dar cabida a la naturaleza dinámica y 'virtual' del proceso mental. Ahora nos ha llegado la hora de reintroducir los frutos de los trabajos de Freud en el campo neurocientífico del cual surgieron originalmente [...] Lo que recomendamos, por lo tanto, y lo que creemos que ha de proveer los fundamentos para la integración duradera del psicoanálisis y la neurociencia, es una investigación totalmente psicoanalítica de los pacientes con lesiones neurológicas focales. En otras palabras, recomendamos que proyectemos la organización neurológica de los procesos mentales humanos que el psicoanálisis ha revelado, usando una versión modificada del método de Luria del análisis del síndrome, para estudiar la estructura profunda de los cambios mentales en pacientes neurológicos de manera que dicha estructura pueda discernirse dentro de un marco psicoanalítico" (Kaplan-Solms \& Solms, 2000/2005: 66).
} 
psíquicos pueden ser observados y redefinidos como magnitudes físicas de la actividad cerebral, ha indagado en el terreno compartido entre psicoanálisis y neurobiología. En 1968 dio a conocer la primera investigación sobre respuestas cerebrales a estímulos visuales inconscientes, arguyendo que ello proveía una fuerte evidencia objetiva sobre la existencia de procesos inconscientes (Shevrin \& Fritzler, 1968). En los últimos años, Shevrin aportó nuevos datos que corroboran un vínculo causal entre la noción de "conflicto inconsciente" y los síntomas experimentados por sujetos con trastornos de ansiedad, por ejemplo fobias. Él mismo ha reconocido que su investigación ha sido motivada por la crítica de Grünbaum: "en respuesta a estos desafíos, hemos aplicado nuestro método de investigación con el fin de encontrar pruebas independientes para la validez de las construcciones de la represión y el conflicto inconsciente" ${ }^{38}$ (Shevrin et. al., 2013: 2).

El espíritu de estas investigaciones interdisciplinarias ha sido sintetizado coherentemente por Juan Pablo Jiménez:

\begin{abstract}
La confianza absoluta -y excluyente- en el método clínico como forma de validación ha tenido importantes consecuencias para el desarrollo de la teoría y de la práctica psicoanalítica, las que se pueden resumir en una sola palabra: aislamiento. El aislamiento auto impuesto, tanto de las ciencias médicas como de las psicológicas, es quizás el mayor obstáculo para que el psicoanálisis se haga un lugar en la mesa de la academia del siglo veintiuno. (Jiménez, 2004).
\end{abstract}

También Fonagy denuncia el "espléndido aislamiento" del psicoanálisis respecto de las ciencias de nuestra época:

Mientras que el psicoanálisis clínico necesita poca ayuda para llegar a conocer la subjetividad de un individuo del modo más detallado posible, cuando desea generalizar a un modelo global de la mente humana, la disciplina no puede existir por sí sola. El hecho de que hace 50 años no hubiera otros campos de investigación relativos a la mente que ofrecieran una información merecedora de integrarse con el modelo psicoanalítico, es probablemente la raíz de nuestro encomiable esfuerzo por "recorrer el camino solos". Pero la escena científica ha cambiado radicalmente en las dos últimas décadas. Para decirlo en otras palabras, si bien se llega a conocer mejor la mente de un individuo en un marco de

\footnotetext{
38 "In response to these challenges, we applied our research method in order to find independent evidence for the validity of the constructs of repression and unconscious conflict."
} 
trabajo exclusivamente psicoanalítico, el modelo psicoanalítico general de la mente, si es que existe, debería alinearse con el conocimiento más amplio de la mente conseguido gracias a un abanico de disciplinas. $Y$ esto ya está sucediendo, si bien es cierto que de manera informal. (Fonagy, 2003: 218).

Fonagy considera que la investigación interdisciplinaria no puede testear la teoría psicoanalítica, pues "no puede demostrar que unas ideas psicoanalíticas determinadas son verdaderas o falsas" (ibíd. p.11), pero considera que sí puede contribuir a "elaborar los mecanismos mentales que se ponen en funcionamiento para generar los fenómenos que describen los escritos psicoanalíticos" (ibíd.). Es en ese sentido que

\begin{abstract}
el psicoanálisis podría beneficiarse si integrara sus teorías con los hallazgos de investigación de otros campos elaborando los modelos psicológicos psicoanalíticos de los mecanismos implicados en los procesos mentales claves. Esto ayudaría a su vez a sistematizar nuestra base de conocimiento de modo que esa integración con las nuevas ciencias de la mente se volviera cada vez más fácil. No sólo seríamos capaces de mostrar más fácilmente que nuestro tratamiento funciona, sino que tendríamos nuevas posibilidades de comunicar nuestros hallazgos a otros científicos. (ibíd. p.12).
\end{abstract}

Fonagy examina el caso de las investigaciones en genética del comportamiento y cómo el psicoanálisis podría aportar a las discusiones actuales, pues puede elucidar el "eslabón perdido en la cadena de la explicación que va desde los genes a la personalidad y la conducta" (ibíd., p.18), a saber, la forma en la que los sujetos interpretan su experiencia en el mundo: la realidad psíquica. Sugiere que las formas de constituir la realidad psíquica determinan la expresividad o no de ciertos genes, como parecen insinuar los estudios sobre el apego.

Más allá de los intercambios específicos, Fonagy cree que el "aislamiento autoimpuesto de los psicoanalistas" es autodestructivo:

privarnos de oportunidades de colaborar en el progreso científico podría dar lugar muy pronto a una pérdida injustificada de credibilidad científica e incluso, algo relacionado con esto pero más trágico todavía, a la pérdida de nuestra respetabilidad profesional en el mercado clínico dominado por la ciencia (ibíd.).

Una pregunta que ha cobrado forma en el seno de estos debates es si puede el psicoanálisis entablar un diálogo productivo con las neurociencias sin poner en 
riesgo su propia perspectiva. Aunque muchos analistas parecen apreciar los intercambios interdisciplinarios con las neurociencias, hay quienes expresan sus inquietudes respecto a un posible efecto deletéreo sobre la teoría y la práctica psicoanalíticas. Varios de los promotores de este tipo de desarrollos, dentro de la tradición naturalista, piensan que tales intercambios pueden ser necesarios (aunque no sean suficientes) para la viabilidad futura del psicoanálisis (Yovell et. al., 2015). Vemos, una vez más, la presencia de un cierto afán de viabilidad como motor de estos programas de investigación en psicoanálisis; cuyo supuesto de partida es el de una inquietante inviabilidad antecedente, originada fundamentalmente por las críticas epistemológicas y sobre un mismo núcleo de aspectos problemáticos. Todo esto a pesar de que formalmente se reconozca que "la neurociencia ya no es el tribunal de apelación final para el psicoanálisis, así como tampoco el psicoanálisis lo es para la neurociencia. El último tribunal de apelación para los psicoanalistas es la situación clínica” ${ }^{39}$ (Solms, 2013: 18; cursiva del original).

\section{c) Las investigaciones sobre la efectividad del psicoanálisis}

El asunto de la efectividad comparada de las distintas psicoterapias ha sido y sigue siendo uno de los tópicos más controversiales en diversos campos de la psicología clínica. En psicoanálisis han sido los partidarios de la tradición naturalista los que se han ocupado sistemáticamente del tema, dando cuenta de lo que podríamos llamar la contracara clínica de las mismas pretensiones de viabilidad epistemológica.

Entre las diversas razones por las que se han venido promoviendo y realizando estudios sobre la eficacia del psicoanálisis en las últimas décadas en el seno de la IPA, se destaca la necesidad de persuadir a los sistemas de salud de la necesidad de financiar los tratamientos psicoanalíticos (Lancelle, 1997); sobre todo cuando hay competidores cada vez mejor establecidos: "cuando diversos métodos terapéuticos se ofrecen como alternativas más rápidas, menos costosas y más eficaces que el psicoanálisis, el estudio de la eficacia del análisis se convierte en un desafío para los psicoanalistas"

\footnotetext{
39 "Neuroscience is no more the final court of appeal for psychoanalysis than psychoanalysis is for neuroscience. The final court of appeal for psychoanalysts is the clinical situation".
} 
(Rubistein y Trotta, 2004). Estos problemas, que en principio parecieran poder separarse de los asuntos de los que tradicionalmente se ha ocupado la epistemología, son vinculados una y otra vez con los problemas relativos a la legitimidad de la disciplina:

La llamada "paradoja de la equivalencia" -según la cual hasta el momento no ha sido posible demostrar la superioridad terapéutica de algún tipo de psicoterapia-, refuerza la afirmación de Grünbaum de que el psicoanálisis no ha aportado ninguna prueba de que sus resultados terapéuticos se deban a la verdad de las interpretaciones dadas a los pacientes y no al efecto placebo. (Jimenez, 2004).

Actualmente disponemos de evidencia contundente sobre la efectividad del psicoanálisis y de las distintas variedades de psicoterapias psicoanalíticas. Jonathan Shedler, en un interesante artículo de revisión, especifica que contamos con datos "que demuestran que los beneficios terapéuticos de sujetos que han recibido terapia psicodinámica no solo se mantienen, sino que además hacen que los pacientes sigan mejorando al cabo del tiempo" 40 (Shedler, 2010: 98). Incluso, hay evidencia de que "las terapias no psicodinámicas pueden ser efectivas en parte porque los terapeutas más experimentados utilizan técnicas que durante mucho tiempo han sido elementos centrales de la teoría y la práctica psicodinámica”" ${ }^{41}$ (ibíd.).

Las investigaciones de los últimos años comprueban que la eficacia de las psicoterapias psicoanalíticas tiene equivalente magnitud de efecto terapéutico que otras psicoterapias que suelen catalogarse como "basadas en la evidencia" o "apoyadas empíricamente". Shedler comenta su impresión al recabar la información sobre los metanálisis de estudios de eficacia:

\footnotetext{
En la redacción de este artículo me han sorprendido diversas ironías. Una es que los académicos que rechazan los enfoques psicodinámicos, a veces vehementemente, con frecuencia lo hacen en nombre de la ciencia. Algunos defienden una ciencia de la psicología fundamentada exclusivamente en el método experimental. $\mathrm{Y}$ pese a ello, el mismo método experimental llega a
}

\footnotetext{
40 "...evidence that patients who receive psychodynamic therapy not only maintain therapeutic gains but continue to improve over time".

41 "Nonpsychodynamic therapies may be effective in part because the more skilled practitioners utilize interventions that have long been central to psychodynamic theory and practice".
} 
conclusiones que apoyan los conceptos y tratamientos psicodinámicos ${ }^{42}$ (Shedler, 2010: 106).

Shedler se asombra también del hecho de que la mayoría de los psicoanalistas clínicos no estén familiarizados con los resultados generales de tales estudios sobre la eficacia: "del mismo modo que el sentimiento antipsicoanalítico puede haber impedido la divulgación de esta investigación en los círculos académicos, igualmente la desconfianza en los métodos de investigación académica puede haber impedido su divulgación entre los círculos psicoanalíticos"43 (ibíd.). Sin embargo, Shedler sostiene que la mayoría de los informes de resultados de investigación sobre estudios de eficacia terapéutica, están escritos en un lenguaje poco accesible para los analistas clínicos: son densos, complejos y muy técnicos; y con frecuencia parecen haber sido escritos principalmente para otros investigadores de psicoterapia y no para los clínicos. Todo lo cual redunda en un escaso o nulo aprovechamiento de los resultados.

Peter Fonagy comienza un artículo reciente destinado al tema afirmando que "la terapia psicodinámica (PDT) está en retirada en todo el mundo, ante las críticas de su credibilidad científica" (Fonagy, 2015: 137). Lo cual nos deja entrever nuevamente que el interés por este tipo de estudios se origina en las demandas epistemológicas mencionadas.

Fonagy considera que la mayoría de los metanálisis utilizados (que carecen de datos de pacientes individuales y se basan en tasas de respuesta y valores medios) para ponderar la significación general de la eficacia terapéutica encierran un problema crucial: pueden ser engañosos cuando los estudios aleatorizados controlados que se toman en cuenta no son homogéneos en cuanto a la población elegida como objetivo, el método de tratamiento y los criterios de valoración (ibíd.). Este suele ser el caso de los estudios sobre la

\footnotetext{
42 "In writing this article, I could not help being struck by a number of ironies. One is that academicians who dismiss psychodynamic approaches, sometimes in vehement tones, often do so in the name of science. Some advocate a science of psychology grounded exclusively in the experimental method. Yet the same experimental method yields findings that support both psychodynamic concepts"

43 "Just as antipsychoanalytic sentiment may have impeded dissemination of this research in academic circles, distrust of academic research methods may have impeded dissemination in psychoanalytic circles"
} 
eficacia de las terapias psicoanalíticas ${ }^{44}$. Otra de las dificultades señaladas por Fonagy es en torno a la definición misma de "psicoterapia psicodinámica", pues el conjunto que este término designa se ha vuelto cada vez más heterogéneo y sus límites cada vez más difusos.

Luego de analizar una serie de metanálisis, Fonagy concluye su artículo afirmando que para hacer avanzar este campo, no alcanza con reflexionar sobre la eficacia general de una categoría heterogénea de enfoque psicoterapéutico aplicado a un grupo heterogéneo de pacientes (p.ej. los que experimentan depresión); sino que se necesita una sistemática modularización de las intervenciones posibles y su interrelación, en combinación con las necesidades de pacientes individuales, a los fines de poder indagar coherentemente la eficacia ${ }^{45}$.

Algunos analistas francófonos también han sabido advertir el valor que implica conocer sobre la eficacia del psicoanálisis. Colette Soler, por ejemplo, no duda en afirmar que la prevalencia dada al dispositivo analítico se justifica porque

\begin{abstract}
...hay un éxito del psicoanálisis, es decir que hay logros terapéuticos: eso nos asegura, y eso le aseguró de entrada a Lacan, que hay un real en juego en este dispositivo. Por eso no hay que hablar con demasiado desprecio de los logros terapéuticos, porque, por empezar, no hay psicoanálisis sin éxito terapéutico, que aunque parcial es ciertamente necesario, y porque si no hubiera efecto terapéutico, eficiencia terapéutica, no quedaría, después de todo, nada del psicoanálisis, no quedaría nada para aseguramos de que todo ese bla-bla está conectado con algo real. (Soler, 1988/2007: 15).
\end{abstract}

\footnotetext{
${ }^{44}$ Recordemos, de pasada, que éste es el problema que Freud supo advertir en los estudios estadísticos sobre la eficacia. Es clara su manifestación luego de que el Instituto Psicoanalítico de Berlín hubiera publicado en 1930 el primer estudio estadístico, abarcando diez años de labor: "los éxitos terapéuticos no justifican la jactancia, pero tampoco dan lugar a avergonzarse. Sin embargo, tales estadísticas no esclarecen nada; el material procesado es tan heterogéneo que sólo muy grandes números significarían algo. Lo mejor es indagar las propias experiencias" (Freud, 1933/2004: 141).

${ }^{45}$ Otra revisión reciente con similares resultados es la de Leichsenring \& Klein (2015). Para una lectura interesante de algunas dificultades en el establecimiento de criterios para efectuar este tipo de metanálisis, cf. Leichsenring et. al. (2015). Un debate reciente sobre estos aspectos puede encontrarse en las objeciones de "poca claridad" de Stefan Hofmann (2016) a los metanálisis existentes y en la réplica de Leichsenring et. al. (2016).
} 
Aunque dudo mucho de que Soler y Fonagy se pudiesen poner de acuerdo sobre qué entender por eficacia y qué por éxito terapéutico, lo cierto es que gran parte de lo que motoriza el desafío de los estudios de eficacia de nuestra práctica, asumido por muchos comunidades analíticas, pareciera derivar, implícita o explícitamente, de los problemas epistemológicos y metodológicos que han promovido e instalado los grandes movimientos críticos en la disciplina.

\section{d) Las resistencias a la investigación empírica}

La relación entre la investigación empírica sistemática extra-clínica y el trabajo que realiza la mayoría de los psicoanalistas, ha sido siempre controvertida. Resulta muy sugerente el título de un trabajo de Peter Fonagy: "Agarrando la ortiga: o de por qué la investigación psicoanalítica es tan irritante" $^{46}$ (2000); pues alude metafóricamente a la difícil situación en la que se hallan los psicoanalistas dedicados a la investigación, habitualmente frustrados y desestimados por sus colegas clínicos, quienes rechazan vehementemente la naturaleza de su trabajo y sus resultados. Hay, al decir de Otto Kernberg (2006), una notoria "ansiedad de investigación" en la comunidad psicoanalítica, debido a las inquietudes que ella provoca.

Jonathan Shedler (2002) ha examinado el escepticismo con que los analistas ven a la investigación empírica y ha distinguido tres tipos de objeciones principales: que es imposible, que es innecesaria y que es irrelevante. Shedler cree que la primera objeción puede ser la opinión prevalente, pues debido a los intentos frustrados de vincular la investigación empírica con el ámbito de trabajo clínico, muchos se han sentido tan decepcionados por los resultados que han abandonado la esperanza:

No ven modo de cuantificar las construcciones psicoanalíticas importantes $\sin$ trivializarlas y distorsionarlas. Les desanima el tipo de reduccionismo que ha

\footnotetext{
46 "Grasping the nettle: Or why psychoanalytic research is such an irritant"
} 
caracterizado la investigación empírica en el pasado. A partir de la observación "no se ha hecho" han razonado "no puede hacerse". ${ }^{47}$ (Shedler, 2002: 430)

La segunda objeción (que la investigación empírica es innecesaria) proviene de aquellos analistas que consideran al método analítico como algo necesario y suficiente para generar, validar y revisar la teoría. Shedler afirma que uno de los problemas de esta consideración es que décadas de investigación analítica tradicional no han podido resolver las diferencias teóricas que dividen a nuestra disciplina:

Tenemos modelos que compiten entre sí con diferentes implicaciones para la técnica y los defensores de cada uno de esos modelos publican regularmente estudios de casos que "demuestran" la superioridad de su enfoque. Los estudios de casos no parecen hacer cambiar a nadie de opinión, porque los analistas de diferentes tendencias ven cosas diferentes en un material clínico prácticamente igual. ${ }^{48}$ (Shedler, 2002: 430)

Las creencias teóricas de los analistas parecen apoyadas más en la identificación con quienes estuvieron a su cargo en su formación, con sus supervisores y con su propio analista, que en la significación de la evidencia empírica. A su vez, sostiene Shedler, las pruebas obtenidas son mayoritariamente a partir de casos clínicos, cosa que ha servido como evidencia sólo para los propios analistas y que ha sido insuficiente para los interesados provenientes de otras disciplinas (ibíd. p. 431).

La tercera objeción (que la investigación empírica es irrelevante) es mantenida por aquellos analistas que piensan que las reglas de la ciencia no se pueden o no se deben aplicar al psicoanálisis; cuya versión central ha sido sostener que el psicoanálisis es hermenéutica, no ciencia (ibíd. p.431). Una versión postmoderna de esta postura proviene de las corrientes intersubjetivistas según Shedler, que consideran al encuentro psicoanalítico

\footnotetext{
47 "They see no way to quantify important psychoanalytic constructs without trivializing and distorting them. They are turned off by the kind of reductionism that has characterized empirical research in the past. From the observation 'it has not been done' they have reasoned 'it cannot be done'."

48 "We have competing models with different implications for technique, and advocates of each model regularly publish case studies "demonstrating" the superiority of their own approach. The case studies do not seem to change anyone's mind, because analysts of different persuasions see different things in much the same case material"
} 
como una construcción intersubjetiva en la que el analista y el analizando construyen juntos una realidad única. Pero,

\begin{abstract}
Por mucho que valoremos la singularidad de nuestros pacientes, no nos aproximamos a ellos en un vacío. Si tenemos experticia en el tratamiento del sufrimiento humano, es precisamente porque podemos reconocer aspectos comunes en los pacientes y comprender su sufrimiento en un contexto más amplio de patrones y síndromes conocidos. ${ }^{49}$ (Shedler, 2002: 431-432).
\end{abstract}

Como podemos notar, en las objeciones que Shedler ubica en el escepticismo hacia la investigación empírica aparecen involucrados varios aspectos de diferente índole: desde objeciones pesimistas basadas en la experiencia previa hasta argumentos basados en asunciones epistémicas (no siempre explicitadas) respecto a la naturaleza del conocimiento psicoanalítico.

Los defensores del método clínico tradicional para la investigación en psicoanálisis tienen, sin embargo, una mirada diferente de estas cuestiones.

\title{
e) La defensa del método clínico psicoanalítico para investigar
}

Los partidarios de la investigación clínica parten de una crítica a la concepción de ciencia preponderante en los enfoques naturalistas de investigación, a la vez que sostienen al procedimiento tradicional de estudio de casos como el único método apropiado para investigar y desarrollar el psicoanálisis (Green, 1996; Lothane, 1998; Nasio, 2001; Perron, 1999; Wolff, 1996).

Según Roger Perrón la investigación clínica tiene tres objetivos fundamentales. En primer lugar, en sintonía con la investigación clínica de la medicina y la psiquiatría, apunta a definir síndromes psicopatológicos, a establecer y a revisar categorías nosológicas. En segundo lugar, se propone formular construcciones teóricas: es la investigación clínica la que ha permitido el desarrollo de los grandes modelos teóricos en psicoanálisis, incluso después

\footnotetext{
49 "However much we may value the uniqueness of our patients, we do not approach them in a vacuum. If we have expertise in treating human suffering, it is precisely because we can recognize commonalities across patients and understand their suffering in the broader context of familiar patterns and syndromes".
} 
de Freud. En tercer lugar, la investigación clínica aspira a proveer fundamentos conceptuales para el abordaje terapéutico (Perron, 1999: 4).

Los defensores de esta metodología sostienen que éste es el camino que Freud siguió para investigar, llegando a establecer modelos de funcionamiento de la neurosis obsesiva, la histeria, la fobia y la paranoia, genialmente ejemplificados con sus conocidos casos ejemplares. Muchos afirman que éste debe seguir siendo el recurso esencial de toda investigación psicoanalítica y que no hay necesidad alguna de buscar vías alternativas. Por otro lado, intentar cumplir con varios de los requisitos metodológicos ideados para evaluar la investigación en ciencias naturales, no contribuye sino a una destrucción del objeto de estudio psicoanalítico. Además de ello, tales requisitos (cuantificación de las variables, replicabilidad de la observación, posibilidad de predicción, etc.), lejos de ser universalmente aceptados han sido discutidos desde diversas perspectivas filosóficas de las ciencias naturales; lo cual resta razonabilidad a su extrapolación indiscutida al psicoanálisis.

Se ha afirmado que toda investigación fuera de la situación psicoanalítica, por ejemplo la investigación cuasi-experimental de las teorías, resulta imposible porque no puede captar la complejidad de los conceptos y modelos psicoanalíticos en situación natural y por lo tanto resulta irrelevante para el psicoanálisis y su práctica (Masling y Bornstein, 1996; Westen, 2002; Shedler, 2002). Por lo tanto, para los partidarios del enfoque clínico, la tesis freudiana de la unión inseparable entre curar e investigar, mantiene su vigencia.

André Green (1996, 2000a) no ha vacilado en sugerir que la investigación extra-clínica, en tanto que atenta contra la pureza del psicoanálisis, puede resultar peligrosa: sólo el método tradicional de estudio de casos puede captar las complejidades de los modelos psicoanalíticos sin distorsionarlas o trivializarlas.

Por otro lado, algunos hacen hincapié en el instrumentalismo que deben tener los modelos metapsicológicos, lo cual vuelve absurda su pretendida ampliación experimental. Donald Spence (1984), por ejemplo, quien defiende la perspectiva de atenerse a una verdad narrativa para entender el valor de los hechos clínicos, desestima por ello toda búsqueda de relaciones nomológicas relativas a la conducta. 
Una buena manera de entender la posición de unos y otros es analizar el modo en que el debate se ha materializado en agentes concretos, con todo lo que ello supone.

\section{Encarnaduras de esas diferencias}

\section{a) El debate de Green vs. Wallerstein y Stern}

Es conocida la polémica que Green mantuvo con Robert Wallerstein sobre la forma en que debería articularse la investigación en psicoanálisis. Wallerstein afirmó que pese al pluralismo teórico y técnico del psicoanálisis es posible notar una conceptualización clínica común a medida que nos acercamos a un nivel empírico y que sólo en los niveles más abstractos o metafóricos de la metapsicología existen disidencias significativas (Wallerstein, 2005/2006a). Este "terreno común en nuestra teoría clínica" incluye "las conceptualizaciones compartidas acerca de los fenómenos perceptibles en nuestros consultorios: la resistencia y la defensa, la angustia, el conflicto y las formaciones de compromiso, la representación del self y del objeto, la transferencia y contratransferencia, etc." (ibíd. p. 659). Wallerstein considera factible esperar que tales convergencias a nivel de la base clínica se deriven a nivel de la teoría, en un movimiento que aspire a "trascender el pluralismo teórico compartimentalizado retóricamente de nuestros días, con vistas a una 'convergencia' o 'terreno común'” (ibíd. p. 653).

Por su parte, Green creía que esas afirmaciones de Wallerstein debían comprenderse en términos políticos y a partir de su situación de Presidente de la IPA: "le incumbe a un presidente fomentar, entre los miembros de la entidad que dirige, una unidad que trascienda las fronteras geográficas e ideológicas" (Green, 2005/2006, p. 657); pero piensa que esa base común es una ilusión peligrosa (al igual que el Esperanto) y que si nos remitimos a las discusiones actuales no hallamos ningún ejemplo convincente de ello, sino un pseudopluralismo en el que no hay una verdadera apertura a las ideas del otro.

Green caracteriza de caóticos a los debates contemporáneos, situación que refuta la pretendida existencia de un pluralismo con base común. "Ya que este 
pluralismo no existe -afirma Green-, tenemos que comenzar a crearlo, lo cual significa instituir una comunicación genuina entre las distintas corrientes de pensamiento y fomentar una discusión en profundidad de los principios subyacentes en las principales posturas teóricas que rigen el psicoanálisis contemporáneo" (Ibíd., p. 663). En ese sentido, la existencia de una "base común" no puede postularse a partir de la simple comparación entre conceptos de distintas teorías. Green cree que el único procedimiento válido que nos permitiría hablar de una base común es

\begin{abstract}
indicar de qué manera cierto material clínico consistente y basado en la exposición de una secuencia de sesiones y de un proceso psicoanalítico de suficiente extensión puede demostrar el parentesco entre dos teorías distintas, que recordémoslo- se fundan en diferentes técnicas e interpretaciones. No obstante, por lo que sé, esto nunca se ha intentado ${ }^{50}$ (Green, 2005/2006, p. 659).
\end{abstract}

Para Green, el psicoanálisis es una práctica basada en el pensamiento clínico que da origen a hipótesis teóricas, por lo que la investigación conveniente es exclusivamente clínica. El diálogo con otras disciplinas supone el riesgo de contaminación de este pensamiento clínico, susceptibles de destruir el verdadero psicoanálisis (p.661). Unos años antes, apoyado en el pensamiento de la complejidad, había manifestado ampliamente estas ideas:

El psicoanálisis se sitúa en la encrucijada entre estas dos grandes tendencias [naturaleza y cultura]. [...] Cualquiera que sea el interés de las informaciones recibidas por parte del campo de las ciencias conexas, lo esencial de la investigación en psicoanálisis me parece que debe situarse del lado de la práctica y la clínica psicoanalíticas cuya referencia es indispensable para mantener el rumbo del pensamiento psicoanalítico. El psicoanálisis es la ciencia fundamental del psiquismo y no encuentra su referencia en otras ciencias fundamentales de las que él mismo sería una aplicación (Green, 2000/2010: 315).

En ese sentido, esa noción de "pensamiento clínico" coagula una perspectiva sobre la naturaleza de la disciplina y de la investigación:

El pensamiento clínico crea conceptos que tratan con las razones del inconsciente y sus parámetros, la diversidad de respuestas que son exigidas por ellas, sus transformaciones, su racionalización, bajo la influencia de contrainvestidura que en

\footnotetext{
${ }^{50}$ Wallerstein, como veremos, rescatará elogiosamente esta afirmación de Green.
} 
ciertas instancias inducen desinvestiduras [...]. Es dialógico: es una racionalidad entre psicoanalistas que comparten la misma experiencia y convicción de que el así llamado razonamiento científico objetivo no es apropiado para la comprensión de los problemas mentales. (Green, 2000/2010: 28-29).

Green se pregunta qué han aportado las metodologías científicas al psicoanálisis hasta el momento, y responde sin ambages que "el método científico hasta el presente ha demostrado ser estéril en psicoanálisis" 51 (Green, 2000a: 47):

\begin{abstract}
Comparada con la riqueza de la experiencia clínica del psicoanálisis, los hallazgos de los investigadores parecen magros. Por tanto, uno tiene que ser muy cauto con la pretensión de liderazgo de los que están tras la investigación. Es esencial preservar lo que es específico del esfuerzo psicoanalítico, ya que algunos de los requisitos que hacen posible la investigación implican una simplificación del conocimiento psicoanalítico, convertida en precondición de la vía que conduce el psicoanálisis a ser una ciencia de hechos $\operatorname{probados}^{52}$ (Green, 2000b: 21).
\end{abstract}

Para Green, el hecho de que muchos psicoanalistas realicen investigaciones empíricas no vuelve a su trabajo una actividad que se relacione directamente con el psicoanálisis. Lo que Green desestima es la aplicación práctica de los resultados de tales investigaciones empíricas a la situación clínica; por ejemplo los trabajos de Stern (2000) y de Fonagy (2003).

Sabemos que Daniel Stern, considerando las relaciones intersubjetivas en la construcción psíquica, se ha ocupado principalmente de investigar las interacciones pre-verbales y no-verbales de la relación madre-bebé a partir de diseños observacionales fuera de la sesión analítica; intentando de este modo construir puentes de comunicación interdisciplinaria. Respecto de ello, Green mantiene el mismo posicionamiento: cree que los datos empíricos obtenidos con métodos observacionales están bien para los conductistas, pero no para investigar en psicoanálisis:

La observación no es algo muy apropiado para el psicoanálisis. La observación de la relación entre la madre y el bebé, o cualquier otra observación, sólo puede ver

\footnotetext{
51 "the scientific method till the, present has proved to be sterile in psychoanalysis".

52 "Therefore, one has to be very cautious about the pretence to leadership of those who stand behind research. As some of the results of the requirements to make research possible end with an oversimplification of psychoanalytic knowledge, defended as a precondition of the path that would lead psychoanalysis to a science of proven facts..."
} 
las manifestaciones externas de cada partícipe. Lo que se expresa exteriormente y puede observarse no es una traducción de lo que sucede interiormente, en el mundo inconsciente interno. (Green, 2003/2011: 288).

Los únicos "observables" en psicoanálisis son, para Green, los fenómenos psíquicos tal y como se le presentan al clínico en el contexto analítico; de modo que para abordarlos no se poseen herramientas directas sino recursos indirectos aportados por el material verbal:

\begin{abstract}
Tenemos que preguntarnos qué método es apropiado para tratar con el tipo de material con que nos encontramos en nuestra experiencia psicoanalítica. He llegado a la conclusión de que, en lo que concierne a la actividad psíquica (diferente en esencia de los mecanismos neurológicos y, por supuesto, de las computadoras), la ciencia tiene que cambiar sus parámetros para hacer justicia a los hechos que investiga. [...] En la mayoría de las investigaciones hay una negligencia en cuanto a la especificidad de lo que es intrapsíquico e inconsciente y una subestimación de los parámetros de la situación analítica relacionados con el concepto de encuadre, con la idea implícita de que un procedimiento observacional de la relación interpersonal puede explicar mejor el objeto del psicoanálisis que las especulaciones que los psicoanalistas elaboran partiendo de su experiencia terapéutica ${ }^{53}$ (Green, 2000b: 23-24).
\end{abstract}

El problema de la observación de bebés ${ }^{54}$, a los ojos de Green, es que allí se produce una separación ilícita del marco teórico en el que son formalizados los descubrimientos. Green rechaza la utilización de otros marcos de la ciencia para interpretar los datos, pues considera que así se pierde la esencia del psicoanálisis. Sin embargo, Green sostiene: "nosotros seguimos en búsqueda

\footnotetext{
53 "We have to ask ourselves what method is appropriate for dealing with the type of-material met with in our psychoanalytic experience. I came to the conclusion that as far as psychic activity was concerned (different in essence from neurological mechanisms and, needless to say, computers), science has had to change its parameters to do justice,to the facts that it investigates. [...] There is a neglect in most of the investigations of the specificity of what is intrapsychic and unconscious, and an underestimation of the parameters of the analytic situation related to the concept of the setting, with the implicit idea that an observational procedure of interpersonal relationships can better account for the object of psychoanalysis than the speculation of psychoanalysts drawn from their therapeutic experience."

${ }^{54}$ Estas objeciones también alcanzan el modelo teórico de raigambre kleiniana de Esther Bick para la observación de bebés. No nos detendremos en ello porque el de Bick no constituye propiamente un método de investigación sino más bien un procedimiento pedagógico que suele estar incluido en la formación de terapeutas y psicoanalistas de niños, tendiente al perfeccionamiento del observador y sus implicancias para el ejercicio clínico (Bick, 1964; 1968, 1986).
} 
de un método de investigación que sea coherente, no con el contenido del psicoanálisis sino con el tipo de pensamiento que es su verdadero objeto" 55 (Green, 2000a: 37).

Ricardo Steiner sintetiza bien esta diferencia de perspectivas cuando afirma que "según Green nosotros solo podemos reconstruir aquellos eventos postfactum con todas las complicaciones, distorsiones, procesos inconscientes y defensas, y personales proyecciones del adulto observador o interpretador 0 narrador de estos eventos. Este punto de vista está en el núcleo del desacuerdo de Green con Stern y otros investigadores"56 (Steiner, 2000: 4). Más allá de estas divergencias teóricas, no podemos obviar que también existen diferencias vinculadas a la disputa por la hegemonía del pensamiento francés o anglosajón en los diferentes países. André Green y Daniel Stern han sido y siguen siendo referentes de corrientes de pensamiento en la actualidad, en sus respectivas orientaciones.

Wallesrstein no está de acuerdo con Green en la naturaleza absolutamente sui generis del psicoanálisis ni en la independencia que debería mantener respecto a otras disciplinas:

Mi postura en esto difiere, ya que creo que desde luego el psicoanálisis es una disciplina independiente, que tiene sus raíces en la exploración del funcionamiento de los procesos psíquicos inconscientes, pero que tiene puntos de conexión -y la oportunidad de realizar intercambios mutuamente enriquecedores- con toda una gama de disciplinas que estudian la conducta humana, desde la filosofía y la lingüística en un extremo del espectro, hasta la psicología cognitiva y las neurociencias modernas, en el otro. (Wallerstein, 2005/2006b: 671).

Wallerstein adopta el ejemplo de la física, que a su entender no tolera las incompatibilidades teóricas a su interior y procede esforzándose por trascender la parcialidad de teorías en apariencia inconciliables, apuntando a configurar una perspectiva abarcadora. Sostiene que "cualquier disciplina que pretenda alcanzar un estatus científico necesita tratar de hacer lo mismo y no 'celebrar'

\footnotetext{
55 "We are still in want of the method for research that is coherent, not with the content of psychoanalysis, but with the type of thinking that is its true object."

56 "....according to Green we can only reconstruct those events post factum with all the complications, distortions, unconscious processes and defences, and personal projections of the adult observer or interpreter or narrator of those events. This viewpoint is at the core of Green's disagreement with Stem and other researchers."
} 
la diversidad de teorías incompatibles en su seno, como hacen una proporción significativa de psicoanalistas actuales" (ibíd. p.671).

Además, Wallerstein sostiene que Green reprueba la situación actual tildándola de caótica, pero que no tiene respuesta para las preguntas sobre "cómo se decide, o quién decide, cuándo un pensamiento psicoanalítico es auténtico, o cuándo un autor "ha expuesto bien sus argumentos"' (ibíd. p.672). Sin embargo, Wallerstein cree encontrar un punto de significativo encuentro entre su perspectiva y la de Green: "lo que anhela Green es, precisamente, lo que siempre quise significar yo cuando hablaba de la investigación empírica necesaria sobre la cual debe descansar la construcción gradual del conocimiento psicoanalítico, nada más y nada menos" (ibíd. p.673).

La discrepancia fundamental entre ambos radica en que para Wallerstein, a diferencia de lo que piensa Green, el psicoanálisis necesita enmarcar sus particularidades en el terreno de los requerimientos generales de la ciencia, estableciendo criterios de validación empírica que permitan estipular la validez y la confiabilidad de las teorías y prácticas psicoanalíticas. Es atendiendo a esta perspectiva que puede comprenderse su opinión sobre un futuro signado por "el crecimiento conjunto de un marco general primero clínico y luego, cabe esperar, teórico para el psicoanálisis." (Wallerstein, 2005/2006a: 653).

A una década de su producción, el debate entre Green y Wallerstein, lejos de haberse resuelto, parece estar radicalizándose.

\section{b) El debate de Hoffman vs. Eagle, Wolitzky y Safran}

En virtud de que la discusión sobre la naturaleza hermenéutica o naturalista del psicoanálisis tuvo un lugar central en las décadas de 1970 y 1980, se podría presuponer que está superada. A mi modo de ver, lejos de haber sido superada, continúa renovándose y permanece vigente. Como ejemplo, además del debate de Green con Wallerstein y Stern, podemos detenernos en la polémica mantenida entre Irwin Hoffman por un lado y David Wolitzky, Morris Eagle y Jeremy Safran por el otro.

Irwin Hoffman ha ido en la dirección hermenéutica para sostener que quienes aspiran a la investigación naturalista terminan dañando el trabajo clínico del analista, que actualmente no es otro que el estudio en profundidad 
de casos únicos, basado en una orientación hermenéutica y constructivista que admite la incertidumbre y la singularidad (Hoffman, 2009).

Hoffman considera que la investigación empírica sistemática sobre el proceso y los resultados del análisis se ha puesto de moda por razones políticas, económicas y morales; y se propone denunciar los peligros de esta tendencia:

\begin{abstract}
Mi tesis es que la posición privilegiada que este movimiento concede a la investigación sistemática y a la neurociencia, en comparación con los estudios de caso en profundidad y las consideraciones estrictamente psicológicas del proceso psicoanalítico, es epistemológicamente injustificada y potencialmente perjudicial tanto para el desarrollo de nuestra comprensión del proceso analítico en sí mismo como para la calidad de nuestro trabajo clínico. ${ }^{57}$ (Hoffmann, 2009: 1044).
\end{abstract}

Este analista de Chicago aclara que no desestima la investigación empírica sistemática, pero sostiene que concederles un estatus de orden superior en relación con otras fuentes de conocimiento, como los estudios de caso, es injustificado y potencialmente destructivo. También se ve en la necesidad de aclarar que sus ideas no se basan en la distinción entre el analista y el investigador, sino en una separación más amplia que no se confunde con la anterior: el objetivismo y el constructivismo, en tanto que ambos tipos de perspectivas psicoanalíticas se hallan en el trabajo clínico y en el trabajo investigativo (ibíd. pp. 1045). Veremos que el autor apoya esta última dicotomía en la misma distinción general que hemos utilizado entre una tradición naturalista y otra hermenéutica.

La investigación empírica sistemática presupone, dice Hoffman, que como resultado de tales estudios un analista podría llegar a conocer mejor, por ejemplo, qué tipo de pacientes bajo qué circunstancias requieren qué tipo de intervenciones. El problema que ve Hoffman es que las hipótesis que surgen de tales investigaciones resultan tener una legitimidad superior y que fácilmente pueden conducir prescripciones autoritarias sobre la práctica clínica (ibíd. pp. 1046). Además, Hoffman cree que existe un prejuicio arraigado en los

\footnotetext{
57 "My thesis here is that the privileged status that this movement accords systematic research and neuroscience as compared with in-depth case studies and strictly psychological accounts of the psychoanalytic process is unwarranted epistemologically and potentially damaging both to the development of our understanding of the analytic process itself and to the quality of our clinical work".
} 
partidarios de la investigación empírica sistemática: la alternativa a ello es un relativismo posmoderno radical en el que prácticamente cualquier teoría sería tan válida como cualquier otra. Este prejuicio es un efecto, nos dice el autor, del hecho de que los partidarios del naturalismo no abordan las objeciones al paradigma de las ciencias naturales (críticas que están en consonancia con lo mejor de la tradición hermenéutica), ni consideran a la perspectiva alternativa en la generación de conocimiento que esa tradición promueve. A su modo de ver, los naturalistas desestiman el valor del diálogo crítico constructivo que distintos autores de la tradición hermenéutica promueven (como Gadamer o Habermas) y que puede ser recuperado para cuestionar las premisas del enfoque de investigación empírica sistemática, a la vez que explorar otras vías de conocimiento (ibíd. pp. 1052).

Hoffman considera que en la práctica analítica lo que cuenta es la "singularidad consecuente" de cada una de las elecciones subjetivas, enmarcadas en la relación transferencial con el analista. Tales aspectos difieren, en lo esencial, de las disciplinas médicas por ejemplo, en las que lo singular es secundario respecto de los rasgos comunes que permiten identificar y clasificar al caso, y en donde las destrezas técnicas predominan por sobre la personalidad del médico (p. ej., un antibiótico es eficaz o no más allá de quien lo recete). Es decir, hay elementos activos en un tratamiento médico que pueden descontextualizarse hasta el punto en que nada relevante se pierda en su comprensión cuando se hacen estudios sistemáticos; mientras que en el conocimiento psicoanalítico los aspectos centrales son contexto-dependientes y sólo pueden captarse a partir de los estudios de caso: "los estudios empíricos sistemáticos simplemente no controlan la singularidad consecuencial del analista, del paciente, de su relación, y del momento"58. (Ibíd. p. 1050).

Hoffman analiza los resultados que dan Westen y Shedler sobre la conformidad de los analistas en la utilización del SWAP ${ }^{59}$ para describir un

\footnotetext{
58 "Systematic empirical studies simply do not control for the consequential uniqueness of the analyst, of the patient, of their relationship, and of the moment."

${ }^{59}$ El Procedimiento de Evaluación Shedler-Westen (SWAP), diseñado por Jonathan Shedler y Drew Westen $(1998,1999)$ es un instrumento basado en la metodología Q-sort y diseñado para que el clínico pueda evaluar la personalidad del paciente a partir de su conocimiento longitudinal del caso. Consta de 200 ítems con afirmaciones que se clasifican en categorías a partir de su grado de aplicabilidad al paciente. Según los autores, "el método se utiliza para desarrollar una nueva taxonomía de los trastornos de la personalidad, como alternativa al DSM,
} 
paciente y admite que son impresionantes: la gran mayoría de los analistas y psiquiatras entrevistados están conformes con su potencial descriptivo. Pero Hoffman le pregunta al lector:

Si estaba buscando un terapeuta, a quién prefiere: ¿a un terapeuta que siente que los 200 elementos ordenados del SWAP captura la mayoría de lo que es verdad acerca suyo como persona, o un terapeuta de la minoría del $20 \%$ que siente que las cosas importantes acerca suyo se pierden por este instrumento? Piénselo ${ }^{60}$. (ibíd.).

Hoffman afirma que pondría su confianza y su dinero en el segundo, en la medida en que seguramente se trata de alguien respetuoso de la singularidad individual de cada paciente, abierto a trabajar con eso nuevo y desconocido respecto de su experiencia previa. Es la preponderancia de este carácter irrepetible de cada caso, la singularidad de los fenómenos clínicos, lo que nos debe llevar a privilegiar la perspectiva ideográfica por sobre la nomotética, según Hoffman. El desafío cosiste en buscar un punto intermedio entre el conocimiento universalizable y su aplicación ecuménica por un lado, y la idiosincrasia personal de cada paciente en cada singular situación transferencial por el otro.

Lo que Hoffman ve como peligroso, en el pretendido privilegio que algunos quieren darle a la investigación empírica sistemática, es el hecho de que los defensores de la psicoterapia basada en la evidencia aspirarán a configurar nuestras "normas" de la práctica clínica; algo que está lejos de tener un justificativo epistemológico (ibíd. p. 1056). Sostiene que algunos de los que defienden la investigación "objetivista" (refiriéndose explícitamente a Peter Fonagy) caen en una especie de "doblepensar" (doublethink) como el que describe George Orwell en su novela $1984^{61}$, en tanto afirman que "nuestras

que es empíricamente sólida y psicoanalíticamente relevante” (Shedler, 2002: 429). [“The method is being used to develop a new personality disorder taxonomy, as an alternative to the DSM, that is both empirically grounded and psychoanalytically relevant"].

60 "....if you were looking for a therapist, whom would you prefer: a therapist who feels that the 200 sorted items of the SWAP captures most of what is true of you as a person, or a therapist in that 20 percent minority who feels that important things about you are missed by this instrument? Think about it".

61 Recordemos que "doblepensar" es un neologismo que forma parte del léxico de la "neolengua" en la obra de Orwell: "Doblepensar significa el poder, la facultad de sostener dos opiniones contradictorias simultáneamente, dos creencias contrarias albergadas a la vez en la 
preocupaciones metodológicas y epistemológicas 'no deben ser apartadas $\mathrm{u}$ olvidadas', pero también que no deberíamos permitir que 'se conviertan en un enfoque alternativo', y que no deberíamos dejar que 'debiliten nuestras energías' al hablar de ellos, incluso entre nosotros mismos!"”2 (Ibíd. pp. 1058; cursiva añadida). Otro ejemplo de este doblepensar se halla, nos dice Hoffman, en el corazón del Manual Diagnóstico Psicodinámico (PDM), en donde se reconoce que, con el tiempo, cada paciente termina por desencajar de la categoría diagnóstica debido a su individualidad; pese a lo cual, a los efectos de la planificación del tratamiento y del proceder del terapeuta en las primeras fases, se sostiene que es clínicamente útil la clasificación ${ }^{63}$. Es decir, se sostiene y sugiere hacer una clasificación y, al mismo tiempo, se alerta sobre la inutilidad consecuente de la taxonomía.

Hoffman considera que toda la literatura emergente en los últimos años, en la que se da privilegio a los estudios controlados y se contemplan ciertas críticas autorizadas al psicoanálisis, sirve, al fin y al cabo, para mantener el dominio sobre otras concepciones del psicoanálisis como ciencia y sobre otros puntos de vista en cuanto a lo que se requiere para establecer su legitimidad.

Jeremy Safran, en una mesa redonda organizada a partir del escrito de Hoffman, manifiesta su desacuerdo con él ${ }^{64}$. Lo primero que manifiesta Safran,

mente" (Orwell, 1948/1980: 103). Es algo que, forzando un poco el sentido y yendo más allá del propio Hoffman en su metáfora, podemos vincular con la desmentida freudiana. Llevando el asunto al extremo podríamos preguntarnos si una investigación que reniega de la naturaleza de los fenómenos clínicos no es acaso una forma de perversión.

62 "...we are told that our methodological and epistemological concerns "should not be set aside or forgotten about," but also that we should not allow them "to become an alternative focus," and that we should not let them "sap our energies" by talking about them even among ourselves!"

\footnotetext{
63 "Me parece que fácilmente podría argumentarse -dice Hoffman- que el terapeuta haría bien, incluso al principio, o especialmente al principio, en superar su ansiedad de no saber exactamente cómo categorizar a esta persona, por eso mismo, no sabiendo exactamente qué sería lo óptimo para hacer de momento a momento, en lugar de retirarse a una ilusión de 'conocimiento' sobre la persona y sobre el 'tratamiento de elección'" (ibíd. p. 1059; cursivas añadidas). [lt seems to me it could easily be argued that the therapist would do well, even at the beginning, or especially at the beginning, to overcome his or her anxiety about not knowing just how to categorize this person and therefore not knowing just what would be the optimal thing to do from moment to moment, rather than retreating into an illusion of "knowledge" about the person and about the "treatment of choice"].
}

${ }^{64}$ Un par de años más tarde, Safran publica el trabajo de esta ponencia como artículo de revista (Safran, 2012). Aunque los argumentos son prácticamente los mismos, tomaremos como referencia la ponencia original. 
aclarando que se considera a sí mismo un psicoanalista y un investigador en psicoterapia, es que la investigación comparativa de resultados o ensayos clínicos aleatorios (RCT) tiene serias limitaciones cuando se trata de utilidad clínica inmediata: "Información sobre cómo el paciente promedio responde a una determinada marca de tratamiento es irrelevante para el clínico en ejercicio, quien necesita ayuda reflexionando sobre cómo responde a un paciente particular en un momento particular" (Safran, 2010: 1). En ese sentido, concede que las preocupaciones de Hoffman están bien fundadas: las corrientes principales hacen caso omiso de tales limitaciones y promueven este tipo de estudios en relación con orientaciones biológicas o cognitivoconductuales. Sin embargo, Safran considera que Hoffman se equivoca al asumir en su argumento una premisa falsa, a saber: aquella que sostiene que el estudio de caso sería adecuado solo para el "contexto de descubrimiento" mientras que la investigación empírica sistemática se ubicaría en el "contexto de justificación". Safran recuerda que esa distinción es obsoleta en la filosofía contemporánea de la ciencia y que hoy podemos entender a la ciencia como una empresa más compleja. En la búsqueda constante de caminos para sortear los extremos del objetivismo y el relativismo, podemos ver que los procesos de diálogo tienen un lugar privilegiado. En ese sentido, Safran sostiene que "si bien los ensayos clínicos aleatorizados y otras formas de investigación en psicoterapia tienen varias limitaciones, ellos juegan un papel significativo en el contexto de una conversación en marcha más amplia, que incorpora, interpreta y sopesa varias formas de evidencia"65 (ibíd. p.2). Safran piensa que Hoffman ignora cómo la filosofía contemporánea de la ciencia reconoce los aspectos hermenéuticos de la ciencia, y como, a pesar de criterios universales para decidir sobre teorías rivales, hace hincapié en la naturaleza progresiva del conocimiento.

Entiende que en el argumento de Hoffman hay dos aspectos que conviene distinguir. Por un lado, la crítica a la tendencia de privilegiar la investigación empírica debido a que "diseca la experiencia humana". Tendencia exacerbada por el modelo de la práctica basada en la evidencia que ha llegado a dominar

65 "While randomized clinical trials and other forms of psychotherapy research have various limitations, they do play meaningful roles within the context of a broader ongoing conversation that incorporates, interprets and weighs various forms of evidence." 
nuestro sistema de salud. Por otro lado, la crítica al "doble pensamiento". Según Safran, Hoffman cree que aquellos que defienden la investigación empírica son colaboradores del establishment científico que trata de debilitar a los psicoanalistas que defienden valores como la complejidad, la libertad humana y la dignidad de la persona. Es por eso que Hoffman pretende contestar a las demandas, reales y posibles, sobre cómo trabaja el psicoanálisis, en términos filosóficos; y Safran acuerda con el planteo de Hoffman, quien sostiene:

\footnotetext{
Preguntas como '¿Qué es una buena manera de estar en este momento?' ‘Qué motivos humanos son los más importantes?' ¿Qué constituye la buena vida?', están implícitamente implicadas. Este tipo de preguntas no pueden y no deben ser adjudicadas enteramente por 'la ciencia'66 (Hoffman, op. cit. p. 1049).
}

Sin embargo, Safran considera que responder en estos términos es contraproducente para el psicoanálisis, pues reafirma la posición de un público cada vez más frustrado y resentido con este tipo de respuestas. Para él hay cierto nivel de arrogancia y elitismo sutilmente arraigado en la posición psicoanalítica tradicional, que se filtra en la postura de Hoffman. Para Safran, Hoffman está peleando con los contrincantes equivocados: los defensores de la investigación empírica sistemática son quienes pueden defender al psicoanálisis en los principales organismos académicos y ante los principales organismos de financiación. El debate que Hoffman quiere dar, debe plantearse en un marco de discusiones más amplias que exceden la órbita del psicoanálisis. En ese sentido hay, sostiene Safran, una serie considerable de investigadores no psicoanalíticos que mantienen una postura crítica respecto al modelo de la práctica basada en la evidencia en el ámbito de la salud mental, y que convendría tener como aliados: "en esta importante coyuntura histórica necesitamos estar participando en el diálogo crítico y constructivo con la comunidad en general, en lugar de girar hacia el interior" ${ }^{67}$ (ibíd. p.5).

\footnotetext{
66 "Questions such as "What is a good way to be in this moment?" "Which human motives are most important?" "What constitutes the good life?" are implicitly involved. Such questions cannot and should not be adjudicated entirely by "science."

67 "At this important historical juncture we need to be engaging in critical and constructive dialogue with the larger community rather than turning inwards".
} 
Un par de años después al artículo de Hoffman, Eagle \& Wolitzky (2011) también esbozaron una respuesta crítica a su planteamiento. Para estos autores la postura de Hoffman es deletérea para el futuro de la disciplina, y aun a sabiendas de que representa bien la perspectiva de gran parte de los analistas de todas partes, consideran necesario analizarla críticamente.

Para Eagle y Wolitzky las exigencias de la investigación sistemática no tienen que ver con un rendir cuentas ante las presiones políticas del campo, sino con una dimensión ineludible de la responsabilidad profesional de la disciplina que debe quedar al margen de las demandas foráneas. "Aunque estamos de acuerdo con Hoffman -sostienen- en que uno debe ser cauteloso de conceder privilegio epistemológico a la investigación empírica sistemática en todos los ámbitos, debe ser privilegiada en relación a cuestiones generales de los resultados del tratamiento" 68 (Eagle \& Wolitzky, 2011: 3). Acuerdan con las observaciones de Green sobre el hecho de que los resultados de la investigación empírica son muy magros en comparación con la riqueza de las experiencias clínicas; sin embargo, afirman que

\begin{abstract}
...la función de la investigación empírica sistemática no es capturar la riqueza de la clínica ni de ninguna otra experiencia, ni es ofrecer prescripciones específicas y detalladas sobre cómo llevar a cabo la psicoterapia en un momento dado. Más bien, sus principales funciones incluyen poner nuestras convicciones -que de hecho pueden estar basadas en una rica experiencia clínica- a prueba, proporcionando pautas generales y generando principios generales. ${ }^{69}$ (ibíd.).
\end{abstract}

Los autores deciden atacar las premisas del argumento de Hoffman. En primer lugar, afirman que es difícil imaginar cómo o por qué la investigación empírica sistemática podría ser potencialmente dañina para el desarrollo de nuestra comprensión del proceso analítico y para la calidad de nuestro trabajo clínico, siendo que la mayoría de los analistas ignoran la literatura ligada a la

\footnotetext{
68 "Although we agree with Hoffman that one should be cautious about granting epistemological privilege to systematic empirical research across the board, it should be privileged in relation to general questions of treatment outcome".

69 "...the function of systematic empirical research is not to capture the richness of clinical or any other experience, nor is it to offer specific and detailed prescriptions regarding how to conduct psychotherapy at any given moment. Rather, its main functions include putting our convictions - which indeed may be based on rich clinical experience-to the test, providing general guidelines, and generating general principles."
} 
investigación y no le dan el estatuto privilegiado que Hoffman tanto teme. En segundo lugar, estos autores creen infructuoso el dilema que Hoffman fomenta entre estudios de caso por un lado e investigación empírica sistemática por el otro:

Cada método tiene diferentes pretensiones de conocimiento. Si queremos saber algo sobre una persona en particular, es mejor recurrir a un estudio de caso en profundidad. Sin embargo, si queremos determinar el resultado general de un enfoque terapéutico debemos buscar con la investigación empírica sistemática ${ }^{70}$ (ibíd. p.4).

Ahora bien, los autores consideran que la caracterización que hace Hoffman del estudio de casos, considerando la ambigüedad de los datos clínicos y el sesgo de cada analista, muestra sus debilidades más que sus virtudes. Además de ello, Hoffman no tiene en cuenta toda una serie de problemas para los que la metodología del estudio de casos resulta insuficiente; problemas como por ejemplo el de la eficacia diferencial de los tratamientos, que ha sido abordado con investigación empírica y con favorables resultados para el psicoanálisis. Es la falta de interés de los analistas por estos asuntos lo que allana el terreno para que circulen las críticas más hostiles a la disciplina.

Eagle y Wolitzky dicen no entender a qué se refiere Hoffman cuando caracteriza de "objetivistas" las aspiraciones de la investigación empírica sistemática, pues "al igual que el positivismo, el objetivismo se ha convertido en una palabra de moda que significa diferentes cosas para diferentes personas"71 (ibíd. p. 8). El término es vago y poco claro, pero los autores asumen que Hoffman se refiere con él a la investigación empírica de tipo cuantitativa. Sea como fuere, los autores creen que, del mismo modo en que se debe rechazar el privilegio del "objetivismo", también resulta necesario oponerse a lo que podría caracterizarse como "subjetivismo autoritario" (authoritarian subjectivism), es decir, la creencia de que todo lo que es necesario para

\footnotetext{
70 "Each method makes different knowledge claims. If we want to know something about a particular person, we are likely better off turning to an in-depth case study. If, however, we want to determine the general outcome of a therapeutic approach, we should look to systematic empirical research."

71 "Like positivism, objectivism has become a buzz word that means different things to different people"
} 
justificar o validar un enfoque terapéutico son los propios sentimientos subjetivos y convicciones, o la propia adhesión y lealtad a una particular corriente teórica (ibíd. p. 8). Y esto, aunque Hoffman no lo reconozca, es algo que la investigación empírica puede mitigar, según los autores.

Eagle y Wolitzky tampoco ven razonable la acusación de Hoffman de que la investigación empírica no puede ofrecerle ayuda inmediata al clínico en el consultorio, pues aunque eso es correcto "la conveniencia de realizar investigación psicoanalítica sobre los procesos y los resultados del tratamiento y sobre los procesos básicos postuladas por la teoría psicoanalítica no debe descansar sobre si ofrece o no ayuda inmediata para el analista"72 (ibíd. p.10). Los autores no dudan en citar investigaciones que han contribuido, con el tiempo, al trabajo clínico. Y lo hacen criticando un presupuesto que subyace, según ellos, a la base del planteo de Hoffman, a saber: que "medir" o "clasificar" aspectos de la experiencia humana suponen destruirla o "disecarla". No necesariamente intentar aprender algo de la experiencia analítica con sistematicidad supone desvirtuar su naturaleza:

\begin{abstract}
Conducidos de una manera clínicamente significativa, estos esfuerzos y la investigación en la que están insertos son la mejor protección contra el control del pensamiento autoritario, precisamente porque este enfoque implica la evidencia empírica replicable en lugar de persuasivas y carismáticas apelaciones, encaminadas a tocar un acorde emocional resonante en otros. ${ }^{73}$ (ibíd. p. 14).
\end{abstract}

Según Eagle y Wolitzky hay distintas preguntas que la investigación empírica sistemática puede ayudarnos a responder y que difícilmente podríamos abordar con estudios de caso. Cuestiones como: ¿es el número óptimo de sesiones por semana diferente para los pacientes con diferentes diagnósticos?, ¿hacer a pacientes borderline interpretaciones enfocadas en la transferencia (en comparación con las no transferenciales) permite rápidas y más estables mejorías en las relaciones, así como una disminución de la conducta

\footnotetext{
72 "..the desirability of conducting psychoanalytic research on the process and outcome of treatment and on basic processes posited by psychoanalytic theory should not rest on whether it offers immediate help to the analyst."

73 "Conducted in a clinically meaningful manner, such efforts and the research in which they are embedded are the best protection against authoritarian thought control precisely because this approach involves replicable empirical evidence rather than persuasive, charismatic appeals aimed at striking a resonant emotional chord in others".
} 
autodestructiva?, ¿cuál es la relación entre el resultado y la calidad de la alianza en diferentes puntos en el tratamiento?, ¿qué tipo de cambios en la personalidad son más duraderos cuando se los trata con psicoanálisis, en comparación con otras formas de tratamiento?, ¿bajo qué circunstancias la revelación de la contratransferencia permite revertir un tratamiento previamente estancado? Pareciera, sostienen los autores, que no es posible extraer de los estudios en profundidad de casos clínicos la información necesaria para responder a estos problemas.

Respecto de la metodología del estudio de casos, los autores se detienen en lo que consideran sus insuficiencias: los sesgos del analista para la recolección de la información relativa a lo que acontece en la sesión, la distorsión de los datos a los fines de persuadir al oyente o debido al carácter de la contratransferencia. Todo ello se puede entender a partir del denominado "problema del sesgo confirmatorio": la tendencia a buscar información que confirme las propias conjeturas y a desestimar la contraevidencia que potencialmente las refute (ibíd. p.17). Por todo ello, afirman:

la principal limitación de este método es que no ofrece una buena manera de elegir entre hipótesis alternativas. Además, los datos son generalmente poco fiables. A menudo están ficcionalizados, compuestos o contando como recuerdos selectivos diseñados para hacer una observación. Rara vez hay una oportunidad para que otros examinen los datos en que se basan las conclusiones del clínico ${ }^{74}$ (ibíd. p. 19).

Es recordando varias de las críticas de Grünbaum a la fiabilidad de los datos clínicos que Eagle y Wolitzky consideran necesario "identificar los criterios por los cuales se considera que los estudios de caso proporcionan conocimiento fiable"75 (ibíd.); y es por eso que ellos establecen una extensa lista con algunos de tales criterios, a los fines de volver más fuerte su "valor probatorio" (evidential value).

\footnotetext{
74 "...the main limitation of the method is that it does not offer a good way of choosing among alternative hypotheses. In addition, the data are often unreliable. Often they are fictionalized, composite, or selectively remembered accounts designed to make a point. Rarely is there an opportunity for others to examine the data on which the clinician's conclusions are based."
}

75 “...to identify the criteria by which case studies are deemed to yield reliable knowledge." 
Sostienen que, si bien la historia ha mostrado en repetidas ocasiones que cualquier método o procedimiento puede ser mal utilizado, deliberada o involuntariamente, con propósitos nefastos,

la ventaja del método científico con su énfasis en accesibilidad a los datos observables, replicación y condiciones controladas es, en principio, una mejor garantía, contra ser gobernado por el dogma y la obediencia ciega, que el punto de vista de un teórico clínico persuasivo y carismático"76 (ibíd. p.20).

Además, a partir de la introducción de "medidas objetivas aplicadas por observadores externos" la investigación empírica nos permite, según los autores, "reducir las inferencias especulativas", "controlar el sesgo" y "elegir entre hipótesis alternativas"; cosas que el estudio de caso no permitiría realizar (según Grünbaum). Todo ello puede hacerse sin "disecar la experiencia humana" ni contrariar la "singularidad consecuente" de cada díada analítica, como Hoffman quiere hacernos creer (ibíd.). También mencionan, aunque en menor medida, algunas desventajas de las investigaciones empíricas sistemáticas, como el problema de sacrificar excesivamente la "validez ecológica" de los fenómenos abordados.

Eagle y Wolitzky culminan su trabajo afirmando la posibilidad y necesidad de complementar estudios de caso con investigaciones empíricas sistemáticas: "en lugar de esta visión polarizada, lo que necesitamos en este momento de nuestra historia no es una relación de confrontación entre clínicos e investigadores [...] sino un esfuerzo conjunto para encontrar los usos legítimos y constructivos de cada enfoque metodológico."77 (ibíd. p.23). Consideran que la preocupación central de Hoffman es legítima, pero que podría alcanzarse un acuerdo sobre qué lugar debe ocupar cada tipo de investigación si se hace un esfuerzo por identificar los contextos en los que cada una de ellas merece el privilegio.

\footnotetext{
76 "...the advantage of scientific method with its emphasis on accessibility to observable data, replication, and controlled conditions is, in principle, a better safeguard against being ruled by dogma and blind obedience than the point of view of a charismatic, persuasive clinical theorist"

77 "Instead of this polarized view, what we need at this juncture in our history is not an adversarial relationship between clinicians and researchers [...] but rather a joint effort to find the legitimate and constructive uses of each methodological approach."
} 
En 2012 Hoffman escribe una respuesta a los autores que lo han criticado en la que sostiene que éstos han omitido varios aspectos de su planteamiento (Hoffman, 2012). Los críticos ignoran "mi propia crítica de los estudios de casos tradicionales y la apertura de mi versión del constructivismo a muchos enfoques, incluyendo los desarrollados y apoyados por la investigación sistemática"78 (Hoffman, 2012: 105-106).

Aunque Hoffman no está de acuerdo con los estudios empíricos de resultados, considera que, además de ser "menos destructivos que los estudios de procesos", pueden ser pragmáticamente significativos en la medida en que ayuden a ganarse el respeto de amplios sectores de la opinión pública y de las compañías de seguros, por ejemplo (ibíd. p.107). Sin embargo, considera que debemos sincerarnos en el hecho de que esos resultados no determinarán, para un individuo, el tipo de terapia y de terapeuta que va a elegir. El término "psicoterapia psicodinámica de largo plazo" sugiere, falazmente, que existe algo esencialmente homogéneo en lo que respecta al tipo de terapia y de díadas paciente-terapeuta; y oculta el hecho de que cada sujeto, junto con sus determinantes y potencialidades es singular, sin que haya manera de hacer intrascendentes sus diferencias.

Hoffman insiste en que al privilegiar la investigación empírica "se tiende a reificar categorías diagnósticas y métodos de tratamiento, sacándolos del contexto del entorno sociopolítico y destacando su condición objetiva con el sello de "ciencia"”79 (Hoffman, 2012: 114). De ese modo, por más variables que se controlen en los estudios empíricos, cualquier tendencia a establecer "tipos" de intervenciones se vuelve insostenible: palidece la complejidad de los contextos singulares de cada díada analítica. A esto subyace, según Hoffman, una perspectiva esencialista: "la idea de que se puede prescribir un determinado comportamiento de la manera en que se puede prescribir un antibiótico, bajo la asunción de una 'singularidad insignificante' regulando la

\footnotetext{
78 "The critics largely ignore these two aspects of my view: my own critique of traditional case studies and the openness of my version of constructivism to many approaches, including those developed and supported by systematic research".

79 "It tends to reify diagnostic categories and treatment approaches, taking them out of the context of the sociopolitical environment and highlighting their objective status with the stamp of 'science'."
} 
prescripción"80 (ibíd.). Además, cuestiona el hecho de que el conocimiento sobre cómo actuar con un paciente en un momento determinado pueda tener mayor legitimidad por provenir de un estudio empírico "objetivo" que por derivarse del saber "subjetivo" del propio analista.

Defendiendo la metodología del estudio de casos, Hoffman denuncia también un error en la postura de Eagle y Wolitzky: ellos consideran necesario separar las "observaciones" de las "inferencias" en cada reporte. Para Hoffman esa separación es imposible y revela la presuposición de un viejo ideal positivista: la creencia de que es posible establecer observaciones puras, sin que haya inferencias apoyadas en presupuestos teóricos. En nuestro caso, el compuesto "observación-inferencia" es dependiente de innumerables factores contextuales.

Hoffman concluye aseverando una diferencia radical entre su punto de vista y el de sus críticos:

su pensamiento está incrustado en un paradigma que difiere radicalmente de la que tengo en mente [...] El suyo sigue siendo un paradigma de las ciencias naturales, mientras que mi perspectiva es la de un paradigma crítico constructivista o hermenéutico. $^{81}$ (ibíd. p.117).

Hoffman asevera que este positivismo es la "filosofía subyacente" a muchas perspectivas psicoanalíticas de investigación y que está en las antípodas del paradigma constructivista/hermenéutico que, desde su punto de vista, debe ser el fundamento más propicio para el psicoanálisis: en tanto que reconoce la singularidad consecuente de cada díada terapéutica y de cada encuentro analítico, pone en primer plano la mutua responsabilidad para la co-creación de la experiencia analítica, aceptando la ambigüedad y la indeterminación del proceso, así como la necesidad de elecciones valorativas respecto de la incertidumbre existencial (ibíd. p.118).

A estos debates se han sumado diversos actores a cada uno de los bandos, enriqueciendo y acentuando diversas aristas de la controversia; y también hay

\footnotetext{
80 "...the idea that you can prescribe a certain behavior the way you can prescribe an antibiotic, with the assumption of "inconsequential uniqueness" governing the prescription."

81 "...their thinking is embedded in a paradigm that differs radically from the one that I have in mind $[\ldots]$ Theirs remains a natural science paradigm, whereas my perspective is that of a critical constructivist or hermeneutic paradigm."
} 
quienes abogan por posiciones conciliadoras (Strenger, 2013; Bernardi, 2015). No ha sido mi intención presentar exhaustivamente este conjunto de controversias, sino reseñar sus principales líneas de fuego y el conjunto general de estrategias argumentativas con las que se ha venido estableciendo el combate; a los fines de poder extraer un núcleo de problemas que sí voy a intentar analizar en detalle.

\section{Síntesis, focalización e ingreso al terreno de indagación}

El camino recorrido por la historia de las discusiones epistemológicas sobre el psicoanálisis, en el que hemos podido reconocer y señalar algunos mojones fundamentales de cada lado, lejos de delinear un trayecto recto constituye un derrotero sinuoso, con múltiples accesos y puntos de bifurcación. Un rasgo interesante de este paisaje histórico lo conforma el hecho de que, inicialmente, las controversias epistemológicas y metodológicas aparecen protagonizadas por bandos que se ubican diferencialmente respecto al psicoanálisis: casi siempre los críticos han sido foráneos. Sin embargo, con el transcurrir del siglo $\mathrm{XX}$, este tipo de debates es sostenido y promovido por los propios psicoanalistas al interior de sus comunidades psicoanalíticas. Apasionantes discusiones, como las que hemos examinado, no pueden sino constituir un signo inequívoco de salud epistemológica en la disciplina. Pese a lo cual, en muchos aspectos significativos apenas se han logrado algunos acuerdos regionales y todavía persisten divergencias considerables cuya resolución parece distante.

A pesar de que las disputas sobre la legitimidad de la disciplina se mantienen, ellas también han ido modificándose: mientras que originalmente el acento pareciera haber estado puesto en qué tipo de disciplina es el psicoanálisis, en lo que va del siglo XXI el principal asunto de debate es cómo producir conocimiento válido en psicoanálisis. Naturalmente, ambos problemas están interrelacionados. Quienes asumen que el psicoanálisis no es una ciencia y reconocen una identidad hermenéutica, han resistido la intromisión de otras metodologías y el desarrollo naturalista de técnicas y procesos de 
indagación que vayan más allá de lo que el método clínico permite. Ahora bien, ¿en qué se ha justificado este movimiento de hermeneutización, originado a mediados del siglo pasado y persistente hasta nuestros días? Aunque podríamos enumerar y sopesar distintas razones, no podríamos omitir las objeciones provenientes de la filosofía de la ciencia, especialmente, del espectro de críticas comprendidas entre la obra de Karl Popper y la de Adolf Grünbaum.

Por el contrario, quienes reconocen una identidad científica en el psicoanálisis y rechazan su redefinición hermenéutica, han patrocinado la testabilidad extra-clínica en búsqueda de evidencias empíricas aprovechables, así como el desarrollo de nuevas metodologías de investigación para continuar ampliando el campo de nuestro saber en estrecha relación con otros dominios cognitivos aparentemente ineludibles. Pero, ¿en qué se ha justificado este movimiento de naturalización, originado a mediados del siglo pasado y persistente hasta nuestros días? También podríamos enumerar y sopesar distintas razones, pero tampoco podríamos omitir las objeciones provenientes de la filosofía de la ciencia, especialmente, del espectro de críticas comprendidas entre la obra de Karl Popper y la de Adolf Grünbaum.

Descendamos entonces al terreno seleccionado y emprendamos el recorrido estipulado en base a nuestros interrogantes iniciales. 


\section{SEGUNDA PARTE. El psicoanálisis de Karl Popper: una pseudociencia}

"Siempre será un asunto a resolver por una convención o una decisión el de a qué cosa hemos de llamar una "ciencia», el de a quién hemos de calificar de "científico»." (Karl Popper, La lógica de la investigación científica, p. 51).

"Pero el progreso del conocimiento no tolera rigidez alguna, tampoco en las definiciones" (Sigmund Freud, Pulsiones y destinos de pulsión, p. 113). 


\section{CAPÍTULO 3: El falsacionismo de Popper y su crítica al Psicoanálisis freudiano.}

\section{Introducción}

m este tercer capítulo analizaremos una serie de temas interrelacionados. En primer lugar nos dedicaremos a considerar la principales asunciones epistemológicas de Karl Popper, destacando el contexto de su surgimiento y las características distintivas de su propuesta. Sólo así estaremos en condiciones de comprender la trama histórica y la tradición en la que se inscriben las objeciones de Popper a la teoría psicoanalítica de Sigmund Freud; asunto del que nos ocuparemos en segundo lugar.

Antes de expedirnos acerca de la pertinencia de dicha crítica, daremos un breve rodeo. Asumiendo que la descalificación popperiana no es irracional, sino que es fruto de la aplicación de argumentos filosóficos elaborados, nos será necesario conocer su propuesta en detalle y expedirnos sobre su viabilidad. En ese sentido, haremos hincapié en los aspectos discutibles de su filosofía de la ciencia, recuperando para ello una serie de debates acaecidos en la segunda mitad del siglo $\mathrm{XX}$ y acentuando el análisis crítico de algunos de los interlocutores destacados de nuestro autor, así como su propia contraargumentación.

Para finalizar el capítulo, luego de habernos detenido en una serie de aspectos problemáticos de la filosofía popperiana, intentaremos balancear su propuesta. Confiamos en que hacia el final de este sucinto recorrido habrán quedado vislumbradas ciertas virtudes de su epistemología, pero también se apreciarán sus principales falencias y las razones por las que el objetivo principal de la misma no ha podido realizarse. Todo ello será necesario para elucidar, ya en el cuarto capítulo y con argumentos específicos, el alcance y la legitimidad de la crítica popperiana al psicoanálisis de Freud. 


\section{El falsacionismo de Karl Popper.}

Admito que mi criterio de falsabilidad no nos conduce a una clasificación desprovista de ambigüedades (Popper 1934/1980: 78).

\section{a) Contexto histórico de su surgimiento.}

La obra de Popper aparece en la Viena de principios del siglo xx, cuyo clima social e intelectual puede verse como una suerte de hervidero de nuevas ideas científicas, culturales y sociales; un verdadero epicentro de nuevas experiencias, que van desde el arte hasta el nazismo (Lorenzano, 1993: 32-33). En lo que a la filosofía de la ciencia respecta, es indudable que las propuestas del Positivismo y Empirismo Lógico han sido una referencia ineludible para los desarrollos de Popper.

Puede decirse que la Filosofía de la Ciencia se constituyó como tal a partir de la configuración del Círculo de Viena y sus repercusiones. Ya desde 1907 Otto Neurath, Hans Hahn y Philipp Frank habían organizado un grupo de trabajo sobre temas científicos y desde una perspectiva filosófica, pero fue alrededor de 1923 cuando una serie de lógicos, matemáticos, economistas, psicólogos y filósofos, comenzaron a agruparse en la capital de Austria con el objetivo de reflexionar sobre el funcionamiento de la ciencia y su función en el mundo $^{82}$. No es sino hasta 1926 que ese grupo de pensadores daría origen a la Sociedad Ernst Mach y, a partir de un célebre Manifiesto de 1929 (obra de Carnap, Hahn y Neurath) con el que aspiraban a posicionarse de manera hegemonía en el campo filosófico, pasarían a denominarse y hacerse conocer como el Círculo de Viena. Fue desde esa época que los Positivistas Lógicos darían a conocer sus preocupaciones filosófico-científicas y su manera de abordarlas.

Casi al mismo tiempo, en la Universidad Central de Alemania aparecía el Grupo de Berlín; un grupo de estudio creado por Hans Reichenbach, Kurt

\footnotetext{
${ }^{82}$ Este agrupamiento fue inicialmente en torno a Moritz Schlick, quien había sucedido a Ernst Mach en la cátedra de "Filosofía de las Ciencias Inductivas" de la Universidad de Viena, e incluyó a figuras como Rudolf Carnap, Herbert Feigl, Otto Neurath, Victor Kraft, Friedrich Waissmann y Kurt Gödel. Además, otras figuras contribuyeron y acompañaron los desarrollos que allí se estaban gestando, aunque no vivieran en Viena: Frank Ramsey, Hans Reichenbach, Carl Hempel, Bertrand Russell y Albert Einstein.
} 
Grelling y Walter Dubislav e integrado por filósofos y científicos como Carl Gustav Hempel, David Hilbert y Richard von Mises. Las similitudes con el Círculo de Viena eran notables ${ }^{83}$. Conjuntamente al Círculo de Viena, publicaron la célebre revista Erkenntnis y organizaron diversos congresos y coloquios acerca de la filosofía de la ciencia, el primero de los cuales se realizó en Praga en 1929.

Entre los rasgos más destacados de esta filosofía neopositivista, cabe mencionar dos muy acentuados: por un lado, la creencia de que todo conocimiento se origina en datos sensoriales, conforme a lo establecido por la tradición empirista de David Hume, John Stuart Mill y Ernst Mach; y el consecuente rechazo a toda metafísica especulativa, en continuación con las ideas de Auguste Comte. Por otro lado, la suposición de que la estructuración del conocimiento podía representarse a partir de la lógica matemática de Bertrand Russell y del atomismo lógico del joven Ludwig Wittgenstein ${ }^{84}$.

Tanto el empirismo gnoseológico como el análisis lógico del lenguaje fueron los baluartes con los que estos pensadores intentaron desarrollar su proyecto de la Ciencia Unificada:

\begin{abstract}
La aspiración del trabajo científico radica en alcanzar el objetivo de la ciencia unificada por medio de la aplicación de ese análisis lógico al material empírico. Debido a que el significado de todo enunciado científico debe ser establecido por la reducción a un enunciado sobre lo dado, de igual modo, el significado de todo concepto, sin importar a qué rama de la ciencia pertenezca, debe ser determinado por una reducción paso a paso a otros conceptos, hasta llegar a los conceptos de nivel más bajo que se refieren a lo dado. Si tal análisis fuera llevado a cabo para
\end{abstract}

\footnotetext{
${ }^{83}$ Aunque esas similitudes no los hicieron semejantes, pues ambos grupos mantuvieron diferencias significativas. Por empezar, Reichenbach consideraba que la denominación de "Positivismo Lógico" no resultaba adecuada para caracterizar la nueva filosofía; debido a las connotaciones dogmáticas de la palabra "positivismo" (que remiten a la infalibilidad de las bases del conocimiento) prefería utilizar la de "Empirismo Lógico" (Moulines, 2008/2011: 5051). Aquí no repararemos en los aspectos diferenciales que distinguen a ambos movimientos, sino en sus aspectos compartidos. Tampoco haremos demasiado hincapié en los aspectos controversiales entre los miembros al interior de cada grupo, cosa para nada desdeñable.
}

${ }^{84}$ En el célebre manifiesto mencionado, se especifican ambos aspectos: "hemos caracterizado la concepción científica del mundo en lo fundamental mediante dos rasgos. Primero, es empirista y positivista: hay sólo conocimiento de la experiencia que se basa en lo dado inmediatamente. Con esto se establece la demarcación del contenido científico legítimo. Segundo, la concepción científica del mundo se distingue por la aplicación de un método determinado, a saber, el del análisis lógico" (Asociación Ernst Mach, op. cit. 1929/2002: 115). 
todos los conceptos, serían de este modo ordenados en un sistema de reducción, un "sistema de constitución". (Asociación Ernst Mach, 1929/2002: 115).

Pareciera de común aceptación en la época la idea de que la ciencia está constituida por conjuntos de proposiciones de distinto tipo; por lo que unificar el conocimiento científico suponía reducir todas las afirmaciones de la ciencia a proposiciones observacionales que fueran comúnmente aceptadas (por todas las ciencias positivas) ${ }^{85}$. Es decir, se concebía que la manera de lograr la unificación de las ciencias era por la vía de la reducción a un lenguaje observable (ya sea desde una postura fisicalista o fenomenista) y común.

Ahora bien, la forma que los Empiristas Lógicos hallaron para poder discriminar las proposiciones que formaran parte de las ciencias de las que no, dando así respuesta al problema de la demarcación (entre ciencia y metafísica), se conoce como criterio verificacionista del significado. Este criterio asume que es posible diferenciar enunciados analíticos (cuyo valor de verdad puede determinarse a priori, partiendo del significado de los términos involucrados y de las reglas del lenguaje utilizado) de enunciados sintéticos (cuyo valor de verdad sólo puede determinarse a posteriori, a partir de referencias a la realidad empírica); y sostiene que toda ciencia empírica debe contener enunciados susceptibles de ser verificados por la experiencia sensible. Las dificultades de este criterio originario no tardaron en aparecer: las leyes científicas, al tener la forma de enunciados universalmente cuantificados, no son susceptibles de verificación (no es posible comprobar que lo afirmado ocurra para todos los casos y en todo tiempo y lugar ${ }^{86}$ ). Problemas como este condujeron a plantear otro criterio que permitiría incluir los enunciados universales en el conjunto de los enunciados científicos (ya que rechazarlos por

\footnotetext{
85 Reduccionismo inspirado en el programa logicista, particularmente en los Principia Mathematica de Whitehead y Russel.

${ }^{86}$ Un enunciado universalmente cuantificado tiene la siguiente forma esquemática: "para todo $x$, si $x$ tiene la propiedad $P$, entonces $x$ también tiene la propiedad Q"; por ejemplo, "para todo $x$, si $x$ es un perro, entonces $x$ tiene cuatro patas". Adoptar el criterio de verificabilidad implicaría que sólo podemos adjudicarle cientificidad al enunciado si logramos mostrar que es equivalente a una conjunción de enunciados observacionales particulares (por ejemplo, "cláusulas protocolares" según Neurath y "enunciados elementales" según Carnap), tales como "este perro que veo en mi patio a las $15 \mathrm{hs}$ tiene cuatro patas", "observo el miércoles que el perro de mi tía tiene cuatro patas", etc. Pero esa equivalencia no puede ser establecida porque no es fácticamente posible observar todos los perros que existen, que han existido y que existirán.
} 
carentes de significado parecía absurdo). Surgió así la noción de confirmabilidad inductiva: un enunciado universal puede considerarse científico si puede ser confirmado por la experiencia; es decir, si sus consecuencias derivadas pueden ser confrontadas con enunciados básicos ${ }^{87}$.

Es en este contexto de problemas en el que Popper se inserta. Su planteamiento filosófico estuvo en discusión con esta filosofía naciente y fue incluso aceptado por varios de sus representantes (como Carnap y Hempel ${ }^{88}$ ).

\section{b) Las críticas al inductivismo y al criterio de demarcación positivistas}

Cuando Popper se da a conocer en el escenario filosófico, el libreto de la metodología de la ciencia estaba escrito en clave inductivista. Es conocido el común y extendido acuerdo que legitima la caracterización del proceder investigativo a partir de los razonamientos inductivos: desde que Aristóteles esbozara las posibilidades del procedimiento inductivo como manera de conocer una ley universal a partir de la observación de un número finito de casos, el problema de las inferencias que pretenden ampliar el contenido conservando la verdad, ha sido abordado por la mayoría de los filósofos dedicados al estudio del conocimiento, desde la antigüedad hasta nuestros días $^{89}$. Como es sabido, en el marco de su crítica a la noción de causalidad,

\footnotetext{
${ }^{87}$ Mientras que Hempel $(1943 ; 1945)$ esbozó una teoría sintáctica, en la que se propone una definición cualitativa de la confirmación, Carnap (1950) desarrolló un programa tendiente a establecer, cuantitativamente, una medida del grado de confirmación.

${ }^{88}$ Debido fundamentalmente al ascenso del nazismo en Austria, la mayoría de los miembros del Círculo de Viena emigraron a otros países. También Popper debió emigrar y lo hizo a Nueva Zelanda, un destino cuyas escasas conexiones con el mundo filosófico contribuyó a que sus ideas se dieran a conocer en la versión de los integrantes del Círculo de Viena. Como estos adquirieron un peso significativo en las universidades más prestigiosas del mundo anglosajón, contribuyeron a difundir una versión de la propuesta popperiana que estaba tamizada por sus propias concepciones. Sólo a partir de la década de 1950, cuando Popper reeditó su obra principal en inglés, el falsacionismo se amplió considerablemente y empezaron a evidenciarse las diferencias mantenidas para con la filosofía del Empirismo Lógico (Diez y Moulines, 1997: 419; Lorenzano, op. cit. pp. 36).

${ }^{89}$ El estudio sistemático de la metodología inductiva se reconfigura en la Edad Media con la teorización de un método de concordancias y diferencia para el descubrimiento de principios explicativos generales, por parte de Robert Grosseteste (1175-1253). También Duns Scoto (1266-1308) y Guillermo de Ockham (1300-1349) plantearon procedimientos similares; pero es recién con Francis Bacon (1561-1626), William Whewell (1794-1866) y John Stuart Mill (18061873) cuando la metodología inductiva adquiere una sofisticación inédita (como veremos en la siguiente parte de la tesis). Ya en el siglo xx, Rudolf Carnap se encargó de elaborar una lógica
} 
David Hume había proclamado en el siglo XVIII la imposibilidad lógica de justificar las inferencias inductivas (Hume, 1739/2001: libro 1, parte III y 1748/2004: secciones 4-7). Este problema fue retomado por algunos representantes del Empirismo Lógico (como Reichenbach y Carnap) que intentaron, sin éxito, hallar una solución definitiva.

La aparición de la propuesta de Popper a principios de los años treinta se enmarca en estos problemas metodológicos y puede considerarse un programa rival. Popper desarrollará una serie de argumentos tendientes a reenfocar el problema de la justificación del conocimiento, tal y como había sido planteado por el Círculo de Viena. Así lo asevera tempranamente:

De acuerdo con una tesis que tiene gran aceptación $-\mathrm{y}$ a la que nos opondremos en este libro-, las ciencias empíricas pueden caracterizarse por el hecho de que emplean los llamados «métodos inductivos»: según esta tesis, la lógica de la investigación científica sería idéntica a la lógica inductiva, es decir, al análisis lógico de tales métodos inductivos. (Popper, 1934/1980: 27).

Se trata de un análisis crítico de la metodología inductiva en lo que respecta al conocimiento científico en su contexto de justificación. Popper afirma que la ciencia no utiliza inferencias inductivas para proceder en el establecimiento de sus teorías: la metodología científica no implica la verificación o confirmación observacional de hipótesis. Retoma así el denominado problema de la inducción:

\footnotetext{
...la cuestión acerca de si están justificadas las inferencias inductivas, o de bajo qué condiciones lo están.

El problema de la inducción puede formularse, asimismo, como la cuestión sobre cómo establecer la verdad de los enunciados universales basados en la experiencia —como son las hipótesis y los sistemas teóricos de las ciencias empíricas (Popper, 1934/1980: 27-28).
}

Para alcanzar esta justificación, según Popper, habría que explicitar alguna regla lógica que fundamentase dichas inferencias: el llamado principio de inducción. Pero, a diferencia de otras reglas lógicas, nuestro autor argumenta

inductiva, cuya continuación llega hasta nuestros días con autores como Jaakko Hintikka. Se trata de un intento por mostrar que la ciencia utiliza la inducción como método para acceder a la verdad o para afirmar la probabilidad de las teorías (Rivadulla, 1993: 128). 
que tal principio no puede ser ni una tautología ni un enunciado analítico (pues de haber un principio puramente lógico no habría problema alguno de la inducción); por lo que cabría considerarlo un enunciado sintético universal. Pero, ¿cómo podríamos saber si un principio así es verdadero? Popper advierte que si nos dispusiéramos a afirmar que es verdadero en virtud de nuestra experiencia, entonces sólo estaríamos desplazando el problema: como nuestra experiencia es de casos singulares, sólo podríamos justificar este principio inductivo de manera inductiva y, con ello, nos veríamos envueltos en una regresión al infinito. Tampoco es viable para Popper la solución de Kant al problema, pues aceptar que el principio de inducción constituye un juicio sintético a priori, supondría una caída en el apriorismo (ibíd. pp. 29).

El filósofo vienés mira también con recelo los intentos de establecer una lógica probabilística (Reichenbach) o una lógica inductiva (Carnap), tendiente a justificar la veracidad probabilística de las conclusiones inductivas. Considera que las dificultades se transportan a toda tentativa que pretenda sustituir la exigencia de validez de las inferencias inductivas por la exigencia de probabilidad. Su planteo consiste en suponer que las hipótesis científicas que son leyes, es decir enunciados universales, abarcan un número potencialmente infinito de consecuencias confirmadoras; motivo por el cual, independientemente de la cantidad de ejemplos confirmatorios que hallemos a su favor, su probabilidad es siempre cero ${ }^{90}$.

A su modo de ver, toda defensa de la inducción responde a una concepción justificacionista del conocimiento científico, basada en la suposición de que es posible el conocimiento cierto y demostrable. Por el contrario y como veremos él defiende una concepción falibilista: "nuestra ciencia no es conocimiento

\footnotetext{
90 Podemos comprender el argumento de Popper recordando lo siguiente del cálculo de probabilidades: la probabilidad de que ocurra un hecho es igual al cociente del número de casos favorables sobre el total de casos posibles; así, la probabilidad de obtener el número 4 en una tirada de dados es de aproximadamente 0,16 y la probabilidad de obtener 4 o 5 es de aproximadamente 0,33 . Esto es así porque en el primer ejemplo la calculamos dividiendo 1 (cantidad de casos favorables: una cara del dado) sobre 6 (cantidad de casos posibles: todas las caras) y en el segundo ejemplo la obtenemos dividiendo 2 (dos caras del dado: la del 4 y la del 5) sobre 6 (todas las caras del dado); por lo que nuestra probabilidad aumenta del primer al segundo ejemplo. Ahora bien, en lo relativo a la confirmación de hipótesis Popper rechaza rotundamente que la probabilidad pueda servirnos como medida de confirmación inductiva, pues toda vez que queramos calcular la probabilidad de un enunciado universal estaremos dividiendo un número finito por un número infinito, por lo que siempre obtendremos cero por mucho que aumentemos el número finito de enunciados observacionales confirmatorios.
} 
(episteme): nunca puede pretender que ha alcanzado la verdad, ni siquiera el sustituto de ésta que es la probabilidad" (Popper, 1934/1980: 259).

En función de las críticas anteriores, parece coherente que Popper se haya mostrado disconforme con el criterio de demarcación positivista ${ }^{91}$, puesto que su base es inductiva. Según nuestro autor, el criterio de demarcación de los neopositivistas establece "que la ciencia se distingue de la pseudociencia - 0 de la 'metafísica'- por su método empírico, que es esencialmente inductivo, o sea que parte de la observación o de la experimentación. Pero esa respuesta no me satisfacía" (Popper, 1963/1991: 57). Sostiene que los enunciados de la metafísica, aunque deben ser diferenciados de los enunciados científicos, no necesariamente carecen de sentido:

Creo, pues, que si una teoría no es científica, si es "metafísica" (como podríamos afirmar), esto no quiere decir, en modo alguno que carezca de importancia, de valor, de "significado" o que "carezca de sentido". Pero a lo que no puede aspirar es a estar respaldada por elementos de juicio empíricos, en el sentido científico, si bien, en un sentido genético, bien puede ser el "resultado de la observación" (ibíd. pp. 63).

Para Popper las teorías metafísicas no son desdeñables sino que tienen un valor intrínseco; e incluso también, muy frecuentemente, son importantes para la elaboración de teorías científicas. Es decir, Popper cree que la metafísica contribuye al contexto de descubrimiento de hipótesis ${ }^{92}$ y rechaza "sobre todo, el dogma de que la metafísica tiene que ser absurda" (Popper, 1982/1985: 215); dogma mantenido, como hemos dicho, por los positivistas:

\footnotetext{
${ }^{91}$ Como todos los epistemólogos del período clásico, Popper estaba interesado en los temasproblemas relativos a lo que Hans Reichenbach había llamado "contexto de justificación" (1938/1957); más específicamente, en el problema de la demarcación. Esto es, el problema de distinguir a la ciencia del resto de los productos y procesos cognitivos del hombre (en especial de la metafísica) a partir del establecimiento de un criterio objetivo.

92 Un ejemplo de ello puede ser extraído de El mundo de Parménides, un texto editado postmortem, en el que Popper plantea que la obra de Parménides incorpora un "programa metafísico de investigación" y afirma: "el programa de investigación parmenídeo se articuló cada vez más con el transcurso del tiempo. De este modo, al provocar la oposición, dio lugar antes que nada al programa de investigación atomista, y después, al desencadenar a su vez otra oposición, al programa de investigación de la teoría continuista de la materia. Finalmente dio lugar a las teorías científicas sobre la estructura de la materia, especialmente a la teoría atómica moderna" (Popper, 1993/1999: 214).
} 
Los positivistas son filósofos que se oponen a las teorías especulativas: quieren mantenerse tan cerca como sea posible de las ideas dadas y perceptibles. Ahora bien, yo he sido siempre enemigo de todo dogmatismo, y desde mis primeras publicaciones, he combatido siempre este positivismo. El positivismo proclama: 'No salgas de lo perceptible', mientras que yo he enseñado: 'Atrévete a exponer hipótesis especulativas, pero después critícalas y analízalas sin piedad' (Popper et. al., 1971/1989: 60).

Este lugar dado por Popper a la metafísica resulta innegable si consideramos que él mismo ha sido gestor o defensor de importantes suposiciones metafísicas: la teoría de la verdad, el realismo, el indeterminismo, teoría de los tres mundos, la inmaterialidad de la inteligencia, entre otras. En torno a ellas, ha ido consolidando una posición filosófica cuyos ejes supo explicitar: "para decirlo con mayor precisión: primero, y ante todo, soy un indeterminista; segundo, soy un realista; tercero, un racionalista" (Popper, 1963/1991: 241).

Pese a la favorable actitud popperiana respecto a la metafísica, nuestro autor va a insistir en la necesidad de establecer una clara delimitación entre esta y la ciencia. Reprochando las insuficiencias del criterio del "sentido" o "significado" que los positivistas habían adoptado siguiendo a Wittgenstein, Popper afirma que su metodología falsacionista aporta un criterio contundente de demarcación, sin incurrir en las ambigüedades del primero (cf. Popper, 1934/1980: 39 y 289).

En lo que sigue veremos porqué para Popper los argumentos justificacionistas suponen una falacia lógica de base, y cómo alega una superación posible a condición de que la ciencia resigne su pretensión de verificar proposiciones y parta de la posibilidad de alcanzar la falsedad de sus teorías. Antes de ello, queremos resaltar que si bien la concepción popperiana se opone al neopositivismo lógico, es posible notar -como lo ha señalado Federico Schuster- la coincidencia de ambos enfoques en algunos puntos para nada desdeñables:

1. La idea de que la ciencia es centralmente un conjunto de enunciados de distintos niveles de generalidad y abstracción, testeables empíricamente y organizados en las teorías científicas ${ }^{93}$.

\footnotetext{
${ }^{93}$ Apropósito de ello, coincidimos con Ricardo Gómez cuando afirma que "Popper no fue el primero que utilizó la noción de sistema hipotético-deductivo. Las teorías científicas habían sido concebidas como sistemas, y no como meros agregados, ya desde Aristóteles, aunque en este
} 
2. La confianza en la capacidad de la lógica para explicar y comprender los procesos científicos y su legitimidad a través de la reconstrucción del método científico.

3. La creencia en el progreso científico y en la racionalidad (lógica) de los procesos de cambio teórico.

4. La idea de que ante dos o más teorías coexistentes en determinado momento, sólo una de ellas debería poder sostenerse legítimamente.

5. La confianza, directa o indirecta, ingenua o sofisticada, en la experiencia como ultima ratio objetiva de la verdad científica.

6. La creencia en que la ciencia es la única forma legítima de conocimiento humano. (Schuster, 2002: 34)

\section{c) El método de las conjeturas y refutaciones como criterio de demarcación}

El procedimiento que Popper propone consta de dos fases diferenciables:

la etapa inicial, el acto de concebir o inventar una teoría, no me parece que exija un análisis lógico ni sea susceptible de él. La cuestión acerca de cómo se le ocurre una idea nueva a una persona -ya sea un tema musical, un conflicto dramático o una teoría científica- puede ser de gran interés para la psicología empírica, pero carece de importancia para el análisis lógico del conocimiento científico (Popper, 1934/1980: 30).

La distinción (efectuada por Popper y por Hans Reichenbach) entre "el proceso de concebir una idea nueva y los métodos y resultados de su examen lógico" (ibíd. pp. 31), conlleva la suposición de que esa primera fase no puede formar parte del análisis lógico. Dicho de otro modo, el inventar libremente conjeturas que tiendan a resolver los problemas en juego, es un aspecto creativo que, por carecer de lógica alguna ${ }^{94}$, condujo a Popper a desdeñar el contexto de descubrimiento como objeto de análisis de la epistemología (entendida por él como lógica de la ciencia).

\footnotetext{
último tal sistema estaba constituido por verdades y no por meras hipótesis" (Gómez, 1995: 18). Un análisis interesante sobre los precursores popperianos del hipotético-deductivismo puede verse en La Viena de Popper, de Darío Antiseri (2000/2001).

${ }^{94}$ Contrariaremos este planteamiento en la cuarta parte de la tesis, apoyándonos en la obra de Charles Sanders Peirce.
} 
En la segunda fase que Popper concibe, el científico deriva una serie de consecuencias observacionales a partir de las conjeturas libremente inventadas: enunciados que refieran a situaciones observables y que estén implicados por la conjetura postulada. Seguido de ello, Popper propone que se contrasten esas consecuencias con enunciados básicos aceptados convencionalmente. Ello permitirá, según el vienés, decidir si la hipótesis contrastada debe ser rechazada o si puede aceptarse provisionalmente. Popper cree que el resultado de la contrastación empírica nunca puede ser la verificación de una conjetura, y argumenta que intentar verificar es razonar a partir de un tipo de falacia: de afirmación del consecuente. Esto lo conduce a sostener que la justificación inductiva de la verdad de una hipótesis es lógicamente imposible ${ }^{95}$.

Pese a ello, considera que la contrastación empírica sí puede brindarnos un conocimiento seguro sobre la falsedad de una hipótesis. Ello es posible porque, a diferencia del afán por verificar, el dictamen de falsedad no se basa en la lógica inductiva sino en un procedimiento deductivo: la regla inferencial del modus tollendo tollens. Popper llamará "asimetría lógica entre verificación y refutación" a esta estructuración diferencial:

asimetría que se deriva de la forma lógica de los enunciados universales. Pues éstos no son jamás deductibles de enunciados singulares, pero sí pueden estar en contradicción con estos últimos. En consecuencia, por medio de inferencias puramente deductivas (valiéndose del modus tollens de la lógica clásica) es posible argüir de la verdad de enunciados singulares la falsedad de enunciados universales (ibíd. pp. 41).

Como puede notarse, la primera fase marca un claro contrapunto con el inductivismo: Popper afirma que la investigación científica no comienza por observaciones de la naturaleza, sino por la visualización de problemas que aparecen a la luz de teorías preexistentes ${ }^{96}$. Es ante esos problemas que el

\footnotetext{
${ }^{95}$ Esto lo separa netamente, como hemos dicho, del inductivismo.

96 "Así pues, la situación real es bastante diferente de la que era visible para el empirista ingenuo, o para el creyente en la lógica inductiva. Este cree que empezamos por recopilar y ordenar nuestras experiencias, y que así vamos ascendiendo por la escalera de la ciencia; o bien -para emplear el modo formalizado de hablar-, que si queremos edificar una ciencia tenemos que recoger primero cláusulas protocolarias. Pero si se me ordena «registre lo que experimenta ahora», apenas sé cómo obedecer a esta orden ambigua: ¿he de comunicar que estoy escribiendo?; que oigo llamar un timbre, vocear a un vendedor de periódicos o el hablar
} 
científico inventa conjeturas: un enunciado ${ }^{97}$ cuyo valor de verdad es desconocido (lo que le da su carácter hipotético).

La hipótesis propuesta para resolver un problema debe ser, afirma Popper, lo más audaz posible. Con ello se refiere a conjeturas que resulten más fácilmente refutables: aquellas hipótesis que prohíben más. Popper afirma que las teorías más restrictivas deben ser preferibles porque son las que informan más sobre el mundo (aportan más información que las menos restrictivas) y, debido a ello, poseen mayor cantidad de falsadores potenciales; es decir, poseen mayor cantidad de hechos que, de acontecer efectivamente, falsarían a la teoría que los implica.

El científico debe intentar falsar la teoría que ha inventado. Si logra refutarla, estamos en presencia de un triunfo para la ciencia porque sabemos con seguridad que esa teoría no era verdadera. Ha sido eliminado un error y nos hemos acercado más a la verdad. En este caso, el ciclo se reanuda con la creación de otra conjetura para ponerla a prueba. Ahora bien, si la contrastación empírica no nos lleva a refutarla, su estatuto no es el de una hipótesis con mayores probabilidades de ser verdadera, sino que sólo podemos decir que "ha mostrado su temple" o que "ha sido corroborada por la experiencia" 98 (ibíd. pp. 33, 234 y 247). Popper afirma que las hipótesis que han resistido la contrastación se mantienen utilizables hasta que puedan ser refutadas.

Según el criterio popperiano, una teoría o proposición es científica cuando está en condiciones de ser refutada (falsada) por la experiencia ${ }^{99}$. Esto es, si el

monótono de un altavoz?; ¿o he de informar, tal vez, que tales ruidos me llenan de irritación? Incluso si fuera posible obedecer semejante orden, por muy rica que fuese la colección de enunciados que se reuniese de tal modo, jamás vendría a constituirse en una ciencia: toda ciencia necesita un punto de vista y problemas teóricos" (ibíd. pp. 101).

${ }^{97}$ Recordemos que, al igual que sus contemporáneos, Popper adopta el giro lingüístico en su análisis del conocimiento. Como consecuencia, acepta que el conocimiento es posible a partir de su expresión en proposiciones (Lorenzano, 1988/2012: 37).

98 Este es el aspecto más importante de los que separan su teoría del método de la teoría inductivista: mientras que para el inductivismo una hipótesis es más segura cuanto más confirmada esté (en virtud del apoyo inductivo que aporta el éxito de sus consecuencias observacionales), para Popper, como detallamos anteriormente, es un error vincular la corroboración empírica a la probabilidad de ser verdadera.

${ }^{99}$ Exponiendo su idea al respecto, señala su distancia con el criterio de los Positivistas Lógicos: "obsérvese que propongo la falsabilidad como criterio de demarcación, pero no de sentido [...] la falsabilidad separa dos tipos de enunciados perfectamente dotados de sentido, los falsables 
científico puede imaginarse "falsadores potenciales" que, de efectivizarse, impliquen la falsedad de la teoría. Otra forma de enunciarlo es afirmar que una teoría es científica si existe por lo menos un enunciado observacional incompatible con ella; de no suceder eso, la teoría en cuestión será pseudocientífica. Así lo expresa Popper:

se llama "empírica» o "falsable» a una teoría cuando divide de modo inequívoco la clase de todos los posibles enunciados básicos en las dos subclases no vacías siguientes: primero, la clase de todos los enunciados básicos con los que es incompatible (o, a los que excluye o prohíbe), que llamaremos la clase de los posibles falsadores de la teoría; y, en segundo lugar, la clase de los enunciados básicos con los que no está en contradicción (o, que «permite»). Podemos expresar esta definición de una forma más breve diciendo que una teoría es falsable si la clase de sus posibles falsadores no es una clase vacía (ibíd.).

Popper dirá que la exposición de una teoría a las situaciones de refutación debe ser la base de nuestra confianza en ella: "sólo si una teoría resiste exitosamente la presión de estos intentos de refutación puede pretender que está confirmada o corroborada por la experiencia” (Popper, 1963/1991: 313). Afirma que la contrastabilidad no es una cuestión de todo o nada, sino que:

además, hay grados de testabilidad (como descubrí más tarde): algunas teorías se exponen a las refutaciones más audazmente que otras [...] Lo anterior indica que el criterio de demarcación no puede ser absolutamente tajante, sino que tiene grados. Habrá teorías bien testables, otras apenas testables y otras no testables. Estas últimas carecen de todo interés para los científicos empíricos. Se las puede llamar metafísicas (ibíd. pp. 314).

En base a estas caracterizaciones generales, Popper afirma la unidad del método: "todas las ciencias teóricas o generalizadoras usan el mismo método, ya sean ciencias naturales o sociales [...] ha sido llamado a veces el método hipotético-deductivo" (Popper, 1961/1973: 145-146) ${ }^{100}$.

y los no falsables: traza una línea dentro del lenguaje con sentido, no alrededor de él" (Popper, 1934/1980: 40, $\mathrm{n}^{\circ} 3$ ).

100 Conviene recordar aquí, aunque no vamos a detenernos en ello porque trasciende los objetivos de esta tesis, que Popper distinguió (tanto en La miseria del Historicismo como en La sociedad abierta y sus enemigos) una serie de rasgos propios de la metodología de las ciencias sociales; fundamentalmente en aquellas donde se buscan explicar fenómenos históricos. Popper propone para estas ciencias lo que llama "método de análisis situacional": elaborar modelos de situaciones sociales que reconstruyan situaciones históricas concretas (en 


\title{
3. La pseudociencia freudiana de Popper
}

\author{
"No parece nuestro destino trabajar en paz en la \\ construcción de nuestra ciencia" (Freud, 1921a/2004: 169).
}

Ha sido un error frecuente homologar la producción de Popper con la del Círculo de Viena, confundiéndolos bajo la nominación rala de "positivistas" (en sentido despectivo). Es cierto que Popper estuvo vinculado intelectualmente con varios miembros del Empirismo Lógico y que comparte con ellos una significativa serie de presupuestos sobre el conocimiento científico. No obstante, como hemos mostrado, los puntos en los que se separa son aún más significativos y esa es la razón por la que no puede ser homologado al positivismo ${ }^{101}$.

La confusión mencionada es frecuentemente reencontrable al interior de las ciencias de lo humano: allí se suele otorgar el mote de "positivistas" a un vasto

términos de los intereses y objetivos de sus agentes involucrados) para poder explicar la racionalidad de las acciones. En su autobiografía nos cuenta que "fue desarrollado a partir de lo que previamente fue desarrollado como 'método cero'. La cuestión principal aquí era el intento de generalizar el método de la teoría económica (la teoría de la utilidad marginal) para que fuera aplicable a otras ciencias sociales. En mis últimas formulaciones, este método consiste en la construcción de un modelo de la situación que incluya especialmente la situación institucional, donde el individuo actúa tal como lo explica la racionalidad (el carácter cero) de su acción. Estos modelos son, entonces, las hipótesis comprobables de las ciencias sociales, y esos 'modelos' son singulares más particularmente, las hipótesis singulares de la historia (comprobables en principio)" (Popper, 1976/1985: 93-94). Se trata de una forma de reconstrucción lógica de las desviaciones comportamentales de los individuos en base a un supuesto ideal de racionalidad. Según Popper, estas hipótesis se pondrían a prueba a partir de lo que llama "ingeniería social fragmentaria": la introducción de pequeñas transformaciones sociales constituirían una suerte de experimentación para testear hipótesis, pues así se permite la obtención de conocimiento "mediante la comparación de los resultados obtenidos con los resultados esperados" (Popper, 1961/1973: 99).

${ }^{101}$ Popper conocía este asunto: "estoy resignado al hecho de que, a pesar de todo, llevaré esta etiqueta hasta el final de mis días" (Popper, 1956/2011: 216). En su última obra publicada, afirmó "todo lo que he dicho hasta ahora [venía expresando sus ideas sobre la verdad, la certeza y el relativismo] sin duda hará que me vuelvan a asociar con el «positivismo» o con el «cientifismo». No me importa, aun cuando estas expresiones se utilicen en el sentido de un abuso. Pero sí me importa que quienes las utilizan o bien no saben de qué están hablando o violentan los hechos" (Popper, 1994/1996: 21). 
y difuso conjunto de perspectivas, con la intensión de significar así su descalificación ${ }^{102}$.

En los ámbitos psicoanalíticos, como efecto secundario de ese equívoco, se suele adjudicar al Positivismo Lógico la negación del estatuto de cientificidad al psicoanálisis, cuando en realidad fue Karl Popper quien inició esa operación de descrédito. Se omite el hecho, para nada fútil, de que antes de Popper los Positivistas Lógicos habían visto en el psicoanálisis de Freud una ciencia nueva y promisoria. Como prueba de ello puede verse afirmado en su célebre Manifiesto que "el psicoanálisis freudiano" podría venir a explicar los "extravíos de la metafísica" (preocupación central en la concepción científica del Círculo de Viena). No solo el psicoanálisis sino también el marxismo aparecen allí como empresas científicas:

\begin{abstract}
De parte de la concepción científica del mundo se rechaza la filosofía metafísica. ¿Cómo, sin embargo, se explican los extravíos de la metafísica? Esta pregunta puede plantearse desde varios puntos de vista, referidos a la psicología, la sociología, la lógica. Las investigaciones en la dirección psicológica se encuentran todavía en una etapa inicial; propuestas para una explicación más penetrante se presentan quizás en las investigaciones del psicoanálisis freudiano. Lo mismo ocurre con las investigaciones sociológicas; podemos mencionar la teoría de la "superestructura ideológica". Aquí el campo permanece abierto a una investigación posterior que vale la pena realizar (Asociación Ernst Mach, op. cit. 1929/2002: 113).
\end{abstract}

La crítica popperiana al psicoanálisis no fue, entonces, realizada en términos consuetudinarios: no existe en la tradición filosófica de su época sino hasta que él la realiza. Se trata, entonces, de una conjetura de Popper. Más adelante, retomaré este dato histórico para dar apoyo al carácter oportunista de su crítica. Continuemos por ahora, con la dimensión argumental de la misma.

El filósofo vienés expresó sin ambages que el requisito de falsabilidad está ausente en el psicoanálisis. Simultáneamente denunció que la teoría de Freud se basaba en el criterio inductivo-verificacionista, objeto predilecto de la denostación popperiana:

\footnotetext{
102 Para Rodolfo Gaeta cabe hablar de un "fantasma del positivismo en las Ciencias Sociales" (Gaeta, 2012).
} 
...después del derrumbe del Imperio Austríaco se había producido una revolución en Austria: el aire estaba cargado de lemas e ideas revolucionarias, y de nuevas y a menudo audaces teorías. Entre las teorías que me interesaban, la teoría de la relatividad de Einstein era, sin duda, la más importante. Otras tres eran la teoría de la historia de Marx, el psicoanálisis de Freud y la llamada "psicología del individuo" de Alfred Adler [...] Durante el verano de 1919 comencé a sentirme cada vez más insatisfecho con esas tres teorías, la teoría marxista de la historia, el psicoanálisis y la psicología del individuo; comencé a sentir dudas acerca de su pretendido carácter científico [...] Hallé que aquellos de mis amigos que eran admiradores de Marx, Freud y Adler estaban impresionados por una serie de puntos comunes a las tres teorías, en especial su aparente poder explicativo. Estas teorías parecían poder explicar prácticamente todo lo que sucedía dentro de los campos a los que se referían. El estudio de cualquiera de ellas parecía tener el efecto de una conversión o revelación intelectuales, que abría los ojos a una nueva verdad oculta para los no iniciados. Una vez abiertos los ojos de este modo, se veían ejemplos confirmatorios en todas partes: el mundo estaba lleno de verificaciones de la teoría. Todo lo que ocurría la confirmaba. Así, su verdad parecía manifiesta y los incrédulos eran, sin duda, personas que no querían ver la verdad manifiesta, que se negaban a verla, ya porque estaba contra sus intereses de clase, ya a causa de sus represiones aún "no analizadas" y que exigían a gritos un tratamiento (Popper, 1963/1991: 58-59).

Como puede notarse, lo que Popper veía era lo que estaba teorizando como un déficit lógico-metodológico: "la incesante corriente de confirmaciones y observaciones que 'verificaban' las teorías en cuestión; y este aspecto era constantemente destacado por sus adherentes" (ibíd.). Pero no sólo Popper vio pretensiones de verificabilidad inductiva, sino que también vio irrefutabilidad: "las teorías en cuestión eran compatibles con las más divergentes conductas humanas, de modo que era prácticamente imposible describir conducta alguna de la que no pudiera alegarse que es una verificación de esas teorías" (ibíd. pp. $60)$.

Entonces, la crítica popperiana es a la supuesta irrefutabilidad del psicoanálisis: “¿qué tipo de respuestas clínicas refutarían para el analista, no solamente un diagnóstico analítico particular, sino el psicoanálisis mismo? ¿Y alguna vez han discutido o acordado tales criterios los analistas?" (ibíd. pp. 62). En los ojos de Popper, el psicoanálisis (junto al marxismo y la astrología) en lugar de disponerse a refutar sus enunciados hipotéticos, los confirma con 
pretendidas verificaciones ${ }^{103}$; y es de allí que obtendría (basándose en el método inductivo) las credenciales de cientificidad. Además, salvaguarda cualquier evidencia empírica refutatoria mediante la introducción de hipótesis auxiliares ad-hoc. Esto último ya había sido denominado como "estratagema convencionalista" por Popper en $1934^{104}$ y constituye el centro de su noción de pseudociencia: todo conjunto de enunciados que, independientemente de su racionalidad o verdad, evita dar lugar a meticulosas contrastaciones empíricas. Nótese que, como ya hemos dicho, para Popper las posibilidades de cientificidad tienen que ver con una actitud en la forma de enunciar la teoría y con las consecuencias lógicas de ello ${ }^{105}$.

Sintetizando la cuestión diremos que para Popper "la teoría de Freud [...] simplemente carece de falsadores potenciales" ${ }^{106}$ (Popper 1974: 1004), es decir de una clase (no-vacía) de enunciados empíricos que, por estar implicados por la teoría y ser incompatibles con ella, permitirían abandonarla si resultasen corroborados. Popper entendía que los partidarios del psicoanálisis preferían hallar acontecimientos confirmatorios en lugar de imaginar falsadores potenciales, motivo que tornaba a la teoría irrefutable. De modo que no sólo consideró deficitaria a la teoría, sino también a la actitud metodológica de Freud y de todos los psicoanalistas ${ }^{107}$.

\footnotetext{
${ }^{103}$ En Realismo y el objetivo de la ciencia Popper dice haber analizado La interpretación de los sueños y haber encontrado una inminente tendencia al verificacionismo en el proceder de Freud (Popper, 1982/1985: 165-168).

${ }^{104}$ Allí Popper había expuesto su rechazo al convencionalismo (a pesar de reconocerle una sólida argumentación general) porque éste contradecía su criterio de demarcación (cf. Popper 1934/1980: 77-78) y había señalado, sin dar fundamento alguno, que es una "tentación a la que el psicoanálisis, por ejemplo, sucumbe frecuentemente" (ibíd. pp. 79). Volveré sobre este punto en la sección de las críticas a Popper.

105 "Así, el enunciado «lloverá o no lloverá aquí mañana» no se considerará empírico, por el simple hecho de que no puede ser refutado; mientras que a este otro, «lloverá aquí mañana», debe considerársele empírico" (Popper, op. cit. 1934/1980: 40).

106 "Freud's theory [...] simply does not have potential falsifiers".

${ }^{107}$ En La sociedad abierta y sus enemigos podemos leer una suerte de caricaturización sin fundamento: "el psicoanalista siempre puede explicar cualquier objeción demostrando que ésta se debe a las represiones del crítico" (Popper, 1945/1991: 428). Popper, a estas alturas, parece haberse inventado un estereotipo de "el psicoanalista", que utiliza para ejemplificar todo lo que no debe hacer el hombre de ciencia. Es evidente que aquí no podremos dedicarnos a discutir los usos y abusos de las distintas teorías psicoanalíticas a lo largo de su historia, pero si podremos hacer notar, en el capítulo siguiente, que la actitud crítica de Freud distaba mucho de esa caricaturización infundada y que su legado contraría ese tipo de actitudes dogmáticas.
} 
En obras posteriores a la de 1934, Popper reconocerá el valor que tienen las ideas de Freud, aunque sin retractarse de su conjetura. Admite estar "convencido de que existe un mundo del inconsciente y de que los análisis de los sueños de Freud en su libro son fundamentalmente correctos" (Popper, 1956/2011: 204) y no tiene problemas en reconocer que "La interpretación de los sueños de Freud es un gran logro"; peso a ello, declara que la teoría allí esbozada "tiene un carácter más parecido al del atomismo anterior a Demócrito -o quizá al de la colección de relatos de Homero sobre el Olimpo- que al de una ciencia contrastable" (ibíd. p. 212). Más tarde, reiterará su opinión de que las hipótesis (mitológicas) de Freud "contienen sugerencias psicológicas sumamente interesantes, pero no en una forma testable", concediendo que "tales mitos son susceptibles de desarrollo y pueden llegar a ser testables" (Popper, 1962: 62-63). Es decir que Popper no solo admitió sino que también alentó la posibilidad de "cientificizar" la teoría psicoanalítica. Ello se debe a que el criterio falsacionista es, para nuestro filósofo, independiente de la "verdad" de las conjeturas; en ese sentido, afirmó que el psicoanálisis "constituye una interesante metafísica psicológica (y no cabe duda de que hay alguna verdad en él, como sucede tan a menudo en las ideas metafísicas), pero nunca fue una ciencia". (Popper, 1974/1995: 140).

Más allá de su idea inicial de que el psicoanálisis es una pseudociencia (nunca abandonada) Popper pareciera haber moderado en varias oportunidades su opinión. Considérese este pasaje: "yo critico mucho al psicoanálisis, pero me parece que el hincapié que hacía Freud en la influencia formativa de las experiencias sociales, en la más tierna infancia, era correcto" (Popper, 1977/1995: 297).

Como el lector podrá notar, la añadidura de estas afirmaciones condescendientes de Popper al conjunto original de sus afirmaciones sobre el psicoanálisis da por resultado, cuanto menos, una incoherencia en su argumento. Por si quedasen dudas, voy a mostrarlo haciendo uso de sus propias ideas sobre la explicación científica. Consideremos la siguiente afirmación, realizada en el marco de una reflexión sobre la dogmatización posible de las teorías científicas: 
Pienso que este es un problema serio en un tiempo en que los intelectuales, incluyendo a los científicos, son propensos a caer en ideologías y modas intelectuales. Ello puede muy bien ser debido al ocaso de la religión, o a las insatisfechas e inconcientes necesidades religiosas de nuestra sociedad huérfana [en nota al pie añade:] Nuestras sociedades occidentales por su estructura no satisfacen la necesidad de la figura de un padre [...] Mi reciente amigo ${ }^{108}$, el psicoanalista Paul Federn, me mostró poco después un inicial artículo suyo dedicado a este problema [luego continúa, en el texto, diciendo:] A lo largo de mi vida he sido testigo, prescindiendo completamente de los movimientos totalitarios, de una serie considerable de movimientos de índole intelectual y pretendidamente no-religiosos que encerraban elementos cuyo carácter religioso es inconfundible una vez se tienen abiertos los ojos [aquí hace una nueva nota al pie y nombra cinco intelectuales, entre ellos Sigmund Freud; y destaca el papel de "profeta" que ellos han jugado en diversos movimientos]. El mejor de estos movimientos fue aquel que estaba inspirado por la patriarcal figura de Einstein (Popper 1975/1983: 132).

La incoherencia aparece si notemos que el pasaje anterior es una suerte de esbozo de explicación que hace Popper. Ahora bien, recordemos que la historiografía lo señala como pionero en el establecimiento del modelo de "cobertura legal" de explicación científica, junto con Carl Hempel. Y que su propuesta establece como requisito de las explicaciones científicas que los enunciados explanantes (ya sean leyes o condiciones iniciales) deben ser falsables y estar corroborados independientemente ${ }^{109}$. Como puede advertirse, no podría haber explicaciones científicas hechas en base a enunciados irrefutables, como los psicoanalíticos (la premisa explanante del ejemplo es: nuestras sociedades occidentales por su estructura no satisfacen la necesidad de la figura de un padre). Por lo tanto, esgrimiendo el espíritu crítico que nos ha legado, no podríamos dar otro veredicto (a su esbozo explicativo) que el de ser una pseudo-explicación científica. Junto con ello, no podemos menos que

\footnotetext{
${ }^{108}$ Este mismo artículo de Popper aparece en un libro de lan Hacking. La traducción es similar, pero esta oración dice así: "Mi difunto amigo, el psicoanalista Paul Federn" (Popper, 1975/1985: 189). Federn muere de 1950, por lo que la versión que he utilizado parece tener un error que conviene señalar: Popper había conocido a Federn mucho antes (no eran amigos "recientes").

${ }^{109}$ Una "explicación causal será sólo aceptable científicamente si las leyes universales han sido bien experimentadas y corroboradas..." (Popper, 1961/1973: 138). Ya en su Logik der Forschung se había ocupado de la estructura de la explicación causal (cf. Popper, 1934/1980: cap. 3 § 12).
} 
juzgar sus palabras como una suerte de "crimen de lesa epistemología": la autocontradicción inminente.

El anterior no es el único ejemplo de Popper utilizando las hipótesis freudianas como premisas explanantes de una explicación propia. En Realismo y el objetivo de la ciencia, por ejemplo, discutiendo que el objetivo de la filosofía sea la intuición de esencias, reconoce que: "hay que agradecer a Freud su profunda comprensión del animismo y de la creencia en la «omnipotencia de los pensamientos», símbolos y palabras [...] [quien] se acerca mucho (pero no lo suficiente) a decir que el esencialismo es una actitud pre-científica, y a descubrir así, sus raíces mágicas y animistas" (Popper, 1956/2011: 304). ¿Cómo sabe Popper que Freud se "acerca" al descubrimiento de las raíces mágicas o animistas del esencialismo, siendo que tales ideas forman parte de una teoría según él incontrastable? La actitud popperiana es incoherente y conduce al absurdo ${ }^{110}$.

En la sección siguiente nos detendremos en las principales críticas que la propuesta de Popper suscitó a partir de la segunda mitad del siglo XX; y veremos que es bastante común la actitud popperiana de desestimar en el plano metacientífico lo que incansablemente recomienda apreciar y hacer en el plano científico.

Luego de contrabalancear su propuesta epistemológica, retomaremos a Freud para contradecir las especulaciones gratuitas de Popper: mostraremos que el accionar metodológico del creador del psicoanálisis se asemeja al proceder general del hipotético-deductivismo, a un punto tal que Popper hubiera elogiado.

\footnotetext{
${ }^{110}$ Admito que esta forma de leer a Popper carece de benevolencia. Pero, no olvidemos que Popper tuvo el mismo tipo de carencia para con el psicoanálisis. No podrá reprochársenos que no hemos intentado leer y entender a Popper; y que le devolvemos así la gentileza que no supo tener para con Freud. Para una lectura más indulgente de las inconsistencias popperianas, cf. David Miller (discípulo y editor de sus obras), quien sostiene: "Es imposible que todo lo que dijo sea correcto, cuando menos porque él se contradijo a sí mismo en alguna cantidad de asuntos centrales; no solamente, como nos sucede a todos, en nombre de alguna reconsideración, sino porque él en ocasiones abordó el mismo problema desde perspectivas diferentes, y de ese modo enfatizó indebidamente algunos aspectos a expensas de su contrastación. Sin embargo, el escritor español Miguel de Unamuno seguramente tenía razón al afirmar que 'un hombre que ha logrado no contradecirse nunca debe ser sospechado de nunca haber dicho nada en realidad"' (Miller, 2004: 2). Esto mismo puede leerse en un trabajo posterior de Miller (2006: 82).
} 


\title{
4. Problemas del falsacionismo de Popper
}

\author{
"Una de las tareas más características de la filosofía es \\ atacar, si es necesario, al propio marco" (Popper, \\ 1982/1985: 58).
}

Antes de discutir la pertinencia de la crítica popperiana al psicoanálisis de Freud, veamos algunos de los obstáculos con los que la teoría de Popper se ha topado. Analizaremos, concretamente, dos aspectos interrelacionados que nos permitirán ponderar la propuesta del filósofo vienés: a) las principales críticas que se han hecho a su epistemología y la réplica de Popper a las mismas; y b) el lugar de transición de la figura de Popper en la filosofía de la ciencia del siglo $X X$.

\section{a) Las principales críticas recibidas y las réplicas de Popper.}

Aunque no podemos referir aquí a la enorme cantidad de ataques que el criterio popperiano de la falsación ha recibido, sí podemos mencionar sintéticamente algunas de las principales líneas de fuego.

Nos detendremos en la conversación que tuvo lugar al interior de cierta tradición general de la filosofía analítica de la ciencia y circunscribiremos la órbita de las críticas (efectuadas o posibles) orientándonos por lo que han señalado algunos interlocutores reconocidos, en particular Thomas Kuhn, Imre Lakatos y Paul Feyerabend, durante la segunda mitad del siglo pasado.

\section{No hay observación sin teoría}

Es sabido que muchos científicos y filósofos se vieron cautivados por el falsacionismo, pero desde una ingenua perspectiva. Se creyó que la metodología de Popper impedía la verificación de una teoría y, al mismo tiempo, permitía su refutación definitiva. Esta idea de la contrastación, que se puede representar lógicamente con el esquema del modus tollendo tollens, condujo a muchos a pensar que era posible derribar grandes teorías con el sólo hecho de encontrar observaciones que se les opongan ${ }^{111}$.

111 Como veremos en el siguiente capítulo, Lakatos llamó a este conjunto de creencias "falsacionismo dogmático" y lo atribuyó a la equivocada lectura que algunos como Ayer, Nagel y Madewar, hiciesen de Logik der Forschung, sentando posiciones críticas del "hombre de paja llamado Poppero". Lakatos, en un afán por darle coherencia a las contradicciones popperianas, 
El principal supuesto infrateórico que guía esa idea, posiblemente sea el de que las observaciones son neutras y objetivas; lo cual conduce a pensar que puede haber enunciados observacionales completamente seguros.

Contra ello atentaron diversos autores, fundamentalmente los protagonistas del giro historicista de la filosofía de la ciencia. Thomas Kuhn, por ejemplo, postuló su teoría de la evolución del conocimiento científico suponiendo que la observación y los datos son siempre relativos a un paradigma; y que, como no es posible salirse del paradigma para ver el mundo tal y como es en sí mismo, entonces no puede sostenerse la tesis de la observación objetiva ni la del progreso teleológico del conocimiento (Kuhn, 1962/2004). Antes que él, Norwood Hanson había afirmado que las teorías no se descubren generalizando inductivamente a partir de los hechos, sino realizando retroducciones de hipótesis probables a partir de datos conceptualizados; es decir, había postulado que las observaciones empíricas se realizan desde teorías que las organizan conceptualmente (Hanson, 1958/1977).

Si toda observación contiene una carga teórica ${ }^{112}$, entonces el proceso de contrastar una hipótesis con un enunciado empírico básico es menos concluyente de lo que muchos supondrían. No siendo la observación una base firme (en virtud de que está cargada de teoría), toda discrepancia entre la teoría y la observación puede deberse tanto al error de los enunciados teóricos como al de los enunciados observacionales. No hay razones lógicas que nos obliguen a conservar uno en detrimento del otro. Imre Lakatos ha sido categórico al respecto:

distingue "tres Poppers: Popper $_{0}$, Popper $_{1}$ y Popper $_{2}$. Popper $_{0}$ es el falsacionista dogmático que nunca publicó una sola palabra; fue inventado (y criticado) primero por Ayer y después por muchos otros [...] Popper ${ }_{1}$ es el falsacionista ingenuo, Popper $_{2}$ el falsacionista sofisticado. El Popper auténtico evolucionó desde el falsacionismo dogmático hasta una versión ingenua del falsacionismo metodológico en la década de 1920; llegó a las «reglas de aceptación» del falsacionismo sofisticado en la década de 1950 [...] Pero el Popper auténtico nunca abandonó sus primeras reglas falsacionistas (ingenuas). [...] el Popper real se compone de Popper $_{1}$ con algunos elementos de Popper ${ }_{2}$ " (Lakatos 1978/1989: 123-4). A nuestro modo de ver, esta forma lakatosiana de entender la teorización de un autor (en este caso Popper) responde a un equivocado presupuesto antropológico: el de que es posible reconocer una auténtica versión de los sujetos, en la que no haya contradicciones ni inconsistencias. Desde el psicoanálisis podemos argumentar que ese supuesto no representa adecuadamente lo que es un sujeto (ya sea científico, ya sea filósofo). Retomaremos esta cuestión más adelante, a los fines de no hacer perder el hilo de argumentación que ahora estamos siguiendo.

112 La expresión pareciera haber sido acuñada por Hanson: "En cierto sentido, entonces, la visión es una acción que lleva una «carga teórica»" (Hanson, 1958/1977: 99). 
si las proposiciones fácticas no pueden ser probadas, entonces son falibles. Si son falibles, entonces los conflictos entre las teorías y las proposiciones fácticas no son «falsaciones» sino simples inconsistencias [...] Por tanto, no podemos probar las teorías y tampoco podemos refutarlas (Lakatos 1978/1989: 27).

Debido a ello, la lógica de la falsación pierde su fuerza: si la refutación de una hipótesis $h_{1}$ se debe a un desfavorable informe observacional -e, y si ese informe observacional es aceptado por apoyarse en la hipótesis $h_{2}$ (que nunca podría estar verificada sino, como máximo, corroborada), lo que en realidad tenemos es un conflicto lógico entre dos hipótesis $h_{1}$ y $h_{2}$.

\title{
La réplica de Popper.
}

Como veremos, Popper se ha defendido de sus críticas apelando fundamentalmente a la incomprensión de sus detractores: en su opinión él nunca defendió un falsacionismo ingenuo y las críticas que se le dirigen coinciden con su mismo punto de vista.

En lo que al problema de la carga teórica de la observación respecta, es cierto que Popper ya había manejado la suposición de que no hay observación sin teoría y había afirmado que las percepciones sensoriales no llevan a enunciados observacionales infalibles. En su célebre escrito de 1934 (y en las reediciones posteriores) abordó "el problema de la base empírica" diciendo:

\begin{abstract}
Siempre que una teoría se someta a contraste, ya resulte de él su corroboración o su falsación, el proceso tiene que detenerse en algún enunciado básico que decidamos aceptar: si no llegamos a decisión alguna a este respecto, y no aceptamos, por tanto, un enunciado básico, sea el que sea, la contrastación no lleva a ninguna parte (Popper, 1934/1980: 99).
\end{abstract}

Seguido de ello, dirá que "desde un punto de vista lógico, el contraste de una teoría depende de ciertos enunciados básicos, que, a su vez, se aceptan o rechazan en virtud de nuestras decisiones ${ }^{113}$. Así pues, son las decisiones las que determinan el destino de las teorías" (ibíd. pp. 104).

\footnotetext{
${ }^{113}$ Ricardo Gómez afirma, con razón, que "la decisión de aceptar un determinado enunciado básico es una decisión grupal. Ello involucra la intromisión de ingredientes sociológicos en la postura de Popper, contra su propia y siempre vociferada vocación anti-sociologista, al mismo tiempo mina su pretensión de elaborar una epistemología sin sujeto cognoscente; sujeto que, en este caso, no es un individuo sino una comunidad de investigadores" (Gómez, 1995: 19).
} 
Popper supo y afirmó desde el inicio que todas las observaciones son siempre falibles; pero intentó resolver esta situación de incerteza apelando a un convencionalismo empiricista:

La base empírica de la ciencia objetiva, pues, no tiene nada de «absoluta»; la ciencia no está cimentada sobre roca: por el contrario, podríamos decir que la atrevida estructura de sus teorías se eleva sobre un terreno pantanoso, es como un edificio levantado sobre pilotes. Estos se introducen desde arriba en la ciénaga, pero en modo alguno hasta alcanzar ningún basamento natural o «dado»; cuando interrumpimos nuestros intentos de introducirlos hasta un estrato más profundo, ello no se debe a que hayamos topado con terreno firme: paramos simplemente porque nos basta que tengan firmeza suficiente para soportar la estructura, al menos por el momento (ibíd. pp. 106).

Este costado popperiano será incluso reforzado con citas posteriores a la versión original de su Logik der Forschung; p. ej.: "las observaciones [...] son siempre interpretaciones de los hechos observados, es decir, que son interpretaciones a la luz de teorías" (ibíd. pp. 103, n 2).

Sin embargo el asunto es más complejo. Pese a las afirmaciones anteriores (que parecen sintonizar con las de sus críticos), hay también en ese escrito célebre y en otros, toda una serie de aseveraciones discordantes con esta idea. En ellas se basan Kuhn y Lakatos para acusarlo de falsacionista ingenuo. Considérese, por ej., los siguientes pasajes: "ha de ser posible refutar por la experiencia un sistema científico empírico" (Popper, 1934/1980: 40); "las teorías científicas [...] deben ser eliminadas si entran en conflicto con observaciones" (Popper, 1963/1991: 72); o "la refutación de una teoría puede ser inferida de datos empíricos y esta inferencia es puramente deductiva" (ibíd. pp. 82).

Vista desde el psicoanálisis, esta contradicción puede ser conceptualizada como división subjetiva y dar lugar a toda una serie de lecturas, rastreos y argumentaciones de diversa índole. Desistiremos sin empezar, pues no es nuestro objetivo.

Retomando nuestra óptica epistemológica, diremos que esa eminente contradicción popperiana decanta en un dilema ${ }^{114}$ metodológico interno a su

\footnotetext{
114 Dilema del que algunos pretenden resguardarse por apelación a elementos hermenéuticosociológicos: "la aceptación o el rechazo de los enunciados de base descansan, en última
} 
propuesta: "no hay nada en la lógica de la situación que exija que siempre haya de ser la teoría la rechazada en caso de un choque con la observación" (Chalmers, 1976/1990: 90). Pero la contradicción va más lejos: "o bien los enunciados básicos son convenciones no falsables y la base empírica de la ciencia es no-científica, o bien son conjeturas falsables y el científico tiene tanto deber de intentar refutarlas como a cualquier otra conjetura" (Brown, 1977/1983: 98).

\section{El papel de las hipótesis auxiliares en la contrastación.}

Una segunda crítica es a la incompleta representatividad del esquema del modus tollendo tollens; en particular, al antecedente del condicional de la primera premisa. La mencionada regla de inferencia tendría la siguiente escritura en lógica proposicional:

$$
[(p \rightarrow q) \wedge \neg q] \rightarrow \neg p
$$

Simbolizando con $\mathrm{H}$ a la hipótesis puesta a prueba y representando con $\mathrm{O}$ a la consecuencia observacional derivada, podemos graficar así la forma popperiana de la refutación:

$$
\begin{gathered}
\mathrm{H} \rightarrow \mathrm{O} \\
\neg \mathrm{O} \\
\neg \mathrm{H}
\end{gathered}
$$

Desafortunadamente, este esquema deja por fuera toda una serie de enunciados hipotéticos que juegan un rol igual de importante en la refutación. Además de la hipótesis específica que se intenta contrastar, al menos otros tres tipos de conjeturas deberían estar también representadas en el esquema lógico: las hipótesis y teorías presupuestas, las conjeturas relativas a las propiedades del material de trabajo y las hipótesis sobre las condiciones del

instancia, sobre una decisión. Decisiones que, en todo caso, no son tomadas arbitrariamente, sino de acuerdo con unas reglas. La determinación de estas reglas es de naturaleza institucional, no lógica. Nos motivan a orientar decisiones de este tipo a un objetivo previamente comprendido de modo tácito, sin llegar a definirlo. Así procedemos en la comunicación cotidiana y en la interpretación de textos. No hay, a decir verdad, otra salida, dado que nos movemos en un círculo y, sin embargo, no queremos renunciar a la explicación". (Habermas, 1969/1973: 228). 
contexto singular de la contrastación o datos observacionales ${ }^{115}$. Es importante notar que la hipótesis central sometida a prueba en general es insuficiente para derivar una predicción contrastadora, necesitándose para ello de las otras conjeturas mencionadas.

Si tuviéramos que representar toda la variedad de hipótesis intervinientes en un proceso de contrastación cuya consecuencia observacional resulta inadecuada, deberíamos incluir tales hipótesis en el lugar del antecedente del condicional en juego:

$$
\begin{gathered}
{\left[\left(A_{1} \wedge A_{2} \wedge A_{3} \wedge A_{n} \ldots\right) \wedge H\right] \rightarrow O} \\
\neg O \\
\neg\left[\left(A_{1} \wedge A_{2} \wedge A_{3} \wedge A_{n} \ldots\right) \wedge H\right]
\end{gathered}
$$

Admitiendo la intervención de otras hipótesis (además de $\mathrm{H}$, que se pretende someter a contrastación), ante una refutación nos encontramos con la necesidad de tener que rechazar un antecedente compuesto por un conjunto de proposiciones $\left(A_{1} \wedge A_{2} \wedge A_{3} \wedge A_{n} \ldots \wedge H\right)$; de modo tal que: si el consecuente (O) es falso ${ }^{116}$, entonces no es posible que el antecedente sea verdadero; es decir, no es posible que todas las proposiciones contenidas en él lo sean al mismo tiempo.

Utilizando una transformación basada en las leyes de Morgan puede decirse que esa conclusión, en la que se niega una serie de conjunciones, es equivalente a otra en la que se niegan proposiciones conectadas por disyunciones:

$$
\begin{gathered}
{\left[\left(A_{1} \wedge A_{2} \wedge A_{3} \wedge A_{n} \ldots\right) \wedge H\right] \rightarrow O} \\
\neg O \\
\neg A_{1} \vee \neg A_{2} \vee \neg A_{3} \vee \neg A_{n} \ldots \vee \neg H
\end{gathered}
$$

\footnotetext{
${ }^{115}$ Gregorio Klimovsky ha analizado y tipificado la diversidad de hipótesis intervinientes en el proceso de contrastación, defendiendo una "versión compleja del método hipotético-deductivo" (cf. Klimovsky, 1994/2005, cap. 13.). Aquí no utilizaremos exactamente esa tipología de hipótesis intervinientes, pues para nuestros fines basta con mantenernos a un nivel más inespecífico de descripción.

${ }^{116}$ Falsedad que, como vimos en torno a la crítica anterior, es siempre fruto de una decisión y no el resultado de un algoritmo.
} 
Es decir, una de las hipótesis que integran el antecedente del condicional debe necesariamente ser falsa, pero la lógica (aquí tampoco) nos indica cuál. La pregunta crítica dirigida a Popper es ¿por qué deberíamos rechazar la hipótesis central en lugar de alguno de los supuestos auxiliares? Después de todo, la historia de la ciencia está plagada de ejemplos de contrastaciones negativas en los que se responsabilizó a los supuestos auxiliares y no a las teorías específicas que se ponían a prueba ${ }^{117}$. Más adelante abordaremos este punto con mayor detalle.

La crítica a este aspecto lógico es, en última instancia, una crítica hacia el carácter no determinante de la falsación. Todo esto suele conocerse como una forma de holismo metodológico o como tesis Duhem-Quine: es lógicamente imposible poner a prueba una proposición de forma aislada, pues ella siempre está acompañada de asunciones implícitas que tienen la misma probabilidad de ser falsas ante una contrastación negativa ${ }^{118}$.

\title{
La réplica de Popper
}

También aquí debe reconocerse que Popper era absolutamente conciente de este problema: en su Logik der Forschung, afirma:

\begin{abstract}
Me veo obligado a admitir que esta crítica es justa; pero no necesito, por ello, retirar mi propuesta de adoptar la falsabilidad como criterio de demarcación. Pues voy a proponer [...] que se caracterice el método empírico de tal forma que excluya precisamente aquellas vías de eludir la falsación que mi imaginario crítico
\end{abstract}

\footnotetext{
117 Cf. el capítulo 3 de Diez \& Moulines (1997), en donde los autores hacen un abreviado compendio de episodios históricos de contrastación (en distintas disciplinas de las ciencias naturales) y en muchos de los cuales se muestra la "responsabilidad" de las hipótesis auxiliares.

${ }^{118}$ Por esto, Pierre Duhem rechazó la idea de que la lógica sea suficiente para vincular teoría y observación o para elegir una entre dos teorías, idea que Popper adoptó luego y sintetizó con el término "falsación". Posteriormente Willard Quine continuó esa idea aduciendo que sólo pueden someterse a confirmación o refutación conjuntos enteros de creencias (cf. Duhem, 1914/2003 y Quine, 1953/2002; 1975/2001). Por otro lado, como señala Ulises Moulines, la denominación "tesis Duhem-Quine" es un poco injusta, por dos motivos "primeramente, porque el holismo de Duhem no es tan radical como el de Quine [mientras que este último lo postula como una característica del conocimiento científico general, para el primero sólo se reducía a algunas disciplinas como la física y no se aplicaba a otras como la fisiología]; en segundo lugar, porque además de Duhem y Quine, hay otro gran defensor del holismo: Otto Neurath [defendido 20 años antes que Quine]" (Moulines, 2008/2011: 26-7, el texto entre corchetes es nuestro).
} 
señala insistentemente, con toda razón, como lógicamente posibles (Popper, 1934/1980: 41).

Popper denomina allí "estratagema convencionalista" al proceso que consiste en transformar a una teoría refutable en otra irrefutable, por la introducción de hipótesis ad hoc con el propósito de evitar la falsación. Así define la forma de solucionar esta cuestión:

El único modo de eludir el convencionalismo es tomar una decisión; la de no aplicar sus métodos. Decidimos que, en el caso de que se presente una amenaza para nuestra teoría, no la salvaremos por ningún género de estratagema convencionalista; así pues, nos guardaremos de explotar la posibilidad que acabamos de mencionar - y que está siempre abierta - de «...conseguir, para un sistema... cualquiera dado, lo que se llama su 'correspondencia con la realidad'» (ibíd. pp. 79).

Años más tarde, Popper va a reconocer que es innecesario renunciar al uso de una teoría por el mero hecho de hallarse una falsación. Concede la posibilidad de modificar la teoría falseada introduciendo nuevas hipótesis, pero -agrega- a condición de que ellas no sean hipótesis "ad hoc". Él entiende que tales hipótesis se caracterizan por agregarse en auxilio de una teoría "puesta en jaque" y sin poder ser contrastadas de forma independiente (por lo que no tienen consecuencias observacionales diferentes de la hipótesis jaqueada). De ahí que para nuestro filósofo vienés "una «buena» teoría no es ad hoc, mientras que una «mala» teoría lo es" (Popper, 1963/1991: 90).

Lakatos va a analizar la respuesta de Popper y a distinguir diversos tipos de hipótesis ad-hoc ${ }^{119}$. Utilizando un ejemplo inventado va a mostrar que, aún sin introducir el tipo de hipótesis que Popper considera ad hoc (aquellas que no pueden contrastarse de forma independiente), el criterio popperiano no logra su cometido:

La historia se refiere a un caso imaginario de conducta anómala de un planeta. Un físico de la era preeinsteiniana combina la mecánica de Newton y su ley de gravitación (N) con las condiciones iniciales aceptadas (I) y calcula mediante ellas

\footnotetext{
119 "ad hoc: las que no tienen un exceso de contenido empírico con relación a sus predecesoras («ad hoc») ); las que tienen tal exceso de contenido, pero ninguna parte del mismo está corroborada \{ «ad hoc» ${ }_{2}$ ) y finalmente aquellas que no son ad hoc en estos dos sentidos pero que no forman parte integral de la heurística positiva («ad hoc» 3$)$ ” (Lakatos, (1971/1987: 146).
} 
la ruta de un pequeño planeta que acaba de descubrirse, $p$. Pero el planeta se desvía de la ruta prevista. ¿Considera nuestro físico que la desviación estaba prohibida por la teoría de Newton y que, por ello, una vez confirmada tal ruta, queda refutada la teoría N? No. Sugiere que debe existir un planeta hasta ahora desconocido, $p^{\prime}$, que perturba la ruta de $p$. Calcula la masa, órbita, etc., de ese planeta hipotético y pide a un astrónomo experimental que contraste su hipótesis. El planeta $p^{\prime}$ es tan pequeño que ni los mayores telescopios existentes podrían observarlo: el astrónomo experimental solicita una ayuda a la investigación para construir uno aún mayor. Tres años después el nuevo telescopio ya está disponible. Si se descubriera el planeta desconocido p', ello sería proclamado como una nueva victoria de la ciencia newtoniana. Pero no sucede así. ¿Abandona nuestro científico la teoría de Newton y sus ideas sobre el planeta perturbador? No. Sugiere que una nube de polvo cósmico nos oculta el planeta. Calcula la situación y propiedades de la nube y solicita una ayuda a la investigación para enviar un satélite con objeto de contrastar sus cálculos. Si los instrumentos del satélite (posiblemente nuevos, fundamentados en una teoría poco contrastada) registraran la existencia de la nube conjeturada, el resultado sería pregonado como una gran victoria de la ciencia newtoniana. Pero no se descubre la nube. ¿Abandona nuestro científico la teoría de Newton junto con la idea del planeta perturbador y la de la nube que lo oculta? No. Sugiere que existe un campo magnético en esa región del universo que inutilizó los instrumentos del satélite. Se envía un nuevo satélite. Si se encontrara el campo magnético, los newtonianos celebrarían una victoria sensacional. Pero ello no sucede. ¿Se considera este hecho una refutación de la ciencia newtoniana? No. O bien se propone otra ingeniosa hipótesis auxiliar o bien... toda la historia queda enterrada en los polvorientos volúmenes de las revistas, y nunca vuelve a ser mencionada (Lakatos, 1978/1989: 27).

Como podrá notarse, el científico del ejemplo lakatosiano se dedica a introducir hipótesis que bien podrían ser contrastadas de forma independiente. Por ende, aduce Lakatos, la noción de "adhocidad" de Popper resulta demasiado permisiva e impide una concreta definición del problema procedimental del falsacionismo.

Ninguna teoría, concluye Lakatos, puede prohibir fenómenos observables. "El «inexorable» procedimiento de refutación del falsacionismo dogmático se viene abajo en tales casos incluso si existiera una base empírica sólidamente establecida que sirviera como ballesta para lanzar la flecha del modus tollens: el blanco fundamental seguiría siendo irremediablemente evasivo" (ibíd. pp. 
30). Dicho de otro modo, siempre es posible proteger una teoría de la falsación culpabilizando a otro sector de la compleja red de supuestos auxiliares ${ }^{120}$.

Para Gregorio Klimovsky, gran parte de las discusiones sobre el problema de la falsación se debe a una "diferencia de temperamentos" entre Popper y sus críticos (1994/2005). La posición de estos últimos sobre la falsación, podría considerarse basada en un "temperamento conservador": ante una contrastación empírica desfavorable, conviene buscar la hipótesis falsa por etapas (empezando por los datos observacionales y las hipótesis de trabajo, antes que por la hipótesis específica). Agreguemos, basándonos en lo anterior, que este "avance por aproximaciones sucesivas y cada vez más amplias en busca de responsabilidades" (ibíd. pp. 216), es una elección que se apoya, irreprochablemente, tanto en los supuestos de la "carga teórica de la observación" y de "la presencia de hipótesis auxiliares", como también en la misma "historia de la ciencia".

Por otro lado, afirma Klimovsky, la posición de Popper (en su Logik der Forschung) parece basada en un "temperamento revolucionario": ante una contrastación empírica negativa, la hipótesis en juego debe ser desechada. Lo que Popper ve, en la búsqueda ampliada de culpables (entre las hipótesis auxiliares), es un peligro para la ciencia: el de justificar y mantener en pie a las teorías, a pesar de los obstáculos que antepone la contra-evidencia empírica.

La decisión de actuar de forma revolucionaria (sustituir la teoría) o de forma conservadora (sustituir supuestos auxiliares), no puede ser tomada en base a algoritmos: es una cuestión de confianza y no de lógica ${ }^{121}$. Dicho de otra

\footnotetext{
${ }^{120}$ Comentando este tema y su vínculo con el convencioalismo, Lakatos realiza una afirmación que no puede menos que sorprender a cualquier psicoanalista: "Popper trató de encontrar un criterio que fuera más objetivo y más demoledor. No podía aceptar la castración del empirismo inherente incluso en el enfoque de Duhem, y propuso una metodología que acepta la fortaleza de los experimentos incluso en la ciencia «madura»" (ibíd. pp. 34, las negritas son nuestras). Difícilmente pueda hallarse una mejor manera de mostrar el problema.

121 Feyerabend se había referido a este problema casi en los mismos términos y había concluido que "la lucha entre los conservadores y los liberales" no conduce a que haya "cambios racionales". Se trata siempre de "una 'lucha por el poder' pura y simple, repleta de 'sórdida controversia personal' [y] constituye un tópico no de la metodología, o de la teoría de la racionalidad, sino de la 'psicología de masas'” (Feyerabend, 1975/1986: 188). Por todo ello, juzgó que "la metodología de programas de investigación se introdujo con el propósito de apoyar el racionalismo. Sin embargo, dicha metodología no puede condenar una sola acción como 'irracional' [...] Lakatos no se diferencia realmente de los epistemólogos tradicionales; muy al contrario, les suministra un potente instrumento nuevo de propaganda" (ibíd. pp. 193-4). A nuestro modo de ver, Feyerabend ha ido coherentemente hasta las últimas consecuencias del asunto.
} 
manera: ante la contradicción que resulta de las contrastaciones negativas, el sistema teórico, que bien puede metaforizarse como una red ${ }^{122}$, debe ser modificado. Entre retocar la red en el más mínimo punto y sustituirla completamente, hay un abanico incalculable de posibilidades de decisión para las que la lógica no aporta cálculos deductivos. Por ende, la racionalidad de esas decisiones no es representable con formas algorítmicas sino que permanece ligada a cuestiones de índole pragmática ${ }^{123}$ (en sentido amplio).

En este punto debemos adelantar nuestra conjetura. Respecto de la falsación, el "temperamento de Freud" puede diferenciarse del popperiano: sin ser un conservador a ultranza, su proceder no es de tipo revolucionario. Lo intentaré mostrar más adelante.

Pero veamos, antes de pasar al psicoanálisis, otro perfil de las críticas a la teoría de Popper.

\section{El comportamiento de los científicos desde la óptica histórica}

Una tercera objeción es que los científicos, según nos muestra la historia de la ciencia, no se comportan como Popper prescribe. Retomando la terminología del apartado anterior, la objeción podría formularse de este modo: raramente los científicos tienen un temperamento revolucionario.

En primer lugar, Kuhn sostiene que Popper "caracteriza a la ciencia entera en términos que se aplican sólo a sus ocasiones revolucionarias" (Kuhn, 1970/1977: 296), desestimando los períodos de ciencia normal. Conceptualización que Kuhn critica: "he argumentado ampliamente que la expresión de sir Karl «revoluciones permanentes» no describe, al igual que «círculo cuadrado», un fenómeno que pueda existir" (Kuhn, 1970/2002: 165).

\footnotetext{
${ }^{122}$ El propio Popper utilizó tempranamente esta metáfora: "Las teorías son redes que lanzamos para apresar aquello que llamamos «el mundo»: para racionalizarlo, explicarlo y dominarlo. $Y$ tratamos de que la malla sea cada vez más fina" (Popper, 1934/1980: 57)

123 Ya Pierre Duhem había abordado este problema sin rechazar la subjetividad del investigador: "puesto que el momento en que una hipótesis insuficiente ha de ceder el paso a una suposición más fecunda no está marcado por la lógica con precisión rigurosa, sino que corresponde al sentido común reconocer ese momento, los físicos pueden adelantar ese juicio y aumentar la rapidez del progreso científico, esforzándose por lograr que su propio sentido común sea más lúcido y atento. Ahora bien, nada contribuye más a poner trabas al sentido común y a perturbar su clarividencia que las pasiones y los intereses. Así pues, nada retrasará más la decisión que ha de determinar una afortunada reforma en una teoría física que la vanidad, que hace al estudioso demasiado indulgente con su propio sistema y demasiado severo con el sistema del otro". (Duhem, 1914/2003: 287).
} 
En segundo lugar, el abandono de una teoría no se produce (como Popper parece creer) por el mero resultado de contrastaciones negativas. Kuhn afirma, basándose en sucesos históricos, que "la decisión de rechazar un paradigma conlleva siempre simultáneamente la decisión de aceptar otro, y el juicio que lleva a tal decisión entraña la comparación de ambos paradigmas con la naturaleza y entre sí" (ibíd. pp. 166). Lakatos, por su parte, dice lo siguiente sobre este aspecto: "la historia de la ciencia sugiere que 1') las contrastaciones son, como mínimo, enfrentamientos trilaterales entre teorías rivales y experimentos, y 2') algunos de los experimentos más interesantes originan, prima facie, una confirmación en lugar de una falsación" (Lakatos, 1978/1989: 45). Para él, los científicos que trabajan en un programa de investigación siguen una "doble heurística", entendida como un conjunto de reglas tendientes a proteger al núcleo duro absorbiendo y anticipando anomalías ${ }^{124}$. Así, un hecho se ve como "refutador" de una teoría sólo si es "corroborador" de otra teoría alternativa.

En tercer lugar, desde la óptica de sus críticos la historia nos muestra (en contra de lo que Popper postula) que las teorías científicas nacen falsadas; es decir, se originan sin concordar absolutamente con todos los datos de manera coherente y con la necesidad de ajustes que las tornen viables. Esto indica que la ciencia, inicialmente, desestima la falsación. En palabras de Lakatos, "las llamadas «refutaciones» no indican un fracaso empírico como Popper ha enseñado, porque todos los programas crecen en un océano permanente de anomalías" (Lakatos, 1978/1989: 15). Análogamente, Kuhn ha mostrado que "no existe investigación sin contraejemplos" (1962/2004: 168) y que los cambios teóricos no responden a la lógica de la falsación popperiana ${ }^{125}$.

\footnotetext{
124 "La heurística negativa del programa impide que apliquemos el modus tollens a este «núcleo firme». Por el contrario, debemos utilizar nuestra inteligencia para incorporar e incluso inventar hipótesis auxiliares que formen un cinturón protector en torno a ese centro, y contra ellas debemos dirigir el modus tollens". (Lakatos, 1978/1989: 66). Profundizaremos la teorización lakatosiana en el próximo capítulo.

125 Durante el Coloquio Internacional de Filosofía de la Ciencia en 1965, Kuhn le critica a Popper que, pasando por alto la distinción (crucial para el primero) entre ciencia normal y ciencia extraordinaria, sólo analice lo que le sucede a la ciencia en tiempos de crisis y olvide su práctica normal. Popper contesta que no desconoce el hecho de que "los científicos desarrollan necesariamente sus ideas dentro de un marco general teórico definido" (Popper, 1970/1975: 149), y respecto a la noción de "ciencia normal", sostiene: "Afirmaré [...] que lo que Kuhn ha descrito existe, y que los historiadores de la ciencia deben tenerlo en cuenta. Que sea un fenómeno que a mí no me guste (porque lo considero un peligro para la ciencia) mientras que a
} 
Por todo ello, para Lakatos la falsación, "como se produce en la historia real, es prima facie irracional de acuerdo con los criterios de nuestro falsacionista. Según estos criterios los científicos a menudo parecen actuar con una lentitud irracional... ${ }^{126 " \text { " }}$

Retomando la inquisidora pregunta popperiana por las condiciones de refutabilidad del psicoanálisis, Lakatos sostuvo:

\begin{abstract}
Los freudianos han sido puestos en apuros por el requisito básico de Popper relativo a la honestidad científica. En realidad, se han negado a especificar condiciones experimentales bajo las que estarían dispuestos a abandonar sus presupuestos básicos. Para Popper ésta fue la señal de su deshonestidad intelectual ¿Pero qué sucede si hacemos la pregunta de Popper al científico newtoniano? ¿Qué tipo de observación refutaría, a satisfacción del newtoniano, no meramente una explicación particular de Newton sino su misma dinámica y su teoría de la gravitación? ¿Han sido jamás examinados y acordados tales criterios por parte de los newtonianos?' El newtoniano apenas estará dispuesto a dar una respuesta afirmativa ${ }^{127}$. Pero entonces si los analistas han de ser condenados como deshonestos por los cánones de Popper, los newtonianos también deben ser condenados. Sin embargo, la ciencia newtoniana, a pesar de esta especie de 'dogmatismo' es considerada de gran valor por los mejores científicos, y por el mismo Popper. El 'dogmatismo' newtoniano es en consecuencia una 'falsación' de
\end{abstract}

él al parecer no le disgusta (porque lo considera "normal") es otra cuestión" (ibíd. pp. 151). Popper no critica tanto la descripción kuhniana (aunque va a relativizarla) sino la valoración que éste hace del fenómeno, en tanto que algo esperable e inevitable. Volveremos más adelante sobre esta cuestión axiológica.

${ }^{126}$ La cita continúa ejemplificando: “...por ejemplo, transcurrieron ochenta y cinco años desde la aceptación del perihelio de Mercurio como anomalía y su aceptación como falsación de la teoría de Newton a pesar de que la cláusula ceteris-paribus estaba razonablemente bien corroborada. Por otra parte, en ciertas ocasiones los científicos parecen actuar con un apresuramiento irracional; por ejemplo, Galileo y sus discípulos aceptaron la mecánica celeste heliocéntrica de Copérnico a pesar de la abundante evidencia en contra de la rotación de la tierra; Bohr y sus discípulos aceptaron una teoría sobre la emisión de la luz a pesar de que contradecía a la teoría, bien corroborada, de Maxwell." (Lakatos, 1978/1989: 45).

127 Considérese, apropósito de esto, lo afirmado por Kuhn respecto a la falsación de la mecánica newtoniana: "se ha observado a menudo, por ejemplo, que la segunda ley del movimiento de Newton, por más que su consecución hubiese exigido siglos de difícil investigación empírica y teórica, para los comprometidos con la teoría newtoniana funciona en gran medida como un enunciado puramente lógico que ningún conjunto de observaciones podría refutar" (Kuhn, 1962/2004: 167). Hanson, por su parte, había considerado diversas interpretaciones posibles de $« F=m\left(d^{2} s / d^{2}\right) »$, una de las cuales es que "la segunda ley, aunque empírica, no puede ser refutable de una manera ordinaria [...] ningún resultado de un experimento en que se usa este instrumento [la notación] puede refutar la ley" (Hanson, 1958/1977: 204). 
la definición de Popper: contradice su reconstrucción racional (Lakatos, 1971/1987: 50-51).

Paul Feyerabend, por su parte, también se basa en la historia de la ciencia para mostrar cómo la actividad de los científicos desmiente el falsacionismo popperiano. Según su análisis, no es cierto que los científicos busquen desarrollar teorías consistentes con los hechos o con otras teorías aceptadas; e incluso dirá que la ciencia no debería comportarse de ese modo: "Hemos descubierto además que los principios lógicos no sólo desempeñan un papel muy pequeño en los pasos (argumentativos y no argumentativos) que hacen avanzar la ciencia, sino que el intento de darles fuerza universal obstaculizaría gravemente la ciencia" (Feyerabend, 1975/1986: 254).

Basándose en el supuesto de que no hay observación sin teoría, Feyerabend arremete contra la idea de proponer alternativas teóricas únicamente luego de la refutación. Para él, los datos empíricos constituyen evidencia contra una teoría sólo cuando son vistos a la luz de otra teorización incompatible. Por ende, propone proceder contra-inductivamente: generar hipótesis inconsistentes con los hechos y con teorías aceptadas, pues así funciona la ciencia en sus mejores momentos. Se trata, como es sabido, de una postura anti-metodológica enmarcada en un enfoque anarquista-dadaísta del conocimiento. Así se expresa:

\footnotetext{
Si nos volvemos a la lógica, comprobamos que incluso las exigencias más simples no son satisfechas por la práctica científica, y no pueden ser satisfechas debido a la complejidad del asunto. Las ideas que los científicos emplean para actualizar lo conocido y avanzar por lo desconocido sólo rara vez se conforman a los preceptos estrictos de la lógica o de la matemática pura y el intento de hacerlas conformes privaría a la ciencia de la elasticidad sin la que no se puede conseguir progreso. Vemos que los hechos por sí solos no son bastante fuertes para hacernos aceptar, o rechazar, las teorías científicas, el margen que dejan al pensamiento es demasiado amplio; la lógica y la metodología, por el contrario, eliminan demasiadas cosas, son demasiado estrechas. En medio de estos dos extremos se encuentra el dominio siempre cambiante de las ideas y deseos humanos (Feyerabend, 1975/1986: 298).
}

\section{La réplica de Popper}


Ante estas objeciones desde la práctica y la historia de la ciencia, Popper insiste en que su propuesta fue desde el inicio prescriptiva y no descriptiva: establece cómo debería comportarse un científico para hacer progresar a la ciencia, a partir de lo que él entiende como actitud metodológica más racional. En ese sentido, el científico kuhniano que trabaja en ciencia normal es visto como "una persona a la que habría que compadecer [...] un peligro para la ciencia y aun para nuestra civilización” (Popper, 1970/1975: 151-2).

Basándose en un "principio de transferencia" Popper pretende subordinar la historia a la lógica: "lo que es verdad en el dominio de la lógica, lo es también en el método científico y en la historia de la ciencia" (Popper, 1972/1974: 19).

Por nuestra parte, creemos que la postura de Popper se explica sólo a partir de su empeño por instaurar su canon falsacionista. Imposición que es a expensas de la historia misma:

\begin{abstract}
la Logik der Forschung, en su totalidad, es rigurosamente abstracta y ahistórica en grado sumo. Cuando Popper se arriesga a hacer observaciones fortuitas sobre la falsabilidad de las más grandes teorías científicas, o bien cae en algún disparate lógico, o distorsiona la historia para acomodarla a su teoría de la racionalidad (Lakatos 1971/1987: 54).
\end{abstract}

Se trata de una reconstrucción racional que acomoda procústicamente la historia de la ciencia a sus parámetros filosóficos ${ }^{128}$. Pero la historia de la ciencia no se comprende si se la reduce a la lógica de las refutaciones, puesto que dicha modelización exagera un tipo de racionalidad que (en el mejor de los casos) convive con otras en el contexto social de las comunidades científicas concretas. Alexandre Koyré ha dicho, contrariando ese principio popperiano que citamos más arriba, que “... la historia del pensamiento científico no es enteramente lógica. Por eso, para comprender su evolución hay que tener en cuenta factores extralógicos" (Koyré, 1973/1978: 83). Dicho en otras palabras, la ciencia es una actividad cultural entre otras y debemos estudiar su historia

\footnotetext{
${ }^{128}$ Lakatos abarca con esta crítica también al inductivismo y al convencionalismo, sosteniendo que 'todas las metodologías, todas las reconstrucciones racionales pueden ser 'falsadas' historiográficamente: la ciencia es racional, pero su racionalidad no puede ser subsumida por las leyes generales de ninguna metodología" (ibíd. pp. 59). Párrafos más adelante, considerando las críticas que se han expuesto a su propia metodología (falsacionismo sofisticado), sentencia: "ninguna reconstrucción racional puede jamás coincidir con la historia real" (ibíd. pp. 61).
} 
como sometida a los mismos avatares que cualquier otra empresa humana. Quizás sólo partiendo de este supuesto se logre captar el peso que tienen, en la evolución histórica de cada dominio cognitivo, los factores (pretendidamente) externos al contenido de las teorías. En el capítulo siguiente retomaremos este problema.

La reducción que pretende Popper de los problemas epistemológicos al estudio lógico-sincrónico de las relaciones entre teoría y experiencia, soslaya toda elucidación sobre la constitución histórico-política de las teorías, así como el sentido que ellas mantienen en las comunidades que las utilizan en un momento dado. Asimismo, su anteposición de un afán de normatividad en respuesta a las críticas de su inadecuada descriptividad histórica, constituyen una actitud de huida en evidente contradicción con su metodología.

Para sintetizar este punto diremos que los estudios históricos de la ciencia mostraron que la concepción de racionalidad manejada por Popper no era coherente con los datos históricos. Y mientras que para algunos como Kuhn, Lakatos y Feyerabend, eso indicaba claramente la necesidad de modificar la concepción adoptada de racionalidad y progreso científico; para Popper eso indicaba la lamentable situación de la ciencia y su metodología, siendo la actitud de los científicos lo que debía cambiar.

Como puede notarse a esta altura, tanto las objeciones de tipo lógicometodológicas como histórico-sociológicas, atentan contra la simplicidad del canon popperiano. En lo que sigue, nos detendremos en una serie de dificultades adicionales que presenta la filosofía de Popper y que tienen incidencia en los problemas analizados. Luego haremos un balance de su propuesta.

\section{b) La permanencia de los problemas de la inducción y la verosimilitud}

El tratamiento realizado por Popper a estos problemas, merece una mención entre las principales dificultades a su postura. 


\title{
l. La pretendida solución al problema de la inducción
}

Popper expone, sobre todo en su libro Conocimiento Objetivo. Un enfoque evolucionista (Popper, 1972/1974), que ha sido el primero en resolver el problema de la inducción, tal y como había sido planteado por David Hume en su libro Investigación sobre el entendimiento humano (Hume, 1748/2004). Sin embargo, hay quienes dudan de que esto haya acontecido, aduciendo o bien que el problema sigue vigente, o bien que el problema que abordó Popper es de una naturaleza distinta al propuesto por Hume.

Según Popper, Hume planteó dos problemas distintos (aunque relacionados) sobre la inducción: uno lógico y otro psicológico. El problema lógico puede resumirse, según el vienés, en el interrogante: "¿cómo se justifica que, partiendo de casos (reiterados) de los que tenemos experiencia, lleguemos mediante el razonamiento a otros casos (conclusiones) de los que no tenemos experiencia?”; y el psicológico en este otro: “¿por qué, a pesar de todo, las personas razonables esperan y creen que los casos de los que no tienen experiencia van a ser semejantes a aquellos de los que tienen experiencia. Es decir, ¿por qué confiamos tanto en las experiencias que tenemos?" 129 (Popper, 1972/1974: 17-18).

Para el vienés, el problema lógico que aparece implícitamente en Hume es susceptible de ser reformulado en otros términos:

\begin{abstract}
al tratar cualquier tipo de problemas lógicos, una de las maneras principales que tengo de plantear la cuestión consiste en traducir a términos objetivos todos los términos subjetivos o psicológicos, especialmente 'creencia', etc. Así, en vez de hablar de 'creencias', hablo, por ejemplo, de 'enunciado' o de 'teoría explicativa', en lugar de hablar de 'impresión', hablo de enunciado observacional o 'enunciado contrastador' y en lugar de hablar de 'justificación de una creencia', hablo de 'justificación de la pretensión de que una teoría sea verdadera', etc.
\end{abstract}

\footnotetext{
${ }^{129}$ Respecto del denominado problema psicológico de la inducción, Popper rechaza la idea de Hume de que el hábito es causa de la disposición a inducir y propone la hipótesis de que la expectativa de encontrar regularidades es innata: "la repetición presupone la similitud, que a su vez presupone un punto de vista -una teoría o expectativa-." (Ibíd. pp. 34). Pese a desplegar su argumento Popper sostiene, allí mismo, que él no se toma en serio el problema psicológico de la inducción (ibíd. pp. 36). A nuestro modo de ver, una respuesta teórica respecto a este asunto, puede hallarse en Jean Piaget (quien sí se ha tomado en serio éste y otros problemas de la génesis y desarrollo cognitivos), qué sin recurrir gratuitamente al innatismo ni al empiricismo ha proporcionado un programa explicativo sumamente coherente del desarrollo de los procesos cognitivos.
} 
Más adelante agrega:

sustituiré la expresión de Hume "casos de los que tenemos experiencias" por "enunciados contrastadores" [...] y "casos de los que no tenemos experiencia" por "teorías explicativas universales" (Ibíd. pp. 20) ${ }^{130}$.

De este modo, Popper reformula el problema lógico interrogándose: “¿se puede justificar la pretensión de que una teoría explicativa universal sea verdadera mediante 'razones empíricas', es decir, suponiendo la verdad de ciertos enunciados contrastadores u observacionales (los cuales, hay que decirlo, están 'basados en la experiencia')?"; problema al cual responde, al igual que Hume, por la negativa. Pero, Popper enseguida agrega una aparentemente inocua complementación (él dice "generalización") del problema: remplaza la pregunta por la verdad de la inducción por otra pregunta sobre la verdad o la falsedad de la inducción ${ }^{131}$. Así lo expresa: “¿Se puede justificar la pretensión de que una teoría explicativa universal sea verdadera $o$ falsa mediante 'razones empíricas'?" (ibíd.; cursivas añadidas).

Ahora bien, esta variación de la pregunta conlleva una diferencia en la respuesta: esta última pregunta es contestada afirmativamente por Popper. La razón que da implica la esencia de su propuesta epistemológica y ya ha sido elucidada: tras aceptar una serie de enunciados básicos, es posible justificar lógicamente (por la vía deductiva del modus tollens) que una explicación general de los mismos resulte falsa.

Como puede advertirse, la solución que Popper aproxima al problema de Hume es del mismo estilo que la desarrollada por su falsacionismo: demostrar por la negativa lo que no puede probarse positivamente. "Ningún principio inductivo que nos permita extraer inferencias inductivas será válido: será refutado por la primera refutación de una teoría que se haya inducido de

\footnotetext{
130 "La única diferencia es que Hume habla de casos (singulares) futuros de los que no tenemos experiencia -es decir, de expectativas- mientras que L1 [letra con la que Popper designa el problema lógico] habla de leyes universales o teorías". Este cambio le permite a Popper pasar del problema de Hume al problema de la validez de las teorías universales; conectando así (tal y como lo había hecho ya Russell) el problema de la inducción con el de las teorías científicas (Popper, 1972/1974: 22).

${ }^{131}$ El propio Popper admitió que era "decisiva" su "peculiar reformulación del problema": "ya que creo que lo que hizo posible la solución del problema tradicional fue dicha reformulación" (ibíd. pp. 16).
} 
acuerdo con el principio inductivo en cuestión" (Popper, (1982/1985). Dicho de otro modo: no puede haber principio de inferencias infalibles en la teorización (incluyendo un principio de inducción), pues la historia sigue mostrándonos que las teorías resultan, tarde o temprano, erradas. En función de ello es que Popper considera innecesario buscar tal principio:

si suponemos que lo que llamamos 'conocimiento científico' consiste sólo en suposiciones o conjeturas, entonces, este supuesto es suficiente para resolver el problema de la inducción -al que Kant llamó 'el problema de Hume'- sin sacrificar al empirismo: es decir, sin adoptar un principio de inducción y sin atribuirle validez a priori. Porque las suposiciones no se 'inducen a partir de las observaciones' (aunque pueden, desde luego, sernos sugeridas por las observaciones). Este hecho nos permite aceptar sin reservas (y sin los límites de Russell al empirismo) la crítica lógica de Hume a la inducción y renunciar a la búsqueda de una lógica inductiva, a la búsqueda de certidumbre, e incluso de probabilidad ${ }^{132}$, mientras seguimos nuestra búsqueda científica de la verdad" (ibíd. pp. 53).

Entonces, al no existir para Popper ningún principio inductivo que vuelva infalibles las inferencias y al no existir tampoco ningún conocimiento seguro, cualquier refutación de una teoría se considera una situación esperable y no supone la invalidación de un supuesto principio inductivo.

\section{Algunas críticas}

Ahora bien, si analizamos detenidamente lo que Popper nos presenta como "la solución al problema", hallamos que radica en un rechazo inminente: como la inducción es un problema insoluble y podemos prescindir de ella en el contexto de justificación (adoptando el método deductivo de las conjeturas y refutaciones), entonces no hay necesidad alguna de preocuparse por ella. Lo que pareciera haber querido hacer nuestro autor es, en definitiva, despojar a la actividad científica de su problemática inductiva, sin pretender resolverla. Se trata, a fin de cuentas, de un intento promotor de la separación entre

\footnotetext{
${ }^{132}$ Este abandono de toda búsqueda de conocimiento seguro es lo que le hace opinar a Lakatos que "el criterio de demarcación de Popper nada tiene que ver con la epistemología. Nada afirma sobre el valor epistemológico del juego científico" (Lakatos, 1978/1989: 201). Pese a ello, Popper ha dicho en reiteradas oportunidades que el objetivo de la ciencia es alcanzar la verdad, ante lo cual cabe la pregunta, a modo introductorio del apartado siguiente: ¿cómo puede alcanzarse la verdad, sea como sea que se la defina, si no es posible arribar a ningún conocimiento seguro?
} 
racionalidad científica e inducción. Rehusamiento de abordar las relaciones entre uno de los problemas metafísicos más desafiantes de la racionalidad moderna y la actividad científica, pretendidamente racional ${ }^{133}$. Si el problema humeano de la inducción muestra el exilio del conocimiento hacia lo irracional, entonces sólo rechazando la relación de la ciencia con dicho problema se logra repatriarla a terreno racional.

Por otro lado, al contrario de lo que Popper piensa, la inducción resulta insoslayable en toda actividad científica. Incluso se cuela en su propia propuesta metodológica. Veámoslo. Considerando que para Popper la falsación de una hipótesis o teoría no es posible a partir de un "acontecimiento aislado no reproducible", sino solamente "si descubrimos un efecto reproducible que la refute"134 (Popper, 1934/1980: 83), entonces se nos plantea el problema de cuándo considerar a un suceso como reproducible y cuándo no. Sólo podemos afirmar que un suceso que ha venido repitiéndose en el pasado se continúe repitiendo en el futuro si aceptamos un principio como el de la uniformidad de la naturaleza. Dicho de otra manera: la reproducibilidad de un suceso puede establecerse a condición de aceptar, inductivamente, el principio de uniformidad de la naturaleza.

Otra maniobra para solventar el problema de la reproducibilidad de los acontecimientos que utilizamos para testear hipótesis, radica en plantear que "aceptamos la falsación solamente si se propone y corrobora una hipótesis empírica de bajo nivel que describe semejante efecto [reproducible] y podemos denominar a este tipo de hipótesis una hipótesis falsadora" (ibíd.). Coincidimos en este punto con Ricardo Gómez:

Obsérvese que la refutación de una determinada hipótesis requiere la corroboración de una hipótesis empírica que cumple una función falsificadora en tanto el enunciado básico que se refiere a un suceso repetible (que refuta a la

\footnotetext{
${ }^{133}$ No debemos dejar de mencionar que esta argumentación popperiana ha sido matizada a lo largo de su obra; así, posteriormente sostuvo también una solución positiva que complemente su solución negativa: puede justificarse la elección de teorías en base a las corroboraciones y a la "verosimilitud" comparada (cf. Lakatos, 1978/1989: 214).

134 Luego de diferenciar acontecimientos (fenómenos singulares expresables proposicionalmente) y eventos ("lo que hay de típico o universal en un acontecimiento"), Popper afirma: "Podemos decir de una teoría falsable que excluye o prohibe no solamente un acontecimiento, sino, por lo menos, un evento" (Popper, 1934/1980: 86).
} 
hipótesis que se está testeando empíricamente) es el que ha de corroborar a la hipótesis falsificadora. Resulta pues claro que Popper no puede estrictamente afirmar la supremacía de la refutación por sobre la corroboración, pues toda refutación, como dijimos, involucra una corroboración [...] Popper ha fracasado rotundamente en la solución del problema, porque su misma metodología, reiteramos, está impregnada por ingredientes inductivos [...] estamos ante un verdadero fiasco. (Gómez, op. cit. 1995: 24 y 31).

\section{La fallida teoría de la verosimilitud}

Otro aspecto que merece atención es la teoría de la verosimilitud, propuesta por Popper en la década de $1960^{135}$ para dar cuenta del problema del progreso científico. Conviene recordar que en Logik der Forschung el desarrollo del conocimiento es concebido como una corrección del conocimiento anterior, de manera que el progreso científico se concibe por la negativa. Más tarde, inspirándose en los desarrollos de Alfred Tarski, Popper propuso una definición de la verosimilitud. En lo que sigue, explicaremos brevemente en qué consistió esa propuesta y porqué resultó inviable.

Popper admite que antes de conocer la teoría de la verdad de Tarski le parecía más seguro discutir el problema del progreso científico sin penetrar en el problema vinculado con el uso de la palabra verdad: "aunque aceptaba como casi todo el mundo la teoría objetiva, absoluta o de la correspondencia acerca de la verdad -la verdad como correspondencia con los hechos- prefería evitar la cuestión" (Popper, 1963/1991: 273). Confiesa que desde la obra de Tarski ya no teme decir que considera a la búsqueda de la verdad como tarea de la ciencia; y afirma:

En realidad, sólo con respecto a este objetivo, el descubrimiento de la verdad, podemos decir que, aunque seamos falibles, tenemos la esperanza de aprender de nuestros errores. Sólo la idea de la verdad nos permite hablar con sensatez de errores y de crítica racional, y hace posible la discusión racional, vale decir, la discusión crítica en busca de errores, con el serio propósito de eliminar la mayor cantidad de éstos que podamos, para acercarnos más a la verdad. Así, la idea

\footnotetext{
${ }^{135}$ Fundamentalmente en dos artículos: el primero se titula Sobre las fuentes del conocimiento y de la ignorancia y es fruto de la Conferencia Filosófica Anual leída ante la Academia Británica; y el segundo es una ampliación de la conferencia impartida en el Congreso Internacional de Filosofía de la Ciencia celebrado en Stanford, cuyo título es La verdad, la racionalidad y el desarrollo del conocimiento científico. Ambos datan de 1960 y fueron incluidos en Conjeturas y refutaciones (Popper, 1963/1991).
} 
misma de error $-\mathrm{y}$ de falibilidad- supone la idea de una verdad objetiva como patrón al que podemos no lograr ajustamos. (Es éste el sentido en el cual la idea de verdad es una idea reguladora.) (ibíd. pp. 280).

Popper redefine la noción de verdad de Tarski a partir de la idea de "correspondencia con los hechos"; y considera que "en la búsqueda del conocimiento tratamos de hallar teorías verdaderas 0 , al menos, teorías que estén más cerca de la verdad que otras, que correspondan mejor a los hechos" (ibíd. pp. 276). Retoma así el aspecto semántico de la definición de tarskiana y sostiene: "debemos usar un metalenguaje en el que podemos hablar de dos cosas: de enunciados, y de los hechos a que se refieren" (ibíd. 274) ${ }^{136}$. La teoría tarskiana le permite a Popper argumentar a favor de una distinción que, según su opinión, no puede trazarse desde otras teorías de la verdad: la diferencia entre la pregunta por la verdad de una teoría y la pregunta por las razones para su utilización ${ }^{137}$.

Popper retoma la noción de Tarski del contenido de un enunciado $A$, " $\mathrm{Cn}(\mathrm{A})$ ", como la clase de sus consecuencias lógicas, para distinguir entre el "contenido de verdad" de un enunciado (el conjunto de sus consecuencias verdaderas) y su "contenido de falsedad" (el conjunto de sus consecuencias falsas) (Popper, 1963/1991: cap. 10, §XI; 1972/1974: cap. 2, §8). Pero, como un enunciado

\footnotetext{
136 "Es verdadero" se sustituye así por "corresponde con los hechos", en tanto que predicado metalingüístico. Popper pareciera no utilizar de hecho el resto de la definición tarskiana y pareciera reducirla exclusivamente al aspecto semántico, que no es precisamente el más importante para Tarski (cf. Martínez Solano, 2005: 174). En Conocimiento Objetivo, insistió sobre ello diciendo que "la clave para la rehabilitación de la teoría de la correspondencia viene dada por una observación muy simple y obvia que hizo el propio Tarski. A saber, si deseo hablar acerca de la correspondencia entre un enunciado, $\mathrm{E}$, y un hecho, $\mathrm{H}$, tengo que recurrir a un lenguaje en el que pueda hablar acerca de ambos: enunciados del tipo de $\mathrm{E}$ y hechos del tipo de H. Aunque eso parece terriblemente trivial, resulta ser decisivo" (Popper, 1972/1974: 284).

137 Popper cree que las tres rivales de la teoría de la correspondencia (la teoría de la coherencia, la teoría de la evidencia y la teoría pragmatista) son teorías subjetivas o epistémicas "... en el sentido de que todas ellas parten de la posición subjetivista fundamental que sólo puede concebir el conocimiento como un tipo especial de estado mental, o como una disposición, o como un tipo especial de creencia, caracterizada, por ejemplo, por su historia o por su relación con otras creencias [...] La teoría de la verdad objetiva da origen a una actitud muy diferente. Esto puede verse en el hecho de que nos permite hacer afirmaciones como las siguientes: una teoría puede ser verdadera aunque nadie crea en ella y aunque no tengamos razón alguna para creer que es verdadera; y otra teoría puede ser falsa aunque tengamos razones relativamente buenas para aceptarla" (Popper, op. cit. 1963/1991: 275-6).
} 
falso puede tener consecuencias lógicas falsas y verdaderas ${ }^{138}$, Popper introduce la noción de "contenido relativo" para distinguirlas: el conjunto de las consecuencias lógicas del enunciado $A$, que se obtienen con la ayuda del enunciado B pero trascendiendo su contenido, constituye el contenido relativo de A con relación a $B$.

Entonces,

suponiendo que sean comparables ${ }^{139}$ los contenidos de verdad y los contenidos de falsedad de dos teorías $t_{1}$ y $t_{2}$, podernos decir que $t_{2}$ es más semejante a la verdad o corresponde mejor a los hechos que $t_{1}$ si y sólo si

(a) el contenido de verdad, pero no el contenido de falsedad, de $t_{2}$ es mayor que el $\operatorname{de~}_{1}$;

(b) el contenido de falsedad de $t_{1}$, pero no su contenido de verdad, es mayor que el de $t_{2}$. (ibíd. pp. 285).

Como puede notarse, la conceptualización que hace Popper está en concordancia con la idea intuitiva de aproximación a la verdad: decimos que una teoría es aproximadamente más verdadera que otra si contiene más consecuencias verdaderas sin contener más consecuencias falsas; o, dicho inversamente, si contiene menos consecuencias falsas sin contener menos consecuencias verdaderas ${ }^{140}$. Esto puede verse a la luz de su teoría metodológica: si una teoría ha superado intentos de refutación en los que otra

\footnotetext{
138 “... supongamos que hoy es lunes; en tal caso, el enunciado «hoy es martes» será falso. Pero este enunciado falso implicará una serie de enunciados verdaderos, tales como «hoy no es miércoles» $u$ «hoy es lunes o martes»; y la clase de todos los enunciados verdaderos que implica será su contenido de verdad (lógico). En otras palabras, el hecho de que todo enunciado falso implique una clase de enunciados verdaderos es la base para asignar un contenido de verdad a todo enunciado falso" (ibíd. pp. 467).

${ }^{139}$ Los contenidos son comparables si suponemos que el contenido de t1 está incluido en el de t2; es decir si suponemos que toda consecuencia lógica de $t 1$ es también una consecuencia lógica de t2. Véase, más adelante, la crítica de Feyerabend.

${ }^{140}$ Nótese que la noción de verosimilitud no debe ser confundida con las nociones de "grado de confirmación" de una teoría (posibilidad de ser verdadera) y de "grado de corroboración" (medida del éxito con el que ha superado los test empíricos propuestos), puesto que las teorías refutadas tendrían siempre un grado de confirmación y de corroboración nulo, pese a lo cual podrían tener un grado de verosimilitud mayor que otras teorías (o mayor que algunos enunciados verdaderos, como las tautologías). Análogamente, dos teorías confirmadas no necesariamente tendrían el mismo grado de verosimilitud, pues ello dependería de la cantidad de información de cada una, pudiendo tener ambas un grado de confirmación igual a cero.
} 
teoría rival ha fracasado, y si ambas tienen los mismos aciertos, tenemos un índice de que la primera es más verosímil que la segunda ${ }^{141}$.

Ahora bien, para poder sostener que una teoría es más verosímil que otra, es ineludible comparar sus contenidos y, para esto, es necesario medirlos. Surge así, además de la anterior definición intuitiva o cualitativa (como la ha llamado Miller, 1974: 166), una versión cuantitativa de la verosimilitud (cuyo resultado es un valor numérico). La propuesta popperiana es la de elaborar un procedimiento para calcular lógicamente el contenido de verdad y de falsedad de las hipótesis o teorías científicas, y así estipular su grado de verosimilitud a partir de la diferencia entre tales medidas de sus contenidos de verdad y falsedad. Para ello, Popper propone una relación de proporcionalidad inversa entre la cantidad del contenido y de la probabilidad de un enunciado (Popper, 1934/1980: §83 y apéndice *IX; 1963/1991: §6). Veámoslo. El contenido puede verse como la cantidad de información proporcionada, independientemente de su valor de verdad. Además, la probabilidad lógica máxima que un enunciado puede tener está representada por el caso de la tautología: al decir "mañana hará calor o no hará calor" estamos enunciando una proposición verdadera pero que carece de contenido (no nos brinda información). Inversamente, cuando el enunciado es poco probable, la información que nos brinda es mucha pero su probabilidad es escasa; el caso extremo está representado por las contradicciones lógicas: por ejemplo, al decir "mañana hará calor y no hará

\footnotetext{
${ }^{141}$ Así lo expresa nuestro filósofo: "permítaseme aclarar, ante todo, que yo no sugiero que la introducción explícita de la idea de verosimilitud origine cambios en la teoría del método. Por el contrario, creo que mi teoría de la testabilidad o corroboración mediante tests empíricos es el complemento metodológico adecuado de esta nueva idea metalógica. La única mejora consiste en la clarificación del problema. Así, he dicho a menudo que preferimos la teoría $t_{2}$, que ha pasado ciertos tests severos, a la teoría $t_{1}$, que ha fracasado en esos tests, porque una teoría falsa es ciertamente peor que otra que, de acuerdo con nuestro conocimiento, puede ser verdadera. Podemos agregar a lo anterior que, aun cuando $t_{2}$ haya sido refutada a su vez, podemos seguir afirmando que es mejor que $t_{1}$, pues aunque ambas hayan resultado falsas, el hecho de que $t_{2}$ haya resistido tests que $t_{1}$ no resistió puede ser un buen índice de que el contenido de falsedad de $t_{1}$ supera el de $t_{2}$, mientras que su contenido de verdad no es superior al de ésta. Así, podemos continuar prefiriendo $t_{2}$, aun después de su refutación, porque tenemos razones para pensar que está en mayor conformidad con los hechos que $t_{1}$ " (ibíd. pp. 287). Pero este vínculo popperiano entre verosimilitud y grado de corroboración tampoco está exento de críticas. Newton-Smith, por ejemplo, afirma: "puede muy bien ser que la teoría que ha superado las pruebas hasta la fecha tenga también una inmensa cantidad oculta de contenido falso [...] ¿cómo puede Popper justificar la afirmación de que una teoría que supera muchas pruebas, en oposición a una teoría que falla ante muchas pruebas tiene (o es probable que tenga) mayor verosimilitud, es decir mayor verdad y menos falsedad?" (Newton-Smith, 1981/1987: 78). En su opinión, se necesita de estrategias inductivas para dar una respuesta razonable; lo cual va en contra de lo pretendido por el propio Popper (ibíd. pp. 79-89).
} 
calor" estamos afirmando un enunciado con probabilidad nula pero con la mayor información posible (recuérdese que del absurdo se sigue cualquier enunciado). En base a esto pueden compararse enunciados: el contenido, por ejemplo, del enunciado "hoy hace frío y mañana hará calor" es mayor que el de "hoy hace frío" (en virtud de que, en el primero, se dice más sobre el mundo que en el segundo), mientras que la probabilidad lógica es menor para el primer enunciado que para el segundo (en virtud de que es menos probable que sea verdadero: al ser "más audaz", tiene más probabilidades de resultar falsado ${ }^{142}$ ).

Para satisfacer esa correlación inversa entre probabilidad y contenido, Popper define la medida del contenido de un enunciado utilizando el cálculo de probabilidades:

$$
\mathrm{Ct}(\mathrm{a})=1-\mathrm{p}(\mathrm{a})
$$

Definirá, luego de una serie considerable de rodeos técnicos, el grado de verosimilitud de una teoría como la diferencia entre sus contenidos de verdad y de falsedad:

$$
\mathrm{V}_{\mathrm{s}}(\mathrm{a})=\mathrm{Ct}_{\mathrm{v}}(\mathrm{a})-\mathrm{Ct}_{\mathrm{f}}(\mathrm{a})
$$

Así, Popper asume que es posible dar una medida de la verosimilitud de las teorías científicas y, con ello, una estimación cuantitativa del progreso científico.

\section{Algunas Críticas}

La propuesta popperiana mostró una serie de falencias que la hacen inviable, tanto en su versión cualitativa como cuantitativa. Mencionaremos brevemente las más significativas.

Las críticas que tornaron inviable a la teoría popperiana de la verosimilitud han sido una serie de ataques elaborados en el mismo estilo formalista, es decir, conforme a las mismas reglas analíticas de la lógica utilizada por él; y es

\footnotetext{
142 "si la elevada probabilidad fuera un objetivo de la ciencia, los científicos deberían decir lo menos posible, y con preferencia, exclamar solamente tautologías. Pero su objetivo es hacer «avanzar» la ciencia, esto es, aumentar su contenido informativo. Pero esto significa disminuir su probabilidad" (Popper, op. cit. 1963/1991: 347).
} 
de ahí que se sigue su contundencia. Lo que distintos autores vinieron a demostrar fue que las definiciones de Popper conducían a resultados que contradecían las explícitas expectativas del filósofo vienés.

La crítica más letal fue una de las primeras históricamente hablando, realizada en simultaneidad por dos autores: David Miller (1974) y Pavel Tichý (1974). En especial Tichý demostró que dos teorías falsas no pueden vincularse por la relación "ser más verosímil que", debido a que siempre "crece" simultáneamente el contenido de verdad y el contenido de falsedad entre ambas. La demostración puede sintetizarse como sigue: imaginemos que $\mathrm{T}_{1} \mathrm{y}$ $\mathrm{T}_{2}$ son falsas y que el contenido de verdad de $\mathrm{T}_{1}$ es menor que el de $\mathrm{T}_{2}$ (lo que equivale a decir que el contenido de verdad "crece" de $T_{1} a T_{2}$ ). Esto puede expresarse en lenguaje (semi-formal) de teoría de conjuntos, diciendo que el contenido de verdad de $\mathrm{T}_{1}$ es un subconjunto propio del contenido de verdad de $T_{2}$. Dicho de otra manera, que existe al menos un elemento (la proposición $v$ ) en el contenido de verdad de $T_{2}$ que no pertenece al contenido de verdad de $T_{1}$. Además, como $T_{2}$ es falsa, existe al menos un elemento (la proposición $f$ ) en su contenido de falsedad. Ahora bien, la conjunción de los elementos $v$ y $f$ es falsa (puesto que una de las proposiciones es falsa) y, por lo tanto, tal conjunción pertenece al contenido de falsedad de $T_{2}$. Sin embargo, dicha conjunción no podría pertenecer al contenido de falsedad de $T_{1}$ : si así fuera, la proposición verdadera $v$, tendría que pertenecer al contenido de verdad de $\mathrm{T}_{1}$; pero esto es imposible porque, como ya dijimos, $v$ es el elemento del contenido de verdad de $\mathrm{T}_{2}$ que no pertenece a $\mathrm{T}_{1}$. Entonces, aunque el contenido de verdad aumente de $T_{1}$ a $T_{2}$, también aumenta el contenido de falsedad: hay un elemento del contenido de falsedad de $\mathrm{T}_{2}$ (la conjunción de $v$ y $f$ ) que no pertenece al contenido de falsedad de $\mathrm{T}_{1}$. Puede probarse, del mismo modo, que si el contenido de falsedad de $T_{1}$ es menor que el de $T_{2}$, entonces el contenido de verdad de $T_{1}$ es también menor que el de $T_{2}$.

Esta crítica de Tichý echa por tierra la pretensión popperiana de establecer una cardinalidad de teorías falsas que se acercan a la verdad, tornando inaplicable el criterio de verosimilitud. Aunque es cierto que la crítica de Tichý sólo vale para el caso en que las dos teorías son falsas, hay que decir que es el caso históricamente frecuente y es el que sustancialmente interesaba a 
Popper (aunque la definición no haya resultado afectada para la comparación mutua de teorías verdaderas, este caso es prácticamente trivial).

Pero no sólo la versión cualitativa ha sido contundentemente criticada, sino que también la versión cuantitativa de la verosimilitud adolece de dificultades que la vuelven inviable. A penas unos años más tarde, el filósofo germanoestadounidense Adolf Grünbaum (1978b), de quien nos ocuparemos especialmente en la siguiente parte de esta tesis, efectuó el siguiente señalamiento: como Popper admite que la probabilidad de toda teoría es igual a cero ${ }^{143}$, entonces no puede explicarse cómo distintas teorías podrían tener diferente contenido (en virtud de que el contenido varía inversamente respecto de la probabilidad). Dicho esquemáticamente: bajo esa vieja consideración popperiana, si aceptamos la medida del contenido propuesta luego $(\operatorname{Ct}(a)=1$ $\mathrm{p}(a)$ ), entonces no podemos probar $\mathrm{Ct}(b)>\mathrm{Ct}(a)$ en el caso de que a esté contenida en $b$. Así todas las teorías universales falsas tendrían el mismo grado de verosimilitud, por lo que el criterio es inútil para determinar la distancia relativa respecto de la verdad.

Las objeciones anteriores son algunas de las que atacan el formalismo de la definición popperiana ${ }^{144}$; y es en base a su consideración que Popper aceptó que su definición era equivocada, aunque desestimó que ello pudiera repercutir en el valor de su teoría general de la ciencia:

\begin{abstract}
Otra objeción a mi teoría del conocimiento está mejor fundada, aunque su impacto en mi teoría es insignificante. Es el admitido fracaso de una definición (de la similitud con la verdad o aproximación a la verdad) que propuse en 1963. [...] Pero la concepción, muy extendida, de que el abandono de esta definición debilita mi teoría, carece por completo de fundamento. Puedo añadir que acepté la crítica hecha a mi definición a los pocos minutos de su presentación, preguntándome cómo no habría visto el error yo mismo antes, pero nadie ha demostrado nunca que mi teoría del conocimiento, que desarrollé ya en 1933 y que lleva creciendo vigorosamente desde entonces y que es muy utilizada por los científicos en activo,
\end{abstract}

\footnotetext{
${ }^{143}$ Como ya dijimos, debido a que toda ley universal implica infinitos casos de enunciados singulares y que la probabilidad de cada uno de estos es menor a uno, entonces el producto de las probabilidades de tales enunciados (equivalente a la probabilidad de la ley) tiende a cero (cf. Popper, op. cit. 1934/1980: apéndice VII, pp. 338 y ss.).

144 Las que hemos explicitado son pioneras pero no son las únicas. También podemos mencionar las objeciones de Miguel Angel Quintanilla (1982: 475-478) y de Andrés Rivadulla (1991: 105-110).
} 
haya resultado debilitada en lo más mínimo por esta infortunada definición errada o que la idea de la similitud con la verdad (que no es una parte esencial de mi teoría) no pueda seguir usándose dentro de mi teoría como concepto sin definir. [...] La aserción de que mi autoridad ha resultado dañada por este incidente es obviamente cierta, pero nunca he pretendido ni deseado tener ninguna autoridad. La aserción de que mi teoría ha resultado dañada se ha lanzado sin siquiera intentar dar una razón, y me parece que es una afirmación incompetente. (Popper, 1982/1985: 39-40).

Pese a lo aseverado por Popper, debido al entrelazamiento que la teoría de la verdad ha mantenido (primero implícita y luego explícitamente) con el resto de los desarrollos del autor, puede dudarse seriamente de esa conclusión ${ }^{145}$.

El conjunto de objeciones formales antepuesto a las pretensiones de Popper, lejos de haber desterrado el concepto de verosimilitud del campo de la filosofía de la ciencia, lo han convertido en objeto de toda una suerte de desarrollos que continuaron complejizándose ${ }^{146}$. Desarrollos que no han logrado, a pesar de las modificaciones y redefiniciones posteriores de la verosimilitud, elaborar un teorema que permita establecer que una teoría científica es más verosímil que otra (ya sea en virtud de su corroboración o de su refutación).

Además de las críticas formales, hay otro conjunto de objeciones que atacan el espíritu mismo de las pretensiones popperianas; pero lo hacen sin necesidad de adentrarse en el formalismo de sus definiciones.

En su célebre libro, cuya confección es prácticamente simultánea a la teoría de la verosimilitud popperiana, Kuhn afirmaba:

Es posible que tengamos que renunciar a la noción, explícita o implícita, de que los cambios de paradigma llevan a los científicos, y a aquellos que de tales

\footnotetext{
${ }^{145}$ Popper afirma, en el prefacio de la edición inglesa a su libro primordial, que "el problema central de la epistemología ha sido siempre, y sigue siéndolo, el del aumento del conocimiento" (Popper, 1934/1980: 16); y en el capítulo dos de su Conocimiento objetivo lo repite al detalle: "el problema fundamental de la teoría del conocimiento es la clarificación e investigación de ese proceso mediante el cual aumentan o progresan, como aquí pretendemos, nuestras teorías" (Popper, 1972/1974: 43). Si consideramos que su teoría de la verosimilitud es un intento fallido por resolver el problema fundamental de la epistemología, no podemos más que encogernos de hombros ante la evidente pérdida de atractivo que dicho fracaso conlleva para su propuesta filosófica.

${ }^{146}$ Para un examen detallado de tales desarrollos hasta la última década del siglo XX, cf. Zamora Bonilla (1996).
} 
aprenden, cada vez más cerca de la verdad. [...] Todos estamos profundamente acostumbrados a considerar a la ciencia como la empresa que se acerca cada vez más a alguna meta establecida de antemano por la naturaleza.

Pero, ¿es preciso que exista esa meta? ¿No podemos explicar tanto la existencia de la ciencia como su éxito en términos de evolución a partir del estado de conocimientos de una comunidad en un momento dado? ¿Ayuda realmente el imaginar que existe alguna explicación plena, objetiva y verdadera de la naturaleza y que la medida apropiada de la investigación científica es la elongación con que nos acerca cada vez más a esa meta final? Si podemos aprender a sustituir la-evolución-hacia-lo-que-deseamos-conocer por la evolucióna-partir-de-lo-que-conocemos, muchos problemas difíciles desaparecerán en el proceso (Kuhn, 1962/2004: 262-3) ${ }^{147}$.

El éxito sucesivo que pueden tener una serie de teorías al interior de un campo determinado no implica que debamos apelar al realismo científico ni al correspondentismo alético para poder dar una explicación satisfactoria.

Feyerabend, por su parte, también criticó la noción de verosimilitud de Popper. Sostuvo que, para que el esquema popperiano de la comparabilidad de los contenidos de dos teorías sea realizable, "tienen que existir enunciados que se sigan [...] a la vez de $\mathrm{T}$ y de $\mathrm{T}^{\prime}$. Pero hay casos que invitan a un juicio comparativo sin que satisfagan las condiciones que acaban de indicarse" (Feyerabend, 1970/1975). Tales casos están conformados por teorías inconmensurables, y es en virtud de esta tesis que el anarquista epistemológico sostuvo que es "claramente imposible emitir un juicio que implique la comparación de las clases de contenido. Por ejemplo, no puede decirse que T' esté más cerca de la verdad, o más lejos, que T" (ibíd.). En virtud de la preponderancia adjudicada a la tesis de la inconmensurabilidad, para Feyerabend "el desarrollo del conocimiento o, más específicamente, la

147 En la Postdata de 1969, quizás ya habiendo analizado las ideas de Popper sobre la verosimilitud, afirma: "A menudo se oye decir que las teorías sucesivas crecen aproximándose cada vez más a la verdad [...] no hay un medio, independiente de teorías, para reconstruir frases como 'realmente está alli'; la idea de una unión de la ontología de una teoría y su correspondiente 'verdadero' en la naturaleza me parece ahora, en principio, una ilusión; además, como historiador, estoy impresionado por lo improbable de tal opinión. Por ejemplo, no dudo de que la mecánica de Newton es una mejora sobre la de Aristóteles, y que la de Einstein es una mejora sobre la de Newton como instrumento para resolver enigmas. Pero en su sucesión no puedo ver una dirección coherente de desarrollo ontológico. Por el contrario, en algunos aspectos importantes, aunque, desde luego, no en todos, la teoría general de la relatividad, de Einstein, está más cerca de la de Aristóteles que ninguna de las dos de la de Newton" (Kuhn, 1962/2004: 314). 
sustitución de una teoría global por otra implica tanto pérdidas como ganancias" (ibíd. pp. 370) ${ }^{148}$. Aún más, Feyerabend afirma que el aumento en el grado de verosimilitud es una mera "ilusión epistemológica" (Feyerabend, op. cit. 1975/1986: 164), producto de la tendenciosa forma en que los científicos presentan sus teorías y teorizan a sus predecesoras: "así es como se fabrica el aumento de contenido, mediante el uso combinado de entusiasmo, olvido y cambio histórico" (ibíd. pp. 184).

Larry Laudan también ha criticado las presunciones de Popper: afirmando que, como no disponemos de un criterio infalible para estipular la supuesta aproximación a la verdad, entonces debemos rechazar que la ciencia deba tener como objetivo epistémico primordial el hallazgo de la verdad. ${ }^{149}$ En la perspectiva de Laudan, la ciencia tiene por objetivo la resolución de problemas (algo que sí es realizable), y ello no implica consideración alguna respecto de la verdad o falsedad de las teorías (Laudan, 1977/1986: 121 y ss.).

A pesar de que Lakatos muere cuando los problemas de la verosimilitud popperiana empezaban a evidenciarse, él supo expresarse sobre el tema en varias oportunidades. Aunque parece acordar con la utilidad potencial de la idea de verosimilitud, Lakatos reconoce que su manejo sólo puede fundamentarse en una lógica inductiva. Podemos sostener que

\begin{abstract}
...nuestras teorías mejor corroboradas suelen poseer una verosimilitud relativamente grande en el conjunto de aquellas de sus consecuencias que se refieren a aquella pequeña región espacio/temporal que constituye nuestro "hogar"; y sostener que su verosimilitud crece con el avance de la ciencia. Este simple pero crucial supuesto metafísico explicaría el éxito tecnológico de la
\end{abstract}

\footnotetext{
${ }^{148}$ Nótese que la crítica de Feyerabend es una objeción lógica que bien podría ubicarse entre las detracciones formalistas antes mencionadas. Hemos preferido mencionarla aquí debido a su basamento en la tesis de la inconmensurabilidad, con íntima relación a las ideas de Kuhn. El razonamiento de Feyerabend también aparece en el cuarto apéndice de su célebre Tratado contra el método (Feyerabend, 1975/1986; específicamente en la pp. 281).

149 Laudan ha contribuido a desarrollar un significativo argumento en contra del realismo científico, denominado "metainducción pesimista": como la historia de la ciencia está plagada de ejemplos de teorías exitosas que contenían términos referentes a entidades cuya existencia fue posteriormente rechazada, entonces no podemos hablar de un progresivo crecimiento de teorías cada vez más verdaderas (Laudan, 1981/1984: 231). El argumento constituye una crítica a la tesis popperiana; pero, además, se incluye en un conjunto más vasto de debates ontológicos y epistemológicos sobre el realismo y antirrealismo científicos; que hemos reseñado en otra parte (Azcona, 2014) y que aquí no consideraremos porque trascienden nuestros objetivos.
} 
humanidad, pero puede que sea falso. Pero, como es irrefutable, no podemos descubrir que es falso [...] "Aceptamos, ${ }_{0}$ " este supuesto en el cuerpo de teorías metafísicas "influyentes" sin creer en él (Lakatos, 1968/1981: 251).

Pero utilizar un principio de verosimilitud debido a su utilidad y a expensas de su fundamentación lógica, parece una propuesta más cercana al pragmatismo que al realismo subyacente a las ideas de Popper. Volveremos sobre la concepción lakatosiana del progreso científico en el siguiente capítulo.

Sintetizando este apartado, podemos afirmar que Popper establece una vinculación negativa entre inducción y verosimilitud a través de la noción de corroboración: rechazada la posibilidad de inferencias verificadoras, el falsacionismo sugiere que los grados de corroboración pueden constituir indicadores racionales de la verosimilitud de las teorías. Hemos visto que hay varias razones para dudar tanto del antiinductivismo como de la verosimilitud popperianas.

\section{c) Popper como figura de transición.}

Para finalizar, dejaremos de lado las dificultades popperianas en torno a la inducción y la verosimilitud, y reanudaremos nuestras consideraciones críticas sobre su metodología falsacionista.

Tal y como hemos expuesto, no es el reconocimiento de la posibilidad (lógica o histórica) de escapar a la falsación lo que pareciera estar en el centro de la discusión entre Popper y los críticos considerados, puesto que todos la admiten. En ese sentido, Kuhn parece acertar con su imagen panorámica del pensamiento popperiano: "Sir Karl no es, desde luego, un refutacionista ingenuo. Sabe lo que acaba de decirse y lo ha subrayado desde el principio de su carrera [...] Si bien no es un refutacionista ingenuo, creo que, legítimamente, puede tratárselo como tal" (Kuhn 1970/1977: 306).

Pero si Popper conoce las críticas que se le han dirigido (e incluso ha anticipado en varias oportunidades sus respuestas), ¿a qué se debe esa valoración diferencial de la metodología de la ciencia? Sin pretender agotar el asunto, nos detendremos en dos aspectos que separan a Popper de sus críticos y que parecen estar a la base de las diferencias analizadas. 


\section{Diferencias axiológicas}

Hemos visto cómo, para sus críticos, las estrategias antifalsación son muy comunes en la historia de la ciencia e incluso han sido necesarias para su evolución (sin ciencia normal -para Kuhn- o sin heurística positiva -para Lakatos- la ciencia sería imposible). Pero para Popper, tales estrategias constituyen el foco de la irracionalidad que acecha siempre a la lógica de la ciencia.

En un pasaje de El mito del marco común, se ve claramente esa valoración que lo separa de sus críticos:

podemos escoger la persecución de una meta o un objetivo como la meta de comprender mejor el universo en el que vivimos, y comprendernos mejor nosotros mismos como parte de él, lo cual es independiente de las teorías o los marcos particulares que construimos para tratar de satisfacer ese propósito. Podemos escoger el darnos niveles de explicación y reglas metodológicas que nos ayuden a alcanzar el objetivo y cuya satisfacción no es precisamente fácil para la teoría o marco. Por supuesto, podemos escoger no hacer tal cosa: podemos decidir que nuestras teorías se autorrefuercen. Podemos no fijarnos ninguna otra tarea que aquella de cuya satisfacción por nuestras teorías actuales podamos estar seguros. Por cierto que podemos escoger esto. Pero si obramos de esta manera, no solamente estaremos dando la espalda a la posibilidad de percatarnos de que nos equivocamos, sino también a la tradición del pensamiento crítico (que viene de los griegos y del choque de culturas), que es lo que ha hecho de nosotros lo que somos, y que nos ofrece la esperanza de más autoemancipación a través del conocimiento. (Popper, 1994/1997: 71-72).

Popper parece creer que sólo si el científico mantiene una actitud de "crítica permanente", la ciencia está a salvo del adoctrinamiento dogmático. En ese sentido, se comprenden las adjetivaciones que Popper hace del científico kuhniano que trabaja en ciencia normal como alguien "peligroso".

Independientemente de lo que pueda decirse de la conceptualización Kuhniana en sí misma, parece que la divergencia que Popper mantiene con ella se debe a la valoración diferencial que hacen de las actitudes críticas del científico. Para Popper "se trata de una concepción de la ciencia que considera el enfoque crítico de ésta como su característica más importante" (Popper, 1963/1991: 312). Esto pareciera ser lo sustancialmente distintivo del conocimiento científico para nuestro autor: "las teorías científicas se distinguen 
de los mitos simplemente en que pueden criticarse y en que están abiertas a modificación a la luz de las críticas. No pueden verificarse ni probabilificarse" (Popper, 1982/1985: 47).

En su último libro, En busca de un mundo mejor, sostuvo:

a pesar de mi admiración por el conocimiento científico, no soy un partidario del cientifismo, pues el cientifismo afirma dogmáticamente la autoridad del conocimiento científico; mientras que yo no creo en autoridad alguna y siempre me he resistido al dogmatismo; y sigo resistiéndome, especialmente en la ciencia. Me opongo a la tesis de que el cientifismo debe creer en su teoría. Por lo que a mí respecta, "yo no creo en la creencia», como dice E.M. Forster; y yo, especialmente, no creo en la creencia en la ciencia. A lo sumo creo que la creencia tiene un lugar en la ética, e incluso aquí sólo en algunos casos. Creo, por ejemplo, que la verdad objetiva es un valor -es decir, un valor ético, quizá el mayor valor que exista- y que la crueldad es el mayor mal (Popper, 1994/1996: 21).

A partir de estos últimos pasajes se atisba, quizás de una forma óptima, la fundamentación axiológica de la teoría epistemológica de Popper ${ }^{150}$.

\section{Diferencias en la noción de teoría}

La divergente valoración que Popper y los mencionados críticos hacen de la metodología general de las ciencias, se comprende mejor si se considera la noción diferencial de teoría que hay en juego. Mientras que Kuhn y Lakatos parecen hacer hincapié en la complejidad sincrónica y diacrónica de los productos de la ciencia, Popper maneja una noción trivializada de las teorías: "pensaba en las teorías como entidades simples, monolíticas, entidades ante las cuales la única opción es del tipo todo o nada" (Diez, 1998: 196). Esta noción simplificada de las teorías, que soslaya la distinción entre cambios inter e intra teóricos ${ }^{151}$ (p. ej.), es lo que le impidió a Popper articular las premisas que compartía con sus críticos en una concepción epistemológica más comprehensiva. Asimismo y pese a sus diferencias, las nociones de teoría de

\footnotetext{
${ }^{150}$ Coincidimos en este punto con Javier Echeverría, cuando dice que las conceptualizaciones popperianas sobre la metodología de la ciencia "están "cargadas de axíología», o si se quiere, de ethos científico" (Echeverría, 1995: 82).

151 Lakatos sostuvo: "el hecho de que Popper no distinguiera entre «teorías» y «series de teorías» le impidió tener un acceso afortunado a las ideas básicas del falsacionismo sofisticado" (1978/1989: 50, n. 111)
} 
Kuhn y Lakatos ${ }^{152}$ comparten la suposición de que tales entidades existen durante un período de tiempo; suposición que les permitió una mejor descripción y evaluación de la práctica contrastacional que la realizada por Popper ${ }^{153}$.

En el capítulo siguiente veremos que esta concepción simplificada de las teorías es fundamental para poder comprender la crítica popperiana al psicoanálisis: en la medida en que Popper no distingue conceptualmente los componentes de una teoría (leyes, hipótesis específicas, presupuestos auxiliares, etc.) ni de su evolución temporal (modificación y permanencia de aspectos parciales), su condenatoria conclusión respecto al psicoanálisis in toto resulta trivial o ingenuamente fundada.

Sin embargo, en nuestro análisis de la propuesta popperiana, no deberíamos redoblar el error (popperiano) y ver allí una mera conceptualización sincrónica: sería más justo considerar su teoría, al igual que cualquier otra, de una forma más compleja.

Sin pretender una elucidación metateórica de la propuesta de Popper, debemos reconocer cierta evolución de su postura sobre el asunto de la falsación. Sintetizaremos nuestra idea diciendo que su postura va desde "metodólogo empiricista" a la de "ético de la ciencia". El propio Kuhn recomienda ver en la obra popperiana una serie de imperativos morales para la actividad científica: "en lugar de una lógica, Sir Karl nos da una ideología; en lugar de reglas metodológicas, nos da máximas aplicables a los procedimientos" (Kuhn, 1970/1977: 307).

En sus obras tardías, Popper ubica a la falsación en el lugar de un ideal ético de la investigación: aun admitiendo que el científico necesita de la posibilidad de ver confirmadas sus teorías, prefiere destacar la posibilidad de que estas se

\footnotetext{
152 Feyerabend se ha hecho eco de esta postura: "Dada una teoría nueva, no hemos de emplear enseguida los criterios habituales para decidir su supervivencia. $\mathrm{Ni}$ las fragantes inconsistencias internas, ni la escasez obvia de contenido empírico, ni el conflicto masivo con los resultados experimentales, deberían impedirnos conservar un punto de vista detallado que por una razón u otra nos gustara. Lo que cuenta en nuestras evaluaciones metodológicas es la evolución de una teoría a lo largo de grandes períodos de tiempo, y no su forma en un momento particular" (Feyerabend, 1975/1986: 170).

${ }^{153} \mathrm{Si}$ bien hemos hecho foco en el aspecto de la contrastabilidad empírica, no debemos desconocer que una representación de las teorías como entidades estructuralmente complejas y temporalmente genidénticas (como pretendieron Kuhn y Lakatos), ha posibilitado una mayor comprensión de diversos aspectos procesuales de la actividad científica concreta.
} 
mantengan refutables (alejadas de la verdad). Veámoslo brevemente con algunos ejemplos.

Varios años después de su Logik der Forschung, en un Congreso celebrado en octubre de 1961 en Tübingen, Popper sostuvo que "la pureza de la ciencia pura es un ideal [...] he calificado de prácticamente imposible el intento de desterrar los valores extracientíficos del quehacer de la ciencia" (Popper, 1969/1973: 111). De este modo, Popper termina dando un lugar a los condicionamientos sociológicos e históricos en los procesos de investigación científica (lugar que pareciera habérsele negado en su Logik).

Un poco más adelante, en un simposio filosófico realizado en Burgos (España) en 1968, explicitó una conciliadora definición del asunto de la falsación:

una y otra vez he dicho que si nuestro fin es aprender, que nuestro conocimiento crezca, deberíamos ser al mismo tiempo críticos y dogmáticos. Si no somos dogmáticos, es decir, si no intentamos defender nuestras teorías durante el mayor tiempo posible, la parte crítica tendrá una tarea demasiado fácil y no encontraremos todos los elementos importantes que sean de hecho sostenibles en nuestra teoría. [...] Por otro lado, todo científico debe tomar en consideración el momento en que debe abandonar su teoría como derrotada; pues si no se fija un punto en absoluto, su teoría tiende a vaciarse de contenido. Si un científico no está dispuesto a ponerse un límite en las maniobras evasivas que ejecute para defender su teoría, abandona la asunción de riesgos y con eso abandona la ciencia (Popper, 1968/1970: 19).

El lector podrá notar cómo estas aseveraciones distan mucho de lo que Popper había manifestado en su Logik der Forschung sobre la actitud del científico respecto a sus teorías. Lo cual nos muestra que sus ideas también pueden ser dilucidadas diacrónicamente.

\section{Entre el Empirismo Lógico y la "nueva" filosofía de la ciencia}

Gran parte de la complejidad de las ideas de Popper posiblemente se deba a que, a pesar de las críticas metodológicas que realiza a los empiristas lógicos, sigue compartiendo con ellos una serie de supuestos básicos. Tal y como lo hemos mencionado antes, ambos consideran por ejemplo que los problemas de la ciencia son esencialmente lógicos y que su abordaje puede llevarse a cabo mediante los Principia Mathemática. Además, conciben que la objetividad 
de la ciencia sólo puede lograrse a partir de la constitución de una "base empírica", es decir a partir de proposiciones existenciales ("enunciados básicos" en su terminología) que ubican sucesos en coordenadas temporoespaciales. Proposiciones que, si bien para Popper se aceptan convencionalmente, para ambos se originan en la observación y sirven como premisas para la refutación. Es por esto que Popper ha sido considerado como una "figura de transición" entre el Empirismo Lógico y la "nueva" filosofía de la ciencia (Brown, 1977/1983).

En esa transición, hay toda una serie de presupuestos filosóficos adoptados por Popper y que no todos comparten. Hemos visto, por ejemplo, los problemas implicados en su rechazo de la inducción y en suponer una verdad correspondentista como ideal regulativo de la ciencia; pero también supone el realismo científico, la disociación metafísica de "mundos" con la consecuente exclusión del sujeto hacedor de ciencia, la separación epistémica entre "contextos", el monismo metodológico para todo tipo de ciencias, el valor de la demarcación y la noción de innatismo cognitivo, entre otros. Tales asunciones son de hecho cuestionables (y cuestionadas), motivo por el cual podemos también sospechar de la viabilidad universal de la filosofía de Popper.

\section{El fracaso popperiano}

Pese a la complejidad de su obra, hay que decir que el principal afán popperiano no cumple con las expectativas que se propone. A propósito de ello, Kuhn ha dicho, con razón, que

a pesar de todas las impugnaciones explícitas, sugeriré que [Popper] ha buscado consecuentemente procedimientos de evaluación aplicables a teorías, los cuales posean la seguridad evidente que caracteriza a las técnicas por las cuales se identifican los errores en la aritmética, la lógica o la medición. Me temo que está persiguiendo una quimera..." (Kuhn, 1970/1977: 304).

A similar conclusión arriba Lakatos cuando afirma que

hay que abandonar el viejo sueño racionalista de un método mecánico, semimecánico o, al menos, de acción rápida, para poner al descubierto la falsedad, la ausencia de pruebas, los absurdos carentes de sentido o incluso las elecciones irracionales. Es necesario mucho tiempo para evaluar un programa de investigación: la lechuza de Minerva vuela al anochecer (Lakatos, op. cit. pp. 193). 
$\mathrm{Y}$, por su parte, Feyerabend sostiene:

un principio de falsación que elimine teorías porque no se conforman con los hechos, tendría que eliminar toda la ciencia (o tendría que admitir que partes enormes de la ciencia son irrefutables) (Feyerabend, 1975/1986: 298).

En síntesis, en lo que Popper ha fracasado es en el hallazgo de un método mecánico de elección de teorías, basado en una supuesta racionalidad algorítmica. Popper conceptualizó mejor que nadie la crítica a los afanes justificacionistas del conocimiento, pero la consecuencia inevitable de esa crítica ha de ser que tampoco podemos establecer un conjunto de operaciones que, mecánicamente aplicadas, nos lleven a desechar definitivamente teorías ${ }^{154}$. Las conjeturas pueden pasar de falsadas a corroboradas (y viceversa), sin que exista la posibilidad de ser conclusivos. Así, la pretensión popperiana de establecer una "asimetría lógica entre verificabilidad y refutabilidad" resulta frustrada: la imposibilidad lógica de verificar un enunciado teórico y la imposibilidad lógica de refutarlo, constituyen un binomio proporcionado. Por ende, al no haber verificación ni tampoco falsación definitiva, quedamos a la deriva de nuestras decisiones.

Podemos concluir que las consideraciones críticas reseñadas constituyen un serio problema a la filosofía de Popper ${ }^{155}$.

\footnotetext{
${ }^{154}$ Aunque nos hemos reenfocado en su propuesta metodológica, esta crítica vale también para su abordaje de los problemas de la inducción y de la distancia con la verdad.

${ }^{155}$ El lector familiarizado con la obra de Popper notará que nuestra crítica ha dejado por fuera otros aspectos igualmente discutibles, como por ejemplo el modelo que propone de las explicaciones científicas o la propuesta para la metodología de las ciencias sociales. Nos excusamos remitiendo al lector a nuestros objetivos en esta tesis, que no implican una elucidación de toda la obra de Popper ni mucho menos.
} 


\title{
CAPÍTULO 4: Elementos para una reconstrucción del proceder falibilista de Freud
}

\section{Introducción}

E n primer lugar, en este capítulo explicitaremos la tradición crítica en la que Freud se formó y la perspectiva que tenía del conocimiento y de la empresa científica, a los fines de mostrar la inviabilidad de algunas suposiciones popperianas sobre el psicoanálisis.

En segundo lugar, adheriremos a la necesidad de trascender la perspectiva de Popper para poder efectuar un coherente análisis de las teorías científicas y presentaremos la propuesta de Imre Lakatos. Esto nos permitirá concebir los desarrollos teórico-metodológicos de Freud como un programa de investigación y allanará el terreno para que podamos, en el quinto capítulo, mostrar con ejemplos concretos el proceder falsacionista del creador del psicoanálisis.

\section{a) La omisión popperiana}

\begin{abstract}
“...al poco tiempo podrán convencerse de que esos juicios severos se habían formulado antes de toda información, que apenas si alguno de esos opositores ha tomado alguna vez en sus manos un libro analítico o, si lo ha hecho, no sobrepasó la primera resistencia en el encuentro con el nuevo material" (Freud, 1933b/2004: 126).
\end{abstract}

El principal error de Popper es que su objeción parece más una diatriba infundada que una crítica racional guiada por la empiria. Salvo raras excepciones, no cita nunca artículos de Freud, ni parece conocer sus teorizaciones ${ }^{156}$; su acusación de pseudociencia está hecha en base a lo que él

\footnotetext{
${ }^{156}$ A decir verdad, el único análisis que Popper efectúa de los argumentos de Freud es una lectura de La interpretación de los sueños, en el capítulo dos de su libro Realismo y el objetivo de la ciencia (Popper, 1956/2011: 199-233).
} 
imagina o le han dicho que es el psicoanálisis. Esto puede verse en el tipo de ejemplos que Popper inventa para argumentar su supuesta irrefutabilidad:

Puedo ilustrar esto con dos ejemplos diferentes de conductas humanas: la de un hombre que empuja a un niño al agua con la intención de ahogarlo y la de un hombre que sacrifica su vida en un intento de salvar al niño. Cada uno de los dos casos puede ser explicado con igual facilidad por la teoría de Freud y por la de Adler. De acuerdo con Freud, el primer hombre sufría una represión (por ejemplo, de algún componente de su complejo de Edipo), mientras que el segundo había hecho una sublimación. De acuerdo con Adler, el primer hombre sufría sentimientos de inferioridad (que le provocaban, quizás, la necesidad de probarse a sí mismo que era capaz de cometer un crimen), y lo mismo el segundo hombre (cuya necesidad era demostrarse a sí mismo que era capaz de rescatar al niño). No puedo imaginar ninguna conducta humana que no pueda ser interpretada en términos de cualquiera de las dos teorías. Era precisamente este hecho -que siempre se adecuaban a los hechos, que siempre eran confirmadas - el que a los ojos de sus admiradores constituía el argumento más fuerte en favor de esas teorías. Comencé a sospechar que esta fuerza aparente era, en realidad, su debilidad. ${ }^{157}$ (Popper, 1963/1991: 59-60).

Jean Laplanche, leyendo este pasaje, comenta de su "vergüenza en reproducir tamañas necedades en las que términos como «represión» o «sublimación» son utilizadas sin escrúpulos en un razonamiento de tipo metafísico" (Laplanche, 1999/2001: 214); y en nota al pie agrega una interesante observación contestataria:

\begin{abstract}
¿Qué pensaríamos de un epistemólogo que se empeñara en demostrar el carácter pseudocientífico de la teoría de la gravitación mediante el «razonamiento» siguiente: «que un edificio se hunda o se mantenga en pie, cada uno de estos casos podría explicarse con idéntica facilidad en términos de gravitación»? Aserto en el que, es evidente, la palabra «gravitación» es alegada de manera mitológicometafísica, abstracción hecha de cualquier contenido científico (ibíd. n. 5).
\end{abstract}

\footnotetext{
157 Este ejemplo aparece también en Realismo y el objetivo de la ciencia (Popper, 1956/2011: 208-209). Años más tarde, con la repercusión del libro de Grünbaum (1984), Popper volvió a citar este mismo ejemplo para discutir la idea de que la causa de los estados inobservables pueda ser establecida, agregando que las hipótesis freudianas no pueden testearse: "Dado que un psicoanalista no puede predecir si alguien va a reprimir o sublimar, no puede predecir la conducta manifiesta. Por otro lado, una teoría psicológica puede ser puesta a prueba sólo si se puede predecir la conducta manifiesta." (Popper, 1986: 254). [Since a psychoanalyst cannot predict whether anybody will repress or sublimate, he cannot predict overt behavior. On the other hand, a psychological theory can be put to the test only if it can predict overt behavior.]
} 
Es lamentable que Popper no se haya remitido a la obra de Freud ni a la de Adler ${ }^{158}$ para cotejar el sinsentido de sus especulaciones. Así y todo, este tipo de ejemplos inventados por Popper es la base de su crítica y, mutatis mutandis, de su criterio de falsación; pues el mismo reconoce, en el post scriptum a su Logik der Forschung, que sus "intentos de analizar sus argumentos [los de Freud] tuvieron un papel importante en el desarrollo de mis concepciones sobre la demarcación" (Popper, 1956/2011).

Ahora bien, la superficialidad del abordaje popperiano, que deviene en una caricaturización del psicoanálisis, está lejos de ser una simple omisión histórica. Veámoslo.

Popper dice haber empezado a ocuparse del problema de la demarcación en el año de $1919^{159}$, aunque su publicación no se hizo hasta 1934 . Es allí donde aparece, como hemos visto, su poco fundamentada injuria contra el psicoanálisis. $\mathrm{Y}$ posteriormente Popper hará las reiteradas menciones, que también hemos citado, sobre el asunto de la falsabilidad de la teoría freudiana; sin modificar sustancialmente su idea de que no se ajusta al célebre canon. ¿Cómo es posible que un filósofo de la envergadura de Popper no haya, durante todo ese tiempo, pretendido siquiera cotejar su crítica con lo que aparecía en la obra de Freud? ¿Cómo es posible que alguien tan fervorosamente declarado en favor de la crítica racional y en contra de los dogmatismos, no haya tenido la voluntad (pues no dudamos de su capacidad) de revisar, mínimamente, tamaña conjetura? No resulta exagerado afirmar que

\footnotetext{
${ }^{158}$ No nos ocuparemos aquí de la Psicología Individual de Adler. De todas formas, no podemos obviar el hecho de que Popper, según nos cuenta, había tenido la oportunidad de trabajar con Adler y había "quedado muy impresionado" tras advertir su tendencia constante a confirmar la teoría (cf. Popper, 1963/1991:59). Ponderar las afirmaciones popperianas respecto del proceder metodológico de Adler nos llevaría un trabajo que no estamos dispuestos a realizar ahora. Sin embargo, debe quedar claro que la teoría adleriana y su perspectiva psicológica terminaron teniendo muy poco que ver con el psicoanálisis de Freud; y no debemos olvidar (en virtud de lo que a continuación mostraremos) la opinión del vienés: "La teoría de Adler fue desde su comienzo mismo un "sistema», cosa que el psicoanálisis evitó cuidadosamente." (Freud, 1914b/2004: 50).

159 “... otoño de 1919, época en que empecé a abordar el problema siguiente '¿Cuándo debe ser considerada científica una teoría?' o '¿Hay un criterio para determinar el carácter o status cientifico de una teoría?' [...] Yo quería distinguir entre la ciencia y la pseudo-ciencia" (Popper, 1963/1991: 57). "Ya en el invierno de 1919-20 había yo formulado y resuelto el problema de la demarcación entre la ciencia y lo que no es ciencia, si bien entonces no creía que mereciese la pena publicarlo" (Popper, 1972/1974: 15, n. 1).
} 
la de Popper es una detracción paradójica: está hecha contrariando el espíritu de su racionalismo crítico.

Sin poder salir del desconcierto que nos generan estas preguntas, intentaremos una respuesta que, pese a su simpleza y humana factibilidad, no es fácil de corroborar. El psicoanálisis le sirvió a Popper, desde el inicio, como ejemplo-modelo de pseudociencia. Una revisión cuidadosa de su conjetura podría haberlo llevado a tener que relativizar o dejar caer el ejemplo, con lo que su criterio de demarcación perdería terreno ${ }^{160}$. No encuentro otra explicación más sencilla y plausible de lo que pudo haber llevado a Popper a ser siempre tan poco cuidadoso con la teoría de Freud.

También podemos esbozar nuestra conjetura en términos lakatosianos: Popper sólo se ha interesado por el psicoanálisis en tanto ejemplo negativo del núcleo duro de su metodología falsacionista. Su (des)calificación del psicoanálisis fue hecha acomodando procústicamente el freudismo a lo que su perspectiva filosófica contrariaba. Esto no es novedad, pues la deformación del psicoanálisis es sólo un ejemplo particular de algo que Popper ha hecho generalmente: "distorsiona la historia para acomodarla a su teoría de la racionalidad" (Lakatos, 1971/1987: 54).

Eso permitiría explicar por qué Popper, aun desconociendo completamente el proceder de Freud, espetó y reiteró varias veces su acusación. El hecho de que su crítica, tan categórica como superficial, haya sido mantenida por él a lo largo del tiempo, no parece más que una especie de defensa obstinada de su producto intelectual ${ }^{161}$. Defensa que bien puede ser caracterizada como dogmática y contrariar el ideal de la crítica permanente del que se jacta su canon epistemológico.

\footnotetext{
${ }^{160}$ Nos parece que él mismo lo sabía y que por eso añadió, en 1956, una afirmación totalmente curiosa, cuyo sentido se comprende bien desde nuestra perspectiva; pues parece orientada a defenderse de las críticas inminentes, intentando persuadirnos: "En el contexto actual, no importa si tengo o no razón respecto a la refutabilidad de ninguna de esas tres teorías: aquí sólo sirven como meros ejemplos, ilustraciones". (Popper, 1956/2011: 214). Pero, permítasenos preguntar, ¿cómo podría la invalidez de sus ejemplos centrales, tendientes a ilustrar el funcionamiento de su nuevo criterio de demarcación, resultar indistinta para su argumentación? Y aún más: ¿por qué razón necesitaría Popper hacer esta aclaración si no fuese porque, en el fondo, sabía muy bien que se equivocaba respecto a la falsabilidad de, por ejemplo, la teoría de Freud?

161 Valga, a propósito de ello, esta reflexión freudiana: "Ios juicios de valor de los seres humanos derivan enteramente de sus deseos de dicha, y por tanto son un ensayo de apoyar sus ilusiones mediante argumentos" (Freud, 1930a/2004: 140).
} 
De este modo, la obstinación popperiana encuentra su racionalidad; pero lo hace a expensas de su teoría de la ciencia. De manera tal que podríamos esbozar una conjetura auxiliar derivada: Popper falsa a Popper.

\section{El psicoanálisis y la cosmovisión científica}

Popper ha calificado a Freud de "dogmático"162 y ha dicho en varias oportunidades que el psicoanálisis "pareciera explicarlo todo ${ }^{163 " . ~ L a ~ o b r a ~}$ freudiana es, para el filósofo vienés, una de esas "imponentes teorías que todo lo explican y que ejercen el efecto de revelaciones sobre las mentes débiles" (Popper, 1963/1991: 63). ${ }^{164}$

Comenzaremos mostrando que el creador del psicoanálisis se mantuvo alejado de todo dogmatismo y que siempre contradijo abiertamente la omniexplicatividad de su teoría. No podemos decir lo mismo de Popper, quien pareciera haber intentado hacer de su filosofía un sistema autosuficiente para la comprensión de todos los problemas relativos al conocimiento; y que no

\footnotetext{
162 "...no cabe duda de que Freud era mucho menos dogmático que la mayoría de sus seguidores, que se sintieron inclinados a hacer una religión de la nueva teoría dotada de todo lo necesario: mártires, herejes y cismas y que consideraron a todo crítico como un enemigo o al menos como «mal informado» (es decir, necesitado de ser analizado) (Popper, 1956/2011: 208).
}

${ }^{163}$ En su autobiografía, Popper asevera que le "impresionó" la actitud crítica de Einstein, que parecía dispuesto a abandonar su teoría si no resistía ciertos test; actitud que era "totalmente diferente de la actitud dogmática de Marx, Freud, Adler" (Popper, 1976/1985: 51-52). En unas conversaciones con Franz Kreuzer durante el verano de 1979, sostuvo: “... el psicoanálisis no excluye ninguna conducta humana posible. No dice que bajo ciertas circunstancias sea imposible que un hombre haga esto o aquello. De ahí que siempre que un hombre actúe, confirme la teoría psicoanalítica" (Popper, 1984: 15). Este tipo de aseveraciones de Popper aparecen en casi todo lugar en el que nos habla de su criterio de demarcación.

\footnotetext{
${ }^{164}$ Adolf Grünbaum ha señalado cabalmente el error de este argumento: “...si una teoría, en conjunción con particulares condiciones iniciales, no excluye ningún comportamiento en absoluto, entonces no puede explicar deductivamente ningún comportamiento en particular. A fin de cuentas, explicar deductivamente es excluir: como Spinoza sostuvo, afirmar [implicar] $P$ es negar toda proposición incompatible con ella. Por lo tanto, si el psicoanálisis fuera infalsable, ¿cómo podría cualquier comportamiento real (por no hablar de todo el comportamiento físicamente posible) ser explicado por él, confirmándose inductivamente, como afirma Popper? Por el contrario, la supuesta no-falsabilidad impediría tal confirmabilidad hipotético-deductiva." (Grünbaum, 2009: 126). ["...if a theory, in conjunction with particular initial conditions, does not exclude any behavior at all, then it cannot deductively explain any particular behavior. After all, to explain deductively is to exclude: As Spinoza emphasized, to assert [entail] $P$ is to deny every proposition incompatible with it. Thus, if psychoanalysis were unfalsifiable, how could any actual behavior - let alone all physically possible behavior - be explained by it so as to confirm it inductively, as Popper claims $(1962$, p. 35)? On the contrary, the alleged unfalsifiability would preclude such hypothetico-deductive confirmability"].
} 
mostró, paradójicamente, haber modificado mucho sus ideas, a pesar de las conocidas y significativas críticas recibidas.

En 1932, un par de años antes de la publicación de Logik der Forschung, Freud escribe una conferencia titulada En torno de una cosmovisión. Lo que allí se plantea es sumamente ilustrativo de su imagen de la ciencia y del progreso. Pero también nos muestra lo que Popper omitió:

\begin{abstract}
Entiendo, pues, que una cosmovisión es una construcción intelectual que soluciona de manera unitaria todos los problemas de nuestra existencia a partir de una hipótesis suprema; dentro de ella, por tanto, ninguna cuestión permanece abierta y todo lo que recaba nuestro interés halla su lugar preciso. Es fácilmente comprensible que poseer una cosmovisión así se cuente entre los deseos ideales de los hombres. Creyendo en ella uno puede sentirse más seguro en la vida, saber lo que debe procurar, cómo debe colocar sus afectos y sus intereses de la manera más acorde al fin.

Si tal es el carácter de una cosmovisión, la respuesta es fácil para el psicoanálisis. Como ciencia especial, una rama de la psicología — psicología de lo profundo o psicología de lo inconciente-, es por completo inepta para formar una cosmovisión propia; debe aceptar la de la ciencia. Pero la cosmovisión científica ya se distancia notablemente de nuestra definición. Es cierto que también ella acepta la unicidad de la explicación del mundo, pero sólo como un programa cuyo cumplimiento se difiere al futuro (Freud, 1933c/2004: 146).
\end{abstract}

Luego de brindar una descripción diferencial entre las empresas científica, religiosa y filosófica, concluye:

Opino que el psicoanálisis es incapaz de crear una cosmovisión particular. No le hace falta; él forma parte de la ciencia y puede adherir a la cosmovisión científica. Pero esta apenas merece ese grandilocuente nombre, pues no lo contempla todo, es demasiado incompleta, no pretende absolutismo ninguno ni formar un sistema. El pensamiento científico es todavía muy joven entre los hombres, elevado es el número de los grandes problemas que no puede dominar todavía. Una cosmovisión edificada sobre la ciencia tiene, salvo la insistencia en el mundo exterior real, esencialmente rasgos negativos, como los de atenerse a la verdad, desautorizar las ilusiones. Aquel de nuestros prójimos insatisfecho con este estado de cosas, aquel que pida más para su inmediato apaciguamiento, que se lo procure donde lo halle. No se lo echaremos en cara, no podemos ayudarlo, pero tampoco pensar de otro modo por causa de él. (ibíd. pp. 168). 
Incluso varios años antes, a poco tiempo de haber modificado sustancialmente la teoría y hallándose en plena reconceptualización, el creador del psicoanálisis sostenía:

El psicoanálisis no es un sistema como los filosóficos, que parten de algunos conceptos básicos definidos con precisión y procuran apresar con ellos el universo todo, tras lo cual ya no resta espacio para nuevos descubrimientos y mejores intelecciones. Más bien adhiere a los hechos de su campo de trabajo, procura resolver los problemas inmediatos de la observación, sigue tanteando en la experiencia, siempre inacabado y siempre dispuesto a corregir o variar sus doctrinas. Lo mismo que la química o la física, soporta que sus conceptos máximos no sean claros, que sus premisas sean provisionales, y espera del trabajo futuro su mejor precisión (Freud, 1923a/2004: 249).

El analista vienés nunca dejó de afirmar que su producto se oponía a la aspiración de ser un sistema perfectamente cerrado (religioso o filosófico) y que los conceptos psicoanalíticos no están axiomáticamente determinados desde el inicio ${ }^{165}$. Adhiere, por el contrario, a la cosmovisión científica: ésta supone que el conocimiento es parcial e incompleto, que permanece abierto a la experimentación; y por ello sus conceptos son supuestos provisionales, perfectibles. Freud es un convencido de que "la ciencia no es ninguna revelación; carece, aunque sus comienzos ya estén muy atrás, de los caracteres de precisión, inmutabilidad e infalibilidad, tan ansiados por el

\footnotetext{
${ }^{165}$ Freud se opuso explícitamente al intento de algunos analistas por anexar el psicoanálisis a un sistema especulativo. Por ejemplo, James Jackson Putnam abrió el Congreso Internacional de Psicoanálisis de 1911 con una comunicación titulada La importancia de la filosofía en el desarrollo futuro del psicoanálisis, en la que manifestaba su aspiración a injertar el sistema hegeliano, estimado por él, en la obra freudiana (sistema que representaba, para el espíritu científico de la época, la tentativa de especulación filosófica más acabada y más desdeñable). Freud le manifestó a Jones: "La filosofía de Putnam me hace pensar en un decorativo centro de mesa. Todos lo admiran, pero nadie lo toca" (Jones, 1953/1981: 84); y unos años más tarde escribió: "Putnam ha cedido luego en demasía a la inclinación ética y filosófica de su naturaleza, y dirigió al psicoanálisis una exigencia a mi juicio incumplible para este, a saber, que debería estar al servicio de una cosmovisión ético- filosófica determinada..." (Freud, 1914b/2004: 30). En su Presentación autobiográfica volvió a expresar su "disgusto con este hombre sobresaliente", por su "propuesta de uncir el psicoanálisis a un sistema filosófico determinado y ponerlo al servicio de afanes morales" (Freud, 1925/2004: 48). También por 1911, Arthur Kronfeld había intentado una exposición completa del psicoanálisis, otorgándole a las experiencias psicoanalíticas, por la vía de la síntesis conceptual, una perfección sistemática que no poseían. En realidad, Kronfeld había omitido las experiencias analíticas para elaborar un juicio filosófico adverso sobre las ideas de Freud. Éste se expresa contundentemente: "Kronfeld ha demostrado por vía filosófica y matemática que todas las cosas por las que tanto nos afanamos no existen, porque no pueden existir. Ahí está la cosa»" (Jones, 1953/1981: 126). Un examen detallado de estos aspectos y de la relación general de Freud con la filosofía y los filósofos, puede verse en el clásico libro de Assoun (1976/1982).
} 
pensamiento humano. Pero, así como es, es todo lo que podemos tener." (Freud, 1926b/2004: 179).

Su creador manifiesta que el psicoanálisis es una nueva ciencia natural ${ }^{166}$, apenas una parte de la psicología, sin pretensiones omniexplicativas. En ese sentido su pensamiento parece acordar con el de Lakatos, en que "Nunca se debe permitir que un programa de investigación se convierta en una Weltanschauung..." (Lakatos, 1978/1989: 92).

Las razones por las que Freud mantiene una devoción por el pensamiento crítico (por momentos no muy lejana a la de Popper) pueden retrotraerse a su formación personal como médico neurólogo y a la tradición en la que se desarrolló su pensamiento.

\section{La tradición científico-filosófica de Freud: el lugar de la crítica}

Los inicios de la carrera científica de Freud se enmarcan en la decadencia de una cosmovisión conocida como Filosofía de la Naturaleza y en el surgimiento de la Fisiología moderna, de la mano de la Escuela Médica de Helmholtz (Hermann von Helmholtz, Karl Ludwig, Ernst von Brücke y Emil Du Bois-Reymond eran sus protagonistas). Al poco tiempo de haber comenzado sus estudios de medicina, Freud se encontraba investigando sobre la histología del sistema nervioso en el Instituto de Brüke; y más tarde, ya egresado, trabajó bajo la dirección de Theodor Meynert en el Hospital General de Viena.

En lo que respecta a la tradición en la que Freud desarrolló su pensamiento, podemos mencionar, además de los autores arriba mencionados, el bagaje conceptual recibido de las obras Friedrich Herbart, Theodor Fechner, Franz Brentano y de John Stuart Mill. Pero, apropósito de nuestra perspectiva, cabe destacar sin dudas la figura de Ernst Mach como uno de sus referentes epistemológicos principales.

Sabemos que Mach (físico, filósofo e historiador de la ciencia), enseñó entre 1895 y 1901 en una cátedra creada para él en la Universidad de Viena, que versaba sobre Filosofía, en especial Historia y Teoría de las Ciencias

\footnotetext{
${ }^{166}$ Aunque por esta época la "querella de los métodos" estaba siendo instalada, Freud adopta una posición monista: reconoce sólo a las naturales como verdaderas ciencias y prácticamente no se introduce en el debate metodológico. En distintas oportunidades se preocupó por diferenciar su producto intelectual de las ciencias del espíritu, a las que caracterizó siempre como "colaboradoras" (cf. Assoun, 1981/1982: $41-52$ y 1993/2003: 20-34).
} 
Inductivas. Cátedra que hoy es vista por muchos como un punto de origen de la filosofía de la ciencia contemporánea; tengamos en cuenta que esta cátedra será heredada en 1922 por Moritz Schlick, quien, como se ha dicho, un par de años más tarde organizó los primeros encuentros de lo que luego sería el Círculo de Viena; y además, que los miembros de este movimiento inicialmente darían en Ilamarlo "Asociación Ernst Mach". Lo cierto es que Mach fue un ferviente detractor de toda forma de metafísica y uno de los principales representantes del positivismo de comienzos del siglo XX. Sus ideas se hallan basadas en un enfoque evolucionista y empirista, en el que la ciencia representa la mejor herramienta para la supervivencia; y se orientan por una preocupación central: hallar, debido a la insuficiente solidez que los fundamentos de la física habían mostrado, nuevas bases para el edificio científico. Mach se propuso encontrar una respuesta a partir de la reconstrucción unificante del conocimiento científico desde sus bases sensoriales (pues la "sensación" era el único dato positivo). Más específicamente, se propuso encontrar un punto de continuidad entre la física y la psicología, aspirando a la reducción del universo cognitivo a complejos de sensaciones inmediatas $^{167}$.

\footnotetext{
167 Las sensaciones no son consideradas representantes o signos de las cosas; por el contrario, Mach cree que los objetos son una composición intelectual de un cúmulo de sensaciones relativamente estables y que no es necesario ir más allá de las sensaciones para explicar el mundo. Es decir que la ontología de Mach no se compone de objetos físicos o mentales sino de experiencias o sensaciones individuales (cf. Mach, 1883/1974: 579). Así, entidades como "átomos", "masa", "espacio absoluto", etc. no son realidades objetivas sino meros símbolos para una descripción económica de las sensaciones. Este afán antimetafísico lo llevó a una postura fenomenalista que fue muy discutida por algunos físicos de la época (en Gómez, [2004] puede verse un análisis de la disputa de Mach con Max Planck). Mach cree que no hay diferencia esencial entre lo físico y lo psíquico, pues son aspectos idénticos constituidos por elementos homogéneos y sólo el punto de vista permite distinguirlos (cf. Mach, 1886/1987: 265). Mach entiende por "análisis de las sensaciones" la determinación de las relaciones entre una sensación y las que le siguen. Según esta propuesta, la ciencia es experiencia organizada en un orden económico, y tiene solamente un valor práctico en tanto medio para la lucha por la existencia.

Gran parte de estas ideas de Mach pueden retrotraerse a la fisiología sensorial de Hermann von Helmholtz, cuyas implicancias alcanzan también al arte, en el neoimpresionismo: "como resultado de esta forma de pensar, el mundo de la sensación se llegó a considerar independientemente del mundo externo, idea que llevó al monismo de sensaciones de Mach: contra el dualismo del mundo (o el cuerpo) y el ego, Mach, provocadoramente clamó por el punto de vista monista en que el mundo consiste solo en nuestras sensaciones" (Roque, 2007: 140). Freud adhirió a la tesis de Mach, con base helmholtziana, sobre la secuencia estímulosensación-representación; veremos esta adherencia cuando analicemos una de las tempranas teorías etiológicas del analista vienés.
} 
Además de la enorme popularidad de las obras de Mach en la Viena del 1900, es indudable que el vínculo de Freud con este científico se debe a que también él había trabajado con Joseph Breuer, en la fisiología del aparato vestibular y su relación con las sensaciones (juntos postularon una hipótesis que lleva sus nombres) ${ }^{168}$. Por otro lado, Mach había brindado unos cursos de epistemología en la Universidad de Viena (entre 1895 y 1898) y había tenido entre sus alumnos a Sandor Ferenczi y a Paul Federn; es decir, existieron diversas raíces de esta filiación filosófica.

Paul Laurent Assoun señala, en apoyo a la filiación de Freud con Mach, la participación del inventor del psicoanálisis en la redacción en 1911 de un manifiesto a favor de la creación de una sociedad para la difusión de la filosofía positiva $^{169}$ (Assoun, 1981/1982: 85). Como parte de este núcleo de filiaciones originales Assoun también menciona un hecho anecdótico: al pie de ese manifiesto de 1911 el nombre de Freud aparece cerca del de Albert Einstein, con quien mantendría un importante intercambio de ideas ${ }^{170}$ (cf. ¿Por qué la guerra?).

Freud cita a Mach en varias oportunidades, ${ }^{171}$ y hoy sabemos que en su biblioteca había varios de sus libros con marcas de lectura. Pero la adherencia

\footnotetext{
${ }^{168}$ En estudios sobre la histeria, Breuer retoma las conceptualizaciones de Mach, luego de haber encontrado en sus ideas el "esquema fisiológico para la génesis de los fenómenos histéricos" (Freud \& Breuer, 1895/2004: 221).
${ }^{169}$ Las críticas de Mach a la concepción tradicional de la física habían decantado en una serie de intentos de renovación conceptual. Inspirado en esta renovación, Wilhelm Ostwald había desarrollado una nueva Naturphilosophie y había invitado en 1910 a Freud a escribir un artículo para su revista; según Assoun, Freud decidió no escribir ese artículo por temor a que el psicoanálisis se afiliara a esta nueva cosmovisión. Unos meses más tarde, consolidando su filiación, firma el manuscrito de Mach.

${ }^{170}$ Decimos "filiaciones originales" porque es sabido que Einstein evoluciona sus ideas hasta afianzarlas en una forma de realismo científico que dista mucho del convencionalismo machiano de su juventud. En Freud no pareciera haberse dado algo similar, sino que sus supuestos ontológicos y epistemológicos constituyen una amalgama de aspectos realistas e instrumentalistas difícil de asir en lo que respecta a su diacronía (cf. Azcona 2013a).

${ }^{171}$ En una carta del 12 de Junio de 1900 asegura, después de haber leído El análisis de las sensaciones (junto a un libro de otro autor), que "persiguen orientaciones semejantes a las de mi trabajo" (Freud, 1985/1986: 458). El analista vienés se refiere a su reciente obra La interpretación de los sueños y se alegra de que ninguno de esos autores leídos haya postulado lo que él estaba teorizando: "lo que saben decir acerca del sueño, me alegra sin embargo, como al trasgo del cuento, que "la princesa no lo sepa»" (ibíd.). Podemos comprender el sentido de esta expresión a partir de una carta anterior, en la que Freud comunicaba algo parecido: "He examinado la bibliografía y se me antoja que me parezco al trasgo celta "iAh! cuán contento estoy, porque nadie, nadie sabe ... ». Nadie tiene idea de que el sueño no es un dislate sino que es un cumplimiento de deseo" (Freud, 1985/1986: 259). En Lo ominoso 
de Freud a la propuesta empiriocriticista puede rastrearse más allá de esas referencias, hasta ver que gran parte de la construcción metapsicológica aparece apoyada en el programa machiano. Assoun ha mostrado cómo la introducción de Pulsiones y destinos de pulsión, al retomar casi literalmente las palabras de un por entonces muy popular texto de Mach (Conocimiento $y$ error), nos permite atisbar la importación de un modelo epistemológico (Assoun, 1981/1982: 77). Allí Freud afirma:

\begin{abstract}
Muchas veces hemos oído sostener el reclamo de que una ciencia debe constituirse sobre conceptos básicos claros y definidos con precisión. En realidad, ninguna, ni aún la más exacta, empieza por tales definiciones. El comienzo correcto de la actividad científica consiste en describir fenómenos que luego son agrupados, ordenados e insertados en conexiones ${ }^{172}$. Ya para la descripción misma es inevitable aplicar al material ciertas ideas abstractas que se recogieron de alguna otra parte, no de la sola experiencia nueva. ${ }^{173} \mathrm{Y}$ más insoslayables todavía son esas ideas -los posteriores conceptos básicos de la ciencia- en el ulterior tratamiento del material. Al principio deben comportar cierto grado de indeterminación; no puede pensarse en ceñir con claridad su contenido. Mientras se encuentran en ese estado, tenemos que ponernos de acuerdo acerca de su significado por la remisión repetida al material empírico del que parecen extraídas, pero que, en realidad, les es sometido. En rigor, poseen entonces el carácter de convenciones, no obstante lo cual es de interés extremo que no se las escoja al azar, sino que estén determinadas por relaciones significativas con el material empírico, relaciones que se cree colegir aun antes que se las pueda conocer y demostrar. Sólo después de haber explorado más a fondo el campo de fenómenos en cuestión, es posible aprehender con mayor exactitud también sus conceptos científicos básicos y afinarlos para que se vuelvan utilizables en un vasto ámbito, y para que, además, queden por completo exentos de contradicción. Entonces
\end{abstract}

\footnotetext{
también aparece citado ese libro de Mach, a propósito de las sensaciones ante lo siniestro del doble y el examen de realidad (Freud, 1919a/2004: 247, n. 30). También aparece en el relato de su contacto con Josef Popper-Lynkeus, amigo de Mach (Freud, 1932/2004: 208).

172 Según Assoun, esta noción de "conexiones" o "relaciones" corresponde a la teoría del límite $U$ de Mach y se halla en toda la base del edificio de las conceptualizaciones freudianas. También puede reconocerse en este pasaje el principio machiano de economía del pensamiento (Assoun, 1981/1982: 82).

${ }^{173}$ Esta expresión muestra a las claras el rechazo de la clásica postura inductivista que hubo de suponer un comienzo por la sola observación (postura que aparece comentada críticamente por Popper (1972/1974: 307-325) y Hempel (1966/1999: 25-37), entre tantos otros). No es exagerado decir que Freud actúa conforme a la teoría de la carga teórica de la observación, explicitada mucho tiempo después (cf. el punto 4.a.I del capítulo 3 de esta tesis).
} 
quizás haya llegado la hora de acuñarlos en definiciones. Pero el progreso del conocimiento no tolera rigidez alguna, tampoco en las definiciones. Como lo enseña palmariamente el ejemplo de la física, también los "conceptos básicos» fijados en definiciones experimentan un constante cambio de contenido. (Freud, 1915a/2004: 113).

Para Freud, los conceptos abstractos de una ciencia deben permanecer en íntima conexión con el suelo de la experiencia. La metapsicología freudiana puede ser entendida como un estadio avanzado en esa travesía tendiente a la construcción conceptual del psicoanálisis. En su tardío Esquema de Psicoanálisis sostiene que para abordar los procesos inconcientes, al igual que el resto de las ciencias naturales, el psicoanálisis "no puede prescindir de nuevos supuestos ni de la creación de conceptos nuevos" (Freud, 1940/2004: 156). Creación de constructos metapsicológicos que han de ser estimados como

enriquecimientos de la ciencia; poseen títulos para que se les otorgue, en calidad de aproximaciones, el mismo valor que a las correspondientes construcciones intelectuales auxiliares de otras ciencias naturales, y esperan ser modificados, rectificados y recibir una definición más fina mediante una experiencia acumulada y tamizada (ibíd.).

Nuestro autor considera que todo saber que no se apoye lo suficiente en este plano experiencial es especulación pura y desdeñable. Obsérvese que Freud no rechaza la especulación (de hecho la utiliza) si ésta funciona en combinación con la indagación de hechos concretos ${ }^{174}$; lo desacreditado es la especulación exclusiva, numerosas veces adjudicada por él a las cosmovisiones filosóficas. Este andar híbrido de especulación combinada y limitada por la experiencia observacional, es el modo que Freud sigue al elaborar su propuesta teórica (más adelante especificaremos y ejemplificaremos este proceder).

Según Darío Antiseri, Mach puede considerarse uno de los precursores del hipotético-deductivismo desarrollado por Popper, al punto tal que entre sus ideas aparece un explícito rechazo de la inducción como método y la creencia

$\overline{174}$ En la cuarta parte de la tesis podremos examinar algunos aspectos de la lógica del descubrimiento freudiano. 
de que la ciencia "se mueve por conjeturas y correcciones" (Mach, citado en Antiseri, 2000/2001: 52). Mach también parte de suponer que todo experimento está guiado por teorías, pero que "la experiencia trabaja incesantemente para transformar y completar nuestras representaciones" (ibíd. pp. 57).

La misma diferenciación entre ciencia y filosofía que luego reencontramos en Freud, ya aparece claramente formulada en Mach:

\begin{abstract}
El modo de pensar y de trabajar del hombre de ciencia es muy distinto del que tiene el filósofo. Al no tener la suerte de poseer principios indefectibles, ha adquirido la costumbre de considerar como provisionales, y susceptibles de modificación a través de nuevas experiencias, aun las más seguras y fundadas opiniones y principios. De hecho, los mayores progresos y descubrimientos han sido posibles sólo por esta actitud (ibíd. pp. 58).
\end{abstract}

En virtud del carácter falibilista que le adjudica al conocimiento, Mach considera que "el científico debe estar siempre dispuesto a ser desmentido" (ibíd. pp. 59) ${ }^{175}$. Por lo expuesto más arriba (y por lo que mostraremos más adelante), el pensamiento de Freud pareciera haberse apuntalado en esta perspectiva crítica de Mach.

Estas breves consideraciones sobre la formación y filiación epistemológica de Freud, que contornean una postura epistémica en la que se enfatizan el empirismo y el criticismo, han sido esbozadas como preludio sintónico a la argumentación que enseguida desplegaremos.

\title{
III. El falibilismo freudiano
}

La principal razón que podemos dar en contra de la crítica de Popper es muy simple: el psicoanálisis freudiano es falsable porque, de hecho, su historia interna está hecha de falsaciones. Para cuando Popper formuló su crítica descalificadora de la teoría freudiana ésta ya llevaba más de treinta años de constantes modificaciones. Una manera contrafáctica de decirlo es la siguiente: si el psicoanálisis no hubiera sido falsable, Freud no lo hubiera modificado

\footnotetext{
${ }^{175}$ En los escritos de Freud podemos leer, con bastante frecuencia, pasajes que denotan elocuentemente su perspectiva falsacionista. Considérese este por ejemplo: "Y aunque el mecanismo de las fobias siga presentando tantos puntos oscuros, mi doctrina sólo se podrá refutar si se me muestra la existencia de fobias con una vida sexual normal o aun con una perturbación de esta última no determinada específicamente." (Freud, 1895/2004: 133; cursivas añadidas). Se ve en esta simple oración que Freud no sólo consideraba falsables a sus ideas sino que a veces también se encargaba de explicitar sus falsadores potenciales.
} 
como lo hizo. En ese sentido, Freud sabía que la inestabilidad de las teorías era un rasgo definicional de la ciencia: "sólo los creyentes que piden a la ciencia un sustituto del catecismo abandonado echarán en cara al investigador que remodele o aun rehaga sus puntos de vista" (Freud, 1920a/2004: 62).

Lógicamente, al soslayar Popper la complejidad inherente a las teorías científicas, su "consideración" del corpus teórico de Freud es sumamente superficial. Coincidimos aquí con Gregorio Klimovsky cuando sostiene que

...según el momento de la evolución freudiana las teorías son distintas y, además

[...] aun haciendo un corte de carácter sincrónico en el pensamiento freudiano, no es claro que se trate de una única teoría, ya no por razones de evolución, sino por razones de estructura [...] es perfectamente posible que uno encuentre en Freud cosas como una teoría de la energía psíquica, una teoría de los instintos, una teoría hedonista, una teoría económica, una teoría de los mecanismos de defensa, una o varias teorías de lo inconsciente, etc. (Klimovsky, 1981/2009: 79).

Aquí partiremos de asumir lo que fue puesto en evidencia durante la denominada "fase historicista" ${ }^{176 "}$ de la filosofía de la ciencia del siglo XX (Moulines, 2008/2011) respecto de las teorías científicas; a saber, que son entidades eminentemente complejas y cambiantes, desarrolladas al interior de marcos más amplios cuyos compromisos y presupuestos son de diversa índole, alcance y explicitación; que entre sus elementos constitutivos necesariamente deben destacarse (cuanto menos) partes "esenciales" y partes "accesorias", de manera tal que podamos representar cómo evolucionan a través del tiempo sin por ello perder su identidad; y que suponen diversos niveles de empiricidad y teoricidad. Tales aspectos han dado lugar a una serie de nociones diversas pero emparentadas, cuyos desarrollos por parte de los epistemólogos del período historicista (paradigmas, programas de investigación, tradiciones de investigación) han sido retomados por la concepción semántica o modeloteórica de las teorías, entre otras perspectivas.

En el ámbito del psicoanálisis no abundan los trabajos de reconstrucción epistemológica, ni siquiera de la teorización freudiana. Pero aquí podemos

\footnotetext{
${ }^{176}$ Moulines aclara que su caracterización de "fases" no se refiere a "períodos históricos" en sentido estricto: "se trata más bien de maneras diferentes de comprender la tarea de la filosofía de la ciencia que más o menos se suceden en el tiempo, pero que también se pueden solapar $y$, a veces incluso, desarrollar en paralelo" (Moulines, 2008/2011: 17).
} 
destacar dos reconstrucciones que resultan sumamente esclarecedoras: una a partir de los desarrollos de Thomas Kuhn y otra a raíz de los aportes de Imre Lakatos.

Leticia Minhot ha mostrado que las elaboraciones freudianas admiten un análisis desde la meta-teoría de Kuhn. Su reconstrucción es particularmente ilustradora sobre el modo en que los historiales clínicos freudianos pueden verse como ejemplares que sentaron las bases para la práctica científica normal del psicoanálisis (Minhot, 2003). Sin embargo, como bien explica la autora en su libro, el modelo kuhniano de las "matrices disciplinares" no se presta fácilmente para una reconstrucción del cambio teórico en el tiempo. Y como nuestro propósito es analizar si el proceder de Freud puede reconstruirse como una forma de hipotético-deductivismo (justamente analizando la dinámica de algunos cambios intrateóricos concretos), aquí no lo utilizaremos ${ }^{177}$. Debe decirse que no es nuestro afán el de participar en la polémica Kuhn-Lakatos, sino aproximamos a las herramientas que mejor permitan reconstruir la propuesta freudiana de cara a los objetivos propuestos.

El otro de los empeños aludidos pertenece a Juan de la Cruz Argañaráz (2007, 2012), quien se orienta por los desarrollos filosóficos de Irme Lakatos para entender a las teorías freudianas en el contexto de su aparición. Inspirándonos en estos trabajos, aquí sostendremos la siguiente conjetura: el psicoanálisis de Freud puede ser visto como un programa de investigación en sentido lakatosiano. Si esto es así, gran parte de las modificaciones teóricas pueden considerarse como transformaciones racionales en su cinturón protector. $Y$ su desarrollo general puede ser visto como el esfuerzo de una actividad en competencia con otros programas rivales pertenecientes al mismo contexto cognitivo.

Ahora bien, no es nuestra intención realizar una reconstrucción sistemática de las elaboraciones freudianas en clave lakatosiana (cosa que nos llevaría, en sí mismo, otra tesis), sino mostrar la viabilidad de tal formalización a los fines de ponderar la racionalidad freudiana. En el capítulo siguiente reconstruiremos algunos ejemplos históricos de la evolución del programa, para apoyar esta idea: el proceder de Freud coincide con lo que Lakatos ha denominado

\footnotetext{
177 Otro trabajo interesante que articula cuestiones metodológicas del psicoanálisis con una lectura desde las ideas kuhnianas, es el de Luis Juri (1999).
} 
falsacionismo sofisticado. Pero antes, conviene que presentemos a la teoría lakatosiana y, luego, que fundamentemos por qué las teorizaciones de Freud pueden ser vistas como un programa de investigación.

\section{b) Los programas de investigación: una herramienta reconstructiva}

\section{Introducción contextual}

Imre Lipschitz nació en Hungría en 1922 y estudió matemáticas, física y filosofía en la Universidad de Debrecen. Durante la invasión Nazi cambió su apellido a "Molnár" con el objetivo de evitar la caza de judíos; luego de combatir en la Resistencia y una vez vencido el nazismo, decidió cambiar nuevamente su apellido por el de "cerrajero" (Lakatos), que carecía de resonancias judías. Su actividad militante en el Partido Comunista Húngaro lo llevó al cargo de secretario del Ministerio de Educación y, más tarde, a ser internado en el peor campo de concentración de Hungría, en el que permanece tres años.

Lakatos abandonó Hungría en 1956 para dirigirse al Reino Unido, donde trabajó en filosofía de la matemática y filosofía de la ciencia, primero en Cambridge y luego, sucediendo a Popper en la London School of Economics and Political Science, hasta su repentina muerte en 1974. Allí realizó su tesis doctoral titulada "Ensayo sobre la lógica del descubrimiento Matemático", base de su Pruebas y refutaciones (Lakatos, 1976/1978).

Aunque fue discípulo de Popper y afirmó haber llevado sus ideas hasta una forma más acabada, Popper nunca reconoció tales desarrollos ni lo incluyó entre sus continuadores intelectuales. Lakatos intentó perfeccionar el falsacionismo popperiano atendiendo a las críticas antepuestas por Kuhn y Feyerabend, pero sin caer en algunas tesis extremas de éstos que no compartía (fundamentalmente en lo relativo a la racionalidad científica).

\section{Falsacionismo dogmático y falsacionismo ingenuo}

Lakatos rescata de la filosofía de Popper su carácter antijustificacionista; esto es, la postura de que los enunciados científicos no pueden ser probados concluyentemente (ya sea por apelación a la razón o a la experiencia). A su vez, va a analizar críticamente el falibilismo, diferenciando para ello tres formas de falsacionismo: dogmático, metodológico ingenuo y metodológico sofisticado. 
En un intento de aplicación de su propio esquema teórico, Lakatos dirá que Popper "atravesó" sucesivamente estas tres etapas (cf. nota al pie del capítulo anterior).

En contra del justificacionismo (tradición dominante durante siglos), inductivo o probabilista, Lakatos piensa que se erigió un falsacionismo dogmático: una postura que supone la falibilidad de todas las teorías científicas, pero admite una base empírica absolutamente sólida, constituida por hechos indudables que pueden utilizarse para refutar las teorías. Surge de aquí este criterio de demarcación: una teoría es científica siempre que prohíba determinados hechos que, de observarse, nos lleven a refutarla. La falsación coincide con el rechazo.

Lakatos entiende que este falsacionismo es "dogmático" e "insostenible" por estar basado en tres supuestos falsos:

1- Que existe una frontera natural, psicológica, entre las proposiciones teóricas y las proposiciones observacionales.

2- Que las proposiciones observacionales pueden probarse a partir de los hechos.

3- Que una teoría es científica si y sólo si posee una base empírica (entendida como conjunto de enunciados infalibles) que contenga "falsadores potenciales" de la teoría.

Lakatos analiza cada una de estas afirmaciones (los dos primeros son supuestos y el tercero es un criterio de demarcación derivado) y concluye su falsedad. El primer supuesto es inadmisible, "porque no hay ni puede haber sensaciones no impregnadas de expectativas y por ello no hay demarcación natural (psicológica) entre las proposiciones observacionales y teóricas" (Lakatos, 1978/1989: 26).

El segundo es falso porque "el valor de verdad de las proposiciones «observacionales» no puede ser decidido de forma indubitable: ninguna proposición fáctica puede nunca ser probada mediante un experimento", es decir, "las proposiciones sólo pueden ser derivadas a partir de otras proposiciones; no a partir de los hechos: no se pueden probar enunciados mediante experiencias" (ibíd.)

Finalmente, el criterio de demarcación resulta inútil, pues aun dando por ciertos los dos supuestos previos podemos constatar que "precisamente las 
teorías más admiradas no prohíben ningún acontecimiento observable" (ibíd. pp. 27). Para Lakatos esto es así no sólo porque muchas de tales teorías contienen leyes probabilísticas (irrefutables por naturaleza) sino porque aquellas teorías que sí prohíben la aparición de un acontecimiento, lo hacen con la inclusión de "cláusulas ceteris paribus": la hipótesis (universal) añadida de que no hay otro factor adicional que intervenga en el fenómeno estudiado. Es decir, nunca, por sí solas talas teorías contradicen un enunciado básico; y el falsacionista dogmático no puede pretender que estas cláusulas auxiliares se prueben empíricamente (ibíd. pp. 29). En el capítulo anterior hemos visto porqué ante una contraevidencia empírica es posible o bien rechazar la teoría o bien uno de sus supuestos auxiliares. La lógica no impide modificar, por ejemplo, la cláusula universal de inexistencia de un fenómeno para retener la teoría.

En síntesis, los tres supuestos son inaceptables: "la psicología testimonia contra el primero, la lógica contra el segundo $y$, finalmente, la opinión metodológica testifica contra el criterio de demarcación" (Lakatos, 1978/1989: 25). Es por ello que si pretendiéramos reconstruir la historia de la ciencia a partir de este modelo, deberíamos, además de admitir que el progreso es una ilusión, rechazar a las teorías más importantes de todos los tiempos, por considerarlas metafísica irracional.

Lakatos entiende que el colapso del falsacionismo dogmático ante la potencia de los

argumentos falibilistas nos devuelve al punto de partida. Otra forma de responder a las preguntas sobre la falibilidad, la racionalidad y el progreso científicos, es aportada por el falsacionismo metodológico ingenuo. Esta postura, habiendo sometido a crítica los supuestos anteriores, adopta un punto de vista convencionalista. Lakatos distingue, para ponderar el alcance de este postulado, dos formas: un convencionalismo conservador y un convencionalismo revolucionario. El primero afirma que los científicos adoptan por convenio ciertas teorías universales que, en virtud de su éxito adquirido, son declaradas infalsables; es decir que toda incongruencia entre estas teorías y los datos observacionales se resuelve con la modificación de las hipótesis auxiliares (algunos como Le Roy y Poincaré serían sus representantes). El segundo tipo, revolucionario, también sostiene que lo convenido son las teorías 
científicas; pero agrega criterios para decidir bajo qué condiciones es razonable abandonarlas. Según Lakatos, tanto Duhem como Popper son partidarios de este convencionalismo, pero difieren en torno al tipo de enunciados que se aceptan por convenio y al tipo de criterios que se deben emplear para rechazar una teoría: Duhem considera que ninguna teoría se elimina por una contraevidencia empírica, pero que debe ser rechazada cuando las modificaciones introducidas (para salvarla de la refutación) devienen un complicado sistema de hipótesis auxiliares. Es decir, se basa en el valor de la simplicidad como criterio del abandono. El convencionalismo de Popper, como sabemos, está limitado a los enunciados básicos (espacio-temporalmente singulares) que se utilizan para refutar a las teorías.

Lakatos afirma que el falsacionismo dogmático ha sido superado al revocarse sus supuestos: al admitir que todos los enunciados de la ciencia están cargados de teoría y que sólo por la vía del acuerdo puede convenirse cuales servirán de "base" para la falsación de las teorías, se está poniendo en primer plano a las decisiones metodológicas. Nuestro autor sintetiza este aspecto diciendo:

El falsacionista metodológico separa el rechazo y la refutación que habían sido unidos por el falsacionista dogmático. Él es falibilista, pero su falibilismo no debilita su actitud crítica: convierte a las proposiciones falibles en una «base» para una política dura. Desde esta perspectiva propone un nuevo criterio de demarcación: sólo son científicas aquellas teorías (esto es, aquellas proposiciones no «observacionales») que prohíben ciertos acontecimientos observables y que por ello pueden ser «falsadas» y rechazadas; o dicho de forma más breve, una teoría es «científica» (o "aceptable») si tiene una «base empírica». Este criterio pone de relieve la diferencia entre el falsacionismo dogmático y el metodológico (ibíd. pp. 37-38; cursivas del original).

Mientras que para el falsacionismo dogmático los falsadores potenciales son enunciados verificables empíricamente, el falsacionista metodológico ingenuo admite que tales enunciados son el resultado de una convención y que sólo después de tal decisión convencional pueden ser utilizados para refutar.

A pesar de que, para nuestro autor este criterio de demarcación es "mucho más liberal" que el dogmático, este falsacionismo metodológico conserva una serie de debilidades que merecen corrección. Fundamentalmente, cree 
Lakatos, el hecho de que la historia de la ciencia muestra sucesos que deberían ser tildados de irracionales si se los observara a la luz de esta metodología:

Según estos criterios los científicos a menudo parecen actuar con una lentitud irracional; por ejemplo, transcurrieron ochenta y cinco años desde la aceptación del perihelio de Mercurio como anomalía y su aceptación como falsación de la teoría de Newton a pesar de que la cláusula ceteris-paribus estaba razonablemente bien corroborada. Por otra parte, en ciertas ocasiones los científicos parecen actuar con un apresuramiento irracional; por ejemplo, Galileo y sus discípulos aceptaron la mecánica celeste heliocéntrica de Copérnico a pesar de la abundante evidencia en contra de la rotación de la tierra; Bohr y sus discípulos aceptaron una teoría sobre la emisión de la luz a pesar de que contradecía a la teoría, bien corroborada, de Maxwell. (ibíd. pp. 45).

Estas dificultades llevaron a Lakatos a intentar una nueva fundamentación de la racionalidad científica, con base en la falsabilidad. Llamará a su postura "falsacionismo metodológico sofisticado".

\section{Falsacionismo metodológico sofisticado}

Hemos afirmado en el capítulo anterior que la teoría de Popper resulta en abierta contradicción con la historia real de la ciencia. Para Lakatos, esto es así porque el falsacionismo popperiano implica que:

1) una contrastación es, o se debe hacer que sea, una confrontación bilateral entre teoría y experimento, de modo que en el enfrentamiento final ellos son los únicos actores, y 2) que el único resultado interesante de tal confrontación es la falsación (concluyente): (los únicos) descubrimientos (auténticos) son refutaciones de hipótesis científicas. Sin embargo, la historia de la ciencia sugiere que 1') las contrastaciones son, como mínimo, enfrentamientos trilaterales entre teorías rivales y experimentos, y 2') algunos de los experimentos más interesantes originan, prima facie, una confirmación en lugar de una falsación. (Lakatos, 1978/1989: 45; cursivas del original).

La historia de la ciencia indica que las teorías no se descartan porque sus predicciones no se han confirmado. La idea de que una anomalía debe conducirnos a abandonar una teoría es una ingenuidad inaceptable, pues como todas las teorías engendran tarde o temprano anomalías entonces deberíamos estar dispuestos a rechazar la empresa científica en su totalidad. Lakatos 
considera que una ciencia puede verse como una empresa racional en la que coexisten simultáneamente teorías en competencia y que las refutaciones son sucesos históricos a explicar a partir de esa lucha natural ${ }^{178}$. Así, una teoría científica T puede considerar falsada si y sólo si otra teoría T' ha sido propuesta y tiene las siguientes características:

1) $T^{\prime}$ tiene un exceso de contenido empírico con relación a $T$; esto es, predice hechos nuevos, improbables o incluso excluidos por T; 2) T' explica el éxito previo de $\mathrm{T}$; esto es, todo el contenido no refutado de $\mathrm{T}$ está incluido (dentro de los límites del error observacional) en el contenido de $\mathrm{T}^{\prime}$, y 3 ) una parte del exceso de contenido de T' resulta corroborado (Lakatos, 1978/1989: 47).

Contrariando el falsacionismo ingenuo de Popper, nuestro filósofo húngaro llega a la conclusión de que
...los experimentos no destruyen simplemente a las teorías y de que ninguna teoría prohíbe unos fenómenos especificables por adelantado. No es que nosotros propongamos una teoría y la naturaleza pueda gritar NO; se trata, más bien, de que proponemos un conjunto de teorías y la naturaleza puede gritar INCONSISTENTE (Lakatos, 1978/1989: 62).

Rechazando la idea de "refutaciones instantáneas", Lakatos esboza el concepto central de su epistemología: el de "programa de investigación científica" (en adelante PIC), que podemos definir como un encadenamiento de investigaciones sucesivas realizadas por un grupo de científicos que adhieren a ciertas reglas metodológicas. Es decir, no se trata de teorías aisladas ni de científicos trabajando individualmente, como en las consideraciones de Popper; pero tampoco supone la amplitud de los paradigmas de Kuhn ni su naturaleza homogeneizante e invisibilizadora, puesto que Lakatos concibe la existencia de varios PICs en un mismo momento de una comunidad determinada ${ }^{179}$.

\footnotetext{
${ }^{178}$ Lakatos rechaza el sentido que Popper le da a los "experimentos cruciales", entendidos como sucesos dramáticos de refutación empírica. Para él serán una suerte de "título honorífico" que, por supuesto, podemos conferirle a ciertas anomalías; pero sólo mucho después del suceso y a partir de que una teoría resulte rechazada por otra (Lakatos, 1978/1989: 145).

${ }^{179}$ La discusión de Lakatos con las obras de Popper y de Kuhn debe ser leída considerando los desarrollos previos a 1974, fecha de su deceso. No puede perderse de vista que estos trabajos iban a finalizar con una extensa monografía titulada, en referencia directa a la obra de Popper, The Changing Logic of Scientic Discovery, y que todo ello quedó truncado al morir su autor. Sólo disponemos de sus primeros trabajos, como fuente de sus ideas sobre la estructura de los programas de investigación; trabajos que el propio Lakatos consideraba muy insuficientes y provisionales (Diez \& Moulines, 1997: 318).
} 
Uno de los aspectos cruciales del falsacionismo sofisticado es que sustituye el concepto de teoría, como concepto básico de la lógica de la investigación, por el concepto de serie de teorías. Lo que ha de ser evaluado como científico o pseudocientífico es una sucesión de teorías y no una teoría dada. Pero los miembros de tales series de teorías normalmente están relacionados por una notable continuidad que las agrupa en programas de investigación. Esta continuidad (reminiscente de la «ciencia normal» de Kuhn) juega un papel vital en la historia de la ciencia; los principales problemas de la lógica de la investigación sólo pueden analizarse de forma satisfactoria en el marco suministrado por una metodología de los programas de investigación. (Lakatos, 1978/1989: 65; cursivas del original).

Esta conceptualización lakatosiana es una descripción histórica pero que tiene implicancias normativas puesto que la competencia entre programas es una situación tan común como deseable:

La historia de la ciencia ha sido y debe ser una historia de programas de investigación que compiten (o si se prefiere, de "paradigmas»), pero no ha sido ni debe convertirse en una sucesión de períodos de ciencia normal; cuanto antes comience la competencia tanto mejor para el progreso. El «pluralismo teórico» es mejor que el «monismo teórico»; sobre este tema Popper y Feyerabend tienen razón y Kuhn está equivocado. (Lakatos, 1978/1989: 92; cursivas del original).

En base a estas consideraciones nuestro autor va a redefinir el criterio de demarcación:

Se puede decir que es científica o no científica una serie de teorías, y no una teoría aislada: aplicar el término "científica» a una teoría única equivale a equivocar las categorías.

Durante mucho tiempo el requisito empírico de una teoría satisfactoria era la correspondencia con los hechos observados. Nuestro requisito empírico, para una serie de teorías, es que produzca nuevos hechos. La idea de crecimiento y la noción de carácter empírico quedan soldadas en una. (Lakatos, 1978/1989: 50; cursivas del autor).

Más adelante veremos cómo, según este criterio, no parece haber ningún problema en adjetivar de científicos a los desarrollos de Freud. 


\title{
IV. Estructura de los programas de investigación
}

Lakatos postula una estructura precisa de los PIC, a partir de la distinción de dos componentes principales: el "núcleo duro" y el "cinturón protector". El primero es lo que le confiere unidad e identidad, es el conjunto de hipótesis fundamentales que se declaran irrefutables por decisión metodológica de la comunidad de científicos adheridos al PIC. Mientras que para Popper eran los enunciados singulares de la base empírica lo que debía volverse irrefutable por convención, Lakatos entiende que los científicos a menudo extienden ese convencionalismo a conjeturas que trascienden lo observacional, declarándolas inatacables ${ }^{180}$. El segundo componente consiste en el conjunto de hipótesis auxiliares que se utilizan para "proteger" al núcleo duro de la falsación. Este cinturón protector sí resulta expuesto a la crítica empírica y resulta constantemente modificado en la evolución de un PIC.

\section{Diacronía de los programas de investigación}

Lakatos considera además que existen al menos dos reglas metodológicas que los científicos respetan en el curso de sus investigaciones: las denomina heurística negativa y heurística positiva:

\begin{abstract}
La heurística negativa especifica el núcleo firme del programa que es «irrefutable» por decisión metodológica de sus defensores; la heurística positiva consiste de un conjunto, parcialmente estructurado, de sugerencias o pistas sobre cómo cambiar y desarrollar las «versiones refutables» del programa de investigación, sobre cómo modificar y complicar el cinturón protector «refutable». (Lakatos, 1978/1989: 68-
\end{abstract} $69)$.

Es decir, la heurística negativa consiste en el evitamiento de modificar el núcleo central de un PIC; por lo que todo problema deberá resolverse exclusivamente en el cinturón protector. Pero también implica la delimitación de aspectos que no tiene sentido indagar. En cambio la heurística positiva establece cómo debe

\footnotetext{
180 Ejemplos de núcleo duro podrían ser: en los desarrollos de Claudio Ptolomeo las afirmaciones relativas a la centralidad de la Tierra y su inmovilidad, la división en dos mundos, la necesidad de movimientos celestes perfectos (circulares y constantes), etc. Contrariamente, en el PIC copernicano el núcleo duro aparece constituido por la movilidad de la Tierra y la centralidad e inmovilidad del Sol. En la teorización newtoniana el núcleo parece constituido por las tres leyes de la mecánica y la ley de gravitación. En el materialismo histórico de Karl Marx el núcleo contiene sin dudas la hipótesis de que toda modificación social sólo puede ser explicada por la lucha de clases. Enseguida veremos qué conjeturas aparecen "intocables" en el caso del psicoanálisis de Freud.
} 
evolucionar el cinturón protector para mejorar el PIC: qué instrumental debe desarrollarse, qué modelos conviene complejizar, qué observaciones deben efectuarse, etc. ${ }^{181}$

Lakatos afirma que la aplicación de esta metodología es lo que hace evolucionar a un PIC, a partir de la sucesión de teorías emparentadas por un mismo núcleo en común. Esto no resulta siempre de la misma manera, por lo que nuestro autor establece dos tipos de evolución, conforme a su éxito: programas progresivos y programas regresivos:

\begin{abstract}
Un programa de investigación se dice que es progresivo mientras su desarrollo teórico anticipa su desarrollo empírico, esto es, mientras continúe prediciendo nuevos hechos con cierto éxito ('problemática progresiva'); está estancado si su desarrollo teórico queda rezagado respecto a su desarrollo empírico, esto es, cuando sólo aduce explicaciones post-hoc, o bien sólo proporciona descubrimientos por casualidad, o predice hechos anticipados por y descubiertos en un programa rival, ('problemática estancada') ${ }^{182}$. Si un programa de investigación explica de modo progresivo más que otro rival, el primero 'reemplaza' al segundo, y el programa rival puede eliminarse (o si se prefiere, 'archivarse' indefinidamente. (Lakatos, 1971/1987: 28; cursivas del autor).
\end{abstract}

Lakatos especifica que un PIC es teóricamente progresivo cuando las modificaciones introducidas para proteger el núcleo duro no son ad hoc (es decir que son contrastables independientemente) y es empíricamente progresivo cuando alguna de tales modificaciones teóricas queda corroborada empíricamente. Contrariamente, es teóricamente regresivo cuando los cambios en el cinturón protector, efectuados para salvar al núcleo, son ad hoc. Y es empíricamente regresivo cuando ninguna de las nuevas predicciones resulta confirmada.

Como puede notarse, además de las variables descriptas, la tipología del desarrollo de los PICs responde a un criterio relativo: sólo puede decirse que un $\mathrm{PIC}$ es progresivo o regresivo en comparación con un PIC rival. Sin

\footnotetext{
${ }^{181}$ Aunque se trata de unidades de análisis diferentes, podemos ver cierta similitud entre estas tareas y las efectuadas por la comunidad científica en los períodos de ciencia normal de Kuhn: allí se resuelven problemas sin cuestionar la legitimidad del paradigma (Kuhn, 1962/2004).

${ }^{182}$ El propio Lakatos intercala una nota al pie en esta parte: "En realidad, defino un programa de investigación como estancado incluso si anticipa, hechos nuevos, pero lo hace según un desarrollo fragmentario, más que por medio de una heurística positiva, previamente planificada y coherente" (ibíd.).
} 
embargo, no hay en la teoría lakatosiana pretensiones de establecer un criterio aritmético de sustitución de PICs: si bien nuestro autor considera que es preferible, en virtud de tales criterios, un programa progresivo a uno regresivo, también considera la posibilidad de que un PIC regresivo se torne progresivo (pasaron veintiún siglos antes de que Copérnico desenterrara el programa de Aristarco de Samos y lo tornara progresivo, por ejemplo). Es decir que Lakatos no considera irracional continuar trabajando en un PIC regresivo con la expectativa de revertir su situación.

El propio Lakatos reconoce que "estas consideraciones acentúan la importancia de la tolerancia metodológica" (Lakatos, 1978/1989: 95); y nosotros podemos reconocer que esta idea supone una flexibilización del criterio popperiano $^{183}$. No debemos olvidar que la propuesta de Lakatos pretende servir de guía al historiador antes que al científico:

\begin{abstract}
...defiendo que la filosofía de la ciencia fundamentalmente constituye una guía para el historiador de la ciencia más bien que para el científico. Puesto que creo que las filosofías de la racionalidad van retrasadas con relación a la racionalidad científica incluso en la actualidad, me parece difícil compartir el optimismo de Popper de que una mejor filosofía de la ciencia será una ayuda considerable para los científicos... (Lakatos, 1978/1989: 199).
\end{abstract}

En el tercer capítulo hemos expuesto, en el contexto de las objeciones a Popper, algunas ideas lakatosianas sobre la metodología científica que no tiene sentido repetir aquí. No podemos dejar de recordar, sin embargo, el valor dado por la perspectiva de Lakatos a la práctica científica, es decir al comportamiento de los investigadores en el trabajo real, a partir del análisis de casos históricos concretos.

Con su perspectiva, Lakatos arremete contra el falsacionismo ingenuo y su indicación de eliminar aquellas teorías que han sido refutadas por la experiencia; pero también se opone a la irracionalidad de la diacronía kuhniana, modelizada como cambios gestálticos a expensas de la lógica:

\footnotetext{
${ }^{183}$ En el capítulo anterior vimos por qué la lógica no aporta algoritmos decisionales ante las contrastaciones empíricas que resultan desfavorables. Podemos aquí ver cómo, tanto la actitud recomendada por Popper y la actitud propuesta por Lakatos, parecieran mostrarnos el peso de un componente valorativo que excede la pretendida (por muchos) neutralidad metodológica.
} 
En contra de Popper, la metodología de los programas de investigación científica no ofrece una racionalidad instantánea. Hay que tratar con benevolencia a los programas en desarrollo; pueden transcurrir décadas antes de que los programas despeguen del suelo y se hagan empíricamente progresivos. La crítica no es un arma popperiana que mate con rapidez mediante la refutación. Las críticas importantes son siempre constructivas; no hay refutaciones sin una teoría mejor. Kuhn se equivoca al pensar que las revoluciones científicas son un cambio repentino e irracional de punto de vista. La historia de la ciencia refuta tanto a Popper como a Kuhn; cuando son examinados de cerca, resulta que tanto los experimentos cruciales popperianos como las revoluciones de Kuhn son mitos; lo que sucede normalmente es que los programas de investigación progresivos sustituyen a los regresivos (Lakatos, 1978/1989: 16).

Podemos decir que la perspectiva diacrónica de la ciencia de Lakatos supone dos tipos de movimiento: por un lado el dinamismo del cinturón protector al interior de un PIC determinado, que origina sucesivas teorías emparentadas por el mismo núcleo duro. Por otro lado, hay también un dinamismo externo, propio de las comunidades científicas que deciden sobre la utilización o abandono de un PIC en un momento determinado: "...las revoluciones científicas consisten en que un programa de investigación reemplaza (supera progresivamente) a otro" (Lakatos, 1978/1989: 144).

\section{El papel de las historias}

Lakatos reconoce la valorización de la historia efectuada por Kuhn y la necesidad de adoptar categorías de análisis filosófico para reconstruir el pasado. Parafraseando a Kant, afirma: "la filosofía de la ciencia sin la historia de la ciencia es vacía; la historia de la ciencia sin la filosofía de la ciencia es ciega" (Lakatos, 1978/1989: 134). En virtud de ello, nuestro autor diferencia "dos tipos de historia": la historia interna y la historia externa:

La «historia interna» se define normalmente como la historia intelectual; la «historia externa», como la historia social. Mi nueva demarcación, no ortodoxa, entre la historia «interna» y «externa», constituye un cambio importante del problema y puede parecer dogmática. Pero mis definiciones forman el núcleo firme de un programa de investigación historiográfico; su evaluación forma parte de la evaluación de la fertilidad de todo el programa. (Lakatos, 1978/1989: 135, nota 1). 
La "historia interna" lakatosiana se refiere a aquellas variables que en una disciplina determinada se declaran pertinentes para el análisis de cuestiones metodológicas (aspectos lógicos, matemáticos, empíricos, etc.). Nuestro autor considera que éste tipo de análisis debe ser central en la tarea del epistemólogo que quiere comprender cambios en la historia de los PICs. Pero también existen, reconoce Lakatos, factores extra-epistémicos que inciden en la evolución de los PICs: la "historia externa" (aspectos psicológicos, sociológicos, etc.).

\title{
Ahora bien, según Lakatos
}

\begin{abstract}
La metodología de los programas de investigación - como cualquier otra teoría de la racionalidad científica - debe ser complementada por la historia empíricaexterna. Ninguna teoría de la racionalidad resolverá jamás problemas como el de por qué la genética mendeliana desapareció de la Rusia soviética en 1950, o por qué ciertas escuelas de investigación genética de las diferencias raciales o de investigación económica de ayuda al exterior cayeron en desgracia en los países anglosajones en 1960. Sin embargo, para explicar los diferentes ritmos de desarrollo de distintos programas de investigación, podemos vernos precisados a invocar la historia externa. La reconstrucción racional de la ciencia (en el sentido en que yo uso el término) no puede ser comprehensiva, puesto que los seres humanos no son totalmente racionales; e incluso cuando actúan racionalmente, pueden tener una concepción falsa de sus propias acciones racionales. (Lakatos, 1971/1987: 32).
\end{abstract}

Lakatos examina cuatro teorías sobre la racionalidad del progreso científico, considerándolas programas de investigación historiográficos (inductivismo, convencionalismo, falsacionismo ingenuo y falsacionismo sofisticado ${ }^{184}$ ) y concluye que la delimitación entre historia interna e historia externa es relativa a cada uno de estos programas y que no puede establecerse a priori. Considera que su propuesta historiográfica supone, en comparación con las otras, una ampliación significativa de la historia interna; esto es así porque la

\footnotetext{
184 "La historia interna de los inductivistas consta de supuestos descubrimientos de hechos firmes y de las llamadas generalizaciones inductivas. La historia interna de los convencionalistas consta de descubrimientos factuales, de la construcción de sistemas de casillas y su sustitución por otros sistemas supuestamente más simples. La historia interna de los falsacionistas expone conjeturas audaces, anticipos que, se dice, constituyen siempre un aumento de contenido y, sobre todo nos presenta 'experimentos cruciales negativos' victoriosos. La metodología de programas de investigación, por último, enfatiza la rivalidad prolongada, teórica y empírica, de programas mayores de investigación, problemáticas estancadas y progresivas, y la victoria, lentamente conseguida, de un programa sobre otro" (Lakatos, 1971/1987: 38).
} 
metodología de los PICs permite explicar racionalmente toda una serie de fenómenos que desde las otras metodologías constituyen aspectos irracionales y delegables a la historia externa (ibíd. pp. 35). Sin embargo, todas estas reconstrucciones normativas pueden ser completadas por teorías externas empíricas para explicar los factores residuales no-racionales, porque la historia de la ciencia es siempre más rica que su reconstrucción racional (ibíd. pp. 38).

Entonces, cuando el filósofo de la ciencia se disponga a considerar la historia interna, "será en alto grado selectivo: omitirá todo lo que sea irracional a la luz de su teoría de la racionalidad" (ibíd. pp. 40). Dicho de otra manera, "la historia de la ciencia es una historia de eventos seleccionados e interpretados de forma normativa" (ibíd. pp. 43). Lakatos supone que es esta historia interna lo fundamental en la reconstrucción racional del devenir de los PICs, mientras que la historia externa debe quedar a pie de página. Su idea es que siempre las reconstrucciones racionales comienzan por una historia interna y sólo desde allí se establecen los problemas de la historia externa.

La historia de la ciencia constituye una suerte de tribunal de apelación para la confrontación de metodologías rivales; es decir la base empírica para la contrastación de las distintas reconstrucciones racionales.

La metodología de los programas de investigación científica constituye, como cualquier otra metodología, un programa de investigación historiográfica. El historiador que acepte tal metodología como guía, buscará en la historia programas de investigación rivales, problemáticas progresivas y estancadas. (Lakatos, 1971/1987: 31).

Pues bien, eso es lo que haremos en la sección siguiente: utilizaremos el instrumental lakatosiano para reconstruir el contexto de los desarrollos freudianos.

Pero antes, conviene que reseñemos mínimamente algunas de las principales objeciones que se le han hecho a la propuesta de Lakatos.

\section{Algunos aspectos críticos del falsacionismo sofisticado}

Además de amigo, Paul Feyerabend ha sido posiblemente el mayor adversario intelectual de Lakatos. A su modo de ver los estándares lakatosianos son vanos porque no fijan un límite temporal para abandonar un PIC; y es por ello que los considera meros "ornamentos verbales", "en memoria 
de tiempos más felices en los que todavía se pensaba que era posible llevar una empresa tan compleja y a menudo catastrófica como la ciencia siguiendo unas cuantas reglas simples y 'racionales'” (Feyerabend, 1970/1975: 366).

Lakatos insistió en que no corresponde al filósofo de la ciencia recomendar al científico decisiones sobre su investigación, y denunció que Feyerabend confunde la evaluación metodológica de un programa con su heurística firme (que señala lo que hay que hacer). Para nuestro autor nada impide que un científico continúe trabajando en un PIC degenerativo con la esperanza de volverlo progresivo: "es perfectamente racional jugar con riesgo: lo que es irracional es engañarse a sí mismo sobre tal riesgo" (Lakatos, 1971/1987: 36).

Pero Feyerabend no parece haber comprendido este punto, pues continuó afirmando que la teoría de la racionalidad de Lakatos evidencia la inexistencia de criterios sobre cómo han de proceder los científicos, acercándose así a su propia teoría anarquista:

\begin{abstract}
Al considerar un programa de investigación que se encuentre en estado avanzado de degeneración, se sentirá la necesidad urgente de abandonarlo y sustituirlo por un programa rival más progresivo. Este es un paso completamente legítimo. Sin embargo, también es legítimo hacer lo opuesto y conservar el programa, pues cualquier intento de exigir su eliminación sobre la base de una regla puede criticarse con argumentos casi idénticos a los argumentos que conducen en primer lugar a la 'defensa de un período de respiro': si es imprudente rechazar teorías defectuosas en el momento de su nacimiento porque podrían desarrollarse y mejorarse, entonces también es imprudente rechazar programas de investigación que vayan cuesta abajo porque podrían recuperarse y conseguir un esplendor insospechado (la mariposa sale cuando la oruga ha alcanzado su estado más bajo de degradación). En consecuencia, no se puede criticar racionalmente a un científico que se adhiere a programa degenerativo y no hay forma racional de demostrar que sus actos son irrazonables. (Feyerabend, 1975/1986: 172; cursivas del autor).
\end{abstract}

También sostuvo que Lakatos empleaba una noción de racionalidad que variaba según el contexto de la argumentación; ello le permitía disponer de criterios liberales y aplicarlos de modo conservador, pretendiendo "que se le considere racionalista en ambos casos" (ibíd. pp. 189).

Kuhn, por su parte, ha criticado algunos aspectos puntuales, como por ejemplo la diferenciación lakatosiana entre "historias". Reconoce que la 
distinción interno-externo no es firme ni segura, que existe un amplio consenso entre los historiadores respecto a su aplicación; y es por ello que pareciera volverse trivial la explicitación lakatosiana. Pero además, afirma Kuhn, la utilización que hace Lakatos violenta el uso general, pues su "historia interna" es mucho más restringida que la del historiador: excluye la idiosincrasia personal del investigador, lo relativo al acto de creación teórica, la percepción que el científico y las generaciones siguientes tienen de los aciertos y de los errores, etc.:

\footnotetext{
Puesto que Lakatos insiste en excluirlos de la historia interna, yo me pregunto por qué razón adopta el término. ¿No podría fácilmente, en su lugar, haber hablado de historia racional, o mejor, de historia construida con los elementos racionales del desarrollo de una ciencia? Creo que esto es lo que fundamentalmente quiere decir 'interno' en el sentido de Lakatos y en este contexto equivale estrechamente a 'racional' en el sentido ordinario (Kuhn, 1971/1987: 86-87).
}

Kuhn sostiene que Lakatos se excede con sus consideraciones sobre cómo el historiador selecciona los hechos desde su preconcepción filosófica, puesto que subordinar netamente la teorización histórica a la filosofía contradice la posibilidad de que la historia funcione como base empírica de contrastación:

\footnotetext{
si 'historia interna' es simplemente la parte racional de la historia, entonces el filósofo sólo puede aprender de ella, por lo que a método científico se refiere, lo que previamente introduzca. El método meta-metodológico de Lakatos está en peligro de quedar reducido a una tautología. (ibíd. pp. 87).
}

Kuhn considera que "la historia ha de ser construida sin violentar los datos disponibles por causa de la selección e interpretación" pues sólo así "las conclusiones de la investigación histórica podrán contradecir y cambiar la posición filosófica con la que el historiador empezara" (ibíd. pp. 89). Sin embargo, Lakatos pareciera tener en mente estas dificultades cuando propone distinguir niveles en los que pueden concebirse los PICs: los programas de investigación que utilizan los científicos pueden así diferenciarse de los programas de investigación historiográfica que utilizan los filósofos e historiadores. En este segundo caso, se trata de distintas teorías de la racionalidad científica que compiten entre sí bajo similares reglas de juego. Para nuestro autor 
Incluso la ciencia en su conjunto puede ser considerada como un enorme programa de investigación dotado de la suprema regla heurística de Popper: «diseña conjeturas que tengan más contenido empírico que sus predecesoras». Como señaló Popper, tales reglas metodológicas pueden ser formuladas como principios metafísicos (Lakatos, 1978/1989: 65) ${ }^{185}$.

Otro crítico célebre ha sido Newton-Smith, quien denuncia cierta oscilación de Lakatos entre el realismo heredado de Popper y una suerte de convencionalismo. Así, mientras que por un lado hace afirmaciones sobre la corroboración y la verosimilitud, por otro lado pareciera evitar comprometerse con la teoría correspondentista de la verdad (Newton-Smith, 1981/1987: 112116). Pero Newton-Smith también critica la vaguedad de los criterios lakatosianos para identificar PICs concretos o sus componentes, incluso para identificar programas pseudocientíficos. Particularmente, sostiene que lo descripto en términos de "heurística positiva" no concuerda con la historia de la ciencia, porque las teorías exitosas no suelen anticipar y digerir las anomalías:

Las respuestas a las anomalías -ya empíricas, ya conceptuales- son posteriores a su descubrimiento. $\mathrm{Y}$ así tiene que ser. Pues formular ahora cuál sería nuestra respuesta a anomalías totalmente hipotéticas constituiría el uso más ineficaz posible de nuestros recursos intelectuales. (Newton-Smith, 1981/1987: 99).

Asimismo, la idea de que es preferible un PIC que predice más hechos nuevos (parte de los cuales resultan corroborados) constituye una sobrevaloración de las predicciones y de los aspectos empíricos en general, cuando en la historia de las ciencias se puede ver que gran parte de las discusiones entre programas rivales son de tipo conceptual, relativas al significado e inteligibilidad; "y cualquier modelo de ciencia ha de dejar espacio para la valoración diferencial de teorías en función de su capacidad para predecir hechos nuevos y explicar hechos conocidos"186 (ibíd. pp. 104).

lan Hacking considera que Lakatos se formó en una tradición que desestimaba la teoría correspondentista de la verdad, emparentándose con

\footnotetext{
185 Por nuestra parte, nos expediremos sobre la distinción interno-externo en el siguiente capítulo y a partir de la reconstrucción de un episodio histórico en la teoría de Freud.

${ }^{186}$ Newton-Smith no deja de reconocer que "la noción que Lakatos tiene de una heurística, a pesar de sus problemas, nos llama la atención sobre aspectos importantes de la práctica científica, que Popper no ha subrayado de manera adecuada" (ibíd. pp. 114).
} 
autores como Charles Peirce. Ambos "intentaron buscar un sustituto de la verdad. Siendo de tradición hegeliana, decían que este sustituto yace en el proceso, en la naturaleza del crecimiento del conocimiento mismo" (Hacking, 1983/1996: 138). Para Lakatos, al igual que para Hilary Putnam, pareciera que "la verdad es aquello que sea racional creer" (ibíd. pp. 144). Según Hacking, el hegelianismo oculto de Lakatos se atisba bien en sus consideraciones sobre la historia. Su historia interna es "la historia del conocimiento enajenado hegeliano, la historia de los programas de investigación anónimos y autónomos" (ibíd. pp. 148); es algo que pareciera homologable al tercer mundo de Popper, entendido como el lugar de los productos del conocimiento humano. De este modo, según Hacking, la caracterización del aumento del conocimiento mediante la metodología de los PIC deriva en una caracterización de la racionalidad que soslaya la verosimilitud; lo cual es visto como un obstáculo para los adeptos del realismo científico (como Hacking).

Pero Hacking también le critica a Lakatos que éste sólo ofrece una visión de la ciencia en clave retrospectiva:

no nos ayuda para nada a la hora de decidir qué es razonable creer o hacer ahora. Está totalmente dirigida hacia atrás. Nos puede decir qué decisiones en la ciencia del pasado fueron racionales, pero no nos ayuda con el futuro. (Hacking, 1983/1996: 137).

Puesto que la metodología de los PICs sólo permite identificar casos de auténtico desarrollo del conocimiento, pareciera estar en desventaja respecto a otras propuestas: "Carnap y Popper trataron de darnos un concepto de «buena razón» o sustituto de ella que pudiésemos emplear ahora al evaluar hipótesis, con el objeto de emplearlas en el futuro inmediato" (Hacking, 1981/1985: 250251). Hay que decir que esta crítica de Hacking no parece considerar el rechazo lakatosiano de una racionalidad instantánea, ni tampoco repara en que podemos dudar seriamente de la bondad de (al menos) la racionalidad popperiana. Además, considerando que la teorización lakatosiana pretende servir de guía al historiador antes que al científico, la ausencia de criterios prospectivos no necesariamente debería suponer un problema.

Estas breves consideraciones críticas sobre la propuesta de Lakatos no inhiben la progresividad de sus aportes a la Filosofía de la Ciencia, 
fundamentalmente en lo que refiere al papel desempeñado por la historia en la construcción del conocimiento. Lakatos ha logrado enriquecer el debate epistemológico, ofreciendo un modelo de cambio teórico que evita tanto el escepticismo como el justificacionismo, a la vez que rescata la racionalidad de todo procedimiento basado en el ensayo y el error.

La anterior exposición de la metodología de los programas de investigación (junto con algunas críticas recibidas) ha sido apenas una introducción, pero con ello nos basta para lograr nuestro siguiente propósito: presentar las elaboraciones freudianas como un programa de investigación lakatosiano.

\section{El programa psicoanalítico de Freud}

Comenzaremos recordando que el propio Lakatos sostuvo, un poco antes de su muerte, que los desarrollos de Freud podían considerarse un PIC:

\footnotetext{
la teoría de la gravitación de Newton, la teoría de la relatividad de Einstein, la mecánica cuántica, el marxismo, el freudianismo son todos programas de investigación dotados cada uno de ellos de un cinturón protector flexible, de un núcleo firme característico pertinazmente defendido, y de una elaborada maquinaria para la solución de problemas. Todos ellos, en cualquier etapa de su desarrollo, tienen problemas no solucionados y anomalías no asimiladas. En este sentido todas las teorías nacen refutadas y mueren refutadas (Lakatos, 1978/1989: 14).
}

Según el filósofo húngaro, el historiador que adopte su perspectiva metametodológica se orientará por el afán de hallar programas de investigación rivales en la historia de la ciencia. De ese modo, podrá reconstruir, correlativamente, los estancamientos de uno y las progresiones de otro, las predicciones acertadas y la adhocidad compensadora, etc. Es decir, dos o más cuerpos de ideas en pugna por imponerse al interior de un campo disciplinar.

\section{a) Surgimiento del programa freudiano}

Según Argañaráz (2007: 15-58), el programa psicoanalítico puede ser comprendido a partir de su relación con al menos otros cuatro programas de 
investigación existentes en el ámbito $\mathrm{Psi}^{187}$ alrededor de 1900: el programa neuropsicológico (a partir de Bayle, Meynert y Wernicke), el programa científico espiritual (iniciado con Jaspers), el programa conductista (Watson) y el programa clínico (que iría desde algunos como Pinel y J. P. Falret hasta otros como Kahlbaum, Krafft-Ebing y Charcot).

Retomamos así la tesis de Argañaráz sobre la filiación freudiana en el origen:

\begin{abstract}
Como caso del científico que se ve precisado a desarrollar otro programa para demostrar sus límites, Lakatos da el ejemplo del desarrollo de la teoría de los vórtices por Newton para demostrar su incompatibilidad con Kepler. Freud es otro ejemplo de trabajo en dos programas simultáneamente. Habiendo desarrollado al máximo las posibilidades del modelo neuropsicológico Freud lo abandona ${ }^{188}$ (Argañaráz, 2007: 43; cursivas del autor).
\end{abstract}

Aunque en sus inicios Freud participó del programa neuropsicológico (desarrollándolo al máximo en su Proyecto de psicología) y luego del programa clínico (junto a Breuer), las insuficiencias que ambos mostraban para con la problemática de la histeria, lo condujeron a establecer un nuevo programa de investigación. En ese sentido, desde el inicio, las vicisitudes de los procedimientos freudianos de investigación distan mucho de lo que Popper habría supuesto: por empezar, el tipo de problemas que Freud hereda le hace trascender (debido a su estancamiento) las respuestas anómalas de los programas en los que participó originalmente, hasta el punto de elaborar un programa nuevo y desde allí establecer una agenda de problemas y respuestas sui generis. En segundo lugar, la forma de someter a prueba las respuestas a tales problemas debe entenderse en el marco de ese esfuerzo por aventajar a los demás programas y posicionarse institucionalmente. Resulta evidente que

\footnotetext{
${ }^{187}$ La expresión "ámbito Psi" o "campo Psi" suele ser utilizada para referir a un espacio cercado por teorías y prácticas de la psiquiatría, psicopatología y psicología, a las que vino a sumarse el psicoanálisis una vez constituido. Para un análisis crítico de la construcción de este campo y sus mitos historiográficos de origen, véase la clásica conferencia de Canguilhem (1956/1994) y también los trabajos de Klappenbach (1994) y Vezzetti (1998).

${ }^{188}$ Coincidimos con Lakatos en que "el trabajo simultáneo en programas rivales, ciertamente, socava la tesis de Kuhn sobre la inconmensurabilidad de paradigmas rivales". (Lakatos, 1971/1987: 29); y también con Argañaráz en que otras reconstrucciones históricas parecieran desconcertadas ante este hecho, por ejemplo la de Assoun y su idea de un "barroco epistemológico" en Freud.
} 
fue la progresividad temprana del PIC psicoanalítico lo que llevó a Freud a dedicarse por completo a él, abandonando los anteriores. Recuérdese que "en la metodología de los programas de investigación, el significado pragmático de «rechazo» (de un programa) resulta absolutamente claro: significa la decisión de dejar de trabajar en él" (Lakatos, 1978/1989: 95). Ese rechazo freudiano coincide con lo que Lakatos entiende que sucede en la historia de las ciencias:

El progreso de un programa es un hecho vital para la degeneración de su rival. Si el programa $\mathrm{P}_{1}$ produce constantemente hechos nuevos, estos serán, por definición, anomalías con respecto al programa rival $\mathrm{P}_{2}$. Si $\mathrm{P}_{2}$ explica estos hechos nuevos sólo de una forma ad hoc, este programa está degenerando por definición. Así, cuanto más progrese $\mathrm{P}_{1}$, tanto más difícil es que progrese $\mathrm{P}_{2}$. (Lakatos, 1978/1989: 147, nota 37).

\section{b) Identificación de algunos elementos del programa freudiano}

Los principales elementos del núcleo duro del programa psicoanalítico ya desarrollado, pueden cercarse a partir de los fundamentos de la metapsicología; es decir el triple punto de vista tópico, dinámico y económico. Se trata de algunas conjeturas generales que, por una decisión metodológica, fueron consolidándose como puntos de partida irrefutables para Freud: a) lo inconciente es un sistema localizado en el aparato psíquico; b) el psiquismo es el escenario de fuerzas en conflicto; c) que se expresan en formaciones de compromiso y d) son susceptibles de análisis; etc. ${ }^{189}$.

Debemos tener en cuenta que el establecimiento del núcleo de un PIC no es un proceso repentino: "el auténtico centro firme del programa realmente no nace ya dotado de toda su fuerza como Atenea de la cabeza de Zeus. Se desarrolla lentamente mediante un proceso largo, preliminar, de ensayos y errores." (Lakatos, 1978/1989: 67, nota 161). En base a ello, pareciera plausible intentar cercar elementos nucleares en diversos momentos de la gestación de un PIC. En nuestro caso, si quisiéramos ubicar el germen de la originalidad freudiana en los albores del programa, deberíamos considerar los

\footnotetext{
${ }^{189}$ Coincidimos con Newton-Smith cuando afirma que "no contamos con principio explícito alguno que nos oriente en la identificación del núcleo central en el seno de la retícula de creencias de la comunidad científica sobre un tema dado" (Newton-Smith, 1981/1987: 97), situación que habilita tanto la posibilidad de realizar diversas reconstrucciones como de volver a revisarlas.
} 
puntos de quiebre significativos para con algunos consensos programáticos de la época, que habían decantado en estancamientos. El propio Freud sitúa dos esquemas explicativos, inherentes a la etiología de la histeria: uno estaba originado en torno a las ideas de Pierre Janet (discípulo de Charcot) y el otro postulado por Josef Breuer.

Janet había planteado en 1892 la existencia de predisposiciones neuropáticas hereditarias y explicaba la naturaleza de los fenómenos histéricos a partir de una disociación y estrechamiento de la conciencia del enfermo, causada por una degeneración para la síntesis psíquica. De allí se seguía una terapéutica disciplinaria basada en la sugestión y tendiente a restituir la descomposición del yo del paciente ${ }^{190}$.

Breuer, apartándose de Janet, conjeturaba la existencia de unos "estados hipnoides" como base y condición de la histeria. Se trataba de estados contingentes y anormales de conciencia en los que se generaban las representaciones patógenas causantes de los síntomas; representaciones muy intensas pero cuyo comercio asociativo con el resto de la conciencia aparecía después bloqueado (cf. Freud y Breuer, 1895/2004: 37-38).

El programa de Freud nace diferenciándose de ambas posturas: considerando a la escisión de la conciencia como un movimiento secundario, introducirá la tesis de que dicha escisión es producto de un acto voluntario de defensa psíquica. Esta "defensa", entonces, no es efecto ni de una degeneración constitucional (Janet) ni de un estado de conciencia fortuitamente adquirido (Breuer), sino de un modo de reacción psíquico que se realiza a raíz del contenido displacentero de tales representaciones y a expensas del conocimiento del sujeto. Una vez en estado inconsciente, tales representaciones adquieren una intensidad desmesurada que determina los síntomas $^{191}$. El tratamiento de la histeria consistía, por esta época, en la

\footnotetext{
190 "El psicoanálisis se encontró pronto en aguda oposición con las concepciones de Janet, debido a que: a) se negaba a reconducir directamente la histeria a la degeneración hereditaria congénita; b) ofrecía, en vez de una mera descripción, una explicación dinámica basada en la interacción de las fuerzas anímicas, y c) atribuía el origen de la disociación anímica (cuya importancia también Janet había reconocido), no a una falla de la síntesis psíquica, resultante de una afección congénita, sino a un especial proceso anímico conocido como "represión»" (Freud, 1913b/2004: 211).
}

191 Esta noción de "defensa", aunque ya había sido establecida en 1893 en la Comunicación preliminar, aparece claramente estipulada en Las neuropsicosis de defensa (Freud, 1894/2004: 49). Conviene recordar que esta hipótesis etiológica no tiene en esta época la universalidad 
rememoración de las representaciones inconciliables para abreaccionar el exceso de afecto.

Elucidar el núcleo de conjeturas que Freud adoptó y mantuvo casi sin modificación durante el desarrollo de sus ideas, no debería llevarnos a pensar que tales ideas puedan definir al psicoanálisis en su totalidad ni que hayan sido adoptadas por todo programa que se pretenda psicoanalítico ${ }^{192}$. Coincidimos con Lakatos en su valoración de este tipo de conjeturas:

Según mi posición, es probable que todos los centros firmes de los programas científicos sean falsos $y$, en consecuencia, sólo sirven en cuanto ideaciones fuertemente imaginativas para incrementar nuestro conocimiento del universo ${ }^{193}$ (Lakatos, 1971/1987: 146).

Es decir, son una serie de hipótesis generales que, independientemente de su grado o tipo de veracidad, posibilitan una nueva conceptualización de los fenómenos del ámbito en cuestión, orientando la elección de los problemas y respuestas posibles.

En lo que respecta al cinturón protector, coincidimos con Argañaráz en que allí puede ubicarse un primer cordón de teorías auxiliares cuya heurística positiva se mostró rápidamente progresiva: las leyes relativas a los procesos primario y secundario del aparato psíquico, que permitieron investigar una gran variedad de fenómenos clínicos, ya sean disfuncionamientos psicopatológicos (síntomas histéricos, obsesivos, fóbicos, etc.) o normales (sueños, amnesias, actos fallidos, chistes, etc. $)^{194}$. La posibilidad de abordar y explicar ese abanico

que va a alcanzar posteriormente, y que aquí Freud la utiliza para explicar un subconjunto, especificado en el título mismo del artículo, de tipos psicopatológicos.

192 La historia del psicoanálisis, vista desde la perspectiva de Lakatos, puede mostrarnos la evolución del programa freudiano y de los subsiguientes programas que luego fueron emergiendo. No caben dudas de que Jacques Lacan ha dado origen a un programa distinto del freudiano. Para un excelente análisis de las diferencias (no siempre tenidas en cuenta) entre ambos programas, cf. Argañaráz (2012).

${ }^{193}$ Unas líneas más adelante agrega: "mientras prevalezca el punto de vista de que el objetivo supremo de la ciencia es la búsqueda de la verdad, se debe saber que el camino hacia la verdad pasa por teorías falsas que se mejoran continuamente. Es por ello ingenuo pensar que un paso particular forma ya parte de la verdad o pensar que alguien se encuentra en el verdadero camino" (ibíd. pp. 147)

194 "Este giro etiológico hace que el psicoanálisis se libre de las disputas ya barrocas (problemática estancada) sobre nosografía descriptiva, alterando radicalmente el eje de la discusión de los clínicos" (Argañaráz, 2007: 45). Con sus desarrollos sobre el factor infantil, el PIC freudiano reabsorbe y reformula, de manera inimaginada por la psicopatología, uno de sus 
de fenómenos psíquicos, especialmente el hecho de postular que la "normalidad" responde al mismo modelo explicativo que lo considerado patológico (evidenciando las dificultades de esta dicotomía), ha sido sin lugar a dudas uno de los principales aspectos de la progresividad del PIC freudiano.

Asimismo, en lo que a la heurística negativa respecta, podemos situar la suposición de que todo abordaje de los procesos psíquicos que prescinda del núcleo duro freudiano se topará con anomalías que el programa psicoanalítico puede resolver.

La consolidación del PIC freudiano fue paralela a un proceso de modificaciones sucesivas del cinturón protector, conforme a las heurísticas señaladas. Según Argañaráz, es posible elucidar un segundo cordón de hipótesis auxiliares en la constitución del programa, producido a partir de los nuevos observables clínicos que el método psicoanalítico permitía distinguir. Se trata del establecimiento de que las representaciones reprimidas han sufrido ese destino por su vínculo con la sexualidad del paciente. Esto supone

un paso segundo en la constitución del programa y funciona como hipótesis auxiliar progresiva respecto a las explicaciones barrocas o ad hoc de Breuer o de Janet sobre los estados hipnoides o la disociación, que explica porqué las representaciones son rechazadas de la conciencia y el paciente no acepta tramitadas por la vía de elaboración consciente.

Es decir que en la comunidad científica de la época - en la primera mitad del siglo $X X$ - el Psicoanálisis sustituye con su discusión sobre Psicología, etiología y terapéutica, a la influencia del programa clínico estancado en discusiones nosográficas. Ese estancamiento hace que a partir de 1913 Jaspers o Watson compitan con el Psicoanálisis pero ya centrados de lleno en teorías psicológicas, clausurando gran parte de la riqueza del programa clínico, descripción, evolución, clasificación, que se había negado a discutir eso. [...] Pero, fundamentalmente, sustituye ese pragmatismo terapéutico que usaba alternativa o simultáneamente, lo que los clínicos consideraban reeducación, castigos, cambios ambientales, medios físicos y químicos; por una teoría discutible y racional que garantizaba el no retorno del filósofo, del sacerdote o del moralista en el tratamiento psíquico de los pacientes (Argañaráz, 2007: 49-50).

En términos generales, diremos que la racionalidad lograda con el programa freudiano al interior del campo Psi, venía a llenar un hueco explicativo en una

principales postulados del programa clínico: el principio de evolución de la enfermedad y su abordaje diacrónico (ibíd.). 
vasta serie de fenómenos problemáticos ( $\mathrm{y}$ a relacionarlos originalmente con otros fenómenos hasta entonces inadvertidos). A partir de las teorizaciones de este programa emergente, la base empírica metodológica se complejizaba significativamente: el PIC freudiano suponía un dispositivo metódico original (asociación libre - atención flotante), a partir del cual se constituyeron nuevos observables clínicos (formaciones del inconciente, resistencias, transferencia) que posibilitaron la invención de diversas hipótesis etiológicas y el accionar terapéutico-investigativo del analista. La progresividad inicial del programa psicoanalítico (hacia 1915) puede explicarse a partir de tales aspectos mencionados y su reabsorción de distintos puntos de estancamiento de sus programas rivales $^{195}$.

Los esbozos anteriores están hechos a base de un trazado muy grueso: consideramos que su valor radica en que muestran la plausibilidad de reconstruir el PIC freudiano, pero una reconstrucción relativamente significativa deberá ser objeto de indagaciones ulteriores.

Para concluir este capítulo, recordaremos nuestro propósito. Si bien la finalidad de reconstruir las teorías freudianas como un programa de investigación puede ser múltiple, aquí sólo hemos manifestado su posibilidad a los fines de establecer el valor y lugar que la falsabilidad empírica ha ocupado en el proceder de Freud. Al igual que en cualquier otro conjunto de teorías sistemáticamente relacionadas, en el programa freudiano la refutabilidad empírica ocupa un lugar mucho menos preponderante que el supuesto por la filosofía de Popper. En el caso de Freud, la heurística positiva deslindada por el núcleo metapsicológico (aún antes de esa nominación ${ }^{196}$ ) impedía dirigir las falsaciones a ciertas conjeturas fundamentales. Ahora bien, ¿significa eso que el programa freudiano se sostuvo sólo en base a procedimientos

\footnotetext{
195 "[el psicoanálisis] aparte de los mencionados descubrimientos procesó abundante material que se conocía de otras fuentes: resultados de las doctrinas del gran neuropatólogo Charcot, e impresiones extraídas del mundo de los fenómenos hipnóticos" (Freud, 1925a/2004: 228; cursiva añadida).

196 El término "metapsicología" comienza a aparecer en los escritos de Freud desde Lo inconciente (Freud, 1915b/2004: 178), con excepción de una mención previa, al pasar, en Psicopatología de la vida cotidiana (Freud, 1901/2004: 251). Sin embargo, el término había sido acuñado mucho antes: en la carta a Fließ del 13 de febrero de 1896 aparece por primera vez (Freud, 1985/1986: 182). Cf. también la carta del 10 de marzo de 1898 (ibíd. pp. 329).
} 
confirmacionistas o verificacionistas? El siguiente capítulo está destinado a mostrar que no.

Aquí hemos expuesto que el espíritu de la tradición crítica en la que Freud se insertaba le hubiera impedido de cualquier modo tales pretensiones. Ahora nos resta ver cómo, aunque Popper lo ignoraba, el creador del primer PIC psicoanalítico dedicó gran parte de su tiempo a corregir las hipótesis del cinturón protector que se volvían incoherentes con cierta base empírica consensuada en la época y con su núcleo programático. Sin embargo, eso no debe llevarnos a pensar que la inducción enumerativa o la confirmación empírica hayan jugado un rol nulo en su evolución. Pero, insistimos, ese rol no es el que suponía Popper.

A los fines de abordar el conjunto de problemas en el que estamos inmersos, la meta-teoría de Lakatos pareciera ofrecer mayores posibilidades de una reconstrucción racional del proceder freudiano. Particularmente, de ciertos aspectos diacrónicos cuyo abordaje en clave kuhniana, como hemos dicho, pareciera más dificultoso. Va de suyo que la elección de esta herramienta reconstructiva y el modo en que parcialmente la estamos aplicando, no la convierte en el único modo posible de elucidar epistemológicamente la teoría freudiana ni mucho menos. Se trata de una tarea interpretativa a partir del instrumental elegido y de nuestras posibilidades de utilizarlo. 


\title{
CAPÍTULO 5: El falsacionismo sofisticado de Freud: una reconstrucción de dos ejemplos de cambio teórico
}

\begin{abstract}
"Mientras que el acuerdo relativo a un criterio universal del carácter científico de las teorías ha sido escaso, se ha dado, durante las dos últimas centurias, un considerable acuerdo sobre los logros particulares. Mientras que no ha habido acuerdo general sobre una teoría de la racionalidad científica, lo ha habido sobre si un paso particular del juego fue científico o no, o sobre si una táctica particular fue empleada correctamente o no." (Lakatos, 1971/1987: 49).
\end{abstract}

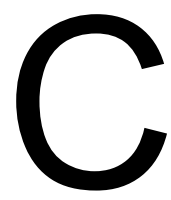
omo hemos visto, Popper piensa que la teoría de Freud se alimenta por la vía de la justificación inductiva y que así permanece inmune a la refutación empírica. Esto lo llevó a concluir que se trataba de una teoría pseudocientífica.

En contra de lo que Popper hizo, aquí mantendremos la perspectiva de que una discusión sensata del problema de la "falsabilidad de las teorizaciones de Freud" debe comenzar, antes que nada, por una revisión del criterio de falsación; y, seguido de ello, debe continuar por una prudente consideración de la teoría freudiana. Habiendo examinado en el tercer capítulo las ideas centrales de Popper y sus obstáculos principales, en este capítulo nos centraremos en la teoría de Freud: abordaremos dos ejemplos de cambio teórico acontecidos en la historia de lo que podemos llamar, inspirándonos en Lakatos, el programa de investigación freudiano.

Hemos elegido dos ejemplos de cambio teórico que se ubican en los albores de dicho programa, con la siguiente intención: al dirigir una mirada histórica a las teorizaciones de Freud, notaremos que la crítica popperiana no se sostiene. Mostraremos así, la doble omisión popperiana: por un lado que la teoría psicoanalítica conlleva, desde sus orígenes, la posibilidad de ser evaluada mediante la experiencia (y que efectivamente eso fue lo que hizo Freud). Además, mostraremos que un análisis epistemológico serio no puede 
prescindir de la complejidad de los procesos históricos que conciernen a la teoría en cuestión.

Dos interrogantes generales nos guiarán en nuestro recorrido subsiguiente: ¿puede el proceder de Freud reconstruirse como una forma de hipotéticodeductivismo?, y ¿qué papel juegan los aspectos no epistémicos en la validación de las hipótesis? Intentaremos mostrar que las razones que llevaron a Freud a realizar estos cambios teóricos, (a) obedecen a una racionalidad en la que predominan las refutaciones empíricas, pero (b) no se reducen a ellas. Aquí nuestra intención se doblega: corroborando (a) estaremos atacando el mito popperiano de la infalsabilidad de la teoría; y dando apoyo a (b) nos haremos eco de la crítica a una supuesta reconstrucción racional con base exclusiva en la historia de las contrastaciones; en virtud de lo cual intentaremos determinar el valor de la historia externa en el segundo de los ejemplos considerados. Esto último nos permitirá mostrar la inadecuación del canon popperiano para representar la evolución de sucesos históricos en toda su complejidad.

\title{
1. Las parálisis histéricas
}

\author{
"Es que en la neuropatología quedan muchísimas cosas no \\ aclaradas todavía y cuestionables, cuyo discernimiento sólo \\ se alcanzará por medio del debate" (Freud, 1892a/2004: \\ 170)
}

Hemos decidido dar cuerpo a una intuición de Gregorio Klimovsky sobre los escritos freudianos:

\begin{abstract}
Mi opinión, sin embargo, es que una manera de leer que ordene sus afirmaciones según sus nexos lógicos mostrará que aquellos se adaptan al modelo hipotético deductivo más de lo que es costumbre sospechar, evidenciando una notable claridad de pensamiento (Klimovsky, 1981/2009: 78).
\end{abstract}

Para ello, nos dispondremos a una formalización del principal razonamiento que Freud efectúa en un texto de 1893, intitulado Algunas consideraciones con miras a un estudio comparativo de las parálisis motrices orgánicas e histéricas (Freud, 1893a/2004). Este escrito, que no siempre se ha estimado en su justa 
medida, constituye no sólo un punto inaugural para el programa psicoanalítico sino también un punto de inflexión a los supuestos cartesianos que dominaban las ciencias de lo humano desde hacía varios siglos. Pero no es por tales virtudes que lo analizaremos, sino para mostrar que ya en el origen del programa freudiano prepondera una metodología crítica que se basa en la contrastabilidad empírica.

Antes de reconstruir la argumentación freudiana, conviene que situemos brevemente su importancia histórica.

\section{a) Contextualización histórica}

Cabe recordar que la histeria era, para la medicina del siglo XIX (psiquiatría y neurología), un cuadro cuya sintomatología no había encontrado aún explicaciones convincentes ${ }^{197}$. Y si tuviéramos que sintetizar al máximo la intervención de Freud en este terreno, desde una óptica kuhniana podría decirse que consistió en abordar esta anomalía (que la fenomenología de la histeria suponía para la comunidad médica) y convertirla en el ejemplar fundamental de una nueva matriz disciplinar. $\mathrm{O}$, desde la metodología de los programas de investigación, podría decirse que Freud dio origen a un nuevo PIC, cuya progresividad en lo relativo a la histeria llega hasta nuestros días. Pero veamos brevemente el contexto de esta revolución.

Desde la escuela de la Salpêtrière, el eminente neurólogo francés JeanMartin Charcot, había apostado por la fructífera extrapolación del método anátomo-patológico para el estudio de los fenómenos histéricos, con la intención de precisar síntomas típicos y diferenciales de esta entidad mórbida, poniendo fin a la idea de que la histeria es susceptible de imitar todo. Pero, el éxito que este procedimiento permitía alcanzar en otras patologías resultó ser insuficiente para el campo de la histeria y, a partir de 1878, Charcot inicia sus

\footnotetext{
${ }^{197}$ Etimológicamente, el vocablo "histeria" proviene del griego "hystera" (útero), y parece haber sido acuñado por Hipócrates $(460 \mathrm{aC}$. $-370 \mathrm{aC}$.) para designar una serie de dolencias propias de la mujer, que se manifestaban generalmente en paroxismos y que eran causadas por el movimiento del útero al interior del cuerpo. Galeno, en el marco de su teoría de los "humores", consideró a tales dolencias como el efecto de una retención de la sangre menstrual o del "semen femenino". Luego de varios siglos la histeria pasó a ser considerada una enfermedad cerebral, a partir de los trabajos de Charles Lepois (1563-1633), Thomas Willis (1621-1675) y, fundamentalmente, Thomas Sydenham (1624-1689). Para un examen detallado de la evolución de estas concepciones cf. Bercherie, 1983/1988 (en especial la primera parte: "Constitución del campo clínico histérico").
} 
estudios sobre el hipnotismo. Establece, mediante esta nueva vía de estudio, que si los síntomas histéricos pueden producirse experimentalmente por sugestión hipnótica es porque hay una conexión psicofisiológica que determina su producción en situaciones naturales; y es desde allí que pueden asirse sus rasgos diferenciales. El futuro maestro de Freud postula una hipótesis explicativa de este hallazgo: hay un equivalente dinámico de la lesión orgánica para las parálisis histéricas traumáticas. Así, Charcot acuñó la idea de "lesión funcional" para diferenciarla de la lesión orgánica (destructiva del tejido tisular observable en la autopsia). Sin embargo, ese concepto de lesión funcional conllevaba la idea de que en el futuro, a partir de un refinamiento de las técnicas necrópsicas, sería posible descubrir las alteraciones materiales, orgánicas, de la sintomatología histérica. Como sostiene Bercherie, el reconocimiento de la naturaleza psíquica de muchos síntomas histéricos por parte del neurólogo francés, así como su tendencia a tratarlos mediante sugestión, no le impidió mantener intacta la doctrina organicista de una "lesión dinámica de asiento cortical" para fundamentar fisiológicamente los trastornos (Bercherie, 1983/1988: 95).

Charcot equiparaba la hipnosis a un estado patológico (sirviéndose de ella sólo para para producir síntomas y brindar un estatuto de neurosis a la histeria). Tal concepción fue muy discutida por Hippolyte Bernheim y la escuela francesa de Nancy, postulando que la hipnosis era un fenómeno debido enteramente a la sugestión (idea instalada en el cerebro mediante una orden y transformable en acto), pasible de ser provocado en cualquier persona (no reductible al ámbito de la patología) y que debía considerarse un método terapéutico (más que un procedimiento de investigación). Asimismo, para Bernheim, la histeria era sólo una expresión emocional hipertrofiada. Fueron los esfuerzos de Charcot por replicar esta postura los que culminaron en la mencionada tesis etiológica.

La idea que orientó al maestro de la Salpêtrière en sus discusiones con la escuela de Nancy, era que las parálisis psíquicas se definían por su condición patológica especial (diferenciándose de las orgánicas) y cuyos efectos serían clínicamente observables en rasgos propios. Hasta 1885 Charcot buscó inútilmente hallar esos signos específicos, cuando los resultados de un caso de histeria traumática le obligaron a revisar sus ideas. 
Vinculando patogenia traumática con patogenia sugestiva (el shock nervioso del accidente brinda eficacia patógena a una ideación, cuyo surgimiento se produce en un estado equivalente al estado cerebral de la histeria en sonambulismo) Charcot se topa con el elemento psíquico del traumatismo, sin poder sortearlo ${ }^{198}$.

La posición de Freud por aquel entonces, así como la evolución de sus ideas originales sobre la histeria, no puede ser comprendida a expensas de estos debates $^{199}$. En términos generales puede decirse que si Charcot le mostró a Freud que la histeria y la hipnosis podían estudiarse racionalmente como cualquier otro problema científico, con Bernheim halló la posibilidad de una terapéutica para la histeria que no provenga de la medicina sino de la psicología.

El artículo que analizaremos es, posiblemente, el mejor testimonio del apartamiento de Freud respecto de las ideas de su maestro Charcot. Según nos cuenta al inicio del escrito, el neurólogo de la Salpêtrière tuvo la deferencia de confiarle un estudio comparativo entre las parálisis motrices orgánicas y las parálisis histéricas, en el contexto de su estadía en París ${ }^{200}$. Pese a ello, el escrito apareció publicado siete años más tarde; y, según sabemos por la correspondencia de Freud, su confección pareciera haberse dado en oleadas. Las primeras tres secciones están dedicadas a la neurología y posiblemente

198 Se trata del tope de las articulaciones conceptuales de Charcot, punto crítico que la heurística de su programa no le permite sortear. Por esto Marcel Gauchet lo llama el "hombrefrontera": aquel que encuentra un límite e incluso vislumbra del otro lado, pero sin atreverse a cruzar (Gauchet \& Swain, 1997/2000).

199 Conviene recordar que Freud mantuvo una posición oscilante respecto al debate entre Charcot y Bernheim. En 1888 se publicó, en el primer volumen del diccionario de Medicina General de Villaret, un breve escrito titulado Histeria cuya autoría se adjudica a Freud. Allí se atisba una fuerte crítica a la escuela de Nancy y, al mismo tiempo, se defiende una concepción fisiológica de la histeria con apoyo explícito en lo aprendido en la Salpêtrière (Freud, 1888a/2004). Unos meses después, en el prólogo a la traducción alemana de un libro de Bernheim, Freud defenderá el uso terapéutico de la hipnosis ubicándola de lleno en el campo de la psicología. Allí dirá, con salomónica lucidez, que: "sería tan unilateral considerar únicamente el lado psicológico del proceso, como pretender imputar a la mera inervación vasomotora los fenómenos de la hipnosis [...] No poseemos criterio alguno que permitiera separar con exactitud un proceso psíquico de uno fisiológico" (Freud, 1888b/2004: 90). En una carta a Fließ contextualizaba la opinión allí vertida: "no comparto las opiniones de Bemheim, que me parecen unilaterales, y he intentado defender en el «Prólogo» el punto de vista de Charcot" (Freud, 1985/1986: 10).

${ }^{200}$ Freud estuvo desde octubre de 1885 hasta febrero de 1886 realizando estudios en la Salpétriêre, junto a Charcot. Sabemos por sus esquelas que supo seguir apasionadamente las lecciones del maestro, e incluso que obtuvo su permiso para traducir algunos de sus trabajos al alemán. 
hayan sido redactadas tras su retorno a Viena; pero la cuarta sección tiene que haber sido escrita ya en 1893, puesto que allí se cita la Comunicación preliminar (originalmente publicada en 1893 y, dos años después, añadida como introducción a los Estudios sobre la Histeria).

\section{b) El contenido del escrito}

Freud comienza puntualizando los rasgos "comúnmente admitidos" de las parálisis motrices orgánicas. Según nos dice, la clínica neurológica de la época reconocía dos clases: la parálisis perifero-espinal y la parálisis cerebral (PC de aquí en más). Distinción que resulta acorde con los dos segmentos de vías motoras descriptos por la anatomía del sistema nervioso. La diferencia clínica de esos tipos de parálisis es que la parálisis perifero-espinal es una parálisis "detallada", en donde cada fibra muscular puede ser paralizada de manera individual y aislada (dependiendo del sitio y la extensión de la lesión nerviosa); mientras que la parálisis cerebral es una parálisis "masificada", es decir que ataca una zona amplia de la periferia (una extremidad, un segmento de esta) pero nunca afecta a un músculo individualmente. El vienés da ejemplos y propone nuevas denominaciones para cada una, en función del tipo de relación que los elementos de la periferia guardan con las zonas de llegada ("de proyección" para las perifero-espinal y "de representatividad" para las espinocorticales).

Seguido de ello, ubica un tercer tipo de parálisis: las histéricas ( $\mathrm{PH}$ de aquí en más); y reconoce que se le ha atribuido la facultad de simular las afecciones nerviosas orgánicas más diversas. Allí el vienés plantea el problema: "se trata de saber si, de una manera más precisa, simula los caracteres de las dos clases de parálisis orgánicas, si hay parálisis histéricas de proyección y parálisis histéricas de representación, como en la sintomatología orgánica" (ibíd. pp. 199); e inmediatamente destaca "un primer hecho importante": "la histeria nunca simula las parálisis perifero-espinales o de proyección" y "presenta los mismos caracteres que la parálisis cerebral orgánica" (ibíd. pp. 200). Pero, a pesar de esa semejanza, Freud señala que la PH se distingue por algunos caracteres importantes: 
En primer lugar, no está sometida a la regla, constante en las parálisis cerebrales orgánicas, de que el segmento periférico es siempre más afectado que el segmento central. En la histeria, la espalda o el muslo pueden estar más paralizados que la mano o el pie. Los movimientos pueden llegar a los dedos mientras el segmento central está todavía absolutamente inerte. No ofrece la menor dificultad producir artificialmente una parálisis aislada del muslo, de la pierna, etc., y con suma frecuencia es posible hallar en la clínica estas parálisis aisladas, en contradicción con las reglas de la parálisis orgánica cerebral.

Por tal motivo, Freud dice que la $\mathrm{PH}$ es intermedia entre las parálisis de proyección y la parálisis de representación orgánica.

En el segundo apartado del texto el vienés se propone indagar otros rasgos característicos de las $\mathrm{PH}$ y de las parálisis corticales (el tipo "más perfecto de parálisis cerebral orgánica"). Comienza notando que las $\mathrm{PH}$ son menos sistematizadas que las parálisis corticales; por ejemplo, dice, de la hemiplejía común orgánica (parálisis de los miembros superior e inferior, y del facial inferior), la histeria sólo reproduce la parálisis de ciertos miembros disociados. Otro ejemplo se halla en la comparación de las afasias: la afasia histérica reproduce rasgos inauditos para el síndrome de la afasia orgánica, como por ejemplo la creación de una afasia total (motriz y sensitiva) sólo para un idioma determinado.

Freud agrega que las $\mathrm{PH}$ presentan un rasgo general de las neurosis: son manifestaciones excesivas, que tienden a producir sus síntomas con la mayor intensidad posible. Así, por ejemplo,

el afásico no profiere una palabra, mientras que el afásico orgánico conserva casi siempre algunas sílabas, el «sí» y el «no», un juramento, etc.; el brazo paralizado está absolutamente inerte, etc. [...] por el contrario, se sabe que en la parálisis orgánica la paresia es siempre más frecuente que la parálisis absoluta (ibíd. pp. 202).

En síntesis, nos dice, la $\mathrm{PH}$ posee una delimitación exacta y una intensidad excesiva; y ambos rasgos contrastan con las presentaciones orgánicas, en las que difícilmente se dan asociados.

Freud pasa a señalar dos puntos significativos. En primer lugar, un problema que "resulta inexplicable": las parálisis histéricas se acompañan de significativas perturbaciones de la sensibilidad (anestesia y analgesia) mucho 
más a menudo que las parálisis orgánicas. En segundo lugar, el hecho de que algunas formas de parálisis cerebral no se encuentran en la histeria; como por ejemplo, la parálisis del facial inferior y la hemianopsia lateral homónima.

En base a las observaciones y comparaciones anteriores, el incipiente creador del psicoanálisis explicita una pregunta que vehiculiza su problema de investigación:

\begin{abstract}
Ahora bien, ¿a qué se debe que las parálisis histéricas, no obstante simular ceñidamente las parálisis corticales, diverjan de ellas por los rasgos distintivos que he tratado de enumerar, y a qué carácter general de la representación especial será preciso referirlas? La respuesta a esta cuestión contendría una buena parte, e importante, de la teoría de la neurosis. (Freud, 1893a/2004: 204).
\end{abstract}

Hasta allí, el vienés se ha limitado a señalar las diferencias observacionales que surgen a partir del registro de datos empíricos consensuados. Al comenzar el tercer apartado del escrito Freud sostiene que no hay dudas acerca de las condiciones que dominan la sintomatología de la parálisis cerebral: "son los hechos de la anatomía -la construcción del sistema nervioso, la distribución de sus vasos- y la relación entre estas dos series de hechos y las circunstancias de la lesión" (ibíd.). Afirma, sintéticamente, que "en todos los casos existe una razón derivada de la anatomía [...] todos los detalles de las parálisis cerebrales son la expresión clínica de un hecho anatómico" (ibíd.). Seguido de ello, esboza el siguiente razonamiento:

\footnotetext{
Puesto que sólo puede haber una sola anatomía cerebral verdadera, y puesto que ella se expresa en los caracteres clínicos de las parálisis cerebrales, es evidentemente imposible que esta anatomía pueda explicar los rasgos distintivos de la parálisis histérica. Por esta razón no es lícito extraer, respecto de la anatomía cerebral, conclusiones basadas sobre la sintomatología de estas parálisis (Freud, 1893a/2004: 205).
}

Freud sostiene que para obtener una explicación de las $\mathrm{PH}$, debe atenderse a la naturaleza de la lesión. En las parálisis orgánicas, la naturaleza de la lesión desempeña un papel secundario y sólo su extensión y su localización son significativas para poder explicarlas. Por lo que inmediatamente se pregunta: “¿cuál podría ser la naturaleza de la lesión en la parálisis histérica, que por sí sola domina la situación, con independencia de la localización, de la extensión 
de la lesión y de la anatomía del sistema nervioso?" (ibíd.). Allí Freud retoma la tesis etiológica de su maestro Charcot (la histeria es efecto de una lesión funcional en la corteza cerebral) para señalar su equívoca interpretación y recordar que se trata siempre de lesiones orgánicas (de carácter pasajero). Luego sostiene:

Yo afirmo, por el contrario, que la lesión de las parálisis histéricas debe ser por completo independiente de la anatomía del sistema nervioso, puesto que la histeria se comporta en sus parálisis y otras manifestaciones como si la anatomía no existiera, o como si no tuviera noticia alguna de ella (Freud, 1893a/2004: 206, cursiva del original).

Freud prosigue a explicitar su justificación:

La histeria es ignorante de la distribución de los nervios, y por ello no simula las parálisis perifero-espinales o de proyección; no tiene noticia del quiasma de los nervios ópticos, y en consecuencia no produce la hemianopsia. Toma los órganos en el sentido vulgar, popular, del nombre que llevan: la pierna es la pierna, hasta la inserción de la cadera; el brazo es la extremidad superior tal como se dibuja bajo los vestidos. No hay razón para reunir parálisis del brazo y parálisis de la cara. La histérica que no sabe hablar carece de motivo para olvidar su comprensión de la lengua, puesto que afasia motriz y sordera verbal no tienen ningún parentesco según la noción popular, etc. (Freud, 1893a/2004: 206-7).

Esta tercera sección del texto pareciera funcionar como un gozne entre las anteriores y la última. Conviene destacar que en ella Freud pareciera efectuar un viraje desde el terreno neurológico inicial hacia un campo psicológico, apoyándose en la noción de "representación".

Finalmente, en el último apartado, el vienés esboza una hipótesis sobre la naturaleza de la lesión histérica diciendo que "puede existir una alteración funcional sin lesión orgánica concomitante" (ibíd.). Siguiendo a Janet, afirma que

es la concepción trivial, popular, de los órganos y del cuerpo en general la que está en juego en las parálisis histéricas, así como en las anestesias, etc. Esta concepción no se funda en un conocimiento ahondado de la anatomía nerviosa, sino en nuestras percepciones táctiles y, sobre todo, visuales. Si es ella la que determina los caracteres de la parálisis histérica, es evidente que esta última debe mostrarse ignorante e independiente de toda noción sobre la anatomía del sistema 
nervioso. La lesión de la parálisis histérica será, entonces, una alteración de la concepción \{representación\}; de la idea de brazo, por ejemplo. Pero, ¿de qué índole es esta alteración para producir la parálisis? (Freud, 1893a/2004: 207).

En un esfuerzo creativo Freud inventa la conjetura de que las parálisis histéricas se producen por abolición de la función asociativa, debido a una asociación inconciente de la representación de la parte del cuerpo afectada con un hecho traumático (hipótesis que continuará desarrollando).

\section{c) Centralidad del razonamiento crítico}

Aunque es bastante evidente, conviene recordar aquí que la forma en la que un científico comunica sus ideas no equivale a sus razonamientos durante los diversos momentos de su investigación, mucho más complejos y humanos, sino que supone la realización sintética de un resultado que se quiere destacar.

Para comprender el espíritu crítico de Freud haremos hincapié en el tercer apartado del texto, en donde Freud efectúa una contundente objeción a la tesis de Charcot utilizando un razonamiento que podemos reconstruir utilizando la regla del modus tollens. Lo expresaremos primero en prosa y luego lo formalizaremos: si las parálisis histéricas tienen una causa orgánica pasajera (una lesión funcional, según Charcot), entonces "Es necesario que las parálisis producidas por las lesiones de este orden compartan en un todo los caracteres de la parálisis orgánica" (pp. 206). Pero, "El edema, la anemia, no podrían producir la disociación y la intensidad de las parálisis histéricas [sus rasgos característicos], como tampoco pueden hacerlo la hemorragia y el ablandamiento" (ibíd.). Por lo tanto, concluye Freud, "puesto que la histeria se comporta en sus parálisis y otras manifestaciones como si la anatomía no existiera, o como si no tuviera noticia alguna de ella", "la lesión de las parálisis histéricas debe ser por completo independiente de la anatomía del sistema nervioso" (ibíd.).

Pasemos a formalizar lo esencial del razonamiento freudiano con la regla favorita de Popper: 
Si PH tiene por causa una lesión funcional (orgánica), entonces $\mathrm{PH}$ tiene síntomas similares a PO.

No es cierto que $\mathrm{PH}$ tenga síntomas similares a PO

Por lo tanto, no es cierto que PH tiene por causa una lesión funcional (orgánica)

Para Freud, esta contraevidencia empírica tiene el estatuto de una refutación. Coincidimos con Bercherie cuando sostiene que fue el rigor del razonamiento neurológico lo que llevó a Freud a las puertas del inconciente y que, por ello, puede decirse que el saber médico fue la condición de posibilidad del saber psicoanalítico (Bercherie, 1983/1988: 278).

Luego de ello, Freud postula la tesis de que en la génesis de la $\mathrm{PH}$ se encuentra una representación anatómica popular [llamemos a esto RAP] y extrae de ello una importante consecuencia observacional: los síntomas de las parálisis histéricas no pueden seguir las reglas anatómicas descriptas por la neuropatología. El razonamiento aparece escrito de esa forma y ya lo hemos citado: "si es ella [RAP] la que determina los caracteres de la parálisis histérica, es evidente que esta última debe mostrarse ignorante e independiente de toda noción sobre la anatomía del sistema nervioso" (ibíd. pp. 207). Como esa consecuencia observacional resulta altamente corroborada, Freud cree que su hipótesis queda confirmada por la experiencia. De ese modo se hace inteligible el hecho enigmático que diferencia y caracteriza a las $\mathrm{PH}$ : al haber una concepción de "sentido común" del sistema nervioso, entonces resulta esperable que su afectación no siga las reglas de la neuroanatomía. Freud se topa así con otra anatomía, que deberá explorar y conceptualizar.

Ahora bien ¿cuáles son esos rasgos descriptos por la minuciosidad freudiana que lo llevaron a postular RAP?, dicho de otro modo: ¿se sigue RAP de los hechos tan cuidadosamente cotejados? Resulta evidente que se trata de un salto creativo de Freud y que RAP es una hipótesis abducida: es producto de una inferencia plausible para explicar $\mathrm{PH}$. En ese sentido, notamos que Freud no ha reducido su trabajo de teorización a la recolección de regularidades y su clasificación (operando inductivamente), sino que ha buscado una conjetura y se ha dispuesto a contrastar sus consecuencias 
observacionales. Notamos así que su proceder, en el ejemplo analizado, es semejante al del método hipotético deductivo.

Por otro lado, conviene recordar que la explicación dada aquí para la etiología de la histeria irá siendo constantemente revisada y complejizada por Freud durante los años subsiguientes. Podemos notar, en el texto que estamos analizando, cómo se vincula la hipótesis propuesta con los desarrollos de la futura introducción a los Estudios sobre la histeria:

\footnotetext{
Cada suceso, cada impresión psíquica están provistos de cierto valor afectivo (Affektbetrag \{monto de afecto\}), del que el yo se libra por la vía de una reacción motriz o por un trabajo psíquico asociativo. Si el individuo no puede o no quiere tramitar el excedente, el recuerdo de esta impresión adquiere la importancia de un trauma y deviene la causa de síntomas permanentes de histeria. La imposibilidad de la eliminación es notoria cuando la impresión permanece en el subconciente. Hemos llamado a esta teoría "Das Abreagteren der Reizzuwachse» « «la abreacción de los aumentos de estímulo»\} (Freud, 1893a/2004: 209).
}

Este conglomerado hipotético constituye el germen de todo un entramado teórico sobre los procesos psíquicos inconscientes, que irá confeccionando el núcleo duro del programa psicoanalítico.

En esta sección hemos intentado mostrar cómo Freud pudo ser crítico respecto de una parte de la tradición en la que se insertaba. Hemos visto cómo su rechazo de la teoría etiológica de Charcot se produjo en base a un razonamiento deductivo: la contrastabilidad empírica de las consecuencias observacionales de la hipótesis de la lesión funcional lo llevaron a rechazar la teoría de su maestro francés. En base a ello se orientó a la búsqueda empírica y a la postulación de otras perspectivas etiopatogénicas, sin dejar de reformular significativamente sus hipótesis explicativas.

En la sección siguiente continuaremos analizando otro ejemplo específico, y veremos en qué medida tal reformulación hubo de obedecer a la contraevidencia empírica. 


\section{La "teoría de la seducción" y su reformulación}

En sus incipientes esbozos nosográficos, Freud comenzó manejando la categoría de neuropsicosis de defensa (histeria, neurosis obsesiva y psicosis alucinatoria/paranoia ${ }^{201}$ ) y, con el correr de la década de 1890, distinguió las neurosis actuales (neurastenia y neurosis de angustia). En estas últimas Freud ve la expresión automática de un exceso o ausencia de excitación sexual, y plantea que en su formación no actúa ningún mecanismo psíquico desfigurador sino que se trata de una descarga directa. Pero para las primeras, elabora un modelo del funcionamiento psíquico en el que actúa una defensa contra los recuerdos traumáticos no abreaccionados, dejándolos no disponibles y no eliminados. El funcionamiento diferencial de la memoria en las psiconeurosis (falsos enlaces y representaciones hiperintensas) es correlativo de una serie de procedimientos terapéuticos para contrarrestarlo. Todo ello sin dejar de reconocer la existencia de casos mixtos, en los que la etiología se considera múltiple. Esta noción de defensa constituye, como hemos visto en el capítulo anterior, una hipótesis teórica decisiva en los albores del PIC freudiano.

En 1896 Freud propuso una teoría etiológica con la que esperaba revolucionar la neuropatología de la época ${ }^{202}$ : la neurosis adulta sólo se

\footnotetext{
${ }^{201}$ Hemos mencionado ya que en 1894 escribe Las neuropsicosis de defensa. (Ensayo de una teoría de la histeria adquirida, de muchas fobias y representaciones obsesivas y de ciertas psicosis alucinatorias), donde ubica a las psicosis alucinatorias y su modo particular de operar la defensa (Freud, 1894/2004). Dos años más tarde, en un artículo que ahora mencionaremos, sustituye la "locura alucinatoria" por la "paranoia", a la vez que vincula y distingue su curso típico del de la "neurosis obsesiva", que ahora aparece como organización independiente (Freud, 1896b/2004).

202 Mostrándose muy convencido de su idea, metaforizó su hallazgo con uno de los descubrimientos más importantes de la geografía del siglo XIX: "Estimo que esta es una revelación importante, el descubrimiento de un caput Nili de la neuropatología..." (Freud, 1896c/2004: 202). Recordemos, brevemente, cuál había sido el problema de ese desconocimiento geográfico que sirve de analogía: “¿Cómo es posible -se preguntaba la genteque el río fluya indefectiblemente todos los días del año a lo largo de casi dos mil kilómetros a través del desierto más grande y más seco del mundo conocido sin recibir ni un solo afluente que incremente su caudal? No es de extrañar que la inundación anual del delta del Nilo durante el mes más caluroso del año causara respeto y no poca ansiedad por si un día sus misteriosas fuentes se agotaban y Egipto perecía" (Tim, 2011/2013: 5). El problema constituía un misterio milenario (Alejandro Magno fue el primero en enviar una expedición para averiguar la causa de las curiosas crecidas); pero fue recién en los años de la infancia de Freud que se realizaron una serie de expediciones reveladoras: las encabezadas por Richard Burton y John Speke, entre 1857 y 1860 . Podríamos explayar la analogía de Freud, en dos sentidos. Él la realiza en torno a la importancia de un hallazgo milenario, pero bien puede extendérsela hacia el espíritu que guiaba sus exploraciones psicopatológicas: lo que causa el extraño fenómeno es un existente que se remonta a un lugar desconocido, pero que la exploración del territorio puede
} 
desarrolla en aquellas personas que en su infancia han sufrido alguna experiencia de abuso sexual. Creía con ello haber encontrado un factor predisponente de mayor peso que el de la herencia, por aquel entonces central $^{203}$.

La primer referencia explícita de Freud a esta teoría parece ser la de una carta a Fließ del 8 de octubre de $1895^{204}$, pero su publicación se hará en una serie de artículos durante 1896: La herencia y la etiología de las neurosis (Freud, 1896a/2004) (escrito originalmente en francés), Nuevas puntualizaciones sobre las neuropsicosis de defensa (Freud, 1896b/2004) y, fundamentalmente, La etiología de la histeria (Freud, 1896c/2004).

A pesar de no haber sido bautizada así por él, esta conceptualización temprana de Freud suele conocerse como "teoría de la seducción"205 y supone

revelar. Por otro lado, resulta significativo que, tanto en el problema de las fuentes del Nilo como en el de las fuentes de la neurosis, se trate de caudales y sus localizaciones topográficas.

${ }^{203}$ Freud adhería, en sus comienzos, a las tesis de Charcot sobre la herencia. Por ejemplo, en el temprano y breve artículo con el que Freud contribuyó a una enciclopedia de medicina de la época (y que ya hemos mencionado), se puede leer: "La etiología del status hystericus ha de buscarse por entero en la herencia" (Freud, 1888a/2004: 55). Unos años más tarde sostuvo: "la comprobación de la herencia no dispensa de buscar un factor específico, en cuyo descubrimiento, por otra parte, se concentra todo el interés terapéutico. Pues terapéuticamente, ¿a qué se atinaría con la herencia como etiología? Desde siempre estuvo ella en el enfermo, y seguirá estando en él hasta el fin. En sí y por si no permite comprender la emergencia episódica de una neurosis, ni su cesación por obra del tratamiento. Ella no es nada más que una condición de la neurosis, cierto que indeciblemente importante, pero sobrestimada en detrimento de la terapia y de la inteligencia teórica" (Freud, 1895/2004: 137).

\begin{abstract}
${ }^{204}$ Allí escribió: “... entre otras cosas olfateo la siguiente íntima condicionalidad: para la histeria, que una vivencia sexual primaria (anterior a la pubertad) se haya producido con repugnancia y espanto, para la neurosis obsesiva, que se haya producido con placer. Pero no logro el esclarecimiento mecánico, más bien me inclino a prestar oídos a la queda voz que me dice que mis explicaciones no dan en el blanco" (Freud \& Fließ, 1985/1986: 146). En la carta $n^{\circ} 76$, fechada una semana más tarde, puede leerse: "La histeria es la consecuencia de un espanto sexual/presexual. La neurosis obsesiva es la consecuencia de un placer sexual que después se mudó en reproche. "Presexual» significa, en rigor, anterior a la pubertad, anterior a la desligazón de las sustancias sexuales, los acontecimientos pertinentes producen efecto sólo como recuerdos" (ibíd. pp. 147-8). Esta gran oleada de especulación teórica, que al decir de Paul Bercherie constituye "la parte sumergida del témpano" respecto a lo visible en sus publicaciones (Bercherie, 1983/1988: 322), se consolida con el denominado Proyecto de Psicología (septiembre-octubre de 1895) y con la Carta 52 (6 de diciembre de 1896).
\end{abstract}

${ }^{205}$ La denominación parece haber sido acuñada por Ernst Kris, en su "Estudio preliminar" a Los orígenes del psicoanálisis (Kris, 1950/1973). Nótese, en base a lo que sigue, que la noción de "seducción" no remite al contenido que la teoría postula; por lo que nos parece una designación desacertada. Aunque "seducción" (Verführung) es un vocablo que Freud utiliza, también aparecen otros para designar esas escenas sexuales infantiles: "violación" (Vergewaltigung), "abuso" (Missbrauch), "ataque" (Angriff), "traumas" (Traumen) y la palabra francesa “Aggression” (agresión). (Masson, 1984/1985: 29). 
que la etiología de las neuropsicosis de defensa (histeria y neurosis obsesiva) se explica a partir de una serie interactuante de procesos psíquicos:

a- Exposición, durante la infancia, a actos de seducción o de abuso sexual efectuados por un adulto, cuyo sentido es originalmente desconocido por el entonces niño-víctima.

b- Re-significación de esos sucesos durante la pubertad, a partir de una vivencia nimia pero asociada a la anterior, y consolidación de su efecto traumático.

c- Represión en lo inconciente de la escena infantil ahora intolerable, mientras que la segunda escena nimia se mantiene en la conciencia, pero cualificada como displacentera e incomprensible.

d- Retorno desfigurado de lo reprimido vía el síntoma.

En uno de sus últimos escritos, Freud sintetizará: "trauma tempranodefensa-latencia-estallido de la neurosis-retorno parcial de lo reprimido: así rezaba la fórmula que establecimos para el desarrollo de una neurosis" (Freud, 1939/2004: 77).

Para cuando Freud postula esta teoría, ya había explicitado su perspectiva sobre la causalidad de las enfermedades. Se trata de lo que había dado en llamar "ecuación etiológica", una compleja interrelación de diversos tipos de causas en la producción de una enfermedad: condición, causa específica, causa concurrente y causa desencadenante (Freud, 1895/2004). Su tesis de 1896 para las psiconeurosis, es que vivencias de abuso sexual infantil son la causa específica ${ }^{206}$; esto es, “...aquella que no está ausente en ningún caso de realización del efecto y que poseyendo una cantidad o intensidad proporcionadas basta para alcanzarlo, con sólo que estén cumplidas las condiciones" (ibíd. pp. 135).

Freud sostuvo que esa hipótesis fue realizada a partir de los hallazgos que obtenidos con el método catártico, pues en su aplicación

\footnotetext{
${ }^{206}$ Considerando que Freud intentó modelizar mecánicamente el psiquismo y que hasta el siglo XIX tales explicaciones mecánicas adoptaban un sentido de la causalidad orientado por la noción aristotélica de "causa eficiente", Leticia Minhot ha señalado que en las psiconeurosis de defensa (de la primera etiología) la causa específica puede verse como la causa eficiente, que se halla en la realidad material externa al psiquismo; asimismo, en la segunda etiología, la causa eficiente/específica radica en el conflicto entre aspiraciones sexuales y represión (Minhot, 2003: 160 y 171).
} 
se rastreaban cada vez más lejos los traumas psíquicos de que derivaban los síntomas histéricos, al final se llegaba a vivencias que pertenecían a la infancia del enfermo y concernían a su vida sexual. $Y$ ello aun en los casos en que una emoción trivial de naturaleza no sexual había ocasionado el estallido de la enfermedad. Sin tomar en cuenta estos traumas sexuales de la infancia no era posible esclarecer los síntomas, cuya determinación ellos hacían comprensible, ni prevenir su reaparición. (Freud, 1906/2004: 265).

Sin detenernos por ahora en este entramado de suposiciones ni en la complejidad misma que la teoría de la seducción implica, haremos foco en su evolución a los fines de evaluar el modo de sustitución de una de sus principales conjeturas por otra nueva.

\section{a) El cambio de hipótesis}

Pese a que este sistema de pensamiento ocupó significativamente los esfuerzos de Freud, no tardó en revelarse inconsistente: las contradicciones aparecieron entre la teoría de la seducción, los datos empíricos y las presuposiciones del vienés; hasta el punto de volverse insostenible.

Como consecuencia de estas inconsistencias, Freud pareciera haber abandonado un componente central de esa teoría etiológica: la facticidad completa de esas escenas infantiles (sexuales), obtenidas a partir del relato en análisis. Se trata de un cambio de hipótesis sobre el estatuto ontológico de las escenas sexuales infantiles recordadas por los pacientes histéricos durante las sesiones: Freud abandonará la conjetura de que la causa específica de las psiconeurosis es una representación cuyo referente es una vivencia de abuso sexual acaecida en la infancia. Es decir, la idea de que los síntomas de la psiconeurosis responden a una amenaza que proviene completamente del exterior, determinando (junto a la defensa) la realidad psíquica del paciente.

Prácticamente al mismo tiempo, adopta la hipótesis de que tales escenas de seducción (que se han constituido en un dato clínico) son en verdad fantaseadas por el paciente: su referente es ahora la realidad psíquica y ya no, únicamente, la realidad material ${ }^{207}$.

${ }^{207}$ Otra forma de describir el cambio teórico es haciendo hincapié en el rol jugado por las fantasías durante esos meses, puesto que su origen y función fue variando. Inicialmente la fantasía se concibe como una defensa respecto de sucesos traumáticos; es decir que Freud integra esa noción de fantasías a la conjetura de la seducción (cf. las cartas $n^{\circ} 118,119,126$ y 
En el marco de nuestra lectura de este difícil episodio histórico, abreviaremos como ST a la siguiente conjetura: las escenas de abuso sexual infantil que los pacientes adultos recuerdan en el tratamiento, han acontecido fácticamente (con independencia de la imaginación) tal y como son allí relatadas.

También abreviaremos esta otra conjetura con la expresión FT: las escenas de abuso sexual infantil que los pacientes adultos recuerdan en el tratamiento, son producto de la fantasía. Dicho sintéticamente, ST equivale a "seducción traumática" y FT a "fantasía traumática".

En términos generales puede decirse que analizaremos el cambio que está comprendido en la transición ST-FT que Freud efectúa, y del que dará cuenta en diversos momentos de su obra. Sin embargo, como veremos luego, esa transición no siempre es narrada del mismo modo por Freud; e incluso hay pasajes que indican menos una transición que un complemento.

\section{b) La célebre carta a Fließ y el proceder falsacionista en el cambio ST-FT}

Suele verse, como evidencia de este cambio ST-FT (además de lo explícitamente publicado por Freud) la famosa carta escrita a Fließ el 21 de septiembre de 1897 . Veamos lo que allí se sostiene:

\footnotetext{
Y ahora quiero confiarte sin dilación el gran secreto que se me puso en claro lentamente los últimos meses. No creo más en mi neurótica. Por cierto que esto no se comprende sin explicación; tú mismo encontraste creíble lo que pude relatarte. Por eso comienzo a exponer históricamente los motivos del descreimiento. Las continuas desilusiones en los intentos de llevar 'un' análisis a su efectiva conclusión, la deserción de la gente durante un tiempo mejor asida, la falta del éxito pleno con el que yo había contado, la posibilidad de explicarme los logros parciales diversamente, de la manera común: he ahí el primer grupo. Después, la sorpresa de que en todos los casos el padre debiera ser inculpado corno perverso sin excluir al mío propio, la comprobación de la inesperada frecuencia de la histeria para la cual debería repetirse esta misma condición
}

132 a Fließ; en Freud, 1985/1986). Posteriormente, a partir de la carta $n^{\circ} 139$, la fantasía pasará a ser un invento cuya función es cubrir defensivamente los impulsos sexuales orgánica y periódicamente acaecidos por estimulación bioquímica endógena. Todo ello en el marco de las influencias recibidas por las ideas de Fließ y su intención declarada de alinearse con ellas. (cf. una lectura del vínculo Freud- Fließ apropósito del cambio ST-FT en Birch, 2000: 36-40). 
cuando es poco probable que la perversión en perjuicio de niños esté tan difundida. (La perversión tiene que ser inconmensurablemente más frecuente que la histeria porque en efecto una enfermedad sólo se hace realidad si los sucesos se han acumulado y se agrega un factor que debilite la defensa.) En tercer lugar, además, la evidencia cierta de que en lo inconciente no existe un signo de realidad de suerte que no se puede distinguir la verdad de la ficción poblada con afecto. (Según esto, queda la solución de que la fantasía sexual se adueña regularmente del tema de los padres). En cuarto lugar, la consideración de que en las psicosis más profundas el recuerdo inconciente no se abre paso, con lo cual el secreto de las vivencias juveniles no se trasluce ni en el delirio más confuso. Si de este modo se ve que lo inconciente nunca vence la resistencia de lo conciente, entonces se hunde también la esperanza de que en la cura se pueda proceder en sentido inverso hasta el total domeñamiento de lo inconciente por lo conciente" (Freud, 1985/1986: 283-4).

Como hemos adelantado, la conjetura que puede sostenerse a propósito de este ejemplo es que la transición ST-FT puede ser formalizada como un razonamiento que sigue la regla de inferencia lógica favorita de Popper (el modus tollendo tollens). Esto es así porque se trata de un cambio cuya racionalidad histórica responde, en gran parte, a la contrastabilidad empírica. Dicho de otra manera: la contraevidencia empírica ocupa un lugar preponderante en la modificación que Freud hace de su teoría etiológica de la neurosis, por lo que parece justo y plausible representarlo de ese modo (aunque, más adelante, veremos la insuficiencia de este formalismo).

En 1913 Freud da una versión de la transición ST-FT que nos permite ponderar el papel decisivo de la contrastación empírica:

Es verdad que en los tiempos iniciales de la técnica analítica atribuíamos elevado valor, en una actitud de pensamiento intelectualista, al saber del enfermo sobre lo olvidado por él, y apenas distinguíamos entre nuestro saber y el suyo. Considerábamos una particular suerte obtener de otras personas información sobre el trauma infantil olvidado, fueran ellas los padres, los encargados de la crianza o el propio seductor, como era posible en algunos casos; y nos apresurábamos a poner en conocimiento del enfermo la noticia y las pruebas de su exactitud, con la segura expectativa de llevar así neurosis y tratamiento a un rápido final. Serio desengaño: el éxito esperado no se producía (Freud, 1913a/2004: 141-142, cursiva añadida). 
Vemos aquí relatar al vienés una lógica procedimental cuyo espíritu es falsacionista: si la teoría etiológica de la histeria es cierta, entonces es posible observar una serie de consecuencias clínicas derivadas (el "éxito esperado"). Pero, como no es cierto que tales consecuencias esperables se observen, es necesario concluir que la teoría debe ser modificada. Freud decide entonces rehabilitar la coherencia de un modo que Popper hubiera elogiado: rechaza la formulación original de la teoría y la sustituye.

Tras advertir que la decisión de abandonar ST es efectuada sobre un trasfondo de anomalías o falsaciones que Freud asume como tales, debemos rechazar lo que Popper cree y declara: que el padre del psicoanálisis se limitó a intentar confirmar sus ideas.

\section{c) La falsación sofisticada de Freud y la progresividad del programa en el cambio ST-FT}

Pese a notar que el proceder de Freud en este ejemplo (y en general) responde a la lógica de la contrastación empírica, veremos ahora que la refutación que hace Freud no es "a la Popper", por diversas razones:

A) No abandona su teoría etiológica in totto por desencajar con los hechos, sino que logra modificarla de manera tal que encaje con los datos clínicos.

B) Tampoco parece que Freud haya abandonado o modificado su teoría ante la presencia incisiva de la primer contraevidencia empírica, sino que su proceder en este caso parece más complejo.

C) Freud no comunica su abandono de ST hasta que puede dar una versión superadora (FT).

Puede decirse, como adelantábamos en el tercer capítulo, que el espíritu freudiano de la refutación es "más conservador" que el de Popper. Esto se ve si analizamos con cierto detalle la carta a Fließ, pues allí Freud le comunica una serie histórica de motivos que lo han llevado al abandono de ST. De lo cual podemos conjeturar que ese abandono no se produjo ante la primer anomalía del sistema (teoría-datos), sino que es la maduración de un conjunto frondoso de contraejemplos clínicos.

Freud ofrece cuatro tipos de motivos en la citada carta del 21 de Septiembre de 1987: 
1) El no haber culminado con éxito ni una sola terapia utilizando ST: Ios pacientes más impresionados por el tratamiento, lo dejaban apresuradamente; y los éxitos parciales obtenidos podían explicarse sin apelar a ST.

2) La perversión del padre en todos los relatos de abuso sexual infantil y la sorpresiva frecuencia de la histeria, implicaban la existencia de una cantidad enorme e improbable de padres abusadores.

3) La dificultad de distinguir entre verdad y ficción en los relatos de abuso (emocionalmente cargados) que se lograban en el tratamiento.

4) La consideración de que, si en las psicosis más profundas el recuerdo de vivencias de abuso sexual infantil no se hace conciente, entonces eso tampoco sucedería en el tratamiento de las neurosis más leves (cuya defensa es más eficaz).

Al esquematizar las razones que da Freud, surge la impresión de que el cambio ST-FT supone un complejo sistema de elementos. Esa complejidad no impide a Freud advertir que es necesario recomponer el entramado teórico para que explique los resultados obtenidos y los fenómenos observados y supuestos.

Sin embargo, el valor de las falsaciones empíricas no es, como Popper propone, fulminante: Freud reconoce las discordancias entre sus ideas y las consecuencias observacionales derivadas, pero no procede desechando completamente la teoría etiológica de la histeria. Por el contrario, sólo luego de cierto tiempo el vienés decide modificar algunas conjeturas auxiliares para hacerla viable. Este proceder, como hemos visto, se corresponde al modelo lakatosiano y resulta más adecuado que el de Popper para entender cómo se producen los cambios teóricos.

Es posible notar, además, que el abandono freudiano de ST tampoco se produce hasta que está en condiciones de sostener una conjetura alternativa; es decir que "no hay falsación sin la emergencia de una teoría mejor" (Lakatos, 1978/1989: 50) ${ }^{208}$. Aunque la citada carta suele ser vista como una especie de

\footnotetext{
${ }^{208}$ Más adelante veremos que, independientemente de los intercambios epistolares, Freud no comunica públicamente su abandono de ST hasta entrada la década de 1900. Así, Freud aparece reflejado en la imagen lakatosiana: "Ios científicos tienen la piel gruesa. No abandonan una teoría simplemente porque los hechos la contradigan. Normalmente o bien inventan alguna hipótesis de rescate para explicar lo que ellos llaman después una simple anomalía o, si no pueden explicar la anomalía, la ignoran y centran su atención en otros problemas" (Lakatos, 1978/1989: 12-13).
} 
necrológica de ST, también puede considerarse el acta de nacimiento de FT, pues antes de los dos meses siguientes Freud envió a Fließ otra carta con un esquema de su teoría de la sexualidad infantil y sus ideas sobre el papel que juegan en la formación de síntomas neuróticos en la vida adulta. Esto acuerda con la crítica de Lakatos a Popper, que citábamos en el capítulo anterior: la contrastación no es una contienda cerrada entre teoría y experiencia, sino un "triple enfrentamiento" entre teorías rivales y experimentación.

En ese sentido, puede plantearse que FT se había estado gestando a la par que las anomalías de ST se habían estado presentando: puede verse que el interés de Freud, al momento del abandono declarado a Fließ, venía estando situado en el tema de las fantasías infantiles (cf. Manuscritos $M$ y N). Pero hasta que Freud no es capaz de hallar una formulación convincente para reemplazar ST, no decide abandonarla. Ello también parece sintonizar con la idea lakatosiana de que un hecho se ve como "refutador" de una teoría sólo si es "corroborador" de otra teoría alternativa (cf. el capítulo 3).

\section{d) Progresividad del programa}

La órbita de las indagaciones freudianas fue ampliada notablemente entre una y otra conjetura: mientras que ST funciona como premisa explicativa de la potencialidad patógena de la memoria de aquellos adultos que han sido víctimas de una sexualidad parásita en su infancia; FT ha de situarse como base explicativa de las consecuencias para el desarrollo de la sexualidad infantil (que ahora se supone existente, no por la violenta introducción del adulto, sino por la constitución psico-biológica del propio niño), la impulsividad hostil, las fantasías de abandono, etc. El cambio de hipótesis es un cambio en los problemas, en la base empírica contrastacional y en la metodología de indagación.

En virtud de los resultados que produjo el cambio ST-FT en la teoría psicoanalítica, es posible sostener que el accionar de Freud se asemeja a lo descripto por Lakatos en términos de progresividad de los programas de investigación: abandonar ST y adoptar FT le permitió al vienés teorizar la 
sexualidad infantil y el Complejo de Edipo ${ }^{209}$; teorías que suscitaron un mayor potencial explicativo e interventivo que sus predecesoras. No sólo permitieron conceptualizar una amplia variedad de fenómenos clínicos y su abordaje, sino que brindaron una comprensión mayor a las teorizaciones del psiquismo en general.

En la célebre carta a Fließ, Freud mismo se preguntaba: “¿Y si estas dudas no fueran sino un episodio en el progreso hacia un conocimiento más amplio?" (Freud op. cit., 1985/1986: 285). Y mucho tiempo después se haría consciente de los beneficios que ese cambio intrateórico había permitido: "aclarado el error [ST], quedaba expedito el camino para el estudio de la vida sexual infantil. Así se llegó a aplicar el psicoanálisis a otro ámbito del saber, y a colegir a partir de sus datos un fragmento, desconocido hasta entonces, del acontecer biológico" (Freud, 1925b/2004: 33).

En términos lakatosianos, la transición ST-FT es una modificación progresiva del programa, por dos motivos: es teóricamente progresivo en la medida en que FT supone mayor "contenido empírico" que su predecesora (predice la sexualidad infantil, p. ej.) y conserva el contenido no refutado de ST (procesos inconcientes y factor energético, p. ej.); y es empíricamente progresivo porque algunas de las nuevas predicciones resultan corroboradas (la sexualidad infantil es el ejemplo más claro).

Por todo lo anterior, la modificación freudiana puede considerarse una sustitución de hipótesis auxiliares conforme a una heurística positiva. Algo de esto debe haber sido intuido por Freud, pues en la carta de 1897 le escribe a Fließ: “... tengo en verdad más el sentimiento de un triunfo que el de una derrota (lo cual, empero, no es justo)" (Freud, 1985/1986: 285).

En uno de los textos que dieron difusión a ST, el padre del psicoanálisis afirmaba: "...Charcot, para quien la herencia nerviosa ocupaba el lugar que yo reclamo para la experiencia sexual precoz" (Freud, 1896a/2004: 154), a la vez que entregaba al lector una serie de argumentos críticos en contra de la suposición de que la herencia es el factor determinante de las neurosis. Y

\footnotetext{
${ }^{209}$ Coincidimos con Argañaráz en este punto: "es frecuente que se confundan los 'hechos nuevos', que caracterizan el éxito de un PIC, con el programa mismo. El Psicoanálisis descubrió la sexualidad infantil como resultado de su heurística diacrónica de investigación. No es que investigue la infancia porque 'postula' la sexualidad infantil, sino a la inversa: descubre la sexualidad infantil o el método de la asociación libre, porque su heurística le ordenó indagar la diacronía del síntoma, la historia de la enfermedad, la etiopatogenia" (Argañaráz, 2012: 38).
} 
luego, en la carta en que declara a Fließ el abandono, afirma: "el factor de una predisposición hereditaria recupera un imperio del que me había impuesto como tarea desalojarlo - en interés del esclarecimiento total de la neurosis" (Freud, 1985/1986: 285). En base a esto no parece exagerado decir que el "factor hereditario" es parte del núcleo duro de un programa rival (el de Charcot y sus discípulos), y que parte de la astucia freudiana fue aprovechar el rechazo de ST para continuar con la formulación de una conjetura que no contrariaba ese papel de la herencia sino que lo integraba: mientras que ST constituyó un intento de explicación de los patrones familiares de morbilidad sin apelar a la degeneración biológica ${ }^{210}$, su reemplazo por FT va a desembocar en una serie de postulados que vincularán "herencia" con lo "histórico-vivencial" ( $p$. ej. la idea de protofantasías $y$, más adelante, la noción de series complementarias $^{211}$ ).

Como hemos visto, el cambio intrateórico ST-FT es progresivo. Ello no supone, necesariamente, que adoptemos la suposición de que FT es "más verdadera" que ST. Recordemos que en el tercer capítulo hemos visto las deficiencias de la teoría popperiana de la verosimilitud y en el cuarto capítulo advertimos cierta ambigüedad de Lakatos al respecto. Aquí no abordaremos directamente el problema de la verdad, pero sí nos expediremos sobre este

\footnotetext{
${ }^{210}$ En los tres textos freudianos de 1896 que hemos citado, puede notarse una utilización estratégica de la noción de "pseudoherencia" (Pseudoheredität), de manera tal que permitía ubicar la etiología de las neurosis más ligada a la crianza familiar que a enigmáticos influjos hereditarios (cf. Vallejo, 2012: 58 y ss.). Quizás resulte oportuno señalar un pasaje de las Nuevas conferencias de introducción al psicoanálisis en el que Freud expresa contundentemente su perspectiva sobre el asunto de la herencia biológica: "La experiencia analítica de que es posible ejercer vasto influjo sobre ellas [las neurosis] si uno se apodera de las ocasiones históricas de la enfermedad y de los factores accidentales concurrentes nos ha inducido a descuidar el factor constitucional en la praxis terapéutica; es cierto que, de todos modos, no tenemos por dónde asirlo, pero en la teoría deberíamos considerarlo siempre". (Freud, 1933b/2004: 142)

${ }^{211}$ Es sabido que la teoría de Freud tiene estrechos lazos con algunas tradiciones biológicas de su época. Eso no lo convierte, como se ha querido ver sobre todo a partir del libro de Frank Sulloway (1979/1992), en un biólogo de la mente encubierto. El trabajo de Sulloway peca en la omisión de todas aquellas referencias y filiaciones freudianas a la filosofía, la literatura, la arqueología, etc.; que impiden reconducir la órbita de sus teorizaciones al exclusivo impacto que en ellas se atisba del evolucionismo darwiniano. Criticar la historiografía hegemónica del psicoanálisis para poner en su lugar una constelación tan simplificadora como esta es, a nuestro juicio, una sustitución que no apunta a desentrañar la complejidad del fenómeno histórico sino a discutir la oficialidad de un discurso. Retomaremos estas discusiones más adelante.
} 
asunto; y lo haremos retomando un señalamiento que ha hecho Larry Laudan a propósito de su modelo de cambio teórico:

para determinar si una teoría resuelve un problema, es irrelevante si la teoría es verdadera o falsa, o si está bien o escasamente confirmada; lo que se toma como solución a un problema en un momento determinado no contará necesariamente como tal en todo momento (Laudan, 1977/1986: 52) ${ }^{212}$.

Si consideramos la transición ST-FT como un ejemplo de "aumento en la efectividad de la resolución de problemas" (criterio central para estimar el progreso científico según Laudan), la pregunta por su verdad pasa a un segundo plano. Entonces, el cambio analizado no implica más que una ponderación de las capacidades explicativas y predictivas de ambas hipótesis (ST y FT) en el contexto de los problemas que Freud abordó ${ }^{213}$.

Nos hemos basado en este ejemplo para mostrar cómo el proceder del creador del psicoanálisis se acerca más a lo que Popper proponía como metodología científica que a lo que imaginó que Freud hacía. Incluso más: hemos intentado mostrar que el proceder de Freud (al menos en el ejemplo analizado) se puede comprender mejor si se lo analiza desde la óptica de los críticos de Popper, por ejemplo Lakatos, y que su metodología puede reconstruirse como una forma de falsacionismo sofisticado.

\section{e) El cambio ST-FT, más allá de la contrastación empírica}

Entre las críticas al planteamiento de Popper que retomamos en el tercer capítulo se encuentra el hecho de que los científicos, vistos desde una óptica histórica, raramente adoptan un temperamento revolucionario: las teorías nacen falsadas (pues nunca concuerdan exactamente con los datos de

\footnotetext{
${ }^{212}$ Agreguemos a ello lo dicho por el propio Lakatos: "no importa si ponemos el énfasis en el aspecto «instrumental» de los programas de investigación imaginativos que sirven para descubrir hechos nuevos y para realizar predicciones fiables, o si lo ponemos en la creciente «verosimilitud» popperiana [...] El falsacionismo sofisticado combina de este modo los mejores elementos del voluntarismo, del pragmatismo y de las teorías realistas del crecimiento empírico" (Lakatos, 1978/1989: 132).

${ }^{213}$ En este punto nos oponemos doblemente a Masson (1984/1985), quien intentó defender la idea de que ST era una hipótesis más acertada que su sucesora FT. Independientemente de las razones que él da para sostenerlo (y que revisaremos más adelante) creemos, por el contrario, que la mejor forma de enfocar el problema del cambio teórico es en torno a la progresividad del programa (Lakatos) o a la resolución de problemas (Laudan).
} 
observación) y los científicos conviven con las anomalías durante un tiempo. Así, la historia nos muestra que la reconstrucción de Popper no es enteramente adecuada.

Considerando que las teorías no son entidades abstractas del cielo platónico, sostendremos que es insoslayable historizarlas para poder comprenderlas. En lo que sigue haremos foco en una serie de problemas históricos, a los fines de sostener la siguiente conjetura: al igual que sucede con otros episodios de cambio teórico en la historia de las ciencias, la transición ST-FT que Freud efectúa al interior de su teoría etiológica de las neurosis obedece a una racionalidad no reductible al canon popperiano. Es decir, no puede entenderse ese cambio si se lo intenta pensar como el exclusivo resultado de la contrastación empírica, tal y como aparece narrado por Freud en la carta a Fließ. Esto, veremos, no lo hace a Freud "menos científico" (como muchos han proferido); sino que, por el contrario, contribuye a pensar el fracaso del criterio popperiano.

Para comprender la magnitud del problema, utilizaremos dos recursos. Primero, elucidaremos el valor que Freud le dio al cambio ST-FT en las sucesivas narraciones que supo elaborar del mismo conforme pasaban los años. Segundo, retomaremos un elemento que no puede ser obviado para comprender las razones que condujeron al cambio teórico en este caso: la relación original de Freud con ST y el peso de las objeciones recibidas.

\section{Divergencias en la narrativa freudiana del cambio ST-FT}

Realizaremos un recorrido por los pasajes en los que Freud expone su opinión sobre el cambio ST-FT. El orden de exposición elegido es cronológico: presentaremos y analizaremos las principales menciones freudianas sobre el cambio ST-FT, tal y como han ido apareciendo en sus escritos y publicaciones.

El creador del psicoanálisis presenta públicamente su cambio de perspectiva recién en los primeros años del siglo XX, en dos obras fundamentales. En Tres ensayos de teoría sexual afirma:

...no puedo conceder que en mi ensayo sobre «La etiología de la histeria» yo haya sobrestimado su frecuencia o su importancia [se refiere a la influencia de la seducción], si bien es cierto que a la sazón todavía no sabía que individuos que siguieron siendo normales podían haber tenido en su niñez esas mismas 
vivencias, por lo cual otorgué mayor valor a la seducción que a los factores dados en la constitución y el desarrollo sexuales (Freud, 1905d/2004: 173).

Como vemos, aquí Freud sostiene que ST es falsa, pero no porque los acontecimientos que designa no hayan existido sino porque ellos no revelan el valor etiológico que se les había supuesto. La anomalía de ST se revela ante casos de pacientes que relatan vivencias de abuso sexual en la infancia, sin que hayan desarrollado una neurosis. Es entonces la confirmación del enunciado "hay pacientes que relatan escenas de seducción sin padecer síntomas neuróticos", lo que obliga a acomodar la teoría. Es decir, el proceder falsacionista se basa en otro falsador potencial. Obsérvese también que Freud admite no haberle otorgado su merecido valor a los factores constitucionales; lo que parece significar, en este argumento, que el abandono de ST supone una revalorización de la hipótesis de la herencia biológica.

A pesar de lo anterior, nótese que en este texto Freud comienza diciendo que no puede él conceder que haya sobrestimado (en el artículo que deriva de la conferencia de 1896) la frecuencia o importancia de la seducción. Esto es interesante pues en un pasaje significativo de otro trabajo (escrito ese mismo año) que ahora analizaremos, Freud no da las mismas razones del cambio.

Ese otro trabajo es en verdad el primero en el que se dedica explícitamente al asunto del abandono de ST; se trata de Mis tesis sobre el papel de la sexualidad en la etiología de las neurosis. Allí afirma:

El material todavía limitado de entonces me había aportado, por azar, un número desproporcionadamente grande de casos en que la seducción por adultos u otros niños mayores desempeñaba el papel principal en la historia infantil. Sobrestimé la frecuencia de estos sucesos (los cuales, por otra parte, no pueden ponerse en duda), tanto más cuanto que a la sazón yo no sabía distinguir con certeza entre los espejismos mnémicos de los histéricos acerca de su infancia y las huellas de los hechos reales; desde entonces he aprendido, en cambio, a resolver muchas fantasías de seducción considerándolas como unos intentos por defenderse del recuerdo de la propia práctica sexual (masturbación infantil) (Freud 1906/2004: 266).

Observamos que Freud admite aquí la dificultad para diferenciar relatos con referencia a hechos pasados, de relatos con referencia a fantasías. Allí sostiene que la casualidad lo había llevado a toparse con muchos casos en 
donde la existencia de vivencias de abuso sexual infantil era determinante en la neurosis de los sujetos. Es decir, el motivo por el que habría generalizado (sobrevalorado equivocadamente) la frecuencia de estos sucesos realmente acaecidos (ST), es ahora el azar. Al mismo tiempo, allí parece haber adoptado la hipótesis de que el relato de tales vivencias infantiles puede, en ciertos casos $y$ no en todos, encubrir el recuerdo penoso del onanismo infantil. En ese sentido, la "concepción del mecanismo de los síntomas histéricos" ha cambiado:

ya no aparecían más como retoños directos de los recuerdos reprimidos de vivencias sexuales infantiles, sino que entre los síntomas y las impresiones infantiles se intercalaban las fantasías (invenciones de recuerdos) de los enfermos, casi siempre producidas en los años de la pubertad (ibíd.).

Apenas unos años más tarde, en el caso del Hombre de las ratas, sostiene que "si uno no quiere equivocarse en la apreciación de la realidad objetiva", debe recordar que los recuerdos infantiles se establecen en edades posteriores y que "entonces son sometidos a un complejo trabajo de refundición que es enteramente análogo a la formación de sagas de un pueblo sobre su historia primordial". Allí puede discernirse que

\footnotetext{
...el ser humano en crecimiento busca, en estas formaciones de la fantasía sobre su primera infancia, borrar la memoria de su quehacer autoerótico, elevando sus huellas mnémicas al estadio del amor de objeto; o sea, como un genuino historiógrafo, procura contemplar el pasado a la luz del presente. De ahí, en esas fantasías, la abundancia de seducciones y atentados, cuando verdaderamente la realidad se limita a un quehacer autoerótico y a la incitación para este mediante ternuras y castigos. Además, uno descubre que quien fantasea sobre su infancia sexualiza sus recuerdos, es decir, vincula vivencias triviales con su quehacer sexual, extiende sobre ellas su interés sexual, en lo cual es probable que siga los rastros del nexo efectivamente presente. (Freud, 1909b/2004: 162 n. 39; cursivas del original).
}

En 1914 Freud volverá sobre este asunto dando una nueva versión: ahora todos los relatos de abuso sexual infantil son considerados como fantasías malinterpretadas. El vienés cuenta los avatares de la historia del movimiento psicoanalítico, afirmando: 
fue preciso superar un error que habría sido casi fatal para la joven disciplina. Bajo la influencia de la teoría traumática de la histeria, originada en Charcot, se tendía con facilidad a juzgar reales y de pertinencia etiológica los informes de pacientes que hacian remontar sus síntomas a vivencias sexuales pasivas de sus primeros años infantiles, vale decir, dicho groseramente, a una seducción. Cuando esta etiología se desbarató por su propia inverosimilitud y por contradecirla circunstancias establecidas con certeza, el resultado inmediato fue un período de desconcierto total. El análisis había llevado por un camino correcto hasta esos traumas infantiles, y hete aquí que no eran verdaderos. Era perder el apoyo en la realidad. En ese momento, con gusto habría dejado yo todo el trabajo en la estacada, como hizo mi ilustre predecesor Breuer en ocasión de su indeseado descubrimiento. Quizás perseveré porque no tenía la opción de principiar otra cosa. $Y$ por fin atiné a reflexionar que uno no tiene el derecho de acobardarse cuando sus expectativas no se cumplen, sino que es preciso revisar estas. Si los histéricos reconducen sus síntomas a traumas inventados, he ahí precisamente el hecho nuevo, a saber, que ellos fantasean esas escenas, y la realidad psíquica pide ser apreciada junto a la realidad práctica. Pronto siguió la intelección de que esas fantasías estaban destinadas a encubrir, a embellecer y a promover a una etapa más elevada el ejercicio autoerótico de los primeros años de la infancia. Así, tras esas fantasías, salió al primer plano la vida sexual del niño en todo su alcance (Freud, 1914b/2004: 16-7).

Freud dice aquí, sin sutilezas, que ST fue un error. Es importante señalar, pues constituye otra réplica concreta al mito popperiano, que Freud trató de corregir su teoría para no "perder el apoyo en la realidad ${ }^{214 " . ~}$

Tres años más tarde, en la vigesimotercera de las Conferencias de introducción al psicoanálisis, el vienés retomará el asunto del abandono de ST diciendo que va a hablar de "algo que sorprende y confunde":

lo sorprendente reside en que estas escenas infantiles no siempre son verdaderas. Más aún: en la mayoría de los casos no lo son, y en algunos están en oposición directa a la verdad histórica (Freud, 1917h/2004: 334).

\footnotetext{
${ }^{214}$ El énfasis dado aquí por Freud a la vinculación de las fantasías con hechos fácticos (como el autoerotismo infantil o las vivencias de los antepasados que él supone heredadas filogenéticamente) y el empeño de ubicar ahí el centro de la tarea del analista, debe comprenderse a partir de las rupturas al interior del movimiento que él ha formado y de sus intentos por separar el "legítimo psicoanálisis" de los desarrollos detractores. Así, los rasgos teórico-metodológicos que Freud enfatiza en este escrito y cuya repercusión es directa sobre el tema que estamos analizando, se pueden contraponer a la teoría de los arquetipos de Jung (cuya disidencia era reciente), e incluso a la psicología individual de Adler (con quien había roto el lazo hacía unos años).
} 
Y unas líneas más abajo afirma:

Si las vivencias infantiles que el análisis saca a la luz fueran reales en todos los casos, tendríamos la sensación de movernos en terreno seguro; si por regla general estuvieran falseadas, si se revelaran como inventos, como fantasías de los enfermos, tendríamos que abandonar este suelo movedizo y ponernos a salvo de otro. Pero no es ni una cosa ni la otra; puede demostrarse que la situación es esta: las vivencias infantiles construidas en el análisis, o recordadas, son unas veces irrefutablemente falsas, otras veces son con certeza verdaderas, y en la mayoría de los casos, una mezcla de verdad y falsedad (ibíd. p. 334-5, cursivas añadidas).

Como vemos, Freud aquí vuelve a relativizar la distinción entre fantasía y realidad, admitiendo las dificultades que ello supone. Incluso dirá que el paciente puede no comprender "nuestro designio de fantasía y realidad y de no preocuparnos al comienzo por saber si esas vivencias infantiles que han de explicarse son lo uno o lo otro. No obstante, es evidentemente la única actitud correcta frente a estas producciones del alma" (ibíd. pp. 336).

Freud adopta aquí el supuesto de que las fantasías "poseen realidad psíquica" y que "en el mundo de las neurosis la realidad psíquica es la decisiva" (ibíd.). Al mismo tiempo, explicita un dato proveniente de la indagación clínica: las asociaciones de los neuróticos siempre conducen a los mismos tres tipos de escenas, que llamará fantasías primordiales. Y enseguida aclara: "sería un error suponer que nunca les corresponde una realidad material" (ibíd.).

Luego se expide sobre la seducción:

\begin{abstract}
Particular interés presenta la fantasía de seducción, aunque solo sea porque a menudo no es una fantasía, sino un recuerdo real. Pero, afortunadamente, no lo es con tanta frecuencia como lo sugerirían a primera vista los resultados del análisis [...] Con la fantasía de seducción, cuando no la ha habido, el niño encubre por regla general el período autoerótico de su quehacer sexual. Se ahorra la vergüenza de la masturbación fantaseando retrospectivamente, para estas épocas más tempranas, un objeto anhelado. No crean ustedes, por lo demás, que los abusos sexuales cometidos contra las niñas por sus parientes masculinos más próximos pertenecen por entero al reino de la fantasía (ibíd. pp. 337).
\end{abstract}

Debemos resaltar que el pasaje que Freud hace aquí de la sustitución de ST por FT es mucho más relativo que en los escritos anteriores. Tal es así que admite la posibilidad de que ST y FT coexistan en la determinación de la 
neurosis. Los intentos explicativos que aquí elabora de esa interrelación, decantan en lo que pareciera una nueva hipótesis explicativa:

\begin{abstract}
No se tiene otra impresión sino que tales hechos de la infancia son de alguna manera necesarios, pertenecen al patrimonio indispensable de la neurosis. Si están contenidos en la realidad, muy bien; si ella no los ha concedido, se los establece a partir de indicios ${ }^{215}$ y se los completa mediante la fantasía. El resultado es el mismo, y hasta hoy no hemos logrado registrar diferencia alguna, en cuanto a las consecuencias de esos sucesos infantiles, por el hecho de que en ellos corresponda mayor participación a la fantasía o a la realidad. De nuevo, lo que tenemos aquí no es sino una de las tan a menudo mencionadas relaciones de complementariedad; en verdad es la más extraña de todas las que hemos conocido (ibíd. pp. 338).
\end{abstract}

Freud se pregunta por el origen de estas fantasías primordiales y esboza una respuesta apoyada en supuestos lamarkianos: el contenido de tales fantasías ha sido vivenciado por los antepasados de la especie humana y se transmite por herencia filogenética. En base a esta conjetura el vienés le da un estatuto de necesidad a tales protofantasías: completan el rudimentario vivenciar ontogenético con las huellas vividas filogenéticamente.

Entonces, en este momento la teoría freudiana supone que las fantasías son una suerte de bisagra entre dos órdenes de fenómenos interrelacionados: el autoerotismo infantil y las vivencias de la especie. La fantasía viene al lugar de cubrir lo vergonzoso de la masturbación y, al mismo tiempo, completar con material hereditario lo no vivenciado a nivel de ciertos contenidos mnémicos.

A propósito de la reedición de los escritos de 1896 en 1924, el padre del psicoanálisis agrega en ellos una serie de notas aclaratorias al pie de página. En la nota 15 de las Nuevas puntualizaciones de las neuropsicosis de defensa, afirma:

\footnotetext{
${ }^{215}$ En la carta a Fließ del 2 de mayo de 1897, había afirmado: "Las fantasías provienen de algo oído que se comprendió supletoriamente, desde luego son auténticas en todo su material. Son edificios protectores, sublimaciones de los hechos, embellecimientos de estos, sirven al mismo tiempo al autodescargo" (Freud, 1985/1986: 254). Y en el Manuscrito L, añadido a esta esquela, agrega: "Las fantasías sirven simultáneamente a la tendencia de refinar los recuerdos, de sublimarlos. Son establecidas por medio de las cosas que fueron oídas y que se apreciaron supletoriamente, y así combinan lo vivencia do y lo oído, lo pasado (de la historia de los padres y abuelos) con lo visto por uno mismo" (ibíd. pp. 256).
} 
Esta sección está bajo el imperio de un error que después he admitido y rectificado repetidas veces. Por aquel tiempo yo aún no sabía distinguir entre las fantasías de los analizados acerca de su infancia y unos recuerdos reales. A consecuencia de ello, atribuí al factor etiológico de la seducción una sustantividad y una validez universal que no posee. Superado este error, se abrió el panorama de las exteriorizaciones espontáneas de la sexualidad infantil, que describí en Tres ensayos de teoría sexual. Sin embargo, no todo lo contenido en este texto es desestimable; la seducción conserva cierta significatividad para la etiología, y todavía hoy considero acertados muchos de los desarrollos psicológicos aquí expuestos (Freud, 1896/2004: 169).

Puede advertirse en esta nota aclaratoria algo similar a lo expuesto en Tres ensayos: el vienés no descarta ST, sino que rechaza el valor universalizante que le había adjudicado. Es decir, Freud no está rechazando la facticidad de las escenas relatadas de abuso sexual infantil (ST) sino que ese sea el único factor causal de las neurosis de defensa.

Un año más tarde a esa reedición publicará su presentación autobiográfica, abocándose nuevamente al asunto. Antes de hablar de la sexualidad infantil, declara:

debo mencionar un error en que caí durante un tiempo y que pronto se habría vuelto funesto para toda mi labor. Bajo el esforzar a que los sometía mi procedimiento técnico de aquella época, la mayoría de mis pacientes reproducían escenas de su infancia cuyo contenido era la seducción sexual por un adulto. En las mujeres, el papel del seductor se atribuía casi siempre al padre. Di crédito a esas comunicaciones y supuse, en consecuencia, que en esas vivencias de seducción sexual durante la infancia había descubierto las fuentes de las neurosis posteriores [...] Cuando después hube de discernir que esas escenas de seducción no habían ocurrido nunca y eran sólo fantasías urdidas por mis pacientes, que quizás yo mismo les había instilado, quedé desconcertado un tiempo. Mi confianza en mi técnica así como en sus resultados recibió un duro golpe [...] cuando me sosegué, extraje de mi experiencia las conclusiones correctas, a saber, que los síntomas neuróticos no se anudaban de manera directa a vivencias efectivamente reales, sino a fantasías de deseo, y que para la neurosis valía más la realidad psíquica que la material. Tampoco creo hoy que yo instilara, "sugiriera», a mis pacientes aquellas fantasías de seducción. En ellas me topé por primera vez con el complejo de Edipo [...] la seducción en la infancia conserva su parte etiológica, aunque en escala más modesta. (Freud, 1925b/2004: 32-3, cursivas añadidas). 
En esta versión Freud parece más tajante y hace de su tránsito ST-FT algo más determinado; es decir, algo que se apoya en la posibilidad de separar contundentemente realidad psíquica de realidad material (lo cual aparece contrariado, no obstante, en la última línea de la cita). Por otro lado, es notorio que aquí introduzca (y rápidamente descarte) la hipótesis de que él podría haber "instilado" esos recuerdos de seducción infantil ${ }^{216}$. Es posible notar, además, que los fenómenos de la seducción aparecen ahora leídos a la luz de la teoría del complejo de Edipo: la seducción, fantaseada, es un resultado de la conflictiva edípica.

Pareciera que esa versión de 1924 se separa de las anteriores, en los puntos mencionados. Da la impresión, a la vez, que se aproxima a la siguiente de 1933. En esta última el vienés extrema la separación posible entre ambos órdenes deslindados (fantasía y realidad) y utiliza al complejo de Edipo como clave principal de lectura de la seducción:

\begin{abstract}
En la época en que el principal interés se dirigía al descubrimiento de traumas sexuales infantiles, casi todas mis pacientes mujeres me referían que habían sido seducidas por su padre. Al fin tuve que llegar a la intelección de que esos informes eran falsos, y así comprendí que los síntomas histéricos derivan de fantasías, no de episodios reales. Sólo más tarde pude discernir en esta fantasía de la
\end{abstract}

\footnotetext{
${ }^{216}$ Mucho se ha dicho sobre el papel desempeñado por la sugestión en los procedimientos freudianos, olvidándose, a menudo, que el propio Freud conocía bien la naturaleza del problema. Aunque en 1914 el vienés se exprese diciendo que "los histéricos reconducen sus síntomas a traumas inventados" (op. cit.), en sus escritos de 1896 había dejado en claro que "los enfermos jamás cuentan esas historias espontáneamente" y que ellas sólo se obtenían por la aplicación del método (técnica de la "imposición de manos"): "Sólo se logra despertar la huella psíquica del suceso sexual precoz bajo la más enérgica presión del procedimiento analizador y contra una resistencia enorme..." (Freud, 1896a/2004: 152). En base a este tipo de diferencias, entre lo originalmente expuesto por Freud y lo historizado posteriormente, algunos historiadores han postulado el origen sugestivo de esas escenas de abuso sexual infantil. A nuestro modo de ver, aunque no puede desconocerse que los primeros esbozos de la técnica de la "asociación libre" parecieran haberse dado en aproximada coincidencia cronológica con el abandono de ST (en la última cita Freud habla de un "duro golpe" a la confianza en su técnica), esa lectura soslaya la complejidad del problema de los datos clínicos y desestima las propias advertencias tempranas de Freud. Valga este pasaje como ejemplo: "los títulos etiológicos de las escenas infantiles no descansan sólo en la constancia de su aparición en la anamnesis de los histéricos, sino, sobre todo, en la comprobación de los lazos asociativos y lógicos entre ellas y los síntomas histéricos, prueba que les resultaría a ustedes evidente como la luz del día si hiciéramos la comunicación completa de un historial clínico" (Freud, 1896c/2004: 208; cursivas añadidas). Incluso más adelante, dirá que "sin tomar en cuenta esos traumas sexuales de la infancia no era posible esclarecer los síntomas, cuya determinación ellos hacían comprensible" (Freud, 1906/2004: 265). Esto conduce a pensar que no es el hallazgo del recuerdo traumático lo que da crédito a ST, sino la capacidad explicativa que aporta la suposición de tales vivencias en lo que respecta al material clínico. Reservamos un capítulo en la siguiente parte de la tesis para analizar el problema de la sugestión en la validación de los datos clínicos.
} 
seducción por el padre la expresión del complejo de Edipo típico en la mujer (Freud, 1933a/2004: 111-2).

Como hemos podido notar, Freud relata el cambio teórico ST-FT haciendo hincapié en diversos aspectos. Posiblemente, esa diferencia se deba a que cada vez que comenta este cambio, lo hace apropósito de interlocutores diferentes y con finalidades distintas. Coincidimos en este punto con George Makari, quien afirma que el tipo de referencias etio-epidemiológicas que Freud utiliza en sus primeras declaraciones del abandono de ST, se debe a que sus interlocutores eran fundamentalmente médicos; mientras que las comunicaciones posteriores a 1914, en donde el vienés pareciera utilizar el cambio de hipótesis como evidencia a favor de su teoría pulsional, se comprende a partir del contexto de disputas y disidencias al interior del movimiento psicoanalítico (Makari, 1998).

Por otro lado, a partir de la narrativa de Freud, notamos que la transición STFT no es tanto una sustitución de conjeturas que haya pivoteado sobre el binomio "hecho acaecido - hecho fantaseado", sino una complejización de la teoría en la cual se le otorga un peso diferencial a los distintos factores intervinientes en la etiología de las psiconeurosis. La correspondencia de Freud nos muestra sus propias dudas respecto a la centralidad que debe otorgar a cada uno de ambos factores. Pueden leerse expresiones de indecisión antes del declarado abandono de 1897 , por ejemplo en la carta del $1^{\circ}$ de marzo de 1896:

Por mi parte, siempre he oscilado entre conjeturar herencia tras estos casos, o más bien vivencias infantiles. Pero es cierto que se trata de un punto oscuro en la teoría y el oponente tiene derecho a considerarlo un punto débil (Freud, 1985/1986: 186).

Y también puede verse esta vacilación posteriormente, por ejemplo en la carta del 27 de septiembre de 1898:

...un niño que regularmente, hasta el séptimo año, moja la cama (sin ser epiléptico o cosa parecida), tiene que haber pasado por excitaciones sexuales en la niñez temprana. ¿De manera espontánea o por seducción? Ahí está pues la cuestión... (ibíd. pp. 360). 
Estos pasajes epistolares nos muestran la vacilación freudiana, a expensas de sus decisiones explícitas; a la vez que nos alertan de toda lectura simplificadora del asunto.

Coincidimos con Paul Robinson cuando dice que la idea de un cambio súbito es aquí un mero "constructo histórico" elaborado a posteriori; y que no debería obviarse el papel desempeñado por la "fantasía" en los tiempos en que Freud sostuvo la preponderancia etiológica de la seducción real, ni el papel adjudicado a los factores "accidentales externos" en los tiempos en que Freud adoptó la conjetura de las fantasías traumáticas (Robinson, 1993).

Por nuestra parte, creemos que el tránsito ST-FT puede ser comprendido como una sustitución de factores en el lugar de la causa específica de las psiconeurosis: las escenas reales de seducción juegan el rol de la causa específica durante un tiempo y luego ese rol pasó a ser adjudicado a las fantasías (y su relación conflictiva con la represión). Pero de ahí no se sigue que las seducciones reales hayan dejado de ocupar un lugar en la ecuación etiológica, aunque ese lugar no fuera completamente aclarado. Sin embargo, no puede obviarse que para Freud, con el correr de los desarrollos, el conflicto psíquico deja de ser visto como algo contingente y pasa a ocupar el lugar de algo constitucional. Así, el vienés terminó estableciendo un continuum "saludenfermedad" y desestimando la posibilidad de hallar causas cualitativamente diferenciales. En la vigésimo octava conferencia de las Conferencias de introducción al psicoanálisis sostiene:

La diferencia entre salud nerviosa y neurosis se circunscribe, pues, a lo práctico, y se define por el resultado, a saber, si le ha quedado a la persona en medida suficiente la capacidad de gozar y de producir. Probablemente se reconduzca a la proporción relativa entre los montos de energía que han quedado libres y los ligados por represión, y es de índole cuantitativa, no cualitativa (Freud 1917c/2004: 416; cursiva añadida).

Pareciera, entonces, que la causa eficiente pasa a ser la intensidad del conflicto entre las entidades consideradas (que varían en los diversos esquemas etiológicos). En otras palabras, puede decirse que Freud fue abandonando no una u otra conjetura etiológica específica, sino la noción misma de "causa cualitativamente específica". Así, observando su última 
referencia al tema, en el capítulo VII de Esquema del psicoanálisis, leemos lo que adjetivó como "uno de nuestros principales resultados":

Las neurosis no tienen (a diferencia, por ejemplo, de las enfermedades infecciosas) causas patógenas específicas. Sería ocioso buscar en ellas unos excitadores de la enfermedad (Freud, 1940/2004: 183).

Seguido de ello, retomará su criterio cuantitativo para distinguir salud enfermedad, diciendo que "las neurosis no se distancian de la norma en nada esencial" (ibíd. pp. 184). Y luego, tras admitir que "esta explicación no es satisfactoria" porque "es excesivamente general, explica demasiado", admitirá la necesidad de especificar los caracteres necesarios para la producción de una neurosis. Dirá, sin invalidar lo anterior, que se trata de un complemento entre factores constitucionales (hereditarios) y adquiridos (vivenciales) de variable intensidad cuantitativa.

En síntesis, las distintas formas en las que Freud narra su cambio teórico, nos dan la pauta de su complejidad inherente; y nos permiten afirmar que las falsaciones empíricas (de innegable importancia en el proceso decisional del analista vienés) no explican la totalidad del fenómeno histórico tal y como hoy se nos aparece. Dicho sintéticamente: el ejemplo analizado muestra cómo la lógica de la falsación no agota el problema del cambio teórico.

A partir de lo anterior, puede plantearse este interrogante: ¿qué otros factores, si no los epistémicos, han contribuido significativamente a la evolución del programa freudiano en el tránsito ST-FT? Responder cabalmente a ello supondría extendernos más allá de los límites de esta tesis. No obstante, intentaremos cercar un núcleo de elementos que posiblemente hayan incidido en las decisiones teóricas de Freud.

\section{La relación original de Freud con ST y el peso de la crítica}

"No puede existir un conjunto concreto de reglas de elección adecuado para dictar la conducta individual deseada en los casos concretos con los que los científicos se encontraran a lo largo de sus carreras. Sea lo que sea el progreso científico, debemos explicarlo mediante la inspección de la naturaleza del grupo científico, descubriendo lo que valora, lo que tolera y lo que desdeña" (Kuhn, 1970/2002: 160). 
Considerando que ST era un componente central de lo que Freud veía como un magnífico descubrimiento, no es exagerado decir que su abandono significó tanto un desmoronamiento anímico como una ruptura clave en su pensamiento teórico. Coincidimos aquí con Paul Bercherie, quien sostiene que "con la teoría de la seducción, Freud cree haber alcanzado por fin el plano de la determinación etiológica de la enfermedad" (Bercherie, 1983/1988: 323), por lo que su abandono era un retorno a la incertidumbre causal.

Recordemos que antes de ST, Freud había estado teorizando sobre el origen de los síntomas neuróticos sin hallar una explicación etiológica convincente y sin lograr, por lo tanto, una clara orientación terapéutica ${ }^{217}$. La teoría de la seducción viene al lugar de ese vacío teórico-técnico: explica la patología nerviosa (deslindando un factor causal específico para cada tipo de enfermedad) y brinda un promisorio procedimiento de cura ${ }^{218}$.

En virtud del valor adquirido, se comprende que el fracaso del conjunto teoría-procedimiento (por los motivos expuestos) haya derivado en una transformación paulatina de ciertas conjeturas auxiliares y no en un radical abandono del programa en conjunto. Asimismo, el viscoso abandono de $\mathrm{ST}^{219}$ se comprende a partir de la importancia relativa que tuvo en el contexto de su producción y en el marco de las expectativas que el propio Freud se había

\footnotetext{
${ }^{217}$ En los Estudios sobre la histeria, puede leerse: "sólo nos hemos acercado al conocimiento del mecanismo de síntomas histéricos, y no al de las causas internas de la histeria" (Freud \& Breuer, 1895/2004: 43); por ello, el método catártico "no influye sobre las condiciones causales de la histeria, y por lo tanto no puede impedir que en lugar de los síntomas eliminados se generen otros nuevos" (ibíd. pp. 269). Incluso en La etiología de la histeria, sostuvo: "Debemos tener en claro que la reconducción de un síntoma histérico a una escena traumática sólo conlleva una ganancia para nuestro entendimiento si esa escena satisface dos condiciones: que posea la pertinente idoneidad determinadora y que se deba reconocerle la necesaria fuerza traumática" (Freud, 1896c/2004: 193). El vienés tenía clara su carencia de comprensión sobre las causas específicas de la histeria: "sólo tenemos noticia de una pequeña parte de los motivos de los cuales brota" (ibíd. pp. 215).

218 En 1896 había anticipado (e inmediatamente mesurado) su perspectiva terapéutica: "mi expectativa es que un psicoanálisis completo ha de significar la curación radical de una histeria. Sin embargo, ¡no anticipemos en este punto las doctrinas a la experiencia!" (Freud, 1896c/2004: 2005).

219 Recordemos que, a pesar de la carta del 21 de septiembre a Fließ, Freud volvió a darle crédito a ST en los meses siguientes; y que se demoró varios años en comunicar públicamente su abandono.
} 
generado $^{220}$. Tras su abandono, el vienés se vio profundamente afectado por la desilusión:

La expectativa de la fama eterna era demasiado bella, y la de la segura riqueza, la plena independencia, el viajar, el preservar a los hijos de los serios cuidados que me consumieron en mi juventud. Todo ello dependía de que la histeria cediera o no (Freud, 1985/1986: 286);

e incluso a principios del siglo $\mathrm{XX}$ seguirá recordando el penoso abandono de ST: "En lo interior estoy profundamente empobrecido, tuve que demoler todos mis castillos en el aire y sólo ahora 'cobro' un poco de ánimo para volver a edificarlos" (ibíd. pp. 444).

Además del valor teórico que ST había adquirido para Freud, deberíamos recordar la valorización que otros hicieron a su conjetura, puesto que de allí surge la posibilidad de discriminar un factor incisivo para el proceso de abandonarla. ${ }^{221}$

Los tres artículos con los que Freud pretendió dar difusión a ST en 1896, fueron rápidamente confeccionados y estratégicamente diseminados: el primer boceto completo de sus ideas (el Manuscrito $K$, aparentemente confeccionado a fines de 1895, cuyo título -en su envío a Fließ- fue "un cuento de navidad") se transformó, al cabo de un mes, en dos artículos terminados. El 5 de febrero Freud los envió a dos revistas médicas para su publicación: uno fue escrito en francés (L'hérédité et l'étiologie des névroses) y apareció en el número del 30 de marzo de la Revue Neurologique; y se inicia orientando explícitamente la comunicación a los discípulos de Charcot, para objetar las premisas de su neurología hereditarista. El otro artículo se publicó en Berlín (donde

\footnotetext{
${ }^{220}$ Se ha criticado el hecho de que Freud, por momentos, creyera demasiado en sus propias ideas y buscara confirmaciones constantemente. Aunque eso pareciera más una actitud natural de la cognición humana que un error metodológico, lo cierto es que no hay indicios de que Freud haya dado por verificada a ninguna de sus hipótesis o teorías. Michel Onfray, por ejemplo, desplegando un paupérrimo argumento, nos ha dicho que ST "se le plantea a priori como una verdad absoluta, cual si fuera palabra del Evangelio" (Onfray, 2010/2011: 263). Lo que prueba que Freud no aspiraba a verificar (a sentenciar la verdad) es que hipótesis como ST, sobreestimadas por él durante un tiempo, luego serían criticadas y reemplazadas. Insistimos: su proceder se asemeja al del falsacionista sofisticado.

${ }^{221}$ La presencia de los valores merece un lugar central en la elucidación de todo cambio teórico. Desgraciadamente, "en las reconstrucciones llamadas -paradójicamente- racionales del conocimiento científico, al exigirse la sistematización deductiva de los enunciados en las teorías se han dejado de lado los juicios de valor. De ahí el carácter revelador que tiene la adopción de otras unidades de análisis como los paradigmas o las prácticas científicas" (Gómez, 2014: 160).
} 
probablemente Freud quería darse a conocer), en el número del 15 de mayo del Neurologiches Zentralblatt. El tercer escrito vio la luz en junio y fue publicado en Viena, en el Wiener Klinische Rundschau, pero resultó ser fruto de una conferencia que Freud había pronunciado el 21 de abril en la Sociedad de Psiquiatría y Neurología de esa ciudad.

No sabemos el impacto inmediato que tuvieron los primeros dos artículos, pero sí podemos darnos una idea de lo que sucedió cuando el creador del psicoanálisis decidió comunicar sus ideas en Viena. Luego de unos días, Freud le narrará a Fließ lo sucedido en aquel evento:

\begin{abstract}
Una conferencia sobre etiología de la histeria en la Asociación Psiquiátrica fue recibida por los asnos con frialdad, y obtuvo de Krafft-Ebing este raro juicio: Suena como un cuento científico. ¡Y esto después que se les había mostrado la solución de un problema milenario, un caput Nili! Se pueden ir todos a paseo, expresado eufemísticamente (Freud, 1985/1986: 194).
\end{abstract}

Joffrey Masson (el editor de este intercambio epistolar) comenta en nota al pie: "según una comunicación personal de Anna Freud, su padre desde la conferencia citada en el texto nunca más concurrió a una reunión de la Asociación de Psiquiatría y Neurología. No obstante, se lo incluye todavía en la lista de miembros de 1899" (ibíd.).

Ahora bien, conviene recordar que luego de esas detracciones a su teoría, Freud se vio aislado. A los pocos días le expresará a su amigo berlinés:

\footnotetext{
Se han dado consignas de abandonarme, pues todo se desvanece en mi derredor. Hasta ahora lo soporto con ecuanimidad. Más ingrato me resulta que el consultorio este año por primera vez esté vacío, que durante semanas no vea un rostro nuevo, no pueda iniciar una nueva cura, y que de las antiguas aún no haya acabado ninguna (Freud, 1985/1986: 196).
}

Incluso muchos años más tarde el vienés seguirá recordando ese período con amargura:

En los años que siguieron a 1895 ocurrió que dos fuertes impresiones se conjugaron en mí para producir un mismo efecto. Por una parte, había obtenido las primeras intelecciones en las profundidades de la vida pulsional humana, viendo muchas cosas que desencantaban y hasta podían asustarlo a uno al comienzo; por otra parte, la comunicación de mis desagradables hallazgos me 
hizo perder casi todas mis relaciones humanas de entonces; me sentí como despreciado y evitado por todos (Freud, 1926a/2004: 263).

Es sabido que Freud decía haber sufrido una suerte de ostracismo en su vida académica, comprendida entre la publicación de Estudios sobre la Histeria (1895) y los primeros contactos con el grupo de Zurich (1906) 222 . También sabemos que el freudismo posterior supo recoger esa narrativa y construir con ella una mitificación del origen del psicoanálisis. Incluso en los días de Freud algunos tomaron la posta del mito de la soledad; Ferenczi, por ejemplo, sostuvo: "la primera época, la que llamaríamos época heroica del psicoanálisis, está representada por los diez años que Freud peleó solo contra todos y utilizando todos los medios" (Ferenczi, 1911/1984: 178).

Ahora bien, aunque a esta altura podemos afirmar que esa narrativa de la "heroica soledad" no es enteramente coherente con los datos históricos de dicho período (cf. Sulloway, 1979/1992, cap. 13; Klein, 1985, cap. 2 y Vallejo, 2008, cap. 3), no pareciera acertado desestimar el obstáculo que esas críticas tempranas impusieron al itinerario freudiano. En ese sentido y a los fines de nuestro tema, cabe preguntarnos: ¿puede ubicarse esta recepción desfavorable de los psiquiatras y neurólogos vernáculos, entre los factores extra-epistémicos que motivaron el abandono de ST? ¿Es acaso posible separar asépticamente ese tipo de desavenencias, de las falsaciones empíricas que influyeron en la evolución intrateórica de Freud? Nuestra conjetura es que la historia misma de la ciencia no se comprende si se omiten algunos factores de este tipo. Aunque muchos han dado en considerarlos como "externos" a la racionalidad científica, aquí supondremos que no pocas veces ellos juegan un papel central en el cambio teórico. Por lo que respecta a nuestro ejemplo en cuestión (ST-FT), diremos que tales factores nos parecen consustanciales a la evolución del programa ${ }^{223}$. Un ejemplo concreto de ello resultan ser las

\footnotetext{
${ }^{222}$ Freud historizó una "década de soledad" en su recorrido y la mencionó en varios escritos, p.ej. en Breve informe sobre psicoanálisis (Freud, 1924/2004: 209), en el Prólogo a Wilhelm Stekel, Nervöse Angstzustande und ihre Behandlung (Freud, 1908/2004: 227) y en la carta enviada a Lou Andreas-Salomé el 30 de julio de 1915 (Freud, 1968: 36).

${ }^{223}$ Nos alejamos así de las perspectivas que conceden todo el peso a los factores internos a la investigación. Un ejemplo de esto, a propósito del cambio ST-FT, lo aporta Gerald Izenberg cuando afirma: "No es necesario acudir a factores externos al trabajo clínico y teórico de Freud para explicar por qué cambió de opinión. Lo que es necesario entender es el proceso por el cual llegó a hacerlo" (Izenberg, 1991/1996: 32).
} 
innovaciones añadidas a La etiología de la histeria, en aparente respuesta a las objeciones hereditaristas que su conferencia en la Sociedad de Psiquiatría y Neurología de Viena había desatado ${ }^{224}$. Se trata de la complejización de un modelo de seudoherencia, basado en el determinismo familiar de la enfermedad: el abuso sexual infantil (y no la herencia biológica) constituye la predisposición esencial para la neurosis. En ese sentido, la centralidad repentina que cobra la perversión del padre-seductor (entre las demás figuras de la crianza), puede comprenderse como un intento por brindar especificaciones etiológicas que emulen los patrones de la fenomenología hereditarista $^{225}$ (Vallejo, 2012: 82 y ss.); es decir, puede recuperarse su racionalidad a partir de ciertas contingencias acaecidas más allá de la contrastabilidad con los datos clínicos.

Sin embargo, el rechazar la tajante distinción entre historia interna e historia externa, o el admitir el valor que los factores "externos" tienen para la reconstrucción racional de las teorías, no equivale a decir que tales factores son los preponderantes ni a suponer que la historia de la ciencia es al fin y al cabo completamente reductible a una serie de circunstancias caprichosas o irracionales. Cabe esta aclaración porque también ha habido historiadores que, en la reconstrucción del tránsito ST-FT, intentaron ver en las inconsistencias freudianas un signo de acientificidad o amoralidad, explicando esa evolución intrateórica como un simple cambio de ideas manipulado por Freud a gusto $y$ piacere y a expensas de los datos empíricos. A nuestro modo de ver se ha tratado, en la mayoría de esas lecturas, de la concesión de un malicioso sobrepeso a factores accesorios a la lógica de la investigación freudiana y sus avatares.

\footnotetext{
${ }^{224}$ Considerando que Freud dedica todo el segundo apartado de ese texto a responder objeciones posibles a su teoría, no parece disparatado suponer que en él se plasmó cierta discusión (imaginaria) tras la serie de réplicas que sus críticos posiblemente le habrían espetado luego de su presentación oral.

${ }^{225}$ Una de las versiones más desarrolladas del modelo freudiano puede verse en la carta del 11 de enero de 1897, donde el vienés denomina "herencia" a un entramado de relaciones de seducción traumática entre los familiares de un paciente suyo (Freud, 1985/1986: 236). Freud introduce, allí donde la psiquiatría hereditarista trazaba una genealogía de misteriosos flujos sanguíneos, otro orden de determinaciones psicopatológicas.
} 


\title{
III. Otras explicaciones del tránsito ST-FT: el sobrepeso de la historia externa.
}

\begin{abstract}
"Cuando una exposición externalista utiliza, conscientemente o no, una metodología ingenua (que fácilmente puede manifestarse en su lenguaje descriptivo) se convierte en un cuento de hadas que, a pesar de su aparente sofisticación académica, se derrumbará con el escrutinio historiográfico" (Lakatos 1978/1989: 175).
\end{abstract}

Las versiones del propio Freud sobre el cambio teórico ST-FT fueron las únicas disponibles durante varias décadas del siglo XX. Sin embargo, esa situación se vio modificada en al menos tres oleadas revisionistas, que conviene explicitar.

La primera de ellas se corresponde con la edición de las cartas de Freud a su amigo Fließ, en 1950. Allí se puede leer, pese a que se trata de una versión epistolar parcializada e incompleta ${ }^{226}$, el frenesí inicial de Freud por su ST. Y también se pueden leer la perplejidad y los titubeos posteriores, empapados de una incertidumbre que contraría la seguridad aparente de lo que Freud, al mismo tiempo, publicaba. Todo lo cual culmina con la citada carta de 1897.

La segunda revuelta histórica del asunto, se dio recién a partir de la década de 1980 con una serie de trabajos cuyo espíritu pareciera haber sido contradecir la historización autobiográfica de Freud. Allí se ha destacado El asalto a la verdad, el best-seller en el que Jeffrey Masson (1984/1985) esboza una explicación distinta del tránsito ST-FT: el temor al escándalo público es lo que llevó a Freud a abandonar ST, a pesar de que creía en ella. Masson le reprocha a Freud el abandono de la teoría de la seducción traumática no por razones teoréticas sino por el deseo de ser aceptado por sus colegas académicos alemanes, quienes veían a los niños y a las mujeres histéricas como "mentirosas". A nuestro modo de ver, la animadversión de ST no puede haber sido mayor a la producida con otras conjeturas posteriores que Freud adoptó, incluso con menor vacilación. Además, el reconocimiento de su entorno

\footnotetext{
${ }^{226}$ Los responsables de esa compilación, Ernst Kris, Anna Freud y Marie Bonaparte, hicieron aparecer una edición en 1950 (primero en idioma alemán y cuatro años después en inglés), aclarando en una "nota del editor" que "la selección se hizo conforme al principio de hacer público todo lo relativo a la obra y los intereses científicos del escritor y todo lo concerniente a las circunstancias políticas y sociales en que se originó el psicoanálisis; y de omitir o abreviar todo aquello cuya publicación contradijera la confianza personal o profesional" (citado en Mason, 1984/1985: 123).
} 
académico le fue concedido antes de comunicar su abandono de ST, por ejemplo con el nombramiento como profesor en la Universidad de Viena en 1897. Finalmente, no debemos olvidar que el abandono de ST no es una desestimación completa o radical de los factores vivenciales, sino una refutación de su centralidad etiológica ${ }^{227}$.

Otra obra destacada de esta oleada revisionista ha sido Freud and his father de Marianne Krüll (1979/1986). La autora sostiene que la transición teórica en cuestión no puede entenderse excluyendo la muerte del padre de Freud (en octubre de 1896). Krüll afirma que Freud abandonó la teoría de la seducción traumática por motivos inconcientes que lo llevaron a evitar confrontarse con su propia historia (la neurosis de sus hermanos y de él mismo, así como la efectividad de un padre con rasgos perversos). En lugar de ello, desarrolló una teorización universal generalizando (defensivamente) lo que no pudo analizar realmente de sí. Nuestra opinión es que la conjetura de la autora no parece apoyarse más que en una serie caprichosa de sospechas y de interpretaciones salvajes sobre la biografía de Freud, dejando el asunto de la transición ST-FT peormente explicado.

Frank Sulloway, en un libro precursor que hemos citado y que puede ser incluido en este período, retoma la relación de Freud con su discípulo Felix Gattel para elaborar un interrogante sobre el abandono de ST. Es sabido que Gattel (médico berlinés) fue recibido por Freud en mayo de 1897 para realizar una estadía de seis meses con el siguiente objetivo: "validar por vía estadística las hipótesis de Freud sobre la etiología de la neurastenia (masturbación) y de la neurosis de angustia (coitus interruptus) con una encuesta entre 100 pacientes de la Clínica Psiquiátrica de la Universidad de Viena (Krafft-Ebing)" (Masson, en Freud 1985/1986: 335). Pese a no querer incluirla, Gattel se topó en su muestra con diecisiete casos de histeria; de los cuales sólo dos confirmaban la existencia de ataques sexuales infantiles (sin aparecer involucrado el padre). Sulloway hace notar que Freud escribe la carta del abandono un día después de retornar de unas vacaciones en Italia, compartidas con Gattel (entre otros); e introduce la pregunta por la influencia

\footnotetext{
${ }^{227}$ Además, también por esta época, la hipótesis de la seducción traumática fue revisada y dio lugar a diversas teorizaciones que, a pesar de sus diferencias, rescatan el valor de las vivencias de origen exógeno en la constitución subjetiva (p.ej. la "teoría del apego" de John Bowlby, 1969/1990 y la "teoría de la seducción generalizada" de Jean Laplanche 1987/1989).
} 
que las conclusiones del estudio de su discípulo pueden haber tenido para la decisión freudiana de abandonar ST (Sulloway, 1979/1992: 513-515). Un examen crítico de esta lectura y de la relación Freud-Gattel puede hallarse en Schröter y Hermanns (1992).

En tercer lugar, desde fines del siglo $\mathrm{XX}$, diversos trabajos historiográficos (mayormente anglosajones) pusieron en duda la fiabilidad de las narraciones que Freud adjudicaba a sus pacientes. Se ha dicho que el vienés había reconstruido interpretativamente escenas inexistentes (Schimek, 1987), que era deshonesto (Esterson, 1993, 2005/2007) o de pobres aptitudes científicas (Israëls y Schatzman, 1993), que había sugestionado a los pacientes para que relataran las escenas de seducción (Borch-Jacobsen, 1996), que no aportó evidencias válidas sobre los casos de seducción (Triplett, 2004), etc. Se trata de una vertiente variada de críticas, cuyo común denominador pareciera ser la tendencia a defenestrar la credibilidad de Freud, muchas veces a expensas tanto del rigor metodológico necesario en una investigación histórica, como del objetivo por alcanzar coherencia epistémica ${ }^{228}$.

Sabemos que siempre pueden hacerse relatos divergentes entre sí pero igual de compatibles con un mismo conjunto de datos: desde un punto de vista lógico, la tesis de la subdeterminación de la teoría por la experiencia vale lo mismo para la física para la historiografía. Sin embargo, las reconstrucciones históricas están, frecuentemente, motorizadas por intereses de distinta índole. No debería olvidarse, en todo caso, que muchos de estos trabajos no han sido el resultado de un esfuerzo crítico por conocer las razones que llevaron a Freud a cambiar de conjetura, sino por defenestrar su figura a partir de las contradicciones halladas en su relato ${ }^{229}$ : "la controversia a propósito de la

\footnotetext{
${ }^{228}$ Una forma promisoria de considerar esta evolución historiográfica es a partir de lo que Oscar Nudler ha llamado "espacios controversiales" (Nudler, 2004). Se trata de un modelo de cambio conceptual que supone la existencia de un entramado de controversias que se desarrollan en el tiempo a partir de un "foco" variable de problemas discutidos y un "suelo común" (también variable) de aspectos implícitos no controversiales. Según Nudler, muchos procesos de cambio conceptual consisten en refocalizaciones: visibilización y problematización de supuestos comunes, introducción o resignificación de conceptos y problemas, etc. Esto sucede a partir de la participación controversial de distintos actores, pero sin que ello suponga mera continuidad ni ruptura radical del espacio. Lo que venimos analizando puede verse como un espacio controversial, que ha sido objeto de refocalizaciones a partir de la aparición de nuevos datos históricos e historiadores con intereses diversos.
}

${ }^{229}$ En el mejor de los casos, podemos agregar. Puesto que, por desgracia, no pocos historiadores de Freud han elaborado conclusiones sobre su producto teórico-metodológico a 
teoría de la seducción está basada en la descripción que dio más tarde" (Israëls, 2005/2007: 25). Por otro lado y a los fines de nuestro tema, no deja de ser interesante leer, de la pluma de sus detractores, que el cambio ST-FT puede comprenderse a partir del espíritu crítico de Freud: "vemos pues que la explicación es sorprendentemente simple, no hay nada misterioso. Freud simplemente tuvo una idea y no funcionó. Lo intentó a fondo, pero fue un fracaso. Entonces decidió abandonarla. Es tan tonto como esto" (ibíd.).

Nuestra tesis es que el vienés estaba sentando las bases de un nuevo programa de investigación $y$, en ese sentido, se comprende la existencia natural de anomalías (enfrentadas y obviadas) como motor principal de su evolución. Ello no excluye, como hemos dicho, que diversos factores no epistémicos pudieran desempeñar un papel importante en la forma en que evolucionó su teoría. Pero tampoco parece correcto descentrar la investigación clínica y pretender hacer de esos factores el principal motor de la investigación freudiana.

Coincidimos con Lakatos cuando afirma que "las reconstrucciones racionales quedan siempre sumergidas en un océano de anomalías. Estas anomalías tendrán que ser eventualmente explicadas, ya sea por alguna reconstrucción racional mejor o por alguna teoría empírica 'externa”' (Lakatos, 1971/1987: 65). En base a ello puede decirse, a modo de conjetura, que gran parte de los detractores de Freud han apelado, con mayor o menor malicia, a la segunda opción lakatosiana para reconstruir esta historia. Ahora bien, el problema de este proceder historiográfico es que las razones que se dan para explicar el cambio teórico (factores externos causantes de un juicio equivocado) no aparecen firmemente apoyadas de manera independiente, sino que parecieran inventarse y sostenerse ad-hoc. El problema se agudiza cuando se quiere explicar este fenómeno exclusivamente a partir de tales razones. Insistimos en que, si bien no pueden obviarse los factores externos (determinados desde cada perspectiva), intentar explicar ese fenómeno histórico de cambio teórico

partir de indicios sobre su vida personal, evaluados moralmente. Así, se procede para obtener, al fin y al cabo, una serie de argumentos ad-hominem que falazmente pretenden descalificar a las teorías psicoanalíticas y su vigencia. En ese sentido, resultan ilustrativas estas palabras de Lakatos: "Permítaseme, por último, recordar al lector mi chanza favorita - y por ahora perogrullesca- de que la historia de la ciencia es frecuentemente una caricatura de sus reconstrucciones racionales; que las reconstrucciones racionales son frecuentemente caricaturas de la historia real; y que algunas historias de la ciencia son caricaturas de ambas: de la historia real y de sus reconstrucciones racionales" (Lakatos, 1971/1987: 73). 
con base exclusiva a tales factores equivale a desestimar la racionalidad de las investigaciones empíricas de Freud.

Podemos enfocar el asunto de otra manera: para explicar las decisiones tomadas por los científicos en los momentos de cambio teórico debemos referirnos a lo que ellos han creído que es mejor elegir. Aquí hay que decir dos cosas: en primer lugar, que lo que ellos han creído no tiene por qué coincidir con lo que nosotros creamos; y en segundo lugar, que las creencias no son un conjunto homogéneo. Esto último, que es una perogrullada en psicoanálisis, no siempre es tenido en cuenta por los historiadores o filósofos: sabemos que Freud tenía por ideal una forma de racionalidad científica que le exhortaba atenerse a los hechos, y también sabemos que en sus épocas tempranas tenía la esperanza de llevar a buen puerto el psicoanálisis. Podemos suponer que ambas tendencias confluyeron en la decisión de reemplazar ST por $\mathrm{FT}^{230}$.

De todas maneras, lo que las explicaciones externalistas parecen obviar es el hecho de que FT supone una teorización mejor que ST. Esto es así porque FT no desestima el papel de los hechos traumatizantes acaecidos realmente en la historia de un sujeto, sino que los descentraliza. Naturalmente, este complejización implica un aumento de los interrogantes; pero posiblemente, si Freud no hubiera modificado su teoría de ese modo, los problemas infranqueables hubieran sido muchos más y más significativos. De manera tal que FT es progresiva, para nosotros y para Freud; y lo que hay que explicar es un cambio progresivo.

Para finalizar este capítulo diremos que, más allá de este complejo espacio de controversias historiográficas, lo que hemos podido elucidar nos basta como ejemplificación crítica de lo que hemos problematizado sobre la metodología de la ciencia de Popper: la racionalidad histórica es sumamente compleja y es inaprensible por la vía del canon popperiano. Los elementos involucrados en el cambio ST-FT rebasan, sin dudas, la órbita de las falsaciones popperianas. Al menos en lo que a este episodio refiere, Freud no fue un verificacionista sino un falsacionista sofisticado.

\footnotetext{
${ }^{230}$ Considerando que la justificación de las teorías depende de propósitos más amplios que los relativos al encaje entre la evidencia empírica y la teoría, los valores no epistémicos necesariamente aparecen involucrados en toda elección teórica (cf. Anderson, 2004 y Potter, 2006, cap. 3).
} 


\title{
PRIMERA SÍNTESIS RETROSPECTIVA
}

\begin{abstract}
“...así como una creencia abandonada sobrevive en calidad de superstición y una teoría resignada por la ciencia se conserva como opinión popular, del mismo modo aquel originario desprecio de los círculos científicos por el psicoanálisis se continúa en la irrisión de que lo han hecho objeto los legos que escriben libros o platican. Nada de eso, pues, debe asombrarlos ya" (Freud, $34^{\circ}$ conferencia. Esclarecimientos, aplicaciones, orientaciones, p. 128).
\end{abstract}

\section{Algunas conclusiones provisorias a partir del recorrido realizado}

En el tercer capítulo realizamos una breve exposición de la epistemología de Popper, su contexto filosófico de surgimiento y sus propuestas principales. También reseñamos allí la caracterización que nuestro autor hizo del psicoanálisis freudiano como una pseudociencia, e introdujimos nuestras preguntas sobre este juicio y sobre su razón de ser. Luego nos dedicamos a exponer una serie de dificultades que el racionalismo crítico ha presentado con el correr del siglo xx; y finalmente intentamos comprender la figura de Popper a partir de su carácter transitivo en la historia de la filosofía contemporánea de la ciencia.

En el cuarto capítulo intentamos mostrar que Freud perteneció a una tradición crítica y falibilista. Defendimos la posibilidad de elucidar el surgimiento y evolución de sus ideas psicoanalíticas como un programa de investigación lakatosiano y, a partir de esto, propusimos una reconstrucción de dos episodios de cambio teórico. Esta reconstrucción nos permitió mostrar al menos tres cosas: que la sentencia de pseudociencia dictada por Popper al psicoanálisis, indudablemente omitió analizar la metodología falsacionista de su creador. Además, a partir de tales reconstrucciones, hemos podido caracterizar el falsacionismo freudiano como sofisticado, por estar en sintonía con la 
propuesta lakatosiana. Finalmente, abocándonos más profundamente al segundo episodio de modificación intra-teórica, intentamos elucidar las distintas narraciones que Freud mismo fue realizando de dicho cambio, sus incongruencias y aspectos destacados. Asimismo, hemos enfatizado (contrariando al canon popperiano) el valor explicativo que algunos factores no epistémicos pueden tener para una reconstrucción racional de este tipo de cambios intra-teóricos, pero también nos hemos opuesto a ciertas lecturas que tienden a colocar dichos aspectos no epistémicos en el centro de la escena de las discusiones sobre la racionalidad de los cambios científicos. Específicamente, en relación al segundo caso de cambio teórico analizado, expresamos por qué resulta incorrecto descentrar la investigación clínica y pretender hacer de esos factores el principal motor de las indagaciones freudianas.

En síntesis, a partir de nuestro itinerario esperamos haber dado suficientes razones para sostener las siguientes conjeturas:

a) La epistemología de Popper no está exenta de dificultades que vuelven problemática su aplicación directa en todo campo de saber.

b) El rótulo de pseudociencia dado por Popper al psicoanálisis no se apoya en datos fehacientes ni se acerca al proceder efectivo de Freud.

c) La omisión popperiana parece más una maniobra ad-hoc para proteger su criterio de demarcación, que una crítica racional.

d) Entre los factores que incidieron en las modificaciones de la teoría por parte de Freud, las contra-evidencias empíricas tienen un papel importante. Ello no nos autoriza a desdeñar otros factores no epistémicos en la determinación de los cambios intrateóricos, así como tampoco nos permite erguirlos como único blasón explicativo. 


\section{Secuelas de la omisión popperiana}

En nuestro recorrido, hemos partido de la suposición de que no es posible una filosofía (incluso de la ciencia) valorativamente neutra ${ }^{231}$. Esto se traduce en que toda concepción filosófica se asienta sobre una serie de valores que busca preservar y, desde allí, arremete contra aquellos valores opuestos 0 contradictorios.

Aún a expensas de Freud, el psicoanálisis vino a poner en cuestión una serie de valores típicamente modernos, que van desde la moral sexual de la época hasta la posibilidad de autoconocimiento. ¿No es acaso desde Freud que se han podido dar explicaciones racionales que descentran la racionalidad de la órbita humana? No pareciera casualidad que Popper, un acérrimo defensor de la racionalidad moderna, haya sido un agente deslegitimador del psicoanálisis, aún sin estudiarlo ni comprenderlo. ${ }^{232}$ Hemos visto que la crítica popperiana se basa en una omisión tan curiosa como inexcusable, al punto que desde la óptica psicoanalítica se estaría tentado de proponer: Popper no ha querido saber nada de ello ${ }^{233}$.

Pese a lo anterior, sería exagerado y falso decir que la detracción popperiana ha dado origen a todas las críticas o problemas epistemológicos del psicoanálisis. Tal y como hemos visto en la primera parte, ha habido controversias epistemológicas basadas en diversos criterios y posturas, provenientes de muy diversas tradiciones filosóficas y dirigidas a disímiles aspectos de la teoría o práctica psicoanalíticas. Sin embargo, pese a esa heterogeneidad, la crítica de Popper pareciera haber constituido un

${ }^{231}$ Como ya hemos mencionado, el propio Popper reconoció que es "prácticamente imposible el intento de desterrar los valores extracientíficos del quehacer de la ciencia" (Popper, 1969/1973: 111).

${ }^{232}$ En El edificio de la razón Jaime Labastida sostiene que la obra de Freud constituye un verdadero escándalo para la concepción filosófica del sujeto y de la racionalidad: "La filosofía ¿acaso no exige la prioridad de la razón y la conciencia? [...] Si la filosofía escarba, de la caverna hacia la luz, el psicoanálisis escarba hacia dentro del sujeto, hacia lo profundo y la oscuridad. ¿No se debería lisa y llanamente condenar este escándalo?" (Labastida, 2007: 210).

${ }^{233}$ Freud dividía las resistencias al psicoanálisis en dos tipos: intelectuales y afectivas, y pensaba que la mayoría de ellas "no eran de naturaleza intelectual, sino que brotaban de fuentes afectivas. Así se explicaban su apasionamiento y su desprecio por la lógica" (Freud, 1925a/2004: 234). El psicoanálisis, en virtud de sus teorizaciones, "significaba una grave afrenta al amor propio de los seres humanos, afrenta a la que llamé psicológica, situándola en una misma línea con la biológica, infligida por la doctrina de la descendencia [Darwin], y con la anterior, la cosmológica, lanzada por el descubrimiento de Copérnico" (ibíd. pp. 234-235). 
antecedente inevitable para todas las lecturas posteriores; al punto que siempre aparece citada, ya sea para acordar con ella, para moderarla o para rechazarla. El negligente ataque de Popper ha funcionado, diremos, como una especie de estigmatización originaria, retomada en grado variable por diversas voces.

Lakatos, en el último párrafo de la introducción a La metodología de los programas de investigación científica, expresa algo fundamental:

\begin{abstract}
El problema de la demarcación entre ciencia y pseudociencia también tiene serias implicaciones para la institucionalización de la crítica. La teoría de Copérnico fue condenada por la Iglesia Católica en 1616 porque supuestamente era pseudocientífica. Fue retirada del índice en 1820 porque para entonces la Iglesia entendió que los hechos la habían probado y por ello se había convertido en científica. El Comité Central del Partido Comunista Soviético en 1949 declaró pseudocientífica a la genética mendeliana e hizo que sus defensores, como el académico Vavilov, murieran en campos de concentración; tras la muerte de Vavilov la genética mendeliana fue rehabilitada; pero persistió el derecho del Partido a decidir lo que es científico y publicable y lo que es pseudocientífico y castigable. Las instituciones liberales de Occidente también ejercitan el derecho a negar la libertad de expresión cuando algo es considerado pseudocientífico, como se ha visto en el debate relativo a la raza y la inteligencia. Todos estos juicios inevitablemente se fundamentan en algún criterio de demarcación. Por ello el problema de la demarcación entre ciencia y pseudociencia no es un pseudoproblema para filósofos de salón, sino que tiene serias implicaciones éticas y políticas (Lakatos, 1978/1989: 16).
\end{abstract}

En base a ello se comprende por qué la omisión de Popper no es una maniobra inocente ni ha pasado inadvertida para la historia del psicoanálisis. La idea de que la teoría freudiana es pseudocientífica es un mito deslegitimador que Popper inventó y contribuyó a desarrollar sobre la base de esa omisión. Mito que ha proliferado de manera virulenta, al modo de una ideología epistemológica que se reprodujo rutinariamente en diversos ámbitos y contextos académicos. Contra esta situación valgan las palabras de Giordano Bruno, quien fue quemado vivo en la hoguera por pensar diferente: "nunca debe valer como argumento la autoridad de cualquier hombre, por excelente e ilustre que sea [...] es suma estupidez creer por costumbre inveterada; es cosa 
irracional conformarse con una opinión a causa del número de los que la tienen" (Bruno, citado en Mondolfo, 1980: 46). 
TERCERA PARTE. El psicoanálisis de Adolf Grünbaum: una ciencia mal fundamentada

"Casi todos los hombres fundan su escepticismo respecto a una cosa en la fe ciega en otra" (Georg Christoph Lichtenberg, Aforismos, p. 195). 


\section{CAPÍTULO 6: El inductivismo de Adolf Grünbaum y su crítica al psicoanálisis freudiano}

\section{Introducción}

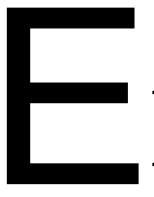

$\mathrm{n}$ virtud de la significancia que se le ha otorgado a la producción filosófica de Adolf Grünbaum sobre el psicoanálisis freudiano, dentro y fuera de él, y considerando que desde el interior de la disciplina sólo han habido respuestas exiguas, de la mano de algunos comentadores que sólo han abordado la cuestión de manera tangencial o por relación a alguna otra problemática específica, en esta parte nos propondremos trascender el límite que impone cualquier lectura panorámica y arribar a un abordaje pormenorizado del tema. Nuestra forma de presentar la crítica de Grünbaum no será, entonces, ceñida a su significado general, sino que intentará ingresar en los peculiares debates epistemológicos que implica y a su fundamentación técnica (siempre que resulte oportuno), elucidando los presupuestos filosóficos desde los que el autor diseña su estrategia argumental y ponderando la pertinencia de sus principales afirmaciones. Una vez hecho esto, estaremos en mejores condiciones de balancear los diversos aspectos de esta crítica en una visión que integre lo antes analizado.

\section{Contexto de la crítica}

Adolf Grünbaum nació en 1923 en Alemania y en 1938, junto a sus padres y hermanos, emigró a Estados Unidos de Norteamérica en calidad de refugiado judío de la persecución Nazi. En Norteamérica realizó sus estudios de grado en física y filosofía, graduándose en 1944; y luego sus estudios de posgrado en 1948 y 1951 . Fue presidente de la Asociación de Filosofía de las Ciencias en 1968 (sucediendo a Ernest Nagel). Para la época en la que inicia sus 
publicaciones sobre psicoanálisis, Grünbaum ya llevaba una profusa carrera de investigación y docencia en temas de filosofía de la ciencia y cosmología. Grünbaum era ya un pensador reconocido y admirado por sus estudios sobre filosofía del tiempo y del espacio ${ }^{234}$. A diferencia de otros críticos del psicoanálisis, como Popper, Grünbaum se dedicó a analizar la teoría de Freud relativamente tarde en su vida y con un significativo historial de logros profesionales en otro campo de investigación.

La crítica de Adolf Grünbaum al psicoanálisis no es de la misma calaña que el diletantismo de Popper: mientras que la de Popper es una diatriba infundada, la de Grünbaum se basa en una precisa indagación de la obra freudiana ${ }^{235}$. Al mismo tiempo, la réplica de Grünbaum debe ser diferenciada de aquellas críticas que hacen hincapié en los aspectos biográficos de Freud (Masson, Sulloway, Onfray, etc.). Grünbaum toma por objetivo de ataque a la evidencia y argumentación que Freud utilizaba para sostener sus teorizaciones principales.

Aunque Grünbaum escribe sus primeros artículos sobre psicoanálisis en la década de 1970 en distintas revistas de filosofía (Grünbaum, 1977a, 1977b, 1978a, 1979a, 1979b, 1980, 1981, 1983a, 1983b, 1983c, 1983d), su perspectiva general del tema se dio a conocer con la publicación de su libro The foundations of psychoanalysis en 1984. Este escrito reúne lo esencial de sus trabajos anteriores y presenta la más completa y sistemática crítica epistemológica al psicoanálisis escrita hasta ese momento y, posiblemente, hasta hoy en día. A pesar de la rápida y contundente recepción que este libro ha tenido en pensadores de lengua inglesa, resulta una desgracia que no haya tenido la repercusión suficiente como para ser traducido al español ${ }^{236}$.

\footnotetext{
${ }^{234}$ Cf. Cohen (1983) y el conjunto de ensayos editados en honor a Grünbaum, con motivo de su sexagésimo cumpleaños.

${ }^{235}$ Coincidimos con Charles Hanly en que "el conocimiento de Grünbaum sobre los textos de Freud, dado su propósito e interés, está años luz por delante del de filósofos como Popper, Habermas y Ricœur, por no mencionar el conocimiento de algunos psicoanalistas" (Hanly 1988: 524). ["Grünbaum's scholarship on the Freud texts, given his purpose and interests, is light years ahead of that of philosophers such as Popper, Habermas, and Ricoeur, not to mention the scholarship of some psychoanalysts"].

236 Tampoco abundan las lecturas en idioma castellano sobre la crítica de Grünbaum al psicoanálisis. Algunos analistas españoles le han dedicado algunas páginas: Joan Coderch (1989: 37-44 y 2006: 144-148) y Alejandro Ávila Espada (1994: 632-640; y 2014: 85-88) lo hacen entreverando el tema con otros aspectos epistemológicos o metodológicos; y Antonio García de la Hoz le ha dedicado un capítulo en uno de sus libros (2010: 255-277). En nuestro ámbito sudamericano, algunos pocos autores han referido al tema: por ejemplo Jorge Ahumada
} 
Grünbaum se propone indagar, en el mencionado libro, un aspecto epistemológico general que podemos reconstruir al modo de una interrogación: hasta dónde la situación del "setting" analítico constituye una base confiable para proveer de validación a la teoría psicoanalítica. Como veremos, lo que diferencia a la crítica de Grünbaum de otras críticas al psicoanálisis es su precisión conceptual y su perspicacia en tanto lector de Freud. Al mismo tiempo, como podremos mostrar, los argumentos críticos que Grünbaum desarrolla aparecen mesturados con otras manifestaciones a favor de las ideas freudianas, al punto que la tendencia general de la obra pareciera sumergida en una cierta ambivalencia ${ }^{237}$. Un ejemplo claro de ello es la crítica fulminante que hace a los pioneros en la orientación hermenéutica del psicoanálisis y a otros filósofos detractores.

Con el correr de los años Grünbaum ha ido refinando algunos matices de su crítica, sin alterar lo central de sus ideas ni agregar, a nuestro modo de ver, aspectos significativos a su planteo original (Grünbaum, 1993; 2003; 2006; 2007; 2008; 2009).

\section{El ataque de Grünbaum a la tradición hermenéutica}

The foundations of psychoanalysis comienza con una lectura crítica de tres filósofos que han intentado instalar nuevas bases conceptuales para identificar

(1997a/1999; 2006) dedicándole algunos párrafos considerables; Ricardo Bernardi (1994/1995) y Gregorio Klimovsky (1987/2009), ambos abordándolo de manera colateral. Algunos analistas que han sido traducidos al español se han referido a la crítica de Grünbaum, pero también insertando sus comentarios en contextos más amplios de análisis (con excepción de la reseña crítica de Sachs, 1993/1996), lo cual arroja como resultado final algunos pocos comentarios e ideas panorámicas: por ejemplo André Green (1991/1993), Helmut Thomä y Horst Kächele (1985/1989), Élizabeth Roudinesco (1999/2000) y Robert Wallerstein, (1986/1987). El resto de las discusiones sobre los aspectos epistemológicos y metodológicos que Grünbaum ha enfocado, se ha venido efectuando fundamentalmente en lengua inglesa y permanece sin traducir.

${ }^{237}$ Paul Robinson ha dicho que la actitud benevolente de Grünbaum hacia Freud no es más que una especie de "maniobra dialéctica", pues forma parte de una mostración falsa de admiración que sólo vuelve más impresionante su tiro de gracia final (Robinson, 1993: 182). Lo cierto es que su carácter crítico no le impidió a Grünbaum decir que el pensamiento freudiano era "una mente elevada" (a soaring mind, p.189), dotada de una "imaginación teórica brillante" (brilliant theoretical imagination, p.278); y su obra algo "memorable" (momentous, p.39), "pionero" (pionnering, p.148), "brillante" (brillant, p.13, 93, 135), entre otras calificaciones. 
a la disciplina freudiana. Bases conceptuales que tienen un único propósito: ubicar al psicoanálisis en las humanidades, es decir por fuera de la órbita de las ciencias, especificando su racionalidad hermenéutica o crítica. De este modo, tanto para Paul Ricœur como para Jürgen Habermas y George Klein, el psicoanálisis puede evitar las acusaciones de pseudociencia que se le habían lanzado.

Aunque Grünbaum no lo explicite, podemos elucidar el sentido que tiene su arremetida inicial contra estos filósofos al comienzo del libro: está en realidad atacando la posibilidad de esa vía de escape del terreno científico. Puesto que la intención de Grünbaum es mostrar cómo el psicoanálisis no cumple con los estándares de prueba de las ciencias empíricas, primero necesita dejar en claro que debe ser considerado una ciencia como las demás, y no una hermenéutica. De lo contrario, si la perspectiva hermenéutica finalmente se consolidase, la crítica de Grünbaum perdería sentido.

Para Grünbaum, la propuesta hermenéutica no es más que "un mito exegético generalizado"238 (Grünbaum, 1984: 1), una "estratagema" con mucho atractivo para los analistas, una forma de evadir las demandas de justificar las explicaciones causales que la propuesta freudiana conlleva (ibíd. p. 57).

Grünbaum sostiene que los hermeneutas se equivocan al pensar que los afanes freudianos de incluir al psicoanálisis en las ciencias de la naturaleza estuvieron sólo presentes al inicio, en el intento de llevar a cabo el Proyecto de psicología con base en una ontología materialista; por el contrario, para Grünbaum, sólo cuando Freud abandona la perspectiva del Proyecto comienza a establecer los fundamentos epistémicos del psicoanálisis: aquellos que le permitieron inferir hipótesis universales del funcionamiento psíquico a partir de fenómenos clínicos singulares, sin por ello identificar entidades materiales del cerebro con aspectos funcionales de la mente. Para Grünbaum, los revisionistas hermenéuticos malinterpretan la metapsicología cuando afirman que se trata de una remanencia freudiana del cientificismo al que adhería, pues considera que la metapsicología es lo que muestra, en tanto superestructura conjetural y perfectible, la relación de Freud con la ciencia. Su tesis es que "además de descansar sobre una exégesis mítica de los escritos de Freud, las

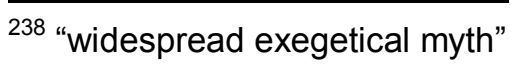


tesis de estos hermenéuticos se basan en profundos malentendidos del contenido mismo y de los métodos de las ciencias naturales"239 (ibíd. p. 1). Sus argumentos son para apoyarla.

\title{
a) La crítica a las ideas de Jürgen Habermas
}

Las principales ideas de Habermas sobre el psicoanálisis aparecieron en la tercera parte de su libro Conocimiento e interés (1968/1990), y parecieran constituir la versión hermenéutica que Grünbaum más desdeña.

Para Habermas,

\begin{abstract}
El psicoanálisis es importante para nosotros como el único ejemplo tangible de una ciencia que recurre metódicamente a la autorreflexión. Con el nacimiento del psicoanálisis se abre la posibilidad de un acceso metodológico, a partir de la lógica de la investigación misma, a esa dimensión ocultada por el positivismo. Esta posibilidad no ha sido realizada por el malentendido cientifista del psicoanálisis mismo, iniciado por el propio Freud, como fisiólogo que es lo que en principio era, traicionando aquella posibilidad. Indudablemente, ese malentendido no es del todo infundado. El psicoanálisis, de hecho, une la hermenéutica a realizaciones que parecían genuinamente reservadas a las ciencias de la naturaleza (Habermas, 1968/1990: 215).
\end{abstract}

Es decir, Habermas sostiene que la metapsicología es una pseudocomprensión cientificista de Freud que lo devuelve al objetivismo positivista de las ciencias de la naturaleza, pero que el psicoanálisis constituye una forma de racionalidad basada en intereses emancipatorios, distintos a los intereses instrumentales de la ciencia.

Una diferencia fundamental de la metodología psicoanalítica respecto de la metodología de las ciencias empírico-analíticas es, para Habermas, que se basa en una noción distinta de causalidad:

Con Hegel la podemos llamar, para distinguirla de la causalidad de la naturaleza, una causalidad de destino, puesto que la conexión causal entre escena inicial, defensa y síntoma no está fijada según leyes naturales en una invarianza de la naturaleza, sino sólo espontáneamente en una invarianza de la biografía,

239 "But besides resting on a mythic exegesis of Freud's writings, the theses of these hermeneuticians are based on profound misunderstandings of the very content and methods of the natural sciences." 
representada por la compulsión a la repetición, pero soluble mediante la fuerza de la reflexión. [...] Mientras en la manipulación técnica de la naturaleza hacemos trabajar en nuestro interés a la naturaleza en razón de nuestro conocimiento de las relaciones causales, la comprensión analítica aprehende la causalidad del inconsciente como tal; la terapia no se basa, como la «causal» en sentido estricto de la medicina somática, en una utilización de las conexiones causales conocidas, debe más bien su eficacia a la abolición (Aufhebung) de las conexiones causales mismas. (ibíd. p. 268-269).

Es por esto que "las interpretaciones generales pueden afirmar su pretensión de validez universal sólo abstractamente, ya que sus deducciones resultan determinadas adicionalmente mediante el contexto" (ibíd. p.270), mientras que las enunciaciones de un paciente en la situación analítica sólo pueden comprenderse en su individualidad contextual (temporal y espacial). Es esta fundamentación hermenéutica de las interpretaciones psicoanalíticas lo que impide equiparar la metodología freudiana con la metodología de las ciencias naturales, que buscan validar sus enunciados independientemente del contexto de su aplicación.

Grünbaum considera que, debido a la perspectiva de su creador, el psicoanálisis no puede ser apartado de las normas científicas generales. Al mismo tiempo, considera que la visión que Habermas tiene de la ciencia es apenas una ridícula caricatura de la misma. Luego de su análisis, Grünbaum sostiene: "por lo tanto, lejos de dar una elucidación filosófica de la teoría clínica, Habermas la confunde y tergiversa en forma exasperantemente indisciplinada"240 (Grünbaum, 1984: 42). Veamos a qué se refiere.

Para Grünbaum, la tendencia de Freud fue siempre la de buscar causas. $Y$ sostiene que lo aseverado por Habermas es inconsistente:

\footnotetext{
Habermas se desliza desde la conquista terapéutica de los efectos por la eliminación de su causa, a la disolución del vínculo causal entre el agente patógeno y la neurosis. La superación de un efecto socavando su causa es
}

\footnotetext{
240 "Thus, far from giving a philosophical elucidation of the clinical theory, Habermas obfuscates and misdepicts it in an exasperatingly undisciplined way".
} 
difícilmente equivalente a disolver la relación de causalidad que los une. ${ }^{241}$

(Grünbaum, 1984: 11-12).

El psicoanálisis, sostiene Grünbaum, no apunta a una supresión de las conexiones causales sino a su utilización; pues apunta a hacer consciente la experiencia reprimida que dio origen al síntoma, mediante la elucidación de las relaciones causales. En ese sentido, el psicoanálisis no se distancia de cualquier ciencia natural.

Grünbaum se muestra particularmente descontento con la lectura que hace Habermas de la evolución del pensamiento freudiano: "Habermas ideó el mito exegético de que el Freud maduro había considerado a la metapsicología como lo primordialmente científico, en base a razones ontológicas; como una presunta reliquia mantenida desde los embriagadores días del 'Proyecto' de 1895"242 (Grünbaum, 1984: 84). Habermas imagina que la cientificidad de la teoría habría pasado, para el Freud maduro, por su reductibilidad a la metapsicología; y luego antepone su tesis de que ello constituyó una malinterpretación cientificista de su propia teoría. Como veremos más adelante, para Grünbaum, el Freud maduro consideraba la cientificidad del psicoanálisis más por su teoría clínica que por su metapsicología.

Por otro lado, en lo que a la validación epistémica respecta, Grünbaum cree que

El pilar de la consideración de Habermas sobre la validación clínica es que el paciente es el último árbitro epistémico de las interpretaciones generales utilizadas retrodictivamente por el médico en la construcción de un escenario etiológico para la explicación de la neurosis del paciente ${ }^{243}$ (ibíd. p.22).

\footnotetext{
241 "Habermas slides from the therapeutic conquest of effects by the removal of their cause into the dissolution of the causal linkage between the pathogen and the neurosis. Overcoming an effect by undercutting its cause is hardly tantamount to dissolving the causal connection that links them".

242 “...Habermas contrived the exegetical myth that the mature Freud had deemed the metapsychology primordially scientific on ontological grounds, as a presumed lifelong relic from the heady 1895 days of the "Project"."

243 "The pillar of Habermas's account of clinical validation is that the patient is the ultimate epistemic arbiter of the general interpretations used retrodictively by the doctor to construct an etiologic scenario for the explanation of the patient's neurosis."
} 
Recordemos que este privilegio epistémico es, según Habermas, debido a una "diferencia específica" en torno al objeto de estudio:

...la aplicación de hipótesis a la realidad queda, en el caso de la verificación de teoría mediante la observación (en la esfera funcional de la actividad instrumental), como asunto propio del sujeto investigador; pero en el caso de la verificación de interpretaciones generales mediante la autorreflexión (en el marco de una comunicación entre médico y paciente), la aplicación se convierte, en cambio, en autoaplicación del objeto de la investigación que toma parte en el proceso de conocimiento. (Habermas, op. cit. p. 259-260).

Habermas considera que el analizante goza de cierta posición epistémica privilegiada, lo que socava cualquier semejanza entre la tarea de un analista y la de un físico o químico: mientras que estos últimos estipulan a qué leyes universales se subsumen las particularidades de los objetos de estudio, en el caso del analista sus construcciones sólo tienen la calidad tentativa de las interpretaciones de las humanidades, que deben ser confirmadas por el paciente antes de que puedan ser aceptadas como verdaderas. Habermas pretende distanciar el psicoanálisis de la ciencia natural a partir de postular una manera fundamentalmente diferente de conocer, que lo conduce a defender un método diferente de validación.

Grünbaum antepondrá a ese privilegio epistémico que Habermas da al paciente como árbitro último de la verdad analítica, una serie de afirmaciones hechas por Freud en Construcciones en análisis. Allí Freud sostiene que

\footnotetext{
El camino que parte de la construcción del analista debía culminar en el recuerdo del analizado; ahora bien, no siempre lleva tan lejos. Con harta frecuencia, no consigue llevar al paciente hasta el recuerdo de lo reprimido. En lugar de ello, si el análisis ha sido ejecutado de manera correcta, uno alcanza en él una convicción cierta sobre la verdad de la construcción, que en lo terapéutico rinde lo mismo que un recuerdo recuperado (Freud, 1937/2004: 267).
}

En la lectura de Grünbaum, Freud no le otorga al paciente ese lugar privilegiado que Habermas declara. Para Grünbaum, Freud mostró en varias oportunidades que las experiencias reprimidas de sucesos etiológicos significativos son construcciones inferidas por el médico y no recuerdos traídos por el paciente; lo cual dista mucho del papel ingenuo que Habermas quiere darle a la memoria del paciente $y$, por ende, a su valor de árbitro en la 
evaluación de las hipótesis analíticas. Según Grünbaum, en varios de los historiales clínicos Freud insiste en que sus interpretaciones son correctas, incluso cuando el paciente las ha rechazado expresamente o precisamente porque el paciente los rechaza. Un ejemplo claro de esta "asimetría epistémica" es el que hallamos en Sobre la psicogénesis de un caso de homosexualidad femenina, en donde

\begin{abstract}
Freud expresó plena confianza en su propia reconstrucción etiológica de la elección de objeto sexual de la paciente. Sin embargo, señaló que ella rechazaba completamente sus interpretaciones y atribuyó ese rechazo a su deseo de castigarlo, como sustituto del padre, aferrándose a su neurosis. ${ }^{244}$ (Grünbaum, 1984: 27).
\end{abstract}

Grünbaum sostiene que la psicología cognitiva aporta evidencia a favor del escepticismo freudiano respecto a la capacidad de recordar fidedignamente, y que contraría la garantía de la auto-reflexión que Habermas defiende. Asimismo, lo que algunos experimentos sobre la memoria muestran es que la relación del sujeto con sus estados mentales pasados es equivalente a la relación de ajenidad que un científico mantiene con ciertos aspectos de la naturaleza, de manera que no habría necesidad de pensar un tipo de relación distinta para el conocimiento psicoanalítico.

Veremos luego que Grünbaum ataca el planteo de Habermas porque contradice una de sus principales tesis en contra del psicoanálisis: que la validación teórica está sujeta a una contaminación de la evidencia. Para Grünbaum, el paciente es una fuente de error (más que de verdad) porque su memoria brinda datos dudosos y porque su intención es cumplir con las expectativas del analista. Es por esto que Grünbaum ataca la posición privilegiada en la que Habermas coloca al paciente, en lo relativo a la validación epistémica.

Otro blanco de la crítica de Grünbaum es la caracterización habermasiana del conocimiento psicoanalítico como esencialmente histórico, a diferencia del conocimiento científico, de carácter universal. Esta concepción del

\footnotetext{
244 "Freud expressed full confidence in his own etiologic reconstruction of her sexual object choice. Yet he pointed out that she completely rejected his interpretive insights, and he attributed the rejection to her desire to punish him as a father surrogate by clinging to her neurosis."
} 
conocimiento científico como algo invariante e independiente del contexto y su historia, sostenido también por Gadamer, es enteramente equivocada según Grünbaum. Para ejemplificarlo Grünbaum recurre a la teoría electrodinámica clásica, mostrando la importancia del pasado y del conocimiento histórico para su utilización; concluyendo que "de ello se sigue que en cualquier instante t, los campos eléctricos y magnéticos producidos a través del espacio infinito, por una carga en movimiento con una aceleración arbitraria, dependerán de la propia historia cinemática pasada de su totalidad particular!"245 (Grünbaum, 1984: 17). Grünbaum brinda varios ejemplos del mismo estilo, dejando traslucir su incomprensión del asunto al que los hermeneutas se refieren, pues pareciera confundir la narración del pasado, en tanto fenómeno constitutivo de toda identidad, con el movimiento de las partículas a través del espacio. Evidentemente, por mucho que le pese a Grünbaum, no parece correcto pretender equiparar la "historia pasada infinita" de un campo eléctrico con la historia de una subjetividad. Nuestro autor parece advertirlo, pues él mismo señala que "algunos hermenéuticos pueden replicar que estos casos físicos no captan el sentido relevante de la 'historia"”246 (ibíd. p.19). Nuestra perspectiva de la lectura de Grünbaum sobre Conocimiento e interés es que, si bien podemos acompañarlo en algunos puntos de su crítica a Habermas, resulta muy difícil defender la tesis de que el psicoanálisis no guarde diferencias fundamentales con ciencias como la física.

\section{b) La crítica a las ideas de Paul Ricœur}

Las primeras ideas de Ricœur sobre la obra de Freud aparecieron publicadas en 1965 en francés, bajo el título: De l'interprétation. Essai sur Sigmund Freud; y luego en un libro posterior de 1969: Le conflit des interprétations. Essais d'herméneutique. Ambos traducidos al castellano como: Freud: una interpretación de la cultura (1965/2007) y El conflicto de las interpretaciones. Ensayos de hermenéutica (1969/2006). Otro libro significativo

\footnotetext{
245 "It follows that at ANY ONE INSTANT $t$, the electric and magnetic fields produced throughout infinite space by a charge moving with arbitrary acceleration depend on its own PARTICULAR ENTIRE INFINITE PAST KINEMATIC HISTORY!". (Mayúsculas en el original).

246 "Some hermeneuticians may retort that these physical cases do not capture the relevant sense of 'history'".
} 
citado por Grünbaum es Hermeneutics and the Human Sciences (1981), una compilación de algunos escritos traducidos del filósofo francés y publicados en lengua inglesa.

Ricœur criticó fuertemente los primeros intentos de reformular al psicoanálisis en clave operacionalista o conductista, a los fines de responder a las demandas epistemológicas de algunos como Ernest Nagel o Rudolf Carnap; pues mientras que

la psicología es una ciencia de observación que versa sobre hechos de conducta; el psicoanálisis es una ciencia exegética, que versa sobre las relaciones de sentido entre los objetos sustituidos y los objetos originarios (y perdidos) de la pulsión. Las dos disciplinas difieren ya en el punto de partida, al nivel del concepto inicial de hecho y de inferencia a partir de los hechos. (Ricœur, 1965/2007: 313).

Para Ricœur "el psicoanálisis consiste por sí mismo en un trabajo verbal con el paciente, cosa que de ninguna manera ocurre en la psicología científica" (ibíd. p.322); y es por esto que "es indiscutible que el psicoanálisis es una

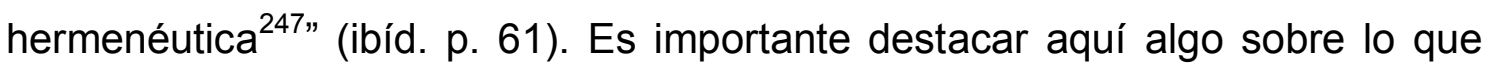
volveré más adelante, la definición de hermenéutica de Ricœur: "entenderemos siempre por hermenéutica la teoría de las reglas que presiden una exégesis, es decir, la interpretación de un texto singular o de un conjunto de signos susceptible de ser considerado como un texto" (ibíd. p. 11). Entonces, el lugar del psicoanálisis "es a la vez el lugar de los símbolos o del doble sentido y aquel donde se enfrentan las diversas maneras de interpretar" (ibíd. p. 11); y es por ello que debe ser una forma de hermenéutica, reconceptualizada a partir de los desarrollos del "giro lingüístico". El filósofo francés considera que la disciplina de Freud debería funcionar como base de una "semántica del deseo" (ibíd. p.10) y de una "arqueología del sujeto" (p. 367), tendiente a redefinir al hombre en una zona intermedia a naturaleza y cultura. Contrariando a Freud, afirma rotundamente:

el psicoanálisis no es una rama de las ciencias de la naturaleza; por eso su técnica tampoco es una ciencia natural aplicada; por eso, en fin, no es una rama

${ }^{247}$ Y afirma: "entenderemos siempre por hermenéutica la teoría de las reglas que presiden una exégesis, es decir, la interpretación de un texto singular o de un conjunto de signos susceptible de ser considerado como un texto" (ibíd. p. 11). 
de la técnica comprendida como dominación de la naturaleza. Por cierto, el precio a pagar por este reconocimiento es muy elevado: el psicoanálisis no satisface los criterios de las ciencias de observación [...] Para hablar con propiedad, en psicoanálisis no hay 'hechos', en el sentido de las ciencias experimentales [...] sino interpretación de una 'historia' [...] de ahí que su método esté mucho más cerca de las ciencias históricas que de las ciencias naturales (Ricœur, [1969] 2006: 173).

Ricœur considera que "reconocer esto último es la única réplica válida contra el ataque de los lógicos, semánticos y metodólogos que cuestionan la cientificidad del psicoanálisis" (ibíd.).

Para Ricœur existe un "desfasaje" notable en la obra de Freud: "su descubrimiento se da en el nivel de los efectos de sentido, pero sigue exponiéndolo en el lenguaje y en la conceptualización del energetismo de sus maestros de Viena y Berlín" (ibíd. p.155). Se trata de una anomalía del discurso freudiano que no se reduce al desfasaje "entre el descubrimiento y el vocabulario disponible", sino que atañe a la "naturaleza misma de las cosas", pues el psicoanálisis opera con nociones pertenecientes a "dos planos de coherencia diferentes: el plano de la fuerza y el del sentido" (ibíd.). En base a esta suposición, Ricœur va a criticar aquellas lecturas que parten de la distinción neta entre causas y motivos:

...la oposición pura y simple entre motivo y causa no resuelve el problema epistemológico planteado por el discurso freudiano, que está regulado por un tipo de ser fuera de serie, al que yo llamaría semántica del deseo; un discurso mixto que cae fuera de la alternativa motivo-causa. (Ricœur, [1965] 2007: 317).

Esta semántica del deseo no es, para Ricœur, una suerte de "error categorial" de Freud, sino una mixtura discursiva que impide la reducción del psicoanálisis, tanto a las ciencias de la naturaleza como a la semiología. La salida que el filósofo francés ve a esta dicotomía es por la vía de la dialéctica (ibíd. p.163).

Algunos años más tarde, Ricœur dedicó un artículo a la cuestión de la prueba en psicoanálisis. Asumió allí que "la cuestión de la prueba en psicoanálisis es tan antigua como el psicoanálisis mismo [...] y sin embargo, el psicoanálisis no ha logrado nunca mostrar plenamente cómo sus aseveraciones se justifican, cómo sus interpretaciones se ven verificadas 0 autentificadas, cómo su teoría es verificada" (Ricœur, 1977/2009: 17). Y esto 
se debe, nos dice el autor, a que aún no se han especificado las condiciones epistémicas de lo que se considera un hecho psicoanalítico ni el tipo de relaciones que existen entre la teoría y la experiencia. El filósofo francés brinda una serie de criterios para esclarecer cómo la relación analítica permite seleccionar los hechos susceptibles de ser tomados en cuenta por la teoría: 1) no son hechos observables sino restringidos a la esfera de la significación; 2) se selecciona lo que es dicho a otro en transferencia (cuya mediación es constitutiva del deseo); 3) que forma parte de la realidad psíquica (indiscernible de la realidad material); 4) y que es susceptible de ser entramado en una narrativa histórica por reelaboración retroactiva. Ricœur piensa que Habermas “tiene razón al denunciar la 'incomprensión cientista' del psicoanálisis por sí mismo como "ciencia de la naturaleza"' (Ricœur, 1977/2009: 36), puesto que la imposición de modelos naturalistas a la experiencia analítica ha devenido en una pérdida de "la especificidad misma del hecho 'psicoanalítico' y su cuádruple propiedad de poder ser dicho -ser dirigido a otro-, ser fantaseado, ser figurado o simbolizado, ser contado en la historia de una vida." (ibíd.).

Según Ricœur, al así caracterizado el hecho psicoanalítico le corresponde una "especie de verdad" particular: "un 'decir verdad', antes que la de un 'ser verdad' [...] la verdad está aquí más cerca de la tragedia griega que de la física moderna" (ibíd. p. 43). Aquí Ricœur vuelve a acordar con Habermas en que la pretensión a la verdad del psicoanálisis consiste en una pretensión de acrecentar la capacidad de autorreflexión "ayudando al sujeto a superar las distorsiones que están en la fuente de la incomprensión de sí mismo" (ibíd.). También retoma el planteo de Michael Sherwood sobre las explicaciones psicoanalíticas, para afirmar que la "validación de los enunciados analíticos extrae su naturaleza específica de su referencia última a un 'compromiso narrativo"” (ibíd. p. 47). Luego concluye que la validación psicoanalítica proviene de la "convergencia de criterios parciales y heterogéneos" (ibíd. p. 52) y que tomando como guía "una constelación formada por la teoría, los procedimientos de investigación, la técnica de tratamiento y la reconstrucción de una historia de caso" pueden establecerse algunos requisitos de la explicación psicoanalítica: 1) que sea coherente con la teoría; 2) que satisfaga reglas de universalización establecidas sobre el desciframiento del texto inconsciente; 3) que sea satisfactoria en términos económicos, incorporándose 
al trabajo del analizado; 4) que pueda elevar una historia particular de caso al género de inteligibilidad narrativa que esperamos ordinariamente de un relato. Concluye que sólo "cuando estos criterios de validación no derivan uno de otro, sino que se refuerzan mutuamente, constituyen el aparato de la prueba en psicoanálisis" (ibíd. p. 55).

Grünbaum considera que el argumento central de Ricœur en este escrito es una parodiada petición de principio. Considera que el filósofo hermeneuta no aporta criterio alguno para evaluar la eficacia causal de las hipótesis freudianas ni brinda respuesta al "problema de la contaminación epistémica por sugestión" (ibíd. p.68); que constituye para él, como veremos luego, un problema mayor de la validación psicoanalítica.

Coincidimos con Grünbaum en que Ricœur no es del todo claro en su caracterización de los criterios de validación de las hipótesis causales, en la medida en que prioriza el lugar del encuadre pero no desestima otros criterios. Nuestro crítico aprovecha esta ambigüedad para decir que "la representación de Ricœur de la epistemología del psicoanálisis es, por lo tanto, fundamentalmente incoherente" ${ }^{248}$ (ibíd. p. 49). Grünbaum considera que "la conceptualización hermenéutica de Ricœur del psicoanálisis no es más convincente que la ofrecida por Habermas"249 (Grünbaum, 1984: 69). Para él, la conceptualización ricœuriana del ámbito psicoanalítico en términos meramente textuales y reducida al intercambio verbal entre analista y paciente, es una "amputación ontológica"250 (p.44), una "cirugía ideológica en el corpus psicoanalítico"251 (p.47), una "emasculación"252 (p. 60) de la perspectiva de Freud. Este truncamiento se advierte, nos dice Grünbaum, cuando Ricœur afirma que "todas las pretensiones de verdad del psicoanálisis son en última

\footnotetext{
248 "Ricoeur's depiction of the epistemology of psychoanalysis is thus fundamentally incoherent." 249 "...Ricœur 's hermeneutic construal of psychoanalysis is no more cogent than the one offered by Habermas".

250 "...ontological amputation..."

251 "...this ideological surgery on the psychoanalytic corpus..."

252 “...emasculation...”
} 
instancia, resumidas en la estructura narrativa de hechos psicoanalíticos"253 (Ricœur, 1981: 268). Así concebido el psicoanálisis, no da lugar a escrutinio científico de ningún tipo. La expresión ricœuriana de que, en psicoanálisis, "la realidad es su significación" (Ricœur, 1977/2009: 24) sintetiza bien el solapamiento entre los planos ontológico y gnoseológico, que Grünbaum intenta separar.

El argumento de Grünbaum consiste en señalar que varias afirmaciones de Freud son hipótesis universales que van más allá de la particularidad de las verbalizaciones clínicas de los casos concretos; es decir, que trascienden ese "campo cerrado de la interlocución analítica" al que Ricœur concibe como supuestamente específico del psicoanálisis (Ricœur, 1965/2007: 322, 324, 362). Como ejemplo, señala que Freud desarrolló una explicación de lo que dio en llamar "carácter anal", partiendo de la agrupación de ciertos rasgos de personalidad en los sujetos, independientemente de si éstos se analizan o no. Y también señala cómo, a partir de la hipótesis freudiana de la etiología de la paranoia, podemos hacer una predicción simple: cabría esperar una disminución epidemiológica de la incidencia de la paranoia, a partir de la disminución del tabú de la homosexualidad; "y esta explicación sería o podría darse al margen de cualquier preocupación por los datos del encuadre del tratamiento analítico." 254 (Grünbaum, 1984: 44). Grünbaum cree que este tipo de hipótesis universales y su forma de validación, atentan contra las pretensiones de Ricœur y Habermas por apartar al psicoanálisis de las ciencias buscando otro tipo de validación. Por ello, lo que Grünbaum no comparte de la perspectiva de Ricœur es el reduccionismo ontológico del objeto de conocimiento psicoanalítico a las verbalizaciones del paciente. Así lo plantea, a propósito de los sueños:

¿Por qué el dominio de la teoría física comprende partículas elementales en lugar
de, solamente, digamos, las pistas que dejan en las cámaras de niebla Wilson u
otros dispositivos de registro, mientras que el dominio de la teoría de los sueños
debe contener sólo recuerdos verbalizadas de sueños? ¿Qué impulsa a Ricœur,

253 "all truth claims of psychoanalysis are ultimately summed up in the narrative structure of psychoanalytic facts"

254 "And this explanation would or could be given quite apart from any concern for data from the analytic treatment setting" 
además de un objetivo ideológico importado, a reducir el objeto de la teoría freudiana del cumplimiento de deseo, que ofrece motivos infantiles reprimidos para los sueños soñados durante el dormir, a meros informes verbales oníricos durante la vida de vigilia? ${ }^{255}$ (ibíd. p. 45).

Del mismo modo, según Grünbaum, los fenómenos transferenciales proporcionan otro ejemplo contra el intento tendencioso de reducción de Ricœur, puesto que se trata de experiencias universales que van más allá de los sujetos que se analizan (ibíd. p.46). En síntesis, Grünbaum considera que las teorizaciones ideadas por Freud son un intento de explicar fenómenos universales, es decir que refieren también a sujetos que nunca han pasado por el análisis y que nunca podrán producir verbalización alguna para un analista. Por esto es que las pretensiones de Freud eran más abarcativas que la "hermenéutica de la autocomprensión" ricœuriana (Ricœur, 1981: 264); constituyendo, efectivamente y a expensas de los hermeneutas, una serie de explicaciones causales. Grünbaum necesita dejar esto en claro porque por aquí entrará su caballo de Troya: "si es así, entonces su validación, en su caso, tendrá que ser de un tipo apropiado a estas declaradas características" 256 (Grünbaum, 1984: 47).

Luego de exponer y criticar las tesis de Habermas y Ricœur, Grünbaum sintetiza su punto de vista sobre los aspectos abordados, subrayando una exégesis que contraría la perspectiva del "auto-malentendido cientificista" de los hermeneutas:

1) El Freud maduro consideró a la represión como el "pilar fundamental sobre el que descansa el edificio del psicoanálisis, su pieza más esencial" (Freud, 1914b/2004: 15); al mismo tiempo que consideró a la metapsicología como una superestructura prescindible.

2) Luego de abandonar el Proyecto, el criterio freudiano de cientificidad era declaradamente metodológico, y no ontológicamente reductivo. Aun

255 "Why does the domain of physical theory comprise elementary particles rather than only, say, the tracks they leave in Wilson cloud chambers or other registration devices, whereas the domain of the dream theory is to contain only verbalized memories of dreams? What, besides an imported ideological objective, prompted Ricoeur to shrink the subject matter of Freud's wish-fulfillment theory, which offers repressed infantile motives for dreams as dreamed during sleep, into mere verbal dream-reports during waking life?"

256 "If so, then their validation, if any, will have to be of a kind appropriate to these avowed features." 
privilegiando las nociones teóricas derivadas de las experiencias clínicas “directas", Freud pretendió que el psicoanálisis fuera una ciencia natural.

3) Sea lo que hayan sido sus afanes reductivos de la teoría clínica a la metapsicología, el Freud maduro no consideraba que esta última fuera más científica que la primera.

4) Freud no veía que la cientificidad del psicoanálisis proviniera desde la metapsicología y descendiera a la clínica; por el contrario, creía que el estatuto de ciencia se edificaría "de abajo hacia arriba", desde la acumulación de evidencia clínica. (Grünbaum, 1984: 84).

\section{c) La crítica a las ideas de George Klein}

Si bien los aportes de George Klein versan sobre distintos temas y problemas psicoanalíticos, en la última década de su vida se orientó por una reformulación de sus bases conceptuales. Psychoanalytic Theory: An Exploration of Essentials (1976a), es el libro póstumamente editado que contiene gran parte de sus aportes y es el que cita Grünbaum.

Para Klein la metapsicología freudiana y la teoría clínica "derivan de dos filosofías diferentes de investigación y explicación” ${ }^{257}$ (Klein, 1976a: 26) y sólo tiene valor la segunda porque apunta a establecer "razones" y no "causas", como busca la primera (ibíd. p.56). A su modo de ver, el psicoanálisis debe recuperar sus orígenes clínicos y mantenerse en un nivel básico de conceptualización de la experiencia clínica, pues ésta es toda la teoría que se necesita. Klein considera que la metapsicología es un agregado innecesario y que debe ser desechado: debemos realizar una "teorectomía". Esto es así porque

El objetivo central de la explicación clínica psicoanalítica es la lectura de la intencionalidad; el comportamiento, la experiencia, el testimonio, se estudian por lo que significan en este sentido, como ejemplificación conjunta de las 'tensiones' directivas, declaradas, repudiadas, reprimidas, defendidas. Aplicada a la comprensión de los síntomas, por ejemplo, esa explicación consiste en volver, desde un síntoma, no al funcionamiento de un mecanismo que es en sí mismo real

257 "derive from two different philosophies of inquiry and explanation" 
o potencialmente observable, sino a un contexto de historia de vida en el que el síntoma se hace inteligible como ejemplo de una solución con propósitos ${ }^{258}$ (Klein, 1976a: 26)

En lo que se refiere a los desarrollos conceptuales sobre la sexualidad, Klein considera que existe una diferencia notoria entre una teoría clínica por un lado, basada en la fenomenología del trabajo analítico y su conceptualización en términos motivacionales; y una teoría del impulso/descarga por el otro, que traduce la fenomenología clínica a un lenguaje fisiológico de fuerzas que buscan descarga:

\begin{abstract}
Quizás la falla de los tradicionalistas para distinguir las dos teorías proviene de la tendencia a considerar las proposiciones clínicas no como una teoría en sí, sino como un hecho confirmado $y$, sus conceptos, simplemente como herramientas descriptivas. Los analistas parecen particularmente reacios a la idea de que no degradan la concepción de la sexualidad infantil cuando la tratan como una teoría, una concepción viable para ser considerada en un espíritu de escepticismo benevolente para la investigación y la contrastación con aseveraciones rivales, y sujeta a revisión. Como resultado, las proposiciones de la teoría clínica han permanecido extrañamente estáticas; desde los tiempos de Freud se han producido muy pocos añadidos desde el campo psicoanalítico al conocimiento sistemático de la sexualidad. Al mismo tiempo, las aplicaciones del modelo pulsional han sido durante mucho tiempo las palabras usadas para "explicar" los datos clínicos, pero insuficientes en pruebas concretas con los datos clínicos. De hecho, estando retirado de la observación y de los conceptos clínicos por pasos indeterminadamente largos, son inmunes a la modificación introducida por los datos clínicos. ${ }^{259}$ (Klein, 1976b: 17).
\end{abstract}

258 "The central objective of psychoanalytic explanation is the reading of intentionality; behavior,
experience, testimony are studied for meaning in this sense, as jointly exemplifying directive
'tensions', avowed, disavowed, repressed, defended. Applied to the understanding of
symptoms, for example, such explanation consists in going back from a symptom not to the
workings of a mechanism which is itself actually or potentially observable, but a life-history
context in which the symptom becomes intelligible as exemplifying an aimful solution".
259 "Perhaps the failure of traditionalists to distinguish the two theories comes from the tendency
to regard the clinical proposition not as theory at all but confirmed as fact and its concepts
simply as descriptive tools. Analysts seem particularly averse to the idea that it is not
downgrading the conception of infantile sexuality to regard it as a theory, a workable conception
to be regarded in a spirit of benevolent skepticism for investigation and test against rival
assertions, and subject to revision. As a result, the propositions of the clinical have remained
static theory; the systematic knowledge of sexuality received from psychoanalytic sources since
Freud's time has been precious little. At the same time, applications of the drive model have
been long on words in "explaining" clinical data but short on actual tests with clinical data. 
Es la teoría clínica lo que posibilita, según Klein, que se establezca la contrastación empírica de hipótesis psicológicas surgidas en íntima relación con la experiencia analítica.

Grünbaum considera que Klein también sucumbió al error de la reducción ontológica, adoptando "la tesis de que el estatus científico de una teoría, en cualquier dominio de fenómenos, supone su reducción ontológica a las entidades fisicalistas de las admitidas ciencias naturales"260 (Grünbaum, 1984: 85; cursivas en el original). Partiendo de esta noción equivocada, Klein arribó a una suposición incorrecta: Freud, incluso en su madurez, aspiró a tal reducción fisicalista como medio para alcanzar el estatuto de cientificidad anhelado. Sin embargo, según Grünbaum, Klein parece haber sido consciente de que Freud había abandonado sus aspiraciones de reduccionismo ontológico en favor de un reduccionismo metodológico o epistemológico. $Y$ en base a ello -sostiene Grünbaum- pretende hacernos creer que Freud degradaba a "no científicas" las explicaciones basadas en los conceptos de su propia teoría clínica, y que habría tenido el afán de reemplazar todo el arsenal de categorías relativas a la intencionalidad. La teoría clínica no habría sido más que una mera parada temporal en su camino a la metapsicología. Así lo expresa Klein:

La filosofía de Freud asume: (1) que los conceptos de intencionalidad y significado son inaceptables como términos de explicación científica; (2) que una explicación aceptable debe ser purgada de implicaciones teleológicas; (3) que las regularidades descritas con conceptos propositivos serán en última instancia explicables mediante el uso de modelos puramente psicológicos, que dan a conocer las causas de las cuales el principio finalista es simplemente una expresión descriptiva ${ }^{261}$ (Klein, 1976a: 43).

Indeed, being removed from observation and from the clinical concepts by indeterminately long steps, they are immune to modification by clinical data".

260 "...the thesis that the scientific status of a theory in any domain of phenomena turns on its ontological reduction to the physicalistic entities of the received natural sciences".

261 "Freud's philosophy assumed: (1) that concepts of purposefulness and meaning are unacceptable as terms of scientific explanation; (2) that an acceptable explanation must be purged of teleological implications; (3) that regularities described with purposivistic concepts will ultimately be explainable through the use of

purely psychological models, which disclose the causes of which the purposive principle is simply a descriptive expression". 
Klein considera que la tradición cientificista en la que Freud se formó se refleja en su fidelidad al indiscutido juramento fisicalista efectuado por BrückeMeynert. Así, los afanes que motivaron la escritura del Proyecto habrían persistido intactos durante toda su vida, determinando al fin y al cabo la invención de la metapsicología (ibíd. p. 46).

Grünbaum considera que esta lectura de Klein es inaceptable y que a partir de los escritos de Freud podemos ver de forma inequívoca que él abandonó la pretensión reduccionista que animó la realización del Proyecto. Para documentarlo, nos remite nuevamente a la lectura de Lo inconciente, donde Freud afirma:

De cualquier modo, resulta claro que esa cuestión, a saber, si han de concebirse como anímicos inconcientes o como físicos esos estados de la vida anímica de innegable carácter latente, amenaza terminar en una disputa terminológica. Por eso es juicioso promover al primer plano lo que sabemos con seguridad acerca de la naturaleza de estos discutibles estados. Ahora bien, en sus caracteres físicos nos resultan por completo inasequibles; ninguna idea fisiológica, ningún proceso químico pueden hacernos vislumbrar su esencia. Por el otro lado, se comprueba que mantienen el más amplio contacto con los procesos anímicos concientes; con un cierto rendimiento de trabajo pueden trasponerse en estos, ser sustituidos por estos; y admiten ser descritos con todas las categorías que aplicamos a los actos anímicos concientes, como representaciones, aspiraciones, decisiones, etc. $Y$ aun de muchos de estos estados latentes tenemos que decir que no se distinguen de los concientes sino, precisamente, porque les falta la conciencia. Por eso no vacilaremos en tratarlos como objetos de investigación psicológica, y en el más íntimo entrelazamiento con los actos anímicos concientes. (Freud, 1915b/2004: 164-165).

Grünbaum afirma que la equivocada lectura de Klein no tiene sus raíces en la obra de Freud sino en las tensiones ideológicas que acontecían en la comunidad psicoanalítica de la que él formaba parte. Para Grünbaum, el mito de Klein sobre el descrédito de Freud por las explicaciones de la teoría clínica, va de la mano con el mito de que las explicaciones causales suponen necesariamente una reducción ontológica de tipo fisicalista, compartido con el resto de los hermeneutas. Esto le resulta evidentemente equivocado: "que Freud imaginó constructivamente la ampliación bioquímica de la teoría clínica en lugar del reemplazo físico-químico de la misma, es atestiguado por el rol 
conjunto que asignó a los factores clínicos y a los presumiblemente biofísicos en la etiología de las neurosis" ${ }^{262}$ (Grünbaum, 1984: 86). Todo esto atenta contra la pretendida autonomía de las explicaciones meramente "clínicas" o "intencionalistas".

La fallida lectura de Klein no se limita a cuestiones filosóficas según Grünbaum, sino que se extiende también a las consideraciones que el autor hace sobre el desarrollo de la teoría de Freud. Por ejemplo, Klein sostiene que
En la teoría clínica el punto de vista genético se refiere al hecho de que los objetivos [disposiciones del sujeto] tienen una historia, no en el sentido de tratar de especificar antecedentes invariables e incondicionales, sino en el sentido de especificar una lógica interna del desarrollo ${ }^{263}$ (Klein, 1976: 29-30).

Pero, si se lo contrasta con las consideraciones que Freud brinda al caracterizar la "ecuación etiológica" o las "series complementarias", notamos que las afirmaciones de Klein contradicen lo aseverado por Freud.

Por otro lado, Grünbaum denuncia una confusión en el planteo de Klein, a saber: su queja del supuesto reduccionismo ontológico de Freud, se apoya en el supuesto errado de que una teoría $B$ que es reducida a otra teoría $A$, implica necesariamente una pérdida del potencial explicativo de B. Grünbaum ejemplifica el error recordando que el hecho de que la termodinámica clásica pueda ser parcialmente reducida a la mecánica estadística no implica en absoluto que la primera pierda poder explicativo; incluso -asegura Grünbaumesa reducción ayudó a consolidar su cientificidad (ibíd. pp. 88). Del mismo modo, la derivación de las leyes de Kepler del movimiento planetario como aproximaciones específicas a partir de las leyes del movimiento y la gravitación, difícilmente signifiquen el destierro de la teoría de Kepler del terreno científico. En ese sentido, aún si en el caso de Freud estuviéramos en

\footnotetext{
262 "That Freud constructively envisioned the biochemical enlargement of the clinical theory rather than the latter's physico-chemical replacement is attested by the conjoint role he assigned to clinical and presumably biophysical factors in the etiology of the neuroses."

263 "In the clinical theory the genetic point of view refers to the fact that aims [the subject's dispositions] have a history, not in the sense of trying to specify invariable and unconditional antecedents, but in the sense of specifying an inner logic of development"
} 
presencia de un reduccionismo ontológico, ello no supondría un deterioro en el valor de las explicaciones psicoanalíticas ${ }^{264}$.

De nada vale afirmar que la teoría clínica y la metapsicología pertenezcan a "universos diferentes de discurso" o que arrojen "dos tipos de explicaciones incompatibles", puesto que en la ciencia a menudo sucede que dos teorías así de disímiles resulten, tarde o temprano, conectadas por una relación de reducción subsuntiva.

Por otro lado, Grünbaum reutiliza aquí su argumento de que la conducta neurótica no supone una acción planificada con base en la creencia de una conexión entre medios y fines, para cuestionar el distanciamiento que Klein hace de ambas dimensiones teóricas (clínica y metapsicológica). Como difícilmente puedan explicarse los síntomas en base a "razones", la dicotomía kleiniana es un "pseudocontraste". Además, Grünbaum considera que las observaciones de fenómenos singulares realizadas a partir de hipótesis metapsicológicas no anula por ello su carácter interpretativo. Lo mismo sucede en otras ciencias: por ejemplo cuando los físicos "leen" los fenómenos, también los interpretan teóricamente a partir de las hipótesis causales que se utilizan para explicarlos. $Y$ agrega: "cada estudiante novato sabe que la identidad genérica de los fenómenos interpretados por el psicoanalista es ideacional, y por lo tanto difiere de la identidad de los fenómenos 'leídos' por el físico" 265 (ibíd. p. 91). Grünbaum desestima la adjetivación de "hermenéutica" en la que se han escudado algunas disciplinas; y aunque no se explaya lo suficiente en su argumentación, concluye que la extrapolación de la concepción "antinomotética" a la "clínica nomotética de Freud", engendra un malentendido insalvable.

\footnotetext{
${ }^{264}$ Aunque en otro lugar he abordado parcialmente el problema del reduccionismo en Freud, lo hice antes de conocer en profundidad las ideas de Grünbaum y Klein. Si bien aquí no voy a detenerme sobre este asunto en particular, creo que la solución a la que llegué permite mostrar que tampoco la lectura de Grünbaum es acertada en este punto y que hay razones suficientes para pensar que el tipo de reduccionismo al que Freud apela la mayoría de las veces es de tipo lingüístico antes que ontológico (Azcona, 2013b).

265 "...every beginning student knows that the generic identity of the phenomena interpreted by the psychoanalyst is ideational, and therefore differs in identity from the phenomena "read" by the physicist".
} 


\section{Síntesis: una distorsión "cientofóbica"}

Luego de examinar críticamente las afirmaciones de Habermas, Ricœur y Klein, Grünbaum concluye la primera parte de su trabajo asegurando que la reconstrucción hermenéutica del psicoanálisis constituye una "exégesis mítica" de la concepción freudiana del psicoanálisis, un giro ideológico que no tiene sustento en las bases psicoanalíticas y que conduce a un callejón sin salida. Además, se trata de una tradición "cientofóbica" que parte de una concepción anacrónica de las ciencias naturales.

Grünbaum cree que una vez reveladas las debilidades de los que pretendieron llevar la hermenéutica al psicoanálisis, queda allanado el terreno para sembrar la crítica a los fundamentos clínicos del psicoanálisis. Su premisa es que, adoptando los mismos estándares de cientificidad con los que Freud se manejaba (que distan mucho de la visión hermenéutica y se acercan a los criterios generales de cientificidad), se evidencian sus puntos endebles: la argumentación que conecta la teoría con sus evidencias y, además, el valor probatorio de los datos clínicos.

\section{El inductivismo eliminativo como modelo para evaluar la relevancia causal}

“...es precisamente la teoría de Freud la que proporciona punzante evidencia de que Popper ha caricaturizado la tradición inductivista..." (Grünbaum, 1984: 280).

\section{a) La falsabilidad de la teoría psicoanalítica: una vía para criticar el canon de Popper}

La crítica de Grünbaum al psicoanálisis sólo puede ser entendida si se la ubica como una réplica a Popper y su concepción metodológica. De hecho, mucho antes de dedicarse al psicoanálisis, Grünbaum había sido un crítico sistemático de las ideas de Popper. Él mismo ha declarado que su "primer impulso para su investigación sobre los méritos intelectuales de la empresa 
psicoanalítica" provino de sus "dudas sobre la filosofía de la ciencia de Karl

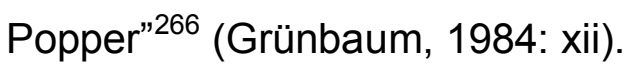

En uno de sus últimos escritos Grünbaum sintetiza la posición de Popper mediante dos afirmaciones centrales: a) la teoría psicoanalítica es irrefutable por cualquier comportamiento humano observable (lo que equivale a decir que no tiene falsadores potenciales) y, b) ante la evidencia aparentemente adversa, Freud y sus seguidores siempre esquivaron la refutación recurriendo a maniobras de inmunización para rescatar su teoría. Para Grünbaum, Popper ha derivado el primer enunciado del segundo, como si fuera una consecuencia evidente; sin embargo:

...esta acusación de no-falsabilidad contra la teoría psicoanalítica misma no se sigue de la objeción sociológica de que los freudianos evaden responder a las críticas de sus hipótesis. Después de todo, una teoría bien puede ser invalidada por evidencia conocida, aún cuando sus verdaderos creyentes se nieguen a reconocer esta refutación ${ }^{267}$ (Grünbaum, 2009: 121).

Grünbaum señala, además, una contradicción flagrante: si Popper tuviera razón en que la teoría freudiana carece de falsadores potenciales, entonces “¿por qué los freudianos iban a necesitar alguna vez esquivar las refutaciones mediante estratagemas de inmunización? Las dos afirmaciones de Popper son evidentemente incoherentes." ${ }^{268}$ (ibíd.). Indudablemente, a pesar de que Popper asume que las teorías, por un lado, y la conducta intelectual de sus usuarios, por el otro, "pertenecen a dos mundos completamente diferentes" (Popper, 1976/1985: 211), en su lectura del psicoanálisis parece haber homologado ambas dimensiones, contrariando así (una vez más) su propia concepción del conocimiento.

Por nuestra parte, anteriormente hemos abordado la caracterización Popperiana del psicoanálisis como una pseudociencia y hemos mostrado las

\footnotetext{
266 "The first impetus for my inquiry into the intellectual merits of the psychoanalytic enterprise came from my doubts concerning Karl Popper's philosophy of science..."

267 "....this charge of unfalsifiability against psychoanalytic theory itself does not follow from the sociological objection that Freudians are evasively unresponsive to criticism of their hypotheses. After all, a theory may well be invalidated by known evidence, even as its true believers refuse to acknowledge this refutation."

268 " ....why would it ever have been necessary at all for Freudians to dodge refutations by means of immunizing gambits? Popper's two claims are evidently incoherent."
} 
razones por las que puede afirmarse que se trata de una diatriba infundada. La opinión de Grünbaum sobre la crítica de Popper al psicoanálisis apunta a la misma conclusión a la que hemos llegado nosotros, pues él considera que Freud adoptaba las reglas de la contrastación empírica, al punto tal que "haría orgulloso a cualquier falsacionista"269 (Grünbaum, 1984: 120). Aunque sin formalizarlos lógicamente, Grünbaum reconoce que algunos argumentos generales de Freud se asimilan a una forma de modus tollens, evidenciando su perspectiva falsacionista; por ejemplo los hallados en $A$ propósito de las críticas a la "neurosis de angustia» (Freud, 1895/2004) y en Un caso de paranoia que contradice la teoría psicoanalítica (Freud, 1915d/2004). A partir de lo cual, para Grünbaum no caben dudas de que

...las sucesivas modificaciones freudianas de muchas de sus hipótesis a lo largo de la mayor parte de su vida, difícilmente eran inmotivadas en lo empírico, caprichosas o idiosincráticas. ¿Qué reconstrucción, me pregunto, haría o podría darnos Popper acerca de la racionalidad de Freud para estos cambios teóricos repetidos, y permanecer aferrado a su acusación de infalsabilidad y/o a su imputación de que Freud era inhóspito para la evidencia adversa? ${ }^{270}$ (ibíd. p.117)

Para Grünbaum, Popper se equivocó porque el proceder de Freud era falsacionista. Como ya he planteado, a mi modo de ver lo que Freud hace notar no es una adherencia al canon popperiano, sino una concordancia entre su proceder y el falsacionismo sofisticado; de hecho, tal y como puede verse en el segundo escrito que Grünbaum retoma, el vienés analiza un caso que contradice la teoría, pero en lugar de abandonar la hipótesis jaqueada, produce nuevos observables que (desde el material clínico) vuelven coherente la relación de los datos con dicha hipótesis. Esto, desde la óptica de un popperiano, podría fácilmente considerarse parte de una "estratagema convencionalista"; de modo que no puedo acordar con Grünbaum cuando lo

269 “....would do any falsificationist proud"

270 "...Freud's successive modifications of many of his hypotheses throughout most of his life were hardly empirically unmotivated, capricious, or idiosyncratic. What reconstruction, I ask, would or could Popper give us of Freud's rationale for these repeated theory changes, and still, cling to his charge of nonfalsifiability and/or to his charge that Freud was inhospitable to adverse evidence?" 
considera un mero falsacionista ${ }^{271}$. La lectura simplificadora de Grünbaum alcanza, como podría esperarse, el episodio del abandono de la teoría de la seducción, respecto de lo cual dice: “...aprendemos, de una carta que Freud escribió en 1897, cómo la evidencia adversa que él mismo había descubierto lo condujo a repudiar su previamente apreciada seducción etiológica de la histeria"272 (ibíd. p. 117). Creo haber dado razones suficientes para mostrar que el cambio teórico respecto a esa tesis etiológica no puede reducirse al interjuego de las contrastaciones empíricas y que no es tanto una sustitución completa de conjeturas que haya pivoteado sobre el binomio "hecho acaecido hecho fantaseado", sino una complejización del entramado teórico que otorga una intensidad cuantitativa diferencial a los distintos factores intervinientes en la etiología de las psiconeurosis; de modo que no insistiré en ello.

Más allá de cómo podamos reconstruir el proceder metodológico de Freud, Grünbaum acierta al sostener que la mayoría de las hipótesis psicoanalíticas son enteramente falsables; lo cual contradice las imputaciones popperianas. Para documentarlo, también recupera el ejemplo de la etiología de la paranoia que Freud hipotetiza con el caso Schreber y la reformulación de la teoría de los sueños luego del giro de 1920. Grünbaum primero sostiene que Popper no dio pruebas a favor de su acusación de que la teoría freudiana era empíricamente incontrastable; y luego establece una serie de consecuencias observacionales que conducen a pensar lo contrario. Finalmente, considera que hay evidencias que permiten refutar algunas tesis freudianas y que, por lo tanto, dichas tesis eran falsables.

En cierta forma Grünbaum entiende que los hermeneutas y los falsacionistas mantienen un punto en común respecto del psicoanálisis: ambos pretenden apartarlo del campo de las ciencias. Sin embargo, ambas posturas se

\footnotetext{
${ }^{271}$ Tampoco acuerdo en lo que Grünbaum dice veinticinco años después, cuando se refiere a este escrito de Freud en términos menos indulgentes: como Freud allí, finalmente, no refuta su hipótesis etiológica, Grünbaum sostiene que "por desgracia [...] esta denominación de su artículo de 1915 es una engañosa pieza de publicidad falsa, irónica e incluso frívola" (Grünbaum, 2009: 123). ["Regrettably, however, precisely this appellation of his 1915 article is a beguiling piece of ironic and even frivolous false advertising"].

272 "....we learn from a letter that Freud wrote in 1897 how adverse evidence that he himself had uncovered drove him to repudiate his previously cherished seduction etiology of hysteria."
} 
sostienen a condición de mantener una relación de superficialidad con el pensamiento de Freud.

Para no pocos analistas, los argumentos con los que Grünbaum desactivaba las críticas de Popper al psicoanálisis fueron motivo de celebración. Robert Holt, por ejemplo, describía el asunto con cierto entusiasmo:

\begin{abstract}
Afortunadamente, un destacado filósofo de la ciencia, Adolf Grünbaum, se interesó en el problema del estatus científico del psicoanálisis en 1976 y comenzó a estudiar su literatura. [...] Aquí, por fin un filósofo que ha hecho su tarea antes de criticar a Freud. [...] Grünbaum ha obtenido el reconocimiento de todos nosotros [los psicoanalistas] al bajarle los humos a Popper, demostrando que sus argumentos no sólo están basados en la ignorancia de lo que Freud dijo en realidad, sino que tienen defectos lógicos también. [...] Grünbaum ha establecido incontestablemente el reclamo de que el psicoanálisis tiene un lugar entre las ciencias según los propios criterios de Popper ${ }^{273}$ (Holt, 1989: 327-328).
\end{abstract}

Ahora bien, lo que moviliza a Grünbaum en su contundente crítica de las ideas de Popper no es (como pueden haber creído algunos) un intento por defender a Freud, sino que se trata de una objeción al criterio falsacionista de demarcación. En 1976 Grünbaum publicó una serie de artículos críticos de la filosofía de Popper (Grünbaum, 1976a, 1976b, 1976c, 1976d) ${ }^{274}$ que tuvieron rápida repercusión en la comunidad filosófica. Allí Grünbaum sostiene que el desprecio de Popper por el psicoanálisis como una ciencia empírica se fundamenta en un rechazo de la tradición de la metodología inductiva en general; y que "Popper no es menos descuidado en su estimación de las

\footnotetext{
273 "Fortunately, a leading philosopher of science, Adolf Grünbaum, became interested in the problem of the scientific status of psychoanalysis in 1976 and began studying its literature. [...] Here at last is a philosopher who has done his homework before criticizing Freud. [...] Grünbaum has earned the gratitude of all of us by taking Popper down a peg, showing that his arguments not only are based on ignorance of what Freud actually said, but have logical flaws as well. [...] Grünbaum has unanswerably established the claim of psychoanalysis to a place among the sciences by Popper's own criteria".

${ }^{274}$ Los títulos de estos trabajos anticipan claramente (tres de ellos en base a preguntas retóricas) el tipo de problemas que Grünbaum analiza: Is Falsifiability the Touchstone of Scientific Rationality? Karl Popper versus Inductivism (¿Es la falsabilidad la piedra de toque de la racionalidad científica? Karl Popper contra el Inductivismo); Can a theory answer more questions than one of its rivals? (¿Puede una teoría responder más preguntas que una de sus rivales?); Is the Method of Bold Conjectures and Attempted Refutations Justifiably the Method of Science? ( ¿Es el método de las conjeturas audaces y los intentos de refutación el método legítimo de la ciencia?) y Ad Hoc Auxiliary Hypotheses and Falsificationism (Hipotesis auxiliares ad-hoc y Falsacionismo).
} 
explicaciones de Freud que en su descripción del inductivismo"275 (Grünbaum, 1979a: 134). A su modo de ver, ese rechazo de Popper del inductivismo es efecto de una caricaturización que él hace de tales procedimientos; y que le impide justipreciar el valor que porta la inducción como base para el establecimiento de un sólido criterio de demarcación (cf. Grünbaum, 1984: 280). En oposición abierta al antiinductivismo popperiano, Grünbaum adhiere a los aportes de Francis Bacon y John Stuart Mill; y, abogando por su recuperación, afirma que la confirmación inductiva aporta lo necesario para establecer la validez empírica de una disciplina como el psicoanálisis. El problema radica ahora en que los procedimientos freudianos, por razones que pasaremos a analizar enseguida, no cumplen con tales parámetros de la tradición inductiva. Es decir, Grünbaum acuerda con Popper en que el psicoanálisis no cumple con los estándares científicos, sólo que difiere en su consideración sobre los mismos:

...voy a presentar en este ensayo el por qué la aplicación de Popper de su criterio de falsabilidad es demasiado insensible para exhibir el más atroz de los defectos epistémicos que acosan a las etiologías freudianas, la interpretación de los sueños, la teoría de actos fallidos, etc. De hecho, como argumentaré, los consagrados cánones inductivistas para la validación de las afirmaciones causales tienen precisamente esa capacidad. ${ }^{276}$ (Grünbaum, 1984: 124-125).

Es en base a esta validación inductiva que Grünbaum intentará concluir que la teorización freudiana es "fundamentalmente defectuosa"277 (ibíd. p. xii, 94, 124, 128). Veamos ahora en qué consisten tales cánones.

\section{b) El inductivismo eliminativo como criterio de demarcación}

Grünbaum considera que la evidencia que brinda apoyo científico a una hipótesis causal no puede ser establecida a partir del inductivismo enumerativo

\footnotetext{
275 "...Popper is no less slipshod in his account of Freudian explanations than in his depiction of inductivism."

276 "...I shall offer in this essay just why Popper's application of his falsifiability criterion is too insensitive to exhibit the most egregious of the epistemic defects bedeviling the Freudian etiologies, interpretation of dreams, theory of parapraxes, etc. Indeed, as I shall argue, timehonored inductivist canons for the validation of causal claims have precisely that capability".
}

277 "Fundamentally flawed". 
del Empirismo Lógico ni del falsacionismo de Popper. El hecho de que las hipótesis psicoanalíticas puedan ser falsadas y/o enumerativamente confirmadas no representa, por lo tanto, un logro tan significativo como algunos creen. Tampoco las críticas provenientes de dichas perspectivas resultan demasiado relevantes.

Lo que Grünbaum advierte sobre el problema del criterio de demarcación podría resumirse en dos aserciones: (a) las refutaciones empíricas contundentes de las hipótesis científicas son un fenómeno raro en cualquier ciencia, y (b) la ciencia nos brinda mucho más que refutaciones, pues utiliza medios empírico-inductivos para conferir credibilidad a sus mejores teorías. Su preocupación recae, entonces, en brindar una manera de fundamentar las inferencias causales de la ciencia recurriendo a la tradición inductivista de la filosofía.

Grünbaum llama inductivismo eliminativo a la concepción según la cual las pruebas cuentan como apoyo a una hipótesis, es decir que le confieren credibilidad científica, si y sólo si: a) la evidencia es deducible de la hipótesis; lo cual es una condición necesaria pero no suficiente para que dicha evidencia cuente como apoyo a la hipótesis; b) la evidencia justifica la preferencia de la hipótesis por sobre alguna otra hipótesis rival; c) la evidencia ha sido obtenida de manera tal que elimina la plausibilidad de explicaciones alternativas que, de otra manera, habrían tenido que ser consideradas (Grünbaum, 1978b). Esta forma de entender el proceder inductivo para dar crédito a las hipótesis causales, dista mucho de la ingenua versión que Popper criticaba y en la que cada una de las instancias positivas de una hipótesis la confirman por igual y de manera paulatina ${ }^{278}$.

Para Marshall Edelson, entre otros, Grünbaum exagera la diferencia entre el falsacionismo y el inductivismo eliminativo, puesto que en realidad los cánones de este último podrían considerarse una elaboración de lo que Popper llamaba

\footnotetext{
278 "En defensa de Popper [reconoce Grünbaum] debe señalarse que ha habido una importante escuela de inductivistas, entre filósofos y eminentes científicos, que defendía la doctrina de que cualquier instancia positiva de una hipótesis también califica necesariamente como una instancia de apoyo de la hipótesis." (Grünbaum, 1978b: 119; cursivas del original). ["But in fairness to Popper, it should be pointed out that there has been one important school of inductivists among both philosophers and eminent scientists who championed the doctrine that any positive instance of a hypothesis also necessarily qualifies as a supportive instance of the hypothesis."]
} 
una rigurosa prueba de hipótesis. Para Edelson, el falsacionismo y el inductivismo eliminativo no representan, en principio, dos visiones distintas de la ciencia, sino que responden a preguntas diferentes:

Popper pregunta: “¿Qué califica a una afirmación como digna de toda la atención del científico?" Él responde: "que sea falsable". Entre esas afirmaciones falsables, algunas sobrevivirán y continuarán sobreviviendo a rigurosas pruebas de competición general con otras rivales. El inductismo eliminativo es más bien una respuesta a la pregunta "¿Qué hace que una afirmación, que ha sido aceptada por la ciencia como científicamente significativa, sea científicamente creíble?"279. (Edelson, 1984: 42).

Ese énfasis diferencial en la obtención del estatus de credibilidad científica en vez del estatus de candidato a la condición de credibilidad científica, junto con el énfasis en "la obtención de evidencia que apoye a una hipótesis sobre su rival específica y sobre sus múltiples hipótesis alternativas" es lo que permite, pese a sus semejanzas, distinguir al inductivismo eliminativo del falsacionismo (ibíd.).

Más allá de esa distancia relativa respecto del falsacionismo, detengámonos en lo que podría considerarse el corazón de la propuesta de Grünbaum. Así sintetiza nuestro filósofo, apoyándose en las ideas de Wesley Salmon (1984: 32-33), su modelo para el discernimiento de la relevancia causal ${ }^{280}$ :

He mencionado repetidamente la siguiente condición necesaria para atribuir relevancia causal a un atributo o factor $\mathrm{X}$ en la ocurrencia de una propiedad $\mathrm{Y}$, en una clase de referencia $C$ en la que hay casos de $X: X$ divide la clase $C$ en dos subclases, $X$ 's y no-X's, de modo tal que la probabilidad de $Y$ en las dos subclases respectivas sea diferente. [...] $\mathrm{Y}$ agregué que las versiones estadísticas, modernizadas o refinadas, de los famosos cuatro métodos de investigación controlada, articulados por John Stuart Mill, sirven para testear la relevancia

\footnotetext{
279 "Popper asks, 'What qualifies a statement as worthy of any attention at all from scientist?' He answers, 'That it is falsifiable'. Among such falsifiable statements, some will survive and continue to survive rigorous tests in a general competition with rivals. Eliminative inductivism is a response rather to the question 'What make a statement, which science has accepted as scientifically meaningful, scientifically credible?' The emphasis on achieving the status of scientific credibility rather than the status of 'candidate for the status of scientific credibility', and on obtaining evidence that supports a hypothesis over specific rival and multiple alternative hypotheses, does serve, however, to distinguish eliminative inductivism from falsificationism."

${ }^{280}$ Grünbaum expresa esta misma idea en diversas oportunidades (1984: 72; 1990: 570-571; 1994a: 54; 1994b: 156-157).
} 
causal de una $\mathrm{X}$ para una $\mathrm{Y}$ : tal investigación controlada muestra si la presencia o ausencia de $\mathrm{X}$ hace una diferencia en la aparición de Y. ${ }^{281}$ (Grünbaum, 1993:

163).

Es importante notar que la noción de causa que aparece involucrada queda reducida al hecho de que un factor haga una diferencia en la ocurrencia de un fenómeno. A su vez, conviene que distingamos dos aserciones implícitas en el esquematismo de Grünbaum, a los fines de comprender cabalmente su sentido:

i) Si el factor $X$ divide a la clase $C$ en dos subclases, de $X$ y de no $X$, y si las probabilidades de $\mathrm{Y}$ en estas dos subclases son diferentes, entonces $\mathrm{X}$ es en realidad causalmente relevante para $Y$.

ii) Si el factor $X$ divide a la clase $C$ en dos subclases y si las probabilidades de $Y$ en estas dos subclases son diferentes, entonces la condición necesaria para que $X$ sea causalmente relevante para $Y$ se conforma de $X$ y de no $X$; quedando aún sin especificar las condiciones suficientes para que $X$ sea causalmente relevante para $\mathrm{Y}$.

Dicho más sencillamente: Grünbaum no parece haber querido decir que una partición de $\mathrm{C}$ por $\mathrm{X}$ en subclases que difieren en sus probabilidades de $\mathrm{Y}$, sea suficiente para determinar la eficacia causal de $X^{282}$.

Más adelante discutiremos si esta formulación general de la condición necesaria para la relevancia causal de un factor por otro, proporciona un

\footnotetext{
281 “...I have repeatedly mentioned the following necessary condition for the causal relevance of an attribute or factor $X$ to the occurrence of a property $Y$ in a reference class $C$ in which there are instances of $X: X$ divides the class $C$ into two subclasses, $X$ 's and non-X's, such that the respective probabilities of $Y$ in these two subclasses are different [...]. And I added that modernized or refined statistical versions of the famous four methods of controlled inquiry articulated by John Stuart Mill (1887) serve to test the causal relevance of an X to a Y: Such controlled inquiry shows whether the presence of $X$ makes a difference to the occurrence of $Y$ ".

282 Un ejemplo simple puede permitir comprender mejor esta restricción. Supongamos que la propiedad de ser alto $(X)$ (donde "ser alto" se podría definir estableciendo una medida arbitraria como, por ejemplo, medir más de $1.80 \mathrm{mts}$ ) divide a una población de personas $(C)$ en los que son altos $(\mathrm{X})$ y los que no (no $\mathrm{X}$ ). Supongamos también que la probabilidad de tener ojos claros (Y) es diferente en cada una de las dos subclases de esa población. Sin lugar a dudas, de ello no se sigue que la altura sea causalmente relevante para el color de ojos. Por lo tanto, Grünbaum parece estar esquematizando lo que da su derecho, en términos conceptuales, a una condición necesaria para la relevancia causal de $X$ sobre $Y$, sin decirnos nada respecto a esa relevancia efectiva en un caso concreto. Es importante retener estas consideraciones, pues constituirán el objeto de nuestra crítica formal a este criterio.
} 
esquema conceptual eficazmente aplicable, en la práctica y en el dominio psicoanalítico, a la prueba de la relevancia causal.

Ahora bien, se nos hace necesario exponer de qué modo estas consideraciones, lejos de ser novedosas ${ }^{283}$, se remontan a los albores de las disquisiciones filosóficas sobre los métodos científicos. En particular a los cánones de John Stuart Mill.

\section{c) El enfoque de Stuart Mill y la inducción eliminativa}

La inducción enumerativa es una perspectiva filosófica que indica que las generalizaciones inductivas permiten arribar a teorías científicas: a partir de casos particulares de fenómenos observados se pueden conocer las leyes causales de las que tales casos constituyen instancias confirmatorias. Sin embargo, a partir de la enumeración simple sólo pueden visibilizarse los reportes de fenómenos en los que la causa y el efecto supuestos estén presentes, sin que tengan lugar las instancias en las que, o bien se halla la causa pero no el efecto, o bien el efecto está presente sin la causa. Por ello no pueden explicarse las excepciones a la ley ni, por lo tanto, diferenciar fehacientemente una ley causal de una generalización accidental. Francis Bacon había tomado plena conciencia de tales limitaciones:

La inducción que procede por simple enumeración, es una cosa pueril que conduce sólo a una conclusión precaria, que una experiencia contradictoria puede destruir, y que dictamina muy a menudo acerca de un restringido número de hechos, y sólo sobre aquellos que por sí mismos se presentan a la observación. La inducción que ha de ser útil para el descubrimiento y demostración de las ciencias y de las artes, debe separar la naturaleza por exclusiones legítimas, y después de haber rechazado los hechos que convengan, deducir la conclusión en virtud de los que admita (Bacon, 1620/1984: libro primero, aforismo 105).

En virtud de tales problemas de la inducción enumerativa para poner a prueba leyes causales, Bacon formuló una inducción por eliminación: oponiéndose al proceder aristotélico de la enumeración simple, proponía

\footnotetext{
${ }^{283}$ Grünbaum no aporta ninguna novedad sustancial a la tradición inductivista, e incluso se basa sólo en algunos desarrollos de la misma (O'Neil, 1993). Para un análisis sistemático de la inducción eliminativa cf. Edelson (1984: 43-46), Earman (1992: cap. 7) y Kitcher (1995: cap. 7).
} 
clasificar y tabular los datos empíricos (en tablas de presencia, ausencia y grados) a los fines de lograr la eliminación de aquellas circunstancias que no varían regularmente con el fenómeno y que, por lo tanto, no podrían ser causa del mismo ${ }^{284}$. Para Grünbaum, "Popper había pasado por alto, muy tendenciosa y ahistóricamente, la importante discrepancia probatoria entre el sofisticado inductivismo eliminativo de Bacon y su ancestro enumerativo"285 (Grünbaum, 2009: 128). Dos siglos más tarde, John Stuart Mill (1843) propuso cinco preceptos (que llamó cánones) para descubrir y para probar vínculos causales: método de la diferencia, método conjunto de la concordancia y la diferencia, método de los residuos y método de la variación concomitante. La siguiente tabla presenta los cinco cánones y sus reglas, que a continuación expondremos sintéticamente:

\begin{tabular}{|c|c|c|c|c|}
\hline Canon & Casos & $\begin{array}{l}\text { Circunstancias } \\
\text { antecedentes }\end{array}$ & Fenómeno & Conclusión \\
\hline Concordancia & $\begin{array}{l}N^{\circ} 1 \\
N^{\circ} 2 \\
N^{\circ} 3\end{array}$ & $\begin{array}{c}\text { A B C } \\
\text { B C } \\
\text { C }\end{array}$ & $\begin{array}{l}X \\
X \\
X\end{array}$ & $\begin{array}{c}\text { C es causa (o } \\
\text { efecto) } \\
\text { probable de X }\end{array}$ \\
\hline Diferencia & $\begin{array}{l}N^{\circ} 1 \\
N^{\circ} 2\end{array}$ & $\begin{array}{c}A B \\
B\end{array}$ & $\begin{array}{c}X \\
\text { no } X\end{array}$ & $\begin{array}{l}\text { A es causa (o } \\
\text { efecto) } \\
\text { probable de X }\end{array}$ \\
\hline $\begin{array}{c}\text { Conjunto de Concordancia } \\
\text { y diferencia }\end{array}$ & $\begin{array}{l}\mathrm{N}^{\circ} 1 \\
\mathrm{~N}^{\circ} 2 \\
\mathrm{~N}^{\circ} 3\end{array}$ & $\begin{array}{c}\text { A B C } \\
\text { B C } \\
\text { C }\end{array}$ & $\begin{array}{c}X \\
X \\
\text { no } X\end{array}$ & $\begin{array}{c}\text { B es causa (o } \\
\text { efecto) } \\
\text { probable de } X\end{array}$ \\
\hline Residuos & $N^{0} 1$ & $\begin{array}{c}\text { A B C } \\
\text { Se sabe que A } \\
\text { Se sabe que B }\end{array}$ & $\begin{array}{c}X Y Z \\
X \\
Y\end{array}$ & $\begin{array}{c}\text { C es causa (o } \\
\text { efecto) } \\
\text { probable de } Z\end{array}$ \\
\hline Variación concomitante & $\begin{array}{l}\mathrm{N}^{\circ} 1 \\
\mathrm{~N}^{\circ} 2\end{array}$ & $\begin{array}{l}A B \\
2 A B\end{array}$ & $\begin{array}{c}X \\
2 X\end{array}$ & $\begin{array}{l}\text { A es causa (o } \\
\text { efecto) } \\
\text { probable de } X\end{array}$ \\
\hline
\end{tabular}

\footnotetext{
${ }^{284}$ Aunque Bacon enfatizó mucho antes que Popper que los casos negativos tienen mayor fuerza probatoria que los positivos, Grünbaum reconoce una falencia central de este padre del empirismo británico: estaba equivocado al suponer que, para cualquier conjunto dado de datos de observación, existe sólo un conjunto finito de hipótesis alternativas susceptibles de explicarlos. Así, la eliminación deviene en descarte de las hipótesis falsas hasta dar con la verdadera. Pero, como hoy sabemos, siempre hay un conjunto potencialmente infinito de hipótesis explicativas para un mismo conjunto de datos de observación, y esto es lo que lleva a Grünbaum a hablar de "inducción eliminativa neo-baconiana" (Grünbaum, 2009: 128).

285 "Popper had very tendentiously and ahistorically glossed over the major probative discrepancy between Bacon's sophisticated eliminative inductivism and its enumerative ancestor."
} 
Método de la concordancia: si dos o más casos del fenómeno que se investiga tienen sólo una circunstancia en común, dicha circunstancia sola en la que todos los casos concuerdan es la causa (o efecto) del fenómeno investigado.

Método de la diferencia: si un caso en el que el fenómeno investigado ocurre y un caso en el que no ocurre, tienen todas las circunstancias en común excepto una, que sólo existe en el primer caso; entonces esta circunstancia en la que únicamente difieren los dos casos es el efecto, o la causa, o una parte indispensable de la causa total, del fenómeno conocido.

Método conjunto de la concordancia y la diferencia: si dos o más casos en los cuales aparece el fenómeno tienen una sola circunstancia en común, mientras que dos o más casos en los cuales no aparece no tienen nada en común excepto la ausencia de esta circunstancia, entonces la circunstancia única en la cual difieren los dos grupos de ejemplos es el efecto, o la causa, o parte indispensable de la causa del fenómeno.

Método de los residuos: réstese de un fenómeno lo que se sabe, debido a inducciones previas, que es efecto de ciertos antecedentes $\mathrm{y}$, luego, el residuo del fenómeno es el efecto de los antecedentes restantes.

Método de la variación concomitante: cualquier fenómeno que varía de alguna manera siempre que otro fenómeno varía en alguna forma particular, es la causa o el efecto de ese fenómeno, o está conectado con él mediante algún factor de causalidad.

El mérito de Stuart Mill no fue la originalidad en el establecimiento de sus célebres cánones, sino el haber podido sistematizar y difundir algunas ideas centrales de Francis Bacon; quien, a su vez, tampoco fue del todo original en formularlas, ya que lo esencial aparece enunciado en importantes pensadores medievales, tales como Robert Grosseteste, Juan Duns Escoto, Guillermo de Occam o David Hume (Losee, 1972/1981; Crombie, 1959/1987). Sea como fuere, muchos aún hoy sostienen que tales cánones constituyen las reglas básicas que utilizan las distintas ciencias para arribar a leyes causales ${ }^{286}$.

\footnotetext{
${ }^{286}$ Cf. el capítulo 12 del libro de Copi y Cohen (2013) para un análisis detallado de los cánones de Mill y para sus vinculaciones como ejemplos concretos de investigaciones contemporáneos de distintos ámbitos.
} 
Los primeros cuatro métodos son de carácter eliminatorio, pues al eliminar alguna causa posible de cierto fenómeno se apoya alguna otra causa hipotetizada:

El método de la concordancia elimina como causas posibles aquellas circunstancias en cuya ausencia, no obstante, puede ocurrir el fenómeno; el método de la diferencia permite la eliminación de algunas causas posibles al eliminar un factor antecedente que se muestra que es crítico; el método conjunto es eliminativo de ambas maneras; y el método de los residuos intenta eliminar como causas posibles aquellas circunstancias cuyos efectos ya se han establecido por inducciones previas. (Copi \& Cohen, 2013: 603).

De ahí la adjetivación de eliminativo que Grünbaum mantiene para esta propuesta inductiva de la que Mill es pionero. En efecto, los cánones

...son de indudable valor en el proceso de llegar a la verdad, pues al eliminar las hipótesis falsas, restringen el campo dentro del cual encontrar las verdaderas. Y aun cuando no logren eliminar todas las circunstancias irrelevantes, nos permiten establecer (con cierto grado de aproximación) de modo tal las condiciones para la producción de un fenómeno que podamos distinguir aquella hipótesis que, desde el punto de vista lógico, es preferible a sus rivales. (Cohen y Nagel, 1961/1990: 90).

A pesar de que Mill no reducía la complejidad de la investigación científica a la aplicación de esquemas inductivos, consideró que la justificación de las leyes científicas es un problema que se resuelve estableciendo la satisfacción de un esquema inductivo. Por eso consideraba que la función de la lógica inductiva era proporcionar reglas para la evaluación de hipótesis causales, de manera tal que un enunciado sobre el nexo causal entre fenómenos pueda justificarse mostrando que la evidencia a favor suyo se ajusta a los cánones inductivos diferenciados.

En base a lo anterior, consideramos posible definir de una forma sencilla al inductivismo eliminativo: es la aceptación de una generalización a posteriori y por defecto, luego de refutar (vía modus tollens) toda una serie de hipótesis causales en competencia menos una; aportando, al mismo tiempo y por enumeración simple, una serie de datos que contradicen a dichas hipótesis rechazadas y confirman a la que prevalece. Podemos ejemplificarlo mediante una formalización sencilla: para acreditar que $A$ es causa de $B$ no es suficiente 
sumar instancias de $A$ y $B$ (pues ninguna cantidad de tales instancias podría excluir la posibilidad de que haya $B$ sin que haya $A$; es decir la posibilidad de que otra hipótesis causal resulte más adecuada para explicar $B$ ), sino adherir instancias de no- $A$ que también sean no- $B$. Sólo si unimos ambos tipos de datos (ejemplos de $A$ que son $B$ y de no- $A$ que son no- $B$ ), tendremos evidencia significativa para acreditar el vínculo causal entre $A$ y $B$.

Esta definición sintética muestra claramente el papel de la refutación por inducción: supone que una sola instancia disconfirmatoria de una formulación causal demostraría que la causa postulada no puede ser considerada como una condición necesaria para el evento que se quiere explicar, ya que o bien la ley o bien las condiciones iniciales del esquema planteado resultarían errados. El mecanismo eliminativo se efectúa refutando todas las causas propuestas menos una, que se considera acertada por defecto: se trata de una utilización de la evidencia para descartar las hipótesis rivales que se revelan falsas.

Grünbaum intentará aplicar estos "consagrados cánones inductivistas" (op. cit.) al psicoanálisis, pues considera que "la teoría de Freud está repleta de hipótesis causales"287 (Grünbaum, 1984: 104). Pese a esta omnipresencia de afirmaciones causales, según nuestro filósofo, la teoría y la terapia psicoanalítica han fomentado la indiferencia respecto de tales cánones inductivos, y su actitud no ha sido otra que la de "burlarse de los resguardos elementales contra las trampas de la inferencia causal aceptados desde los tiempos de Francis Bacon, por no hablar de J. S. Mill." ${ }^{288}$ (ibíd. p. 254). Veremos, en lo que sigue, cómo Grünbaum emplea esta propuesta inductiva para analizar lo que él considera que es el principal argumento freudiano sobre la relación entre la causa de la neurosis y la cura mediante el análisis, bajo la suposición de que "los criterios reales de Freud para la validación de la teoría eran esencialmente los del inductivismo hipotético-deductivo"289 (Grünbaum, 1986a: 220). Nuestro filósofo concluirá que las inferencias causales del

\footnotetext{
287 "...Freud's theory is replete with causal hypotheses..."

288 "...flouting of the elementary safeguards against the pitfalls of causal inference familiar since the days of Francis Bacon, not to speak of J. S. Mill."

289 "Freud's actual criteria for theory validation were essentially those of hypothetico-deductive inductivism"
} 
psicoanálisis, debido a esa refracción a los cánones del inductivismo eliminativo, imposibilitan su validación desde el ámbito clínico.

Luego de acompañar a Grünbaum en su examen de los argumentos freudianos y de presentar nuestras objeciones al mismo, volveremos sobre el inductivismo eliminativo para evaluar críticamente la pertinencia de su empleo en la evaluación de las afirmaciones causales del dominio explicativo inherente a los organismos vivos y, más específicamente, al campo de la subjetividad.

\section{El "argumento de la coincidencia"}

Una vez analizados los puntos de vista de Habermas, Ricœur, Klein y Popper, Grünbaum se dispone a esbozar su crítica central a Freud. Para ello, presenta lo que ha llamado el "argumento de la coincidencia" (Tally argument) en publicaciones anteriores (Grünbaum 1979b, 1980) y que considera una "defensa epistemológica cardinal del método psicoanalítico de investigación clínica, que parece haber pasado hasta ahora totalmente desapercibida" 290 (Grünbaum, 1984: 127). Según nuestro autor, las consideraciones epistemológicas que condujeron a Freud a enunciar su argumento Tally hacen de él un "sofisticado metodólogo científico"291 (ibíd. p.128), muy superior a lo que permiten ver las valoraciones de varios de sus críticos. Sin embargo, como veremos enseguida, Grünbaum intenta exponer la sofisticación metodológica de Freud para luego mostrar cómo, en lo que a la validación teórica respecta, el vienés no respetó los estándares procedimentales que conocía.

Para Grünbaum, el "argumento de la coincidencia" (que esclareceremos enseguida) brinda la justificación epistemológica de los principales conceptos psicoanalíticos y de la práctica clínica misma del psicoanálisis. Más específicamente, este argumento ("o su audaz premisa legaliforme") es la base de cinco afirmaciones fundamentales, utilizadas por Freud para legitimar su teoría:

290 "...cardinal epistemological defense of the psychoanalytic method of clinical investigation that seems to have hitherto gone entirely unnoticed"

291 “...a sophisticated scientific methodologist...” 
i) La negación de una contaminación epistémica irremediable de los datos clínicos debido a la sugestión.

ii) La afirmación de una diferencia fundamental, en relación a la dinámica de la terapia, entre el tratamiento psicoanalítico y todas las terapias rivales que en realidad operan enteramente por sugestión.

iii) La afirmación de que el método psicoanalítico es capaz de validar sus principales afirmaciones causales (como sus etiologías sexuales específicas de las diversos psiconeurosis) mediante procedimientos esencialmente retrospectivos exentos del vicio post hoc ergo propter hoc, y sin el peso de estudios prospectivos empleando los controles propios de las investigaciones experimentales.

iv) La aseveración de que el resultado terapéutico favorable puede ser justificadamente atribuido a la intervención psicoanalítica, sin hacer uso de comparaciones estadísticas relacionadas con los resultados provenientes de grupos control sin tratamiento.

v) La admisión de que, una vez que las motivaciones del paciente ya no están distorsionadas o escondidas por los conflictos reprimidos, se puede dar razonablemente crédito a sus introspectivas autoobservaciones, porque estos datos entonces proporcionan información probatoria significativa. ${ }^{292}$ (Grünbaum, 1984: 127-128).

La validez de estas afirmaciones es lo que nuestro crítico intentará poner en cuestión; y lo hará intentando convencernos de que el argumento de la coincidencia resulta fallido.

Grünbaum reconoce la importancia del concepto de lo inconciente para la teoría: por un lado, refiere a representaciones que desconocemos y que determinan nuestras acciones (p. ej. en los síntomas); por otro lado, se vincula a la represión, el mecanismo por el cual tales representaciones devienen inconcientes. Nos recuerda la importancia que Freud le daba a esta noción: "La doctrina de la represión es ahora el pilar fundamental sobre el que descansa el

292 “(i) Denial of an irremediable epistemic contamination of clinical data by suggestion. (ii) Affirmation of a crucial difference, in regard to the dynamics of therapy, between psychoanalytic treatment and all rival therapies that actually operate entirely by suggestion (iii) Assertion that the psychoanalytic method is able to validate its major causal claims - such as its specific sexual etiologies of the various psychoneuroses - by essentially retrospective methods without vitiation by post hoc ergo propter hoc, and without the burdens of prospective studies employing the controls of experimental inquiries (iv) Contention that favorable therapeutic outcome can be warrantedly attributed to psychoanalytic intervention without statistical comparisons pertaining to the results from untreated control groups (v) Avowal that, once the patient's motivations are no longer distorted or hidden by repressed conflicts, credence can rightly be given to his or her introspective self-observations, because these data then do supply probatively significant information." 
edificio del psicoanálisis, su pieza más esencial" (Freud, 1914b/2004: 15); y se dispone a evaluar sus credenciales epistemológicas.

Lo primero que Grünbaum señala es la fuente de la convicción que todo analista tiene respecto de la hipótesis de la represión: la situación clínica. Los analistas consideran, nos dice Grünbaum, que el encuadre analítico aporta las evidencias necesarias y suficientes para generar y para sostener hipótesis como las de la represión (ibíd. p. 99-100). A partir de lo reseñado en la primera parte de esta tesis, puede decirse que tal apreciación mantiene su vigencia, pues la mayoría de los analistas continúan actualmente considerando a los datos clínicos como la base empírica inherente al psicoanálisis, a la vez que desestimando las investigaciones extra-clínicas o mostrándose profundamente escépticos respecto del valor de otro tipo de pruebas (como las experimentales o estadísticas).

Adelantemos que la tesis de Grünbaum es que los datos obtenidos a partir del análisis no constituyen una evidencia confiable para validar las hipótesis que allí se utilizan. Él considera que la base empírica que aporta el encuadre analítico está irremediablemente contaminada: los pacientes son víctimas de la sugestión y las interpretaciones acontecidas en un análisis son efecto de las expectativas del analista, por lo que carecen de valor probatorio alguno. Según su punto de vista, Freud conocía muy bien estas objeciones y habría intentado darles respuesta. Para apoyar su idea, cita dos pasajes de las Conferencias de introducción al psicoanálisis: en primer lugar de la conferencia $27^{\circ}$, en la que Freud privilegia la noción de transferencia como un componente central en la resolución de las neurosis. Allí Freud destaca lo siguiente: "en la medida en que su trasferencia es de signo positivo, reviste al médico de autoridad y presta creencia a sus comunicaciones y concepciones" (Freud, 1917b/2004: 404). Según Grünbaum, "Freud sabía muy bien" (ibíd.) que decir eso era alimentar la crítica de que los hallazgos clínicos no reflejan un "verdadero autodescubrimiento profundo" (ibíd.), sino que sólo se trata de la sugestión del analista.

El segundo pasaje escogido por Grünbaum se encuentra en la conferencia siguiente, titulada Sobre la terapia analítica; en dónde el padre del psicoanálisis 
"brillantemente, aunque sin éxito, llegó a enfrentarse con toda la magnitud del desafío mortal de la sugestionabilidad"293 (ibíd. p.135). Allí Freud afirma:

\begin{abstract}
Ahora me dirán ustedes que, se llame trasferencia o sugestión la fuerza impulsora de nuestro análisis, persiste de todos modos el peligro de que la influencia ejercida sobre el paciente vuelva dudosa la certeza objetiva de nuestros descubrimientos. Lo que favorece a la terapia es perjudicial para la investigación. Es la objeción que con mayor frecuencia se hace al psicoanálisis, y es preciso confesar que, aun siendo errónea, no es posible desautorizarla por irracional. Pero si fuera correcta, el psicoanálisis no pasaría a ser sino un tratamiento de sugestión muy bien disfrazado y particularmente eficaz, y tendríamos derecho a tomar a la ligera todas sus aseveraciones sobre las influencias de la vida, la dinámica psíquica, el inconciente. Es lo que opinan los oponentes; en particular, todo lo que se refiere a la importancia de las vivencias sexuales, si no estas mismas, se lo hemos «instilado» a los enfermos después que esas combinaciones se formaron en nuestra corrompida fantasía. Tales imputaciones se refutan más fácilmente invocando la experiencia que con ayuda de la teoría. El que ha realizado psicoanálisis ha podido convencerse incontables veces de que es imposible sugerir al enfermo de esa manera. Desde luego, no hay ninguna dificultad en hacerlo partidario de una determinada teoría y hasta en hacerlo participar en un posible error del médico. En esto él se comporta como otro cualquiera, como un alumno, pero por ese medio sólo se ha influido sobre su inteligencia, no sobre su enfermedad. La solución de sus conflictos y la superación de sus resistencias sólo se logra si se le han dado las representaciones-expectativa que coinciden con su realidad interior. Las conjeturas desacertadas del médico desentonan de nuevo en el curso del análisis; es preciso retirarlas y sustituirlas por algo más correcto (Freud, 1917c/2004: 411-412).
\end{abstract}

Grünbaum repara en última parte de la cita y sostiene que se trata nada más ni nada menos que de la conjetura esencial del método psicoanalítico. Considerando que se basó en la Standard Edition, la cita reza así: “...sus conflictos sólo serán resueltos exitosamente y sus resistencias superadas si las ideas anticipatorias que el analista aporta coinciden con lo que es real en él"294.

293 "...brilliantly, albeit unsuccessfully, came to grips with the full dimensions of the mortal challenge of suggestibility..."

${ }^{294}$ Este detalle, como veremos luego, es esencial. La traducción al español (a cargo de Etcheverry) en la edición de Amorrortu, aquí difiere considerablemente de la traducción al inglés de la Standard Edition. En esta última, la parte de la cita en cuestión dice así: "After all, his conflicts will only be successfully solved and his resistances overcome if the anticipatory ideas he is given tally with what is real in him". Más adelante abordaremos esta cuestion con mayor profundidad, pues desde estas disquisiciones terminológicas parece colarse una serie 
Allí ubica nuestro autor al argumento de la coincidencia y sostiene que con él Freud "nos dio su defensa epistemológica cardinal del método psicoanalítico de investigación clínica y prueba, una reivindicación fundamental cuyo alcance había pasado totalmente desapercibida en la literatura"295 (ibíd. p.135).

Grünbaum se dedica a analizar ese argumento desde su concepción del inductivismo eliminativo, a los fines de establecer su supuestamente deficitaria fundamentación filosófica. Para ello, sostiene que el argumento de la coincidencia implica la conjunción de dos supuestos diferenciables, que conforman lo que él llama la "tesis de la condición necesaria" (TCN); tales supuestos son:

“1) sólo el método psicoanalítico de la interpretación y el tratamiento puede obtener o mediar para el correcto insight del paciente en los agentes patógenos inconscientes de su psiconeurosis, y

2) el insight correcto del analizando en la etiología de su aflicción y en la dinámica inconsciente de su carácter es, a su vez, causalmente necesario para la conquista terapéutica de su neurosis"296 (ibíd. p.139-140).

Dicho de otra manera, el argumento de la coincidencia equivale a suponer que, necesariamente, sólo el psicoanálisis puede dar a conocer las determinaciones inconcientes de una psiconeurosis ${ }^{297}$ y, a partir de ello, alcanzar la cura. Eso parece significar, para nuestro autor, que la validez de las hipótesis de Freud está garantizada por el éxito de su terapia. Grünbaum reconoce que Freud no afirmó que el análisis siempre resultara en curaciones, de modo que el insight analítico debe ser entendido como una condición necesaria y no como una condición suficiente de éxito terapéutico.

de asunciones ontológicas y epistémicas (discutibles) en la argumentación de Grünbaum. Ello nos abrirá la puerta para discutir el argumento de la coincidencia desde otro punto de vista.

295 "...he gave us his cardinal epistemological defense of the psychoanalytic method of clinical investigation and testing, a pivotal vindication whose import had gone completely unnoticed in the literature..."

296 "(1) only the psychoanalytic method of interpretation and treatment can yield or mediate to the patient correct insight into the unconscious pathogens of his psychoneurosis, and (2) the analysand's correct insight into the etiology of his affliction and into the unconscious dynamics of his character is, in turn, causally necessary for the therapeutic conquest of his neurosis."

297 Según Grünbaum, Freud hizo referir esta TCN solamente a las psiconeurosis, excluyendo a las neurosis actuales. En virtud de su centralidad, nuestro filósofo había denominado antes a esta conjunción como la "proposición maestra de Freud" (Grünbaum, 1983d: 17). 
Grünbaum entiende que, además, el argumento implica dos conclusiones fundamentales, aplicables a todo paciente "P" que Freud haya tratado exitosamente bajo la suposición de TCN:

Conclusión 1: Las interpretaciones psicoanalíticas de las causas ocultas del comportamiento de $\mathrm{P}$ [paciente con éxito terapéutico] que le son propuestas por su analista, son efectivamente correctas y por eso -como indica Freud- estas interpretaciones "concuerdan con lo que es real" en $\mathrm{P}$.

Conclusión 2: Sólo el tratamiento psicoanalítico puede permitir a $\mathrm{P}$ triunfar sobre su psiconeurosis ${ }^{298}$ (ibíd., p. 139-140).

Debe quedar claro que el "argumento de la coincidencia" no es lo aseverado por Freud sino la reconstrucción que Grünbaum hace de dicha afirmación: sus dos premisas centrales (TCN) y las dos conclusiones arriba mencionadas (Grünbaum, 1984: 140).

Para Grünbaum, el argumento de la coincidencia protege al psicoanálisis del problema de la sugestión, puesto que las interpretaciones pueden evaluarse por su acercamiento a la realidad del paciente $\mathrm{y}$, en última instancia, por su éxito terapéutico. Así, las interpretaciones que no coinciden con la realidad psíquica del paciente no conllevan insight alguno ni redundan en la cura; por lo que el argumento de la coincidencia es "la premisa fundamental sobre la que él [Freud] hace descansar esta impermeabilidad de la neurosis del paciente"299 (Grünbaum, 1984: 139). Grünbaum vincula inexorablemente el éxito terapéutico con dos tipos de hipótesis: las hipótesis interpretativas a nivel clínico, propias de cada caso singular; y las hipótesis metapsicológicas a nivel teórico, de predicación universal. Detengámonos en la forma en la que elabora su razonamiento:

Freud se esfuerza en emplear el Argumento Tally para justificar la siguiente afirmación epistemológica: el éxito terapéutico duradero y real, garantiza no sólo que las interpretaciones analíticas pertinentes suenen verdaderas o creíbles para

\footnotetext{
298 "Conclusion 1. The psychoanalytic interpretations of the hidden causes of P's behavior given to him by his analyst are indeed correct, and thus-as Freud put it - these interpretations "tally with what is real" in P. Conclusion 2. Only analytic treatment could have wrought the conquest of P's psychoneurosis".

299 "...the fundamental premise on which he rests this imperviousness of the patient's neurosis..."
} 
el analizado, sino también que ellas son efectivamente verídicas, o al menos bastante cerca de serlo ${ }^{300}$. (Grünbaum, 1984: 140).

Pero esto no constituye más que un "argumento intermedio", pues en realidad le sirve a Freud -nos dice el filósofo- para una conclusión más general:

...en conjunto, los resultados exitosos de los análisis constituyen evidencia convincente de todo lo que la teoría psicoanalítica general nos dice acerca de las influencias de las dinámicas inconscientes de la mente en nuestras vidas. En síntesis, los éxitos del tratamiento psicoanalítico en su conjunto atestiguan la verdad de la teoría freudiana de la personalidad, incluyendo sus etiologías específicas sobre las psiconeurosis e incluso su teoría general del desarrollo psicosexual”. ${ }^{301}$ (Grünbaum, 1984: 140).

Puede notarse que ambas aseveraciones quedan ligadas por una especie de transitividad, cuyo hilo conducente es el éxito terapéutico.

Además de lo anterior, Grünbaum nos dice que el argumento de la coincidencia presenta otras dos consecuencias fundamentales (no mencionadas por Freud):

1) En primer lugar, como consecuencia de TCN, el argumento excluye implícitamente la posibilidad de remisiones espontáneas de los síntomas, es decir de curaciones que no hayan tenido intervención alguna del psicoanálisis.

2) En segundo lugar, el argumento compromete a Freud con la creencia de que el psicoanálisis es terapéuticamente superior a todos los métodos psiquiátricos rivales; pues para Freud ninguno de ellos brinda una explicación de las causas reprimidas de la neurosis (lo cual es una condición necesaria según, justamente, TCN).

Todo ello hace que para Freud el argumento de la coincidencia sea una suerte de fundamento filosófico indudable, según Grünbaum; al punto que podríamos encontrarlo transversalizando toda la teoría psicoanalítica. Ya desde

\footnotetext{
300 "Freud is at pains to employ the Tally Argument in order to justify the following epistemological claim: actual durable therapeutic success guarantees not only that the pertinent analytic interpretations ring true or credible to the analysand but also that they are indeed veridical, or at least quite close to the mark."

301 “...collectively, the successful outcomes of analyses do constitute cogent evidence for all that general psychoanalytic theory tells us about the influences of the unconscious dynamics of the mind on our lives. In short, psychoanalytic treatment successes as a whole vouch for the truth of the Freudian theory of personality, including its specific etiologies of the psychoneuroses and even its general theory of psychosexual development."
} 
sus pasos iniciales con Breuer, Freud entendió que al levantar las represiones se producía la descarga de afectos y la rememoración de eventos reales que conducían a la desaparición de síntomas específicos; lo cual implica, según Grünbaum, una fundamentación inductiva de la causalidad.

Posiblemente, el apoyo más importante para esta centralidad que Grünbaum le da, sea el que proviene del Caso Juanito, en donde Freud sostiene:

\begin{abstract}
Siempre, en el psicoanálisis, el médico da al paciente las representacionesexpectativa con cuya ayuda pueda este discernir y asir lo inconciente. Unas veces lo hará con más abundancia y otras en medida más modesta; en efecto, unos casos requieren más auxilio, y otros lo precisan menos. Sin esa ayuda nadie sale del paso. Lo que uno puede liquidar por sí solo son perturbaciones leves, nunca una neurosis que se haya contrapuesto al yo como algo ajeno; para dominar esta se necesita del otro, y en la medida en que el otro pueda ayudar, en esa misma medida es curable la neurosis. (Freud, 1909a/2004: 86).
\end{abstract}

Grünbaum considera que este pasaje del caso Juanito constituye una anticipación explayada de la "indispensabilidad causal del insight psicoanalítico para la conquista de la psiconeurosis del paciente"302 (Grünbaum, 1984: 139), sintetizada posteriormente en la "audaz aserción" del argumento de la coincidencia. Incluso mucho antes de Juanito, afirma nuestro crítico, Freud había desplegado el argumento:

Si someten al más riguroso examen mi tesis según la cual también la etiología de la histeria residiría en la vida sexual, ella sale airosa de la prueba, como lo indica el hecho de que en unos dieciocho casos de histeria pude discernir ese nexo para cada síntoma singular y, toda vez que las circunstancias lo permitieron, corroborarlo con el éxito terapéutico. (Freud, 1896/2004: 199).

Grünbaum también considera que el abandono de la teoría de la seducción no refutó la segunda conjunción de TCN; lo cual resulta lógico: la primera razón aducida en la célebre carta a Fließ indica que no había podido culminar con éxito ningún análisis utilizando ST. Si las histéricas se hubiesen curado a partir de sugestionarlas con ideas equivocadas sobre su pasado (episodios de abuso sexual fácticamente acaecido), entonces TCN hubiera sido "fuertemente

\footnotetext{
302 "This bold assertion of the causal indispensability of psychoanalytic insight for the conquest of the patient's psychoneurosis..."
} 
disconfirmada" (ibíd. p. 159). Grünbaum considera que si Freud señala su decepción terapéutica como uno de los motivos de abandono de la teoría de la seducción es justamente porque siguió basándose en la suposición de que las curaciones son el garante de la verdad.

\section{El fracaso del argumento de la coincidencia}

Si el argumento de la coincidencia hubiera sido realmente probado, se habría podido afirmar que "el éxito del tratamiento psicoanalítico en su conjunto testimonia sobre la verdad de la teoría freudiana de la personalidad, incluidas sus etiologías específicas de las psiconeurosis e incluso su teoría general del desarrollo psicosexual”303 (ibíd., p. 140-141). Al mismo tiempo, se hubiera podido afirmar que el método psicoanalítico "tiene la extraordinaria capacidad de validar las principales aserciones causales por investigaciones esencialmente retrospectivas, sin tener la obligación de estudios longitudinales prospectivos utilizando controles (experimentales). Además, estas inferencias causales no están viciadas por el post hoc ergo propter hoc ni por otras conocidas trampas de la inferencia causal”304 (ibíd., p. 141). Grünbaum considera que Freud apoya sus afirmaciones sobre la eficacia del tratamiento analítico y sobre su superioridad respecto de otros, en el argumento de la coincidencia; apoyo que lo exime de realizar comparaciones estadísticas con grupos control $^{305}$ (de pacientes sin tratamiento o tratados con otras terapias rivales). Además, la segunda premisa de TCN previene contra la posibilidad del efecto placebo.

\footnotetext{
303 "...psychoanalytic treatment successes as a whole vouch for the truth of the Freudian theory of personality, including its specific etiologies of the psychoneuroses and even its general theory of psychosexual development."

304 "[Thus, this method] has the extraordinary capacity to validate major causal claims by essentially retrospective inquiries, without the burdens of prospective longitudinal studies employing (experimental) controls. Yet these causal inferences are not vitiated by post hoc ergo propter hoc or other known pitfalls of causal inference"

${ }^{305}$ El lector notará que los estudios de grupo control encuentran su fundamento en el método conjunto de las concordancias y las diferencias de Mill.
} 
Por oposición a lo anterior, Grünbaum pone todo su empeño en mostrar que el argumento de la coincidencia fracasa. Para ello, esboza dos versiones que explican por qué falla el argumento:

1) La primera arguye que se cae no por razones lógicas o empíricas sino porque Freud mismo lo abandonó. En este punto veremos al filósofo anteponer una serie de motivos que condujeron a Freud a abandonar su persuasión respecto del argumento, y que son correlativos de la evolución pesimista que tuvo su perspectiva terapéutica luego de 1920. Dicho de otra manera: las reservas freudianas respecto de la capacidad del análisis para lograr auténticas curaciones duraderas da cuenta, según Grünbaum, de que el vienés ya no cree en el argumento de la coincidencia. Nuestro filósofo entiende que al reconocer Freud que el análisis no puede producir curas, pierde su única garantía contra la carga agobiante de la sugestionabilidad. Esta desconfianza paulatina en la curación habría comenzado en Inhibición, síntoma y angustia (1926), en donde Freud abandona uno de los pilares del argumento: la negación de remisiones espontáneas. En ese escrito el vienés sostiene lo contrario: “...por regla general nuestra terapia debe contentarse con producir de manera más rápida y confiable, y con menor gasto, el desenlace bueno que en circunstancias favorables se habría producido espontáneamente" (Freud, 1926c/2004: 145). Grünbaum entiende que Freud está degradando el papel desempeñado por el análisis, pues ha pasado de considerarlo como una condición indispensable de curación del paciente a concebirlo como un mero "agilizador" de la curación que puede darse sin él. El argumento se derrumba desde el momento en que Freud admite que las recaídas y remisiones sintomáticas están ligados a la relación del paciente con el analista, advirtiendo que este "vínculo afectivo personal era más poderoso que cualquier trabajo catártico" (Freud, 1925b/2004: 26). Para nuestro filósofo "la importación de este pesimismo terapéutico es aplastante"306 (Grünbaum, 1984: 160), pues implica el fracaso metodológico en la certificación del papel causal de la represión mediante la inducción eliminativa: no puede establecerse punto-por-punto la relación entre mecanismos que actúan sobre eventos reales y la presencia/ausencia de síntomas específicos y delimitables.

\footnotetext{
306 "The import of this therapeutic pessimism is shattering"
} 
Una vez que la validación clínica queda sustraída de su legitimidad derivada del éxito terapéutico vía el argumento de la coincidencia, "el amenazador problema de la sugestionabilidad que [Freud] había logrado mantener a raya mediante este argumento, vuelve para acechar con mayor fuerza los datos provenientes del diván”307 (ibíd. p. 172). Además, el fracaso es complementado con un importante peso atribuido por el propio Freud a la relación emocional con el analista, lo cual -según nuestro crítico- allana el camino para sospechar de la contaminación epistémica por sugestión o del efecto placebo, impidiéndose así toda forma de validación clínica. Entonces concluye: "a menos que el tratamiento analítico sea parangón de las terapias de acuerdo con el argumento de Tally, Freud mismo ha reconocido que no se puede asegurar el valor científico inherente del psicoanálisis...”308 (ibíd., p.172).

Como puede verse, sin haberlo propuesto explícitamente como uno de sus objetivos, Grünbaum termina elaborando una tesis sobre el itinerario metodológico de Freud. En su versión, el vienés habría aceptado el argumento de la coincidencia a finales del siglo XIX y lo habría mantenido como fundamento durante treinta años, para finalmente terminar restándole valor a partir de 1926. Es notable -piensa Grünbaum- cómo para el momento en el que escribe Análisis terminable e interminable, el vienés habría dejado completamente de lado sus pretensiones de que el psicoanálisis brinde los mejores y más duraderos resultados, hasta un punto "lindante con un repudio del éxito terapéutico" 309 (ibíd. 160).

2) La segunda versión que Grünbaum brinda para mostrar que el argumento de la coincidencia fracasa es de otra naturaleza. Por un lado, nuestro autor pone en duda el hecho de que la corroboración clínica de los hechos históricamente acaecidos pueda efectuarse, debido a que hay estudios que muestran que los recuerdos recuperados de las experiencias infantiles no son confiables. Citando los primeros estudios de Elizabeth Loftus (1980) sobre la

\footnotetext{
307 "...the menacing suggestibility problem, which he had held at bay by means of this argument, comes back to haunt data from the couch with a vengeance".

308 "Therefore, unless analytic treatment is the paragon of the therapies as claimed in the Tally Argument, Freud himself has acknowledged that he cannot be assured of the inherent scientific value of psychoanalysis..."

309 "...bordered on a repudiation of treatment success."
} 
maleabilidad de la memoria, Grünbaum sostiene que "el tratamiento psicoanalítico no puede entenderse como un recurso bona fide de estimulación mnémica” ${ }^{310}$ (Grünbaum, 1984: 242). En segundo lugar, evoca una serie de estudios experimentales que desacreditan la afirmación de que el psicoanálisis produce mejores resultados terapéuticos que sus terapias rivales. En general, los estudios citados llegan a conclusiones similares: el psicoanálisis no funcionaría mejor que sus competidores; cualquier forma de psicoterapia es preferible a la ausencia de tratamiento; los beneficios de todas las psicoterapias se derivarían de algún factor común. Grünbaum extrae la conclusión de que Freud se equivocó al considerar indispensable el análisis para el tratamiento eficaz de la neurosis (lo cual muestra la falsedad del argumento de la coincidencia) y al presuponer implícitamente la superioridad del tratamiento psicoanalítico; " $y$, si es así, los logros terapéuticos del psicoanálisis no están forjados, después de todo, en la adquisición de autoconocimiento del paciente, para tristeza de Sócrates"311 (Grünbaum, 1984: 161). Así, TCN ha sufrido una "defunción empírica" ${ }^{312}$ (ibíd. p.171) y la defensa metodológica de las hipótesis de Freud ha quedado arruinada.

En síntesis, para Grünbaum el argumento de la coincidencia fracasa como defensa metodológica del psicoanálisis porque: por un lado Freud mismo lo abandonó cuando perdió la confianza en la cura analítica y, por otro lado, porque hay hallazgos empíricos que muestran que el psicoanálisis no es más eficaz que otras terapias, por lo que quedaría refutado. Según nuestro crítico, en virtud de esta falla y "sin un reemplazo viable para el argumento Tally de Freud", resultan insuficientes los motivos para "reivindicar la contrastabilidad intraclínica de los principios cardinales del psicoanálisis (especialmente de sus ubicuas pretensiones causales)"313 (ibíd. p.128). Grünbaum asegura que esta conclusión desfavorable se alcanza por la aplicación de las normas

\footnotetext{
310 "...psychoanalytic treatment ought not to be regarded as a bona fide memory-jogging device..."

311 "And, if so, then the therapeutic successes of psychoanalysis are not wrought after all by the patient's acquisition of self-knowledge, much to Socrates' sorrow."

312 "empirical demise"

313 "...vindicate the intraclinical testability of the cardinal tenets of psychoanalysis (especially of its ubiquitous causal claims)..."
} 
inductivistas neobaconianas ${ }^{314}$, cuyas demandas para la validación de las afirmaciones causales no pueden satisfacerse a menos que el método psicoanalítico se refuerce con un potente sustituto para el fracasado argumento de la coincidencia. Pero, "en ausencia de un sustituto tal, la descontaminación epistémica de la mayor parte de las producciones del paciente en el diván, provenientes de los efectos sugestivos de las comunicaciones del analista, parece ser bastante utópica" ${ }^{315}$ (ibíd. p.128). Por otro lado, el futuro de la validación del psicoanálisis "tendrá que venir en gran parte de los hallazgos extraclínicos" ${ }^{316}$ (ibíd.). Mientras tanto, afirma Grünbaum, "la difundida creencia que algunos segmentos de nuestra cultura tienen respecto de la teoría psicoanalítica no está bien fundamentada" ${ }^{317}$ (1986b).

\section{Sueños, lapsus y síntomas}

Luego de ofrecer tales razones para mostrar su hipótesis de que el argumento de la coincidencia ha fracasado, Grünbaum se dispone a caracterizar su crítica del mismo. De este modo, intentará mostrar que el argumento de la coincidencia es insostenible por sus propias bases. Resulta curioso que Grünbaum se detenga a considerar el argumento de la coincidencia con tanta trascendencia en The foundations, porque en algunos artículos anteriores había señalado categóricamente que se trataba de una defensa fracasada (cf. p.ej. Grünbaum, 1978a: 53).

\footnotetext{
${ }^{314}$ Aquí Grünbaum pareciera apoyarse en el método conjunto de la concordancia y la diferencia de Mill, pues para argumentar en contra de una supuesta relación causal (terapia psicoanalítica - eficacia terapéutica) tiende a señalar la supuesta ausencia de concordancia uniforme entre ambos (tally argument), es decir, apunta al hecho de que las circunstancias que se presentan en algunos casos, pero no en todos, no podrían constituir su causa.

315 "...in the absence of such a substitute, the epistemic decontamination of the bulk of the patient's productions on the couch from the suggestive effects of the analyst's communications appears to be quite Utopian".

316 "...lacking a viable alternative to the aborted Tally Argument with comparable scope and ambition, the future validation of Freudian theory, if any, will have to come very largely from extraclinical findings".

317 “...the widespread belief in psychoanalytic theory in some segments of our culture is hardly well-founded".
} 
Para Grünbaum, TCN nos dice que sólo el insight verdadero nos conduce al éxito terapéutico, por lo que los análisis terapéuticamente exitosos confirman la verdad de los conocimientos analíticos obtenidos y comunicados en cada pareja analítica (analista-paciente). Pero la objeción no se hace esperar: ¿cómo podemos saber, frente a un efecto terapéutico, que éste se ha producido por un insight verdadero y no por otro factor? Nuestro autor cree posible que el efecto terapéutico pueda estar condicionado o determinado por la sugestión ejercida por el analista; es decir que podría basarse en falsos insights y pseudoexplicaciones. ¿Cómo podemos saber si el efecto terapéutico es algo más que un efecto placebo, producido por la fe del analista y del paciente en la verdad y eficacia del insight, y consolidado con la interpretación? Después de todo -afirma Grünbaum- los cambios terapéuticos deseados podrían deberse a otros factores inherentes a la situación analítica, por ejemplo, al tipo de vínculo que allí acontece, y no a verdaderos insights. Estas dificultades de la situación clínica impiden que los datos allí generados puedan ser evaluados mediante la inducción eliminativa, lo cual equivale a decir que no tienen soporte científico.

A partir de lo anterior, Grünbaum postula que el argumento de la coincidencia necesita estar apoyado en comparaciones estadísticas con los neuróticos que no han recibido tales ideas que coinciden con su realidad interior. Los éxitos del análisis, por sí mismos, no pueden ser tomados como evidencia porque de ese modo no es posible adjudicarlos a un factor específico y siempre existe la posibilidad de que sean efecto de otros factores independientes del insight o "coincidencia" (p.ej. la sugestión). Así, para Grünbaum, la única forma de obtener evidencia para el psicoanálisis es a partir de confirmaciones extraclínicas. Esta es, podemos decir, la conclusión más importante de la crítica de Grünbaum: sólo pueden eliminarse explicaciones rivales (conforme a las indicaciones del inductivismo eliminativo) mediante estudios de control experimental, por lo que sólo puede validarse el conocimiento psicoanalítico a través de comparaciones estadísticas entre aquellos pacientes que han sido sometidos a tratamiento analítico y aquellos 
que, compartiendo la tipología, no han recibido ningún insight de las causas inconcientes de su padecer ${ }^{318}$.

De ese modo, más allá del pesimismo terapéutico de Freud e independientemente de los hallazgos experimentales sobre la eficacia terapéutica, Grünbaum considera que el argumento de la coincidencia siempre fue poco sólido. Para probarlo, nuestro filósofo de la ciencia va a detenerse en el papel de los sueños y los actos fallidos en la teoría freudiana, apuntando a mostrar que su existencia no es prueba suficiente para sostener la hipótesis de lo inconciente. De hecho, Grünbaum considera que las conjeturas relativas a tales fenómenos son "epistémicamente parasitarias"319 (ibíd. p.) en la teorización de los síntomas neuróticos, puesto que no tienen autonomía explicativa sino que dependen de la argumentación general de la neurosis. Así, la validez metodológica de la tesis de la determinación inconciente de los sueños y de los lapsus, se obtiene por derivación a partir de la validación de la tesis de la determinación inconciente de los síntomas; es decir: mediante el respaldo del argumento de la coincidencia. De allí se sigue que, para Grünbaum, la validación de las conjeturas freudianas sobre el sueño y el lapsus depende, en última instancia, de la eficacia terapéutica del psicoanálisis. Y, como era de esperarse, el hundimiento del argumento de la coincidencia (fundamentalmente por las dificultades para producir curas contundentes) arrastra consigo la fundamentación de las explicaciones relativas a los sueños y los lapsus.

Grünbaum considera que la analogía entre estos fenómenos es imperfecta, pues los sueños y lapsus carecen de un elemento esencial de la concepción de los síntomas: la asunción de que hay un padecimiento que puede ser aliviado

\footnotetext{
${ }^{318}$ Por momentos, Grünbaum parece no desestimar completamente la evidencia probatoria de los datos clínicos, por ejemplo cuando considera que "en general, los datos del diván adquieren significación probatoria cuando son corroborados de forma independiente por hallazgos extraclínicos o cuando concuerdan inductivamente con ellos [...] los datos clínicos no son de todo irrelevantes desde el punto de vista probatorio. Pero esto sólo confiere condicionalmente una relevancia potencial a los resultados intraclínicos..." (ibíd. p.266) [on the whole, data from the couch acquire probative significance when they are independently corroborated by extraclinical findings, or when they are inductively consilient with such findings [...] clinical data are altogether irrelevant probatively. But this much only conditionally confers potential relevance on intraclinical results...]. Un poco más adelante se muestra reacio a conferirles algún valor a los datos provenientes del diván (p.278).
}

319 "epistemically parasitic". 
al conocer sus causas reprimidas. "Por lo tanto -afirma Grünbaum- veo su teoría de los actos fallidos y los sueños como malas extrapolaciones de la etiología de represión genérica de los síntomas neuróticos, que había tenido, al menos prima facie, apoyo terapéutico" ${ }^{320}$. (ibíd. p. 194). Como sueños y lapsus no encuentran confirmación en algún fenómeno análogo a las curaciones, Grünbaum cree que la afirmación de que brindan testimonio de la influencia del inconsciente es completamente vacía.

Para ejemplificarlo, nuestro autor extracta la conocida anécdota del olvido del pronombre indefinido latino "aliquis" que Freud expone en el capítulo dos de su Psicopatología de la vida cotidiana ${ }^{321}$. Y sostiene que ni la afinidad temática ni el itinerario de las asociaciones tiene el peso necesario para sostener una afirmación causal, pues incluso concediendo que no hay contaminación y que las "asociaciones serpenteantes a partir de la memoria restaurada de aliquis" 322 (ibíd. p.192) son espontáneas, simplemente no hay razones convincentes para asumir que la preocupación inconsciente del joven sobre el embarazo de su amante le hizo olvidar la palabra aliquis. Es decir, aunque se podría argumentar que aliquis lanzó la cadena de asociaciones que trajo la ansiedad reprimida del hombre, es un error invertir la secuencia causal y reclamar que la ansiedad reprimida causó el olvido original:

\begin{abstract}
El ejemplo de aliquis es representativo de otros casos en los que Freud explota de manera engañosa la autenticidad de un temor (o de un deseo) que preocupa al sujeto y su manifestación por asociaciones puestas en marcha por un determinado
\end{abstract}

\footnotetext{
320 "Hence, I view his theory of parapraxes and of dreams as misextrapolations of the generic repression etiology of neurotic symptoms, which had at least had prima facie therapeutic support."

${ }^{321}$ Se trata del encuentro del vienés, en uno de sus viajes, con un joven académico, conocedor de algunas de sus publicaciones y con quien se dispuso a conversar. En determinado momento de la charla, el joven se lamenta de que la presente generación de su pueblo vea cercenados sus derechos e intenta citar un verso de la Eneida en el que la desdichada Dido difiere a la posteridad su venganza contra Eneas. La cita no puede ser completada porque el joven olvidó el mencionado pronombre indefinido. Luego de ello, el joven le pide a Freud que le recuerde el vocablo, a la vez que lo conmina a dar una explicación de lo sucedido. El vienés le pide que asocie libremente hasta arribar con una explicación de lo sucedido: la presencia de una idea angustiosa sobre la posibilidad de que una mujer estuviera embarazada de él constituye un pensamiento que entra en contradicción con la representación aludida de "dejar descendencia". De ese modo, "la perturbación de un pensamiento por una contradicción interna que proviene de lo reprimido" (Freud, 1901/2004: 22) ha de contar entre las causas del lapsus.
}

322 "meandering associations starting out from the restored memory of aliquis" 
acto fallido, para conferir plausibilidad a la atribución causal de ese acto fallido al temor (o al deseo) así suscitado. ${ }^{323}$ (ibíd. p.198).

Además de apoyarse en el trabajo de Sebastiano Timpanaro (1974/1977) para mostrar que existen explicaciones alternativas plausibles para el caso de los actos fallidos ${ }^{324}$, Grünbaum ataca directamente el procedimiento de la asociación libre como forma de establecer las causas inconcientes, pues considera que el analista no resuelve el problema de hasta dónde pedir asociaciones al paciente para arribar a una hipótesis. Considerando que las asociaciones se podrían extender indefinidamente, no queda claro -sostiene Grünbaum- qué determina que una asociación y no otra es la verdadera fuente de un lapsus. Sostiene que la confirmación del paciente tampoco es un recurso suficiente, pues "incluso si la persona que tuvo el fallido no estaba bajo la sugestiva influencia intimidatoria del analista, ¿cómo podría el sujeto posiblemente saber mejor que cualquiera del resto de nosotros que el miedo inconsciente en cuestión ha realmente causado su fallido?"325 (ibíd. p.208).

El problema central, sin embargo, es que el intento de fundamentar la teoría a partir de la asociación libre es una forma de falacia del tipo post hoc ergo propter hoc ${ }^{326}$. Así, la constatación temporal de que la fuente del acto fallido se

\footnotetext{
323 "The aliquis example is representative of other cases in which Freud fallaciously trades on the genuineness of a fear (or wish) with which the subject is preoccupied, and on its elicitation by associations initiated by a given parapraxis, to gain plausibility for the causal attribution of that parapraxis to the elicited fear (or wish)."

${ }^{324}$ Grünbaum sintetiza estas explicaciones rivales de Timpanaro en su capítulo cuatro (p. 194197). Como ellas mismas encierran un esfuerzo deliberado por obturar el hallazgo freudiano, recomendamos al lector recuperar el problema de la obsesionada búsqueda de Ferdinand de Saussure, quien se topó con la presencia de misteriosas estructuras anagramáticas, fundamentalmente en los escritos de poetas griegos y latinos. Desesperado por obtener una explicación racional de ese hallazgo que le mostraba, entre otras cosas, una significación oculta que contrariaba la linealidad de su signo lingüístico, se dispuso a interrogar a los poetas mismos: " ¿Es azar o un hecho intencional el que en un pasaje como Catullo-Calvos, el nombre de Falerni se encuentre rodeado por palabras que reproducen las sílabas de ese nombre?" (en Starobinski, 1971/1996: 150). El poeta interpelado nunca le contestó y Saussure abandonó su búsqueda. Coincidimos con Michel Arrivé: "¿es acaso posible imaginar un reconocimiento más espectacular, aunque negativo (y por eso mismo efectivo), del inconsciente?" (1994/2004: 25).
}

325 "Even if the person who "slipped" were not under the suggestive, intimidating influence of the analyst, how could the subject possibly know any better than any of the rest of us that the pertinent unconscious fear had actually caused his slip?"

${ }^{326}$ Su traducción podría ser "después de esto, por lo tanto, a consecuencia de esto". Se trata del establecimiento de una relación causal entre dos acontecimientos a partir de constatar que uno sucede después del otro. Su carácter falaz viene dado porque la consecución no es un indicador fiable: no siempre es verdad que el primer acontecimiento produce causalmente al 
revela siempre una vez que éste se ha producido, no prueba de ninguna manera -sostiene Grünbaum- que el fallido ha sido causado por esa fuente. Grünbaum considera la interpretación de los sueños y sostiene que la pertenencia temática de la idea asociada libremente al asunto del relato del sueño, no constituye necesariamente una prueba de la existencia de una conexión genética o causal entre ambas. Es decir que, aunque la asociación libre conduzca a determinados aspectos importantes de la vida mental del soñador, esto no es una razón suficiente para que tal aspecto sea considerado como causa o motivo de la producción del sueño ${ }^{327}$. Así, nuestro filósofo considera que las asociaciones libres no permiten confirmar las causas de los actos fallidos ni de los sueños y que es injustificado el "tributo epistémico" que Freud les ha rendido, pues "hasta ahora no se basa en nada más que una falacia causal evidente" ${ }^{328}$ (Grünbaum, 1984: 186).

Además, Grünbaum piensa que la afinidad temática que las asociaciones libres establecen, adolece de una elasticidad excesiva para constituir un instrumento válido de constatación clínica. Para mostrarlo, elabora una continuación hipotética de la conversación de Freud con el joven austro-judío (al que denomina $\mathrm{AJ}$ ), en la que ofrece su propia explicación alternativa:

\begin{abstract}
Supongamos que Freud le habría permitido a AJ continuar mucho más allá de la comunicación del miedo sobre el embarazo. Quizás entonces hubiese surgido que los padres de AJ le habían enseñado temprano que los romanos han crucificado a Jesús, pero que luego los cristianos han injustamente culpado a los judíos de deicidio. Podría, además, haber sugerido que AJ había reprimido su odio
\end{abstract}

segundo. La consecución es, por lo tanto, una condición necesaria pero no suficiente para que el primer acontecimiento sea causa del segundo. La importancia que Grünbaum le otorga a este problema queda plasmada en su diseminación y recursiva recuperación durante el transcurso del libro (cf. pp. 170, 192, 198, 207, 208, 214, 254, 256, 257).

${ }^{327}$ En este punto la postura de Grünbaum se asemeja a la de Wittgenstein, quien apropósito del problema de la asociación libre espetó: "el hecho es que siempre que ustedes están preocupados por algo, por alguna dificultad o por algún problema importante en su vida -el sexo, por ejemplo-, no importa el punto del que partan, la asociación volverá a llevarles final e inevitablemente al mismo lema [...] se puede llegar a descubrir ciertas cosas sobre uno mismo por este tipo de libre asociación pero eso no explica por qué ocurrió el sueño." (Wittgenstein, 1966/1992: 126-127). Aunque, como sabemos, la diferencia entre ambos se hace patente por su manera de entender las explicaciones freudianas: mientras que para Grünbaum son explicaciones causales, para Wittgenstein no pasan de explicaciones "estéticas".

328 "...this epistemic tribute to free associations so far rests on nothing but a glaring causal fallacy". 
resultante hacia los romanos cuando Virgilio, Horacio y otros poetas romanos mostraron gran respeto en su entorno educativo austríaco. Ahora recordemos el criterio freudiano de la "idoneidad determinadora", invocado en los estudios sobre la histeria para dar primacía etiológica a una represión temprana sobre una posterior, aun cuando el recuerdo de la anterior surgió más tarde en la cadena de asociaciones del paciente (SE 1896, 3: 193-196) que el recuerdo de la posterior. ¿No habría tenido, la hipotética represión del odio de AJ por los romanos, mayor "idoneidad determinadora" temática en su fallido de aliquis que su ansiedad sobre el embarazo, a pesar de que aquella presuntamente habría surgido más tarde en la cadena asociativa? Después de todo, Virgilio era romano y AJ estaba citando la línea de la Eneida para expresar su resentimiento consciente del antisemitismo cristiano. ¡Qué gran oportunidad para castigar a los romanos que inconcientemente resentía $\mathrm{y}$, simultáneamente, estropear la línea de Virgilio! Aunque el odio reprimido por los romanos es, por supuesto, puramente hipotético en el caso de AJ, se presta con pertinencia a la queja del sesgo de selección, al que generalmente se le da sustancia por la elasticidad temática de las asociaciones que he enfatizado. ${ }^{329}$ (Grünbaum, 1984: 209-10).

\section{En base a los problemas señalados Grünbaum concluye:}

Si hay algunos lapsus que realmente son causados por auténticas represiones, Freud no nos ha dado ninguna buena razón para pensar que sus métodos clínicos pueden identificar y certificar esas causas como tales, sin importar cuán interesantes puedan ser, por otra parte, las asociaciones 'libres' realizadas por el sujeto. Como se desprende de mis argumentos, esta conclusión adversa parece

\footnotetext{
329 "Suppose that Freud had allowed AJ to continue well past the disclosure of the pregnancy fear. Perhaps it would then have emerged that AJ's parents had taught him early that the Romans had crucified Jesus, but that Christians had then unfairly blamed the Jews for deicide. It might furthermore have emerged that AJ had repressed his ensuing hatred of the Romans when Virgil, Horace, and other Roman poets were shown great respect in his Austrian educational environment. Now let us recall Freud's criterion of "suitability as a determinant" which he invoked in the study of hysteria to give etiologic primacy to an earlier repression over a later one, even though the memory of the earlier one emerged later in the chain of the patient's associations (S.E. 1896, 3: 193- 196) than the memory of the subsequent one. Would AJ's hypothesized repression of his hatred for the Romans not have had greater thematic "suitability as a determinant" of his aliquis slip than his anxiety about the pregnancy, even though the former assumedly emerged only later in his associative chain? After all, Virgil was a Roman, and AJ was citing the line from the Aeneid to express his conscious resentment of Christian anti-Semitism. What a golden opportunity to punish the unconsciously resented Romans simultaneously by spoiling Virgil's line! Although the repressed hatred for the Romans is, of course, purely hypothetical in the case of AJ, it does lend poignancy to the complaint of selection bias, which is given substance generally by the thematic elasticity of the associations I have emphasized."
} 
irrevocable incluso aunque se conceda que el analista no influye en las asociaciones "libres" del sujeto. ${ }^{330}$ (ibíd. p. 206).

De este modo, las teorizaciones freudianas de los lapsus y los actos fallidos no se sostienen adecuadamente por sí mismas según Grünbaum, ni tampoco pueden apoyarse en la teoría de la neurosis porque no hay en ellas el equivalente de la eficacia terapéutica de los síntomas. Aunque, de todas formas, al fallar el argumento de la coincidencia, la teoría de las neurosis también se presenta fallida en sí misma y, por lo tanto, de nada valdría esta derivación.

Algunos años más tarde Grünbaum ratificó su idea diciendo que "la atribución del éxito terapéutico a la remoción de las represiones no sólo fue, sino es hasta nuestros días, el solo sustento epistémico de la supuesta habilidad de las asociaciones libres de los pacientes para certificar las causas." ${ }^{331}$ (Grünbaum, 1993: 24).

En síntesis y a partir de lo expuesto, la postura de Grünbaum consiste en asumir que los datos clínicos no constituyen una evidencia suficiente (no portan las credenciales necesarias) para las principales hipótesis freudianas; ni podrían constituirlo, pues la sola experiencia clínica resulta viciada. Grünbaum expresa claramente esto en un resumen que él mismo hace de su libro: "si existe evidencia empírica para las principales doctrinas psicoanalíticas, no puede obtenerse sin estudios extraclínicos bien definidos que en su mayoría están aún por hacerse"332 (Grünbaum, 1986a: 217).

\footnotetext{
330 "if there are any slips that are actually caused by genuine repressions, Freud did not give us any good reason to think that his clinical methods can identify and certify their causes as such, no matter how interesting the elicited "free" associations might otherwise be. As is apparent from my arguments, this adverse upshot seems indefeasible even if one were to grant that the analyst does not influence the subject's "free" associations."

331 "the attribution of therapeutic success to the removal of repressions not only was but, to this day, remains the sole epistemic underwriter of the purported ability of the patient's free associations to certify causes."

332 "If there exists empirical evidence for the principal psychoanalytic doctrines, it cannot be obtained without well-designed extraclinical studies of a kind that have for the most part yet to be attempted."
} 


\section{CAPÍTULO 7: Análisis crítico de la postura de Grünbaum.}

\section{Réplicas iniciales a los argumentos de Grünbaum}

omo hemos anticipado en la introducción, las ideas de Grünbaum han dado lugar a una serie de objeciones que rápidamente pretendieron amortiguar su impacto. La decisión de referenciar algunas de tales lecturas en esta parte de la tesis y no antes, obedece a un criterio expositivo: se comprenderán mejor las objeciones que a continuación mencionaremos ahora que ya se han expuesto los argumentos centrales de nuestro filósofo.

Las siguientes réplicas a Grünbaum, lejos de agotar la totalidad de lecturas sobre las ideas del autor, componen un conjunto de referencias significativas que hemos elegido en base a tres razones: a) sintetizan suficientemente la variedad de críticas halladas en la bibliografía, con sus puntos de acuerdo y desacuerdo b) provienen de perspectivas filosóficas y psicoanalíticas heterogéneas, haciendo foco en aspectos diferentes del análisis de Grünbaum $y, c)$ nos permiten introducir los principales aspectos por los que circulará nuestra propia lectura y los puntos nodales a los que volveremos a partir de los problemas e interrogantes que hemos delimitado ${ }^{333}$.

\section{a) Robert Wallerstein}

En 1986 Wallerstein publica un artículo cuyo título (Psychoanalysis as a Science: A Response to the New Challenges) refiere tanto a la tradición hermenéutica como a la lectura de Grünbaum. Allí sostiene que la de Grünbaum "se trata de una crítica muy seria que, a su vez, requiere una respuesta igualmente seria" (Wallerstein, 1986/1987: 29); y sostiene que tal

\footnotetext{
${ }^{333}$ Una exposición más pormenorizada de la recepción de las ideas de Günbaum en las comunidades psicoanalíticas y de sus interlocutores de turno, puede encontrarse en Erwin (1993) y Grünbaum (2007).
} 
respuesta debería seguir la vía del análisis crítico de la lectura que el filósofo ha hecho de las dos tesis básicas de Freud (TCN).

Wallerstein sostiene que el argumento de la coincidencia fue un derivado de la convicción más temprana de Freud de que los síntomas específicos en sus primeros pacientes histéricos desaparecían en diversa medida al ponerse de manifiesto los traumas patógenos reprimidos de cada uno de ellos, pero que Freud mismo reconoció que el argumento había dejado de tener validez cuando se refirió a los súbitos cambios en la transferencia, que abruptamente parecían anular esos progresos terapéuticos y permitir el pleno retorno de los síntomas: "de hecho, el argumento de coincidencia representa, en los términos de hoy, una teoría simplista de la génesis de la neurosis, tal como se entendía en el psicoanálisis entre 1895 y 1905." (Wallerstein, 1986/1987). Por eso considera que al atacar la credibilidad del argumento de la coincidencia, "Grünbaum en realidad empuja una puerta ya abierta, ampliamente abierta durante más de medio siglo. La desaparición del argumento de coincidencia del discurso psicoanalítico no es novedad para los teóricos ni para los investigadores en este campo." (ibíd. p. 30) Mostraremos que, si bien es cierto que el argumento de la coincidencia no tenía para Freud el valor que Grünbaum le ha otorgado, tampoco parece acertado pensar que carecía de valor alguno para el vienés ni, tampoco, que haya consenso psicoanalítico respecto a su completa obsolescencia.

\section{b) Marshall Edelson}

Edelson se muestra preocupado, no tanto por el descrédito intelectual que pueden ocasionar las críticas filosóficas al psicoanálisis sino por el hecho de que éstas no sean correctamente respondidas. Considera que es posible hallar evidencia clínica para dar respuesta a lo que ve como un "argumento formidable"334 de Grünbaum (Edelson, 1984: 121); algo que los analistas deberían considerar seriamente.

Edelson también rechaza los intentos de llevar el psicoanálisis al terreno de la hermenéutica; $y$, aunque adopta una perspectiva más general de la curación

\footnotetext{
334 “...Grünbaum's formidable argument...”.
} 
(que no se reduce a la eliminación sintomática), acompaña a Grünbaum en su idea de que es la eficacia terapéutica lo que en última instancia valida a la teoría psicoanalítica. Por ello, respecto del argumento de la coincidencia, Edelson no duda en afirmar que los "insights verdaderos" son una condición necesaria de los cambios terapéuticamente positivos en un psicoanálisis; al mismo tiempo, sostiene que no constituyen una condición suficiente para tales logros. Así, en cada paciente, los cambios terapéuticos son indisociables de los insights verdaderos durante la cura.

Al igual que Grünbaum, admite que es un error suponer que las ideas psicoanalíticas pueden confirmarse a partir de la acumulación de casos terapéuticamente exitosos; pues por sí solos, tales éxitos no prueban la validez de la teoría: deben establecerse formas de eliminar las hipótesis alternativas que priorizan otros factores para explicar esta eficacia; tales como el efecto placebo, la confianza que el paciente deposita en el analista o el vínculo emocional que allí se genera. Sin embargo, afirma que el método experimental no es el único que satisface los criterios del "inductivismo eliminativo" y que el estudio de casos singulares también puede hacerlo; a la vez que puede evitar los "defectos impresionantemente no triviales" 335 de los estudios estadísticos o grupales (Edelson, 1984: 63). Edelson considera que el analista puede disponerse a comparar "intervalos temporales del tema" ${ }^{336}$; esto es, elucidar cómo aparece un mismo fenómeno previa y posteriormente a, por ejemplo, una determinada interpretación. En la medida en que los otros principales factores se mantengan constantes, el analista tiene la posibilidad de elegir entre explicaciones rivales para los cambios producidos en determinado aspecto el paciente. De esta manera, sostiene Edelson, la información obtenida en distintos momentos durante el análisis puede proporcionar controles equivalentes a los que se obtienen con datos provenientes de los estudios experimentales con grupos control. Es decir que la investigación intra-clínica es

\footnotetext{
335 "...breathtakingly nontrivial defects..."

336 "...time-slices of the subject..."
} 
susceptible de adquirir la misma calidad probatoria que posee investigación comparativa de grupos control ${ }^{337}$.

En síntesis, Edelson cree que el método clínico es coherente con el tipo de entidades que el analista se propone conocer y que el estudio de casos (mediante las "comparaciones temporales") ofrece la posibilidad de responder a los desafíos epistemológicos de Grünbaum. A nuestro modo de ver y por razones que se mostrarán, si bien Edelson acierta en rescatar el valor de la metodología de caso único, su esfuerzo se realiza a partir de innecesarias concesiones a los cánones de prueba y cientificidad de Grünbaum. Dicho sintéticamente: ambos asumen que el inductivismo eliminativo es el camino a la credibilidad científica, pero difieren en su opinión sobre la posibilidad de que la situación clínica responda a dicho canon de cientificidad.

\section{c) David Sachs}

Para David Sachs, la crítica de Grünbaum no cumple con su propósito declarado d examinar los fundamentos del psicoanálisis freudiano; puesto que deja por fuera una serie de cuestiones teóricas y filosóficas fundamentales (como por ejemplo el problema fundamental del determinismo y el asunto de la interpretación del simbolismo de los sueños).

Para Sachs el libro de Grünbaum es "provocativo", pese a lo cual "su valor de ninguna manera insignificante, se basa sobre todo en la erudición y la energía de sus desafíos" (Sachs, 1993/1996: 398). A pesar de que su estudio es "sugerente y gratificante", una vez desnudados los argumentos del autor sólo queda una demanda programática: "las ideas freudianas sobre los motivos reprimidos deben someterse a prueba de acuerdo con los cánones de la inducción eliminatoria" (ibíd. p. 397). Sachs llega a esta conclusión a partir de cotejar el peso que da Grünbaum a algunas afirmaciones freudianas con el peso que estas tienen en el propio contexto de su obra. Así, por ejemplo, sostiene que la lectura del argumento de la coincidencia supone una sobrevaloración injustificada, al punto que Grünbaum ignora la amplitud de la

${ }^{337}$ Edelson intenta demostrar su hipótesis a partir de dos ejemplos: su lectura del caso "miss X" de Luborsky y Mintz (1974) y la elaboración de Glymour (1980) sobre el caso del Hombre de las ratas de Freud. 
base probatoria del vienés, que no se reduce al ámbito clínico. A su modo de ver, el argumento de la coincidencia es apenas una afirmación que Freud realiza para defenderse de la acusación de sugestión, pero de ningún modo implica una posición sobre las "curas espontáneas" ni sobre la "eficacia de las terapias no analíticas". Pero el sobredimensionamiento de ese argumento no es tan contundente como la omisión que Grünbaum perpetúa de las múltiples referencias no clínicas que Freud aduce para apoyar sus ideas.

\title{
d) Paul Robinson
}

Para Robinson, el problema de evaluar la crítica de Grünbaum reside en su ambivalencia:

\begin{abstract}
Por un lado, está la defensa apasionada de la agudeza metodológica de Freud, junto con una feroz descalificación de sus críticos mal informados y filosóficamente ineptos. Por otro lado, tenemos la queja reiterada de que la creación freudiana es "fundamentalmente defectuosa" porque no logra estar a la altura de los estándares inductivistas de la ciencia moderna; cuya legitimidad, según Grünbaum, el propio Freud entiende y adopta ${ }^{338}$. (Robinson, 1993: 259).
\end{abstract}

Además de ello, Grünbaum tiene serios problemas en demostrar el valor que él atribuye al argumento de la coincidencia en los escritos de Freud. Más allá de ello, los adeptos a la teoría psicoanalítica extraen su convicción no tanto de la esfera clínica sino de la capacidad que dicha teoría tiene para iluminar una amplia gama de fenómenos psicológicos y culturales.

Aunque Robinson no coincide con Grünbaum en que Freud haya sido un sofisticado metodólogo, eso no le impide notar que este filósofo es el "último y más sofisticado portavoz de la vieja hostilidad empirista para con el psicoanálisis" (ibíd. p.263). De manera más general, es un "representante de la arraigada tradición de la filosofía analítica", por lo que "mantiene una mala opinión respecto de los hábitos especulativos y metafísicos de los pensadores

\footnotetext{
338 "On the one hand, there is the impassioned defense of Freud's methodological acuity and the scathing dismissal of his ill-informed and philosophically inept critics. On the other hand, there is the repeated complaint that Freud's creation is "fundamentally flawed" because it fails to measure up to the inductivist standards of modern science - standards whose legitimacy, Grünbaum argues, Freud himself not only fully understood but embraced."
} 
continentales" ${ }^{339}$ (ibíd.), entre los que se encuentran los representantes de la hermenéutica que él critica.

Robinson analiza la crítica de Grünbaum junto con las de Frank Sulloway y Jeffrey Masson, llegando a concluir que el ataque del filósofo de la ciencia es muy distinto del perpetrado por dichos historiadores: en el caso de Masson, el trasfondo intelectual de su planteo reside en los movimientos sociales que abogaron, hacia 1980, por una toma de conciencia sobre los abusos sexuales infantiles; y en el caso de Sulloway, el trasfondo implícito es, para Robinson, un retorno de la biología a las ciencias del comportamiento (representado con el ascenso de la sociobiología). Pero el espíritu de la crítica de Grünbaum, por el contrario, se encuentra a contramano del Zeitgeist filosófico de fines del siglo XX: “...cuando el giro lingüístico y el entusiasmo por las importaciones francesas, como la deconstrucción, han hecho que el empirismo puro y duro de Grünbaum parezca decididamente anticuado" ${ }^{340}$ (ibíd. p. 264). De ahí que, para Robinson, la de Grünbaum constituya el producto final de la tradición filosóficamente dominante en la mayor parte del siglo pasado.

Robinson cree que, al fin y al cabo, la crítica de Grünbaum sirve para aumentar nuestro conocimiento de la relación tensa y profusamente dialéctica de Freud con los ideales de la ciencia moderna. A la vez que constituye un serio correctivo a los intérpretes hermenéuticos que pretenden distorsionar la figura científica de Freud y llevarla al terreno del arte. El trabajo de Grünbuam sirve para mostrar cómo "Freud sigue siendo un pensador de frontera, ni una cosa ni la otra, siempre a riesgo de parecer atrapado en una contradicción desesperada y destinado a ser disputado constantemente por los representantes de las dos grandes tradiciones intelectuales que han dominado la cultura moderna." ${ }^{341}$ (ibíd. p. 265).

\footnotetext{
339 More generally, he is a representative of the well-established tradition of analytical philosophy (especially popular in Britain and North America but also boasting important adepts in Freud's own Vienna) that takes a dim view of the speculative and metaphysical habits of Continental thinkers.

340 "...when the linguistic turn and the enthusiasm for French imports like deconstruction have made Grünbaum's hard-nosed empiricism seem decidedly old-fashioned."

341 "Freud remains a border thinker, neither fish nor fowl, always at risk of seeming caught in a hopeless contradiction and destined to be fought over perpetually by the representatives of the two great intellectual traditions that have dominated modern culture."
} 


\section{e) Lavinia Gomez}

Lavinia Gomez no está de acuerdo con Grünbaum en que una evaluación del estatus científico de la teoría freudiana deba recaer exclusivamente en los aspectos metodológicos y pasar por alto la metapsicología. A su entender, "su intento de eludir la metapsicología fracasa porque, le guste o no, él se enfrenta al estatus ontológico de los objetos psicoanalíticos y sus implicaciones para su estatuto científico"342 (Gomez, 2005: 17). Como los conceptos metapsicológicos que resultan utilizables en el ámbito clínico no reflejan la organización matemática de la objetividad física, sino la organización no mecánica de la subjetividad práctica, la forma en la que nuestro filósofo pretende evaluarlos resulta inadecuada. Gomez considera que la posición de Grünbaum presupone una especie de "sesgo fisicalista" que lo lleva a considerar sólo una parte del psicoanálisis y que por eso encuentra inapropiado a las pruebas empíricas.

Para Gomez, "las presuposiciones materialistas de las explicaciones hipotético-deductivas les impiden capturar los procesos mentales en sí mismos, o el potencial explicativo del sentido como tal. Sólo las explicaciones interpretativas pueden hacer eso". ${ }^{343}$ (ibíd. p. 30). Concluye que ni los métodos inductivos ni los deductivos de la ciencia empírica son aptos para evaluar la validez de las interpretaciones clínicas, debido a que estas constituyen un género diferente.

La metapsicología es el recurso metafísico inventado para vincular las dimensiones física y psíquica de la realidad: "Freud parece estar imaginando una nueva categoría ontológica en la que la dimensión práctica de la conceptualización psicoanalítica encuentra un punto de reunión con la dimensión teórica de la ciencia empírica." ${ }^{344}$ (ibíd. p. 32).

\footnotetext{
342 "His attempt to circumvent the metapsychology falls through, and whether he likes it or not, he is confronted with the ontological status of psychoanalytic subject matter and its implications for scientific standing."

343 "The materialist presuppositions of hypothetico-deductive explanations prevent them from picking up on mental processes themselves, or on the explanatory potential of meaning as such. Only interpretative explanations can do that."

344 "Freud appears to be envisaging a new ontological category in which the practical dimension of psychoanalytic conceptualization finds a meeting place with the theoretical dimension of empirical science."
} 


\section{f) Linda Brakel}

Más recientemente, Linda Brakel ha propuesto avanzar en la discusión con las críticas de Grünbaum a partir de rechazar uno de sus aspectos centrales, a saber, que la teoría clínica es el núcleo duro del psicoanálisis. Contrariando esta idea, nos dice que es conveniente asumir que lo central en la conceptualización psicoanalítica es la teoría general de la mente; pues así pueden neutralizarse los ataques filosóficos en juego.

Por otro lado, Brakel denuncia que Grünbaum objeta una serie de aspectos característicos de la conceptualización freudiana como si ésta fuera un marco fijo e insusceptible de flexibilización, lo que debilita la postura general del epistemólogo: "como tales, muchos de sus argumentos tienen por oponente a un hombre de paja, viciando la importancia global de su crítica" ${ }^{\text {"345 }}$ (Brakel, 2015: 60).

Puede advertirse que las respuestas reseñadas no son uniformes: no sólo porque no hay consenso en los puntos principales, sino porque tampoco los autores hacen foco en los mismos problemas de los que la crítica de Grünbaum suscita. Sin embargo, las reflexiones referidas han constituido un antecedente ineludible para la elaboración de nuestro propio punto de vista, que pasaremos a exponer en los siguientes apartados.

\section{El argumento de la coincidencia: ¿un reaseguro implícito o una ficción apócrifa?}

Comenzaremos analizando el denominado argumento de la coincidencia en el contexto del razonamiento freudiano, para justipreciar su lugar en la estrategia argumental del vienés. Contrabalancearemos así el papel otorgado por Freud y la revalorización que Grünbaum, aduciendo el hallazgo de algo fundamental, ha querido endilgarle. Finalmente, analizaremos una dificultad

\footnotetext{
345 "As such, many of his arguments have a straw man opponent, vitiating the overall importance of his critique."
} 
añadida que Grünbaum no ha tenido en cuenta y que se origina en un problema de traducción lingüística de los términos utilizados por Freud en torno a dicho argumento.

\section{a) Los argumentos de la coincidencia de Freud y de Grünbaum}

Una primera observación que podemos hacer al argumento de la coincidencia es respecto de la centralidad que Grünbaum le otorga, cuyo contraste es notorio con la forma freudiana de abordar el tema: para el vienés, la afirmación contenida en el argumento no tuvo el mérito suficiente como para ser subrayada o resaltada respecto de otras aseveraciones epistémicas relativas a los fundamentos de la técnica. De hecho, la frase que lo expresa aparece mencionada al pasar en una de sus conferencias (es decir, en un formato de comunicación que está destinado a un público lego o no necesariamente analítico) y no hay ningún escrito de Freud, édito o inédito, en el que se aborde directamente el tema al que se refiere. El contexto de la enunciación hace difícil leer otra cosa que esta: Freud intentaba caracterizar el tratamiento psicoanalítico y responder a las acusaciones de que funcionaba por mera sugestión; y por eso sostiene que sería imposible comprender los conflictos y desmontar las resistencias si no fuera porque las sugerencias del analista se aproximen a la realidad del paciente. Por lo tanto, lo que Freud estaba intentando establecer no tiene, a priori, implicancias sobre la posibilidad de remisiones espontáneas ni sobre el éxito terapéutico del psicoanálisis o de otras psicoterapias. Lo mismo sucede con el pasaje del caso Juanito: de la aceptación de la teoría no se deduce, allí tampoco, que el éxito terapéutico deba concebirse como algo estrictamente necesario; ni tampoco como algo que se reduce al psicoanálisis ${ }^{346}$.

Lo anterior nos habilita a pensar que quizás el argumento de la coincidencia no resulte tan contundente como Grünbaum ha querido hacernos ver. Así, si desde su lectura el argumento parece resonar en todas partes, ello se debe menos a un lugar privilegiado en el sistema teórico de Freud que a la

${ }^{346}$ De hecho, sabemos que Freud difería a futuro la posibilidad de intervenir a nivel físicoquímico y obtener resultados terapéuticos favorables (cf. p. ej. Freud, 1905b/2004: 99; 1917b/2004: 396; 1933b/2004: 143). 
amplificación efectuada por el propio Grünbaum. Algo similar ocurre con la preponderancia que nuestro filósofo otorga a la represión, citando la expresión freudiana de que constituye un pilar fundamental; pues Grünbaum omite vincular este mecanismo con otros igual de preponderantes. Incluso Freud, más tarde, decide referirse a la existencia de "los pilares básicos de la teoría psicoanalítica" (Freud, 1923a/2004: 243), integrando un conjunto de diversas conceptualizaciones sin destacar a la represión por sobre las otras. Si nos atenemos a la metáfora del "pilar" (o de la "piedra angular" en la traducción al inglés), debemos decir que no hay, para Freud, únicamente un mecanismo causal que sirva de fundamento basal al edificio psicoanalítico, sino que en sus cimientos aparecen diversas conceptualizaciones entrelazadas entre sí y que contribuyen por igual a sostener su estructura.

Por otro lado, una curiosa correlación redobla nuestra duda: poseyendo Freud, según Grünbaum, una destacada sofisticación metodológica y siendo el argumento tan fundamental para él, ¿cómo es posible que el vienés no haya notado su evidente debilidad?

En segundo lugar, la narración ideada por Grünbaum de un Freud erigiendo el argumento de la coincidencia en sus años iniciales y abandonándolo posteriormente, no se sostiene. En efecto, puede mostrarse que las dudas del vienés respecto de la eficacia terapéutica no son un fenómeno inherente a un determinado período de su vida, sino que han constituido un problema transversal en sus elaboraciones teóricas, presente desde el inicio. Veámoslo sucintamente.

Recordemos que, según Grünbaum, las remisiones espontáneas quedan excluidas mientras el argumento de la coincidencia es mantenido; pero, luego de 1926, tales remisiones son admitidas porque el argumento es abandonado. Pues bien, es fácil ver que Freud nunca negó la existencia de tales remisiones y que esa afirmación es otro invento de Grünbaum. En el célebre Caso Dora Freud analiza lo que allí llama ganancia secundaria de la enfermedad ${ }^{347}$, y destaca cómo una variación en la relación del paciente con su entorno puede hacer desaparecer el síntoma:

\footnotetext{
347 La noción de ganancia de la enfermedad como factor etiológico es bastante más antigua: aparece en una carta a Fliess del 18 de noviembre de 1897 (Freud, 1350a, Carta 76).
} 
Ora ha expirado cierto plazo, ora ha cesado él miramiento por una segunda persona, o una situación ha variado radicalmente por un acontecimiento exterior, y hete aquí que el padecimiento hasta entonces obstinado desaparece como de golpe, al parecer espontáneamente, pero en verdad porque se le ha sustraído el motivo más fuerte, uno de sus usos en la vida. (Freud, 1905b/2004: 41).

En 1913, describiendo las aplicaciones no médicas del psicoanálisis y a pedido del editor de una revista italiana, Freud escribe El interés por el psicoanálisis (1913c/2004). En el segundo párrafo de este escrito el vienés se expide sobre algunas "enfermedades asequibles a la terapia psicoanalítica", para afirmar que "todos estos son estados que en ocasiones muestran una curación espontánea y están sometidos al influjo personal del médico de una manera caprichosa, hasta hoy no entendida" (ibíd. p.169). A nuestro modo de ver, este tipo de pasajes contraría seriamente la tesis de la indispensabilidad causal que Grünbaum quiere adjudicarle a Freud (y que es la base del argumento de la coincidencia).

En una de sus Nuevas conferencias de introducción al psicoanálisis Freud se expresa sobre las dificultades terapéuticas aclarando de entrada: "nunca fui un entusiasta de la terapia" (Freud, 1933b/2004: 144); pese a lo cual afirma: "...me pesaría que creyeran que mi propósito fue disminuir su respeto por el psicoanálisis como terapia. Quizá comencé, en verdad, torpemente; en efecto, mi propósito era el contrario, disculpar las limitaciones terapéuticas del análisis por referencia a su carácter inevitable" (Freud, 1933b/2004: 144).

Nótese, además, que en la misma conferencia del argumento de la coincidencia pero apenas unas páginas antes, Freud se expide sobre la sugestión hipnótica diciendo que con este procedimiento, "tras pocos esfuerzos se lograba un éxito pleno y duradero. Pero las condiciones de un desenlace tan favorable se ignoraban" (Freud, 1917c/2004:409). Freud reconoce que, pese a esa eficacia terapéutica con los síntomas, la sugestión hipnótica dejaba al terapeuta "sin poder aprehender nada de su sentido y su significado" (ibíd.). Grünbaum, acorralado por esta contradicción flagrante, aduce que ésta última no se trata sino de una "objeción críptica"348 (cf. p.156) e introduce, obstinadamente, un caso de 1892 en el que Freud no consideró "permanente"

\footnotetext{
348 "cryptic demurrer...". Unas líneas más arriba había usado el mismo adjetivo para calificarla como "... a cryptic statement...".
} 
el efecto de la hipnosis. Este último, se encuentra en el escrito titulado Un caso de curación por hipnosis (Freud, 1892b/2004).

Con base a lo anterior, podemos afirmar que el pasaje de las Conferencias que a Grünbaum le resulta crucial, no tiene el peso de una tesis central sobre la fundamentación epistemológica del método psicoanalítico. Pareciera, entonces, que estamos ante dos versiones del argumento, la de Grünbaum y la de Freud. Nuestra postura es que, atendiendo al contexto de su formulación original, resulta mucho más razonable suponer que se trata de una mera respuesta de Freud (nada especial, pues aparece en otras ocasiones) a la objeción de la sugestionabilidad del paciente: allí resalta modestamente que si las sugestiones introducidas por el psicoanalista no correspondieran a la realidad psíquica del paciente, entonces sus conflictos no serían vislumbrados ni sus resistencias sorteadas; sin que ello implique directamente consecuencia alguna sobre las posibilidades de éxito terapéutico del psicoanálisis ni de ningún otro método distinto. La apelación a esa coincidencia no configura un argumento altamente sistematizado ni constantemente invocado, como asegura Grünbaum. En nuestro trayecto posterior mostraremos que la versión de Grünbaum es inviable porque se asienta en una serie de supuestos filosóficos incompatibles con el campo de los fenómenos clínicos. Más adelante aun, mostraremos por qué la versión freudiana de la coincidencia adquiere valor en el proceso clínico, en la medida en que una parte de las maniobras del analista le permiten al paciente acceder a cierto grado de representatividad de sus procesos afectivo-inferenciales inconscientes. Pero de ninguna manera dicha coincidencia agota las complejidades del proceso clínico, cuyo decurso implica cambios y retrocesos que no pueden ser reducidos a la mera superación sucesiva de represiones.

\section{b) Una dificultad añadida: la traducción de «Wirklichkeit»}

Resulta necesario abrir con este apartado una especie de paréntesis, pues la arista del problema que aquí analizaremos no es directamente argumental sino lingüística. Pese a ello, como se atisbará, tiene implicancias indirectas para el razonamiento de nuestro crítico. 
Grünbaum construye su argumento de la coincidencia citando el mencionado texto de la $28^{\circ}$ Conferencia en base a la traducción de James Strachey. La frase de esa cita que Grünbaum ha vuelto célebre reza así en su versión inglesa:

After all, his conflicts will only be successfully solved and his resistances overcome if the anticipatory ideas he is given tally with what is real in him [S.E. 1917, 16: 452] (Grünbaum, 1984: 138).

Más adelante en su libro The Foundations of Psychoanalysis (p.139) y también en su libro posterior Validation in the Clinical Theory of Psychoanalysis (p.182), Grünbaum efectúa esa cita intercalando algunos añadidos entre corchetes:

After all, his conflicts will only be successfully solved and his resistances overcome if the anticipatory ideas [i.e., interpretative depictions of analytic meaning] he is given tally [both objectively and subjectively] with what is real in him (S.E. 1917, 16: 452).

Según Antonio García de la Hoz, esas acotaciones de Grünbaum dejan traslucir, junto con algunos otros detalles de su argumentación, que existe una "defectuosa interpretación del vocablo «real», que aparece en el pasaje" (García de la Hoz, 2010: 268). Para este analista español Grünbaum ha pasado por alto la distinción entre realidad y real tal y como aparece en los escritos de Freud, lo cual tiene implicancias notorias no sólo en la conceptualización del argumento en juego sino en la concepción ontológica que se deriva para la clínica psicoanalítica.

Es sabido que Freud no obraba de forma azarosa en la elección de su terminología y que, pese a su relación ambivalente con la filosofía en muchas de sus obras, se puede notar la influencia de algunos conceptos filosóficos de su tiempo (Assoun, 1976/1982). Por otro lado y casi como contrapartida, sabemos que la traducción de Strachey en la Standard Edition escogió aquellos vocablos del inglés que mejor se adaptaban, a costa de perder cierta rigurosidad con la enunciación del original ${ }^{349}$. Tal es el caso de nociones como

${ }^{349}$ En las traducciones al castellano sucede algo parecido: tanto López Ballesteros como Etcheverry, cada uno a su manera y por factores diferentes, tergiversan, en mayor o menor medida, la inteligibilidad de algunas ideas freudianas (cf. Escars, 2006). 
Seele (alma) que se tradujo como mind (mente), o Triebe (pulsión) como instinct (instinto) y, en relación a nuestro tema, también sucedió algo parecido con la noción de realidad. En alemán existen dos palabras, Realität (realidad objetiva) y Wirklichkeit (realidad efectiva), que Strachey tradujo indistintamente como Reality o Real. Si bien es cierto que es frecuente traducir de ese modo tales vocablos a las demás lenguas, lo que en la Standard Edition resulta omitido es, Según García de la Hoz, la diferencia que Freud establecía en su uso, siendo el párrafo en cuestión un ejemplo cabal de ello. En castellano, como en francés y en inglés, se hace necesario forzar una distinción que en alemán es innecesaria ${ }^{350}$. La cita original de Freud dice así: “...die mit der Wirklichkeit in inm übereinstimmen..." [cursivas añadidas]; y puede ser traducida por "las ideas anticipatorias conscientes ofrecidas por el analista, que con la realidad en él concuerdan" (García de la Hoz, 2010: 270).

¿Qué diferencia semántica hay, entonces, entre Wirklichkeit y Realität? Según García de la Hoz:

Para ver con claridad esa distinción necesitamos echar mano de la filosofía alemana, (principalmente a Kant), de quién Freud, aún sin declararlo demasiado, estaba lo suficientemente impregnado. En alemán hay dos maneras de decir "realidad": 1) Realität, que es el contenido objetivo, cosas del mundo que existen ahí fuera, y 2) Wirklichkeit, realidad efectiva, operante, diríamos casi realidad interna, la realidad que tiene, por ejemplo, el mundo imaginario de un sujeto. Por lo demás, la Wirklichkeit, es precisamente el descubrimiento capital de Freud, cuando deja atrás la teoría de la seducción: Deja atrás la Realität de las escenas de seducción para que la Wirklichkeit de las mismas pase a primer plano.

Luis Cencillo (1968) lo expone con precisión al preocuparse de determinar cuándo algo es en sí mismo real o no. Distingue claramente la Realität proveniente del latín realitas (res $=$ cosa), término que se orienta hacia la objetividad de la cosa, del término alemán Wirklichkeit, cuyo matiz es el de efectividad (de la raíz wrk, gr. Ferg, e idg. *uergom = trabajar), y que lo introdujeron en la lengua literaria los místicos alemanes del siglo XIII. En ocasiones la palabra Wirklich puede significar lo irreal, precisamente por su característica de no localizable en el mundo, por no tener una substancia física. Es por esto que se equipara a las producciones de la fantasía en psicoanálisis, por ejemplo, para las que es preferible la categoría de lo imaginario lacaniana. Pero la Wirklichkeit tiene siempre un matiz de efectividad, de

\footnotetext{
${ }^{350}$ Esto inaugura un espacio de tensión entre el polo de la lengua fuente y el de la lengua meta; algo bastante común en las normas de los traductores en psicoanálisis (Gentile, 2008).
} 
operacionalidad, de actividad, aún sin tener, o precisamente por ello, una consistencia objetiva. (García de la Hoz, 1999: 187).

García de la Hoz considera que la utilización freudiana del término Wirklichkeit en la $28^{\circ}$ Conferencia no es azarosa, sino completamente intencionada, dado que allí se trataba de la realidad interna o psíquica y no de la realidad objetiva o histórica (para la cual hubiera seleccionado Realität, Reale o algún derivado). Grünbaum habría pasado por alto la distinción entre ambos sentidos del concepto de realidad, cayendo en el error de afirmar la preponderancia del argumento de la coincidencia más allá de toda consideración psicopatológica:

\footnotetext{
Este seguimiento un tanto ciego, quizá por su condición de filósofo de la ciencia y no de clínico, no le permite considerar dos cosas muy importantes: a) por un lado, que Freud, en 1917, todavía no tiene una teoría psicoanalítica fija, precisa y completa que delimite las neurosis de las psicosis, y mucho menos en cuanto a la técnica terapéutica para con estas últimas. b) Por otro lado Freud es claramente consciente de que las psicosis - «neurosis narcisistas» tal como las denomina en estos momentos-, no siguen los mismos criterios de curación que las neurosis y mucho menos en cuanto al seguimiento de las dos NCT. Grünbaum [...] malinterpreta a Freud [...] al hacerle declarar la misma «sanción epistémica» para la etiología clínica de las dos clases de psiconeurosis. [...] ¿Por qué, entonces, Grünbaum lo expone así? Descartando que no haya leído bien esa sección, se pueden dar dos razones: 1) por mantener a toda costa su Tally Argument (incluso para las psicosis), pues así toda su crítica epistemológica contra él puede permanecer vigente. 2) Por una defectuosa interpretación del vocablo «real», que aparece en el pasaje antes citado de la lección $28^{\circ}$, traducido por Strachey. En descargo de Grünbaum quizás se pueda aducir la dificultad filosófica del término por un lado, y el que Freud, a pesar de un uso intuitivamente correcto y filosóficamente riguroso, no tiene, pese a todo, consolidado el concepto. (García de la Hoz, 2010: 269).
}

Varias consideraciones pueden hacerse sobre este planteo de García de la Hoz. En primer lugar, es cierto que Grünbaum se equivoca al hacerle decir a Freud que la hipótesis etiológica recibe el mismo tipo de apoyo empírico tanto para las denominadas por ese momento neurosis narcisistas como para las neurosis de transferencia, al menos por dos tipos de razones. Por un lado porque las neurosis narcisistas, en virtud de su incapacidad para la trasferencia, delimitan el campo de aquellos cuadros que no se avienen bien al 
psicoanálisis; como lo hiciesen las neurosis actuales en los albores del tratamiento, por carecer éstas de un mecanismo psíquico que amerite la analizabilidad. Además, porque la aseveración de que el éxito terapéutico constituye el indicador freudiano de la validación teórica, puede ser puesta en cuestión: y así lo haremos en un apartado más adelante.

En segundo lugar, debemos señalar que una vez restado el alcance pretendido por Grünbaum al argumento de la coincidencia, el problema al que se refiere sigue quedando no obstante en pie. Es decir, reducir su alcance al ámbito de los cuadros "analizables" no indica cómo resolver el desafío original de Grünbaum. Y a ello se le suma el hecho de que la interpretación que hace García de la Hoz de los usos freudianos del binomio Wirklichkeit - Realität está teñida por una lectura de Lacan, que dista mucho de ser la única viable. José Perrés, por ejemplo, señala que:

\begin{abstract}
Lacan ha querido ver en la utilización que Freud hace de ambas acepciones un sentido preciso en el que Realität estaría especialmente reservado a la realidad psíquica. Profundos conocedores de la obra de Freud en alemán me han asegurado que si bien en algún momento aislado se podrían buscar matices en la utilización de cada término, en el conjunto de la obra freudiana son utilizados en forma indistinta como verdaderos sinónimos (Perrés, 1989a: 115).
\end{abstract}

Entonces, si bien García de la Hoz repara en una pretensión injustificada del alcance del argumento de la coincidencia por parte de Grünbaum (lectura que compartimos), lo señalado respecto de la traducción de Wirklichkeit no parece constituir un problema para la argumentación del filósofo sino a penas un señalamiento lingüístico de potenciales consecuencias, que García de la Hoz no explora suficientemente ${ }^{351}$. A nuestro modo de ver, si hay un problema en la manera en la que Grünbaum interpreta el concepto freudiano de realidad no se trata tanto de un problema semántico de traducción sino de un problema ontológico vinculado a que ambos autores (Grünbaum y Freud), por partir de

\footnotetext{
${ }^{351} \mathrm{Y}$ el costado que este autor explora (en otro artículo que escribe en coautoría) parece encerrar algunos malentendidos: "Para Grünbaum la interpretación acertada sería aquella que se corresponde con lo real (Realität) y, en consecuencia, no considera que el psicoanálisis sea científico, pues nunca será susceptible de una corroboración externa con garantías." (Rodríguez Sutil y García de la Hoz, 2001: 72-73; cursivas añadidas). Justamente lo contrario: Grünbaum demanda que las hipótesis causales sean puestas a prueba en contextos extraclínicos y siguiendo los cánones del inductivismo eliminativo, pues sólo así podría considerarse bien fundamentado.
} 
suposiciones filosóficas por momentos incompatibles, arriban a conceptualizaciones opuestas de la realidad ${ }^{352}$ y que tienen implicancias directas para la validación teórica. Volveremos sobre estos problemas.

\section{La asociación libre: ¿un método defectuoso o una técnica incomprendida?}

Lo central del ataque de Grünbaum a la teoría de la represión se produce indirectamente: objetando repetidamente el procedimiento de la asociación libre. En este apartado mostraremos porqué ese descrédito no logra su cometido.

Recordemos que Grünbaum ha criticado la analogía freudiana de los lapsus y sueños con los síntomas. Hasta cierto punto, podría decirse, Freud avala tal subordinación ${ }^{353}$; pero sabemos que sostuvo, a pesar de los evidentes denominadores comunes, una especificidad irreductible para cada uno de tales fenómenos. Además, la analogía que Freud establece debe evaluarse por la fecundidad heurística que propone al adentrarse en el establecimiento de principios explicativos comunes entre el campo de la neurosis y el campo de aquellos fenómenos decididamente desdeñados por el conocimiento científico de esa época (sueños, actos fallidos y chistes). En ese sentido, lo que el vienés teoriza como denominadores comunes en esos fenómenos es lo que llamó proceso primario, un modo de funcionamiento psíquico caracterizado por los mecanismos de condensación y desplazamiento. A nuestro modo de entender y contrariando el punto de vista de Grünbaum, Freud desarrolla un sistema de prueba para las hipótesis explicativas de la formación de los lapsus y los

\footnotetext{
352 Como ha señalado Ignacio Barreira, "si bien ambos términos se remiten a una única realidad, se refieren a diversos marcos de concepción del mundo: realidad (Realität) se refiere al mundo como representación y realidad efectiva (Wirklichkeit) al mundo como voluntad" (Barreira, 2009: 99). Aunque Barreira lo afirma en el contexto de su lectura comparativa entre Freud y Shopenhauer, es indudable que aquí aparece indicado el problema de la teleología o de lo que, sin ser observable, permite dar sentido a lo observado; problema que, como veremos, Grünbaum ha tratado injustamente.

${ }^{353}$ Por ejemplo cuando sostiene que "...el sueño está edificado como un síntoma neurótico, es una formación de compromiso entre la exigencia de una moción pulsional reprimida y la resistencia de un poder censurador situado en el interior del yo" (Freud, 1925b/2004: 42).
} 
sueños, basado en la asociación libre. A su vez, el conjunto de evidencias que utiliza para dar apoyo a sus hipótesis no se reduce al ámbito clínico, como Grünbaum cree. Veremos ambas cuestiones.

\title{
a) ¿Qué es y qué no es la asociación libre?
}

El método psicoanalítico se constituye como tal a partir de la configuración de la técnica de la asociación libre (AS de aquí en más), efectuada alrededor de $1898^{354}$ y continuada hasta la actualidad. A pesar de las diversas modificaciones técnicas introducidas por las diferentes orientaciones psicoanalíticas post-freudianas, la técnica AS sigue siendo la única que posibilita y fundamenta el dispositivo psicoanalítico. Constituye, por lo tanto, un elemento consustancial al mismo.

En 1913, exponiendo su manera de invitar a que el paciente asocie, Freud ofrece una metáfora muy ilustrativa del procedimiento:

\begin{abstract}
Diga, pues, todo cuanto se le pase por la mente. Compórtese como lo haría, por ejemplo, un viajero sentado en el tren del lado de la ventanilla que describiera para su vecino del pasillo cómo cambia el paisaje ante su vista. Por último, no olvide nunca que ha prometido absoluta sinceridad, y nunca omita algo so pretexto de que por alguna razón le resulta desagradable comunicarlo. (Freud, 1913a/2004:
\end{abstract} 136).

La asociación libre no produce, por sí misma, conocimiento alguno; sino que permite obtener datos: el material con el que se trabaja. A su vez, para transformar esos datos en información, el analista necesita comenzar con una

\footnotetext{
${ }^{354}$ Evidentemente, el establecimiento de esta fecha es a penas tentativo; pues no resulta fácil establecer con seguridad y precisión en qué momento Freud empezó a utilizar la AL como procedimiento único y distintivo. Si nos atenemos a la explícita denominación de asociación libre, caemos en la sorprendente cuenta de que no es sino hasta 1909 que el vienés la menciona, a la vez que la caracteriza como regla psicoanalítica fundamental (Freud, 1910a/2004: 35 y 38). Adherimos a la propuesta por José Perrés, quien propone 1898 como fecha de inicio; no de la circulación discursiva del término sino de su visualización como fenómeno y su utilización práctica (mientras redactaba el segundo capítulo de su obra magna sobre los sueños y habiendo escrito la sexualidad en la etiología de las neurosis). La delimitación de ese comienzo supone un complejo análisis sobre los orígenes del psicoanálisis mismo: "el Psicoanálisis no nace de meras modificaciones técnicas sino, y a partir de un especifico sustrato sociohistórico, de una compleja articulación entre la teoría, la técnica y el llamado 'autoanálisis' de Freud, siendo éste el verdadero eje estructurante de los otros vectores, en ese pasaje de la prehistoria a la historia del Psicoanálisis." (Perrés, 1989b/2000: 119).
} 
disposición especial de relevamiento: es lo que Freud llamó atención flotante. $^{355}$

Vale la pena recordar que la asociación libre constituyó un avance técnico respecto del procedimiento de la hipnosis. Y que su establecimiento se produce sobre una creencia fundamental de Freud: las asociaciones libres son libres sólo para la conciencia, pues están sobre-determinadas por factores causales que escapan a la conciencia y voluntad del sujeto que las profiere:

\begin{abstract}
Toda vez que un elemento psíquico se enlaza con otro por una asociación chocante y superficial, existe también entre ambos un enlace correcto y que cala más hondo, sometido a la resistencia de la censura [...] Es como cuando un impedimento general, por ejemplo el desborde de los ríos, vuelve impracticables los caminos principales de una zona montañosa, los caminos amplios, y entonces el tránsito se mantiene por sendas incómodas y empinadas que de otro modo sólo hollarían los cazadores. [Cuando] la censura se dirige sólo a la trabazón de dos pensamientos [...] Entonces los dos entran en la conciencia sucesivamente; su trabazón permanece oculta, pero a trueque de ello se nos ocurre un enlace superficial entre ambos, en el cual de otro modo no habríamos pensado y que, por regla general, aborda el complejo de las representaciones \{Vorstellungskomplex\} desde un ángulo diverso del que parte la conexión sofocada, pero esencial. (Freud, 1900b/2004: 524).
\end{abstract}

Asumiendo esa premisa, la escucha del analista constituye una forma especializada de percepción, a los fines de colegir aquellos elementos que se presentan dispersos pero que, una vez reunidos bajo determinadas conjeturas, posibilitan una inteligibilidad orgánica imposible de captar de otra manera. Por esto mismo, la escucha del analista, vía atención flotante, puede ser equiparada con la escucha del músico: así como identificar una secuencia de acordes requiere una habilidad desarrollable a partir del entrenamiento, también el colegir elementos que se reiteran en la asociación de un paciente supone una habilidad que se alcanza con entrenamiento (la formación teóricotécnica, el propio análisis y la supervisión) (Lavin, 2011).

\footnotetext{
${ }^{355}$ Esta capacidad de atención fluctuante, correlativa de la asociación libre del paciente, es conceptualizada por Freud recién en consejos al médico sobre el tratamiento psicoanalítico (Freud, [1912a] 2004), aunque ya aparecía mencionada en el Caso Juanito (1909a/2004). Son las operaciones del analista, basadas en la atención flotante, las que permiten advertir el carácter performativo de lo que la asociación libre hace emerger.
} 
La asociación libre es una herramienta técnica cuya potencialidad debe evaluarse atendiendo al contexto de la situación psicoanalítica. Muchas veces, cuando Freud describe el procedimiento, el contexto de la asociación libre queda implícito y se genera la ilusión de que la técnica podría ser comprendida independientemente de dicho contexto. Grünbaum comente el error de intentar elucidar la validez de la asociación libre separándola de su contexto específico. Este error es inherente a la preconcepción filosófica que él adopta al momento de acercase al psicoanálisis y que supone, entre otras cosas, una noción de los factores causales típicamente propia de las disciplinas experimentales. Para comprender lo esencial del fenómeno de la asociación libre no es posible aislar el fenómeno del entorno natural en el que se efectúa, en la medida en que el contexto mismo encierra variables que no pueden dejarse por fuera para delimitarlo y comprenderlo. Resulta ilustrativo de la complejidad e inseparabilidad contextual que conlleva la asociación libre, la manera en la que André Green expone su funcionamiento durante la sesión:

Demos una descripción simplificada de la secuencia de pensamientos en asociación libre de una sesión y a los cuales designaremos arbitrariamente de acuerdo a la sucesión de las letras del alfabeto. Estos son elementos en la cadena constituida por el material diseñado en una serie $a, b, c, d, \ldots$ La cuestión es cómo estas series adquirirán un significado, no obstante su aparente incoherencia, propia de la asociación libre, en el contenido manifiesto, lo que conducirá a la radical transformación del contenido latente, que aparecerá en relación opuesta al manifiesto. Tomemos, por ejemplo, el elemento $c$, que ha despertado cierta atención en la mente del analista. Tal elemento es asociado con el significado manifiesto, siguiendo la secuencia precedente, con $a$ y $b$. Pero después de un momento, algunos otros elementos más alejados, llamémosles $m$ y $n$, iluminan la relación con $c$ y hacen aparecer en esta nueva luz algo diferente desde su original significado. Entonces, algunas otras relaciones se unen a la nueva relación entre $m, n$, y así $c$ se fundamentará en una relación que había escapado a la atención del analista con algunos enlaces intermediarios, supongamos $g$ y $h$. Esta enteramente nueva serie de conexiones da nacimiento a lo reprimido y lo inconsciente, con la nueva dimensión, la cual tiene que dar cuenta de las resistencias y los mecanismos de defensa también inconscientes. Vemos que todos estos procesos, sucedidos en el silencio del analista, aparecen en ocasiones, de repente, en una mirada que da retrospectivamente sentido a $c$ y a su inclusión en la cadena de palabras y representaciones, en una visión que contradice el significado manifiesto que previamente tuvo cuando fue escuchado al 
principio. Vemos aquí que la recreación del significado, el cual es coexistente con la intervención de las defensas, principalmente la represión, escapa totalmente a la posibilidad de ser observado de cualquier otra manera que no sea el tipo de escucha derivado de la situación clínica. ${ }^{356}$ (Green, 2000c: 33).

La teoría freudiana implica que la asociación libre es una forma de expresión de verbalizaciones que están determinadas por factores inconscientes, pero de esto no se sigue que el analista pueda arribar a un conocimiento cierto de la realidad psíquica. La perspectiva conjetural y falibilista del propio Freud nos alerta contra esta ilusión, al mismo tiempo que permite descartar de antemano objeciones como la siguiente: "la incapacidad del método psicoanalítico de investigación clínica por asociación libre para garantizar las inferencias causales resta todo apoyo a los pilares principales de la teoría de la represión”357 (Grünbaum, 1993: 3; cursivas añadidas). No es coherente con una concepción no fundacionista del conocimiento hablar de garantías, puesto que las inferencias del analista en el contexto clínico podrían a lo sumo aspirar a un apoyo inductivo fuerte mediante confirmaciones, pero nunca estar

\footnotetext{
356 "Let us give a simplified description in which we will designate the sequence of free associated thoughts in the session, which we will arbitrarily name according to the succession of letters in the alphabet. These are elements in the chain constituted by the material designed in a series $a, b, c, d, \ldots$. The question is how the series will acquire a meaning even, in the apparent incoherence, due to free association, in the manifest content, which will lead to radical transformation of the latent content, appearing in opposite relationship to the manifest. Let us take, for instance, element $c$, which arouses some attention in the analyst's mind. Such an element is associated with the manifest meaning following the sequence preceding it with a and b. But after a while, some other further element, let us say $m$ or $n$, enlightens its relationship to $c$ and makes it appear in a new light quite different from its original meaning. Then, some other relationship linking the new relationship between $\mathrm{m}, \mathrm{n}$, and $\mathrm{c}$ is grounded, by a relationship that has escaped the analyst's attention with some intermediary links with, let us suppose, $g$ and $h$. This entirely new set of connections gives birth to the repressed and the unconscious, with the new dimension, which has to be accounted for, that the resistances and mechanisms of defense are also unconscious. We see that all these processes, which happened in the silence, of the analyst, appear sometimes, all of a sudden, in a glance that gives meaning retrospectively to $\mathrm{c}$ and to its inclusion, in the chain, of words, and representations in a view that contradicts the previous manifest meaning it had when it was first heard. We see, here that reversal of meaning, which is coexistent with the intervention of the defences, mainly repression, totally escapes the possibility of being observed in any way other than the type of awareness stemming from the clinical situation."
}

357 "...the inability of the psychoanalytic method of clinical investigation by free association to warrant causal inferences leaves the major pillars of the clinical theory of repression illsupported." 
probadas. En esto, el conocimiento clínico no difiere del conocimiento de cualquier ciencia empírica, entendido como parcial y provisional ${ }^{358}$.

\title{
b) El ejemplo de AJ
}

\author{
Según Grünbaum, suponiendo que Freud hubiera utilizado un modelo \\ nomológico-deductivo de explicación para el lapsus de AJ, todo estaría \\ invalidado porque
}

\begin{abstract}
el nexo causal entre la represión y el lapsus, afirmado en su explanans, habría sido epistémicamente inaceptable. [...] Freud no ha ofrecido nada mejor que post hoc ergo propter hoc como evidencia probatoria necesaria para ese nexo causal; incluso si le concedemos que la secuencia asociativa de AJ fue una cadena causal libre de contaminación. [...] la mera afinidad temática, por sí sola, sencillamente no es indicativa de linaje causal. ${ }^{359}$ (Grünbaum, 1984: 198; cursiva del original).
\end{abstract}

Detengámonos primero en la prolongación contrafáctica que Grünbaum hace de la conversación de Freud con el joven ${ }^{360}$ de aliquis, en la que conjetura otro posible recuerdo susceptible de portar mayor idoneidad determinadora, para finalmente denunciar una especie de sesgo de selección por parte del vienés. Esto, que Grünbaum hace parecer un problema sustancial, tiene una respuesta simple: no es esa la asociación efectivamente proferida por AJ. Además, Grünbaum parece suponer, cuando se refiere a la "elasticidad temática" de la

\footnotetext{
${ }^{358}$ Con la objeción citada Grünbaum contradice su propio punto de vista sobre la justificación inductiva, que sólo permite "cierto grado de credibilidad científica, aunque no de la verdad" (Grünbaum, 1976a: 219-220). [“...some degree of scientific credibility, even if not of truth...”]

359 "...the causal nexus between the repression and the slip asserted in its explanans would have been epistemically unacceptable. [...] Freud has offered nothing better than post hoc ergo propter hoc toward the evidential support needed for that causal nexus, even if we grant him that the sequence of AJ's associations was an uncontaminated causal chain. [...] mere thematic affinity alone simply does not bespeak causal lineage."
}

${ }^{360}$ Recordemos, al pasar, que Peter Swales (1982) sostuvo dos tesis novedosas sobre la vida de Freud y el episodio con el joven AJ. La primera es que esa conversación nunca tuvo lugar y que el joven AJ, en virtud de su descripción y parecido, es en realidad el propio Freud. La segunda tesis es relativa a un supuesto amorío extraconyugal de Freud con su cuñada Minna Bernays, quien vendría a representar la dama cuyo embarazo era temido por el joven ficticio AJ. Grünbaum nos dice que esta investigación es "insustancial para su propósito" [It is quite inessential for our purposes] y que él va a "tomar el texto freudiano a su valor nominal" [l shall take Freud's text at face value.] (p. 190). Sin embargo, no podemos dejar de observar que las tesis de Swales, cuya validez no discutiremos aquí, contrarían la acusación efectuada por Grünbaum ( $\mathrm{y}$ antes por Timpanaro, op. cit. p.51) de que Freud dirigió sutilmente las asociaciones de su interlocutor AJ. 
técnica, que la asociación libre es una suerte de secuencia infinita en la que el analista arbitrariamente realiza una selección del material que le conviene para confirmar sus hipótesis. Evidentemente este tipo de presuposiciones sólo pueden presentársele a quien nunca ha utilizado la técnica, pues encierra un desconocimiento fundamental del hecho de que la asociación libre presenta una estructura convergente, en la que las asociaciones no se ramifican en direcciones independientes, sino que bordean un núcleo identificable al que el discurso apunta en cada momento. Freud, muy tempranamente, discernía que "la cadena asociativa siempre consta de más de dos eslabones; las escenas traumáticas no forman unos nexos simples, como las cuentas de un collar, sino unos nexos ramificados, al modo de un árbol genealógico" (Freud, 1896c/2004: 196). Otra forma de representarlo podría ser imaginando que se trata no tanto de una arborización sino más bien de una especie de telaraña. Este carácter concéntrico que, en determinado momento, adquiere la cadena asociativa, es coherente con una concepción realista de las representaciones-cosa ${ }^{361}$ en lo psíquico y con una conceptualización no-lineal de la causalidad. Freud, muy tempranamente, hacía esfuerzos notables por esclarecer el procedimiento:

Si quisiera yo esquematizar el modo de trabajar, podría decir, tal vez, que uno toma a su cargo la apertura de estratos más internos, el avance en el sentido radial, mientras que el enfermo se encarga del ensanchamiento periférico [...] Hay que adueñarse de un tramo del hilo lógico, pues sólo con su guía puede uno esperar adentrarse en lo interior. (Freud, 1895/2004: 297).

Es por ello que André Green sostiene que "la escucha analítica busca la ininteligibilidad del material fuera de toda linealidad, en una red de sentido arborescente determinado por su conflictividad radical" (Green, 2001/2015: 74).

Grünbaum, incapacitado para comprender este modo de funcionamiento que los analistas han estado intentando cernir, pone en duda la "capacidad de obtención única" de la asociación libre para conocer lo inconciente. Aduce, de la mano de Timpanaro, que las "genuinas preocupaciones" tienden a ser evocadas por un gran número de estímulos, "incluso o especialmente cuando están desprovistas de todo fundamento" (p. 198). Además, su análisis del tema

${ }^{361}$ En el sentido dado por Jean Laplanche al término: huellas o marcas inconscientes que han perdido su condición de representación y que son residuo de experiencias de relación interhumana (cf. Laplanche, 1981/1987: 103 y ss.; 1987: 122-123; 1999/2001: 64-70). 
incluye una conceptualización en clave argumentativa, pues intenta explicar que la $A L$ y las inferencias que el analista basa en ella encierran una serie de falacias.

\section{c) La falacia post hoc ergo propter hoc}

Grünbaum se pregunta qué razones mueven a Freud a suponer un vínculo causal entre: a) un pensamiento venido a la conciencia luego de algunas asociaciones libres y, b) una equivocación al hablar con la que comienzan esas asociaciones. Dicho de otra forma: ¿por qué asume Freud como evidencia de un vínculo causal el arribo a una idea que considera significativa (como el temor en AJ) mediante asociaciones y el olvido disparador de las mismas? Según nuestro filósofo, arribar a un deseo reprimido mediante la asociación libre no demuestra bajo ningún punto de vista que ese deseo haya sido un agente causal del lapsus que le precede, y que razonar de ese modo es ilícito: "al dotar al inconsciente con astutos y misteriosos poderes de intrusión en acciones conscientes, no se hace otra cosa que bautizar a la falacia causal dándole un nombre honorífico" 362 (Grünbaum, 1984: 192). Grünbaum cree que este modo de razonar freudiano procede de una extrapolación indebida de su modelo etiológico de las neurosis; en el apartado siguiente analizaremos con mayor detalle esta suposición y mostraremos su inviabilidad. Pero como intentamos ir por partes, detengámonos por ahora en lo anterior: ¿encierra el argumento freudiano una falacia del tipo post hoc? Nuestra respuesta es negativa y ello se debe a lo siguiente. No es cierto que Freud atribuya un papel causal a determinadas representaciones obtenidas mediante asociación libre por el mero hecho de que estas aparezcan proferidas "luego" del lapsus que se quiere explicar ni por la simple "afinidad temática" que mantienen con el contenido reprimido ${ }^{363}$.

\footnotetext{
362 "To endow the unconscious with cunning, uncanny powers of intrusion upon conscious actions is only to baptize the causal fallacy by giving it an honorific name."

${ }^{363}$ Aunque no constituye más que un dato de color, vale la pena recordar que Freud conocía muy bien este tipo de razonamiento falaz: en La etiología de la histeria el vienés le adjudica a los pacientes bajo anamnésis, el hecho de, entre otras cosas, incurren en "la falacia de tomar como causa lo que no es más que mero antecedente en el tiempo" (Freud, 1896c/2004: 191). Resulta difícil creer que Freud, conociendo el funcionamiento de esta falacia, incurriera en ella, sin advertirlo, y en algo tan fundamental como su conceptualización del procedimiento clínico de la asociación libre.
} 
En su discurrir argumentativo, Grünbaum sigue a Freud y reconoce que no siempre es necesario acudir a las asociaciones del sujeto para arriesgar una hipótesis respecto de la motivación que esconde un sueño o un acto fallido. Así, por ejemplo en los niños y a veces en los adultos, el sueño resulta una trasparente realización de deseo ${ }^{364}$. Grünbaum admite tal "credibilidad de sentido común de esta atribución causal preanalítica de algunos sueños a deseos”365 (Grünbaum, 1984: 219). Mediante esta concesión, nuestro filósofo se permite analizar el caso de algunos actos fallidos que le parecen "transparentes"; como por ejemplo lo siguientes:

a) “...mientras da una conferencia sobre sexualidad humana, una persona se equivoca y dice 'orgasmo' en vez de 'organismo'”366 (p.199).

b) “...el hombre que, ante la visión excitante del seno desnudo de una mujer, se aparta murmurando: 'perdóneme, necesito tomar un pecho de aire fresco"”367 (ibíd.).

Sachs observa, muy atinadamente, que Grünbaum expresa su acusación de post hoc ergo propter hoc respecto de los ejemplos freudianos (como el de aliquis) pero pareciera dar por hecho que sus ejemplos, arriba citados, no adolecen de esta falacia (cf. Sachs, op. cit., p. 394). Cabe preguntarse por qué no, ya que los lapsus "transparentes" muestran que una representación/afecto previa lo habría ocasionado. Pero Grünbaum no nos dice nada al respecto.

Además de los actos fallidos que Grünbaum denomina "transparentes" y cuya motivación puede ser fácilmente identificable, él distingue aquellos en los

\footnotetext{
364 Para Freud, hay "categorías enteras de casos en que el propósito, el sentido del trastrabarse aparece con claridad" (Freud, 1917f/2004: 36). A estos fallidos "se contraponen otros en que el trastrabarse no ha ofrecido nada en sí provisto de sentido, y que por tanto contradicen enérgicamente nuestras expectativas [...] Sólo que una consideración más atenta de tales ejemplos revela que es posible llegar a comprender esas desfiguraciones, y aun que no es muy grande la diferencia entre estos casos más oscuros y los anteriores, más claros." (Íbid. p. 37; cursive añadida).

365 "...commonsense credibility of this preanalytic causal attribution of some dreams to wishes..."

366 "....in the course of giving a lecture on human sexuality a person misspeaks himself by saying 'orgasm' instead of 'organism'."

${ }^{367}$ La traducción es solo aproximada, pues el fallido original, en lengua inglesa, incluye dos homófonos trastocados: "the man who turns from the exciting view of a lady's exposed bosom muttering, 'Excuse me, I have got to get a breast [en lugar de breath] of flesh [en lugar de fresh] air!"”.
} 
que el motivo no resulta evidente, llamándolos "explicativamente opacos" (cf. p. 202). Para él, la utilización de la asociación libre con el fin de hallar el sentido oculto constituye una falacia, que por momentos denomina de "inversión causal" (cf. p. 186-7, 192, 233-4). Antes de analizar esta objeción, hay que notar que el planteo resulta inválido desde el inicio, porque la separación tajante que él establece entre ambos tipos de fallidos no existe como tal en el pensamiento de Freud, para quien en verdad "no es muy grande la diferencia entre estos casos más oscuros y los anteriores, más claros" (Freud, 1917f/2004: 37). Más allá de esto, para nuestro filósofo la falacia de inversión causal acontece cuando se concluye que "una represión que emerge al final de una cadena de asociaciones libres (como su terminus ad quem) fue realmente la causa original del síntoma [o sueño o lapsus] que inició la cadena como su terminus a quo" 368 (Grünbaum, 1984: 186-187, corchetes añadidos). No queda claro por qué Grünbaum ve en esto un problema. Sin embargo, notamos que él parece suponer, equivocadamente, que la representación utilizada para explicar el fenómeno surge necesariamente al final de una secuencia asociativa $^{369}$. Sin embargo, asumir que el fenómeno tiene una causa y que las asociaciones libres están determinadas, para luego proceder a conjeturar retroactivamente esa causa a partir de inferirla desde la asociación libre, no parece ser un problema argumentativo. La falacia podría perpetuarse solamente en el caso de que Freud razonara creyendo alcanzar la certeza, pues este razonar es un tipo de inferencia no demostrativa; pero sabemos de su espíritu falibilista y de la provisionalidad que adjudicó a todo tipo de conocimiento, incluyendo el psicoanalítico. De vuelta hay que decir que Grünbaum mismo asume que el deseo antecede a la equivocación en los lapsus que él considera "transparentes". Pero si la acusación de falacia (del tipo que sea) no se cumple para estos ejemplos que él da, entonces tampoco deberían valer para los fenómenos "opacos", puesto que el proceso inferencial es esencialmente el mismo.

\footnotetext{
368 "....a repression which emerges at the end of a chain of free associations (as its terminus ad quem) was actually the original cause of the symptom that initiated the chain as its terminus a quo"

${ }^{369}$ La misma suposición equivocada ya había sido manifestada por Clark Glymour (cf. 1983: $61)$.
} 
Ahora bien, el tipo de inferencia que vemos aparecer con la $A L$ es, indudablemente, de relevancia causal. No obstante, esto necesita algunas aclaraciones. Así como cada hecho acaecido en un momento y lugar específico tiene una densa historia causal que resulta inaprensible en una explicación utilizable, del mismo modo la cadena asociativa del paciente está constituida por una larga historia causal cuya elucidación completa no se requiere para elaborar una explicación satisfactoria de su devenir. Esto es así porque explicar un hecho no es demostrar su esperabilidad, sino que es brindar información causal sobre su ocurrencia; y aunque "explicar un acontecimiento es proporcionar información acerca de su historia causal"370 (Lewis, 1986: 217), la multiplicidad causal completa de un hecho determinado (de todas las causas parciales antecedentes) resulta algo innecesario (cuando no imposible) para poder explicar. Como una explicación satisfactoria necesita dilucidar y ordenar sólo algunos factores causales, es el contexto explicativo lo que determina la significatividad de la cantidad y densidad de tales factores causales. Al considerar el papel de la $\mathrm{AL}$, debemos tener presentes estas nociones y admitir que la relación de explicación es una relación de relevancia causal y que es el contexto lo que determina, en cada caso, "cuáles de los innumerables antecedentes causales son los relevantes a efectos explicativos" (Diez \& Moulines, 1997: 251).

\section{d) La falacia de la afinidad temática}

Para nuestro crítico la técnica de la asociación libre no permite más que incurrir en una falacia de la afinidad temática (cf. 1984: 55, 198, 199). Aunque Grünbaum no caracteriza explícitamente a qué se refiere con esta etiqueta, asumimos que el problema está directamente conectado con lo anterior y que puede ser planteado así: si dejamos desplegar la asociación libre durante un tiempo suficiente, obtendremos complejas cadenas de representaciones tal que prácticamente cualquier tema podría llegar a resonar en el material. El riesgo para Grünbaum es, de este modo, que el significado inferido surja de la ingenuidad teórica del observador y no de algo necesariamente reprimido en el

\footnotetext{
370 "to explain an event is to provide some information about its causal history"
} 
paciente $^{371}$. Sin embargo, Freud sabía que, enfocado desde el punto de vista de las probabilidades, la emergencia de un enlace específico podría ser calculada sobre la base del total de los enlaces posibles, así como su distancia en el discurrir asociativo y su peculiaridad temática; y por ello cita (en una nota agregada en 1924) a Eugen Bleuler, quien se había dispuesto a

\begin{abstract}
...ensayar la formulación matemática de la credibilidad de las interpretaciones psicoanalíticas; su conclusión fue que su valor de probabilidad es mayor que el de millares de inatacados «discernimientos» médicos, y si resulta extraño, ello se debe a que no se está habituado a contar en la ciencia con unas probabilidades psicológicas. (Freud, 1901/2004: 19, n.5).
\end{abstract}

El problema nos recuerda a la inquietud de Charles Sanders Peirce sobre la capacidad adivinatoria del hombre:

\begin{abstract}
Un hombre tiene que estar categóricamente loco para negar que la ciencia ha hecho muchos descubrimientos verdaderos. [...] Pero, ¿cómo es que toda esta verdad ha llegado a alumbrarse por un proceso en el que no hay compulsividad alguna, ni tendencia hacia la compulsividad? ¿Ha sido por azar? Consideremos la multitud de teorías que pueden haberse sugerido. Un físico, en su laboratorio, da con algún fenómeno nuevo. ¿Cómo sabe que las conjunciones de los planetas no tiene nada que ver con ello, o que no es quizá porque a la emperatriz viuda de China se le haya ocurrido por la misma época, hace un año, pronunciar alguna palabra con poder místico, o porque se encuentra presente algún genio invisible? Pensemos en los trillones de trillones de hipótesis que pueden hacerse de las cuales sólo una es verdadera; $y$, con todo, el físico, después de dos o tres conjeturas, o, todo lo más, de una docena, da muy cerca de la hipótesis correcta. Por azar no lo hubiese conseguido, probablemente ni en todo el tiempo transcurrido desde que la tierra se solidificó (Peirce, 1903d/1988: 134).
\end{abstract}

En el ejemplo de aliquis, en determinado momento el joven AJ le pregunta a Freud: "¿no puede deberse todo al azar?", a lo que el vienés le contesta: "tengo que dejar librado a su parecer que todos esos nexos puedan esclarecerse mediante el supuesto de una casualidad. He de decirle, sin embargo, que cualquier caso semejante que quiera analizar lo llevará a unas «casualidades»

\footnotetext{
${ }^{371}$ Aunque parezca original, Freud se había planteado este problema prácticamente de la misma manera, varias veces. Apropósito de la interpretación de los sueños, sabía que la técnica interpretativa podría despertar la "oposición más decidida", puesto que, entre otras cosas, “¿en qué ocurrencia [del sujeto] habrá que detenerse?” (Freud, 1917e/2004: 95).
} 
igualmente asombrosas". (Freud, 1901/2004: 19). Cada acto fallido remite a un discurso en el que se despliegan elementos verbales que se vinculan con el lapsus de diversas maneras: Grünbaum desconoce todo esto y le parece que el analista se dedica a establecer vínculos causales por el simple hecho de que una verbalización asociativa proceda a otra; pero no se percata de las conexiones lógicas (fonemáticas, metafóricas, etc.) que constituyen el elemento probatorio aducido por Freud.

James Hopkins ha planteado que la afinidad temática utilizada en psicoanálisis es equivalente a la que se utiliza en la psicología de sentido común para entender a las personas en la vida diaria y que, por lo tanto, es un medio adecuado para inferir hipótesis causales vinculadas a factores motivacionales. Este proceso inferencial nunca es cerrado: "en efecto, integramos constantemente la explicación que nos inclinamos a dar para una acción con la que nos inclinamos a dar para las demás, revisando a medida que avanzamos"372 (Hopkins, 1988: 39). A nuestro modo de ver, las afinidades temáticas involucradas en las explicaciones psicoanalíticas son diferentes de aquellas con las que trabaja la explicación de sentido común, puesto que las primeras se basan en la asociación libre y las segundas en las relaciones comunes entre signos comportamentales y discursivos. Desestimando esta diferencia, Hopkins concibe que sean metodológicamente equivalentes en lo referido a su justificación. Podemos preguntarnos si, a pesar de su complejidad diferencial, ese común denominador no se podría comprender como una vertiente de la inferencia abductiva o de la inferencia a la mejor explicación ${ }^{373}$.

Sabemos que para Peirce la capacidad de abducir con éxito, es decir la habilidad para elegir sencilla y eficientemente entre las innumerables conjeturas que podrían imaginarse, se explica por el hecho de que "la mente

\footnotetext{
372 "In effect we constantly integrate the explanation we are inclined to give for one action with that we are inclined to give for others, revising as we go."

${ }^{373}$ Aunque Gilbert Harman acuñó el término en 1965, todavía no disponemos de un consenso suficiente acerca de cómo debe entenderse exactamente este concepto. Destaquemos al pasar que Harman (1965, pp. 88-89) sostiene que una inferencia a la mejor explicación se aproxima en algunos puntos a lo que se ha dado en llamar "inducción eliminativa". En virtud del favoritismo que Grünbaum ha mostrado por esta última, volveremos sobre este asunto para expedirnos sobre dicha comparación. Y también retomaremos las similitudes y diferencias entre la inferencia a la mejor explicación y la inferencia abductiva, para seleccionar qué modelo sirve más a la reconstrucción de la racionalidad psicoanalítica.
} 
del hombre debe haber estado en armonía con la verdad de las cosas para descubrir lo que ha descubierto. Es el fundamento mismo de la verdad lógica" (Peirce, 1908/1996: 86). Más allá de la fundamentación peirceana, notemos que su problema mantiene un punto crucial de contacto con el problema de la afinidad temática de Grünbaum; al punto que pueden resolverse de la misma manera: el modo en que Freud obtiene la evidencia que le permite arribar a un conocimiento del sujeto es a partir de la utilización de razonamientos abductivos (y poco tiene que ver con los cánones del inductivismo eliminativo). Desarrollaremos esta idea y algunas consecuencias en la siguiente parte de la tesis.

Hasta aquí, lo único que parece falaz es la crítica de Grünbaum de la existencia de una supuesta falacia de la afinidad temática; en la medida en que da por probada su crítica a la AL sin comprender cómo funciona realmente este procedimiento. Todo ello sin mencionar el hecho de que, en sus ejemplos de actos fallidos "transparentes", Grünbaum da por sentada cierta afinidad temática entre el lapsus y un anhelo inconsciente, para inferir que este último es causante de la equivocación. En esta pequeña "concesión", nuestro filósofo no sólo que razona a partir de lo que luego critica, sino que también utiliza un tipo de inferencia a la mejor explicación, soslayando los procedimientos epidemiológicos y experimentales sobre los que tanto había insistido. Esta concesión carcome el monismo metodológico y explicativo que él mismo defiende ${ }^{374}$.

Además de lo anterior, su concesión nos permite advertir otro error en la argumentación: Grünbaum supone que es un motivo lo que desencadena la represión que lo torna finalmente inconsciente y produce el lapsus (tal y como se evidencia a partir de su ejemplo del hombre que quiere tomar un respiro de aire fresco), cuando en realidad sabemos que la causalidad del lapsus radica en el conflicto que generan las pulsiones de un sujeto singular en un contexto determinado y que sólo puede ser conocido mediante la asociación libre. Dicho de otra manera: por más transparentes que le parezcan a Grünbaum esos

\footnotetext{
${ }^{374}$ Edward Erwin es uno de los autores que ha recuperado y profundizado, en varias oportunidades (Erwin, 1996, 2015), este argumento de la falacia de afinidad temática propuesto por Grünbaum; pero desgraciadamente no ha reparado en los supuestos equivocadamente asumidos por nuestro filósofo germano-americano.
} 
lapsus, no podremos arribar a la mejor hipótesis posible sobre cuál ha sido el conflicto psíquico que ha llevado en ese momento al lapsus ni por qué, si no escuchamos su producción transferencial en una situación analítica.

\section{e) La pretensión de certeza y el rechazo de la inferencia a la mejor explicación}

Algunos años después Grünbaum explicitó su rechazo a la inferencia a la mejor explicación, considerándola como la "excusa fácil" que suelen dar algunos para no admitir que su razonamiento incurre en una falacia confirmatoria. El problema que Grünbaum advierte comienza con el modo en que Freud infirió las relaciones causales desde sus estudios sobre la histeria:

Primero, Freud infirió que la desaparición terapéutica de los síntomas neuróticos es causalmente atribuible al levantamiento catártico de represiones mediante el método de las asociaciones libres. Basándose en esta hipótesis terapéutica clave, él luego esbozó dos nuevas inferencias teóricas centrales: (i) la aparente eliminación de la neurosis por medio del levantamiento catártico de las represiones es una buena evidencia inductiva para postular que las represiones, acompañadas por la supresión afectiva, son en sí mismas causalmente necesarias para la existencia misma de una neurosis (1895d, págs. 6-7), y (ii) concedido que tales represiones son, por lo tanto, las causas esenciales de la neurosis y que el método de la asociación libre es el único capaz de descubrir estas represiones, entonces este método es exclusivamente competente para identificar las causas o agentes patógenos de las neurosis. ${ }^{375}$ (Grünbaum, 2002/2015: 20).

Para Grünbaum, todo este razonar inductivo está viciado con lo que él llama, apoyándose en una conocida exposición de Wesley Salmon (1971), "falacia de la cruda pseudoconfirmación hipotético-deductiva"376. Este razonar freudiano habría sido tan equivocado como suponer que, a partir de la experiencia de que

\footnotetext{
375 "First, Freud inferred that the therapeutic disappearance of the neurotic symptoms is causally attributable to the cathartic lifting of repressions by means of the method free associations. Relying on this key therapeutic hypothesis, he then drew two further major theoretical inferences: (i) The seeming removal of the neurosis by means of cathartically lifting repressions is good inductive evidence for postulating that repressions accompanied by affective suppression are themselves causally necessary for the very existence of a neurosis (1895d, pp. $6-7$ ), and (ii) Granted that such repressions are thus the essential causes of neurosis, and that the method of free association is uniquely capable of uncovering these repressions, this method is uniquely competent to identify the causes or pathogens of the neuroses."
}

376 "fallacy of crude hypothetico-deductive ('H-D') pseudoconfirmation”. 
el consumo de una aspirina ayuda a reducir el dolor de cabeza, entonces estuviésemos habilitados a inferir la "extravagante hipótesis etiológica" de que el déficit de la ingesta de la aspirina es la causa necesaria del dolor de cabeza; debido a que el efecto de la aspirina se puede derivar de esa extraña hipótesis. El ejemplo pretende mostrar que la validez de la consecuencia observacional derivada de la hipótesis no nos permite confirmar cabalmente tal hipótesis causal. Según Grünbaum,

\begin{abstract}
El confirmacionismo hipotético-deductivista crudo es un paraíso de espurias inferencias causales, como lo han mostrado las erróneas inferencias etiológicas de Freud y Breuer. De este modo, las narrativas psicoanalíticas están repletas con la creencia de que un hipotetizado escenario etiológico incrustado en la narrativa psicoanalítica de la aflicción de un analizado se hace creíble meramente porque la etiología postulada permite luego la deducción lógica o la inferencia probabilística de los síntomas neuróticos a ser explicados ${ }^{377}$. (Grünbaum, 2002/2015: 19; cursivas del original).
\end{abstract}

En la siguiente parte de la tesis, cuando hayamos planteado la posibilidad de utilizar la concepción metodológica de Charles Sanders Peirce para entender mejor el proceder clínico en psicoanálisis, mostraremos por qué esta afirmación de Grünbaum es equivocada si atendemos al tipo de consecuencias observacionales que la evaluación de las conjeturas abducidas amerita. Más allá de lo anterior, podemos notar que, en el fondo, lo que pareciera irritar a Grünbaum es que de la confirmación de una hipótesis causal mediante sus consecuencias observacionales no se pueda garantizar que esa constituye la única explicación posible. Es decir, la naturaleza imprecisa de la asociación libre para circunscribir factores causales precisa e inequívocamente. Este afán responde a un interés moderno (heredado directamente de Bacon) de alcanzar la certeza (y con ello autoridad) a partir de la manipulación técnica. Tal es la concepción disciplinaria que Grünbaum mantiene del método de conocer, nacida en una serie de convicciones ontológicas y epistemológicas que difícilmente pueden servir de fundamento a ciencias que, como el psicoanálisis,

\footnotetext{
377 "Crude H-D confirmationism is a paradise of spurious causal inferences, as illustrated by Breuer and Freud's unsound etiologic inference. Thus, psychoanalytic narratives are replete with the belief that a hypothesised etiologic scenario embedded in a psychoanalytic narrative of an analysand's affliction is made credible merely because the postulated aetiology then permits the logical deduction or probabilistic inference of the neurotic symptoms to be explained."
} 
involucran procedimientos interpretativos de motivaciones o tendencias. Esto contrasta con la perspectiva freudiana, que concibe a las indicaciones procedimentales como un simple conjunto de recomendaciones prácticas. Para Peirce, con cuya concepción metodológica acordaremos, la certeza tenía un valor distinto que para Grünbaum: "la infalibilidad en materias científicas me parece irresistiblemente cómica" ${ }^{378}$ (Peirce, 1994; CP 1.9).

En virtud de sus prejuicios, Grünbaum considera que no hay una justificación probatoria de que el contenido al que se arriba con la $\mathrm{AL}$, un determinado conflicto inconsciente, sea la causa única del fenómeno que se quiere explicar (síntoma, lapsus, etc.); y podemos estar de acuerdo con él, pues el psicoanálisis no asume que el contenido revelado por la $\mathrm{AL}$ deba ser la única causa. Dicho de otra manera: la AL no tiene por afán determinar unívocamente la causa efectiva del efecto observable a nivel clínico en la situación analítica, porque se asume que los fenómenos a explicar, al igual que en cualquier otro dominio cognitivo, pueden admitir más de un explanans posible. El psicoanálisis puede, de este modo, brindar un fehaciente testimonio de la convergencia de: por un lado, la tesis de la subdeterminación de la teoría por los datos (asumida a partir del giro historicista de la filosofía de la ciencia analítica) y, por otro lado, la tesis de la sobreinterpretación del sentido (defendida por la hermenéutica contemporánea): los datos clínicos están sobredeterminados y, por ello mismo, su esclarecimiento psicoanalítico se da por oleadas y en diversos niveles de interrelación. De manera tal que, como la AL no tiene por finalidad determinar un único conflicto inconsciente para dar con una única explicación causal de los fenómenos, la objeción de Grünbaum está fuera de lugar.

A nuestro modo de ver, admitir que el procedimiento de elaboración teórica, al igual que en otras disciplinas, no es infalible, es muy distinto de afirmar que el procedimiento conduce ineluctablemente al error y, por lo tanto, es inútil para la construcción de conocimiento causal. Bien podría teorizarse sobre la naturaleza de las inferencias clínicas y el papel que desempeña el error, pero ello no se reduce a la naturaleza de la técnica de la asociación libre sino a las vicisitudes del conocer humano.

\footnotetext{
378 "Though infallibility in scientific matters seems to me irresistibly comical"
} 
En síntesis, las acusaciones de que existe una falacia causal del tipo post hoc ergo propter hoc, o de que la asociación libre sólo se base en la afinidad temática, resultan infundadas. Ejemplos como el de aliquis le sirven a Freud para ilustrar su hipótesis de que existen conflictos entre aspiraciones contradictorias más allá de la conciencia y voluntad del yo del sujeto. Lo que demuestra que el razonamiento de Freud no es falaz es la estructura de la evidencia que utiliza. El vienés supone que los lapsus son formaciones de compromiso $^{379}$ en las que se expresan (resolviéndose por condensación y desplazamiento) aspiraciones pulsionales contrapuestas, para luego indagar mediante la AL cuáles podrían ser los núcleos de tensión en cada fallido singular. Asumiendo una forma de determinismo (que más adelante analizaremos en detalle) establece una búsqueda en la que se destaca un procedimiento inferencial conocido: la abducción.

\section{Lapsus y sueños: ¿parásitos epistémicos o consiliencia de las inducciones?}

\section{a) La inducción de Whewell en Freud}

Grünbaum insiste en que la concepción freudiana de la metodología de la ciencia debe identificarse con la tradición inductiva de Bacon y Mill. A nuestro modo de ver, si intentamos vincular su dimensión metodológica con el pensamiento del empirismo británico del siglo XIX, Freud parece estar más cerca de William Whewell que de Stuart Mill, no sólo por el rechazo que Whewell manifestó respecto de la pretendida universalidad de los cánones de Mill sino por el papel que daba a las inferencias no demostrativas en el quehacer del científico. Para apreciar esta afinidad de perspectivas entre Whewell y Freud, nos detendremos brevemente en un concepto metodológico

\footnotetext{
${ }^{379}$ Característica que comparten con los sueños y los síntomas; no así con el chiste, que "...no crea compromisos como el sueño..." (Freud, 1905/2004: 165). Grünbaum se equivoca también en esto, pues incluye al chiste en los fenómenos que denotan una formación de compromiso (Grünbaum, 1984: 61).
} 
central de este filósofo, mostrando el modo en que puede ajustarse para describir el proceder freudiano. Se trata del concepto de consilience.

Whewell acuñado dicho término en su Filosofía de las Ciencias Inductivas, fundada en su historia $(1840)^{380}$. Con él, se refiere a una forma de entender el fenómeno inductivo que no es la habitual, pues pone el acento en el aspecto de "coligación" entre premisas y conclusión. Sostiene que en la inducción no se trata de la recurrencia de un mismo fenómeno que da lugar a la postulación de una ley capaz de predecirlo, sino de un procedimiento que parte de indicios provenientes de varios hechos de naturaleza distinta, no repetidos, y que posibilita la invención de una explicación que, de la manera más sencilla y elegante, vincula satisfactoriamente a tales fenómenos en apariencia disímiles. Es decir, la explicación consiliente es aquella que muestra cómo se relacionan distintos fenómenos que hasta ese momento se percibían como separados; muestra la unidad que constituyen al responder a un mismo principio subyacente. El nombre completo con el que Whewell bautizó esta modalidad de conocimiento es consiliencia de inducciones. En el libro mencionado, en el decimocuarto aforismo concerniente a la ciencia, Whewell sostiene una brevísima pero ilustrativa caracterización de la naturaleza de este procedimiento: "la Consiliencia de las Inducciones ocurre cuando una inducción derivada de una clase de hechos coincide en otra inducción obtenida de una clase diferente. Tal Consiliencia es una prueba de la verdad de la teoría en la que ocurre" 381 (Whewell, 1840/1967: 469).

Hoy sabemos que la consiliencia puede interpretarse mejor como una forma de Inferencia a la Mejor Explicación (Lipton, 2004), incluso hay quienes sostienen que "la inducción whewelliana es similar a lo que más tarde Peirce

\footnotetext{
${ }^{380}$ El término pasó relativamente desapercibido hasta que fue rescatado por E. Wilson a finales del siglo XX, aunque con un sentido bastante diferente del original (para un examen de estas diferencias, cf. Gould 2003/2004: 183 y ss.). Desde un punto de vista etimológico, el término "consiliencia" viene del latin y está formado por com (juntos) y salire (saltar); por lo que su referencia general es a cosas que "saltan juntas".

381 "The Consilience of Inductions takes place when an Induction, obtained from one class of facts, coincides with an Induction, obtained from another class. This Consilience is a test of the truth of the Theory in which it occurs."
} 
Ilamaría abducción o retroducción" ${ }^{882}$ (Laudan, 1981a: 164); ambas relaciones serán abordadas más adelante.

Por el momento, diremos que el trabajo de construcción teórica que Freud realiza parece vincularse a este precepto whewelliano ${ }^{383}$, en la medida en que la validación de las conjeturas psicoanalíticas supone una articulación entre hechos aparentemente heterogéneos que el vienés supo conciliar. Es por este carácter unitario del conocimiento psicoanalítico que la crítica de Grünbaum, que reduce la validación al contexto de los fundamentos clínicos (bajo la forma del inductivismo experimentalista que él adopta), es inviable.

El propio Grünbaum afirma percibir esta vinculación en el escrito Construcciones en el análisis, en donde Freud habría abogado por una consiliencia de las inducciones clínicas para determinar la fuerza probatoria del asentimiento o del disentimiento del paciente, respecto de las interpretaciones del analista. Sin embargo, nuestro filósofo crítico sostiene rápidamente que, en virtud de la contaminación por sugestión que presenta el método y de los defectos metodológicos de la libre asociación, la pretendida consiliencia es inútil pues no pueden establecerse claramente las piezas independientes de evidencia clínica que podrían ponerse en relación (Grünbaum, 1984: 129). Grünbaum también reconoce en Freud el recurso de una "consiliencia inductiva" ${ }^{384}$ que apunta a establecer la convergencia armónica de los elementos interpretativos con otros elementos de prueba, a los fines de establecer una teoría integrada (ibíd. p. 274 y 276). No obstante, afirma que Freud recurrió a este recurso sólo al final de su vida y una vez perdida su fe en el argumento de la coincidencia.

\footnotetext{
382 "Whewellian induction is thus similar to what Peirce was later to call abduction or retroduction..."

${ }^{383}$ El propio Grünbaum afirma percibir esta vinculación en el escrito Construcciones en el análisis, en donde Freud habría abogado por una consiliencia de las inducciones clínicas para determinar la fuerza probatoria del asentimiento o del disentimiento del paciente, respecto de las interpretaciones del analista. Sin embargo, Grünbaum sostiene rápidamente que, en virtud de la contaminación por sugestión que presenta el método y de los defectos metodológicos de la libre asociación, la pretendida consiliencia es inútil pues no pueden establecerse claramente las piezas independientes de evidencia clínica que podrían ponerse en relación (Grünbaum, 1984: 129). A nuestro modo de ver, la consiliencia que Freud hace intervenir expresa dos características que Grünbaum ignora: aparece tempranamente en la construcción de las explicaciones freudianas (mucho antes de 1937) y no se reduce al ámbito clínico.
}

384 "inductive consilience" 
Hemos mostrado que su premisa relativa a la invalidez de la asociación libre es completamente impugnable. Pero no hemos dado, todavía, razones para rechazar su premisa sobre la supuesta contaminación epistémica del material clínico, porque hemos reservado para el próximo capítulo nuestro análisis del problema de la sugestión. Nos enfocaremos entonces en sus asunciones sobre la consiliencia freudiana.

A nuestro modo de ver, Freud adopta doblemente la perspectiva whewelliana de la consiliencia y lo hace desde mucho antes de 1937: por un lado en lo que refiere a su teorización general, seleccionando fenómenos aparentemente disímiles y vinculándolos en principios explicativos novedosos. Sachs observa, con razón, que "Grünbaum nunca comenta el convencimiento que Freud tenía de haber hallado aplicación y confirmación de sus teorías fuera de la esfera de la práctica clínica”" ${ }^{385}$ (Sachs, 1993/1996: 379-380). Este desconocimiento del valor que para Freud tenían los hallazgos consilientes resulta bastante más sorprendente por el hecho de que el vienés había sido bastante explícito al respecto: "puedo invocar el hecho de la íntima concatenación de todo acontecer anímico, que de antemano asegura un valor no despreciable para otros campos a cualquier discernimiento psicológico aun sobre un campo distante" (Freud, 1905c/2004: 17). A los fines de obtener "la posibilidad de un entendimiento más profundo" Freud no duda en habilitar la

\footnotetext{
385 Indudablemente Grünbaum tuvo la oportunidad de indagar, en los capítulos de su libro que tratan de los sueños y los lapsus, la amplitud de la base empírica freudiana. En lugar de hacerlo, prefirió esbozar su tesis de que el modelo etiológico de la neurosis, cuando Freud lo aplica a lapsus y sueños, constituye una extrapolación indebida. Su obstinación parece haber sido la de querer convencerse (o convencernos) de que la única base empírica contrastacional que Freud quería o debía utilizar se limitaba a los resultados del proceso terapéutico. Grosero error. Uno de los ejemplos más significativos de lo contrario es, posiblemente, el del simbolismo de los sueños; algo que, pese a las controversias desatadas al interior del psicoanálisis posfreudiano, el vienés defendía enérgicamente, estimando que era "quizás el capítulo más asombroso de la doctrina del sueño" (Freud, 1917d/2004: 138). Ante la pregunta de cómo podemos conocer este simbolismo, Freud afirma: "partiendo de fuentes muy diversas, de los cuentos tradicionales y mitos, de los chascarrillos y chistes, del folklore (vale decir: el saber sobre las costumbres, usos, refranes y canciones de los pueblos), del lenguaje poético y del lenguaje usual. Este mismo simbolismo se presenta por doquier, y en muchos de estos lugares lo comprendemos sin más instrucción. Si estudiamos con detalle estas fuentes, encontraremos tantos paralelos con el simbolismo onírico que nos veremos llevados a dar por ciertas nuestras interpretaciones." (ibíd. p. 145; cursiva añadida). Como puede leerse, Freud apela a datos que no son clínicos, ni epidemiológicos ni experimentales, sino de la vida cotidiana. Y la última parte de la cita acentúa la relación que esa base empírica no-clínica guarda con lo teorizado en la clínica. Si bien es cierto que no toda la evidencia extra-clínica es igual de impresionante y que hay aspectos que permanecen en discusión, resulta innegable el lugar que Freud le daba; y es por eso que estamos seguros de que la tesis de Grünbaum no se sostiene.
} 
introducción de alguna "hipótesis que acaso parezca fantástica", siempre que tenga "la ventaja de establecer una unidad insospechada entre series de fenómenos hasta hoy separadas" (Freud, 1913d/2004: 143).

Por otro lado, Freud adopta también la perspectiva whewelliana en lo que respecta al trabajo clínico, pues lo vemos construir sus casos a partir de indicios de muy diversa índole. Esto resulta plasmado en sus escritos iniciales, como por ejemplo en Psicopatología de la vida cotidiana, en donde conceptualiza las "operaciones fallidas combinadas" como connotando un apoyo especial a su teoría. Se trata de un fenómeno de la vida cotidiana en el que un sujeto, a partir de incurrir en varias operaciones fallidas (de la misma índole o diversas), se ve consecutivamente obstaculizado de realizar lo que consciente se ha propuesto:

\footnotetext{
No quiero insinuar que tales casos de operaciones fallidas combinadas puedan enseñar algo nuevo, algo que no se averiguara por los casos simples; pero es cierto que este cambio de vía de la operación fallida entre diversas formas, pero con un mismo resultado, produce la impresión plástica de una voluntad que procura alcanzar una meta determinada, y por lo mismo contradice, de manera incomparablemente más enérgica, la concepción según la cual la operación fallida sería algo contingente y no requeriría ser interpretada. (Freud, 1901/2004: 231).
}

Las operaciones fallidas combinadas son, entonces, uno de los ejemplos más convincentes de la necesidad de interpretación psicoanalítica. Por eso Freud las reconoce como "las flores más preciadas de su género" (Freud, 1917f/2004: 50). Quizás si Grünbaum hubiese analizado este tipo de razonamientos, podría haber notado que la construcción freudiana encaja perfectamente, en este punto, con el espíritu del inductivismo eliminativo: el carácter "múltiple" o "combinado" de estos fallidos vuelve más improbable la hipótesis de que no encierran nada significativo, a la vez que constituyen evidencia a favor del determinismo psíquico propuesto; además, contribuyen mejor que otros el entendimiento del papel de la resistencia en el conflicto psíquico entre impulsos: "la acumulación de manifestaciones trasluce una obstinación que casi nunca se debe al mero azar, sino que concuerda bien con un designio" (ibíd.). Es decir, el valor de la evidencia de estos fallidos es crucial para su hipótesis y, al mismo tiempo, contraría la principal hipótesis rival: el azar. 
Vale la pena reproducir in extenso un ejemplo que Freud cita, calificándolo de "magnífico":

Una dama de Basilea se entera una mañana de que su amiga de juventud, Selma X., de Berlín, justamente en su viaje de bodas, acaba de llegar a Basilea; la amiga berlinesa pasará sólo un día en esta ciudad, y nuestra dama se apresura a llegarse al hotel. Cuando las amigas se separan, convienen en reencontrarse después del mediodía y permanecer juntas hasta la partida de la berlinesa.

Y a la tarde nuestra dama olvida la cita. No conozco el determinismo de ese olvido, pero, dada la situación (encuentro con una amiga de juventud recién casada), son posibles muchas constelaciones típicas capaces de condicionar una inhibición a repetir el encuentro. Lo interesante en este caso es una operación fallida adicional, que constituye una garantía inconciente de la primera. En el momento en que debía, reencontrarse con la amiga de Berlín, nuestra dama se hallaba en cierta reunión en otro sitio. La conversación recayó sobre el reciente casamiento de la cantante de ópera vienesa Kurz. La dama de Basilea se manifestó de manera crítica (!) sobre ese matrimonio, pero cuando quiso mencionar a la cantante no le acudió, para su máxima turbación, el nombre de pila. (Como es sabido, en el caso de apellidos monosilábicos hay una especial tendencia a mencionarlos junto con el nombre de pila.) La dama de Basilea se enojó mucho por su falta de memoria, pues a la Kurz la había oído cantar a menudo y su nombre (entero) le era asaz familiar. Sin que nadie llegara a mencionar ese nombre que se le pasaba de la memoria, la charla tomó otro giro.

Ese mismo día, por la noche, nuestra dama se encuentra en una reunión en parte idéntica a la de la tarde. Por casualidad, vuelve a hablarse sobre el matrimonio de la cantante de Viena, y la dama menciona sin dificultad alguna su nombre, "Selma Kurz". Y al punto exclama: "¡Ahora me acuerdo! He olvidado por completo que hoy a la tarde tenía una cita con mi amiga Selma". Una mirada al reloj le mostró que la amiga seguramente había partido ya de viaje". (Freud, 1901/2004: 40-41).

Aunque Grünbaum no lo diga, la teoría lingüística de Timpanaro que él cita no puede aportar una explicación racional a ejemplos como éste; los cuales constituyen, para Freud, la evidencia más convincente de su teoría de la determinación inconsciente.

\section{b) La evidencia consiliente}

Considerando que para definir una operación fallida deben reunirse las condiciones de estar "dentro del campo de variación de lo normal", que "debe 
poseer el carácter de una perturbación momentánea y pasajera", y que estaremos "tentados de explicarla como una «desatención» o una «casualidad»" (Freud, 1901/2004: 233), resulta difícil imaginar para estas operaciones un equivalente de la eficacia terapéutica, como pide Grünbaum. Con razón Sachs dice, irónicamente, que esa petición de Grünbaum "se trata de por sí de una crítica surrealista" (Sachs, 1993/1996: 390). Nuestro filósofo, sin embargo, justifica esa objeción aduciendo que en la extrapolación de su modelo etiológico de los síntomas a los fallidos y los sueños, Freud habría necesitado llenar una suerte de "vacío inferencial evidente a primera vista" ${ }^{386}$; para lo cual habría hecho uso de un "supuesto adicional" ${ }^{387}$ (Grünbaum, 1984: 192-193), a saber: "si una represión emerge en la conciencia a través de asociaciones libres desencadenadas por la conciencia del sujeto de su acto fallido, entonces la presencia previa de esa represión fue la causa del acto fallida"388 (ibíd.). Pero como Grünbaum no brinda prueba alguna de que Freud admitiera ese supuesto vacío, queda en evidencia que es un vacío de su propia reconstrucción histórica de la metodología freudiana. El error de Grünbaum es un supuesto de partida cuya falsedad mostraremos en el apartado siguiente: que Freud basaba la validación de sus hipótesis causales en la exclusiva evidencia obtenida a partir de los resultados terapéuticos; supuesto que lo lleva a concluir que la expansión del modelo causal de la etiología de la histeria a otros fenómenos no necesariamente clínicos (lapsus, chistes y sueños) debería, por lo tanto, haber implicado para Freud el reconocimiento de que estaba faltando el equivalente probatorio de esos resultados terapéuticos (este sería el pretendido vacío). Convencido de que ha develado algo fundamental, Grünbaum se permite indicar cómo podría haber subsanado Freud esta falta de un equivalente del resultado terapéutico para los actos fallidos: arribar a un deseo reprimido como causante de un lapsus podría "ser terapéutico en el sentido de capacitar a la persona misma para corregir el lapsus y evitar su

\footnotetext{
386 "...to fill the prima facie glaring inferential gap..."

387 “...further assumption...”

388 "...if a repression emerges into consciousness via free associations triggered by the subject's awareness of his parapraxis, then the prior presence of that repression was the cause of the parapraxis..."
} 
repetición u otros fallidos futuros" 389 . Esto me parece completamente absurdo, pues contraría la definición misma de lo que es un acto fallido. Una objeción similar manifiesta Grünbaum, disfrazándola de propuesta reparadora, para establecer un equivalente del resultado terapéutico en el caso de los sueños; vale la pena citarlo in extenso:

Del misma modo que las represiones son consideradas causalmente necesarias para la génesis neurótica, diversas clases de deseos infantiles reprimidos son presuntamente la condición sine qua non de la incitación onírica. Así, al igual que la cualidad terapéutica del desvelamiento de la represión patogénica es el corolario del primer caso, el segundo parece implicar lo siguiente: en la medida en que el paciente analizado deviene consciente de sus deseos infantiles previamente reprimidos, tal control consciente arrebata a esos mismos deseos el poder de engendrar sueños. Por lo tanto, y a medida que los deseos infantiles del analizando van siendo descubiertos, éste debería experimentar y exhibir neurofisiológicamente (por ejemplo, mediante sueño REM) una notable reducción de formaciones oníricas. Pero, ¿qué ocurre si esa reducción no se materializa? Parecería indicar que, a menos que el analizando típico sea crónicamente incapaz de desenterrar sus deseos infantiles, la explicación freudiana de la incitación onírica es falsa. ${ }^{390}$ (Grünbaum, 1984: 234-235).

Evidentemente, esta objeción implica un desconocimiento de la teoría freudiana del sueño y de la técnica psicoanalítica en general. La primera implica, entre otras cosas, el carácter de la indestructibilidad del deseo infantil. La segunda supone, entre otras cosas, el abordaje de las resistencias. Ninguna de ambas nociones tiene lugar en estas menudencias conceptuales de Grünbaum.

Pero ahora recordemos que Freud no "extrapola" sin más su modelo etiológico inicial a nuevos fenómenos, sino que realiza un recorrido

\footnotetext{
389 "...will be "therapeutic" in the sense of enabling the person himself to correct the parapraxis and to avoid its repetition or other parapraxes in the future."

390 "Just as sexual repressions are deemed causally necessary for neurosogenesis, so also sundry sorts of repressed infantile wishes are avowedly the sine qua non of dream instigation. Thus, just as the therapeuticity of lifting pathogenic repressions is the corollary of the former, so also the latter may seem to entail the following: To the extent that the analyzed patient achieves conscious awareness of his previously repressed infantile wishes, that conscious mastery robs these very wishes of their power to engender dreams! Hence, in proportion as the analysand's buried infantile wishes are brought to light, he should experience, and exhibit neurophysiologically (e.g., via REM sleep), a striking reduction in dream formation. But what if this decrease fails to materialize? It would then seem to follow that, unless the typical analysand is chronically unsuccessful in retrieving his buried infantile wishes, Freud's account of dream instigation is false."
} 
investigativo en el que complejiza insospechadamente su teoría, al punto que le resulta posible explicar con ella una serie novedosa de fenómenos que, si bien le salen al cruce en la esfera clínica ${ }^{391}$ y es allí de donde obtiene los datos probatorios, existen más allá del encuadre analítico:

Aquí el mayor peso probatorio es proporcionado por los fenómenos normales. No se puede reprochar al psicoanálisis que haya trasferido al estado normal unas intelecciones obtenidas en el material patológico. Aporta sus pruebas en uno y otro campo de manera independiente, y de este modo muestra que los procesos normales y los llamados patológicos obedecen a las mismas reglas. Entre los fenómenos normales que cuentan en este contexto [...] se observan [...] las operaciones fallidas y los sueños. (Freud, 1913/2004: 170).

Lo que Grünbaum no tiene en cuenta es el conjunto de evidencias que, de manera independiente de la evidencia sobre la etiología de los síntomas, confirma su hipótesis de la formación de lapsus y sueños. La teoría explicativa de Freud implica, como se sabe, un conjunto de hipótesis sobre los mecanismos de causación eficiente de tales fenómenos; es decir, los mecanismos de la condensación y el desplazamiento, son un intento de capturar la racionalidad constitutiva de lapsus, sueños y síntomas ${ }^{392}$. Pero, además de este esquematismo general que estos fenómenos disímiles comparten en su configuración causal, Freud también intenta avanzar en aquellos agentes causales específicos para cada tipo de fenómeno ${ }^{393}$.

A nuestro modo de ver, considerando que existe logrado consenso en reconocer como un indicador de aceptabilidad a la capacidad que una teoría posee para resolver problemas más allá del dominio de su éxito inicial (Kuhn, 1962/2004; 1977/1993; Lakatos, 1978/1989; Laudan, et. al. 1992), estamos

\footnotetext{
${ }^{391} \mathrm{Si}$ bien es cierto que Freud se interesa por los sueños y los lapsus debido a que ellos aparecen en la asociación que sus pacientes realizan a partir de sus síntomas, sus investigaciones se extienden más allá del ámbito clínico, hacia la vida cotidiana, y luego hacia la historia, la religión, la mitología, el arte, etc.
${ }^{392}$ Evidentemente, si nos dispusiéramos a realizar una reconstrucción de esta teoría freudiana con herramientas de la concepción semanticista, consideraríamos que los sueños, los lapsus y los síntomas constituyen modelos de dicha teoría; pues todos ellos son realizaciones que satisfacen sus afirmaciones principales.

${ }^{393}$ Así, por ejemplo, el trabajo del sueño implica una serie de mecanismos exclusivos del sueño y que no aparecen formulados respecto de los chistes, los lapsus ni los síntomas; y lo mismo con cada uno de ellos.
} 
autorizados a reconocer no sólo que la extrapolación freudiana es una maniobra perfectamente lícita sino que constituye, además, un signo de la fecundidad $^{394}$ (progresividad, en términos lakatosianos) de su programa.

Es curioso cómo el nivel general de la crítica de Grünbaum, bastante erudito por momentos, contrasta significativamente con el desconocimiento que manifiesta de esos desarrollos teóricos de Freud o de esos desarrollos consensuados en el campo epistemológico al que pertenece. Uno está tentado de decir que la ignominiosa etiqueta de "extrapolación indebida" no puede, entonces, ser un mero descuido; sino que constituye otra pieza, cuidadosamente labrada, del engranaje grünbaumiano. Dicho más claramente: pareciera ser una distorsión deliberada, con el propósito de aportar coherencia a su tesis principal, a expensas de Freud.

\section{5. ¿Depende la validación del conocimiento psicoanalítico de la eficacia terapéutica?}

\section{a) La evidencia probatoria que prescinde del éxito terapéutico}

Sin lugar a dudas, el valor que Freud le otorgaba al conocimiento psicoanalítico no era dependiente del valor que el psicoanálisis tenía como procedimiento terapéutico. Freud tenía muy en claro que "el uso del psicoanálisis para la terapia es sólo una de sus aplicaciones" y que "quizás el futuro muestre que no es la más importante" (Freud, 1926b/2004: 232); su aspiración era contundente: “...sólo quiero prevenir que la terapia mate a la ciencia." (ibíd. p. 238). Unos años más tarde, finalizando la $34^{\circ}$ de las nuevas conferencias de introducción al psicoanálisis, el vienés sostiene:

Les dije que el psicoanálisis se inició como una terapia, pero no quise recomendarlo al interés de ustedes en calidad de tal, sino por su contenido de

\footnotetext{
${ }^{394}$ El propio Whewell consideraba que su noción de consiliencia no es sólo para las teorías estáticas o hipótesis: "También cree que la noción consiliencia puede funcionar como un dispositivo para evaluar la fuerza y el valor de prolongadas tradiciones de investigación científica" (Laudan, 1981a: 174). [...it is not only to static theories or hypotheses that Whewell applies his doctrine of consiliences. He also believes that the consilience notion can function as a device for assessing the cogency and value of prolonged scientific research traditions.]
} 
verdad, por las informaciones que nos brinda sobre lo que toca más de cerca al hombre: su propio ser; también, por los nexos que descubre entre los más diferentes quehaceres humanos. Como terapia es una entre muchas, sin duda primus inter pares. Si no tuviera valor terapéutico, tampoco habría sido descubierta en los enfermos mismos ni desarrollado durante más de treinta años. (Freud, 1933b/2004: 145).

Podemos afirmar que la relación estrecha que Grünbaum establece entre la eficacia terapéutica y la validación de hipótesis, es una tesis que no se sostiene en lo aseverado por Freud. En la $16^{\circ}$ conferencia de introducción al psicoanálisis Freud expresa claramente la independencia entre ambas:

\begin{abstract}
Aunque para todas las otras formas de contracción de enfermedades nerviosas y psíquicas el psicoanálisis se mostrara tan huero de éxitos como en el caso de las ideas delirantes, seguiría siendo; con pleno derecho, un medio insustituible de investigación científica. (Freud, 1917a/2004: 234).
\end{abstract}

Grünbaum, obstinado en su perspectiva de defender una relación consustancial entre los contextos de justificación (validación) y de aplicación (terapéutica) psicoanalíticos y habiendo leído este pasaje, afirma: "frente al desafío de la sugestionabilidad, esta declaración es una pieza gratuita del arte de vender, indigna del Freud que nos dio el Argumento Tally" ${ }^{395}$ (Grünbaum, 1984: 141). Es evidente que la afirmación que hace Freud en este pasaje, sobre las limitaciones terapéuticas del psicoanálisis en su abordaje de las ideas delirantes, contradice abiertamente la tesis de Grünbaum. Además, nuestro filósofo no ha notado que Freud ofrece, en la $28^{\circ}$ conferencia, una justificación precisa de la afirmación anterior que él desprecia:

...un gran número de resultados singulares del análisis, que de otro modo caerían
bajo la sospecha de ser productos de la sugestión, nos son corroborados desde
otra fuente inobjetable. Nuestros testigos son en este caso los dementes y los
paranoicos, insospechables, desde luego, de recibir una influencia sugestiva. Lo
que estos enfermos nos cuentan de sus traducciones simbólicas y sus fantasías,
que en ellos han penetrado hasta la conciencia, coincide punto por punto con los
resultados de nuestras indagaciones sobre el inconciente de los que sufren

395 "But in the face of the suggestibility challenge, this statement is a gratuitous piece of salesmanship, unworthy of the Freud who gave us the Tally Argument". 
neurosis de trasferencia, y así confirma la corrección objetiva de nuestras interpretaciones, tan a menudo puestas en tela de juicio. (ibíd. p. 413).

Es decir, la estrecha relación entre las declaraciones de pacientes psicóticos (no sugestionables) con el material proveniente de la asociación libre en neuróticos, constituye un hecho corroborador de la teoría independientemente de los resultados terapéuticos. Se trata de la apelación freudiana a un hecho no terapéutico para fundamentar sus ideas, lo cual desmiente la suposición de Grünbaum de que "la atribución de éxito terapéutico al desmantelamiento de las represiones (...) fue el fundamento, tanto lógica como históricamente, para la significación dinámica central que la ideación inconciente adquirió en la teoría psicoanalítica”" ${ }^{396}$ (Grünbaum, 1984: 182). Además, la cita del vienés también contraría la afirmación grümbauniana de que Freud "otorgó explícitamente la misma sanción epistémica a las etiologías clínicas de las dos subclases de psiconeurosis (...). Y presumiblemente lo hizo extrapolando la justificación terapéutica del método psicoanalítico de investigación etiológica desde las neurosis de transferencia a las neurosis narcisistas"397. (Grünbaum, 1984: 141). A decir verdad, ya en la conferencia $27^{\circ}$ Freud (1917b/2004: 399) había afirmado que la extrapolación técnica para las neurosis narcisistas no daba resultado; aunque no descartaba, como sabemos, que modificaciones futuras lo posibilitasen: "es verdad que en el presente, en este terreno, no todo saber se traspone en poder terapéutico; pero aun la mera ganancia teórica no debe ser tenida en menos, y cabe aguardar con confianza su aplicación práctica" (Freud, 1925b/2004: 57).

Ahora bien, el relato de los pacientes psicóticos no es la única fuente inobjetable desde la que Freud extrae apoyo confirmatorio para sus hipótesis: los chistes, los tabúes, la historia de las religiones, el comportamiento de las masas, la herencia cultural, la literatura, las acciones fallidas, etc., constituyen

\footnotetext{
396 "...the attribution of therapeutic success to the undoing of repressions (rather than to mere suggestion) was the foundation, both logically and historically, for the central dynamical significance that unconscious ideation acquired in psychoanalytic theory: without reliance on the presumed dynamics of their therapeutic results, Breuer and Freud could never have propelled clinical data into repression etiologies."

397 "...he explicitly gave the same epistemic sanction to the clinical etiologies of the two subclasses of psychoneuroses (S.E. 1917, 16: 438-439). And presumably he did so by extrapolating the therapeutic vindication of the psychoanalytic method of etiologic investigation from the transference neuroses to the narcissistic ones."
} 
campos de fenómenos altamente disímiles pero que le sirven para confirmar la teoría más allá de la esfera terapéutica. Para el vienés el psicoanálisis no se reduce a un método terapéutico sino que también constituye una nueva ciencia. A nuestro modo de ver, cuando Grünbaum analiza las "credenciales del psicoanálisis" reduce injustificadamente el conjunto de evidencias empíricas al subconjunto de los fenómenos clínicos (que luego identifica, también injustificadamente, con el subconjunto de "éxito terapéutico").

De todas formas, lo que prueba contundentemente la falsedad de la postura de Grünbaum es lo que podemos atisbar en el trabajo realizado por Freud con sus casos célebres, en donde no muestra en absoluto dificultades en vincular sus desarrollos teóricos con desilusiones desde el punto de vista terapéutico. Se ve claramente en los casos de Dora y del hombre de los lobos que es a partir de las frustraciones en la cura que Freud hace avanzar el conocimiento psicoanalítico, rechazando conjeturas y produciendo otras nuevas. Por eso el psicoanálisis, incluso "allí donde hoy no puede remediar, sino sólo procurar una comprensión teórica, acaso allana el camino para una posterior influencia más directa sobre las perturbaciones neuróticas" (Freud, 1923a/2004: 246). Es decir, Freud valora el conocimiento alcanzado a partir de los fracasos terapéuticos; por lo que la asociación que Grünbaum pretende endilgarle al pensamiento freudiano, no se sostiene. De hecho, en el caso del hombre de las ratas, Freud se lamenta del carácter lagunar del conocimiento alcanzado sobre ese historial y señala explícitamente: "no se consiguió destejer hilo por hilo esta trama de envoltorios de la fantasía; justamente el éxito terapéutico fue aquí el obstáculo". (Freud, 1909b/2004: 163, n. 39). Enseguida agrega:

No se me han de reprochar, pues, estas lagunas en el análisis. En efecto, la exploración científica mediante el psicoanálisis hoy es sólo un resultado colateral del empeño terapéutico, y por eso el botín suele ser mayor justamente en los casos en que el tratamiento ha fracasado. (ibíd., cursivas añadidas).

Algo similar plantea en el caso del hombre de los lobos, cuando sostiene que:

Los análisis que obtienen un resultado favorable en breve lapso quizá resulten valiosos para el sentimiento de sí del terapeuta y demuestren la significación médica del psicoanálisis; pero las más de las veces son infecundos para el avance del conocimiento científico. Nada nuevo se aprende de ellos. Se lograron tan 
rápido porque ya se sabía todo lo necesario para su solución. Sólo se puede aprender algo nuevo de análisis que ofrecen particulares dificultades, cuya superación demanda mucho tiempo. Únicamente en estos casos se consigue descender hasta los estratos más profundos y primitivos del desarrollo anímico y recoger desde ahí las soluciones para los problemas de las conformaciones posteriores. (Freud, 1918/2004: 11).

Lo que estas reflexiones nos muestran es que Freud no hacía depender causalmente la validez de sus teorías de los resultados terapéuticos obtenidos $^{398}$. Es decir, prueban la falsedad de que con el argumento de la coincidencia Freud "invoca el éxito terapéutico" de una forma ineludible (Grünbaum, 1984: 139). Y también muestran que, si bien es evidente la visión moderada que el vienés llegó a tener de los efectos terapéuticos del análisis (posiblemente en contestación al entusiasmo de varios de sus discípulos), de allí no se sigue la caprichosa genealogía de Grünbaum, según la cual el pensamiento metodológico de Freud podría ser tajantemente separado en un período inicial de "optimismo terapéutico" (apoyado en el argumento de la coincidencia) seguido de un período final de "pesimismo terapéutico" (efecto de que el argumento de la coincidencia habría resultado rechazado y el método habría quedado sin fundamentar). Pero, principalmente, tales reflexiones nos conducen a pensar que el argumento de la coincidencia no puede haber sido el supuesto central de la confianza de Freud en el análisis.

Grünbaum ha distorsionado la base empírica que Freud utilizaba, angostándola a los resultados terapéuticos en la esfera clínica. Sintetizando, podría decirse que la íntima vinculación que Grünbaum quiere imponer como natural (incluso en el pensamiento freudiano) entre el éxito terapéutico y la confirmación de la teoría, no es otra cosa que un retoño contemporáneo del perenne furor sanandi denunciado por Freud (1915c/2004: 174).

\section{b) El éxito terapéutico no es el mejor indicio de validación etiológica}

Además de que Grünbaum desarrolla esa vinculación entre éxito terapéutico y verdad teórica con independencia de las presuposiciones mantenidas por

${ }^{398}$ Además de ello, el papel central que Freud otorga a los "obstáculos" constituye otro indicio de su pensamiento crítico y de su filiación falibilista, tal y como lo hemos expuesto antes en nuestro diálogo con la crítica de Popper. 
Freud, su planteo involucra un error argumentativo de otra índole, que es necesario explicitar. Grünbaum sostiene que si el levantamiento de la represión no se deriva en la cura, entonces queda demostrado que los contenidos inconscientes y los conflictos no tienen poderes causales para la presencia de los síntomas neuróticos. Este modo de razonar es equivocado pues encierra una simplificación de la acción causal de la represión, en donde se omite la conceptualización freudiana de los tiempos de la represión y el grado de determinación causal que cada factor hipotetizado mantiene en el proceso de formación de síntomas. Coincidimos con Linda Brakel en que esta falaz simplificación puede ser fácilmente mostrada mediante un ejemplo de la etiopatogenia médica:

\begin{abstract}
Erradicar la bacteria estreptococo beta hemolítico (la causa esencial de la cardiopatía valvular reumática) no hará nada para mejorar esta enfermedad cardíaca una vez que se haya establecido. Por lo tanto, el hecho de que la eliminación de la causa de un padecimiento no dé como resultado una cura, de ninguna manera establece que los poderes causales fueran asignados erróneamente $^{399}$. (Brakel, 2015: 67).
\end{abstract}

En lo que respecta a los síntomas psicoanalíticos también sabemos que, una vez producidos, el sujeto puede extraer de ellos una ganancia secundaria que los mantenga a expensas de sus fuentes originales de causación ${ }^{400}$. Si esta

\footnotetext{
399 "Eradicating beta hemolytic strep bacteria (the essential cause of rheumatic valvular heart disease) will do nothing to improve this cardiac disease once it has been established. Thus, the fact that removing the cause of an ailment does not result in a cure in no way establishes that the causative powers were wrongly assigned."

400 En la célebre comunicación preliminar, Freud y Breuer habían referido su original concepción de la causalidad mediante una inversión del apotegma escolástico "cessante causa cessat effecttis», lo cual significa la suposición de que mientras se mantenga el síntoma (efecto) también los harán las vivencias traumáticas reprimidas (causa), y por eso les fue posible concluir en aquel entonces que "el histérico padece por la mayor parte de reminiscencias" (Freud \& Breuer, 1895/2004: 33). Grünbaum se apoya la mayoría de las veces sólo en estas tempranas elaboraciones de Freud para evaluar la causalidad implicada en las hipótesis etiológicas y terapéuticas del psicoanálisis (cf. Grünbaum, 1984: 181; 2002/2015: 17 18), lo cual supone un anacronismo que desatiende la posterior y fecunda conceptualización freudiana sobre la teoría clínica (en sintonía con las complejidades añadidas a la concepción etiológica de las neurosis); que pasará a incluir, por ejemplo, las diversas formas de resistencia o las manifestaciones de una satisfacción paradójica. Nuestro filósofo soslaya que, a pesar del obvio valor de esas ideas seminales en la constitución del programa freudiano, éste alcanzó, de la mano de Freud, una visión mucho más compleja que la expuesta originalmente en los Estudios sobre la histeria. Complejidad que abarca no sólo a las hipótesis etiológicas sino a la proliferación de los mecanismos defensivos involucrados en la producción de fenómenos (no solamente patológicos).
} 
situación se consolida en el tiempo, se produce una armonización del síntoma con yo:

...una corriente psíquica cualquiera halla cómodo servirse del síntoma, y entonces este alcanza una función secundaria y queda como anclado en la vida anímica. El que pretenda sanar al enfermo tropieza entonces, para su asombro, con una gran resistencia, que le enseña que el propósito del enfermo de abandonar la enfermedad no es tan cabal ni tan serio. (Freud, 1905b/2004: 39).

Freud mismo nos advierte de que "si esa ganancia de la enfermedad, externa o accidental, es muy cuantiosa y no puede hallar un sustituto real, desconfíen ustedes de la posibilidad de influir sobre la neurosis mediante su terapia" (Freud, 1917g/2004: 349). Es decir que la satisfacción obtenida secundariamente del síntoma puede constituir un factor de resistencia ${ }^{401}$ a su eliminación, y ello independientemente de que se haga consciente el conflicto que le dio origen. Evidentemente, esto está muy lejos de la imagen simplificada que Grünbaum se ha hecho de la neurosis, a la vez que contraría su noción lineal de la causación/curación de los síntomas.

Ahora bien, independientemente de lo que Freud creyese, la relación de dependencia causal que Grünbaum establece entre el éxito terapéutico y la verdad aproximada de la teoría psicoanalítica es disparatada en sí misma. Esto es así fundamentalmente porque la validez de una teoría es algo que mantiene relativa independencia epistémica de sus aplicaciones prácticas específicas. En última instancia, el valor de la teoría psicoanalítica de Freud va más allá de su eficacia terapéutica con las psiconeurosis del siglo $X X$, del mismo modo que el valor de las ideas de Ignaz Semmelweis va más allá de sus pretensiones en la reducción de muertes por fiebre puerperal; o del mismo modo que el valor de las ideas de Louis Pasteur va más allá de sus indagaciones sobre la fermentación, etc.

Incluso cerniéndonos al éxito terapéutico, el razonamiento de Grünbaum encierra otra confusión, que ha sido puesta de manifiesto por Zvi Lothane:

\footnotetext{
${ }^{401}$ En Inhibición, síntoma y angustia Freud la incluye como una de las tres resistencias yoicas, junto a la "resistencia de represión" y a "la resistencia de transferencia"; además de las resistencias que provienen del ello y el superyó (cf. Freud, 1926c/2004: 149-150).
} 
El fracaso o el éxito de la técnica psicoanalítica en una situación determinada necesita ser justificado, pero este éxito o fracaso no puede invalidar el método per se, no más de lo que un resultado poco satisfactorio de un tratamiento en Medicina pueda impugnar los tratamientos médicos: por ejemplo, el hecho de que ciertas drogas anti-cáncer tengan sólo un $11 \%$ de probabilidades de lograr la curación no invalida el método de la quimioterapia contra el cáncer per se. (Lothane, 1998: 282).

No corresponde, entonces, asumir la premisa grümbauniana de que la validez de la teoría depende, al fin y al cabo, de la eficacia terapéutica. Si se la asume (como hace Marshall Edelson, por ejemplo) es muy difícil dar una respuesta coherente a las demandas de nuestro filósofo sin quedar entrampado en su argumentación.

Lo que a esta altura queda a la vista de la postura de Grünbaum es su inmanente racionalidad instrumental y el recorte que ella opera en la racionalidad psicoanalítica: la teoría freudiana no es juzgada por su coherencia, por su capacidad de conectar diversos saberes (científicos y humanísticos) o distintos campos (social, histórico, biológico), ni tampoco por las posibilidades de comprensión que brindan sus conceptos ${ }^{402}$. Su enjuiciamiento se reduce a un despótico arbitrio: sus aciertos instrumentales en el campo terapéutico. La justificación pasa exclusivamente por las vías de la eficacia, renunciándose desinteresadamente al valor de los mecanismos explicativos, incluso de dicha eficacia.

\section{c) Evidencia extraclínica contemporánea de la validación teórica}

Resulta pertinente el planteamiento de Helmut Thomä y Horst Kächele respecto a la utilización que se ha hecho, a partir de Grünbaum, de la TCN: "cuando, por ejemplo, se usa el 'argumento de la coincidencia' ('tally' argument) para probar la exactitud de las hipótesis psicoanalíticas, no se está tomando en cuenta suficientemente la divergencia entre verdad y eficacia" (Thomä y Kächele, 1985/1989: 515). Para estos autores, "no es difícil darse cuenta de

\footnotetext{
${ }^{402}$ En contraste con esta racionalidad instrumental, Freud decía que, por ejemplo, su hipótesis en Tótem y tabú era "una hipótesis como tantas otras con que los prehistoriadores procuran iluminar la oscuridad del tiempo primordial -«just-so story», según la llamó jocosamente un crítico inglés [...] pero opino que es valedera como hipótesis si se muestra apta para crear coherencia e inteligibilidad en nuevos y nuevos ámbitos" (Freud, 1921b/2004: 116).
} 
que la controversia acerca de la exactitud de la 'tesis de la condición necesaria' es, en realidad, una controversia sobre la cuestión de si acaso la tesis de Freud de la unión inseparable es o no válida para la práctica psicoanalítica” (ibíd. p. 517). Pero incluso aquellos que asumen la unión inseparable entre investigar y curar (por ejemplo en la forma del argumento de la coincidencia) saben que no se trata de una ley natural y que no está claro cuáles son los factores, además del insight, que contribuyen a los cambios terapéuticos evaluados positivamente $^{403}$. Por eso mismo, Thomä y Kächele piensan que sólo podemos expedirnos sobre las críticas de sugestión o de contaminación de los datos a partir de resultados de la investigación empírica del proceso terapéutico, y no en el marco de discusiones filosóficas (ibíd.).

Pues bien, si nos detenemos a considerar los estudios empíricos con metodologías extraclínicas que apuntan a validar las hipótesis freudianas, encontramos evidencia fuerte. Un ejemplo notorio de este tipo de estudios es la investigación experimental dirigida por Howard Shevrin et. al. (1992, 1996), en la que cuatro psicoanalistas utilizaron datos del psicoanálisis de once pacientes, ocho diagnosticados con fobia y tres con duelo patológico. A continuación, para cada sujeto, los analistas seleccionaron: a) algunas palabras que cada sujeto utilizaba para expresar su vivencia consciente del síntoma, y b) un número de palabras que pudieran representar lo mejor posible el hipotético y singular conflicto inconsciente central de cada uno de tales pacientes. Estas dos categorías de palabras con referencias claramente singularizadas, junto con dos categorías generales de palabras no individualizadas (es decir que no tenían relación con los conflictos inconscientes o los síntomas y que funcionaron como una categoría de estímulos de control para el diseño de la prueba), fueron utilizadas como estímulo en un ambiente controlado: se les presentaron a los once pacientes de manera subliminal (a 1 milisegundo) y supraliminal (30-40 milisegundos), y mediante electroencefalografía se ponderó

403 Sostienen, por ejemplo, que "una contratransferencia insuperable puede influir negativamente el proceso de tratamiento, de modo tal que en dicho caso el éxito o el fracaso no pueden adjudicarse a la teoría" (Thomä y Kächele, 2002/2003: 27). Nótese que podría ser el caso en el que el psicoanalista explique adecuadamente la psicopatología del paciente y que sus interpretaciones sean correctas, pese a lo cual intervienen además otras variables que impiden establecer firmemente la relación pretendida por Grünbaum. Por lo tanto: "los éxitos o fracasos no pueden ser tomados para la verificación o falsación de la teoría" (ibíd.). 
la actividad cerebral mientras los estímulos les eran presentados ${ }^{404}$. resultado general fue una serie alta de correlaciones en las ondas alfa, entre el estímulo subliminal y el estímulo relativo al síntoma consciente; pero solo cuando el estímulo inconsciente fue presentado de forma subliminal. A la vez, no se obtuvieron resultados cuando se reemplazaron las palabras estímulo individualizadas con las palabras del grupo control. Es decir que la relación entre la frecuencia y la latencia reveló un patrón similar para el conflicto inconsciente y las palabras de los síntomas conscientes. Desde la óptica psicoanalítica de los autores, esto sugiere que un proceso como la represión puede explicar estos fenómenos y que, por lo tanto, el experimento constituye un fuerte apoyo empírico para la teoría freudiana del conflicto inconsciente.

Este tipo de investigaciones ha continuado perfeccionándose hasta la indagación de específicas relaciones causales entre conflictos inconscientes y síntomas (Shevrin, et. al., 2013), y los autores han intercambiado sus resultados con Grünbaum, quien se ha manifestado, según los autores, "satisfecho" con estos hallazgos probatorios. Por lo tanto, a pesar de que Grünbaum haya continuado defendiendo, en distintos escritos posteriores, la postura filosófica originalmente consolidada en The Foundations of Psychoanalysis, sabemos que la evidencia empírica que él proclamaba ha llegado conforme a sus expectativas y que él ha reconocido su valor en la estipulación de la causalidad en términos freudianos.

Estudios como los de Shevrin han venido a mostrar de manera contundente que la validación de las hipótesis freudianas puede lograrse con procedimientos extraclínicos y apelando al estudio de casos singulares; pero, sobre todo, muestran que la confirmación puede venir a expensas de las complejas relaciones que guarda la práctica clínica con los resultados terapéuticos. En lo que a nuestra discusión respecta, constituyen una mostración categórica de que Grünbaum estaba equivocado en la identificación de la eliminación sintomática como único garante de la verdad aproximada de la teoría freudiana de la represión. Esto puede concluirse más allá de las

\footnotetext{
${ }^{404}$ Esto se llevó a cabo mediante el análisis de un Potencial Relacionado con Evento (ERP), que consiste en medir la respuesta cerebral a un evento específico; en este caso el estímulo del protocolo de palabras seleccionadas. El análisis de las respuestas estereotipadas de nivel electrofisiológico a este tipo de estímulos, es lo que permitió la correlación entre los distintos tipos de palabras y los distintos tipos de respuesta cerebral.
} 
limitaciones que podrían objetarse a estos estudios neurocientíficos para la validación de las conjeturas psicoanalíticas, cuestión que por el momento no abordaremos.

\section{d) La función de la metapsicología en la teoría clínica}

Finalmente, para cerrar esta parte, nos centraremos brevemente en otra suposición que Grünbaum asume incorrectamente como cierta y que mina, por lo tanto, su argumentación sobre el valor determinante de los resultados terapéuticos.

La estrategia central de nuestro crítico, desde el inicio de su libro de 1984, consiste en centralizar aquellos pasajes de Freud en donde éste afirma que el psicoanálisis es una ciencia natural y que debe, por lo tanto, evaluarse como tal. En ese contexto, analiza la perspectiva original del Proyecto y sostiene que "Freud abandonó su noción inicial, ontológicamente reductiva del estatus científico, en favor de una metodológica, epistémica"405 (Grünbaum, 1984: 3). Su idea es que Freud comenzó basando el estatus científico del psicoanálisis en la constitución física de su objeto de estudio (como lo mostraría la primera página del proyecto de psicología), pero pronto dejó caer esta condición en favor de un basamento exclusivamente metodológico del conocimiento. Según la perspectiva original, que Grünbaum caracteriza como de "reduccionismo ontológico", los fenómenos psíquicos sólo pueden incluirse dentro de la ciencia empírica si se pueden expresar en términos puramente físicos. Mientras que el punto de vista finalmente adoptado consiste en asumir que cualquier proposición teórica puede contar como científica a condición de que pueda ser establecida de acuerdo a los cánones metodológicos de la ciencia empírica establecida. Pero Grünbaum entiende que esta suerte de pasaje implica que Freud "considera explícitamente a la metapsicología como epistemológicamente prescindible en comparación con la teoría clínica” ${ }^{406}$ (Grünbaum, 1984: 84). Como hemos visto y analizado críticamente, nuestro

\footnotetext{
405 "Freud forsook his initial, ontologically reductive notion of scientific status in favor of a methodological, epistemic one"

406 "he explicitly deemed the metapsychology epistemologically expendable as compared to the clinical theory."
} 
filósofo ha querido hacer de la teoría clínica el elemento central de la fundamentación freudiana del conocimiento psicoanalítico; pero lo que este punto de vista también conlleva es la suposición de que Freud habría excluido las consideraciones ontológicas en su fundamentación del conocimiento. Este es exactamente el punto que no compartimos y que, creemos, vale la pena revisar.

A nuestro modo de ver, cuando Freud caracterizaba a la metapsicología como una superestructura especulativa susceptible de transformarse, no pensaba en su completa prescindencia ni en su inutilidad como fundamento del conocimiento psicoanalítico. En todo caso, la perfectibilidad de sus enunciados no supone la contingencia de su existencia: esa superestructura deviene necesaria. Hay varios pasajes que permiten mostrar esta importancia que tiene la metapsicología ( $y$, por ende, las suposiciones ontológicas implicadas); en una de sus declaraciones finales, por ejemplo, sostiene que

\begin{abstract}
La concepción según la cual lo psíquico es en sí inconciente permite configurar la psicología como una ciencia natural entre las otras. Los procesos de que se ocupa son en sí tan indiscernibles como los de otras ciencias, químicas o físicas, pero es posible establecer las leyes a que obedecen, perseguir sus vínculos recíprocos y sus relaciones de dependencia sin dejar lagunas por largos trechos -o sea, lo que se designa como entendimiento del ámbito de fenómenos naturales en cuestión-. (Freud, 1940/2004: 156).
\end{abstract}

Es decir que son las entidades y procesos postulados por su teoría, cuya existencia es independiente, los que hacen a su carácter científico y no sus aspectos metodológicos. Tales conceptualizaciones metapsicológicas

\footnotetext{
...poseen títulos para que se les otorgue, en calidad de aproximaciones, el mismo valor que a las correspondientes construcciones intelectuales auxiliares de otras ciencias naturales, y esperan ser modificados, rectificados y recibir una definición más fina mediante una experiencia acumulada y tamizada. Por tanto, concuerda en un todo con nuestra expectativa que los conceptos fundamentales de la nueva ciencia, sus principios (pulsión, energía nerviosa, entre otros), permanezcan durante largo tiempo tan imprecisos como los de las ciencias más antiguas (fuerza, masa, atracción). (ibíd.).
} 
Como puede notarse, el papel de los desarrollos metapsicológicos fue central para Freud, hasta sus últimos días ${ }^{407}$. Si bien sus contenidos son definidos como provisionales (en virtud del falibilismo al que Freud adhería), su existencia es considerada como necesaria para el psicoanálisis ${ }^{408}$. Esto contradice, evidentemente, la creencia de Grünbaum de que sólo el método clínico aportaría los fundamentos epistemológicos de la cientificidad del psicoanálisis.

Ahora bien, lo que el planteo de Grünbaum omite a partir de esa lectura equivocadamente centralizada en los aspectos metodológicos, es el análisis de los presupuestos filosóficos vinculados a la concepción que Freud tenía de la realidad y de su conocimiento, lo cual nos resulta absolutamente necesario para una coherente elucidación de los fundamentos del psicoanálisis.

\section{6. ¿Es el inductivismo eliminativo una propuesta universalmente válida y particularmente viable para el psicoanálisis?}

La pregunta del título de este apartado merece ser respondida separando las dos cuestiones que allí se plantean. Primero propondremos un decálogo de dificultades presentes en los cánones de Mill e inherentes al inductivismo eliminativo que Grünbaum defiende, pero que no parece haber tenido en cuenta. Y luego intentaremos vislumbrar una serie de dificultades relativas a la pretendida aplicabilidad de dicha metodología al psicoanálisis.

\footnotetext{
407 Para un examen exhaustivo del lugar central que ocupó la metapsicología en el pensamiento freudiano, cf. Assoun (2000/2002).

408 El proceso incesante de elaboraciones metapsicológicas que Freud tiene en mente pareciera análogo al que alude Otto Neurath con su metáfora sobre la construcción del conocimiento científico: "somos como navegantes que tienen que transformar su nave en pleno mar, sin jamás poder desmantelarla en un dique de carena y reconstruirla con los mejores materiales." (Neurath, 1932/1965: 206).
} 


\section{a) Problemas de los cánones de Mill}

Hemos visto antes que para Mill los cánones inductivos eran una especie de instrumento con el que descubrir y probar conexiones causales, esto es: los "antecedentes invariables e incondicionales" de todos los fenómenos (Ferrater Mora, 1965: 205); también hemos visto a Grünbaum denunciar su ausencia en las consideraciones causales freudianas y, a la vez, arengar su uso en el ámbito psicoanalítico en tanto condición necesaria de su cientificidad. Sin embargo, debemos señalar que Mill sobreestimó el valor de sus cánones tanto en el contexto de descubrimiento como en el de justificación, y que Grünbaum ha descuidado estas limitaciones en su lectura del psicoanálisis freudiano. Veamos algunas de las principales dificultades del planteo de Mill.

I) Al formular sus métodos Mill supuso que es posible identificar casos que tienen únicamente una circunstancia en común (canon de la concordancia) y otros casos que tienen toda circunstancia en común excepto una (canon de la diferencia); pero si asumimos literalmente estas formulaciones debemos reconocer que no existe ningún par de objetos en el universo en que vivimos que pueda cumplir con ninguna de ambas reglas: dos objetos cualesquiera siempre tendrán muchas circunstancias en común por más que parezcan completamente diferentes y, al mismo tiempo, nunca dos objetos podrían diferir sólo en un único aspecto. Tampoco podemos, conviene recordarlo, inspeccionar todas esas circunstancias para ver si realmente difieren en una sola.

II) En su exposición de los cánones, Mill parece suponer que todas las circunstancias están a la par; con lo cual, por ejemplo, para dar con la causa de un proceso combustivo que se produce en determinado momento y no en otro, deberíamos entonces considerar por igual información relativa a la cantidad de granos de arena del océano pacífico o la temperatura actual del polo sur. Si todas las circunstancias estuviesen a la par, sólo se podría especificar adecuadamente un caso describiendo por completo el estado del universo en un instante determinado, lo cual es ridículo. Ahora bien, a sabiendas que el investigador que se dispone a establecer una relación causal no necesita, en su actividad real, tener en cuenta todas las circunstancias sino sólo aquellos grupos de fenómenos relevantes para el tipo de vínculo que se propone 
indagar, resulta decepcionante notar que los cánones de Mill no nos dicen nada respecto de esa relevancia: evidentemente su utilización necesita, en cada contexto, de información previa que oriente la búsqueda ${ }^{409}$, es decir de alguna hipótesis previa acerca de cuáles circunstancias pueden ser relevantes. Dicho de otra manera, a diferencia de lo que Mill creía, los cánones no son, en sí mismos, instrumentos suficientes para el descubrimiento de nuevas hipótesis causales.

III) De lo anterior se desprende que los cánones de Mill tampoco constituyen, en sí mismos, estándares sólidos para la prueba de hipótesis: en virtud de que la selección de los fenómenos relevantes se hace en base a hipótesis causales supuestas y que puede, por lo tanto, ser equivocado, entonces las inferencias inductivas que proponen los cánones pueden resultar también inadecuadas. Esta dependencia que la inducción mantiene respecto del mérito de las hipótesis subyacentes muestra que los cánones de Mill están muy lejos de poder probar las conexiones causales.

IV) Considerando que la aplicación de los métodos inductivos depende, en última instancia, de las correlaciones observadas y, a sabiendas de que estas pueden ser engañosas, entonces nunca es posible inferir con certeza una conexión causal entre instancias todavía no observadas.

V) Las correlaciones entre factores observados no necesariamente es indicador de un vínculo causal; pero el canon de las variaciones concomitantes nos invita a buscar e inferir un vínculo causal allí donde hay meras coincidencias $^{410}$.

\footnotetext{
409 La parodia del "bebedor científico" (Copi \& Cohen, 2013: 610) ilustra bien esta dificultad: una noche bebe whisky escocés y soda, bourbon y soda una segunda noche, y en las noches siguientes brandy y soda, luego ron y soda, luego ginebra y soda. ¿Cuál la causa de su intoxicación? Embriagado varias veces ijura no volver a tomar soda nunca más! El ejemplo ilustra claramente cómo la aplicación del canon de la concordancia es inútil sin una correcta identificación de los factores relevantes de las circunstancias antecedentes: de este modo no han podido ser manipuladas (por lo tanto tampoco eliminadas) las conexiones causales erradas. Al revisar la historia de los descubrimientos científicos, vemos que, por un lado, la conexión exitosa de fenómenos inesperados (por ejemplo la sexualidad y la neurosis) implica un proceso creativo que difícilmente pueda ser representado con simples reglas de inferencia lógica; y, por otro lado, que las observaciones siempre parten de presupuestos.

${ }^{410}$ Esta crítica puede hallarse varios siglos antes, cuando Nicolás de Autrecourt (siglo XIV) ponía en duda el método de la concordancia propuesto por entonces, afirmando que no puede establecerse que una correlación hasta el momento observada deba continuar manteniéndose en el futuro; es decir, que no puede establecerse el conocimiento necesario de las relaciones causales (Losee, 1979, p. 52). Como es sabido, esta perspectiva será continuada y desarrollada hasta su máxima expresión en la posición escéptica de David Hume, para quien
} 
VI) Debido a que los cánones permiten la eliminación de las hipótesis causales equivocadas sólo cuando disponemos de un conjunto de hipótesis alternativas que incluyen a la hipótesis verdadera y, considerando que nunca podemos estar seguros de que nuestra enumeración ha sido exhaustiva, por lo tanto "los cánones de la investigación experimental no pueden demostrar jamás, pues, ninguna ley causal" (Cohen y Nagel, 1961/1990: 90).

VII) La afirmación de que los cánones pueden demostrar con certeza conexiones causales reposa en la suposición ontológica de la uniformidad de la naturaleza, cuya validez no puede ser establecida a priori y, por lo tanto, obstaculiza la justificación de toda inferencia inductiva. Así formula Mill este principio: "...hay en la naturaleza casos paralelos; tal que lo que sucede una vez, volverá a suceder, bajo un grado suficiente de semejanza de las circunstancias [...] Esto, digo, es una suposición involucrada en cada caso de inducción." ${ }^{411}$ (Mill, 1843: 224). Mill reconoció que exigirle al principio de uniformidad de la naturaleza (o ley de causalidad universal ${ }^{412}$ ) una justificación empírica, conducía a una paradoja: si dicho principio ha de probarse en la experiencia, entonces ella misma debe ser la conclusión de un argumento inductivo ${ }^{413}$. Intentó, no obstante, demostrar a partir de la enumeración simple que ese principio era necesario, pero hoy sabemos que no tuvo éxito (cf. Losee, 1972/1981: 166). Incluso más: la formulación es sumamente vaga, pues ¿cuál es ese grado suficiente de semejanza al que se refiere Mill? Como esto no está expresado en el principio, toda investigación particular deberá basarse

las relaciones causales no eran más que conjunciones constantes. Mill se posicionó ante esto distinguiendo secuencias causales de secuencias accidentales, e insistió en que una relación causal constituye una secuencia invariable e incondicionada de acontecimientos, admitiendo por lo tanto la posibilidad de que algunas secuencias invariables no sean causales (cf. Mill, 1843: 675).

411 "there are such things in nature as parallel cases; that what happens once, will, under a sufficient degree of similarity of circumstances, happen again [...] This, I say, is an assumption, involved in every case of induction".

${ }^{412}$ Este principio puede formularse de diversas maneras: la naturaleza es uniforme, el universo está gobernado por leyes universales, la misma causa va siempre acompañada del mismo efecto en circunstancias similares, etc. "Pero sea cual fuere su forma -se afirma- la inducción requiere este supuesto. A toda inducción se le puede dar la forma de un silogismo, y el principio de la uniformidad de la naturaleza aparecerá entonces como la 'premisa mayor y última de todas las inducciones"' (Cohen y Nagel, 1961/1990: 91).

${ }^{413}$ Recordemos que es por ello que Popper sostuvo, varias décadas después, que los intentos de justificar la inducción conducían o bien a una regresión al infinito o bien al apriorismo (cf. parte dos). 
en otros criterios para determinar las circunstancias importantes. Además, el principio declara que sólo algunos pares de fenómenos vinculados de ese modo invariante, por lo que en una investigación determinada no podríamos saber cuáles (ya que el principio tampoco lo enuncia). En síntesis, aunque dicho principio fuera verdadero, tampoco nos ayudaría en la demostración de un caso particular de relación causal (Cohen y Nagel, 1961/1990).

VIII) Finalmente, una dificultad del canon de la concordancia es que no nos asegura que el efecto estudiado no tenga más de una causa; y es por esto que Mill consideraba que el método de la diferencia era superior como procedimiento experimental. El canon de la concordancia, entonces, resulta inutilizable cuando tratamos circunstancias en las que están involucradas diversas causas, es decir que un tipo determinado de fenómenos puede ser efecto de diferentes causas en distintas circunstancias. Debido a que esta situación es posible, la inferencia de que un factor es causa del otro debido a la concordancia, no puede ser más que algo probable.

Sin embargo, Mill pensaba que la inferencia de las conclusiones alcanzadas mediante el canon de la diferencia no se veía alterada por existir una pluralidad de causas. Así, sostuvo que si llegamos a una situación en la que podamos aplicar el canon de la diferencia, entonces no hay dudas de que para ese caso la causa interviniente es la delimitada ${ }^{414}$, sin que ello excluya la posibilidad de que en otras circunstancias la causa pudiera ser otra: "...es cierto que al menos en este caso A era, o la causa de a, o una parte indispensable de su causa, aunque la causa que lo produce puede en otros casos, ser en un todo diferente" ${ }^{415}$ (Mill, 1843: 312). Esto, como puede notarse, contradice la propia noción que Mill había asumido de causalidad, entendida como circunstancias que se siguen invariable e incondicionalmente por un tipo de efecto determinado.

\footnotetext{
${ }^{414}$ Para Losee, si bien Mill propuso sus cuatro esquemas inductivos como reglas para la prueba de la conexión causal, "en sus momentos más prudentes, sin embargo, restringió la prueba de la conexión causal a aquellos argumentos que satisfacen el método de la diferencia" (Losee, 1972/1981: 165).

415 "....it is certain that in this instance at least, A was either the cause of a, or an indispensable portion of its cause, even though the cause which produces it in other instances may be altogether different."
} 
Avanzando en su planteo, Mill dividió los casos de causalidad múltiple en dos conjuntos: por un lado casos en los que las distintas causas continúan produciendo sus propios efectos por separado $y$, por otro lado, casos en los que se halla un efecto resultante diferente de los efectos que se producirían aisladamente. A su vez, subdividió este último conjunto en: casos en los que el efecto resultante es la suma vectorial de las causas presentes, y casos en los que el efecto resultante es de diferente tipo que los distintos efectos de las causas por separado (cf. Mill, 1843, libro 3, cap. 10). Cuando se trata de circunstancias que podemos representar como composición de las causas (suma vectorial ${ }^{416}$ ), estamos ante la presencia de un tipo de causas que no puede ser investigado mediante los cánones inductivos. Por ello, concluyó que sus métodos inductivos no eran aptos para los casos de composición de causas: no es posible partir del conocimiento de que ha ocurrido un efecto determinado para proceder inductivamente hasta el conocimiento de sus causas componentes. Por esta dificultad, Mill exhortó el empleo de un método deductivo en la investigación de la causalidad compuesta.

Conviene que subrayemos especialmente esa dificultad que se le presenta al propio Mill cuando se trata de casos en los que hay involucrada más de una causa en la producción de un efecto, pues el ámbito de los fenómenos psicoanalíticos aparece frecuentemente impregnado de este tipo de causalidad. Todo lo que Freud dilucidó en torno a la sobredeterminación constituye, por lo tanto, un punto de desencuentro entre el esquema del inductivismo eliminativo y la causalidad psíquica. Si a ello le sumamos una concepción retroactiva de la causalidad, tal y como fue planteada por Freud, la distancia parece insalvable.

IX) Ya hemos expuesto cómo Mill establecía estrictos cánones para la verificación completa de hipótesis, los cuales trascendían la mera confirmación de sus consecuencias observacionales y pretendían alcanzar la eliminación del resto de las alternativas posibles, de modo que ninguna de ellas implicara el mismo conjunto de fenómenos a explicar. Sin embargo, esta verificación completa a la que aludía Mill en la historia de la ciencia sólo fue respaldada con la lectura de un único ejemplo histórico: la hipótesis newtoniana de una fuerza

\footnotetext{
${ }^{416}$ Considérese que existe un número potencialmente infinito de conjuntos de fuerzas que podrían causar un movimiento resultante determinado.
} 
central inversa al cuadrado de las distancias del Sol a los planetas. Mill creía que Newton había mostrado no sólo que las consecuencias empíricas de su hipótesis eran acertadas sino que, además, ninguna otra hipótesis rival podía explicar tales fenómenos planetarios. Sin embargo, "ni Mill ni Newton propusieron una prueba de que las alternativas examinadas agotasen los posibles modos de dar cuenta de los movimientos de los planetas" (Losee, 1972/1981: 162). De ello podemos concluir que la completa eliminación de las hipótesis rivales parece más un ideal regulativo del modelo inductivista ${ }^{417}$ que algo inherente a la práctica de la investigación. ¿Es justo, entonces, demandárselo al psicoanálisis?

X) Cuando a los cánones de Mill se los interpreta estadísticamente, se suele investigar la correlación entre variables. Pero, para fenómenos como los de las ciencias sociales, la búsqueda de relaciones causales resulta limitada por el hecho de que las cadenas causales probabilísticamente se irán disolviendo: "si pasamos de $A$ a $B$, luego de $B$ a $C$ y de $C$ a $D$, indudablemente la correlación de $A$ a $D$ se irá debilitando, pues empiezan a acumularse pasos probabilísticos que disminuyen la certeza" (Klimovsky e Hidalgo, 1998/2012: 172).

Las anteriores objeciones han llevado a rechazar las afirmaciones de Mill respecto a sus cánones: ellos no parecen ser los únicos métodos posibles para inventar hipótesis causales ni, mucho menos, métodos demostrativos de las mismas.

La utilización que hace Grünbaum de estos procedimientos, cuando analiza la teoría de Freud, muestra muy bien sus falencias inherentes. Los métodos de Mill permiten eliminar hipótesis alternativas sólo cuando se han identificado antes los fenómenos causalmente relevantes sobre la base de hipótesis previas: si esa identificación es apropiada, entonces los cánones sí permitirían arribar a una eliminación de los factores no causales. Pero, como hemos visto antes, Grünbaum analiza simplificada o tendenciosamente los factores

\footnotetext{
417 Popper advirtió en su célebre Logik der Forschung otra dificultad de este ideal: "el único propósito de la eliminación defendida por todos aquellos inductivistas era el de estatuir lo más firmemente posible la teoría superviviente, la cual -según pensaban- tenía que ser la verdadera (o, tal vez, solamente una sumamente probable, ya que podríamos no haber logrado completo éxito en la eliminación de toda teoría a excepción de la verdadera). Mas, contra esta opinión, no considero que podamos nunca reducir seriamente el número de teorías competidoras por eliminación, ya que dicho número es siempre infinito". (Popper, 1934/1980: 391; cursivas del original).
} 
relevantes implicados en la concepción freudiana de la causación de los fenómenos psíquicos. De ahí que la puesta a prueba que él hace de, por ejemplo el argumento de la coincidencia y sus consecuencias, esté mal planteada de base.

Debido a que en su conjunto los cánones de Mill describen el proceder general de la técnica experimental controlada ${ }^{418}$, hay todavía razones más contundentes para rechazar su aplicabilidad irrestricta en el ámbito de los fenómenos humanos y, específicamente, en el dominio psicoanalítico.

\section{b) Otra metodología para los fenómenos humanos}

En La lógica de las ciencias morales ${ }^{419}$ (libro VI de Un sistema de lógica) Mill se dedica a analizar aspectos metodológicos de las ciencias sociales; y lo hace guiado por una intuición metodológica fundamental que podríamos catalogar de programática: "solamente podremos remediar el estado de atraso de las ciencias morales aplicándoles los métodos de la ciencia física, adecuadamente extendidos y generalizados" (Mill, 1873/2010: 51). Pese a esta tendencia monista, Mill consideró las dificultades que imposibilitan la aplicación de sus cánones al ámbito de lo social y terminó proponiendo un abordaje que se aparta de los cánones inductivos: la combinación de investigación empírica y deductivismo es lo que constituye el método histórico o método deductivo inverso, propio de las ciencias sociales. Mill consideró que el científico social no debería imitar los procedimientos de la geometría, pues lo que ocurre en la sociedad siempre está supeditado a la situación histórica de un momento determinado; ni tampoco debería adoptar el experimentalismo de la química, pues no hay manera de calcular el efecto conjunto de diversas tendencias sociales. Lo que sí le es lícito hacer al científico social es comenzar examinando la sociedad directamente y elaborar generalizaciones (tendenciales o estadísticas) basadas en los datos de la historia o del presente,

\footnotetext{
418 Recordemos que Grünbaum parece tener por ideal metodológico a los ensayos de dobleciego, utilizados comúnmente para evaluar el efecto placebo en farmacología y psiquiatría (cf. Grünbaum, 1993: 69-106).

${ }^{419}$ Al entender de Mill, las ciencias morales son aquellas áreas del conocimiento que no tienen carácter normativo (ética o moralidad) ni carácter físico (fisiología), tales como la psicología, la etología o ciencia de la formación del carácter, la sociología, la historia y la economía política.
} 
para luego mostrar cómo esas generalizaciones son precisamente lo que nuestro conocimiento de las leyes fundamentales de la mente y el carácter lleva a esperar. Son derivadas de ellas o, al menos, no entran en contradicción con ellas.

Mill ve al ser humano como influyente e influido por los hechos sociales, por lo que la elección es un aspecto propio de la realidad social que no aparece en ningún otro contexto de la realidad natural. Este hecho, la existencia de autodeterminación junto con la de regularidades, contribuye a la pluralidad de causas de lo social ${ }^{420}$.

\section{c) El problema de los motivos causales}

Si consideramos que para las ciencias de lo humano, como el psicoanálisis, es necesario asumir la existencia de motivos, también debemos subrayar que los cánones inductivos de Mill no son compatibles con esta ontología. Más adelante abordaremos este problema con mayor detalle, pero por ahora nos basta decir que los motivos pueden considerarse un tipo de hipótesis causal, sobre entes no observacionales, que esgrimimos para explicar lo que observamos. Así planteada la relación causal, notamos que no se ajusta a una relación entre observables, como las que los cánones de Mill supuestamente pueden ayudar a establecer; ni tampoco se parte de la necesidad de distinguir cuál es el factor causal, debido a que ya se supone, en el momento en el que se lo hipotetiza, que un motivo es un factor causal de lo que empíricamente requiere explicación. El modo de investigación propuesto por los cánones de Mill no puede, por lo tanto, presentar una base adecuada para las hipótesis interpretativas que orientan el proceso clínico. James Hopkins, recordando que el canon de la concordancia nos permite inferir que A no es la causa de B si A ocurre $\sin B$, ejemplifica esa peligrosidad de la siguiente forma: "a veces, quienes están hambrientos (incluso desesperadamente hambrientos) no

\footnotetext{
${ }^{420}$ Mill (1873/2010: 69) afirma que "...aun si nuestra ciencia de la naturaleza humana fuese teóricamente perfecta, es decir, si pudiéramos calcular cualquier carácter como podemos calcular la órbita de cualquier planeta, a partir de los datos dados aun así, como los datos no están nunca totalmente dados, ni nunca son totalmente iguales en casos diferentes, no podríamos hacer ni predicciones positivas ni establecer proposiciones universales". Esto es así porque "en los fenómenos sociales la composición de las causas es la ley universal" (ibíd. p. 107).
} 
comen, y quienes tienen sed no beben; por lo tanto, contra lo que puede suponerse, el hambre y la sed no son causa del comer y el beber" (Hopkins, 1993/1996: 154). Evidentemente con este proceder no hemos podido cernir la función del motivo, en tanto agente causal, de los fenómenos observados. Y sería equivocado suponer que los motivos no pueden dar lugar a explicaciones debido a que no se avienen a ser evaluados mediante el inductivismo eliminativo. Hay que decir, sin embargo, que Grünbaum no se propone una utilización trivial de los cánones inductivos (como parece ser el caso en el ejemplo de Hopkins), pero lo cierto es que él tampoco nos ofrece una explicación sobre la manera en la que este esquema podría ser utilizado y, el mismo tiempo, evitar tales dificultades.

Los motivos formarían parte, siguiendo la clasificación de Mill, de aquellos fenómenos sociales en donde se produce una complejidad de las causas, sin que podamos establecer leyes causales universales. Ahora comprendemos mejor el porqué de la necesidad de Grünbaum, al inicio de The foundations of Psychoanalysis, de desdeñar toda referencia a la hermenéutica y, por lo tanto, a la presencia de factores causales como los motivos y las razones.

En virtud de todas las limitaciones que los cánones de Mill han mostrado tener y considerando que el propio Mill desaconsejaba su utilización para las ciencias de los fenómenos humanos, cabe preguntarnos: ¿qué le permite a Grünbaum basar su análisis epistemológico de la teoría freudiana en este inductivismo eliminativo, sin miramiento alguno por las restricciones y salvedades consideradas ${ }^{421}$ ?

\footnotetext{
${ }^{421}$ En una reseña de su libro principal Grünbaum declara, al pasar, que él analizó los argumentos de Freud mediante los cánones del inductivismo eliminativo porque esas eran las normas que el vienés consideraba validatorias del psicoanálisis; pero que eso no implica que él, Grünbaum, considere que ese "...es el criterio de demarcación entre ciencia y no-ciencia" (Grünbaum, 1986a: 220) ["...imply that I consider it the criterion of demarcation between science and nonscience"]. ¿Qué pensar de ello? O bien que Grünbaum ejerce de abogado del diablo o bien que sabía perfectamente cuáles eran las limitaciones del inductivismo eliminativo que había omitido incluir en su aplicación al psicoanálisis y por eso guardó cierta distancia. Al orientarnos por lo segundo, también se vuelve más comprensible por qué Grünbaum allí no aborda directamente la tradición inductiva y sus argumentos, sino que se limita a referir una serie de consideraciones que nunca desarrolla.
} 


\section{d) Problemas de la aplicabilidad del inductivismo eliminativo al psicoanálisis: presupuestos filosóficos incompatibles}

La perspectiva de Grünbaum bien puede ser incluida en la tradición positivista de la filosofía de las ciencias. Dicha tradición, como es bien sabido, ha defendido la tesis del monismo metodológico, es decir la afirmación de la unidad del método de las ciencias a pesar de la diversidad de objetos, temas y problemas de la investigación científica. A su vez, el positivismo siempre ha sostenido la idea de que las ciencias naturales exactas, fundamentalmente la física experimental, establecen el canon metodológico ideal que debe utilizarse como parámetro para evaluar los desarrollos en el resto de las disciplinas con pretensiones de cientificidad. Estas dos asunciones han desembocado en una tercera, igual de fundamental: la explicación científica consiste en la subsunción de fenómenos individuales bajo leyes generales, y eso vale tanto para el dominio de las realidades naturales como sociales. El conocimiento científico, así entendido, tiene un interés fundamentalmente dominador: aspira al control y predicción de la realidad.

Teniendo en cuenta lo anterior, los problemas que conlleva la adopción del canon metodológico de Grünbaum respecto del psicoanálisis no son diferentes de los problemas que implica la adopción de ese punto de vista en cualquier otra disciplina en la que ocupen un lugar importante los aspectos ideográficos de su objeto de estudio, o en la que se destaquen las explicaciones que incluyan algún tipo de teleología y, sobre todo, aquellas que hagan uso de procedimientos metodológicos que no provengan de las ciencias naturales idealizadas.

Sin embargo no todo es tan sencillo, pues el psicoanálisis, como es también sabido, nace y se desarrolla bajo la tensión cruzada de las tendencias naturalistas y hermenéuticas: Freud bascula entre el causalismo y el teleologismo ${ }^{422} \mathrm{o}$, al menos, su posición teórica implica casi siempre elementos de ambas perspectivas.

\footnotetext{
422 George Von Wright, por ejemplo, afirma que tanto Marx como Freud oscilan entre una orientación causalista, propia del cientificismo, por un lado, y una orientación hermenéutica o teleológica, por el otro. En la obra de Freud "una explicita búsqueda científico-natural de explicaciones causales frustra a menudo el desarrollo de una tendencia de pensamiento implícita hermenéutica y teleológica. Con uno y otro autor se tiene la impresión de que su pensamiento se vio hasta cierto punto lastrado y pervertido por el «galileanismo» dominante en
} 
El problema con el inductivismo eliminativo de Grünbaum es que se trata de un criterio metodológico que pareciera pretender prescindir de cualquier tipo de consideraciones ontológicas, aunque, sin embargo, resulta firme e implícitamente apoyado en una serie de suposiciones fisicalistas. Coincidimos con Jorge Ahumada en que "lo habitual es que la exigencia de que toda ciencia se modelice sobre la física se plantee en forma encubierta. Grünbaum no es excepción; pero sus criterios de 'causa', 'evidencia', 'garantía', 'líneas de base comprobada' e 'historia natural (de la neurosis)' comportan exigencias fisicalistas no reconocidas" (Ahumada, 1997a/1999: 317). Sabemos de la atracción que lo dado ejerce y cómo eso puede devenir un obstáculo para la imaginación científica (en el sentido de Bachelard, 1948/2000), pero también sabemos que Freud supo trascender esa seducción efectuada por lo empírico e ir más allá en la elaboración teórica. El problema pareciera ser aquí el de distinguir qué estatuto ontológico da Freud a los entes metapsicológicos que postula para explicar los fenómenos que le interrogan, ya que el inductivismo eliminativo de Grünbaum pareciera implicar una posición eminentemente realista. Pero, ¿adoptaba Freud siempre un posición realista?, ¿en qué sentido? Más adelante abordaremos este asunto.

Por otro lado, en lo que a la causalidad respecta, Grünbaum parece suponer que el inductivismo eliminativo permite capturar la estructura causal común a cualquier tipo de fenómeno, pero él no explicita qué concepción de la causalidad mantiene ni tampoco se preocupa por la especificidad que este tópico supone en el dominio de los fenómenos clínicos ${ }^{423}$. En ese sentido, su propuesta parece continuar el espíritu del pensamiento de Mill: como ya expusimos, el filósofo británico mantuvo una concepción fenomenalista de la causalidad, sin inmiscuirse en los problemas metafísicos que esta o cualquier otra asunción conlleva ${ }^{424}$. El problema de esta postura es evidente: las

la ciencia y en la filosofía de la ciencia (positivismo) de su tiempo." (von Wright, 1971/1979: 25, n. 27).

${ }^{423}$ De hecho, su posterior abordaje de la noción de insight presenta una serie de problemas derivados de este desconocimiento, como por ejemplo la suposición de que identificar un insight requiere autentificar el evento pasado "neurogénico" (Grünbaum, 1993: 233), o la creencia de que el psicoanálisis peligra ante la asunción del "riesgoso supuesto de la indispensabilidad causal del insight psicoanalítico" (ibíd. p. 139).

${ }^{424}$ Mill lo dice así: "Cuando [...] menciono la causa de algún fenómeno, no me refiero a una causa que no sea en sí misma un fenómeno; no hago ninguna investigación sobre la causa 
ineliminables suposiciones filosóficas se cuelan inadvertidamente sin ser cuestionadas.

En el siguiente ejemplo podemos apreciar cómo Grünbaum intenta aplicar los cánones inductivistas para formalizar la metodología temprana de Freud: ...el meollo del argumento inductivo [de Freud y Breuer] para inferir la etiología represiva se puede formular de la siguiente manera: la eliminación de un síntoma histérico $S$ mediante el levantamiento de una represión $R$ es evidencia convincente de que la represión $R$ era causalmente necesaria para la formación del síntoma $S[\ldots]$. Porque si una represión actual $R$ es causalmente necesaria para la patogénesis $y$ la persistencia de una neurosis $N$, entonces la eliminación de $R$ debe conllevar la erradicación de $N$. Por lo tanto la etiología inferida brindó una explicación deductiva de la supuesta eficacia terapéutica de las represiones deshechas. ${ }^{425}$ (Grünbaum, 1984: 179; cursivas del original).

Esta formalización muestra a las claras la pregnancia de los cánones de Mill. En base a ellos Grünbaum asegura que el edificio teórico y terapéutico de Freud descansa en "dos inferencias inductivas cardinales" (ibíd. p. 177), que él formaliza bajo el argumento TCN que ya hemos expuesto y rechazado. Ahora estamos en condiciones de postular que el principal problema con esa formalización consiste en la desestimación de los reparos que el propio Mill antepuso a la aplicación de los cánones inductivos para los fenómenos de lo humano. Vale la pena retomar este aspecto y recordar que, en virtud de la complejidad de las causas intervinientes en los fenómenos de lo humano,

última u ontológica de algo [...] las causas de las que me ocupo no son las eficientes sino las físicas." (Mill, 1843: 236) ["when [...] I speak of the cause of any phenomenon, I do not mean a cause which is not itself a phenomenon; I make no research into the ultimate or ontological cause of anything. [...] the causes with which I concern myself are not efficient, but physical causes"]. Mill también sostuvo algo que Grünbaum terminará recuperando en su juicio adverso sobre el método psicoanalítico: "la observación [...] sin experimento [...] puede detectar regularidades y correlaciones, pero no puede probar causalidad" (Mill, 1843: 277) ["Observation, in short, without experiment (supposing no aid from deduction) can ascertain sequences and co-existences, but can not prove causation."]

425 "...the nub of their inductive argument for inferring a repression etiology can be formulated as follows: the removal of a hysterical symptom $S$ by means of lifting a repression $R$ is cogent evidence that the repression $R$ was causally necessary for the formation of the symptom $S$ (S.E. $1893,2: 7)$. For if an ongoing repression $R$ is causally necessary for the pathogenesis and persistence of a neurosis $N$, then the removal of $R$ must issue in the eradication of $N$. Hence the inferred etiology yielded a deductive explanation of the supposed remedial efficacy of undoing repressions." 
Ninguna causa es suficiente por sí misma para producir cualquiera de esos fenómenos, mientras que hay causas innumerables que tienen alguna influencia sobre ellos, y que pueden cooperar ya sea para producirlos, ya sea para impedirlos. Aunque seamos capaces de eliminar algunas circunstancias, no por ello podemos de ninguna de las maneras inferir que dicha circunstancia no sea instrumental para el efecto analizado precisamente en alguno de los casos en que to hemos eliminado. Podemos concluir que el efecto se produce a veces $\sin$ aquella circunstancia, pero no que cuando esté presente no vaya a contribuir con su correspondiente aporte. (Mill, 1873/2010: 113).

La formalización que realiza Grünbaum y la conclusión que de allí desprende (las principales hipótesis causales del psicoanálisis no pueden ser establecidas confiablemente), además de basarse en una historización desacertada del itinerario metodológico de Freud, desestima los reparos originales que ya el propio Mill había tenido respecto a la aplicabilidad de sus cánones para el ámbito de los fenómenos humanos ${ }^{426}$. El filósofo británico sostiene claramente que

El proceso de la ciencia consiste en inferir efectos desde sus causas, pero con frecuencia no tenemos medios de observar las causas, excepto por medio de sus efectos. En tales casos la ciencia deductiva es incapaz de predecir los efectos, pues carece de los datos necesarios. Puede determinar qué causas son capaces de producir un determinado efecto, pero no con qué frecuencia y en qué cantidades existen aquellas causas. (Mill, 1873/2010: 141)

Asumiendo que gran parte del psicoanálisis freudiano debería ser incluido entre las moral sciences de Mill, pareciera ser que, por lo tanto, los cánones de la inducción eliminativa resultan insuficientes para una correcta evaluación de sus hipótesis causales.

Detengámonos brevemente en un comentario de Popper sobre este asunto. Popper, luego de la publicación del libro de Grünbaum (1984), se permite criticar las objeciones que este último efectúa a su idea de la incontrastabilidad de las teorías freudianas. Haciendo uso extensivo del diletantismo a que nos tiene acostumbrados en materia psicoanalítica, Popper esgrime una respuesta confesando: "no he leído la obra en la que Grünbaum ha tratado de refutar este

\footnotetext{
${ }^{426}$ Esto le da la razón a Freud cuando dice que "los hombres no siempre toman en serio a sus grandes pensadores, aunque presuntamente los admiren mucho" (Freud, 1921b/2004: 87).
} 


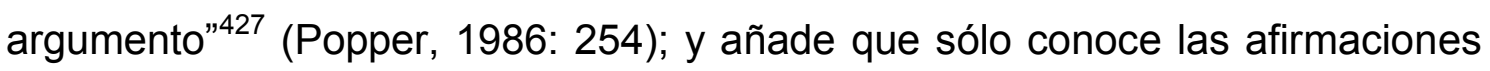
de Grünbaum por intermediarios ${ }^{428}$. Pese a esta insolente desprolijidad, su breve respuesta encierra algo que no resulta tan disparatado. El filósofo vienés analiza una formalización equivalente a la que arriba citamos de Grünbaum:

(A) Si la gente no reprime sus experiencias traumáticas, entonces no devienen víctimas de la neurosis. (B) Si la gente en la infancia está protegida de las experiencias traumáticas, entonces no se espera que se vuelvan neuróticas. [...] (A) y (B) son enunciados con la forma 'si, entonces', pero es imposible contrastarlos, ya que eso exigiría que nos aseguremos de que la parte 'si' (el antecedente) sea verdadero (lo cual casi nunca es posible) incluso siendo la parte 'entonces' falsa en lugar de verdadera (cosa que los psicoanalistas probablemente afirmarán de todas formas) [...] Así que tenemos dos problemas: (1) ¿Quién decide si el posible paciente ha sufrido y "reprimido" un "trauma" o no? Evidentemente no hay conducta manifiesta alguna que permita hacerlo. El otro problema es, por supuesto: (2) ¿Quién decide si el posible paciente es o no es en la actualidad neurótico? Sólo si no fuera neurótico la predicción resultaría comprobable. [...] Pero el psicoanálisis, incluyendo a Freud, a menudo ha afirmado que todo el mundo es neurótico (en mayor o menor grado). Entonces, ¿cómo pueden $(A)$ o $(B)$, cuya capacidad de prueba depende de la predicción de la neurosis no producida, ser claramente comprobable? ${ }^{429}$ (ibíd.).

Lo que Popper está intentando mostrar es que el argumento de Grünbaum falla porque no hay posibilidad de establecer de manera unívoca y a partir de datos observacionales si ha acontecido la represión o no, o si alguien es neurótico o no. Por ello, la testeabilidad "no puede ser alcanzada pronunciando supuestos

\footnotetext{
427 "I have not read the work in which Grünbaum has attempted to refute this argument..."

${ }^{428}$ Alrededor de dos meses después de la aparición de The Foundations of Psychoanalysis, la sección de Ciencia del New York Times del 15 de enero de 1985 presentó un artículo detallado en el que se reportó el desafío de Grünbaum a Popper. A continuación, allí se citó también la respuesta que Popper dio a través del periodista Daniel Goleman, sin haber leído el libro.
}

429 "(A) If people do not repress traumatic experiences, then they will not become victims of neurosis. (B) If in childhood people are protected from traumatic experiences, then they are not expected to become neurotic [...] (A) and (B) are if-then sentences, but it is impossible to test them, for this would demand that we make sure that the 'if' part (the antecedent) is true (which is hardly ever possible) even if the 'then' part is false rather than true (which psychoanalysts are likely to assert anyway)." 
u ocultos estados, como 'represión' o 'trauma' o 'neurosis'; estados cuya hipotética presencia o ausencia no puede ser probada" ${ }^{430}$ (ibíd. p. 255).

A pesar de que Popper no tiene razón en lo que dice, porque si bien es cierto que términos como neurosis o represión encierran cierta complejidad referencial, ello no quiere decir que su referencia no pueda ser estipulada y su presencia claramente discernida ${ }^{431}$. De todas formas, lo que interesa destacar aquí es que esa objeción a Grünbaum termina apuntando algunas cuestiones fundamentales que merecen ser traídas a primer plano: el problema del tipo de variables involucradas en las explicaciones clínicas y el asunto de la referencia ontológica de los términos teóricos de Freud. Lo que denuncia Popper nos permite pensar la dificultad de establecer variables discretas con referencia unívoca a fenómenos observables, a la manera en la que se estipulan en los fenómenos materiales de las ciencias naturales ${ }^{432}$. Grünbaum, comprometido con ello, pareciera lanzarse al mundo de la subjetividad asumiendo la posibilidad de identificar estados subjetivos con observables empíricos. Sin embargo, en disciplinas como el psicoanálisis, en donde es central la intervención de fenómenos relacionales y de sentido, su determinación no puede establecerse sino por medio de la intersubjetividad de los participantes $^{433}$. Pero esta dificultad es efecto de la extrapolación de un criterio de evaluación de las relaciones causales que no ha sido formulado originalmente para el dominio de los fenómenos mentales sino para el dominio

\footnotetext{
430 "...cannot be achieved by speaking of alleged or hidden states, such as 'repression' or 'trauma' or 'neurosis', states whose hypothetical presence or absence cannot be tested..."

${ }^{431}$ Cabe señalar que Silvia Bleichmar, en nuestro ámbito rioplatense, ha desarrollado una concepción de la constitución subjetiva partiendo de la suposición de que los conceptos que denotan momentos fundantes del psiquismo (p.ej. represión originaria) tienen referencia empírica determinable, es decir que refieren a tiempos y procesos clínicamente cercables (Bleichmar, 1993).
}

432 Esto ha sido denunciado por Wurmser, quien afirma que Grünbaum "...describe las cuestiones científicas en términos de un absoluto 'o bien esto o bien aquello', pero nunca en términos de causas parciales ni de éxitos parciales, en términos de 'más o menos' o de 'así como también'." (Wurmser, 1989: 224). ["He describes scientific issues in terms of an absolute either-or, never in terms of partial causes and partial success, in terms of 'more or less' or 'as well as"']. Esta cualidad disyuntiva que impregna su pensamiento, junto con la predilección por las causalidades lineales, le impide a Grünbaum captar la "causalidad del conflicto" que caracteriza la complejidad de los esquemas explicativos freudianos.

${ }^{433}$ Ricœur parece tener razón en que "Ios hechos en psicoanálisis no son de ninguna manera hechos de comportamiento observable" (Ricœur, 1977/2009: 19). 
de los fenómenos físicos. Incluso, como luego veremos, de aquellos sectores que pueden modelizarse como sistemas cerrados, entre los cuales no podríamos ubicar actualmente a lo psíquico. Entre las dificultades más notorias de esa extrapolación causal, cabe destacar las siguientes: por un lado, el fallido intento de delimitar temporalmente una variable causal bajo la suposición ceteris paribus, lo cual resulta difícilmente aceptable para los fenómenos humanos $^{434}$. A su vez, tampoco es posible asumir respecto del devenir de todas las relaciones entre todas las entidades involucradas en las explicaciones de lo humano, el conocido principio de la uniformidad de la naturaleza. Ambas suposiciones contribuyen a que Grünbaum pretenda modelar procesos psíquicos complejos, tales como el desarrollo de una neurosis, en términos de una relación biunívoca e invariante entre hechos fijos fácticamente acontecidos y fenómenos empíricos (signos), conectados en una historia natural del mismo modo en que se conectan acontecimientos físicos en un sistema cerrado. Resulta curioso que Grünbaum omitiera los reparos específicos de Mill para la aplicación de su método de acuerdos y diferencias; pues para su creador, éste procedimiento sólo es viable para aquellos casos que difieren en un solo factor causal y excluye de entrada, por lo tanto, a los seres vivos. Como veremos luego, la noción de causalidad presente en Freud dista mucho de esa simplificación.

Cabe recordar que este asunto ya había sido abordado por Robert Waelder (1962), quien había discutido la postura de Ernest Nagel (1959/1964) en el célebre Simposio de Filosofía y Psicoanálisis de la ciudad de New York de 1958, destacando lo siguiente: la validación de afirmaciones causales mediante estudios longitudinales prospectivos con control experimental demanda la utilización de variables simples y discretas que no se modifiquen cualitativamente durante la recolección de los datos; situación que sólo ocurre en las ciencias exactas o en las parcelas galileico-newtonianas de la ciencia natural $^{435}$.

\footnotetext{
${ }^{434}$ Dicha cláusula suele acompañar las explicaciones nomológico-deductivas afirmando que, dadas ciertas circunstancias que se especifican, se producirán ciertos efectos siempre que se mantengan iguales el resto de las condiciones. Esto último es lo difícil de asegurar en los fenómenos que abordan las ciencias de lo humano.

435 "Esta condición no siempre se cumple en el estudio de los organismos vivos; por ejemplo; $p$. ej. un virus puede cambiar rápidamente su virulencia. En nuestro propio campo, el paciente
} 
Respecto del segundo aspecto señalado, la referencialidad de los términos teóricos, más adelante mostraremos que la preconcepción que el vienés adopta en la construcción y utilización de sus conceptualizaciones no siempre es de tipo realista, sino que muchas veces implica un posicionamiento basculante y que por momentos puede considerarse antirrealista. Cuando ello acontece, los conceptos psicoanalíticos se esgrimen siguiendo un criterio pragmático de explicación y no, como Grünbaum parece creer, aspirando a un isomorfismo entre fenómenos observables e inobservables.

Fiel al espíritu positivista ${ }^{436}$, Grünbaum entiende que el método es prioridad respecto del objeto y de los problemas a investigar. Incluso puede decirse que su lectura de Freud es una construcción que reduce la complejidad del pensamiento del vienés a lo que su perspectiva metodológica inductivista le permite procesar. Por esto, entre otras cosas, André Green califica a Grünbaum como "un lógico perdido en el psicoanálisis" y considera que,

en realidad, él supone, sin otra forma de proceso, que todo conocimiento, cualquiera que sea su objeto, debe ser conforme a la única metodología que la ciencia le permite concebir, con exclusión de la idea de que la estructura del objeto pueda imponer un cuestionamiento de esa metodología (Green, 1991/1993: 186).

Grünbaum acuesta de ese modo a Freud en su lecho inductivista de procusto y procede a cercenar, por omisión, todo aquello que rebase incómodamente. Como asume implícitamente una restricción de la noción de causalidad en términos lineales, los fenómenos de sentido sólo parecen ser valorizados por Grünbaum cuando revisten una dimensión causal susceptible de traducirse en predicciones rigurosas y generalizables, las cuales parten de variables

vivo ante nosotros está cambiando constantemente. Las psiconeurosis parecen haber cambiado desde los primeros días del psicoanálisis..." (Waelder, 1962: 625) [This condition is not always met in the study of living organisms; e.g., a virus may change its virulence quickly. In our own field, the living patient before us is changing constantly. The psychoneuroses seem to have changed since the early days of psychoanalysis..."].

${ }^{436}$ Élizabeth Roudinesco lo describe como "el principal representante norteamericano del antifreudismo de inspiración cientificista" (Roudinesco, 1999/2000: 82). Grünbaum contesta que, a pesar de esta etiqueta, "...ella no se digna a enfrentarse con cualquiera de mis críticas a las ideas de Freud. Tampoco está equipada para hacerlo." (Grünbaum, 2006: 259) [she does not deign to come to grips with any of my criticisms of Freud's ideas. Nor is she equipped to do so]. Lo cierto es que Roudinesco no fundamenta su acusación más allá de algunas afirmaciones presunciosas y sin debatir argumentos. Aquí intentamos no reproducir esa postura. 
homogéneas que pueden entonces ser tratadas como cualquier otro factor causal material y con los mismos procedimientos que en las ciencias naturales experimentales $^{437}$.

En términos generales, entonces, debemos explicitar algo que Grünbaum no discute pero que constituye el fundamento de su crítica al psicoanálisis: una correcta implementación del inductivismo eliminativo supone la adopción de algunos supuestos ontológicos inherentes a la concepción tradicional de la ciencia natural. Es decir que al aplicar esa metodología, Grünbaum transfiere a su consideración de los fenómenos mentales, por ejemplo, el elementarismo y el determinismo (ya presentes en el asociacionismo de Mill) tradicionalmente adjudicados a los eventos de la naturaleza inerte. Al mismo tiempo, desde el punto de vista epistémico, se filtran algunos supuestos típicos del conocimiento y la formalización de los fenómenos naturales, tales como el reduccionismo y el empirismo. La pretendida aplicabilidad irrestricta del inductivismo de Grünbaum a los fenómenos psicoanalíticos soslaya la especificidad diferencial que los caracteriza, impidiendo capturar lo que ellos encierran de cualitativamente distintivo con respecto a otros fenómenos de lo humano ${ }^{438}$. Recordemos que

\footnotetext{
${ }^{437}$ Ahumada acierta al afirmar que, "en su exigencia de especificidades, Grünbaum modela su idea de la causalidad de neurosis según el patrón de la microbiología de Koch [...] Pero aunque cite que tempranamente Freud hizo una analogía de neurosis y tuberculosis, los agentes patógenos de Koch divergen de los psíquicos: son especies extrañas de organismos, en tanto que los patógenos psíquicos son eventos afectivos relevantes con otras personas, intraspecíficos, que impactan en la realidad psíquica..." (Ahumada, 1997a/1999: 324). Aunque Ahumada no lo cite, en Inhibición, síntoma y angustia Freud desestimó especialmente esa analogía etiológica: "Es muy de lamentar que siempre quede insatisfecha la necesidad de hallar una "causa última» unitaria y aprehensible de la condición neurótica \{Nervositat\}. El caso ideal, que probablemente los médicos sigan añorando todavía hoy, sería el del bacilo, que puede ser aislado y obtenerse de él un cultivo puro, y cuya inoculación en cualquier individuo produciría idéntica afección. O algo menos fantástico: la presentación de sustancias químicas cuya administración produjera o cancelara determinadas neurosis. Pero no parece probable que puedan obtenerse tales soluciones del problema". (Freud, 1926c/2004: 143-144). Hacia el final de su obra expresó esta misma idea sin mayores sutilezas: "las neurosis no tienen (a diferencia, por ejemplo, de las enfermedades infecciosas) causas patógenas específicas" (Freud, 1940/2004: 183).

${ }^{438}$ En el epílogo de su libro principal, Grünbaum pareciera llegar a reconocer que la explicación freudiana de los actos fallidos es, pese a no adecuarse a su canon metodológico predilecto, convincente: "pese a la pobreza de las credenciales clínicas, tal vez puede todavía resultar que la brillante imaginación teórica de Freud fuera, en realidad, bastante casual para la psicopatología o la comprensión de alguna subclase de fallidos." (Grünbaum 1984: 278). ["Despite the poverty of the clinical credentials, it may perhaps still turn out that Freud's brilliant theoretical imagination was actually quite serendipitous for psychopathology or the understanding of some subclass of slips"]. Nuestro filósofo parece utilizar aquí otro criterio para hacer esa concesión: ¿será que él mismo sabía, sin asumirlo enteramente, que es viable evaluar una teorización como la de Freud prescindiendo del inductivismo eliminativo?
} 
Mill, a pesar de desdeñar la discusión metafísica, asumía un compromiso ontológico fuerte: "Ios prodigiosamente complejos Hechos de la Vida pueden ser todos deducibles de leyes relativamente simples"439 (Mill, 1843: 269), suposición que también considera "igualmente cierta respecto de los fenómenos mentales"440 (ibíd.). A nuestro modo de ver, el método de las concordancias y las diferencias, tan comúnmente utilizado en la experimentación y que Grünbaum asume como única vía legítima para discernir las causas, resulta insuficiente para representar los procedimientos que conducen al establecimiento de evidencias en sistemas conceptuales que asumen la complejidad. En virtud de las propiedades emergentes, indiscernibles bajo la lógica de la adición simple, la célebre composición de las causas no equivale a la complejidad de las mismas.

En su lectura de Freud, Grünbaum se esfuerza por mantener la coherencia entre sus compromisos metafísicos implícitos y su concepción epistémica de los procedimientos de validación de las explicaciones causales; pero su intento de extrapolación fracasa porque su tratamiento del psicoanálisis como una ciencia natural omite discutir aquellos aspectos que involucran tanto la pragmática de las explicaciones clínicas ${ }^{441}$ como las dificultades ontológicas de la metapsicología. El criterio de demarcación que Grünbaum esboza ha sido concebido sobre la base de unos presupuestos filosóficos típicamente naturalistas, lo cual dificulta enormemente su implementación en cualquier dominio cognitivo que no mantenga similares presuposiciones; de allí que los conceptos psicoanalíticos, irreductibles a cualquier forma de naturalismo, no puedan pasar satisfactoriamente la prueba a la que él pretende someterlos.

\footnotetext{
439 "...the prodigiously complex Facts of Life may all be deducible from comparatively simple laws of life..."

440 "This will be found equally true in the phenomena of mind..."

441 Recuérdese que Grünbaum mismo reconoce, al discutir el caso de los fallidos "transparentes", que es fácilmente posible reconocer su causa en un anhelo bastante evidente. Ello implica, aunque por razones obvias nuestro filósofo no lo explicite, que es posible establecer elementos causales sin apelar a ningún procedimiento metodológico demasiado especial (como el inductivismo eliminativo) y sin aspirar a la obtención de una generalización empírica (pues esa "causa" vale sólo para ese caso) ni, por supuesto, de una predicción. Este atolladero nos conduce a la conclusión, extraíble de su propia formulación, de que las explicaciones que involucran fenómenos de significación no son susceptibles de reconstruirse bajo el modelo de cobertura legal; pese a lo cual pueden ser convincentes. Es decir, esto constituye una invitación a introducir otros modelos explicativos.
} 
En virtud de lo anterior no parece exagerado decir que Grünbaum yerra al pretender manejar una idea de ciencia que se comporta, paradójicamente dada su raigambre empirista, como una suerte de esencia platónica a partir de la cual se juzgan las teorizaciones de diversos campos de saber, en tanto adecuadas o no a ese ideal. Irónicamente, ésta misma crítica era la que Grünbaum le hacía a Popper:

Un filósofo puede intentar legislar normas de cientificidad y luego dejar que pase lo que pase. Pero la legislación filosófica que está libre de trabas en relación con aquellos fines científicos como la fecundidad, corre un serio peligro: el filósofo que presume de sentarse en el pedestal legislativo puede ser abandonado a contemplar su propio ombligo normativo ${ }^{442}$ (Grünbaum, 1979a: 136).

Mutatis mutandis, nuestra crítica a su inductivismo eliminativo es del mismo talante. Naturalmente, entonces, reconocer que las hipótesis del psicoanálisis no pueden ser evaluadas de ese modo no significa que no puedan ser examinadas de otro modo ${ }^{443}$. A ello nos avocaremos en las partes que siguen.

\footnotetext{
442 "A philosopher can try to legislate norms of scientificality and then let the chips fall where they may. But philosophical legislation that is unencumbered by a concern with such scientific aims as fruitfulness runs a serious risk :The philosopher who presumes to sit on the legislative pedestal may be left to contemplate his own normative navel."

443 Para Lavinia Gomez la desautorización a partir del inductivismo eliminativo resulta insuficiente para determinar que una teoría sea considerada no científica, ya que la falla ante este tipo de pruebas no significa que estemos necesariamente ante una teorización falsa: "esto deja una brecha de incertidumbre entre una teoría que falla las pruebas empíricas a través de resultados negativos y una que al parecer es defectuosa porque no se puede probar de esta manera. El psicoanálisis es ejemplo de una asignatura que cae en esta brecha" (Gomez, 2005: 22). ["This leaves a gap of uncertainty between a theory which fails empirical tests through negative results, and one which apparently falls short because it cannot be tested in this way. Psychoanalysis is an example of a subject falling into this gap."]
} 


\title{
CAPÍTULO 8: Una lectura del problema metodológico de la sugestión en psicoanálisis.
}

\begin{abstract}
W $\mathrm{n}$ virtud de su densa especificidad, hemos decidido abordar por separado los aspectos de la crítica de Grünbaum vinculados al problema de la sugestión del analista. Mostraremos que en el propio desarrollo de las ideas freudianas podemos hallar un preciso abordaje del asunto de la sugestión, que conviene revisar. Al mismo tiempo, es provechoso muñirse de nuevas herramientas conceptuales para complejizar el problema, tendiendo a brindar respuestas cada vez más satisfactorias a planteos como el de Grünbaum. Ambas cuestiones serán analizadas a continuación.
\end{abstract}

\section{1. ¿Es válida la acusación de contaminación epistémica vía sugestión?}

\section{a) Las objeciones de circularidad argumental y de adoctrinamiento}

Freud dice haber asistido a un cambio de opinión en la comunidad científica sobre el asunto, pues se ha pasado de las burlas y renuencias a una "voluntad demasiado solícita"; y ello debido no sólo a los trabajos de Liébeault y Bernheim sino también "porque se descubrió cuán grande ahorro de pensamiento aparejaba el empleo de la consigna «sugestión»" (Freud, 1909a/2004: 85). Pero -agrega el vienés- "nadie sabe ni se cuida de saber qué es sugestión, a qué se debe y cuándo sobreviene; basta con que se pueda llamar "sugestión» a todo lo incómodo en lo psíquico" (ibíd.).

Coincidimos con Sachs en que "la acusación de sugestión, aunque desgastada por el tiempo, no deja de ser irritante" (Sachs, 1993/1996: 376). Podemos ver que, setenta y cinco años después de la reflexión citada, Grünbaum repite una delación que deja intacto el problema señalado por 
Freud: las referencias que adopta no parten de esfuerzo alguno por conocer las características del origen y del funcionamiento de la sugestión, sino que constituyen una acusación vaga y simplificadora de los aspectos involucrados.

El creador del psicoanálisis abordó el tema en tanto que acusación a la fundamentación del conocimiento analítico, y logró elaborar una serie de observaciones defensivas que, mal que le pese a Grünbaum, mantienen una vigente consistencia. Al final de la $27^{\circ}$ conferencia de introducción al psicoanálisis, titulada La trasferencia, luego de vincular la sugestión a la trasferencia, Freud reflexiona sobre el pensamiento de su oyente:

Pero he de detenerme y cederles la palabra. Noto en ustedes una objeción que levanta su cresta con tanta fuerza que los privaría de la capacidad para escuchar si no la dejásemos expresarse: «Conque ha admitido finalmente que usted trabaja con el poder auxiliar de la sugestión como los hipnotizadores. Hace ya tiempo que lo sospechábamos. Pero entonces, ¿para qué todo el rodeo por los recuerdos del pasado, el descubrimiento del inconciente, la interpretación y retraducción de las desfiguraciones, el enorme gasto de esfuerzo, de tiempo y de dinero si lo único eficaz sigue siendo la sugestión? ¿Por qué no aplica usted la sugestión directa contra los síntomas, como lo hacen otros, los hipnotizadores honestos? Y además, en caso de que quiera disculparse por el rodeo que dio invocando los numerosos e importantes descubrimientos psicológicos que así ha logrado y que se ocultan cuando se recurre a la sugestión directa, ¿quién garantiza ahora la certeza de esos descubrimientos? ¿Acaso no son también un resultado de la sugestión, o sea, de la no deliberada? ¿No puede ocurrir que imponga al enfermo, también en este campo, lo que usted quiere y le parece correcto?». (Freud, 1917b/2004: 406).

La defensa freudiana de esa acusación parte de una caracterización precisa de los alcances del fenómeno sugestivo:

La sugestión directa es una sugestión dirigida contra la exteriorización de los síntomas, una lucha entre la autoridad de ustedes y los motivos de la enfermedad. Al practicarla, ustedes no hacen caso de estos motivos; sólo exigen al enfermo que sofoque su exteriorización en síntomas (ibíd. p.408).

Y más adelante agrega:

Esta terapia se encuentra en la más plena armonía con una valoración de las neurosis que es profesada aún por la mayoría de los médicos. El médico dice al neurótico: «Usted no tiene nada, sólo está nervioso; por eso puedo hacerle desaparecer su trastorno en pocos minutos» (ibíd. p.410). 
Es decir, la utilización directa de la sugestión constituye para Freud una forma de eludir las causas del sufrimiento psíquico, tal y como son concebidas por el psicoanálisis. A partir de ello el vienés establece una clara contraposición entre la terapia analítica y la pura sugestión:

La terapia hipnótica busca encubrir y tapar algo en la vida anímica; la analítica, sacar a luz y remover algo. La primera trabaja como una cosmética, la segunda como una cirugía. La primera utiliza la sugestión para prohibir los síntomas, refuerza las represiones, pero deja intactos todos los procesos que han llevado a la formación de síntomas. La terapia analítica hinca más hacia la raíz, llega hasta los conflictos de los que han nacido los síntomas y se sirve de la sugestión para modificar el desenlace de esos conflictos. (ibíd.).

Es el análisis de las resistencias y su superación lo que contribuye a modificar duraderamente la vida anímica del paciente (volveremos sobre esto). En este punto, Freud se hace lúcidamente consciente de la objeción que sale al paso:

Ahora me dirán ustedes que, se llame trasferencia o sugestión la fuerza impulsora de nuestro análisis, persiste de todos modos el peligro de que la influencia ejercida sobre el paciente vuelva dudosa la certeza objetiva de nuestros descubrimientos. Lo que favorece a la terapia es perjudicial para la investigación. Es la objeción que con mayor frecuencia se hace al psicoanálisis, y es preciso confesar que, aun siendo errónea, no es posible desautorizarla por irracional. Pero si fuera correcta, el psicoanálisis no pasaría a ser sino un tratamiento de sugestión muy bien disfrazado y particularmente eficaz, y tendríamos derecho a tomar a la ligera todas sus aseveraciones sobre las influencias de la vida, la dinámica psíquica, el inconciente. Es lo que opinan los oponentes... (ibíd. p. 411).

A esto Freud contesta con lo que Grünbaum ha denominado argumento de la coincidencia, y luego agrega algo importante que "en el fondo" es lo que "separa" al tratamiento analítico de la sugestión:

En cualquier otro tratamiento sugestivo, la trasferencia es respetada cuidadosamente: se la deja intacta; en el analítico, ella misma es objeto del tratamiento y es descompuesta en cada una de sus formas de manifestación. Para la finalización de una cura analítica, la trasferencia misma tiene que ser desmontada $^{444}$; y si entonces sobreviene o se mantiene el éxito, no se basa en la

444 “...trabajo cuya meta será entonces descubrir la elección infantil de objeto y las fantasías que trae urdidas." (Freud, 1915c/2004: 171). 
sugestión, sino en la superación de resistencias ejecutada con su ayuda y en la trasformación interior promovida en el enfermo. (ibíd. p.412).

A Grünbaum le parece que este razonamiento freudiano, en donde se invoca el análisis de la trasferencia para rebatir la acusación de auto-validación, incurre en una argumentación "viciosamente circular":

\begin{abstract}
Está claro que la disección psicoanalítica de la sumisión respetuosa del paciente hacia su doctor presupone ya de antemano la validez empírica de la misma hipótesis cuya espuria confirmación, por medio de las respuestas clínicas del analizando, jera lo que estaba en cuestión desde el principio! ${ }^{445}$ (Grünbaum, 1984: 144).
\end{abstract}

Freud estimó necesario que el analista "torne conciente al enfermo de su trasferencia", pues ella es resuelta "cuando se lo convence de que en su conducta de trasferencia revivencia relaciones de sentimiento que descienden de sus más tempranas investiduras de objeto, provenientes del período reprimido de su infancia" (Freud, 1925b/2004: 40). Para nuestro crítico, dado que ese convencimiento podría deberse a las sugestiones del analista, el modo en que Freud quiere defenderse de la sugestión conlleva a una "petición de principio" (op. cit. p.144).

Grünbaum también llama la atención de una conjunción de aseveraciones freudianas en estas conferencias. La primera aparece en la $28^{\circ}$ conferencia y versa sobre el trabajo de superación de las resistencias: "el médico se lo posibilita mediante el auxilio de la sugestión, que opera en el sentido de una educación" (p. 411). La segunda emerge de la conferencia $27^{\circ}$ : "en la medida en que su trasferencia es de signo positivo, reviste al médico de autoridad y presta creencia a sus comunicaciones y concepciones" (p. 405). Según nuestro crítico, fácilmente puede objetarse que esta conducción del médico es similar a la que realiza un abogado cuando lleva un testigo al tribunal, y que es justamente por ello que el uso educativo de la sugestión posibilita "adoctrinar al paciente" hasta convertirlo en un "discípulo ideológico". Este uso de la transferencia en un sentido educativo, sostiene Grünbaum, proporciona incluso

445 "For clearly, the psychoanalytic dissection of the patient's deferential submission to his doctor already presupposes the empirical validity of the very hypotheses whose spurious confirmation by the analysand's clinical responses was at issue from the outset!" 
más margen de adoctrinamiento que la sugestión directa limitada a los síntomas (Grünbaum, 1984: 137).

Podemos decir que la objeción de Grünbaum es, entonces, doble: por un lado imputa una circularidad / petición de principio en la argumentación freudiana que pretende responder a la crítica de sugestionabilidad; por otro lado, denuncia la imposibilidad de evitar un adoctrinamiento del paciente debido a la relación transferencial. Una vez presentada la doble objeción de Grünbaum $^{446}$, conviene que nos detengamos a analizarla con cierto detalle, para luego expedirnos sobre ella. Posteriormente, sin embargo, todavía deberemos aclarar algunas cuestiones sobre el objeto de la crítica de nuestro autor, para lo cual retomaremos la argumentación freudiana. Intentaremos comprender el razonamiento del vienés recordando la génesis de las nociones de transferencia y resistencia, para mostrar cómo posibilitan explicar lícitamente el lugar de la sugestión en el dispositivo analítico. Expidámonos primero sobre la objeción del filósofo.

\section{b) Las objeciones de Grünbaum están mal fundamentadas}

1) A mi modo de ver, si bien la presentación que hace Grünbaum puede considerarse circular en virtud de su forma, la estructura del razonamiento freudiano no lo es. $Y$ aunque la identificación que Grünbaum hace de la circularidad argumental de Freud es de tipo formal, él quiere hacernos ver allí un problema de fundamentación del conocimiento. Dicho de otra manera, él pasa espuriamente de un problema filosófico relativo a la forma (lógico) a otro problema filosófico relativo al conocimiento (epistemológico), manteniendo la suposición de que la circularidad de uno se traslada al otro. Esto es una evidente falacia, pues el problema lógico que él denuncia es efecto de su propia y tendenciosa formalización. Se trata, podemos decir, de un intento de

\footnotetext{
${ }^{446}$ Casi treinta años antes, refiriéndose a los sueños complacientes, Popper había lanzado una objeción similar: "son, como dice el propio Freud, debidos a la sugestión del propio analista, al hecho de que el analista haya impuesto sus ideas a un paciente sugestionable. ¿No deberíamos considerar seriamente, entonces, la posibilidad de que otras «verificaciones clínicas» de las que les gusta hablar a los analistas, o incluso todas ellas, se deban a un mecanismo de este tipo? Y, la mera posibilidad de tal mecanismo, ¿no invalida tales «verificaciones»? El propio Freud ve este problema y es interesante ver cómo lo trata." (Popper, 1956/2011: 210).
} 
Grünbaum por lograr atinencia entre sus premisas y su conclusión, pues notamos cómo combina aseveraciones freudianas que pertenecen a contextos diferentes de enunciación, a los fines de persuadirnos de la existencia de una circularidad semántica que impediría la fundamentación de sus hipótesis. Si aceptamos que un argumento es algo hecho para convencer, debemos reconocer que el argumento que Grünbaum le adjudica a Freud no ha sido expresado de ese modo por él y que, por lo tanto no es de ese modo que el vienés buscó convencer a sus interlocutores. Esto no es un dato menor, pues nos conduce a la dimensión pragmática que subyace a toda falacia de petición de principio: es fácil elaborar contextos de diálogo en los que un mismo argumento no comete una petición de principio, simplemente porque cambia el contexto de relevancia (cf. Walton, 1994: 128).

Mostraremos cómo, si se amplía la lectura de referencias freudianas, se encuentra una elaboración minuciosa ante el problema de la sugestión que se compone de argumentos contundentes basados en evidencias significativas; cuya reducción al razonamiento que Grünbaum critica como viciosamente circular es efecto de un sesgo tendencioso de selección y simplificación del problema, destinado a persuadir y no a dilucidar.

2) Además, debemos decir que Grünbaum maltrata la formulación del problema lógico que señala, pues parece homologar, equivocadamente, el razonamiento circular con la petición de principio. Aunque existe una conexión innegable entre ambos, no es cierto que todo argumento circular realice, necesariamente, una petición de principio. Posiblemente el mejor ejemplo para ilustrarlo provenga de aquellas explicaciones que adoptan una noción no-lineal de la causalidad, apelando a procesos recursivos en los cuales el efecto retroalimenta la causa y relanza el proceso ${ }^{447}$. Si bien los casos de circularidad virtuosa suelen aparecer en determinadas explicaciones y éstas no serían necesariamente argumentaciones, es muy frecuente transformar una explicación en una argumentación manteniendo esa circularidad. Lo virtuoso de

447 Un ejemplo archiconocido lo conforman las profecías autorrealizativas (a las que más adelante volveremos). A mi gusto, el relato de Gabriel García Marquez "Algo muy grave va a suceder en este pueblo", ilustra perfectamente estas intuiciones y su papel destacado en los fenómenos humanos. Cabe recordar que el positivista Ernest Nagel, en un libro clásico, ya había abordado el problema de las predicciones suicidas y predicciones de autocumplimiento, dejando en claro que ellas también pueden hallarse en las ciencias naturales y que, en ningún caso, impiden el establecimiento de generalizaciones o leyes (Nagel, 1961/2006: 605-614). 
una explicación viene dado por el fructífero feedback de los aspectos coimplicados, que favorece su corrección mutua (propia de toda postura falibilista, no-fundacionista).

¿Cómo ponderar, entonces, la circularidad del argumento freudiano en torno a las nociones de sugestión y transferencia? En los apartados siguientes mostraremos que la reciprocidad de esas nociones no conduce a una petición de principio sino a una circularidad virtuosa (pues describe y explica un proceso que escapa a la causalidad lineal) en la que se evidencia el trabajo teórico a partir de un suelo contrastacional previamente existente. Apropósito de esto, resulta útil recuperar un aspecto importante de la filosofía contemporánea de la ciencia, relativo a la distinción teórico/observacional.

En la actualidad existe un significativo consenso, originado a partir de aportes provenientes de diversas teorizaciones ${ }^{448}$, referido a que la distinción teórico/observacional encierra en realidad dos dicotomías no homologables: teórico / no teórico por un lado, y observable / inobservable, por el otro. Utilizando instrumental de la concepción estructuralista de las teorías científicas podemos distinguir entre términos $T$ teóricos y $T$ no-teóricos, entendiendo que su teoricidad es relativa a cada teoría determinada ( $T$ - teoricidad) y que no puede ser concebida de manera absoluta (Diez \& Lorenzano, 2002). Esto es fundamental para nuestro problema, pues la noción de sugestión que Freud utiliza corresponde al vocabulario preteórico o previamente disponible a la Teoría Psicoanalítica (TP- no teórico), ya que se refiere a un fenómeno que, pese a la histórica vaguedad o complejidad de los conceptos que han intentado aprehenderlo, pertenece a una base empírica compartida con otros saberes. Afirmar que la teoricidad de la noción de sugestión es relativa a otras teorías anteriores a Freud, implica que existan procedimientos de determinación ${ }^{449}$

\footnotetext{
${ }^{448}$ Existen algunos trabajos clásicos que, a pesar de su heterogénea procedencia teórica, han contribuido en conjunto a una redefinición sustancial del problema: Hanson (1958/1977), Maxwell (1962), Putnam (1962), Achinstein (1963), Hempel (1966/1999), Bar-Hillel (1970), Sneed (1971) y Suppe (1972), entre otros.

449 "Determinar un concepto es determinar si se aplica o no a un objeto particular dado, o si es cuantitativo, determinar el valor de la magnitud para el objeto. Los modos para proceder a ello son los procedimientos de determinación de los conceptos. [...] Pues bien, si un concepto es $T$ no teórico, si es "anterior" a $T$, entonces tendrá al menos algunos procedimientos de determinación independientes de $T$; en cambio si es $T$-teórico, si es propio de $T$, su determinación depende siempre de $T$. Un procedimiento de determinación se considera dependiente de la teoría $T$ si presupone la aplicabilidad de $T$, la validez de sus leyes, esto es, si
} 
independientes al psicoanálisis (que no suponen su aplicabilidad); como por ejemplo la hipnosis. La noción de transferencia, por el contrario, es eminentemente teórica en relación a la Teoría Psicoanalítica (TP- teórico), ya que forma parte de su vocabulario teórico y se introduce, entre otras cosas, para llevar a cabo la elaboración conceptual que da cuenta de ese fenómeno preteórico descripto bajo el nombre de sugestión; por lo que transferencia es un término que adquiere su significado, al igual que muchos otros términos teóricos, mediante instancias de uso en contextos particulares de la actividad psicoanalítica.

Todo esto nos lleva a pensar que los términos teóricos de cualquier teoría científica están cargados de teoría, pero no de la misma teoría para la que constituyen su base empírica:

\footnotetext{
...una cosa es que la determinación de los datos de contrastación presuponga 'directamente' la teoría que se quiere contrastar mediante dichos datos (autojustificacionismo local), y otra que tal determinación presuponga otra u otras teorías vinculadas a nivel global de una disciplina, o incluso la ciencia entera, con la teoría original (holismo de contrastación). (Diez y Moulines, 1997: 308).
}

Pretender enredar, como hace Grünbaum, las nociones de sugestión y de transferencia en un razonamiento viciosamente circular, implica un desconocimiento de la base empírica contrastacional que la teoría freudiana delimita en este punto: los fenómenos sugestivos que la medicina de la época intentaba conceptualizar, con sus consecuencias terapéuticas y sus implicancias técnicas, etc. Analizando la argumentación freudiana, Grünbaum quiere hacer pasar un caso de holismo de contrastación por un caso de autojustificacionismo local. Esto encubre las relaciones de bidireccionalidad causal que se establecen entre fenómenos sugestivos y transferenciales, a la vez que tergiversan el esfuerzo freudiano por desentrañarlas.

3) Finalmente, conviene exhibir algo que sí me parece una petición de principio, a saber, la denuncia misma de Grünbaum a la supuesta circularidad

usa o presupone modelos actuales de $T$. La idea es que un concepto es $T$-teórico si no se puede determinar sin presuponer la aplicabilidad de $T$, si todo procedimiento para su determinación la presupone; y es $T$-no teórico si tiene algún procedimiento de determinación $T$ independiente, si es posible determinarlo sin suponer la aplicación de la teoría, por más que también tenga otros T-dependientes." (Diez \& Moulines, 1997: 355; cursivas del original). 
del argumento freudiano. Esto es así porque nuestro filósofo somete a prueba la fundamentación freudiana desde un criterio para el que ya se sabe que resultará débil de antemano. El uróboros de Grünbaum se alimenta de su cola cuando él dispone la forma correcta en la que esa supuesta falla freudiana de circularidad debería subsanarse: son procedimientos experimentales, nos dice, los que resultan más adecuados... ¡desde un punto de vista experimentalista!

Resulta curiosamente llamativo que alguien como Grünbaum, que se ha declarado seguidor de Mill en lo atinente al papel de las inferencias causales, cometa los errores que éste último supo describir y clasificar como falacias evitables. Ya que no parece ser otra cosa que una falacia de no-observación (cf. Mill, 1843; Libro V, cap. IV, § 4) lo que ha llevado a Grünbaum a suponer que la transferencia no constituye un hecho; pues ha intentado erguirse como juez de una argumentación que deriva de un suelo observacional para el que es ciego: el contexto clínico del encuadre psicoanalítico. Mill sostuvo que "la más grande de todas las causas de no-observación es una opinión preconcebida" $^{450}$ (Mill, 1843: 541); y ahora resulta cada vez más claro que la devoción que Grünbaum muestra por el experimentalismo parece haber sido uno de sus obstáculos para prestarle crédito a las observaciones naturales del contexto clínico. Como ya hemos expuesto más arriba las dificultades de pretensión universalista que conlleva su inductivismo eliminativo, resulta bastante evidente que esta petición de principio en la que incurre es, por lo tanto, defecto de sus propios presupuestos filosóficos.

Retomemos ahora la racionalidad de la argumentación freudiana y sus encrucijadas.

\section{c) Transferencia y sugestión}

Recordemos que Freud se lamentaba de que la sugestión aparecía considerada como "un fenómeno primordial no susceptible de ulterior reducción, un hecho básico de la vida anímica de los seres humanos" (Freud, 1921b/2004: 85) y "por eso más tarde mi resistencia tomó el sesgo de una rebelión frente al hecho de que la sugestión, que lo explicaba todo, se

\footnotetext{
450 "But the greatest of all causes of non-observation is a preconceived opinion."
} 
sustrajera ella misma a la explicación" (ibíd.). Podríamos decir que la noción de trasferencia se origina en esa suerte de rebelión conceptual.

La transferencia es un concepto que nace para dar respuesta a fenómenos que interrogan a Freud desde los albores de su práctica clínica: "las primeras veces pudo pensarse, acaso, que la cura analítica había chocado con un escollo debido a un suceso contingente, es decir, que no estaba en sus propósitos ni fue provocado por ella", pero en virtud de su reiteración "regular en cada caso nuevo [...] tenemos que abandonar sin duda la idea de una contingencia perturbadora y reconocer que se trata de un fenómeno que está en la más íntima relación con la naturaleza de la enfermedad misma" (Freud, 1917b/2004: 401). En ese sentido, es una teorización que da respuesta a la forma en la que el paciente vive su relación con el analista, justamente allí donde el analista no ha sugerido nada que haga esperables tales reacciones del sujeto analizado. Freud se dedica a indagar este "vínculo que no halla explicación alguna por las circunstancias reales" (Freud, 1925b/2004: 40), para postular su hipótesis: se trata de un conjunto de fenómenos, que varían "desde el enamoramiento apasionado, plenamente sensual, hasta la expresión extrema de rebeldía, encono y odio" (ibíd.), cuya procedencia es el "vínculo con los progenitores" (Freud, 1926d/2004: 256).

Esta teorización del fenómeno viene también a ofrecer una respuesta a un punto central que Bernheim dejó sin resolver sobre el asunto de la sugestión: su origen. Así lo explica el vienés: "su sugestionabilidad no es más que la inclinación a la transferencia [...] Para él [Bernheim] constituía un hecho básico, acerca de cuyo origen no podía aclarar nada. No advirtió que la «suggestibilité» provenía de la sexualidad, de la actividad de la libido" (Freud, 1917b/2004: 405). Debido a ello, es la transferencia positiva del paciente lo que le confiere su autoridad al analista y su disposición a creerle:

\footnotetext{
Sin esa trasferencia, o si ella es negativa, ni siquiera prestaría oídos al médico o a sus argumentos. La creencia repite entonces su propia historia genética; es un retoño del amor y al comienzo no necesitó de argumentos. Sólo más tarde admitió examinarlos siempre que le fueran presentados por una persona amada. Argumentos sin semejante apoyo nunca valieron, y en la vida de la mayoría de los hombres nunca valen. Por tanto, en general, un ser humano es accesible también
} 
desde su costado intelectual únicamente en la medida en que es capaz de investir libidinosamente objetos... (ibíd.).

Para Grünbaum, Freud "sabía muy bien" que brindando esa caracterización de la relación transferencial le estaba "dando la derecha" a sus críticos (Grünbaum, 1984: 130). Todo parece indicar que Grünbaum, al explayar su crítica, confunde y mezcla dos aspectos implicados en la trasferencia, que conviene diferenciar: por un lado la disposición esperanzada que el paciente mantiene, en ciertos momentos, para con su analista, al modo de una "crédula expectativa" (Freud, 1905a/2004: 248). Por otro lado, el tipo de relación que establece con el analista, su coloración afectiva singular, su "clisé (o también varios) que se repite" (Freud, 1912b/2004: 97). El primer aspecto constituye la situación que hace posible el ejercicio de esa modalidad de influencia denominada sugestión y del que Freud llama a hacer uso para que se cumpla la regla fundamental ${ }^{451}$. La segunda dimensión de la trasferencia, el tipo de lazo libidinal, constituye un fenómeno que debe ser analizado y reconducido a la historia vivencial del paciente, pues se trata de una reactualización de sus conflictos: la transferencia no es el clisé en sí mismo sino su reedición; es decir, una investidura de objeto que opera por desplazamiento.

Finalizando la primera década del siglo XX Freud ya ubicaba a la transferencia como el verdadero eje del dispositivo psicoanalítico $\mathrm{y}$, por lo tanto, de la teoría de la cura: "Los síntomas [...] sólo pueden solucionarse y trasportarse a otros productos psíquicos en la elevada temperatura de la vivencia de trasferencia." (Freud, 1910a/2004: 47). Así concebida, la transferencia es "el genuino portador del influjo terapéutico" (ibíd.). El vienés sabía muy bien que "los resultados curativos producidos bajo el imperio de la trasferencia positiva están bajo sospecha de ser de naturaleza sugestiva"

\footnotetext{
451 "Velamos por la autonomía última del enfermo aprovechando la sugestión para hacerle cumplir un trabajo psíquico que tiene por consecuencia necesaria una mejoría duradera de su situación psíquica" (Freud, 1912b/2004: 103). Ese "trabajo psíquico" que debe hacérsele cumplir al paciente es el trabajo de asociación libre; de hecho, ese es el único precepto que él debe obedecer en todo momento. Según Santiago Thompson, el enunciado mismo de la regla fundamental debe ser entendido como un modo de sugestión indirecta: "como tal, debería dar inicio a un proceso cuyos resultados no dependen exclusivamente de la sugestión, independizándose de su punto de partida inicial" (Thompson, 2011: 86). Esta regla constituye, por lo tanto, un referente en la práctica de lo que Freud teoriza como sugestión analítica. Por lo tanto, concluye Thompson, no puede haber psicoanálisis sin sugestión porque ella aparece de entrada, en el empuje a la asociación.
} 
(Freud, 1940/2004: 177), y es por eso que caracterizó específicamente el lugar diferencial que la sugestión ocupa en el dispositivo psicoanalítico, respecto del lugar que ocupa en gran parte de otras psicoterapias (incluso actualmente):

El procedimiento psicoanalítico se distingue de todos los métodos sugestivos, persuasivos, etc., por el hecho de que no pretende sofocar mediante la autoridad ningún fenómeno anímico. Procura averiguar la causación del fenómeno y cancelarlo mediante una trasformación permanente de sus condiciones generadoras. (Freud, 1923a/2004: 246).

De allí que "entre la técnica sugestiva y la analítica hay la máxima oposición posible" (Freud, 1905a/2004: 250); y para ilustrarlo nos remite a la distinción trazada por Leonardo da Vinci con relación a la pintura y la escultura: mientras que la primera trabaja per via di porre, colocando en la tela blanca unos colores que allí no estaban; la segunda procede per via di levare, quitando de la piedra lo que recubre las formas de la estatua contenida en ella:

De manera en un todo semejante, señores, la técnica sugestiva busca operar per via di porre; no hace caso del origen, de la fuerza y la significación de los síntomas patológicos, sino que deposita algo, la sugestión, que, según se espera, será suficientemente poderosa para impedir la exteriorización de la idea patógena. La terapia analítica, en cambio, no quiere agregar ni introducir nada nuevo, sino restar, retirar, y con ese fin se preocupa por la génesis de los síntomas patológicos y la trama psíquica de la idea patógena, cuya eliminación se propone como meta. (Freud, 1905a/2004: 250).

En primera instancia, nótese que esta caracterización distintiva ("per via di porre" - "per via di levare") aparece mucho antes que la diferenciación posteriormente establecida entre una "cosmética" y una "cirugía" (Freud, op. cit. 1917b/2004: 406) que Grünbaum cita y examina. En segundo lugar, a partir de lo aseverado por Freud advertimos que la exigencia curativa consustancial al psicoanálisis no se reduce a la producción de efectos terapéuticos, sino que abarca también una elucidación de las vías seguidas para su obtención, (apoyada en una teorización sobre la génesis del padecer). Lo que Freud nos muestra, en su itinerario metódico, es una constante preocupación por los medios con los que se alcanzan los efectos terapéuticos. Correlativo de ello, Freud maneja una noción de cura que no es equiparable a la de desaparición del síntoma, sino que implica la exigencia de un más allá que concierne a la 
sujeto y su realidad ${ }^{452}$. Es destacable, además, la conciencia que Freud tenía de las dificultades inherentes al procedimiento: "El tratamiento psicoanalítico ha de equipararse a una intervención quirúrgica y, como esta, exige realizarse dentro del marco más favorable para lograr éxito." (Freud, 1917c/2004: 418).

Finalmente, conviene recordar que en 1912 Freud ya había planteado que el análisis de la transferencia, en tanto esta es "una transferencia negativa, o una positiva de mociones eróticas reprimidas" (Freud, 1912b/2004:103) constituye "la más fuerte resistencia al tratamiento" (ibíd. p. 99). Esto es así porque

\begin{abstract}
Al igual que en el sueño, el enfermo atribuye condición presente y realidad objetiva a los resultados del despertar de sus mociones inconscientes; quiere actuar \{agieren\} sus pasiones, sin atender a la situación objetiva \{real\} (...) ellos nos brindan inapreciable servicio al volver actuales y manifiestas las mociones de amor escondidas y olvidadas de los pacientes; pues en definitiva, nadie puede ser ajusticiado in absentia o in effigie". (ibíd. p. 105).
\end{abstract}

Una de las manifestaciones concretas de esta actuación transferencial puede hallarse antes, en el caso Dora:

Así fui sorprendido por la transferencia y, a causa de ésa $\mathrm{x}$ por la que yo le recordaba al Sr K, ella se vengó de mí como se vengara de él, y me abandonó, tal como se había creído engañada y abandonada por él. De tal modo actuó \{agieren\} un fragmento esencial de sus recuerdos y fantasías en lugar de reproducirlos en la cura". (Freud, 1905b, pág. 104)

La teorización que Freud hace aquí de la transferencia poco tiene que ver con el fenómeno sugestivo en cuanto tal. Veamos ahora cómo la sugestión y la transferencia se vinculan con la resistencia, sobre todo luego del giro de 1920.

\title{
d) Resistencia y sugestión
}

En 1920, empujado por la necesidad de modificar sustancialmente su teoría, Freud reconoce que las metas inmediatas de la técnica psicoanalítica han

\footnotetext{
452 "Como meta del tratamiento, puede enunciarse la siguiente: producir, por la cancelación de las resistencias y la pesquisa de las represiones, la unificación y el fortalecimiento más vastos del yo del enfermo, ahorrándole el gasto psíquico que suponen los conflictos interiores, dándole la mejor formación que admitan sus disposiciones y capacidades y haciéndolo así, en todo lo posible, capaz de producir y de gozar. La eliminación de los síntomas patológicos no se persigue como meta especial, sino que se obtiene, digamos, como una ganancia colateral si el análisis se ejerce de acuerdo con las reglas." (Freud, 1923a/2004: 246-247).
} 
cambiado respecto de las iniciales. Al principio "el psicoanálisis era sobre todo un arte de interpretación", pues el trabajo del analista consistía en "colegir, reconstruir y comunicar en el momento oportuno lo inconciente oculto para el enfermo":

Pero como así no se solucionaba la tarea terapéutica, enseguida se planteó otro propósito inmediato: instar al enfermo a corroborar la construcción mediante su propio recuerdo. A raíz de este empeño, el centro de gravedad recayó en las resistencias de aquel; el arte consistía ahora en descubrirlas a la brevedad, en mostrárselas y, por medio de la influencia humana (este era el lugar de la sugestión, que actuaba como «trasferencia»), moverlo a que las resignase. (Freud, 1920a/2004: 18; cursiva añadida).

Como puede verse, el lugar de la sugestión se reduce a la aptitud de mover al paciente para que supere sus resistencias, utilizando la potencia que confiere la transferencia ${ }^{453}$. Lo que resulta claro, es que el analista no hace uso de la sugestión para que el paciente acepte sus interpretaciones o construcciones; sino que, una vez convencido de ello el paciente, la intervención sugestiva es en auxilio de la superación de su conflictiva (no del conocimiento de la misma). Esto es completamente soslayado por Grünbaum, que parece creer que la sugestión opera para "convencer" al paciente en todo momento. Freud fue muy claro sobre esto, jincluso en la misma conferencia!:

...puedo asegurarles que están mal informados si suponen que consejo y guía en los asuntos de la vida sería una parte integrante de la influencia analítica. Al contrario, evitamos dentro de lo posible semejante papel de mentores; lo que más ansiamos es que el enfermo adopte sus decisiones de manera autónoma. (Freud, 1917b/2004: 394).

La aspiración "educativa" a la que se refiere Freud y que nuestro filósofo ve con prejuiciosa sospecha no es otra cosa que "educarse para autoconfesarse la verdad" (ibíd. p. 395). No puede ser de otra manera, pues, en un psicoanálisis,

\footnotetext{
${ }^{453}$ De hecho, esto es lo que caracteriza al psicoanálisis: "La trasferencia a menudo basta por sí sola para eliminar los síntomas del padecer, pero ello de manera sólo provisional, mientras ella misma subsista. Así sería sólo un tratamiento sugestivo, no un psicoanálisis. Merecerá este último nombre únicamente si la trasferencia ha empleado su intensidad para vencer las resistencias." (Freud, 1913/2004: 143-144). Por eso, "la pieza esencial del trabajo terapéutico consiste en el vencimiento de estas resistencias [...] sin esta operación no puede alcanzarse una trasformación anímica duradera del paciente" (Freud, 1923a/2004: 245).
} 
"la ambición pedagógica es tan inadecuada como la terapéutica" (Freud, 1912a/2004: 118).

En otro escrito correspondiente al mismo período, Freud se pregunta si el descubrimiento de las resistencias garantiza su superación por parte del paciente y responde:

Por cierto que no siempre; pero esperamos alcanzar esa meta aprovechando la trasferencia del paciente sobre la persona del médico, para que él haga suya nuestra convicción de que los procesos represivos sobrevenidos en la infancia son inadecuados al fin y de que una vida gobernada por el principio de placer es irrealizable. (Freud, 1919b/2004: 155).

Aprovechar la transferencia para que el paciente "haga suya" la "convicción" del analista, significa que el paciente pueda elegir conforme al principio de realidad, asumiendo la castración. Dicho de otra manera: ese convencimiento no se refiere a un conocimiento proposicional respecto de la realidad psíquica (cosa que el paciente ha venido elaborando), sino a que la solución del conflicto implica renunciar a la satisfacción pulsional entreverada en el síntoma, porque el principio de placer es irrealizable. Entonces, el influjo sugestivo que se da en transferencia apunta a propiciar otro desenlace que el logrado en la formación del síntoma (represión y retorno de lo reprimido). Para lograr esta solución de sus conflictos "es preciso renovar este conflicto y llevarlo a otro desenlace con el auxilio de fuerzas impulsoras que en su momento no estaban disponibles" (1917c/2004: 413). Es en la transferencia que "se crean versiones nuevas de aquel viejo conflicto, versiones en las que el enfermo querría comportarse como lo hizo en su tiempo, mientras que uno, reuniendo todas las fuerzas anímicas disponibles [del paciente], lo obliga a tomar otra decisión" (ibíd.).

Por otro lado, Freud menciona, continuando el último pasaje de 1920 que arriba citamos, que "el devenir-conciente de lo inconciente tampoco podía alcanzarse plenamente por este camino", pues "el enfermo puede no recordar todo lo que hay de reprimido en él, acaso justamente lo esencial" (ibíd.); en ese caso el paciente

...no adquiere convencimiento ninguno sobre la justeza de la construcción que se le comunico. Más bien se ve forzado a repetir lo reprimido como vivencia presente, 
en vez de recordarlo, como el médico preferiría, en calidad de fragmento del pasado. (ibíd.; cursivas añadidas).

Notemos que Freud pone el acento en la falta del convencimiento del paciente, convencimiento que Grünbaum adopta como poseyendo un presumible origen sugestivo. Además, podemos advertir que lo que adquiere estatuto evidencial para Freud radica en un fenómeno que no se reduce al convencimiento del enfermo: la compulsión de repetición. Independientemente de la relación que el paciente tenga con eso que se le impone con "fidelidad no deseada", el vienés ubica allí el suelo empírico que servirá como referencia para las elaboraciones conceptuales que intentan explicarlo (ya sea en los términos universales del nivel metapsicológico o en los términos singulares a nivel de cada caso). Pero Grünbaum malinterpreta a Freud, pues considera que en estas situaciones "Freud justifica su demanda de la fe del paciente en sus retrodicciones por el supuesto de que el analizante tiene una 'compulsión a la repetición"” (Grünbaum, 1984: 131; cursivas añadidas). Insistimos, si hay una "demanda de fe" por parte del analista, ésta no se refiere a un contenido determinado (una retroducción sobre las causas de su neurosis) sino a la imposibilidad de la satisfacción pulsional completa. La sugestión, vía la transferencia, opera en el sentido de la asunción de la limitación pulsional y no, como nuestro filósofo piensa, en el sentido de convencer al paciente de una explicación sobre el pasado. De ahí que "el inevitable influjo sugestivo del médico es guiado en el psicoanálisis hacia la tarea, que compete al enfermo, de vencer sus resistencias, o sea, de efectuar el trabajo de la curación" (Freud, 1923a/2004: 246). Además, por otro lado, tampoco es el "pasado" del paciente lo que debe recibir una explicación; y, en todo caso, si hay fragmentos de la historia fácticamente acontecida que deban ser explicados, esa explicación no podría ser cabalmente representada con el modelo de explicación nomológicodeductiva (por lo que la noción de retrodicción necesitaría especificarse). Sea como fuere, el saber que se obtiene sobre la realidad psíquica es, como veremos más adelante, una co-construcción cuyo establecimiento no se produce por medio de la sugestión sino a partir de la elaboración conjunta del material clínico.

El razonamiento equivocado de Grünbaum es producto de su errada lectura de Freud, complementada posiblemente por su desconocimiento de lo que 
verdaderamente sucede en un psicoanálisis. El error sobre este punto es extraordinario:

\begin{abstract}
Ahora, la principal evidencia que Freud aduce para su postulada compulsión de repetición es que las realidades de los adultos en el momento de la transacción analítica muestran sentimientos positivos del paciente hacia su analista, que resultan extravagantes en grado, así como grotescos en carácter. Sin embargo, este mismo estado de ánimo aumenta claramente la sugestionabilidad del paciente a través de la subordinación intelectual y psicológica a su médico. ${ }^{454}$ (Grünbaum, 1984: 131).
\end{abstract}

Resulta innecesario recordar que los fenómenos que Freud conceptualiza como compulsión de repetición no se reducen a la transferencia positiva -de hecho la transferencia "es sólo una pieza de la repetición" para Freud en $1914^{455}$ (op. cit. p. 152) - y que la noción misma de compulsión de repetición resulta redefinida sustancialmente con el denominado giro de 1920.

En base a lo anterior parece justificado decir que Grünbaum ha razonado con la intención exclusiva de persuadirnos, sin verdaderamente buscar esclarecer el argumento de Freud. Ha partido de una serie de implicaciones tendenciosas, derivadas desde de un conjunto heterogéneo de afirmaciones freudianas que él mismo ha reunido caprichosamente, a los fines exclusivos de llevar agua a su molino filosófico. Para hacer notar al lector hasta qué punto llega esta selección partidaria, detengámonos en lo siguiente: Grünbaum ha examinado los argumentos freudianos del desmontamiento de la transferencia y de la coincidencia con la realidad psíquica del paciente, en tanto defensas de la acusación de sugestionabilidad. Sin embargo, ha omitido otros dos argumentos que también aparecen en la misma conferencia $28^{\circ}$. El primero reza así: "además, el hecho de que durante la cura tenemos que luchar

\footnotetext{
454 "Now the main evidence that Freud adduces for his repetition-compulsion postulate is that the adult realities at the time of the analytic transaction show the patient's positive feelings toward his analyst to be extravagant in degree as well as grotesque in character. Yet this very state of mind clearly heightens the patient's suggestibility via intellectual and psychological subordination to his doctor."

455 Se trata de la escenificación que el paciente despliega en el dispositivo y utilizando al analista como soporte o "palestra". En virtud de que la transferencia es repetición, será fundamental recordar para no volver a repetir, y "el principal recurso para domeñar la compulsión de repetición del paciente, y transformarla en un motivo para el recordar, reside en el manejo de la trasferencia" (Freud, 1914a/2004: 156).
} 
incesantemente contra resistencias que saben mudarse en trasferencias negativas (hostiles) opera en sentido contrario a la producción de sugestiones singulares" (Freud, 1917c/2004: 412). ¿Cómo se las arregla Grünbaum para explicar el hecho de que haya análisis bajo trasferencia negativa? ${ }^{456}$, pues simplemente no tiene en cuenta esta defensa freudiana. Como puede verse, la afirmación es fundamental; pues da cuenta de una situación analítica en la que la sugestionabilidad no podría ubicarse entre las causas del conocimiento ni de los cambios alcanzados. La segunda defensa que Grünbaum omite evaluar consiste en la ya mencionada relación entre las declaraciones de pacientes psicóticos ("insospechables de recibir una influencia sugestiva") con el material proveniente de la asociación libre en neuróticos, que Freud toma como un hecho extraclínico corroborador de la teoría. Incluso en la selección de los argumentos freudianos vemos a Grünbaum operar con una mendacidad impropia de todo filósofo que anhela esclarecer.

\section{Una redefinición del problema de la sugestión en psicoanálisis: minimizando el efecto Pigmalión.}

Es momento de abordar el problema, con relativa independencia de las defensas que Freud elaboró para sortearlo. A nuestro modo de ver, el reto de la sugestión necesita ser conceptualizado a partir de discriminar diversos niveles en los que este fenómeno podría presentarse. En lo que respecta a la teoría clínica, para poder dialogar, asumamos que el desafío es tal y cómo Grünbaum lo ha afirmado sintéticamente: "los analistas inducen a sus dóciles pacientes mediante sugestión, para proporcionar las mismas respuestas clínicas necesarias para validar la teoría psicoanalítica de la personalidad" (Grünbaum, 1984: 130). Como hemos visto, para Freud esta objeción "aun siendo errónea, no es posible desautorizarla por irracional" (Freud, 1917c/2004: 411-412). El desafío es de tipo metodológico, e implica el siguiente interrogante, basado en una sospecha: ¿de qué modo podría justificarse la teoría a partir de los datos

\footnotetext{
456 Lo cual debe ser claramente diferenciado del efecto terapéutico de las interpretaciones inexactas, tempranamente conceptualizado por autores como Edward Glover (1931/1970).
} 
clínicos si estos últimos podrían estar contaminados, mediante sugestión, por las mismas teorías que pretenden fundamentar de manera independiente? Es decir, como la relación entre la teoría y la evidencia resulta objetada con la acusación de sugestión, entonces la fundamentación de la teoría en los datos clínicos es lo que aparece debilitado. En lo que sigue veremos por qué esta acusación es exagerada y poco razonable; para luego presentar un modo de contrarrestarla, independientemente de las consideraciones freudianas que ya hemos antepuesto.

\section{a) Una definición freudiana de la sugestión}

La historia del psicoanálisis nos muestra que el problema de la sugestión ha sido muy frecuentemente anudado, desde Freud en adelante, con el asunto de la transferencia. Sin embargo, el fenómeno de la sugestión bien puede ser considerado de manera más amplia, a partir de una base empírica no limitada a la órbita de fenómenos clínicos.

Freud tempranamente brindó una definición de la sugestión como "una variedad del influjo psíquico", que se distingue de otras (como la orden, la enseñanza o el consejo) por "ser despertada a raíz de ella, en un segundo cerebro, una representación cuyo origen no se somete a examen, sino que se acoge como si se hubiera generado espontáneamente en ese cerebro" (Freud, 1888b/2004: 88). Avanzada su obra, volvió a "analizar el enigma de la sugestión después de haber permanecido alejado de él durante treinta años" (Freud, 1921b/2004: 85), para intentar cernir su significado: "en cuanto a la sugestión, le cabe esta definición: es un convencimiento que no se basa en la percepción ni en el trabajo de pensamiento, sino en una ligazón erótica." (ibíd. p. 121).

Ambas caracterizaciones freudianas, pese a la distancia temporal que las separa y a sus divergencias, encierran los aspectos definicionales que comúnmente se han utilizado en las discusiones psicoanalíticas posteriores ${ }^{457}$,

\footnotetext{
457 Pese a ello, no ha trascendido significativamente las fronteras del campo psicoanalítico. En la psicología ha habido otras definiciones predominantes, por ejemplo la de McDougall: "la sugestión es un proceso de comunicación que resulta en la aceptación con convicción de la propuesta comunicada, en ausencia de fundamentos lógicamente adecuados para su aceptación" (McDougall, 1908/2001: 74). ["Suggestion is a process of communication resulting in the acceptance with conviction of the communicated proposition in the absence of logically
} 
a saber: efectos no racionales producidos a expensas de toda deliberación consciente y que tienen como precondición una ligazón libidinal (Lacewing, 2013; Levy \& Inderbitzin, 2000; Thompson, 2011).

En Psicología de las masas y análisis del yo Freud esclarece que su aporte a esta modalidad de influencia que prescinde de la función del juicio es la hipótesis de su basamento obligado en un tipo de lazo libidinal:

\begin{abstract}
...vínculos de amor (o, expresado de manera más neutra, lazos sentimentales) constituyen también la esencia del alma de las masas. Recordemos que los autores no hablan de semejante cosa. Lo que correspondería a tales vínculos está oculto, evidentemente, tras la pantalla, tras el biombo, de la sugestión. (Freud,
\end{abstract} 1921b/2004: 87).

La explicación freudiana se completa, como es sabido, con una relación entre los fenómenos hipnóticos y de masa, proponiendo como premisa explicativa "el mito científico del padre de la horda primordial" ${ }^{458}$ (ibíd. p. 128); así, el hipnotizador en la hipnosis y el conductor en la masa, ejercen el mismo tipo de influencia que el padre primordial, por encarnar el ideal del yo ${ }^{459}$. Se comprende que la voluntad de ese otro idealizado sea impuesta al yo del sujeto de manera irrestricta. Por otro lado, el otro movimiento libidinal concomitante a esa idealización, es la identificación entre los miembros de la masa, que derivará en su noción de "sugestión recíproca" (cf. próximas notas al pie).

La definición que vamos a proponer asume la descripción funcional y menos especulativa de la explicación freudiana, y puede ser adoptada sin necesidad

adequate grounds for its acceptance"]. Recuérdese que en Psicología de las masas Freud intentó rebatir esta perspectiva, junto con la de Tarde, Brugeilles y Bernheim, puesto que todas ellas suponen que la sugestión sería un hecho irreductible (Freud, 1921b/2004: 85).

${ }^{458}$ Recuérdese que para Freud lo que cohesiona una masa es el amor al conductor, que es puesto en el lugar del ideal del yo y que posibilita por ello la identificación entre sus miembros. En la masa, cada individuo tiene una doble ligazón amorosa: con el conductor y con los otros individuos de la masa. Situación que Freud reconduce hasta el funcionamiento de la horda primordial y el lugar constitutivo del padre. El fenómeno de masa, tal y como es descripto por la psicología, "responde a un estado de regresión a una actividad anímica primitiva, como la que adscribiríamos justamente a la horda primordial" (Freud, 1921b/2004: 117). La sugestión, sostiene Freud, "tiene su buen fundamento en una disposición que se conserva inconciente desde la historia primordial de la familia humana" (ibíd. p. 121).

${ }^{459}$ A estas alturas de su obra, Freud lo expone en términos de introyección del objeto en ese "grado interior del yo", que en poco tiempo pasará a conceptualizarse como superyó (cf. cap. 3 de El yo y el ello, p. 30). Un ideal del yo encarnado no es otra cosa que un superyó, cosa que Freud advierte y vincula directamente con Nietzsche: "en los albores de la historia humana él fue el superhombre que Nietzsche esperaba del futuro" (ibíd. p. 118). 
de comprometerse directamente con las hipótesis relativas al funcionamiento originario; pero para eso debe quedar clara la diferencia entre ambas. Por un lado, Freud conceptualiza a la sugestión como la disposición a transferir el superyó a otro investido de autoridad, movimiento que encuentra realizado en los fenómenos que analiza (masa, hipnosis, etc.) y que constituye el explicandum al que aplicará unas conjeturas de mayor alcance explicativo y, también, especulativo. Tales conjeturas propuestas por Freud, al modo de una serie de premisas explanantes, versan sobre la supuesta estructura del mito primordial en la constitución familiar humana y su retorno en fábulas, leyendas, en el armado de masas y, también, en la hipnosis y el psicoanálisis. A los fines de nuestro análisis, dejaremos de lado esas premisas explanantes de Freud y nos basaremos en la hipótesis funcional con la que caracteriza al fenómeno sugestivo ${ }^{460}$.

Entonces, en base a estas consideraciones y a sabiendas de que no existe una definición unívoca ni consensuada sobre el fenómeno de la sugestión, adoptaremos una aproximación conceptual que pretende limitar las ambigüedades del término y centrarnos en nuestro problema metodológico: es la influencia originada en la estructura comunicacional por un otro investido (generalmente) de autoridad que, sin ser reconocida en cuanto tal ni sometida a deliberación consciente, opera causalmente sobre los estados mentales (creencias, anhelos, recuerdos, sentimientos, etc.) de un sujeto en un momento dado. Esta definición, como puede notarse, hace del fenómeno algo omnipresente en la vida diaria de todas las personas y, por eso mismo, de carácter psicosocial $^{461}$.

\footnotetext{
${ }^{460}$ Dejaremos también de lado, en nuestro análisis, la posibilidad de que la sugestión tenga a la base otro de los modos de lazo libidinal descriptos por Freud, a saber: los distintos tipos de identificación deslindados por él en 1921. Para una elucidación de esta tesis y de sus alcances clínicos, cf. Thompson (2011, pp. 103-110).

${ }^{461}$ Esto es así debido a que la participación de un sujeto en una estructura social supone siempre la asunción de lugares que, implícita y explícitamente, demandan la efectivización de determinados comportamientos y prescriben otros. No sería exagerado decir que cada vez que alguien actúa en sociedad lo hace performando ciertas estructuras y no otras, lo cual es una forma de sugestión. Por esto mismo Ahumada sostiene que "en asuntos ligados a relaciones, como los que implica el psicoanálisis, la cognición surge el campo interaccional, y es absurdo requerir [como Grünbaum pretende] que sea «incontaminada»" (Ahumada, 1997a/1999: 328; corchetes añadidos). Freud, en el noveno capítulo de Psicología de las masas y análisis del yo, advierte este fenómeno: "el enigma del influjo sugestivo aumenta para nosotros si concedemos que no sólo puede ejercerlo el conductor, sino cualquier individuo sobre otro; y nos reprochamos haber destacado de manera unilateral el vínculo con el conductor, omitiendo
} 
Teniendo en cuenta esta definición, asumiremos que el psicoanálisis es una praxis que tiene por pretensión evitar (lo más que se pueda) la sugestión. Para ello, somete a examen del paciente las comunicaciones con las que pretende transformar su realidad psíquica. Sin embargo, conforme a la definición anterior, hay que reconocer que la existencia de la sugestión en el dispositivo psicoanalítico no podría reducirse a las expresiones complacientes que el paciente despliega como respuesta a las interpretaciones del analista (como Grünbaum cree), sino que se trata de un fenómeno ubicuo que circula a expensas de la comunicación consciente. Así como un investigador condiciona (de un modo $u$ otro y en mayor o menor medida) las respuestas del sujeto que está entrevistando, del mismo modo el analista influye en la asociación libre del paciente. Se trata, evidentemente, de un fenómeno ineliminable en el que coinciden cada vez más analistas, oriundos de diversas orientaciones (Ahumada, 1997a/1999; Henry et. al., 1994; Juri, 1999; Mitchell, 1993a; Zukerfeld, 2001) y, por este motivo, epistémicamente inobjetable en sí mismo $^{462}$. Las preguntas que podemos hacernos son, entonces, cuánto y cómo de esta influencia alcanza y altera los fenómenos que pretendemos conocer de la realidad psíquica del paciente.

Debido a que la representación que nos formamos de un problema contiene las posibilidades de accionar para resolverlo, intentaremos reformular el problema de la sugestión en psicoanálisis de manera que sea abordable. Adoptaremos, para tal fin, la propuesta de Michael Lacewing (2013), quien aboga por entender el problema de la sugestión en psicoanálisis como un problema relativo a los efectos de las expectativas del analista en el encuadre de la sesión. Esto no significa que la producción de efectos de tales expectativas del analista agote completamente la localización de la sugestión; tampoco intenta ser una definición que pueda aplicarse por fuera del encuadre. Simplemente consiste en una manera de hacer foco en el problema

indebidamente el otro factor, el de la sugestión recíproca." (Freud, 1921b/2004: 112). Intentaremos, en lo que sigue, cernir algo de esta modalidad de la sugestión que prescinde de la intención de influir y que podemos suponer que circula también en el dispositivo analítico.

462 Robert Holt consideró, por esta razón, que Grünbaum había exagerado su acusación en este punto, ya que la contaminación de los datos clínicos mediante la sugestión no implica necesariamente un "problema de tipo todo-o-nada" (Holt, 1984: 11). 
metodológico de la sugestión, tal y como aparece desprendido de la crítica de Grünbaum.

Los efectos del experimentador pueden considerarse como aquellas influencias que el experimentador tiene sobre los sujetos sometidos a un experimento y que no alcanzan a las propiedades que están bajo investigación; es decir que estimulan las conductas observadas pero no la variable independiente bajo estudio (Rosenthal y Rosnow, 2009, p. 327). Dentro de estos efectos, las expectativas del experimentador constituyen un subtipo que nos interesa considerar: es la manera en la que una determinada expectativa que tiene un experimentador sobre el resultado de un experimento, afecta inadvertidamente el resultado del experimento tendiendo a realizar esa expectativa. ${ }^{463}$ En palabras de Robert Rosenthal, los "efectos de las expectativas interpersonales se refieren a la situación en la que la expectativa de una persona por el comportamiento de una persona diferente, es lo que realmente ayuda a lograr ese comportamiento". ${ }^{464}$ (Rosenthal, 2000: 294).

Dentro de tales efectos y a los fines de nuestro tema, podemos considerar que el problema reside en cómo las expectativas que un analista se hace de un paciente en un momento determinado (por ejemplo, una hipótesis general sobre el origen de su padecer) afectan la manera en la que el paciente responde favoreciendo esa expectativa ${ }^{465}$; y produce material clínico que

\footnotetext{
${ }^{463}$ Debido a que, generalmente, los investigadores en ciencias humanas conocen los objetivos de la investigación que realizan, mantienen expectativas sobre la manera en que los participantes pueden o deben responder. El efecto que tienen tales expectativas en la investigación puede ser determinante, al punto que altera la realidad de los sujetos bajo indagación (que pueden tender, por ejemplo, a efectivizar la expectativa). Si bien las incipientes conceptualizaciones de este fenómeno han sido introducidas en las Ciencias Sociales por Robert Merton, con la denominación (basada en el teorema de William I. Thomas) de profecía auto-cumplida (Merton, 1949/2002, cap. XIII), Robert Rosenthal ha comprobado que se produce en múltiples situaciones de investigación y frecuentemente en la vida cotidiana. En virtud de que constituye un sesgo en los resultados finales de las investigaciones, lo ha bautizado como efecto de las expectativas del experimentador (Rosenthal, 1966, 1967, 1969, 2000). No obstante su popularidad, las investigaciones de Rosenthal han sido objeto de algunos cuestionamientos (después de todo, Rosenthal había diseñado sus cuasiexperimentos con la intención de demostrar el efecto de las expectativas del experimentador) y hoy en día se continúa discutiendo sobre el alcance efectivo de estos sesgos.
}

\footnotetext{
464 "Interpersonal expectancy effects refer to the situation in which it is the expectation of one person for the behavior of a different person that actually helps to bring about that behavior."

${ }^{465}$ Habiendo revisado los presupuestos del inductivismo de Grünbaum, se comprende mejor ahora el modo en que él analizaba el tema: "la falsedad de la confirmación clínica en psicoanálisis no se ve reducida por el hecho, ahora bien reconocido, de que las distorsiones epistemológicas definitivamente no se limitan a las respuestas de los pacientes sometidos a la
} 
podemos denominar, con Freud, complaciente ${ }^{466}$. El problema reside, entonces, en cómo es evaluado este tipo de datos dedicados a complacer al analista, en la medida en que no podrían constituir evidencia para apoyar la conjetura que él se ha formado. Dicho de otra forma, ¿cómo es posible que el analista, actuando per via di levare, no haga con sus interpretaciones lo que Pigmalión con Galatea?

Para poder responder a esto hemos de asumir la siguiente premisa: los efectos de las expectativas del investigador son una forma de sugestión distinta a la que acontece en otras formas comunicativas, por ejemplo en la hipnosis. $A$ su vez, debemos poder distinguir la sugestión del sesgo de confirmación.

\section{b) De la sugestión al sesgo de confirmación}

El sesgo de confirmación es un efecto del procesamiento de la información en virtud del cual una persona evalúa selectivamente la evidencia disponible y tiende a creer, independientemente de la veracidad o falsedad de esa información, que sus expectativas se hacen realidad o son acertadas (Wason, 1966; Evans y Over, 1996; Nickerson, 1998). Es decir que consiste en la

psicoterapia. Las expectativas mantenidas por los psicólogos experimentales pueden colorear fuertemente sus hallazgos observacionales pretendidos, incluso en pruebas de habilidades de aprendizaje de las ratas de laboratorio" (Grünbaum, 1984: 241; cursivas del original). ["The spuriousness of clinical confirmation in psychoanalysis is not lessened by the now wellrecognized fact that epistemological distortions are definitely not confined to the responses of patients undergoing psychotherapy. Expectations entertained by experimental psychologists can strongly color their purported observational findings even in tests of the learning skills of laboratory rats"]. Lo que Grünbaum afirma aquí parece implicar la posibilidad de que los psicólogos experimentales podrían tener resultados observacionales sin colorear, en la medida en que fuera posible dejar por fuera sus propias expectativas. Dicho de manera más simple: datos objetivos. Leemos, entrelíneas, un supuesto de objetividad fenoménica que Grünbaum maneja constantemente sin terminar de asumir explícitamente; y que constituye un elemento anacrónico respecto de la tesis de la carga teórica de la observación y sus consecuencias en la construcción de los hechos observacionales. La pregunta que nos podemos hacer es ¿tener expectativas implica necesariamente sufrir alguna distorsión esencial?; o mejor: ¿qué hacemos si no es posible observar sin expectativas?

${ }^{466}$ Los ejemplo más reconocidos, desde Freud en adelante, son los sentimientos de recuerdo (Erinnerungsgefühle) y los sueños confirmatorios (bestätigenden Träume). En el caso de los sueños, "parece como si el paciente hubiera tenido la amabilidad de brindar en forma onírica eso mismo que inmediatamente antes se le «sugirió». Aunque se trata de sueños que vienen a la zaga del análisis, "sólo se observan bajo determinadas condiciones de influjo por la cura" (Freud, 1911/2004: 92). Freud se preguntaba por el privilegio de los sueños en su capacidad de aportar luz sobre lo inconciente, y afirmó que "difícilmente pueda aducirse otro factor que la deferencia del analizado hacia el analista, deferencia que proviene del complejo parental, vale decir: la parte positiva de lo que llamamos trasferencia" (Freud, 1923b/2004: 118). 
recolección o ponderación selectiva de la evidencia, a los fines de apoyar una determinada hipótesis preconcebida, desestimando o dando menor peso a lo que podría considerarse contraevidencia para la misma. Según Nickerson, si se toman en cuenta los estudios empíricos más relevantes sobre este tema, apreciamos que el sesgo de confirmación puede presentarse de varias maneras:

1) No considerar las hipótesis rivales. Para que una observación apoye significativamente a nuestra hipótesis, su probabilidad debe ser más alta que la de otras observaciones (en virtud de la verdad de la hipótesis). Debido a que este apoyo es comparativo, una observación confirma nuestra hipótesis si le brinda mayor apoyo que a otras hipótesis alternativas: "si uno considera sólo una explicación posible de algún evento o fenómeno, uno se opone a la posibilidad de interpretar los datos como apoyo de cualquier explicación alternativa" $^{467}$ (Nickerson, 1998: 177). Por lo tanto, juzgar que una observación apoya una determinada hipótesis sin tener en cuenta hipótesis rivales, constituye una forma del sesgo de confirmación; puesto que si existe una hipótesis alternativa que da cuenta de la observación del mismo modo o mejor, entonces, obviamente no podremos decir que esa observación apoya nuestra hipótesis.

2) Otorgar un trato preferencial a la evidencia confirmatoria de la propia creencia. Es la tendencia a dar mayor peso a la información que apoya las propias creencias u opiniones, en detrimento de la información que va en su contra. La memoria puede jugar un papel en esto, puesto que las personas son más propensas a recordar las razones que apoyan sus propios puntos de vista que las razones que los contrarían; a la vez que son más propensas a recordar la evidencia favorable como más significativa de lo que en realidad era. Del mismo modo, la creatividad también desempeña su papel aquí, pues los sujetos son más capaces de crear o producir evidencia confirmatorias que refutatoria.

3) Poner a prueba las propias hipótesis buscando sólo confirmaciones. Aunque esto nos recuerda a Popper, Nickerson refiere estudios empíricos que

\footnotetext{
467 "If one entertains only a single possible explanation of some event or phenomenon, one precludes the possibility of interpreting data as supportive of any alternative explanation."
} 
muestran cómo las personas tienden a hallar evidencia positiva incluso en hipótesis cuyo valor de verdad no tiene para ellos un atractivo personal.

4) Percibir, en la evidencia, patrones de lo que uno está buscando. Esta tendencia se efectúa a expensas de la existencia de tales patrones: si tenemos la expectativa de hallar determinado patrón, somos más propensos a juzgar que los datos se ajustan a ese patrón. Esta tendencia ha sido demostrada para una amplia gama de expectativas, incluyendo las basadas en estereotipos étnicos, clínicos, educativos, socioeconómicos y de estilo de vida.

Según Lacewing, a partir de considerar el sesgo de confirmación como algo que puede operar también en las capacidades inferenciales del analista, podemos reconsiderar algunas objeciones clásicas de sugestión. En particular, la crítica tempranamente realizada por Judd Marmor, según la cual los analizados, como resultado de la sugestión, tienden "a que aparezca precisamente el tipo de datos fenomenológico que confirman las teorías y la interpretación de sus analistas! Así, cada teoría [relativa a cada escuela psicoanalítica] tiende a ser auto-validada." (Marmor, 1962: 289; aclaración añadida). Esta objeción ha sido avalada y asumida por diversos autores, entre ellos Grünbaum (1984: 211). Aquí hay que decir dos cosas: por un lado, que Marmor esboza su comentario sin apoyarse en mucho más que el sentido común o su percepción de lo que los analistas cuentan de sus sesiones. Por otro lado, tal y como asevera Lacewing, el fenómeno puede ser explicado de otra manera: si los datos construidos a partir de la asociación libre resultan compatibles con el punto de vista teórico del analista, ello se debe menos a una forma de sugestión sobre el paciente que a una variante del sesgo de confirmación propio del analista. Es decir, no es que el paciente produzca, con sus asociaciones verbales, datos que corroboren la teoría del analista, sino que éste último presta una atención selectiva al material del paciente y tiende a ver realizadas sus expectativas cognitivas. Así, lo que se ha tomado como evidencia del efecto sugestivo sobre el paciente puede ser en realidad un producto del sesgo de confirmación en el analista (ibíd. p. 733).

Ahora bien, volviendo sobre el problema de la sugestión que Grünbaum denuncia, podemos extraer la siguiente conclusión: asumir que los psicoanalistas pueden ser víctimas del sesgo de confirmación cuando construyen sus casos y elaboran sus conclusiones es muy distinto a aseverar 
que los datos clínicos están contaminados por sugestión ${ }^{468}$. Obsérvese que esto no implica la desaparición de la sugestión en el contexto clínico (nuestra definición conlleva su ubicuidad irremediable), sino que, más bien, complica la clásica simplificación del asunto y desplaza el horizonte de nuestros interrogantes.

El problema del sesgo de confirmación en el analista parece ser, fundamentalmente, un problema relativo a la capacidad de reconocer explicaciones rivales; pues para evitar el sesgo el analista debería poder aducir por qué su explicación es mejor que otras posibles. El analista puede, afuera de la sesión, examinar hipótesis alternativas para un mismo conjunto de fenómenos clínicos. Lacewing sostiene, en este punto, que existen dos caminos para buscar hipótesis alternativas y contrarrestar así el sesgo de confirmación: una es examinar conjeturas provenientes de otros marcos teóricos psicoanalíticos y otra es inspeccionar hipótesis que pertenezcan a otros campos disciplinares pero que tengan implicaciones sobre los fenómenos empíricos que estamos intentando explicar (ibíd. p. 734). A nuestro modo de ver, el planteo peca de cierta ingenuidad sobre la disposición cognitiva de los sujetos involucrados, quienes difícilmente mantengan la flexibilidad necesaria para conocer o utilizar diversas teorías metapsicológicas simultáneamente, ni mucho menos la posibilidad de hacer uso de otras teorías ajenas al psicoanálisis. No obstante, el planteo sí resulta interesante en su espíritu y sí parece factible alentar el ejercicio de examinar hipótesis alternativas, aunque sólo sea al interior de la órbita de las posibilidades del analista. Cabe destacar que el espacio de la supervisión implica, entre otras cosas, la misma potencialidad: amplificar la escucha para discernir modos de resolver determinados problemas del curso de cada análisis. A su vez, se podría agregar que para controlar el sesgo de confirmación del analista se necesita mantener una perspectiva crítica en los ámbitos de formación de psicoanalistas. Todo esto responde a la presuposición de que la objetividad

\footnotetext{
${ }^{468}$ La tesis del "terreno clínico común" pese a la diversidad metapsicológica (Wallerstein, 2005a/2006) podría constituir un apoyo a este punto de vista; puesto que el hecho de que un mismo conjunto de fenómenos empíricos conduzca a múltiples construcciones metapsicológicas constituye, posiblemente, un proceso de teorización sesgado. Claro que para darle vía a esta idea, hay que asumir que dicho terreno común existe; y sabemos que para algunos esa observación es producto de, en definitiva, una especie de sesgo de selección.
} 
constituye una cuestión de grado y que a mayor cantidad/calidad de puntos de vista involucrados en la discusión crítica, mayor grado de objetividad ${ }^{469}$.

\section{c) Sugestión y efecto de las expectativas del analista}

Si asumimos que en la construcción de los datos clínicos participan de algún modo las expectativas del analista, la pregunta que merece ser planteada es si, a pesar de esos efectos, podemos acceder a un conocimiento válido sobre la realidad psíquica del paciente y, en base a ello, ayudarlo a transformarla en su beneficio.

La manera común de corregir los efectos de las expectativas del investigador implica alguna forma de replicación, ya que la obtención de información por vías independientes que arroja similares resultados puede considerarse un indicador razonable de que las expectativas del investigador no han tenido influencia significativa en los datos (Rosenthal \& Rosnow, 2009, Cap. 18). Parece razonable afirmar que en el campo del psicoanálisis el espíritu de la replicación encuentra su homólogo en la posibilidad de que los hallazgos sean corroborados por diversos analistas. En este punto Lacewing adhiere al planteo de Wallerstein sobre el terreno clínico común (cf. parte 1 de la tesis), para afirmar que los hallazgos corroborativos estarían disponibles a nivel de la teoría clínica (aunque no a nivel de la metapsicología o etiología), porque es en torno a los fenómenos clínicos fundamentales donde los analistas de las distintas orientaciones mantienen un grado significativo de acuerdo (conflicto, resistencia, represión, transferencia, etc.). Es decir, la asunción compartida por analistas de distintas orientaciones de la existencia de tales fenómenos clínicos implica, por lo tanto, una serie de hallazgos confirmatorios que debilitan (suficientemente) la acusación de sugestión ${ }^{470}$ (ibíd. p. 736).

\footnotetext{
469 "Ciertamente, los analistas de cualquier orientación reconocen que la objetividad absoluta es un mito y que la subjetividad forma parte de sus percepciones acerca del analizado. Sin embargo, un subjetivismo a ultranza supone la renuncia a cualquier pretensión científica del psicoanálisis. En nuestra disciplina, la actitud científica implica necesariamente la creencia en algún tipo de verdades psíquicas comprobables" (Paniagua, 2009: 90).

470 Esta posibilidad de obtener hallazgos confirmatorios se ve carcomida respecto del conocimiento metapsicológico y etiológico, puesto que las hipótesis de las distintas escuelas psicoanalíticas usualmente tienden a la auto-confirmación y, rara vez, a la confirmación de hallazgos ajenos. Según Lacewing, podemos suponer que los desacuerdos entre orientaciones psicoanalíticas sean un efecto del sesgo de confirmación o de la sugestión; y es por ello que no
} 
Como ya ha sido señalado, no todos los analistas comparten la idea de un "terreno común" a partir del cual se edifican las disímiles metapsicologías; ni tampoco que los conceptos de la teoría clínica puedan formularse independientemente de una metapsicología. Sea como fuere, el planteo de Lacewing pareciera ser el siguiente: a mayor corroboración, mayor seguridad tenemos de que la hipótesis no es producto de la sugestión ni de sesgos cognitivos; mientras que un grado bajo de corroboración implica la imposibilidad de afirmar en qué medida tales sesgos se han producido.

A nuestro modo de ver, conviene distinguir la idea wallersteiniana de un terreno clínico común de la noción de hallazgos corroborativos. La idea de Wallerstein pareciera mantener, en el fondo, una remanencia empirista, en la medida en que privilegia los datos "básicos" del encuadre como fundamentales para el consenso. Uno podría objetar que también puede existir el consenso en torno a hipótesis de distinto nivel de t-observabilidad y que no necesariamente sea en un "bajo" nivel; consenso que frecuentemente ha sido enmascarado por las disidencias y las disputas sobre la pertenencia a tal o cual orientación psicoanalítica. Sin pretender entrar en el debate sobre el lugar y la función de la metapsicología, adelantemos la concepción a la que adherimos: así como sólo los lenguajes artificiales logran establecer una clara distinción entre lenguaje objeto y metalenguaje, también en psicoanálisis es imposible una diferenciación tajante entre teoría clínica y metapsicología ${ }^{471}$ (Ahumada, 2014).

podemos apelar a la confirmación inter-escuela para socavar la acusación de contaminación de los datos. La defensa planteada por Lacewing sólo sería eficaz en el plano metapsicológico si le alcanzase un grado significativo de acuerdo entre analistas de distintas orientaciones teóricas, tal y como es alcanzado respecto de la teoría clínica. A nuestro modo de ver, este razonamiento encierra una suposición equivocada: creer que teorizaciones divergentes necesariamente sean contradictorias. Es posible notar que las distintas escuelas psicoanalíticas poseen metapsicologías diferentes y cuyos enunciados, más que resultar semánticamente incompatibles entre sí, muchas veces hacen hincapié en variables observacionales distintas, porque parten de distintas ontologías o de distintas teorías explicativas que las vuelven parcialmente inconmensurables. No hay razones para catalogar de "sesgado" (en sentido peyorativo) al proceso teorizante que así se despliega, sino que este efecto es una consecuencia de la tesis de la sobredeterminación de la teoría por los datos: un mismo conjunto de fenómenos empíricos siempre puede dar lugar a distintas teorías igualmente compatibles con ellos pero fuertemente incompatibles entre sí.

471 El problema con la diferenciación entre teoría clínica y metapsicología es que "la interpretación de un lenguaje de observación está determinada por las teorías que usamos para explicar lo que observamos, y cambia tan pronto como estas teorías cambian" (Feyerabend, 1981a: 31) [the interpretation of an observation language is determined by the theories which we use to explain what we observe, and it changes as soon as those theories change.]. Freud, en coincidencia con ello, reconocía que "el comienzo correcto de la actividad 
Si esto es así, entonces debemos reconocer que la corroboración de hipótesis clínicas supone también la corroboración de aserciones metapsicológicas, aunque sea difícil delimitar cuales y en qué medida. En lo que a nuestro problema respecta, esto implica que también es posible establecer corroboraciones, por distintos analistas de distintas escuelas, de modelos abstractos; lo cual se traduce automáticamente en una defensa coherente frente a la acusación de contaminación sugestiva.

A nuestro modo de ver, existe aún otro argumento (que Lacewing no tiene en cuenta) que versa sobre un fenómeno común en las comunidades psicoanalíticas y que resulta de mayor contundencia para anteponerse a la crítica de la sugestión: un psicoanálisis supone la aparición de datos que van en contra de las expectativas de los analistas. Esto no podría, obviamente, ser un producto de la sugestión ni un efecto de la expectativa del analista. Marshall Edelson reparó en ello, afirmando que no son las explicaciones generales ni los ejemplos positivos obvios de las hipótesis psicoanalíticas los que parecen tener significativa importancia para el paciente o el analista, sino que

\begin{abstract}
...a lo que ambos atribuyen particular significación es al surgimiento de detalles circunstanciales que encierran un sorprendente grado de especificidad y de matiz idiosincrático [...] Detalles que no han sido previamente recordados por el paciente [...] y es casi seguro que no han sido previamente imaginados o conjeturados por el analista. Un psicoanálisis sin sorpresas no puede realmente llamarse psicoanálisis. Es imposible considerar plausible que tales datos se hayan sugerido, en cualquier sentido corriente de esa palabra. Son esos datos los que en última instancia pueden resultar más relevantes para la búsqueda, en la situación analítica, de pruebas que corroboren las hipótesis psicoanalíticas. ${ }^{472}$ (Edelson, 1984: 136-137; cursivas añadidas).
\end{abstract}

científica consiste más bien en describir fenómenos [...] ya para la descripción misma es inevitable aplicar al material ciertas ideas abstractas que se recogieron de alguna otra parte, no de la sola experiencia nueva." (Freud, 1915a/2004: 113). Entonces, en lugar de una distinción neta entre teoría clínica y metapsicología, convendría avanzar en la indagación de las relaciones entre niveles de datos y niveles de teorización; a sabiendas de que no es posible diferenciar completamente los hechos de su conceptualización, pues hay una continua interacción entre teorías y hechos: "las teorías se construyen sobre la base de hechos, a la vez que les dan significación e incluso determinan cuales son 'hechos' para nosotros" (Toulmin, 1961: 95). [...the way in which theories are built on facts, while at the same time giving significance to them and even determining what are 'facts' for us at all...].

472 "...what is given special weight by both is the emergence of circumstantial detail, having an astonishing degree of specificity and idiosyncratic nuance [...] Such details have not previously 
Más adelante veremos que esta capacidad de sorprender constituye el motor directo de las inferencias en el contexto clínico ${ }^{473} \mathrm{e}$, indirectamente, de las inferencias a nivel metapsicológico.

Gran parte de lo que hemos venido aseverando fue anticipado por Glymour, quien en el epílogo a un trabajo clásico esboza la siguiente respuesta a la acusación de Grünbaum ${ }^{474}$ sobre la sugestionabilidad:

\begin{abstract}
El hecho de saber que las pruebas clínicas están expuestas a la sugestión y la confusión, debería movernos a adoptar una actitud de cautela al usar esas pruebas y a mostrarnos receptivos con respecto a cualquier indicación de que el terapeuta determina las respuestas que recibe. No veo, sin embargo, que el conocimiento experimental que ahora tenemos sobre la sugestionabilidad nos obligue a renunciar por completo a los datos clínicos. De hecho, puedo imaginar circunstancias en que la evidencia clínica podría tener una fuerza considerable: por ejemplo, cuando los procedimientos clínicos no muestran signos evidentes de adoctrinamiento del paciente; cuando los resultados configuran un patrón regular $y$ con aparente forma de ley, obtenido independientemente por muchos clínicos; y cuando esos resultados son contrarios a las expectativas y creencias del clínico. No los propongo como criterios para el uso de los datos clínicos sino sólo como indicaciones de rasgos que, en forma combinada, confieren peso a tales datos [...] El conocimiento de que las pruebas clínicas son susceptibles a la sugestión y también confusas, no basta por sí solo, en mi opinión, para recomendar que se las deje de lado, así como el conocimiento de que las observaciones astronómicas están sujetas a error no hace aconsejable que se desechen los datos de la
\end{abstract}

been remembered by the analysand [...] and almost certainly have not previously been imagined or guessed in advance by the psychoanalyst. A psychoanalysis without surprises cannot properly be termed psychoanalysis. One cannot regard as plausible that such data have been suggested in any ordinary sense of that word. It is these data that may in the end prove to be most relevant to the search in the psychoanalytic situation for probative evidence providing support for psychoanalytic hypotheses."

${ }^{473}$ En su libro La sorpresa y el psicoanalista, Theodor Reik (1936) abordó ampliamente este papel de la sorpresa en el contexto clínico; y Jacques Lacan lo retomó refiriéndose al sueño y al acto fallido: "lo que se produce en esta hiancia, en el sentido pleno del término producirse, se presenta como el hallazgo. Así es como la exploración freudiana encuentra primero lo que sucede en el inconciente. Hallazgo que es a un tiempo solución -no necesariamente acabadapero que, por incompleta que sea, tiene ese no sé qué, ese acento tan particular, admirablemente destacado por Theodor Reik -destacado únicamente, porque Freud lo señaló antes que él- que es la sorpresa, aquello que rebasa al sujeto, aquello por lo que encuentra, a la par, más y menos de lo que esperaba: en todo caso, respecto a lo que esperaba, lo que encuentra es invalorable" (Lacan, 1964/1987: 33).

${ }^{474}$ El trabajo original de Glymour (1974) analiza, entre otros, el problema de la sugestión; y Grünbaum (1982: 97-103) critica su perspectiva tildándola de ingenua. A esto Glymour contesta con el epílogo que citamos a continuación. 
astronomía. En este último caso resulta relativamente fácil averiguar algo sobre los límites del error y su dispersión; en el primer caso se hace más difícil. Eso nos obliga, diría yo, a usar la cabeza y nuestro buen juicio en el análisis de evidencia clínica, y tal vez a buscar conocimiento más preciso de la cantidad de error que se introduce en los procedimientos clínicos y bajo qué circunstancias. ${ }^{475}$ (Glymour, 1982: 30).

De hecho, podríamos agregar la siguiente observación: pareciera que algunas ideas de Grünbaum parecen derivar, implícitamente, en esta misma dirección. Cuando nuestro crítico reniega de la lectura de Popper, aduce que las hipótesis psicoanalíticas son perfectamente falsables; por lo que podríamos preguntar ¿cómo es posible que los datos clínicos sean suficientemente sólidos para permitir refutaciones pero no para lograr corroboraciones? Se supone que si hay contaminación epistémica, ésta debería afectar por igual la evidencia en ambas direcciones. Grünbaum, sin embargo, parece no plantearse el problema de la sugestión cuando se trata de la falsabilidad intra-clínica, sino únicamente en lo relativo al apoyo confirmatorio. Nos parece una desproporción injustificada y creemos que esta inconsistencia apoya la perspectiva de que es necesario intentar discriminar grados y tipos de afectación del material.

\footnotetext{
475 "Knowing that clinical evidence is subject to suggestion should make us cautious in using that evidence, and it should make us sensitive to indicators that the therapist is determining the responses he receives. I do not see, however, that the experimental knowledge we now have about suggestibility requires us to renounce clinical evidence altogether. Indeed, I can imagine circumstances in which clinical evidence might have considerable force: when, for example, the clinical proceedings show no evident sign of indoctrination, leading the patient, and the like; when the results obtained fall into a regular and apparently law-like pattern obtained independently by many clinicians; and when those results are contrary to the expectation and belief of the clinician. I do not intend these as criteria for using clinical evidence, but only as indications of features which, in combination, give weight to such evidence. [...] The knowledge that clinical evidence is liable to suggestion and confounding does not, I think, of itself recommend the policy of dismissing all such evidence, nor does the knowledge that astronomical observations are subject to error recommend the policy of dismissing the evidence of astronomy. In the latter case it is relatively easy to find out something about the limits of error and its dispersion; in the former case it is more difficult. That obliges us, I should think, to use our heads and our good judgment in assaying clinical evidence, and perhaps to seek for finer knowledge of how much error is introduced in clinical proceedings, and in what circumstances."
} 


\section{Algunas conclusiones sobre el lugar de la sugestión}

Las consideraciones anteriores se han orientado a cuestionar la acusación de que existe una contaminación sugestiva inevitable de los datos clínicos, lo cual implicaría que el encuadre analítico sería un ámbito inservible para poner a prueba las hipótesis psicoanalíticas $y$, al fin y al cabo, hacer progresar racionalmente a la disciplina. Nuestro cuestionamiento se ha basado en dos ejes:

1) A Grünbaum le parece que el razonamiento freudiano incurre en una argumentación "viciosamente circular" o en una "petición de principio", a la vez que conlleva un "adoctrinamiento" del paciente. Sin embargo, hemos visto que la circularidad viciosa que Grünbaum denuncia se origina en su propia formalización de un argumento de Freud, en la que selecciona premisas provenientes de contextos diferentes. Este estrechamiento de las referencias freudianas, que soslaya la complejidad de su razonamiento y de sus evidencias, no obstante incurre en una significativa equivocación lógica: Grünbaum identifica la noción de circularidad con la de petición de principio; lo cual le impide, entre otras cosas, desentrañar las relaciones existentes entre el fenómeno de la sugestión y el de la transferencia. Por nuestra parte, elucidando el tipo de teoricidad involucrado en tales nociones y atendiendo a la vinculación teórica entre ambos fenómenos, destacamos la posibilidad de establecer una base contrastacional que neutraliza la idea de autojustificación local, alimentada con el planteo de Grünbaum.

Luego de ello, hemos abordado con mayor detalle las relaciones establecidas por Freud entre la sugestión, la transferencia y la resistencia, a los fines de mostrar por qué la metodología del psicoanálisis implica una serie de maniobras técnicas tendientes a localizar y minimizar el efecto de la sugestión, al punto de volverlo una explicación alternativa poco plausible. En este itinerario hemos mencionado algunos argumentos freudianos (en defensa de la acusación de sugestionabilidad) que han sido soslayados por Grünbaum, a la vez que hemos intentado mostrar su vigencia. En virtud de ello nos ha parecido justificado afirmar que Grünbaum ha razonado con la intención exclusiva de persuadir, pues ha partido de una serie de implicaciones tendenciosas, reunidas caprichosamente y a los fines exclusivos de apoyar su crítica y su 
perspectiva filosófica. Esta elucidación ha permitido evidenciar las debilidades del planteo de Grünbaum, así como la presencia de supuestos y valores no explicitados que impregnan su abordaje del problema.

2) En la segunda parte hemos esbozado algunas ideas abogando por una redefinición del problema de la sugestión en psicoanálisis. Asumimos que lo esencial de las definiciones freudianas de la sugestión consiste en su basamento sobre lazos libidinales, lo que convierte al fenómeno sugestivo en algo inherente a las estructuras de relación interhumana. Centrándonos en el costado metodológico del desafío de la sugestión, hemos intentado ir más allá de las defensas que Freud elaboró para sortearlo; haciendo uso de algunas definiciones consensuadas y de algunos planteos contemporáneos: introdujimos la posibilidad de conceptualizar separadamente, en lo que respecta al encuadre de la sesión, la noción de sugestión, la de efectos de las expectativas del analista y la de sesgo de confirmación. Consideramos que lo que se ha tomado como evidencia del efecto sugestivo sobre el paciente puede ser en realidad un producto del sesgo de confirmación del analista. Es muy distinto aseverar que los datos clínicos están contaminados por sugestión que afirmar un tipo de sesgo en el tratamiento de la información clínica no contaminada. Además hemos intentado precisar el lugar que podrían tener las expectativas del analista, sobre todo sus efectos no buscados en el paciente y posiblemente confundibles con fenómenos sugestivos.

A partir de ello hemos intentado deslindar algunas operaciones tendientes a controlar el sesgo de confirmación del analista, a partir de mantener una perspectiva crítica en los ámbitos de trabajo y supervisión clínica, y de formación de psicoanalistas. Además, hemos explicitado la manera común de corregir los efectos de las expectativas del investigador en otras disciplinas, mediante alguna forma de replicación. En lo que a nuestro dominio respecta, la replicación podría homologarse con el establecimiento de corroboraciones de modelos e hipótesis psicoanalíticas; lo cual se traduce automáticamente en una defensa coherente frente a la acusación de contaminación sugestiva. Finalmente, hemos propuesto que la aparición de datos sorprendentes que van en contra de las expectativas de los analistas, constituye una defensa mucho más sólida a la crítica de contaminación sugestiva y que no ha sido tenida suficientemente en cuenta. 
Cabe destacar que el segundo aspecto desarrollado no constituye un conjunto de respuestas cerradas a un problema acabado sino, por el contrario una forma tentativa de redefinir el problema y de abrir nuevas vías posibles para su indagación. Por el momento, a partir del recorrido trazado, debemos concluir rechazando la afirmación de Grünbaum sobre la irremediable contaminación probatoria de los datos clínicos y su insistencia derivada en la necesidad de que las conjeturas psicoanalíticas deban testearse extraclínicamente.

Para finalizar este capítulo, conviene recordar que la acusación de contaminación sugestiva siempre se halla basada en una sospecha y nunca en un hecho probado: debido a que no podríamos saber cuándo y cuáles datos están contaminados por la sugestión del analista, entonces el apoyo que estos prestan al conocimiento teórico es débil. Pese al escepticismo gnoseológico que subyace a este planteo, hemos mostrado que hay buenas razones para afirmar que la acusación de la "posibilidad" de contaminación sugestiva no constituye, por lo tanto, una objeción fundada en datos definitorios, sino una sospecha escéptica que ha hostigado siempre con el mismo ánimo de descrédito y que rara vez (o nunca) se ha traducido en un programa de investigación tendiente a la elucidación esperanzada del problema. En psicoanálisis, esto es parte de los desafíos por asumir.

En lo que sigue intentaremos mostrar que el encuadre clínico posibilita, sin más problemas añadidos que cualquier otro dominio cognitivo, poner a prueba de manera confiable las diferentes hipótesis psicoanalíticas. 


\title{
SEGUNDA SÍNTESIS RETROSPECTIVA
}

\author{
"El oso blanco y la ballena, se ha dicho, no pueden \\ declararse la guerra porque, limitado cada uno a su \\ elemento, nunca se encuentran frente a frente. Igualmente \\ imposible me resulta entablar una discusión con \\ trabajadores del campo de la psicología o de la teoría de las \\ neurosis que no admitan las premisas del psicoanálisis y \\ juzguen artificiosos sus resultados." (Freud, De la historia de \\ una neurosis infantil, p. 47).
}

En esta parte de la tesis hemos expuesto los complejos argumentos que Grünbaum esgrime para considerar que los fundamentos del psicoanálisis son epistemológicamente defectuosos; lo cual impediría establecer su legitimidad como ciencia empírica. En primer lugar hemos reconstruido y expuesto sus argumentos centrales y, en segundo lugar, hemos elucidado críticamente algunas de las premisas que ellos asumen y la manera en la que el autor ha construido su argumentación. Aquí sólo sintetizaremos brevemente este recorrido.

\section{La crítica de Grünbaum}

Nuestro recorrido se inició analizando las objeciones de Grünbaum a los autores que han intentado redefinir las bases epistemológicas y metodológicas del psicoanálisis a partir de la tradición hermenéutica, apartándolo de las discusiones sobre su cientificidad. Él considera que esa identificación de la propuesta freudiana no se condice con las aspiraciones de su creador ni con la estructura de su teoría: constituye una "exégesis mítica" de la que conviene prevenirse porque conduce a un callejón sin salida. El lector podrá notar que no nos hemos adentrado directamente en este argumento; ello se debe a que reservamos un análisis pormenorizado para la parte siguiente de la tesis. Lo 
que sí ha quedado plasmado es el interés de nuestro filósofo crítico por ubicar al psicoanálisis en el campo de las ciencias empíricas conforme a las pretensiones -subrayadas por Grünbaum- de su creador.

Indagamos también las razones por las que Grünbaum rechaza el falsacionismo como criterio de demarcación y afirma que Popper se equivocó al declarar pseudocientífica a la teoría freudiana. En este punto los falsacionistas coinciden con los hermeneutas: ambos pretenden apartar al psicoanálisis del campo de las ciencias, pero lo hacen a condición de mantener una relación de superficialidad con el pensamiento de Freud. Grünbaum se opone al antiinductivismo popperiano y propone, como criterio de demarcación, el inductivismo eliminativo proveniente de la tradición metodológica de Francis Bacon y John Stuart Mill. Desde esta óptica, nuestro crítico analiza las inferencias causales y la evidencia probatoria del psicoanálisis, concluyendo que Freud no ha respetado los cánones inductivistas de la ciencia empírica a los que él mismo adhería.

Vimos que, para Grünbaum, Freud intentó establecer inferencias causales sobre una base exclusiva de datos clínicos. Esto dejaría a la teoría psicoanalítica a merced de tres objeciones principales que conducen a nuestro filósofo a la conclusión de que su metodología sería inviable.

1) el argumento de la coincidencia es lo que, según Grünbaum, utiliza Freud para brindar la justificación epistemológica de las principales hipótesis psicoanalíticas y de su práctica clínica, en tanto que implica una conexión ineludible entre éxito terapéutico y validez teórica. Argumento que, por dos razones, resulta infructuoso: Freud mismo lo habría abandonado cuando, desde 1926 admitió la existencia de remisiones espontáneas. Además, habría estudios empíricos contundentes para desacreditar la afirmación de que el psicoanálisis produce mejores resultados terapéuticos que sus terapias rivales o que atentan contra la posibilidad de establecer la fidelidad de los recuerdos, lo cual mostraría a las claras el error freudiano de asumir ese argumento de indispensabilidad causal.

2) En virtud de ese fracaso, Grünbaum preludia el retorno de una vieja sospecha: los datos clínicos validatorios podrían estar contaminados por la sugestión que ejerce el analista. Además, la amenaza de contaminación sugestiva se ve robustecida por la forma en la que Freud describe la docilidad 
del paciente en transferencia positiva; desafío del que habría intentado defenderse sin éxito, ya que habría incurrido en una argumentación viciosamente circular.

3) Finalmente, la crítica de Grünbaum se centra en el modo inferencial que subyace a la construcción teórica de Freud y a su justificación. Sostiene que las hipótesis sobre los lapsus y los sueños son una extrapolación indebida de la argumentación general de la neurosis, por dos tipos de razones. Primero, porque carecen del equivalente corroborativo del éxito terapéutico de la neurosis $\mathrm{y}$, segundo, porque las retrodicciones esbozadas para explicar su génesis en cada caso clínico son incorrectas: la utilización de la asociación libre incurre en una serie de falacias causales (como post hoc ergo propter hoc) que desestiman los resguardos de la tradición inductivista para prestar apoyo y credibilidad a este tipo de inferencias.

En virtud de tales críticas, Grünbaum concluye que la situación analítica no puede arrojar datos que acrediten las principales hipótesis psicoanalíticas y que la única posibilidad de lograr reunir evidencia probatoria deberá provenir de investigaciones extraclínicas que asuman los cánones del inductivismo eliminativo.

\section{Nuestra tesis sobre la crítica de Grünbaum}

Aquí nos hemos dedicado a analizar uno por uno los argumentos de Grünbaum y hemos arribado a una serie de conclusiones que resumiremos a continuación, para luego plantear nuestra perspectiva general del asunto.

1) Lo que nuestro filósofo crítico denomina argumento de la coincidencia no tiene, al menos para Freud, el valor de una tesis central sobre la fundamentación epistemológica del método psicoanalítico, como él quiere hacernos ver. Hemos mostrado que la narración ideada por Grünbaum de un Freud erigiendo el argumento de la coincidencia en sus años iniciales y abandonándolo posteriormente, es insostenible. Desde sus primeros escritos psicoanalíticos el vienés no sólo admitía la existencia de remisiones 
espontáneas sino que también concedía la existencia de éxitos parciales (aunque inexplicables) a otros procedimientos terapéuticos.

2) La crítica de Grünbaum al procedimiento de la asociación libre, tampoco ha salido bien parada de nuestro análisis. Su principal error es intentar estipular la validez de dicho procedimiento pero separándolo de su contexto específico. Vimos que este error es inherente a la preconcepción filosófica que él adopta al momento de acercase al psicoanálisis y que supone, entre otras cosas, una noción de los factores causales típicamente propia de las disciplinas experimentales. El análisis que Grünbaum efectúa del ejemplo freudiano de aliquis, para denunciar la presencia de las supuestas falacias causales, omite considerar tanto el cúmulo de evidencias que converge en la postulación y justificación de las conjeturas allí elaboradas (que nosotros hemos identificado como un tipo de inferencia abductiva), como el tipo de causalidad (sobredeterminación/no-linealidad) y de entidades causantes (motivos/causas) involucrados en la estructura argumental de Freud. La tesis de la subdeterminación de la teoría por los datos, punto de partida ineludible en la filosofía de la ciencia contemporánea, es curiosamente desestimada por las aspiraciones de certeza epistémica que Grünbaum reclama a la asociación libre.

3) Mucho mayor es nuestra discrepancia con Grünbaum en el carácter parasitario que le adjudica a lapsus y sueños en la extrapolación freudiana de su modelo causal original. Hemos dado razones para reconstruir la base probatoria de esas inferencias causales sobre el concepto whewelliano de la consiliencia de las inducciones, mostrando cómo Freud integra datos provenientes de diversas fuentes y contextos; por lo que la reducción de la validación al contexto de los fundamentos clínicos, tal y como nuestro crítico la presupone, es inviable. Queda así en evidencia que Grünbaum no tiene en cuenta el conjunto de evidencias que, de manera independiente de la evidencia sobre la etiología de los síntomas, confirma las hipótesis freudianas de la formación de lapsus y sueños. Además, la extrapolación freudiana (lejos de ser parasitaria) es una maniobra perfectamente lícita y constituye, en sí misma, un signo de la fecundidad de su programa de investigación.

4) Consecuentemente con lo anterior, hemos argumentado que el valor epistémico otorgado por Freud al conocimiento psicoanalítico no es 
exclusivamente dependiente del valor que el psicoanálisis tiene como procedimiento terapéutico. Hemos expuesto no sólo que Freud extrae apoyo confirmatorio para sus hipótesis, proveniente de los chistes, los tabúes, la historia de las religiones, el comportamiento de las masas, la herencia cultural, la literatura, las acciones fallidas, etc., sino que, además, vemos que en el trabajo investigativo con sus casos clínicos Freud declara reiteradamente cómo sus desarrollos teóricos están ligados a desilusiones desde el punto de vista terapéutico. Por otro lado, hemos argumentado (independientemente de lo que creyese el vienés) que la relación de dependencia causal que Grünbaum establece entre el éxito terapéutico y la verdad aproximada de la teoría psicoanalítica es disparatada en sí misma, debido a tres tipos de razones: a) porque la validez de una teoría mantiene relativa independencia epistémica de sus posibles aplicaciones prácticas; b) debido a que existe evidencia de investigaciones extra-clínicas que confirma significativamente algunas de las principales hipótesis clínicas, sin recurrir a la variable del éxito terapéutico; y c) porque el planteo de Grünbaum omite considerar el papel desempeñado por la metapsicología en la validación de los fundamentos clínicos, para lo que se necesita trascender la racionalidad instrumental y avanzar hacia otro tipo de criterios, que él no ha considerado.

5) Hemos dedicado especial atención a considerar la viabilidad del inductivismo eliminativo como metodología para evaluar la credibilidad del conocimiento causal en las ciencias empíricas en general y en el ámbito psicoanalítico en particular. En primer lugar, hemos intentado mostrar las limitaciones que los cánones de Mill han venido acumulando para sus propósitos originales, concluyendo que su imagen de la metodología científica es, cuanto menos, sumamente simplificada; por lo que su espíritu prescriptivo es ilegítimo y su realizabilidad una quimera. Hemos analizado la propia desestimación de Mill sobre la aplicación de sus cánones al ámbito de las ciencias morales y su complejidad causal, para luego expedirnos sobre su pertinencia en el dominio psicoanalítico: la extrapolación de un criterio de evaluación de las relaciones causales que no ha sido formulado originalmente para el dominio de los fenómenos mentales sino para el dominio de los fenómenos físicos, es irrealizable por la discrepancia de supuestos ontológicos, 
epistemológicos y axiológicos que mantienen ambos tipos de dominios cognitivos.

6) Finalmente, en virtud de la multiplicidad de aspectos involucrados en su análisis, hemos dedicado un capítulo al problema de la contaminación epistémica vía sugestión. Grünbaum ve en ello un obstáculo mayor en el camino de validación psicoanalítica a partir de los datos obtenidos clínicamente. Primero desarmamos las críticas de circularidad y de petitio principii que Grünbaum imputa al razonamiento freudiano, elucidando la confusión conceptual y el escepticismo gnoseológico que subyacen a su planteo. Segundo, introdujimos la posibilidad de redefinir el fenómeno de la sugestión en la situación clínica como una forma de influencia de las expectativas del analista (separándolo además del sesgo de confirmación) que puede ser neutralizada mediante hallazgos confirmatorios compartidos y de hallazgos clínicos sorprendentes. Concluimos rechazando la sentencia de Grünbaum sobre la irremediable contaminación probatoria de los datos clínicos $y$, también, su insistencia derivada en la necesidad de que las conjeturas psicoanalíticas sean testeadas extra-clínicamente (situación que consideramos posible pero prescindible).

Nuestra tesis sobre el planteamiento general de Grünbaum es que constituye una crítica epistemológica insatisfactoria por tres razones: a) su análisis y reconstrucción de los argumentos freudianos oscila entre la agudeza y la exageración, adoleciendo de significativos defectos parciales o siendo, en algunos aspectos, completamente equivocada; b) su argumentación general resulta sesgada por una serie de fundamentos filosóficos indebidamente explicitados y de aspiración injustamente universal; c) sus pretensiones metodológicas soportan la carga de limitaciones y defectos que les son inherentes, pero que se acrecientan exponencialmente en su intento de extrapolación a disciplinas como el psicoanálisis. Consideramos que aunque estas dificultades de la crítica de Grünbaum debilitan el esfuerzo general de sus argumentos, no por ello desvalorizan el sentido general de su propuesta que, al fin y al cabo, ha contribuido a la discusión racional sobre los fundamentos psicoanalíticos como pocas veces se ha visto, manteniéndose en el centro de las discusiones epistemológicas desde hace décadas. El mérito principal de la obra de Grünbaum consiste en brindar una revisión de lo que 
casi siempre se da por sentado en las comunidades psicoanalíticas; de ahí que debamos considerarla, en tiempos donde la discusión crítica de argumentos suele ubicarse detrás de la fe replegada sobre los dogmas de cada parroquia, como agua en el desierto. Dejamos a cada quien el gusto de juzgar, según su recorrido, si lo vislumbrado conduce a algún tipo de oasis o si sólo hemos perseguido otro espejismo.

Ahora bien, en virtud de la centralidad que tienen los aspectos metodológicos en la lectura epistemológica de Grünbaum y considerando que a ello nos abocaremos en lo que sigue de esta tesis, nos permitimos concluir esta parte con algunos comentarios que permitirán reconocer el camino que venimos transitando.

Hemos notado que en el célebre simposio de 1958, Sidney Hook se manifestaba sobre los problemas que implica plantearse el tipo de cientificidad del psicoanálisis. Allí nos alertaba de algo que, si bien parece bastante evidente, a la luz de las objeciones de Grünbaum cobra una significación digna de señalamiento:

Lógicamente, la cuestión relativa al estatus científico del psicoanálisis depende de una respuesta a una pregunta anterior, a saber: ¿qué es lo que convierte en científica a una disciplina? [...] Hasta donde sé, nadie le ha negado estatus científico al psicoanálisis sobre la base de que no es como la física. De hacerlo, tendríamos entonces que descartar la totalidad de la biología como ciencia, lo que sería absurdo. ${ }^{476}$ (Hook, 1959/1964: 214).

Al analizar la crítica de Grünbaum se vuelve transparente que su concepción de la ciencia toma como referente a la física clásica. El inductivismo eliminativo que propone adoptar ha nacido originalmente como un intento de establecer un canon metodológico para las ciencias naturales experimentales; y, por más que en un segundo momento decida refinarlo y aplicarlo al psicoanálisis, no debemos olvidar que su caracterización del método psicoanalítico como "fundamentalmente defectuoso" mantiene como referencia inconmovible unos estándares probatorios previstos esencialmente para la física. Sin embargo,

\footnotetext{
476 "Logically, the question concerning the scientific status of psychoanalysis depends upon an answer to a prior question, viz., What makes any subject scientific? [...] So far as I know nobody has ever denied scientific status to psychoanalysis on the ground that it is not like physics. For we would then have to rule out the whole of biology as a science, which would be absurd."
} 
necesitamos tener presente que la imposibilidad de cumplir con los cánones del inductivismo no es patrimonio del psicoanálisis, sino algo compartido con teorizaciones pertenecientes a la astronomía, a la historia, a la biología evolutiva, la geología, la anatomía comparada, entre varias otras.

No podemos, entonces, compartir enteramente la opinión de Marshall Edelson, para quien la crítica de Grünbaum se basa en argumentos "completamente lúcidos", que la hacen valiosa para el psicoanálisis: "puede funcionar como un poderoso estímulo para pensar seriamente en los problemas que él ha planteado. No sé qué más se le podría pedir a un filósofo de la ciencia"477 (Edelson, 1988: 313). A nuestro modo de ver, por el contrario, mucho más puede esperarse del trabajo de un filósofo de la ciencia que se ocupe del problema de la cientificidad de una teoría; sobre todo si desconoce el oficio de lo que se dispone a evaluar y si su perspectiva adopta una visión adversa. El análisis que Grünbaum efectúa de los argumentos freudianos parte de un desconocimiento del modus operandi de la práctica psicoanalítica y se muestra orientado por una serie de valores epistémicos inherentes a la ciencia natural de tipo experimental, lo cual dista mucho del ideal de análisis epistemológico que podría esperarse de un filósofo que incursiona en las ciencias de lo humano.

Es por ese tipo de desavenencias que la lectura de Grünbaum se suele considerar en sintonía con la de Popper: si bien es cierto que la dedicación del primero supera ampliamente al diletantismo del segundo, la perspectiva de ambos autores sobre el psicoanálisis apunta a la misma descalificación. Tal es así que, para Jorge Ahumada:

\begin{abstract}
...ambas posturas son cara y contracara de una misma moneda. Ambas vertientes del fisicalismo epistémico descartan de modo tajante, en pro del reduccionismo y el deductivismo que las hermana, la cientificidad de la indagación psicoanalítica con argumentos que se muestran como imágenes en espejo. Las ideas de certeza empírica, en el caso del inductivismo estricto, y de realismo teórico, en el caso del falsacionismo popperiano, aunque supongan responder a posturas epistemológicas contrapuestas, desempeñan en la práctica papeles similares. Ambas parten de la idea de que ciencia equivale a formalización, equiparación que
\end{abstract}

477 "... the critique can function as a powerful stimulus to hard thinking about the issues he has raised. I do not know for what more one could ask from a philosopher of science." 
signa a los cartesianismos, para los cuales la ciencia consiste en una mecánica. A partir de Comte la mecánica da su paradigma a todas y cada una de las ciencias: sólo una psicología así planteada merecería para esas posturas el título de ciencia. (Ahumada, 2006: 240).

A nuestro modo de ver, aunque podemos coincidir en que Grünbaum y Popper mantienen similares supuestos respecto al tipo de conocimiento que merece considerarse científico y aunque ambos esbocen una descalificación epistemológica del psicoanálisis, el talante de la crítica de cada uno de ambos es muy diferente. A su vez, lo que resulta bastante evidente luego del análisis y que vale la pena enfatizar, es la ausencia de unanimidad que yace en el seno de la filosofía de la ciencia respecto a la naturaleza de la metodología científica; lo cual debería impedirnos acudirles ingenuamente en busca de algún veredicto de legitimidad para el psicoanálisis.

La legitimidad del ámbito clínico, con sus complejidades y sus problemas, no ha podido ser cabalmente discernida por estas perspectivas epistemológicas. Por eso coincidimos con Ricardo Bernardi en que el cuestionamiento de Grünbaum encierra dos problemas distintos:

\footnotetext{
Tiene razón al señalar la necesidad de que ciertas hipótesis etiológicas o terapéuticas se sometan a estudios de tipo empírico, pero desconoce la necesidad de que otros sectores de la clínica psicoanalítica puedan conservar libre su campo de acción allí donde los procedimientos empíricos resultan demasiado toscos para aportar resultados de interés. La clínica no tiene como única función la de formular hipótesis etiológicas; tampoco se guía en forma directa por ellas, sino que también incluye datos cualitativos de gran valor. El campo de interacción emocional creado constituye un tipo de realidad muy significativa que constituye un campo a bordar desde diferentes perspectivas, no sólo desde las señaladas por Grünbaum. Pero incluso respecto a las hipótesis etiológicas debe tenerse en cuenta que el mantenimiento y crecimiento de la tradición clínica es necesario porque aún cuando sus conceptos se prueben erróneos, constituye el soporte para ulteriores avances, como lo prueba la historia de la medicina. (Bernardi, 1994/1995: 80-81).
}

La clínica es un soporte ineludible, tanto para la validación de las teorías psicoanalíticas como para el desarrollo de la investigación en el campo. En la parte siguiente nos dedicaremos a elucidar algunos aspectos centrales de la fundamentación del conocimiento clínico, cuyos alcances llegan hasta las 
discusiones sobre la identidad de la disciplina y sobre sus metodologías de investigación. 
CUARTA PARTE. De la racionalidad de la indagación psicoanalítica

"Y si cuanto encuentras es en cuanto buscas, siempre, en vano encuentras, en vano buscas" (Antonio Porchia, Voces, p. 102). 


\title{
CAPÍTULO 9: ¿Es posible hacer del programa freudiano una forma de hermenéutica?
}

\begin{abstract}
Con el espíritu hay algo muy especial: ¡se sabe tan poco de él y de su relación con la naturaleza! Yo tengo mucho respeto por él, pero ¿se lo tiene también la naturaleza? Es sólo un fragmento de ella y el resto parece podérselas arreglar muy bien sin este fragmento... (Freud, 1966: 128. Carta a Pfister del 7 de febrero de 1930).
\end{abstract}

as respuestas hermenéuticas a las críticas de Popper y Grünbaum parecen compartir la misma concepción tradicional de la ciencia: al admitir que el psicoanálisis no puede ser evaluado con los criterios probatorios de las ciencias empírico-naturales, concluyen que éste no puede ser una ciencia y que debería ser reconocido como un arte interpretativo. Ambos enfoques parecen adherir a una concepción de la ciencia galileica, que privilegia la certeza empírica y la cuantificación experimental.

En este capítulo intentaremos elucidar qué vínculos guarda el psicoanálisis freudiano con la tradición hermenéutica. Lo primero que mostraremos es que el programa freudiano no puede definirse como una forma de hermenéutica metódica (por razones fundamentalmente metodológicas) y que tampoco puede, como el resto de las ciencias de lo humano en la actualidad, desdeñar toda forma de hermenéutica (por razones fundamentalmente epistemológicas). Intentaremos, por lo tanto, precisar qué tipo de hermenéutica participa en la praxis clínica e investigativa del psicoanálisis y cuáles son sus alcances y limitaciones. Seguido de ello, retomaremos las disidencias entre los partidarios de la hermenéutica psicoanalítica y Grünbaum, respecto al tópico de la causalidad, para intentar abordar algunas aristas del viejo problema de la distinción causas-motivos en la argumentación freudiana. Mostraremos porqué, tanto Grünbaum como los analistas de orientación hermenéutica, se equivocan por igual en sus consideraciones sobre dicho problema. Finalizaremos planteando algunas articulaciones posibles sobre el problema de la causación 
de ciertos fenómenos clínicos singulares, analizando algunas alternativas al modelo de explicaciones nomológico-deductivo.

\section{Desavenencias metodológicas con la hermenéutica metódica}

Ya hemos caracterizado en la primera parte a la tradición hermenéutica y también hemos puntualizado, en la parte destinada a Grünbaum, los aspectos centrales de algunos representantes de esta tradición hermenéutica en psicoanálisis. En este apartado intentaremos mostrar algunas razones que impiden identificar el método psicoanalítico de Freud con la hermenéutica metódica tal y como nace de sus precursores, debido a que hay una serie de supuestos contradictorios que los distancian considerablemente; supuestos que no siempre han sido suficientemente admitidos o tenidos en cuenta y que vale la pena recuperar.

\section{a) La imposibilidad de la comprensión}

Como es bien sabido, todo el esfuerzo de Wilhelm Dilthey (apoyándose en la labor de Friedrich Schleiermacher) estaba puesto en establecer las diferencias entre las ciencias del espíritu y las ciencias naturales, en virtud del tipo de racionalidad que su objeto y su método ponen en juego. El afán de legitimar las ciencias del espíritu traería consigo la distinción de un ámbito de experiencia irreductible por su historicidad, que sólo puede conocerse vía comprensión (y no explicación).

Ahora bien, en términos generales, lo que Schleiermacher o Dilthey designaron como método hermenéutico puede ser vinculado con lo que Freud denominó método psicoanalítico, en lo siguiente: ambos son procedimientos susceptibles de realizarse en ámbitos específicos y en alternancia con otros, pues tanto el hermeneuta como el psicoanalista hacen uso del método para alcanzar sus objetivos en contextos determinados y no en otros.

Dilthey, en su pretensión de obtener fundamentos metodológicos para que las ciencias históricas produzcan conocimiento objetivo, alentó la actitud empática de reconstrucción del mundo de experiencias de la subjetividad 
investigada en la conciencia del investigador (Dilthey, 1883/1949). La clásica tesis de la comprensión podría formularse así: el historiador comprende el sentido de la acción de un agente en el pasado haciendo una analogía con el sentido que él mismo le daría a esa acción si se encontrara en su situación. Hans-Georg Gadamer supone claramente que este procedimiento es equivalente al del psicoanalista:

El psicólogo interpreta porque no puede dejar valer determinadas expresiones vitales en el sentido en el que éstas ponen su referencia, sino que intenta reconstruir lo que ha tenido lugar en el inconsciente. $\mathrm{Y}$ el historiador interpreta los datos de la tradición para llegar al verdadero sentido que a un tiempo se expresa y se oculta en ellos. (Gadamer, 1960/1999: 410).

Asumiendo que Gadamer parece estar refiriéndose a un psicólogo de orientación psicoanalítica, cabe preguntarnos ¿es viable esa comparación? Si así lo fuere, la técnica psicoanalítica no sería más que un tipo especial de hermenéutica, una adaptación de sus presupuestos generales a las circunstancias específicas del encuentro analítico. Una hermenéutica profunda, al decir de algunos como Habermas o Lorenzer.

Sin embargo y visto de cerca, ese carácter empático del método diltheyano, tan criticado posteriormente ${ }^{478}$, se opone a la actitud que Freud prescribió para el ejercicio de su método psicoanalítico:

No sé cómo encarecería bastante a mis colegas que en el tratamiento psicoanalítico tomen por modelo al cirujano que deja de lado todos sus afectos y aún su compasión humana, y concentra sus fuerzas espirituales en una meta única: realizar una operación lo más acorde posible a las reglas del arte. (Freud, 1912a/2004: 114).

La operación analítica parece alejarse de la comprensión empática ${ }^{479}$ diltheyana: se trata de un evitamiento de la identificación con lo que se quiere

\footnotetext{
478 La versión empática o endopática de la comprensión ha sido un punto de discusión significativo al interior de la tradición comprensivista e incluso con algunos filósofos positivistas. Véase, por ej., los debates entre Nagel (1961/2006) y Schütz (1952/1974).

479 Se hace necesaria una aclaración sobre el asunto de la empatía. No es que Freud haya prescindido de dicha noción (Einfühlung), pero el uso que hace nos parece tangencial al procedimiento analítico: la vemos aparecer en relación a lo cómico (Freud, 1905c/2004: 176, 187, 191, 214), en torno al accionar del poeta (Freud, 1907/2004: 38) o en referencia a la identificación (Freud, 1921b/2004: 101, 102, 104). Posiblemente el uso freudiano de la noción de empatía que más cerca esté del método resida en una prescripción sobre los comienzos del
} 
comprender; cuyo recurso concreto es la regla de la atención flotante ${ }^{480}$. Si la interpretación psicoanalítica evita identificarse para comprender, se encuentra en las antípodas de lo que ya Schleiermacher propugnaba para la naciente disciplina: que la identificación del intérprete con el autor es fundamental para alcanzar la comprensión. La posibilidad de la comprensión empática descansa en dos supuestos básicos: 1) la identificación es posible debido a que intérprete y autor comparten una naturaleza humana común que los vuelve coetáneos y elimina la brecha generada por el paso del tiempo y/o la divergencia de contextos; y 2) el sentido es inherente a las cosas mismas. Respecto del primer supuesto, podríamos decir que Freud, implícitamente, primero lo negó y lo aceptó luego: su negación viene dada con las primeras formulaciones del método analítico, en tanto que "asociativo-disociativo" y su asunción se produce con las posteriores introducciones de claves de lectura universales, que le otorgaron al método un carácter "simbólico" (distinción trazada por Jean Laplanche y que abordaremos más adelante). Mientras que la versión inicial del método supone la extrema singularidad de las significaciones inconcientes en juego, luego es complementado por una segunda que opera por la síntesis subsuntiva de toda singularidad en lo universal de los modelos. Esto último se aprecia en los análisis freudianos, desde el Caso Juanito hasta el Moisés de Miguel Ángel y el recuerdo infantil de Leonardo. Esta segunda acepción del método implica algo que podríamos homologar a la primera asunción central de la hermenéutica clásica: es la naturaleza humana común lo que hace posible la comprensión $^{481}$; en Freud esa naturaleza común viene dada, según Jean

tratamiento, en donde recomienda no iniciar las comunicaciones al paciente sin situarse empáticamente (Freud, 1913a/2004: 140). No obstante ese señalamiento, en donde el movimiento empático es apenas un factor interviniente en la instalación de la transferencia, en ningún otro lado Freud parece haber ubicado la noción de empatía como algo central o consustancial al método analítico propiamente dicho (cosa que sí han hecho varios posteriormente a él, p. ej. Kohut, 1959/2009; 1971/1996). Es indudable que las oscilaciones empáticas del analista y su "tacto" para intervenir (cf. p. ej. Ferenczi, 1928/1984) son aspectos ineludibles del dispositivo; pero merecen ser ubicados periféricamente en la definición de la técnica: la detección y selección de los datos analíticos es mediante una forma de escucha específica (atención flotante) que se realiza, al menos inicialmente, en contra de la adjudicación empática e imaginaria de significados compartidos.

480 “... consiste meramente en no querer fijarse \{merken\} en nada en particular y en prestar a todo cuanto uno escucha la misma «atención parejamente flotante»" (ibíd: 111)

481 Asunción que también parece haber adoptado Popper en torno a la supuesta "lógica situacional" de las ciencias sociales: "la 'comprensión' objetiva radica en nuestra consciencia de que la conducta era objetivamente adecuada a la situación [...] El hombre que alimenta 
Laplanche, por el pretendido hallazgo de los mitos dramáticos universales, usados para metaforizar un funcionamiento psíquico trascendental. A la interpretación se le añade una forma de apelación a claves universales de lectura (Edipo, castración, pulsiones, etc.) que opera por subsunción del caso en el modelo teórico.

En este punto es necesario trazar una distinción. Es indudable que el psicoanálisis asume la humanidad común entre intérprete e interpretado, en tanto principio interpretativo fundamental que comparte con las demás disciplinas que abordan lo humano ${ }^{482}$ (Strenger, 1991: 59). Eso supone asumir que el otro es psíquicamente similar a nosotros en aspectos esenciales y que podemos aprehender su sistema de creencias. Pero eso no significa que el conocimiento que podamos obtener de la realidad psíquica del otro sea mediante comprensión empática. Por el contrario, la comprensión, lejos de ser necesaria, es un fenómeno que a menudo el analista debe evitar: recordemos las críticas que Jacques Lacan profirió, basándose en Freud ${ }^{483}$, a la noción Jaspersiana de "relación comprensión" (Lacan, 1955/1995) y sus consecuentes incitaciones a no comprender al analizante (Lacan, 1967). Tal prescripción metódica parte del hecho de que el hablante desconoce las determinaciones inconscientes que producen sus dichos, motivaciones, afecciones y conducta.

tales o cuales deseos es convertido en un hombre a cuya situación se debe que persiga tales o cuales fines objetivos. Lo cual nos posibilita una comprensión de sus actos a la que podemos calificar de objetiva en el siguiente sentido: sin duda, que mis objetivos y mis teorías son diferentes (a las de Carlomagno, por ejemplo); pero si hubiera estado yo en su situación -una situación analizada en éstos y aquéllos términos-, y teniendo en cuenta que la situación incluye objetivos y conocimientos, hubiera actuado, y también hubieras actuado tú, sin duda, de manera semejante" (Popper, 1961/2008: 37). Por su parte, Paul Ricœur también sostiene algo similar: "hay una correspondencia entre la extensión del procedimiento de investigación y lo que podría llamarse el espacio de lo fantástico en general, en el cual llegan a tener lugar producciones psíquicas tan diversas como la ensoñación, el sueño despierto, los juegos infantiles, las novelas psicológicas y otras creaciones poéticas" (Ricœur, 1977/2009: 31).

${ }^{482}$ Carlo Strenger considera que este "principio de humanidad es de crucial importancia en psicoanálisis" e incluso que "el principal paso que dio Freud al inicio de su carrera fue el de radicalizar el principio de humanidad y aplicarlo a fenómenos que antes no eran de su incumbencia. Los síntomas neuróticos y psicoasomáticos comenzaron a ser vistos como humanamente inteligibles" (Strenger, 1991: 62). ["The principle of humanity is of crucial importance in psychoanalytic practice. [...] the fundamental step which Freud took at the beginning of his career was to radicalize the principle of humanity and to apply it to phenomena which were previously exempt from it. Neurotic and psychosomatic symptoms began to be seen as humanly intelligible..."].

${ }^{483}$ Basándose en ese carácter "asociativo-disociativo" que Laplanche posteriormente discriminó como propio de los inicios de la conceptualización metodológica de Freud. 
Este hecho implica la imposibilidad de establecer razones o causas universales para los fenómenos humanos del sentido: como no es posible esperar que un significante tenga anudado un significado universal para todo aquel que lo enuncie, entonces la comprensión empática no es más que un espejismo. Esto tiene, para Lacan, una contracara en la técnica, para analista y paciente. Del lado del analista: "no es lo mismo interpretar que imaginar comprender. Es exactamente lo contrario. Incluso diría que las puertas de la comprensión analítica se abren en base a un cierto rechazo de la comprensión" (Lacan, 1954/2010: 120); y del lado del paciente, el analista francés sostiene que "una interpretación cuyos efectos se comprenden no es una interpretación psicoanalítica" (Lacan, 1966/2012: 229). Posiblemente la diferencia basal reside en la teoría comunicativa en juego y, en última instancia, en la concepción antropológica de ambas perspectivas: para la hermenéutica clásica (Schleiermacher, Dilthey) hay una intención comunicativa que es patrimonio de la conciencia del yo pensante, mientras que los fenómenos clínicos de la neurosis suponen la interferencia de representaciones inconcientes en las intencionalidades comunicativas del yo consciente. Incluso Habermas ha reparado en ello, diciendo que

\begin{abstract}
la interpretación psicoanalítica se ocupa precisamente de esos contextos simbólicos en los cuales un sujeto se engaña sobre sí mismo. La hermenéutica de lo profundo, que Freud contrapone a la hermenéutica filológica de Dilthey, se refiere a textos que indican las ilusiones del autor sobre sí mismo. (Habermas, 1968/1990: 219; cursivas en el original).
\end{abstract}

Se trata de una concepción diferencial que Dilthey y Freud tienen respecto de la biografía. Si para el primero los fenómenos humanos suponen “interioridad" (Dilthey, 1883/1949: 37 y 384), para el segundo los fenómenos humanos suponen una "tierra extranjera interior" ${ }^{484}$ (Freud, 1933d/2004: 53) y es por ello que el psicoanálisis destaca lo enigmáticos que pueden ser, para el propio autor, los fenómenos biográficos. De ahí que el principio metodológico de intentar comprender el punto de vista del agente desde adentro (Spence,

\footnotetext{
${ }^{484}$ Diferencias que repercuten en lo metodológico: "espíritu y alma son objeto de investigación científica exactamente como lo son cualesquiera otras cosas ajenas al hombre" (Freud, 1933b: 147). Es esta reificación original lo que le permitió hipostasiar figurativamente el psiquismo como un aparato y modelizarlo con metáforas naturalistas.
} 
1982), presente limitaciones considerables en el campo analítico. Si quisiéramos expresarlo con terminología de la hermenéutica, diríamos que la interpretación Freudiana trasciende la interpretación hermenéutica clásica puesto que no apunta a vencer supuestas adversidades relativas a la divergencia contextual que separan al autor del lector; por el contrario, apunta a aprehender un sentido deformado por el propio autor e incluso el sentido mismo de esa deformación. Es esto último, el porqué del autoengaño, conjuntamente con la forma de ser realizado (cuyo ejemplo modelo es el sueño) lo que le permite al vienés teorizar reglas para la exégesis de las determinaciones motivacionales del sujeto; es decir, una forma de hermenéutica apartada de la noción clásica de comprensión. Ricœur ha notado que "el desciframiento interpretativo de los síntomas va más allá de una simple hermenéutica filológica, en la medida en que es la estructura misma de estos mecanismos de distorsión la que suscita la explicación" (Ricœur, 1977/2009: $37)$.

El segundo supuesto, de tipo lingüístico, no es asumido por Freud: para él, el sentido es inherente al lector y no al material. Para la hermenéutica, incluso contemporáneamente,

el texto y el intérprete se suponen el uno al otro y se definen mutuamente; no hay texto sin intérprete - presente o virtual- ni intérprete sin texto. En otras palabras, el texto es un llamado dirigido a un intérprete posible y un intérprete es un buscador de textos a desentrañar. (Tubert-Oklander, 2013: 284).

Si asumimos la metáfora de lo inconsciente como texto, debemos no obstante decir que se trata de un texto que no ha sido escrito para nadie. El texto de los sueños freudianos, por ejemplo, data de mucho antes de que sea posible su desciframiento psicoanalítico; justamente porque no posee una intencionalidad comunicativa. Jean Laplanche ha desarrollado bien esta idea:

...el inconsciente es un fenómeno de sentido, pero sin ninguna finalidad de comunicación [...] el inconsciente habla, pero no quiere comunicar nada, no vehiculiza ningún mensaje [...] el síntoma puede existir sin ser mostrado, en esta paradoja de un fenómeno de habla que no está destinado a nadie (Laplanche, 1981: 127-128). 
Quizás la paradoja se disuelva si admitimos que la metáfora de que eso habla nos ayuda sólo hasta cierto punto, a partir del cual debemos reconocer que el diálogo y el lenguaje dejan de ser analogadores viables. Este es un aspecto crucial, pues pareciera que toda la tradición psicoanalítica ligada a la hermenéutica parte del siguiente supuesto: "el gran descubrimiento de Freud fue que toda experiencia y toda conducta humanas son intencionales" (TubertOklander, 2013: 284). A nuestro modo de ver, el problema de los adeptos de la hermenéutica es que han hecho de esa intencionalidad una propiedad inherente al yo consciente. Nosotros aquí coincidimos con Silvia Bleichmar:

\begin{abstract}
El gran descubrimiento del psicoanálisis es haber planteado por primera vez en la historia del pensamiento que es posible que exista un pensamiento sin sujeto [...] Lo difícil de asir es el carácter profundamente para-subjetivo del inconciente, y el hecho de que la realidad psíquica, en sus orígenes mismos, es eso, realidad, al margen de toda subjetividad y conciencia, vale decir, realidad pre-subjetiva, lo cual constituye el rasgo fundamental de su materialidad. Que una vez constituido el sujeto, esta realidad pase a ser para-subjetiva, da cuenta de lo irreductible del modo de funcionamiento del inconciente como ajeno a toda significación, a toda intencionalidad, res extensa, no cogitation. ${ }^{485}$ (Bleichmar, 2004/2005: 83).
\end{abstract}

Una de las nociones que mejor nos permite ilustrar estas desavenencias con respecto a tales nociones, es la de retroacción (nachträglich): supone que el sentido es una elaboración efectuada durante la lectura y no, como para los hermeneutas clásicos, durante la escritura; además supone la hipótesis de que las lecturas no dejan inalterado el material original sino que lo transforman parcialmente, de manera tal que toda lectura conlleva producción y no se reduce al develamiento. En tanto que el sentido es a posteriori, no es posible concebir ninguna interpretación psicoanalítica que pudiera ser absoluta ${ }^{486}$.

\footnotetext{
${ }^{485}$ Vale la pena vincular lo aseverado por Bleichmar con este comentario epistolar de Freud: "para mí es tan arbitrario dotar a todas las criaturas de la Naturaleza con una psique como negar radicalmente que la posean. Concedamos a la Naturaleza su variedad infinita, que va desde lo inanimado a lo orgánicamente animado, desde lo que vive sólo físicamente hasta lo espiritual. Sin duda lo inconsciente es el mediador más adecuado entre lo físico y lo mental, y quizás hasta resulte el muy buscado y jamás hallado "eslabón perdido»." (Freud, 1917/1970: 85-86).

${ }^{486}$ Algo similar expresa Gadamer al finalizar su Verdad y método: "mal hermeneuta el que crea que puede o debe quedarse con la última palabra" (Gadamer, 1960/1999: 673). En términos gadamerianos, podría decirse que nunca hay saber absoluto debido a la imposibilidad de tomar conciencia plena de las condiciones históricas de nuestra situación (nuestros pre-juicios).
} 
Además, si fuese posible hablar de un significado del texto del inconsciente, debería agregarse que no es algo a colegir mediante la interpretación sino que es algo a producir por medio de la construcción. Pero, no debería perderse de vista que la modelización de los aspectos teleológicos del funcionamiento del psiquismo, en términos de sentido o significado, encierra un doble riesgo: o bien el de reintroducir en las explicaciones psicoanalíticas la noción de consciencia yoica como fundamento; o bien el de confundir los supuestos ontológicos de lo inconsciente con su dimensión epistémica, olvidando que el sentido de los hermeneutas es algo relativo a dicho plano epistémico a partir de la existencia del yo reflexionante.

Además de lo anterior, los partidarios de un psicoanálisis hermenéutico no siempre han reparado en las consabidas críticas que la comprensión empática de Dilthey y Schleiermacher ha recibido desde su formulación. Hoy podemos reconocer que se encuentra expuesta a grandes limitaciones, independientemente del psicoanálisis. Carl Hempel, en un texto clásico, ha resumido bien estas objeciones:

Esta comprensión de otra persona según el propio funcionamiento psicológico puede ser un recurso heurístico útil en la búsqueda de principios psicológicos generales capaces de proporcionar una explicación teórica; pero la existencia de empatía por parte del científico no constituye una condición necesaria ni suficiente para la explicación, o la comprensión científica, de ningún acto humano. No es necesaria, porque algunas veces puede explicarse y predecirse en función de principios generales la conducta de psicóticos o de gente que pertenece a culturas muy diferentes de la del científico, aun cuando aquel que establece o aplica esos principios no pueda entender empáticamente a los sujetos. Y la empatía no es suficiente para garantizar una explicación seria, puesto que puede existir un fuerte sentimiento de empatía aun en ocasiones en que estamos completamente errados al juzgar una personalidad dada. (Hempel, 1965/1996: 259).

Más adelante veremos cómo la tradición hermenéutica ha trascendido esta noción empática de la comprensión. Pese a lo cual, la hermenéutica que ha intentado desembarcar al interior del psicoanálisis no pareciera haberse despojado del todo de esta vieja noción de comprensión. 


\section{b. Límites de la metáfora exegética}

Si bien la hermenéutica se define como la teoría y la práctica de la interpretación de textos, la noción de texto ha dejado de remitir al documento escrito para pasar a referir también a otras formas de comunicación humana, como el discurso hablado y la acción expresiva. La noción contemporánea de texto supone, por lo tanto, cualquier expresión significativa susceptible de ser interpretada; es decir, cualquier conjunto de signos susceptible de ser leído.

Teniendo en cuenta esta ampliación de la referencia de la textualidad, debemos situar otra diferencia importante entre hermenéutica y psicoanálisis: un ser humano no es, al menos para Freud, identificable con un texto. Esa metáfora sólo puede ser establecida soslayando las continuidades biológicas existentes entre el hombre y el animal; continuidades que Freud vio inmejorablemente representadas en la obra de Darwin, considerada como la segunda gran injuria al narcisismo del hombre. Esta afrenta biológica implica que

\footnotetext{
El hombre no es nada diverso del animal, no es mejor que él; ha surgido del reino animal y es pariente próximo de algunas especies, más lejano de otras. Sus posteriores adquisiciones no lo capacitaron para borrar la semejanza dada tanto en el edificio de su cuerpo como en sus disposiciones anímicas. ${ }^{487}$ (Freud, 1917/2004: 132).
}

Podría decirse que las orientaciones hermenéuticas han hecho foco en los aspectos que distinguen al hombre del resto de los animales, especialmente el lenguaje simbólico en su función creativa, al punto de borrar sus semejanzas ${ }^{488}$. En ese sentido, los hermeneutas suelen mancillar el método clínico que permite la captura ostensiva de aquellos elementos inconscientes cuya existencia preexiste a su conocimiento.

\footnotetext{
${ }^{487}$ Freud llegó incluso a considerar la aplicabilidad de la segunda tópica al mundo animal: "este esquema general del aparato psíquico habrá de considerarse válido también para los animales superiores, semejantes al hombre en lo anímico" (Freud, 1940/2004: 145).

488 André Green, por ejemplo, considera que el cambio efectuado por Lacan sobre el argumento freudiano de que al principio estaba la acción por la formulación de San Juan de que al principio estaba el lenguaje, es una maniobra típica de los enfoques hermenéuticos (Green, 1984: 231).
} 
Resulta oportuno señalar aquí un dato curioso y que no siempre ha sido tenido en cuenta: Freud no utilizó las frecuentes alocuciones académicas de la tradición hermenéutico-filosófica de su tiempo (Interpretation, Auslegung, Hermeneutik, etc.). Quizás motivado por alguna intensión (no confesa) de evitarlos o quizás por simple utilización de los usos instituidos de la lengua; no lo sabemos, pero el término alemán elegido por Freud para denominar lo que fue traducido al español por interpretación es Deutung. Se trata de un verbo coloquial cuyo sentido se asemeja al que aparece cuando en las costumbres cotidianas de nuestro margen rioplatense se usan los verbos de aclarar, explicar (Escars, 2011a). El hecho de que su fundador, pese a apoyarse en la noción de interpretación, nunca haya afirmado que su nueva ciencia sea de naturaleza comprensiva o hermenéutica, se condice directamente con su rechazo a la supuesta existencia de una discontinuidad radical entre el espíritu y la naturaleza. Esto veto a toda pretensión de originalidad esencial en el objeto de las llamadas ciencias del espíritu, constituye un rechazo implícito del célebre dualismo ontológico psique-materia por parte de Freud (cf. Assoun, 1993/2003: 20-24).

Recordemos, por otro lado, que Freud consideraba a la terapia como la "patria de origen" del psicoanálisis (Freud, 1933b/2004: 140) y que es de allí que proviene el carácter interpretativo de su método. Esto marca una diferencia de base, pues mientras que la hermenéutica de Schleiermacher nace con el objetivo de comprender mediante reglas universales lo enigmático de los textos escritos, el psicoanálisis investiga sistemáticamente la vida anímica inconsciente de sujetos que llegan al analista con la esperanza de aliviar su sufrimiento. Así, la existencia de metas terapéuticas distingue esencialmente la hermenéutica psicoanalítica de otras disciplinas hermenéuticas, tanto en sus orígenes como en sus objetivos. Por eso Thomä y Kächele insistieron en que la interpretación de las obras de arte habitualmente no le causa ningún daño al autor y que "los artistas fallecidos pueden, como máximo, revolcarse metafóricamente en sus tumbas si no logran reconocerse en esa interpretación", pero las interpretaciones psicoanalíticas "se entrometen en los destinos humanos" (Thomä y Kächele, 1988/1990: 33). Es bastante evidente que la metáfora de la exégesis textual suprime el hecho, para nada trivial, de 
que un paciente interactúa activamente con su analista, mientras que un texto no puede angustiarse, hacer insight ni rechazar una interpretación ${ }^{489}$.

Entonces, como las interpretaciones psicoanalíticas no están hechas para textos sino para pacientes con expectativas de alivio o cambio, se coarta de ese modo cualquier repliegue autárquico al círculo hermenéutico: "el intento de probar la eficiencia de las interpretaciones psicoanalíticas conduce al analista a sacar, por lo menos, un pie del círculo hermenéutico confrontándolo con la pregunta sobre la prueba empírica del cambio" ${ }^{490}$ (Thomä y Kächele, 1985/1989: 513). Y aunque algunos hermeneutas saben bien de esta limitación, como por ejemplo Ricœur, no obstante los analistas partidarios de las orientaciones hermenéuticas "se quedan en confesiones de los labios para afuera, en la medida en que sólo se satisfacen con evidencias subjetivas, es decir, con verdades casuísticas, diádico-específicas, dentro del círculo hermenéutico" 491 (ibíd.).

Lo señalado por Thomä y Kächele respeto a los interrogantes sobre el cambio terapéutico habilita otra consideración crítica respecto al planteamiento hermenéutico. Vía la identificación del sujeto con el texto, las perspectivas hermenéuticas suponen una precisa concepción del sufrimiento psíquico, consistente en la distorsión de la propia historia, en tanto que genera alienación y necesidad de interpretación. La labor del analista pareciera consistir en desentrañar esas distorsiones del paciente, ofreciéndole a su comprensión consciente una forma racional de reinterpretar su propia historia. Pues bien, la clínica ha mostrado, desde los días de Freud, que el entendimiento no siempre

\footnotetext{
489 Frecuentemente, cuando se hacen interpretaciones psicoanalíticas de fenómenos biográficos o artísticos, se olvida completamente el hecho de que la actividad del paciente ejerce un rol de control permanente a las pretensiones cognoscitivas del analista; es decir que constituye un factor de retroalimentación constante del rumbo de su pensamiento clínico, del que difícilmente podría prescindirse en la co-construcción del saber de cada paciente o de sus cambios.
}

\footnotetext{
490 Desde una perspectiva diferente, Etchegoyen también critica esta idea: “...si bien el psicoanálisis trabaja efectivamente con elementos significativos (palabras, deseos, símbolos), los trata como datos que pueden ser testeados, no como meros significados o palabras que van a entenderse sólo dentro de un círculo hermeneútico" (Etchegoyen, 2001: 53; cursiva del original).

${ }^{491}$ Aquí Thomä y Kächele, ya no por mor del argumento, llevan el agua de las consecuencias al molino de sus pretensiones de legitimar la investigación extra clínica en psicoanálisis. Veremos en el próximo capítulo que se pueden ver las cosas de otro modo aún en lo que a la racionalidad de la indagación clínicia respecta.
} 
es suficiente para cambiar y que, a menudo, esos cambios se producen sin necesidad de entendimiento alguno por parte del paciente y, no pocas veces, del analista. Si acontece la comprensión consciente de algún cambio en el funcionamiento psíquico, ésta no es inicial sino posterior a dicho cambio; cambio que, por otro lado, difícilmente sea metaforizable como la modificación del sentido de un texto. Si se parte de asumir que "la hermenéutica es la teoría de las operaciones de la comprensión relacionadas con la interpretación de los textos" (Ricœur, 1986a/2002: 71), entonces el problema es evidente: ni la metáfora exegética ni la comprensión que proponen los hermeneutas puede dar cuenta de estos fenómenos constitutivos de la clínica psicoanalítica. ¿Cómo podría la hermenéutica, por lo tanto, dar cuenta de su racionalidad?

Esta polémica puede parecer vetusta pero en realidad no ha sido suficientemente saldada. Por eso Ricardo Bernardi ha insistido recientemente en estas limitaciones que hemos señalado:

\footnotetext{
Si bien el modo de comprensión hermenéutica es en sí mismo enriquecedor, si nos lleva a equiparar en demasía al paciente con un texto, perdemos de vista la dimensión fáctica y con ella la posibilidad de abordajes empíricos, y como consecuencia puede también volverse restrictivo y empobrecedor" (Bernardi, 2015: 841).
}

Advertir las restricciones que conlleva la metáfora de lo psíquico como un texto escrito, nos conduce a cernir mejor las dificultades de reducir el psicoanálisis a una hermenéutica. Hay todavía otro aspecto que merece nuestra atención y que está en relación con lo anterior.

\section{c) La co-construcción de un saber hacer}

Hemos planteado que, a diferencia de lo supuesto por la hermenéutica clásica, en la interpretación psicoanalítica el establecimiento del sentido corre por cuenta del lector. La lectura es en base al intercambio generado entre paciente y analista, por lo cual ambos son, aunque en medidas distintas, autores-intérpretes de una trama singular. Como ya hemos señalado, aunque el establecimiento de sentidos corra por cuenta de la relación analítica, el papel del analista no es apelando a la comprensión o empatía. 
Una conjetura central de Schleiermacher es que la comprensión resulta ser la contracara de la creación del texto, es decir la inversión [Umkehrung] del proceso creativo de su autor (Schleiermacher, 1813/2000). A primera vista, esta idea pareciera guardar alguna relación con lo aseverado por Freud en el ámbito de los sueños, donde el "trabajo del sueño" (la desfiguración de ciertos contenidos representacionales) tiene por contrapartida una operación de lectura: "será la interpretación del sueño la que habrá de restaurar la trama que el trabajo del sueño aniquiló" (Freud, 1900b/2004: 318). Pareciera que, para ambos casos, el resultado es posible si hay cierta recreación del proceso ya acontecido; cuyo resultado es, también en ambos casos, una producción lingüística (un texto o un relato de sueño). Sin embargo, la seductora marcha que este tipo de analogías tiene, para aquellos que se empeñan en reconocer una suerte de esencia hermenéutica de Freud, tropieza rápido con algunas limitaciones: mientras que para la hermenéutica clásica el recrear el estado mental del autor en el momento de crear su texto tiene por finalidad la comprensión o captación de las intencionalidades del autor (arribándose así a conocimiento objetivo), la finalidad del entendimiento analítico es otra. Las operaciones del analista no aspiran a un entendimiento acabado o consistente de los procesos que involucran determinaciones inconcientes ${ }^{492}$, ni tampoco la interpretación tiene una meta en sí misma, sino que constituye un medio privilegiado para contribuir al objetivo de la cura ${ }^{493}$. Para ello, la interpretación psicoanalítica aspira a la producción de un saber-hacer con lo inconsciente, que responsabilice al sujeto y le permita así abordar su sufrimiento. Dicho de otro modo, las pretensiones de hacer consciente lo inconsciente o de llenar las lagunas mnésicas del recuerdo, a pesar de estar en significativa sintonía con la recreación de las condiciones productivas del agente (funcionamiento

\footnotetext{
492 Situación imposibilitada, además, por el estatuto nouménico de lo inconciente, que limita o reduce toda interpretación posible al orden de lo figurativo (cf. Freud, op. cit. 1900/2004).

${ }^{493}$ Es por ello que algunos han decidido concebir al método como una tecnología tendiente a producir resultados predefinidos antes que seguir pensándolo como un procedimiento de pura indagación de conocimientos (Tizón, 1995). Resulta evidente que los cánones de evaluación de la "ciencia pura" y de la "ciencia aplicada" o tecnología, difieren considerablemente; por ejemplo: verdad en una y utilidad en la otra. Thomä y Kächele (1988/1990) se refieren al componente interpretativo del psicoanálisis como una "tecnología hermenéutica". Diversos autores continuan subrayando las semejanzas de la racionalidad psicoanalítica con la techné griega (cf. Vassalli, 2001; Caper, 2009; Echevarría, 2013).
} 
psíquico), no son más que el médium para alcanzar la cura; situación para la cual se necesitan además otras maniobras que no tienen analogía posible con la exégesis textual, como desmontar la transferencia o vencer las resistencias. Se nos antepone, entonces, la definición misma: "el psicoanálisis es una notable combinación, pues comprende no sólo un método de investigación de las neurosis sino también un método de tratamiento basado en la etiología así descubierta" (Freud, 1913b/2004: 211).

Lo anterior contraría evidentemente algunas propuestas, como la de Habermas, que presuponen la posibilidad (utópica o romántica) de que la autorreflexión deja al paciente a disposición de un conocimiento acabado sobre su devenir vital (Habermas, 1968/1990: 215; 1982/1988: 269). Al contrario: "muchos pacientes no son capaces de dar cuenta de los cambios y procesos de formación que se produjeron en ellos. Experimentan sus cambios en la inmediatez del vivir y el actuar, sin poder reflexionar filosóficamente sobre ellos en forma adecuada" (Thomä y Kächele, 2002/2003: 45). Como corolario de lo anterior, la analogía que es frecuentemente esbozada por los hermeneutas entre el método psicoanalítico y el método historiográfico, no pasa de una comparación superficial: al analista le importa el pasado sólo en la medida en que su repetición en el presente constituye una fuente de sufrimiento; por lo tanto, la introducción del pasado es sólo un recurso para la obtención de cambios en el presente a partir de la elaboración de un entendimiento que los aúne. Esto se atisba claramente en Freud, quien no pareciera haber tenido una aspiración historicista ni siquiera en el relato de sus casos clínicos (Laplanche, 1996).

Entonces, el método psicoanalítico no es solamente un camino con el cual llegar a un conocimiento del objeto epistémico, sino que también es, al mismo tiempo, un medio para transformarlo. Esta condición transformativa no es una añadidura variable a la función cognoscitiva (que se supondría principal) sino que es inseparable de ella: el funcionamiento del método psicoanalítico implica la construcción del conocimiento del objeto por la resignificación de la experiencia. Es por ello que la interpretación (junto a las demás operaciones del analista y acciones del paciente) se puede definir más como una labor activa y conjunta que como una contemplación pasiva e individual. Estas son insalvables diferencias respecto del proceder de la hermenéutica de 
Schleiermacher - Dilthey, y han sido completamente pasadas por alto por los que han intentado refundar el psicoanálisis en términos hermenéuticos.

Silvia Bleichmar, asumiendo algunos aspectos del denominado paradigma de la complejidad, sintetiza bien la dimensión plástica de los procesos inconscientes que estamos intentando poner de relieve:

El aparato psíquico es entonces un sistema abierto, capaz de sufrir transformaciones no sólo como efecto del análisis sino de las recomposiciones a las cuales nuevos procesos histórico-vivenciales lo obligan. Al mismo tiempo, y desde el punto de vista de la recepción, el inconsciente es también transformable: el hecho de que los elementos de base que lo componen sean indestructibles no quiere decir que sean inmodificables, en razón de que las relaciones que activan los diversos elementos en conglomerados representacionales -fantasíasnuevos son posibles. (Bleichmar, 1994: 52).

Lo anterior no supone negar que haya muchos aspectos que sintonizan bien entre el proceder de Freud y las aspiraciones generales de la hermenéutica metódica, pero eso no autoriza a desdeñar los puntos en los que sí divergen y que imposibilitan esa identificación epistémica sin renunciar a aspectos fundamentales y vigentes del método psicoanalítico. Esperamos haber podido mostrar que entre el método hermenéutico clásico y el método de Freud hay una divergencia a nivel de las suposiciones antropológico-lingüísticas y axiológicas en juego.

\section{Confluencias epistémicas con la hermenéutica contemporánea}

Un análisis de los intentos de reformulación del psicoanálisis en términos hermenéuticos como el que estamos efectuando, difícilmente podría obviar que la hermenéutica metódica nacida con Schleiermacher y Dilthey en el siglo XIX no constituye más que un punto de partida de una tradición que ha venido complejizándose de manera considerable. En este apartado nos detendremos a precisar el impacto que algunos desarrollos hermenéuticos del siglo XX y XXI han tenido en la empresa que estamos considerando. 
La historiografía de la tradición hermenéutica suele establecer que sus desarrollos en el siglo $\mathrm{XX}$ se desplegaron y consolidaron en dos direcciones divergentes: una ontológica y otra metodológica. La primera, bien representada por el pensamiento de Martin Heidegger y Hans-Georg Gadamer, ha puesto el acento en la comprensión como rasgo inherente a la vida social; mientras que la segunda, representada por Max Weber, Alfred Schütz y Paul Ricœur, ha hecho hincapié en los procedimientos interpretativos de la significación del mundo humano.

A nuestro modo de ver, las orientaciones psicoanalíticas autodenominadas hermenéuticas desde la década de 1970 y 1980, así como el resto de perspectivas afines o derivadas de esta tradición, no siempre han diferenciado suficientemente ambos tipos de orientación hermenéutica. Creemos que el no distinguirlas ha contribuido a mantener vigente algunas dicotomías clásicas (como la de explicación-comprensión) y que ha llevado al error de confundir aspectos ontológicos con epistemológicos y con metodológicos.

\section{a) ¿Aporta la hermenéutica filosófica algo decisivo al psicoanálisis?}

Empecemos considerando, brevemente, las transformaciones de la tradición hermenéutica durante el siglo $\mathrm{XX}^{494}$ y su posible incidencia en las pretensiones hermenéuticas para el psicoanálisis. No podemos obviar cómo la tradición hermenéutica de las ciencias sociales ha llegado a la tesis de que no toda comprensión es comprensión empática ${ }^{495}$, insistiendo en la historicidad de los procesos de comprensión; es decir en los procesos de constitución subjetiva que delimitan en cada momento y lugar los umbrales de la comprensión. Esa

\footnotetext{
494 Respecto a las transformaciones de la tradición hermenéutica, nos basaremos en lo explicitado por Gadamer (1960/1999, en especial el cap. 2.1, § 6 "lo cuestionable de la hermenéutica romántica y su aplicación a la historiografía" y el cap. 3 , §14: "el lenguaje como horizonte de una ontología hermenéutica"); Grondin (1991/1999, especialmente los cap. 5, §3 "La idea de una hermenéutica filosófica de la facticidad" y el cap. 6) y Ricœur (1976/2006, cap. $4, \S$ "Más allá de la hermenéutica del romanticismo").

${ }^{495}$ Se suele conceptualizar la propuesta de Dilthey en términos de "reducción psicologista". En palabras de Carlos Moya Espí: "en esta perspectiva, el significado de una objetivación histórica, aquello que la distingue de un mero objeto físico, estará constituido precisamente por estados de conciencia o vivencias que se expresan en ella. Los procesos y estados psíquicos darán vida y significado al objeto de la historia. Esta tendencia a la reducción psicologista del significado conducirá a una reducción correspondiente en lo que respecta a la comprensión" (Moya, 1985: 8).
} 
tesis supone que un sujeto aprende a dar significado a su entorno a partir de un mundo heredado por una tradición en particular. Analicemos sintéticamente algunos hitos de estas transformaciones.

En su Ser y tiempo (1927/1998) Martín Heidegger sentaba las bases para un viraje ontológico de la hermenéutica: la interpretación dejaba de entenderse como un método para comenzar a ser concebida como una manera de ser del hombre. En este sentido, la hermenéutica ya no es un procedimiento del que pueda hacerse (o no) un uso particular, sino que es una forma de caracterizar la relación del hombre con su experiencia en el mundo (es decir algo omnipresente). Caracterización que radica en el hecho de que no existe experiencia pura del mundo, a la que luego se le podría adosar una u otra interpretación; por el contrario, la realidad se nos presenta interpretada. Se trata de una pre-comprensión cultural (práctica, no intelectual-reflexiva) que nos da la posibilidad de hacer.

Posteriormente, uno de sus célebres discípulos, Hans-Georg Gadamer (1960/1999), retoma la argumentación de su maestro para mostrar el fundamento ontológico de la comprensión. Su tesis versará sobre la determinación que el hombre recibe de su situación histórica, es decir por las condiciones de posibilidad que sus prejuicios le imponen. No es posible deshacernos de tales prejuicios para conocer: aún toda reflexión, en tanto que vuelta del pensamiento sobre sí mismo, es históricamente situada (parte de pre-juicios); por lo que el sentido que se expresa en la alteridad del texto nunca es completamente absorbible. Gadamer llama historia efectual al carácter irrebasable de la tradición histórica, a los límites y posibilidades que dicha historia conlleva para toda configuración de sentido; es decir a las determinaciones de la historia sobre la conciencia del intérprete.

Como no es posible salirse de la historia para observar desde afuera los propios prejuicios que comandan los procesos de comprensión, se dirá que intérprete y texto se encuentran en un círculo hermenéutico ineludible:

El círculo no es, pues, de naturaleza formal; no es meramente subjetivo ni objetivo, sino que describe la comprensión como la interpretación del movimiento de la tradición y del movimiento del intérprete. La anticipación del sentido que guía nuestra comprensión de un texto no es un acto de la subjetividad, sino que se 
determina desde la comunidad que nos une con la tradición. (Gadamer [1960/1999: 363).

En virtud de que "los prejuicios de un individuo son, mucho más que sus juicios, la realidad histórica de su ser" (ibíd. p. 344), Gadamer opera una especie de subordinación de la epistemología a la ontología.

Esta argumentación, de cuño heideggeriano, va en contra de las pretensiones de objetividad que Schleiermacher y Dilthey avizoraron al proferir la necesidad de desprenderse de la propia subjetividad para implementar el método hermenéutico. Tanto Heidegger como Gadamer contribuyeron a superar el carácter psicologista de la Verstehen y su reducción a lo metódico ${ }^{496}$. La hermenéutica pasó a ser concebida como el suelo común sobre el que se edifican las interpretaciones particulares de las diversas ciencias de lo humano. Estas consideraciones sobre la naturaleza lingüística de lo social y sobre la disposición interpretante del hombre, dieron lugar al denominado giro lingüístico de las ciencias sociales: una reformulación de las bases conceptuales del conocimiento por ellas producido.

Todo lo anterior es bien conocido y forma parte de los consensos básicos que los historiadores mantienen respecto al devenir interno de esta tradición. Lo que también resulta bastante conocido, aunque no siempre se repare en ello, es que tales desarrollos de la hermenéutica vinieron a confluir luego con algunos postulados del giro historicista de la epistemología anglosajona; convergencia que coadyuvó a la centralidad que la perspectiva hermenéutica adquiriría luego en el escenario de las ciencias sociales (Lulo, 2002). Cada tradición, más allá de utilizar sus propios términos y estilos narrativos, coincide en algunas conjeturas centrales. Más adelante en este capítulo desarrollaremos esta idea. Veamos ahora algunos ejemplos.

Siguiendo a Karl-Otto Apel, el círculo hermenéutico implica que debemos haber comprendido previamente para poder comprender y, al mismo tiempo, que podemos corregir nuestra precomprensión mediante un esfuerzo de

\footnotetext{
496 Superación en la que también han participado activamente pensadores como Alfred Schütz (1953/1974) y Peter Winch (1958/1990), que por razones de espacio no podremos considerar enteramente; y luego Paul Ricœur y Jürgen Habermas, a quienes recapitularemos a enseguida.
} 
comprensión metódica. Apel ilustra este punto con un ejemplo vinculado al psicoanálisis:

...hay que tener en cuenta, sin embargo, que la interpretación, por ejemplo, de los lapsus verbales como síntomas de motivos ocultos depende de que las «manifestaciones lingüísticas» sean al mismo tiempo «comprendidas» como lapsus a partir de la intención equivocada. Hasta aquí, el psicoanalista permanece en comunicación intersubjetiva con su «objeto». Pero en cuanto encaja los lapsus en el contexto conceptual de su propia teoría como síntomas -digamos en la teoría del complejo de Edipo- se plantea la cuestión de si debe aquí hablarse de una «explicación» o de una «comprensión» más profunda. Porque hay que pensar que el propio psicoanalista considera como conducta conformada a un sentido, esto es, como el lenguaje de una intención inconsciente, a un tipo de conducta que el investigador normal de las ciencias del espíritu no calificaría de conducta "con sentido» - por ejemplo, un tic o un olvido en ciertos asuntos-, es más, a síntomas corporales que dicho investigador normal confiaría desde el principio a la «explicación» del fisiólogo- como, por ejemplo, una afonía que se presenta en determinadas ocasiones. (Apel, 1973/1985: 54).

Pese al distanciamiento que el analista ejerce, la explicación del psicoanalista nos dice Apel- está al servicio de la comprensión. De lo que se trata es de una "corrección de la autocomprensión humana por métodos objetivantes" (ibíd.). A nuestro modo de ver, precomprensión y corrección, junto con la formulación de hipótesis y la puesta a prueba en el tiempo, no son patrimonio de la tradición hermenéutica sino que caracterizan a la ciencia en su conjunto. Si de lo que se trata es de eliminar los errores inherentes a la precomprensión, el procedimiento no es otro que el de la revisión de conjeturas a partir de las inconsistencias que se presentan en un sistema conceptual (con hipótesis sobre los datos e hipótesis explicativas de ellos).

Considérense las siguientes similitudes. Habermas, al reflexionar sobre el abordaje de Popper del problema de la carga teórica de la observación, sostiene: "como hechos fijados empíricamente en los que las teorías científicoempíricas puedan fracasar no cabe considerar sino algo que se constituye en el contexto previo de la interpretación de experiencia posible" (Habermas, 1969/1973: 229). Por su parte, Kuhn ya había planteado algo muy parecido cuando explicaba por qué "lo que ve una persona depende tanto de a qué mira como también de qué le ha enseñado a ver su experiencia visual y conceptual 
previa" (Kuhn, 1962/2010: 215). Aunque cada uno de ambos autores ha dado un lugar distinto al papel desempeñado por la tradición y el aprendizaje, ambos coinciden en su crítica de los fundamentos del positivismo. Considérese ahora la siguiente reflexión de Freud: "el comienzo correcto de la actividad científica consiste más bien en describir fenómenos [...] ya para la descripción misma es inevitable aplicar al material ciertas ideas abstractas que se recogieron de alguna otra parte, no de la sola experiencia nueva [...] tenemos que ponernos de acuerdo acerca de su significado por la remisión repetida al material empírico del que parecen extraídas, pero que, en realidad, les es sometido." (Freud, 1915a/2004: 113). Como puede notarse, estamos ante una crítica compartida al fundacionalismo de los sense data del Empirismo Lógico. Ahora bien, si de lo que se trata es de asumir el papel de los prejuicios implícitos en la conceptualización de la realidad sensible, contrariando el fenomenalismo o fisicalismo de los positivistas ${ }^{497}$, entonces el psicoanálisis no necesita redefinirse en términos hermenéuticos para dar una respuesta. Tampoco son ciertamente novedosas para el psicoanálisis las nociones gadamerianas ${ }^{498}$ relativas a la imposibilidad de tomar plena consciencia de los propios prejuicios o de comprender completamente al otro: Freud había partido de allí cincuenta años antes ${ }^{499}$.

${ }^{497}$ El mito de lo dado, en términos de Wilfrid Sellars, (1956/1967).

${ }^{498}$ Debe recordarse, además, que el propio Gadamer ha reconocido que su primera versión de Verdad y método estaba influenciada por una concepción positivista del método en las ciencias naturales; opinión estereotipada que más tarde supo corregir: "la implicación de una problemática hermenéutica en las ciencias naturales quedó patente para mí, ya en el año 1934, en una acertada crítica de Moritz Schlick al dogma de las proposiciones protocolarias [en Ubre das Fundament der Erkenntnis]. Pero dadas las circunstancias de aislamiento en que se desarrollaron las ideas de este libro, fue el fisicalismo y la Unity of Science la concepción que se impuso finalmente. Aún no había aparecido en el horizonte el linguistic turn de la investigación anglosajona. La obra tardía de Wittgenstein sólo pude estudiarla una vez concluida mi propia trayectoria intelectual, y también comprobé con posterioridad que la crítica de Popper al positivismo entrañaba ciertos temas afines a mi orientación intelectual" (Gadamer, 1985/1998: 12). En otro de sus escritos añadidos a Verdad y método 2, Gadamer se lamentaba de que muchos hayan visto y siguieran viendo en su "filosofía hermenéutica una negación de la racionalidad metodológica" (Gadamer, 1977/1998: 390).

${ }^{499}$ Gadamer insistió en que "lo consagrado por la tradición y por el pasado posee una autoridad que se ha hecho anónima, y nuestro ser histórico y finito está determinado por el hecho de que la autoridad de lo transmitido, y no sólo lo que se acepta razonadamente tiene poder sobre nuestra acción y sobre nuestro comportamiento" (Gadamer, 1960/1999: 348). No es necesario detallar que también para Freud la historia (individual, familiar y de la especie) implica la existencia de determinaciones desconocidas sobre nuestra acción y comportamiento, individual y social. El lugar dado al padre en sus teorizaciones sobre la autoridad y la tradición, quizás sean el mejor testimonio de ello. 
Sabemos que la definición de la hermenéutica como arte de interpretación textual y la consideración del lenguaje como hecho irreductible del mundo social han dado inicio al giro lingüístico de las ciencias sociales, to cual ha implicado un viraje ontológico del saber social: de los hechos observables a textualidades interpretables. Insistimos, sin embargo, que en psicoanálisis no todo es interpretación de una textualidad; si así lo fuere, podríamos afirmar que el proceder analítico sólo supone una reconfiguración del sentido que el analista intenta a partir de la interpretación que el paciente trae sobre su historia, al modo de una "doble hermenéutica", en el sentido de Giddens (1984/2006: 396) por ejemplo. Si es cierto, como sostiene Gadamer en Verdad y método, que la hermenéutica no es tanto una reflexión sobre las ciencias sociales sino una explicitación de los fundamentos sobre los cuales éstas se edifican, entonces debemos decir que la explicitación pretendida por la hermenéutica psicoanalítica no siempre ha podido elucidar cabalmente la complejidad de los fundamentos psicoanalíticos. No podemos estar de acuerdo con él en que sólo "el ser que puede ser comprendido es lenguaje" (Gadamer, 1960/1999: 567; cursiva del original).

El método interpretativo de Freud, del que más adelante nos ocuparemos, apunta al sinsentido de la cosa inconsciente y no al sentido sintético del yo. Así, aunque los efectos de la interpretación no pueden desligarse de la dimensión del sentido, no se agotan en ella. Decir que la ontología de los procesos inconscientes implica la existencia y el funcionamiento de cosas ajenas al yo, significa que eso debe ser explicado como se explican las demás cosas que le son ajenas al yo.

No deberíamos, entonces, confundir entre la comprensión como característica de la vida social (teorizada por la hermenéutica ontológica) y los métodos de interpretación (teorizados por la hermenéutica metódica). La primera se refiere a una condición de base $y$, por ende, necesaria para la segunda. En psicoanálisis, esto es equivalente a la noción de transferencia: su producción es teorizada como inmanente a las relaciones interhumanas, pues se produce desde siempre y más allá de que Freud la haya postulado. Pero esa existencia debe ser diferenciada de su aprovechamiento técnico mediante el análisis, es decir de su instrumentalización. 
La precomprensión ontológica que ha conceptualizado la hermenéutica filosófica es un aspecto básico e ineludible de la cognición humana y no podemos más que estar de acuerdo, como lo están las principales corrientes epistemológicas contemporáneas que, luego del giro historicista de la filosofía de la ciencia, parten de supuestos con consecuencias equivalentes. Sin embargo, el sentido de la comprensión que nace con la hermenéutica metódica, en tanto procedimiento de interpretación del sentido que opera sobre mundos de significación desconocidos, no es parte esencial del método psicoanalítico.

\section{b) Una propuesta actual para el psicoanálisis: la hermenéutica analógica}

A pesar de las consideraciones anteriores, en los últimos años algunos han planteado la importancia de relacionar el psicoanálisis con lo que se ha dado en llamar, a partir de los trabajos del filósofo Mauricio Beuchot, hermenéutica analógica. Juan Tubert-Oklander, psicoanalista argentino radicado en México, sostiene:

\footnotetext{
No basta con decir que el psicoanálisis es una disciplina hermenéutica, ya que existen diversos tipos de hermenéutica, los que determinan formas muy diferentes de concebir los textos, su significado y su interpretación. Tradicionalmente, se han planteado en hermenéutica tres modos posibles de significación, que representan tres formas de distribución de predicados: el univocismo, el equivocismo y la analogía, los cuales a su vez corresponden a las diferentes formas de entender la interpretación en psicoanálisis. La diferencia entre ellos depende del grado de certidumbre que cada hermeneuta asigna a las interpretaciones. Así, el univocismo plantea una certidumbre absoluta, el equivocismo, por lo contrario, maximiza la incertidumbre, y la analogía se ubica en un terreno medio, moderado y prudente, que reconoce las limitaciones de la certidumbre, sin renunciar del todo a ella. (Tubert-Oklander, 2013: 287).
}

Según Beuchot (1997/2009), quien ha diseñado esta propuesta de una hermenéutica analógica, "no se quiere caer en la mera equivocidad ni se pretende una univocidad absoluta, sino una pluralidad de sentidos sujeta a cierto orden, por lo cual puede decirse que se trata de analogía (intermedia entre la univocidad y la equivocidad)" (Beuchot, 1997/2009: 160). El univocismo 
implica, entonces, que para cada expresión significativa existe un solo significado subyacente; por lo tanto las interpretaciones son necesariamente verdaderas (cuando revelan el significado) o falsas (cuando afirman cualquier otra cosa). Como la tarea del intérprete se limita a descubrir el significado oculto del texto, evitando introducir su subjetividad, el significado queda definido exclusivamente en términos de la referencia ontológica del texto (el referente no textual del texto) dejando de lado al sentido, que proviene de la estructura del texto y del código en el que se basa. Esta perspectiva es bien antigua y se encuentra en sintonía con las concepciones epistemológicas que suelen catalogarse como positivistas y han estado a la base de la filosofía analítica de la ciencia. Por otro lado, en virtud de la polisemia natural de cualquier texto, el equivocismo supone que pueden derivarse múltiples interpretaciones, sin que exista un criterio válido para diferenciar entre las buenas y las malas: todas son cognitivamente equivalentes y su elección depende de la conveniencia, la preferencia estética, o cualquier otro atributo subjetivo. Semejante al trabajo del artista, la labor del intérprete no radica ya en el descubrimiento sino en la creación. Esta perspectiva es igual de antigua que la anterior y actualmente se halla representada por las concepciones postmodernistas del conocimiento ${ }^{500}$.

Pues bien, la novedad de la hermenéutica analógica consiste en poner el acento en la noción de analogía ${ }^{501}$, entendida como algo que se ubica entre los extremos mencionados:

se aleja de la univocidad, con lo cual permite abrir el espectro del conocimiento, dando margen para que no haya una sola verdad o una sola interpretación válida, sino varias; pero, como también se aleja de la equivocidad, esas varias posibilidades de verdad se dan jerarquizadas, y además se evita el relativismo; solo se da cabida a un sano pluralismo (Beuchot, 2004: 38-39).

Según esta perspectiva, el criterio que necesitamos para valorar y clasificar las interpretaciones radica en la consideración del "sustrato ontológico del texto

\footnotetext{
500 Puede hallarse un análisis crítico de la recepción psicoanalítica de algunos postulados postmodernistas en Hipermodernidad y teorización en psicoanálisis (Azcona, 2015).

${ }^{501}$ La hermenéutica analógica "se coloca en la línea de Paul Ricœur, que proponía la metáfora como modelo interpretativo [...] sigue su misma tradición, pero intenta llevarla más allá" (Beuchot, 2004: 38).
} 
como objeto y de la realidad no textual a la que éste se refiere -es decir, su referencia-, pero se trata de una ontología parcial y acotada -lo que Gianni Vattimo llama una 'ontología débil'-, necesariamente limitada, pero suficiente como para operar y seguir pensando" (Tubert-Oklander, 2013: 289). Esto es algo que Beuchot (2003) ha denominado una ontología analógica.

Según la perspectiva analógica, por ejemplo, la verdad debe ser conceptualizada en términos de semejanza y no en términos de identidad, porque, entre otras cosas, la primera admite la graduación y la segunda no. Se trata de una verdad parcial y relativa, que permite al intérprete continuar desarrollando su pensamiento y su accionar frente a la realidad ${ }^{502}$.

Las bases analógicas de esta hermenéutica podrían reencontrarse, según Tubert-Oklander, en el propio creador del psicoanálisis:

junto al Freud univocista, que buscaba una certeza científica en la interpretación, hay otro Freud que reconocía el carácter parcial y la multiplicidad de las interpretaciones posibles. No obstante, nunca llega a caer en el relativismo, ya que en momento alguno pierde de vista la referencia a la realidad ontológica de aquello que está siendo interpretado. Lo que plantea, entonces, es un pluralismo, en función de la extrema complejidad del objeto de estudio, que jamás puede llegar a abarcarse plenamente, pero sin abandonar el intento de llegar a saber algo sobre el mismo. Éste es un Freud que hubiera coincidido, probablemente, con la perspectiva de la hermenéutica analógica. (Tubert-Oklander, 2013: 290).

Este carácter analógico de la interpretación freudiana, coincidente con esta forma de entendimiento hermenéutico, llegaría hasta la actualidad de nuestra práctica psicoanalítica: "el analista se enfrenta a las expresiones del analizado a sabiendas de que no llegará a una compenetración plena y perfecta, sino sujeta a límites" (Beuchot, 1997/2009: 162). Reconociendo esto, "el analista se percata de que siempre se infiltra su propia subjetividad (en este caso, la contratransferencia), y tiene que conocer lo mejor posible los alcances de la injerencia de su subjetividad para conocer mejor los alcances de la objetividad que logra." (ibíd.).

\footnotetext{
${ }^{502}$ Planteamiento que ya estaba presente en el pensamiento de Umberto Eco, quien estimó necesario alejarse de los extremos de "la interpretación única" y de "las infinitas interpretaciones", puesto que ambos son fruto del mismo "fanatismo epistemológico" (Eco, 1992: 357).
} 
Además de la analogicidad, Beuchot ha planteado la necesidad de una hermenéutica que considere la iconicidad, es decir aquellos signos no verbales que apuntan a reproducir algún aspecto de la propia experiencia, haciendo uso de imágenes sensoriales —visuales, auditivas, táctiles, olfatorias 0 quinestésicas - para recrearla ${ }^{503}$. A diferencia de los signos verbales, los signos icónicos no se limitan a la referencia a algo sino que nos atrae y conduce a ello.

Según Tubert-Oklander, esta dualidad de las formas de representación coincide con la postulada por Freud a propósito de los sueños: el proceso secundario es un modo de pensamiento verbal y el proceso primario es un modo de pensamiento icónico.

Si bien Freud, fuertemente influido por el racionalismo de la ilustración, concebía a este último como una modalidad primitiva de pensamiento, que debía subordinarse a la lógica y la racionalidad del proceso secundario, algunos de los desarrollos posteriores del psicoanálisis sugieren que existe una complementariedad entre ambos procesos [...] el mayor acceso posible al conocimiento es el que se logra por medio de lo que algunos autores, como Silvano Arieti, Luis Chiozza y André Green denominan el proceso terciario, en el que confluyen los procesos primario y secundario, logrando un equilibrio analógico entre la imaginación y el rigor [...] Estas ideas surgen, en gran medida, de la propuesta de Donald Woods Winnicott... (Tubert-Oklander, 2013: 292).

En virtud de estas coincidencias y del tipo de conocimiento al que conducen, Beuchot desliga una serie de consecuencias sobre su validación epistémica:

De esta manera se puede hablar de una verdad hermenéutica en el psicoanálisis. La prueba de la verdad en éste no puede seguir los moldes de las otras disciplinas. Debe dejársele la verificación que le es específica, a saber: hermenéutica. El procedimiento de verificación es la mejoría en el paciente o analizado. Pero no sólo como resultado utilitario, sino integrando otros criterios. Es la capacidad de dar coherencia a la narración del analizado con la interpretación que da la teoría general; es asimismo el hacer plausible la interpretación de ese

\footnotetext{
${ }^{503}$ Beuchot sigue aquí la caracterización de Umberto Eco: "los signos icónicos no poseen las propiedades del objeto representado sino que reproducen algunas condiciones de la percepción común, basándose en códigos perceptivos normales y seleccionando los estímulos que -con exclusión de otros- permiten construir una estructura perceptiva que -fundada en códigos de experiencia adquirida- tenga el mismo "significado» que el de la experiencia real" (Eco, 1968/1986: 172).
} 
texto narrado y actuado por el analizado, y es también el hacer posible la repercusión de esa interpretación en la conducta y en la vida misma del analizado. Es una verdad más que de coherencia: llega a la verdad práctica. (Beuchot, 1997/2009: 163).

Esta propuesta de pluralidad de criterios parece estar en sintonía con el planteamiento de Ricœur (1977/2009) que ya hemos analizado. Beuchot considera, alejándose de la perspectiva freudiana y emparentándose de lleno con el resto de las pretensiones hermenéuticas para el psicoanálisis, que

es el poder de reconstruir la trama de una vida como una narración coherente lo que ayuda al analizado. Sus bloqueos y confusiones le impiden ver esa trama y el analista tiene que llevar a cabo la humilde y paciente labor de ir entretejiendo los cabos sueltos. (ibíd. p. 166).

A nuestro modo de ver, es en este punto donde se avizora una bifurcación fundamental con el psicoanálisis de Freud, puesto que nada está más alejado de la propuesta freudiana que tejer cabos sueltos para aportar una narrativa coherente a los fines de curar. Por el contrario, el trabajo del analista en el campo de la neurosis es fundamentalmente el de destejer e indicar lo incoherente; sin que ello pueda ser enteramente subsumido en un ejercicio consciencialista.

Evadiendo esta separación que hemos señalado, los partidarios de esta forma de hermenéutica sostienen la existencia de notables coincidencias entre tales desarrollos del psicoanálisis y los de la hermenéutica analógico-icónica, al punto que ambas perspectivas podrían enriquecerse mutuamente. El psicoanálisis podría ganar una "mayor comprensión del sustrato epistemológico de su propia actividad interpretativa, y de la estructura y las leyes que rigen a todos los signos y los textos por ellos formados, que le brinda esta concepción de la hermenéutica" (Tubert-Oklander, 2013: 293).

La hermenéutica analógica parece estar recogiendo la posta dejada por la infatigable carrera de los representantes de la tradición hermenéutica durante la segunda mitad del siglo XX, primero foráneamente y luego desde adentro: redefinir el programa freudiano en términos hermenéuticos apelando a una necesidad disciplinar (Tubert-Oklander y Beuchot Puente, 2008). Esto se advierte bien en los dichos del propio Mauricio Beuchot, quien sostiene que "el 
paradigma hermenéutico es el modelo epistemológico que mejor le conviene [al psicoanálisis]" (Beuchot, 1997/2009: 155). Aunque pareciera que, si se lo expresa en términos de conveniencia es porque se presupone la posibilidad de adoptar otro tipo de fundamentación epistemológica, lo que se está planteando es que sólo "la hermenéutica puede dotar al psicoanálisis freudiano de un andamiaje o modelo epistemológico adecuado" (ibíd. p. 163).

Además, los autores dejan bien en claro que el diálogo propuesto entre hermenéutica y psicoanálisis no es deseable entre cualquier hermenéutica y cualquier psicoanálisis: "resultará más productivo si lo establecemos entre aquellas versiones del psicoanálisis que enfatizan la dimensión relacional y las formas de hermenéutica que buscan un medio analógico entre la identidad que exige el univocismo y la diferencia que rescata el equivocismo, como la hermenéutica analógico-icónica de Mauricio Beuchot” (Tubert-Oklander, 2013: 293).

Como puede verse, los trabajos a partir de la hermenéutica analógica de Beuchot tienen la virtud de admitir la existencia de varias perspectivas hermenéuticas con las que podrían dialogar las orientaciones psicoanalíticas; no obstante lo cual, se propone una fundamentación en la hermenéutica analógica que, pese a sus características distintivas, conserva una serie de supuestos que resultan incompatibles con aquellos aspectos teórico-técnicos de la propuesta freudiana que exceden la dimensión narrativa. Consideramos que el problema relativo al punto de bifurcación fundamental que hemos planteado, ya ha sido abordado por Jean Laplanche en sus consideraciones sobre este tema. Conviene que lo expongamos para extraer de él las implicancias que parece tener toda tentativa de redefinición hermenéutica del psicoanálisis.

\section{c) ¿Es entonces el psicoanálisis una antihermenéutica?}

Jean Laplanche ha abordado el problema de si el psicoanálisis es o no una forma de hermenéutica, representando posiblemente la postura más adversa. Al iniciar su escrito El psicoanálisis como anti-hermenéutica, el autor se pregunta: 
¿cómo habría hecho el psicoanálisis -aunque sólo sea con su obra fundamental, titulada La interpretación de los sueños- para no encontrarse naturalmente con el movimiento hermenéutico que toma vuelo desde finales del siglo XVIII, precisamente como teoría, método y práctica de la interpretación? (Laplanche, 1995/2001: 199).

Para este analista francés, esa identificación sólo puede hacerse a condición de desconocer el proceder psicoanalítico. Reconoce a Ricœur como representante de este desconocimiento y le reprocha "no tener en cuenta en su interpretación de Freud, el método de Freud mismo" (ibíd.). Laplanche asimila a su manera una de las tesis que hemos expuesto de la hermenéutica filosófica: "no hay interpretación sin código o clave de traducción. La hermenéutica se define como una acogida, una transposición o una lectura, de un texto, de un destino, de un Dasein; lectura fundada, evidentemente, en una precomprensión o protocomprensión previa" (ibíd. p. 199-200); y se empeña en sostener que el descubrimiento freudiano va en la dirección opuesta. Para comprender esta idea debemos retomar algo que señalamos sintéticamente más arriba: Laplanche propone distinguir una separación decisiva en la propuesta metódica de Freud, mostrando un punto de bifurcación desde el cual se abre, junto al nominalismo inicial de las descomposiciones en elementos singulares, una variante de lectura con claves universales. El saldo de esta bifurcación pareciera ser la existencia de dos perspectivas metodológicas mutuamente excluyentes en el propio Freud: primero una asociativa-disociativa y luego una simbólica. Una vez efectuada esa separación, Laplanche sostiene que la versión hermenéutica del método psicoanalítico, defendida por algunos como Ricœur, es equivalente a la versión simbólica del método de Freud; y se propone rechazarlas por igual ${ }^{504}$. La razón de este rechazo de Laplanche es su consideración de que el descubrimiento de Freud se efectuó originalmente con en el método asociativo-disociativo; método que constituye, por antonomasia,

\footnotetext{
${ }^{504}$ Laplanche no duda en calificar de "funesto" al cambio operado en el método freudiano hacia 1900, por la "aparición de esos códigos de lectura llamados simbolismo y tipicidad" (ibíd. p. 201). Se trata de un "retorno de la síntesis, de la «lectura», de la hermenéutica" (ibíd. p. 206). En la teoría de Laplanche, el único hermeneuta verdadero es el ser humano en su condición de niño, en tanto que está conminado a descifrar el enigmático mensaje que proviene del otro. Por esto mismo, toda práctica hermenéutica del psicoanálisis no sería más que un "redoblamiento de la represión" (ibíd. p. 210). Contrariando la complementariedad pretendida por Freud para ambas versiones del método, sostiene que hay entre ambos "una relación de exclusión recíproca" (Laplanche, 1997/2001: 226).
} 
una antihermenéutica ${ }^{505}$. Esto es así porque este procedimiento original supone que el modo de acceso de la representación inconsciente vía asociación libre, es el de una cosa, es decir de algo sin sentido inconsciente y carente de toda síntesis consciente. Se trata de un procedimiento de análisis: separación de elementos asociativos que "desdeña cualquier búsqueda de sentido, cualquier comprensión previa [...] no es en absoluto una traducción, una comprensión o una lectura. El método es de detraducción, en busca de elementos llamados inconscientes" (ibíd. p. 201-202). Es decir, se trata de un método que, a diferencia del método simbólico añadido, rechaza la síntesis, en tanto que ésta hace callar a lo inconsciente:

el método analítico original no apunta a un segundo sentido, coextensivo al sentido consciente, sino a elementos significantes que fueron originalmente excluidos, reprimidos, sin organizarse por ello en un segundo discurso. Para decirlo de una vez, el ello no es un segundo yo, eventualmente más verdadero que el primero [...] Ahora bien, el método simbólico [...] se opone al método analítico asociativo por cuanto es cabalmente lectura de un sentido oculto... (Laplanche, 1997/2001: 225; cursivas del original).

Como dijimos, la tesis mencionada lleva a Laplanche a oponerse explícitamente a Ricœur en su definición de la hermenéutica como un arte de interpretación textual mediante reglas. Recordemos que Ricœur había deslindado, desde su propia teorización, consecuencias metodológicas para el psicoanálisis; por ejemplo en su escrito La cuestión de la prueba en psicoanálisis, donde sostuvo que "una buena explicación psicoanalítica debe satisfacer las reglas de universalización establecidas por los procedimientos de investigación en vista del desciframiento del texto del inconsciente" (Ricœur, 1977/2009: 53). Pero debemos señalar que esta afirmación va seguida de una aclaración importante que Laplanche no parece haber tenido suficientemente en cuenta: "la universalización de las reglas de desciframiento descansa en la solidez de la extrapolación analógica que conduce síntomas y sueños a otras expresiones culturales" (ibíd. p. 54). Es decir que con reglas universales Ricœur parece referirse menos a un contenido específico susceptible de

\footnotetext{
505 De hecho, Laplanche llega incluso a decir que "el descubrimiento original de Freud es descubrimiento de un método" (ibíd. p. 206).
} 
generalización que a las hipótesis sobre los mecanismos de formación de fenómenos transaccionales. Además de ello, el planteo de Laplanche encierra un punto oscuro: si el método asociativo-disociativo busca elementos inconscientes (metaforizadas como cosas) entonces necesariamente necesita un marco conceptual para poder dirigir la búsqueda, al igual que lo necesita cualquier otra búsqueda de la índole que sea. Entendemos que lo rechazado por Laplanche es la preexistencia de narrativas generales para la decodificación de los datos de manera estandarizada, en la medida en que ello atentaría contra la singularidad de cada funcionamiento psíquico. En particular, Laplanche parece referirse a la diversidad de fantasías inconscientes, correlativa de la diversidad de sujetos. Pero esto no debería alimentar la fantasía de suponer que pudiera haber observaciones de los fenómenos psíquicos completamente exentas de conceptualizaciones previas: como ya expusimos, siempre observamos desde marcos teóricos (llámeselos teoría, tradición, paradigma, programas de investigación o como sea) y eso supone estructurar previamente, de algún modo u otro, el campo de observación.

Entonces, el argumento de Laplanche (el "abordaje narrativo" es un tipo de "subsunción nomológica" en la que los fenómenos serían casos-ejemplo de alguna trama universal) parece no coincidir con lo que Ricœur estaba planteando. Un tiempo después, el filósofo francés nominó a ese tipo de relación denostada por Laplanche como "comprensión teórica" y la deslindó explícitamente del tipo de comprensión que debería realizar el psicoanálisis hermenéutico (Ricœur, 1985/2004). En lugar de subsumir fenómenos a leyes universales, el narrativismo ricœuriano propone crear una trama singular para cada conjunto de acontecimientos en juego, concediéndoles así un sentido. Se trata, en palabras del autor, de una "comprensión configurante" que debe ser claramente distinguida de la anterior $^{506}$ y cuya implementación libera al psicoanálisis de las estereotipias interpretativas (ibíd.).

\footnotetext{
${ }^{506}$ Ricœur distingue tres modos de comprensión: teórica, categorial y configurante. Las define del siguiente modo: "según el teórico, los objetos se 'comprenden' como casos o ejemplos de una teoría general [...] Para el categorial [...] comprender un objeto es determinar de qué tipo de objeto proviene, qué sistema de conceptos a priori da forma a una experiencia que, en su ausencia, seguiría siendo caótica. [...] Es propio del modo configurante el colocar elementos en un complejo único y concreto de relaciones. Es el tipo de comprensión que caracteriza a la operación narrativa." (Ricœur, 1985/2004: 265).
} 
Como es sabido, Ricœur desarrolla su teoría de la triple mímesis, donde explicar y comprender se distinguen pero también se complementan y condicionan. Además, hemos visto que Ricœur defiende la mixtura irreductible del discurso freudiano, en el que se entreveran causas y motivos. Esto lo ha llevado a distinguir la dimensión técnica de la dimensión teórica del psicoanálisis: mientras que la primera es una especie de oficio, la segunda implica una forma de hermenéutica porque el conocimiento de sí que el análisis ofrece está mediado por relatos. La metodología psicoanalítica es, diríamos, parcialmente hermenéutica para Ricœur.

En virtud de lo anterior, pareciera que las ideas de Ricœur y de Laplanche podrían coincidir respecto a una cuestión central: ambos critican la tendencia universalizante y subsuntiva de los modelos freudianos de interpretación. Para Ricœur el psicoanálisis consiste en la configuración sintética de una trama para la comprensión de los acontecimientos histórico-singulares que aborda y, para Laplanche, es necesario rescatar el método asociativo-disociativo de Freud y su nominalismo.

Hay, sin embargo, un punto fundamental esbozado por Laplanche que vuelve infranqueable la distancia de ambos planteos. Para el analista francés, existe una "tentación fenomenológica" en la que suele caerse a menudo en las perspectivas hermenéuticas: "se trata en todos los casos de restituir al ser humano su condición de sujeto «en primera persona», autor de sus actos y de sus intenciones significantes" (Laplanche, 1993/2001: 93). Tentación que deviene un programa que presupone a la intencionalidad como el fundamento último de todos los actos humanos:

la reducción del inconsciente a un sentido oculto es a mi juicio la tentación constante que lleva al descubrimiento freudiano para atrás, hacia la hermenéutica milenaria. [...] Una hermenéutica donde el «sentido sexual» vendría a superponerse a la infinidad de los demás sentidos posibles (ibíd. p. 64-65).

Este programa constituye un rechazo de la experiencia freudiana, entendida como el "descubrimiento de otra-cosa en nosotros, la cual no actúa regida por el sentido sino según modalidades de orden causal". Este "cuerpo extraño inexpugnable" es lo que habilita a Laplanche a basarse en un "realismo del inconciente" (ibíd.). 
A nuestro modo de ver, este planteo de Laplanche está bien orientado pero encierra una equivalencia injustificada, a saber: que asumir ontológicamente una posición realista respecto de lo inconsciente nos debe llevar a considerar factores causales exentos de intencionalidad. Los modelos explicativos teleológicos y funcionales hacen uso de factores causales intencionales (por ejemplo en biología) sin por ello perder de vista el realismo de las entidades postuladas ni hacer introducir algo parecido a la conciencia o significación humana. Vemos también la utilización de tales modelos explicativos en dominios cognitivos que, aun asumiendo la intencionalidad, prescinden del lenguaje verbal (por ejemplo en etología). Dicho de otra manera, la intencionalidad no necesariamente equivale a intencionalidad de un yo consciente $^{507}$ y trasciende los límites del lenguaje verbal. ¿No ubicó acaso Freud a las representaciones cosa, diferenciándolas de las representaciones palabra, como una forma de significación no verbal? Veremos enseguida que la definición freudiana de sentido es lo suficientemente ambigua como para dar cuenta de estas cuestiones.

Entonces, si por anti-hermenéutica debemos entender el rechazo de la tendencia a interpretar lo inconsciente singular a partir de claves narrativas de lectura universal, tal como propone gran parte de la tradición hermenéutica y como se desprende del método simbólico de Freud, estamos de acuerdo con Laplanche. También Ricœur, pese a la ambigüedad de sus planteamientos, se rehusó a reducir el método freudiano a una hermenéutica, en virtud de la intervención de procesos incomprensibles que deben ser explicados. Es decir que, por distintas vías, ambos autores terminan resistiéndose a la posibilidad de identificar el psicoanálisis con la hermenéutica: para Laplanche está en las antípodas de toda hermenéutica y, para Ricœur, la hermenéutica no permite captar la complejidad del discurso freudiano.

La hermenéutica analógica, en tanto que hermenéutica especial que se ofrece al psicoanálisis contemporáneo como forma de fundamentación epistemológica, conlleva por igual este aspecto que estamos criticando en base a la argumentación de Laplanche. Por eso, aunque podría llegarse a

\footnotetext{
507 André Green parece asumir este supuesto cuando afirma que "la represión es parte integrante de una perspectiva que implica intencionalidad" (Green, 1995/2005: 262).
} 
coincidencias importantes sobre el asunto de la analogicidad e iconicidad, el punto que Laplanche ha señalado constituye un límite irremediablemente para la pretendida identificación del psicoanálisis con cualquier forma de hermenéutica. Resta entonces un última cuestión: ¿tiene algo, entonces, el psicoanálisis de lo que servirse de la tradición hermenéutica?

\section{d) La hermeneutización de la filosofía de la ciencia}

A nuestro modo de ver, hay una serie de aspectos generales que la mayor parte de las disciplinas científicas y de la filosofía de las ciencias contemporáneas ha asumido a partir de la tradición hermenéutica. Ulises Moulines, representante de la concepción estructuralista de las teorías, ha planteado que "la filosofía de la ciencia es esencialmente una parte de las ciencias de la cultura [...] una interpretación de interpretaciones de la realidad" (Moulines, 1995: 110); es decir que le adjudica una naturaleza hermenéutica en sentido amplio.

Moulines se refiere a la epistemología o metaciencia (como él la llama), pero no llega a manifestar abiertamente algo que parece estar implicado: que las ciencias sean esencialmente hermenéuticas. Este planteo sí se encuentra en los desarrollos de Ambrosio Velasco Gómez, quien reconoce cómo las sucesivas fallas de la tradición analítico-naturalista en establecer criterios objetivos para distinguir verdad y falsedad, ciencia y metafísica, etc., que desembocaron en los debates historicistas, muestran una convergencia significativa: "en estos nuevos intentos por explicar la racionalidad científica, los más destacados representantes de la filosofía de la ciencia anglosajona han virado hacia un acercamiento o convergencia con tesis centrales de una tradición alternativa: la hermenéutica" (Velasco Gómez, 1995: 55). Dicha convergencia, que nos parece oportuno recuperar, parece existir en al menos cuatro tesis:

1) Toda investigación científica parte de presupuestos conceptuales de diversa índole (teóricos, metodológicos, axiológicos, etc.) que no siempre son explícitamente formulables pero que guían de manera determinante la observación, formulación y contrastación de hipótesis; 
así como las decisiones respecto a la aceptación, rechazo o modificación de las teorías.

2) La validez de una teoría, su aceptación o rechazo, no puede establecerse en función del grado de corroboración de sus hipótesis sobre una base empírica firme y segura. Tal evaluación implica ponderar la fertilidad de una propuesta en función de un encuadre más amplio (paradigma, programa de investigación, etc.) y a través el tiempo.

3) La racionalidad científica está determinada por el modo de resolución de las tensiones generales entre los presupuestos y convenciones de una tradición y las propuestas innovadoras que emergen en su interior como fruto de la investigación. En tanto que el modo de resolución contribuya a cambios progresivos de la tradición, tanto en términos de adecuación empírica como de capacidad heurística, la actividad científica será una empresa racional.

4) Las tensiones esenciales al interior de una tradición, por ejemplo entre lo aceptado previamente y la innovación, o entre las hipótesis explicativas y la interpretación de lo observado, etc., no pueden resolverse mediante algún procedimiento metodológico, preciso e invariante. La resolución exitosa de tales controversias depende de un juicio prudente ${ }^{508}$ de la comunidad científica competente, a través de sus procesos comunicativos, argumentales, persuasivos y consensuales, que trascienden cualquier criterio estrictamente metodológico. (ibíd.).

Según Velasco Gómez estos puntos de convergencia entre las tradiciones hermenéuticas (postheideggerianas) y naturalistas (postpositivistas) de la filosofía de la ciencia, constituyen un buen indicio para explorar por caminos distintos una nueva noción general de la racionalidad científica, tanto en el ámbito de las ciencias naturales, como de las ciencias socio-históricas. Su

\footnotetext{
${ }^{508}$ En Gadamer, la racionalidad de la decisión de conservar o cambiar determinados prejuicios de la tradición radica en el buen juicio surgido del diálogo y la comunicación en la comunidad a la que pertenece el intérprete: "el buen juicio que involucra la phrónesis, no es un argumento demostrativo. Buen juicio se refiere aquí a un atributo juicioso del que juzga recta y equitativamente. El que posee buen juicio está dispuesto a reconocer el derecho de la situación concreta del otro" (Gadamer, 1960/1999: 396). El lector podrá notar la analogía de esta reflexión de Gadamer, basada en la noción aristotélica de buen juicio, con la perspectiva del buen sentido común de Pierre Duhem (1914/2003: 287), que hemos citado en la segunda parte de esta tesis.
} 
propuesta es tomar como fundamento no a la argumentación metódica y demostrativa, sino a "la argumentación comunicativa, pública, deliberativa, no demostrativa, pero sí convincente, que tradicionalmente se ha asociado al saber práctico y no a las teorías científicas" (ibíd. p. 64). Más allá de esta proposición, con la que adherimos en su espíritu pero que no tenemos por objetivo desarrollar en los términos del autor, consideramos que la hermeneutización de la filosofía de la ciencia debe alcanzar también a la epistemología del psicoanálisis, mostrando una vía para trascender los afanes por reducir la identidad disciplinar a uno u otro de los extremos en tensión. No obstante, hay que decir que esta apuesta programática está lejos de haberse asentado, puesto que aún persisten específicos problemas por resolver.

Gabriel Zanotti también se ha referido a un movimiento de hermeneutización semejante, destacando que el redescubrimiento de la racionalidad no algorítmica se produjo en el seno mismo de la filosofía analítica de la ciencia:

\footnotetext{
lo interesante del debate epistemológico contemporáneo es que el descubrimiento de una noción de ciencia más elástica, más amplia, no fue desde "fuera" de la ciencia. No fueron las sabias palabras de Gadamer, en 1960, las que despertaron a la ciencia de su sueño dogmático. El debate Popper-Kuhn-Lakatos-Feyerabend, que precisamente a partir de la década del 60 toma un gran impulso, fue producto de las semillas plantadas por el mismo Popper en su debate con el neopositivismo. (Zanotti, 2003: 65).
}

Todo ello ha de conducir, según Zanotti, a explorar el papel de la racionalidad prudencial en la actividad científica.

La saludable convergencia analizada por autores como Velasco Gómez y Zanotti debería llevarnos a despejar al menos dos vías usuales de malentendidos: primero, aquellas ideas quiméricas que en las discusiones epistemológicas sobre el psicoanálisis algunos analistas se han fabricado sobre la filosofía de las ciencias naturales o sobre éstas, ya sea para imitarlas o para oponérseles. Segundo, la innecesaria radicalización de la perspectiva hermenéutica como fundamento para el psicoanálisis, cuyo ápice de racionalidad culmina en un rechazo de toda pretensión de objetividad que o bien no se condice con la experiencia clínica o bien no puede servir como supuesto de base para la investigación psicoanalítica. 
A nuestro modo de ver, la confluencia analizada no presenta obstáculo alguno para el psicoanálisis freudiano, que hemos decidido formalizar como un programa de investigación ${ }^{509}$. Sin embargo, también debemos reconocer que la hermenéutica filosófica no ha permitido al psicoanálisis dar una respuesta certera y no evasiva a las críticas epistemológicas de Popper y de Grünbaum, ni arreglárselas con los ineludibles elementos naturalistas que se hallan presentes desde la teorización freudiana. En virtud de todo ello, nuestra tesis en lo que respecta a las relaciones del psicoanálisis con la hermenéutica es la siguiente: si el psicoanálisis ha de tener un fundamento hermenéutico ello se debe a que tiende a compartir las mencionadas tesis sobre la racionalidad del conocimiento y de su evolución, inherentes a la hermeneutización de la filosofía de la ciencia; pero, ello no le impide anteponer a determinados supuestos antropológicos, metodológicos y axiológicos de la tradición hermenéutica, sus propias conjeturas de base a partir de la racionalidad inmanente a su campo de experiencia clínica. Dicho de otra manera, el psicoanálisis es hermenéutico en un sentido amplio y al igual que cualquier otra disciplina científica; pero no puede ser hermenéutico en sentido estricto, ya que no puede compatibilizar algunas de sus asunciones centrales con los fundamentos de esta tradición.

Planteada la tesis anterior, debemos reconocer que el propio desarrollo de la historia de la filosofía de las ciencias muestra que algunos de los aspectos centrales que sostenían la controversia entre naturalismo y hermenéutica, o bien no se excluyen tajantemente o bien pueden trascenderse. A nuestro modo de ver, considerando que la propuesta freudiana supone la presencia de elementos heterogéneos, debe sacar provecho de esta situación elucidando las formas de entrelazamiento de su propia racionalidad epistémica.

En lo que sigue analizaremos uno de esos aspectos controversiales, indagando sus principales aristas con cierta precisión y a los fines de trascender las propuestas programáticas que proponen una disolución de las controversias sin inmiscuirse realmente en su elucidación.

\footnotetext{
${ }^{509}$ El espíritu de la obra de Imre Lakatos parece estar guiado por esas tesis que Velasco Gómez ha puesto de manifiesto.
} 


\section{El debate sobre las causas y las razones en psicoanálisis}

\section{a) ¿Es adecuada la crítica de Grünbaum a la lectura hermenéutica de la causalidad freudiana?}

Según la mayoría de los representantes de la tradición hermenéutica, la explicación freudiana de la acción supone una concepción causal que privilegia o se basa en razones; y que sería incompatible con la explicación mediante las causas de la acción. Comenzaremos analizando la argumentación crítica que efectúa Grünbaum a este planteo hermenéutico.

El primer libro de Grünbaum sobre psicoanálisis (The foundations of psychoanalysis) resulta bastante desordenado: pareciera, al menos por momentos, una especie de miscelánea epistemológica sobre la obra de Freud. Tal es así que entre las páginas que destina a la crítica de Ricœur, intercala una lectura crítica del problema de la distinción causas-razones, que merece ser atendido más allá de la discusión con el filósofo francés.

Grünbaum piensa que Freud no intentaba entender el "significado" de los fenómenos clínicos (síntomas, sueños, lapsus, etc.) a partir de algún modelo lingüístico o comunicacional, sino que apuntaba a elucidar su "causa". Tales fenómenos serían como huellas en la arena: "la huella no es, como tal, un vehículo de comunicación; no es un signo lingüístico o símbolo; no se mantiene semánticamente para, denotar, designar, o referir a la incursión pedal pasada" ${ }^{210}$ (ibíd. p.64). Del mismo modo, la teoría etiológica de la paranoia no supone que el delirio de persecución sea un fenómeno destinado a comunicar la homosexualidad reprimida del sujeto:

La conducta paranoide bien puede ser una salida vicaria para la homosexualidad reprimida, ipero en ningún caso se trata de una etiqueta verbal por ello! Por lo tanto, como hemos visto, etiológicamente el comportamiento es el intento de la persona afectada para hacer frente a las ansiedades generadas por sus impulsos sexuales inconscientes, no su intento de comunicar esos anhelos por medio de delirios y comportamiento de persecución. ${ }^{511}$ (Grünbaum, 1984: 66).

\footnotetext{
510 "The footprint is not, as such, a vehicle of communication: it is not a linguistic sign or symbol; it does not semantically stand for, denote, designate, or refer to the past pedal incursion"

${ }^{511}$ Paranoid behavior may well be a vicarious outlet for repressed homosexuality, but in no case is it a verbal label for it! Thus, as we saw, etiologically that behavior is the afflicted person's
} 
Como vemos, Grünbaum desestima aquí también el intento de vincular los fenómenos que el psicoanálisis aborda con meros hechos lingüísticos ${ }^{512}$, apelando a la concepción freudiana que, en su lectura, es esencialmente causal. Se rechaza así el carácter teleológico de los fenómenos clínicos que la lectura hermenéutica supone, asimilando las pretensiones freudianas con las del científico natural: establecer causas. Por esto mismo, Grünbaum desestimará la posibilidad de reconstruir las explicaciones psicoanalíticas a partir del silogismo práctico ${ }^{513}$; en la medida en que no hay motivos (creencias y anhelos) de ningún tipo que conduzcan al paranoico a realizar sus deseos eróticos homosexuales mediante su paranoia, "no hay una acción inconsciente planificada, basada en la creencia de una conexión entre medios y fines" ${ }^{514}$ (ibíd. p.78). Freud explica la paranoia a partir de una "especie de microestructura causal" ${ }^{515}$ (ibíd. p.76) que media entre la hipótesis de la represión de los impulsos homosexuales y el delirio de persecución ${ }^{516}$. Grünbaum cita un pasaje de Freud sobre el mecanismo de la conversión, que aparece en el historial de Elisabeth y que muestra claramente este punto:

...no puedo proporcionar una especificación del modo en que se establece una conversión así; es evidente que no se la crea como se ejecuta adrede una acción

attempt to cope with the anxieties generated by his unconscious sexual urges, not his/her attempt to communicate these yearnings by means of persecutory delusions and behavior.

512 Nótese que se trata prácticamente de la misma tesis que Jean Laplanche había propuesto algunos años antes; y que ya hemos analizado antes (cf. Laplanche, 1981: 127-128).

513 El silogismo práctico es una estructura formal que permite reconstruir los procesos inferenciales implícitos en la ejecución de una acción, sin recurrir al clásico modelo de cobertura legal: "viene a representar para la explicación teleológica y para la explicación en historia y ciencias sociales, lo que el modelo de subsunción teórica representa para la explicación causal y para la explicación en ciencias naturales" (von Wright, 1971/1979: 49). El esquema, originalmente propuesto por Aristóteles, podría ser descripto así: una serie de premisas explicativas como "el sujeto $S$ se propone dar lugar a $Q$ " y "el sujeto $S$ cree que no puede dar lugar a $Q$ a menos que haga h", seguidas de una conclusión como "el sujeto $S$ se dispone a hacer h" (que resulta inferida de tales premisas).

514 “...there was no unconsciously planned action, based on a belief in a means-ends connection..."

515 "...a kind of causal microstructure as mediating between the hypothesized repressed homosexuality and the engendered paranoid delusions"

516 Ya hemos visto cómo, en el capítulo $4^{\circ}$ de su libro, Grünbaum reconstruye el conocido ejemplo freudiano del olvido de la palabra latina "aliquis", señalando que no se adecúa a la estructura de un silogismo práctico sino de una explicación causal. 
voluntaria: es un proceso que se consuma en un individuo bajo la impulsión del motivo de la defensa, cuando ese individuo -en su organización, o en una eventual modificación de esta- es portador de la proclividad para ello (Freud, 1895/2004: 179-180).

No obstante, Grünbaum sostiene que hay pasajes de Freud que pueden "malinterpretarse" y dar lugar a un intento de aplicación del silogismo práctico. Para mostrarlo, recuerda la postura que Freud mantenía para con la esencia de los procesos inconcientes:

...de muchos de estos estados latentes tenemos que decir que no se distinguen de los concientes sino, precisamente, porque les falta la conciencia. Por eso no vacilaremos en tratarlos como objetos de investigación psicológica, y en el más íntimo entrelazamiento con los actos anímicos concientes. (Freud, 1915b/2004: 165)

Según Grünbaum, constituye un serio error aprovechar estas declaraciones para asimilar la estructura de las explicaciones psicoanalíticas al silogismo práctico. Si bien la expresión freudiana parece la de un modo subjuntivo: "si el agente que alberga ciertos propósitos reprimidos (deseos, metas, o 'intenciones') se hiciera conscientes de ellos, entonces creería que su conducta neurótica es un medio para su cumplimiento y se implicaría en esa conducta desadaptativa"517 (Grünbaum, 1984: 79), en el caso de la paranoia, insiste Grünbaum, la conducta paranoica no es un medio deliberado o planeado por el agente para satisfacer las supuestas representaciones homosexuales reprimidas: dado que el paranoico no tiene la "creencia" de que su conducta le permita alcanzar sus anhelos, entonces tales anhelos no pueden considerarse como "razones de" su comportamiento. Pese a lo cual, tales representaciones son consideradas la causa necesaria del delirio paranoico: "¿no es claro que la transformación hipotética de formación reactiva (donde 'lo amo' es suplantado por 'lo odio') no es menos lógicamente contingente que, por ejemplo, la ley newtoniana del cuadrado inverso de la gravitación?"518. Por ende, resulta

517 "If the agent who harbors certain repressed aims (desires, goals, or "intentions") were made conscious of them, then he/she would believe his/her neurotic conduct to be a means to their fulfillment and would engage in that maladaptive conduct".

518 "Is it not clear that the hypothesized transformation of reaction-formation (in which "I love him" is supplanted by "I hate him") is no less logically contingent than, say, Newton's inverse square law of gravitation?" 
negado el modo subjuntivo y no se trata de una estructura asimilable a la del silogismo práctico. Grünbaum concluye que la noción de intencionalidad apropiada a las explicaciones psicoanalíticas es sólo una noción metafórica, y que no debe, en virtud de faltarle el componente de la creencia o la utilización deliberada de los medios, homologarse a la de intencionalidad mantenida por los defensores del binomio causa-motivo.

Grünbaum sabe muy bien que el esfuerzo por repatriar el psicoanálisis al terreno hermenéutico, se sostiene en premisas más generales:

\begin{abstract}
Parte de la apelación de una conceptualización hermenéutica del psicoanálisis no deriva de los argumentos específicos dados por Ricœur o Habermas. En cambio, esta pretendida reconstrucción gana plausibilidad desde varias tesis afines que se refieren a la función de la intencionalidad en la acción humana. Como se nos dice en algunos sectores, la explicación de la acción por razones es incompatible con la explicación de las causas ${ }^{519}$ (Grünbaum, 1984: 69).
\end{abstract}

Retoma algunos desarrollos sobre la formalización de las acciones humanas mediante el silogismo práctico, en el que se supone la distinción entre causas y razones. Y luego sostiene que Freud, a quien califica aquí de determinista, defendió la inclusión de las razones en el conjunto de las causas. Grünbaum cree que, sin embargo, Freud no perdió de vista la especificidad de las causas ideacionales de la conducta humana (conscientes o no).

Según Grünbaum, los partidarios de la reconstrucción hermenéutica de las explicaciones psicoanalíticas, que parten de oponer causas a motivos, han incurrido en un "error fisicalista ontológicamente reductivo":

Ellos desgraciadamente han pasado por alto que la relevancia causal de un estado antecedente $X$ respecto a una ocurrencia $Y$ no es en absoluto una cuestión de la fisicalidad de $X$; en cambio, la relevancia causal es una cuestión de si X (ya sea física, mental o psico-física) HACE UNA DIFERENCIA para la ocurrencia de Y, o AFECTA LA INCIDENCIA de Y. ${ }^{520}$ (Grünbaum, 1984: 72).

\footnotetext{
519 "Some of the appeal of a hermeneutic construal of psychoanalysis does not derive from the specific arguments given by Ricoeur or Habermas. Instead, this purported reconstruction gains plausibility from assorted cognate theses that pertain to the role of intentionality in human action. As we are told in some quarters, explanation of action by reasons is incompatible with explanation by causes"

520 “.... ontologically reductive physicalistic error: [...] they have unfortunately overlooked that the causal relevance of an antecedent state $X$ to an occurrence $Y$ is not at all a matter of the
} 
Quienes consideren a los motivos como una especie de causa de las acciones, adoptan los mismos fundamentos ontológicos que en cualquier ciencia, afirma Grünbaum; como en el caso en que antecedentes físicos "hacen una diferencia en el resultado" y contribuyen a causar, por ejemplo, eventos astronómicos. Es "lógicamente contingente" el hecho de que sea un "motivo ideacional" (en vez de físico) lo que haga la diferencia para que ocurra un fenómeno comportamental (ibíd. p.72). Una razón es causalmente relevante cuando determina un comportamiento diferencial en el agente, cuando lo mueve a la acción en una forma determinada.

Grünbaum cita algunos analistas que apoyan la distinción entre causas y razones. Roy Schafer, por ejemplo, quien sostuvo que sólo cabe hablar de razones pero no en un sentido causal, en la medida en que la presencia de una razón generalmente no basta para la aparición de una acción derivada. Para Grünbaum esto contradice la concepción freudiana de la causalidad, en la que se apela claramente a la sobredeterminación para explicar: "sostengo que lo dicho por Schafer es simplemente ajeno a este principio fundamental de la explicación causal en la teoría clínica psicoanalítica ${ }^{521}$ (ibíd. p.74). Para Grünbaum, Schafer "se ha apoyado en una concepción mitológica de las ciencias naturales, para erigir un pseudocontraste entre ellas y el psicoanálisis" (ibíd. p.75), pues ha apelado a una noción de causalidad que no resulta viable para ninguna ciencia de nuestro tiempo: considerar que una causa es un fenómeno necesario y suficiente para la producción de una consecuencia.

Según Grünbaum, Ricœur, inicialmente y siguiendo a Stephen Toulmin, diferenció ontológicamente entre causas y motivos, en lugar de considerar a los motivos como un tipo específico de causa. Más tarde, influido por Michael Sherwood, repudió esa tajante dicotomía.

Como se habrá podido notar, la objeción de Grünbaum a los partidarios de la hermenéutica se condice con algunos de los aspectos que hemos señalado antes. Sin embargo, encierra también, junto a las pretensiones de los

physicality of $X$; instead, the causal relevance is a matter of whether $X$ (be it physical, mental, or psycho-physical) MAKES A DIFFERENCE to the occurrence of $\mathrm{Y}$, or AFFECTS THE INCIDENCE of $Y "$

\footnotetext{
521 "I submit that Schafer 's account is simply oblivious of this fundamental principle of causal explanation in the psychoanalytic clinical theory"
} 
hermeneutas que critica, un malentendido respecto a la noción freudiana de intencionalidad. Lo expondremos y analizaremos a continuación.

\section{b) ¿Suponen las explicaciones freudianas una confusión inviable entre causas y motivos?}

La pregunta que titula este apartado ha sido contestada afirmativamente por aquellos que parten de alguna perspectiva hermenéutica, para luego, generalmente, leer en Freud una teoría de los motivos inconscientes. Aunque ya hemos presentado nuestras objeciones a ello, esa pregunta merece ser complementada con la siguiente: ¿se basa la propuesta freudiana en una concepción exclusivamente causal, como han querido ver algunos naturalistas, como Grünbaum? En este apartado argumentaremos una respuesta negativa para ambos interrogantes: la concepción freudiana de la causalidad es desconcertante sólo para aquellos que adoptan como punto de partida el binomio causa-razón, pero su racionalidad se hace viable cuando asumimos un punto de vista que lo trasciende.

Freud cuenta su historia intelectual afirmando que, a diferencia de los intentos de Breuer por hallar explicaciones fisiológicas, él “...entendía las cosas menos científicamente ${ }^{522}$, discernía dondequiera tendencias e inclinaciones análogas a las de la vida cotidiana..." (Freud, 1914b/2004: 10). Los fenómenos psíquicos que Freud analiza constituyen estructuras cuyo esclarecimiento no se alcanza si no se las entiende a partir de su sentido. Pero ¿qué entiende Freud por sentido?:

Pongámonos de acuerdo otra vez sobre lo que entendemos por el «sentido» de un proceso psíquico. No es otra cosa que el propósito a que sirve, y su ubicación dentro de una serie psíquica. Para la mayor parte de nuestras investigaciones podemos sustituir «sentido» también por «propósito», «tendencia» ${ }^{523}$. (Freud, 1917f/2004: 36).

\footnotetext{
${ }^{522}$ La acotación de Strachey es absolutamente pertinente aquí: "«Wissenschafilich», vale decir, en el sentido de las ciencias físico-naturales".

${ }^{523}$ En nota al pie, Etcheverry comenta algo fundamental: "«Tendenz», en alemán, como la palabra castellana "tendencia», abarca los dos sentidos: el subjetivo (orientación de la conducta) y el objetivo (orientación de un proceso), que en inglés se vertirían, respectivamente, por «purpose» $\mathrm{y}$ «trend»".
} 
Ahora bien, admitir que el sentido es una dimensión propia de las explicaciones psicoanalíticas no implica que debamos excluir la dimensión de la causalidad, como han creído generalmente los partidarios de la hermenéutica. Esto es así porque el tratamiento que Freud hace de los fenómenos de sentido, al dejar en suspenso a la voluntad consciente del sujeto, hace intervenir una teleología no equiparable con la intencionalidad de los hermenéuticos. Por ejemplo, en La interpretación de los sueños el vienés plantea que "«interpretar un sueño» significa indicar su «sentido», sustituirlo por algo que se inserte como eslabón de pleno derecho, con igual título que los demás, en el encadenamiento de nuestras acciones anímicas." (Freud, 1900a/2004: 118). Como hemos visto, indicar su sentido es señalar el propósito al que sirve y el modo de funcionamiento de los procesos (psíquicos) intervinientes. Es decir que se trata de una operación que apunta a una conflictividad pulsional del paciente y sus modos de resolución.

Por otro lado, Freud mismo intentó elucidar "el propósito a que sirve" un fenómeno psíquico mediante analogías con procedimientos conocidos del mundo natural o social, y a partir de explicaciones que bien podríamos caracterizar de funcionales ${ }^{524}$. Un ejemplo cabal de ello es la explicación que da de la compulsión a la repetición desde 1920, en la que se establece que ciertas formas de la repetición responden a una necesidad del aparato psíquico que es previa al establecimiento del principio de placer: si puede decirse que esa repetición tiene un sentido, no se trata del mismo sentido exegético que tienen los fenómenos cifrados por la vía del proceso primario ${ }^{525}$, sino de una intencionalidad funcional del psiquismo (dominar y ligar el excedente de

\footnotetext{
${ }^{524}$ Existen considerables aportes que han puesto de manifiesto, en el seno de la filosofía de las ciencias naturales, que no toda explicación implica una pregunta por las causas del explanandum y que hay otras formas de explicar lícitamente un fenómeno o proceso (Braithwaite, 1960: 319; Van Fraassen, 1980/1996: 156; Achinstein, 1983: 219; Cartwright, 1983: 75). La explicación funcional constituye, como ya hemos mencionado, uno de esos tipos diferentes de explicación, que se caracteriza por dar razón de un comportamiento o funcionamiento haciendo alusión a sus finalidades u objetivos.

${ }^{525}$ Respecto de éstos, también vemos a Freud elaborar hipótesis explicativas en donde la significación y la funcionalidad van de la mano: Respecto al síntoma "la tarea que se nos plantea no es otra que esta: para una idea sin sentido y una acción carente de fin, descubrir aquella situación del pasado en que la idea estaba justificada y la acción respondía a un fin." (Freud, 1917j/2004: 247).
} 
estímulo) que se explica a expensas del arte de interpretación que el psicoanálisis venía hasta allí consolidando.

Según Thomä y Kächele, en los historiales clínicos freudianos vemos aparecer un especial tipo de explicación funcional, que puede ser caracterizado como disposicional ${ }^{526}$; ya que es en virtud de las constelaciones conflictivas inconscientes que cada paciente despliega en el espacio analítico determinadas conductas y características personales que se explican mediante disposiciones:

\begin{abstract}
Como el paciente persigue inconscientemente una repetición de su frustración infantil temprana, estructura la situación transferencial de un modo semejante. La constitución de la neurosis de transferencia puede interpretarse como el traslado de tales disposiciones a relaciones objetales revividas. La superación de la neurosis de transferencia llevará entonces al levantamiento de los conflictos inconscientes determinantes previos y con ello al levantamiento de la disposición como modo de reaccionar con fuerza de ley. Si los enunciados disposicionales a menudo no se consideran explicaciones es porque normalmente no se explicita su vinculación con leyes subyacentes. (Thomä y Kächele, 2002/2003: 57).
\end{abstract}

¿Es necesario vincular, nos preguntamos, las disposiciones singulares de un paciente con leyes subyacentes? Veremos luego que no necesariamente. Según estos analistas, el proceso de formación de síntoma podría ser representado siguiendo el esquema lógico del análisis de funciones:

El sistema $S$ es el individuo en el que se forman síntomas patológicos; la disposición $D$ es el patrón de comportamiento neurótico obsesivo que se impone como síntoma; los efectos de la disposición $\mathrm{D}$ pueden caracterizarse como $\mathrm{N}$, que en el caso de la formación de síntomas es la ligadura de la angustia. La explicación funcional consiste en que la condición $\mathrm{N}$ se considera necesaria para un funcionamiento normal de $S$, lo que en el caso dado consiste en que el individuo pueda continuar viviendo en forma soportable, sin crisis anímicas severas. (ibíd. p. 58)

Aunque los autores no lo plantean directamente, la noción de función implica algo que no está implicado por la noción de efecto (propia de las explicaciones

\footnotetext{
${ }^{526}$ Para estos analistas, las explicaciones disposicionales (o intencionales) se refieren, en el contexto de las ciencias de lo humano, a los casos en los que se necesita apelar a tendencias, convicciones, objetivos y otros factores disposicionales para explicar una acción.
} 
nomológico-deductivas): la idea de un beneficio u objetivo esperable. La noción freudiana de beneficio del síntoma, primario o secundario, ejemplifica la pertinencia de esta formalización ${ }^{527}$.

En base a lo anterior podemos decir, entonces, que los hermenéuticos se equivocan tanto como Grünbaum: mientras que los primeros pretenden alejar las explicaciones freudianas del formalismo nomológico-deductivo, omitiendo el afán nomotético que las impregna; el segundo también erra al reducir la estructura teórica a sus elementos causales, soslayando los aspectos teleológicos implicados o equiparándolos con una forma de intencionalidad hermenéutica.

Ricœur ha sido, pese a su propuesta, uno de los primeros en notar la complejidad del pensamiento freudiano respecto de este asunto, planteando que la mediación entre el método de investigación y el método de tratamiento opera de la siguiente forma:

al coordinar la interpretación y la manipulación de las resistencias, la praxis
analítica hace un llamado a una teoría donde la psique es representada a la par
como un texto por interpretar y como un sistema de fuerzas susceptibles de ser
manipuladas. En otros términos, el carácter complejo de la práctica efectiva obliga
a la teoría a superar la contradicción aparente entre la metáfora del texto por
interpretar y la de las fuerzas por manipular; en suma, la práctica nos obliga a
pensar en juntar significación y fuerza en una teoría inclusiva. A través de la
coordinación práctica de la interpretación y de la manipulación de las resistencias
la teoría recibe la tarea de formar un modelo capaz de articular los hechos
considerados como pertinentes en la experiencia analítica. (Ricœur, 1977/2009: 34).

Aunque Grünbaum lo ha omitido, el propio Ricœur había manifestado que el modelo económico preserva algo fundamental: "que la alienación del hombre

\footnotetext{
${ }^{527}$ No obstante, al igual que en el resto de las explicaciones funcionales, las dificultades de esta formalización radican en la definición efectiva de $S$ y en la existencia de distintas disposiciones susceptibles de producir en el efecto N. Thomä y Kächele ejemplifican estas dificultades: "...para ligar la angustia un neurótico obsesivo puede utilizar no solamente el mecanismo de defensa de la desmentida sino también el aislamiento, la transformación en lo contrario, etc. Pero la inclusión de disposiciones adicionales debilita recíprocamente el valor explicativo de las originales [...] La debilidad del análisis funcional radica entonces en su gran amplitud de aplicación descriptiva, mediante la cual se olvida fácilmente su carácter heurístico. Si en el psicoanálisis puede demostrarse que en diferentes clases de individuos operan disposiciones igualmente diferentes, la explicación funcional puede aspirar también a tener valor explicativo." (ibíd. p. 58-59).
} 
por él mismo es tal que el funcionamiento mental se parece efectivamente al funcionamiento de una cosa"; y que esta metaforización tiene consecuencias fundamentales para la identidad de la disciplina:

\begin{abstract}
...impide al psicoanálisis constituirse en una provincia de las disciplinas exegéticas aplicadas a los textos -en hermenéutica en el sentido de Gadamer- y exige que la epistemología del psicoanálisis incorpore los procedimientos exegéticos que participan de la autocomprensión de los segmentos explicativos emparentados con los procedimientos usuales en las ciencias naturales. (Ricœur, 1977/2009: 38).
\end{abstract}

Pese a ello, como ya hemos expuesto, Ricœur considera que el modelo teórico freudiano no resulta adecuado para la experiencia analítica, pues la metapsicología no logra "codificar e integrar en un modelo coherente significación y fuerza, interpretación textual y manipulación de las resistencias" (ibíd. p. 35). Ricœur primero ve en esta duplicidad de la epistemología freudiana un rasgo de fragilidad, pero luego parece haber elevado esta mixtura al rango de ejemplar de una nueva concepción que llamó teoría del arco hermenéutico ${ }^{528}$.

Su planteo no era totalmente novedoso, pues algunos años antes Michael Sherwood había sentado las bases para trascender la dicotomía entre causas y motivos, aduciendo que esa separación nunca estuvo presente en Freud. En la parte crítica de su Logic of Explanation in Psychoanalysis sostiene que lo característico de la explicación psicoanalítica es hacer intervenir motivos que son causas y que requieren una explicación de su participación y funcionamiento en los procesos psíquicos (Sherwood, 1969). Ricœur se apoya en las ideas de Sherwood para decir que Freud no podía distinguir entre causa y motivo, "en la medida en que invita a una explicación en términos de causas, en vista de alcanzar una interpretación en términos de motivos" (op. cit. p. 41). De ahí que el filósofo francés no pueda más que señalar el impasse al que nos conduce la elucidación del modelo explicativo freudiano:

\footnotetext{
${ }^{528}$ En un ensayo posterior Ricœur sostiene que "explicar y comprender no constituirían los polos de una relación de exclusión, sino los momentos relativos de un proceso complejo que se puede llamar interpretación" (Ricœur, 1986b/2002: 150).
} 
Si el modelo económico de Freud puede ser legítimamente acusado de suscitar un malentendido concerniente a la relación entre teoría y situación analítica, hay también que añadir, con no menos fuerza y en sentido inverso, que un modelo de comprensión - ya sea fenomenológico, lingüístico o simbólico - que no integra un segmento explicativo, una fase económica, desconoce los hechos mismos que han sido llevados a la luz por la experiencia analítica. Por esta razón, hoy no se puede ni quedar satisfecho con la metapsicología freudiana, ni encontrar otro punto de partida para rectificar y enriquecer el modelo teórico, de tal suerte que sea cierto decir que la incomprensión del psicoanálisis que lo reduce a una ciencia natural no está desprovista de fundamento. (ibíd. p. 42).

Ricœur considera que la explicación psicoanalítica tiene la virtud de poder "insertar algunos segmentos de explicación causal en el proceso de autocomprensión formulada en términos narrativos. $Y$ este rodeo explicativo justifica el recurrir a medios no narrativos de prueba" (ibíd. p. 49). Tales medios no narrativos estarían representados, en la estructura conceptual freudiana, mediante tres tipos de enunciados: generalizaciones, leyes y axiomas (nombre que utiliza para las "hipótesis muy generales"). Lo interesante del planteo en este punto es que Ricœur afirma que ya en el nivel de las generalizaciones aparecen involucrados elementos no narrativos:

\footnotetext{
los motivos esgrimidos -por ejemplo los celos- no son fenómenos singulares, sino clases de inclinación bajo las cuales se sitúa una acción particular con vistas a volverla inteligible. Decir de alguien que ha actuado por celos, es invocar a través de una acción particular un rasgo que es captado desde el principio como repetible y común a una variedad de individuos. Tal motivo extrae su fuerza explicativa de su capacidad para situar una acción particular en un contexto significativo caracterizado desde el principio por una cierta universalidad de significación. (ibíd. p. 50).
}

Así, explicar apelando a los celos del agente equivale a caracterizar una acción asignándole por causa un motivo que ejemplifica una clase. Aunque Ricœur no lo diga, esto se acerca bastante al espíritu del modelo explicativo de cobertura legal. La pregunta que merece ser planteada es si resulta necesario vincular los aspectos no narrativos de la explicación psicoanalítica a la estructura de las explicaciones causales mediante leyes universales o si, por el contrario, es necesario buscar otras alternativas. 
Algunos años después, ciertos analistas con vocación epistemológica reafirmaron este carácter híbrido de la identidad disciplinar del psicoanálisis freudiano (Assoun, 1981/1982; Kolteniuk Krauze, 1976), en tanto que no podía ser completamente reducido a ninguna de las grandes tradiciones epistemológicas que habitaban al interior de las ciencias de lo humano. PaulLaurent Assoun lo expresó cabalmente de la siguiente manera:

...en el centro del freudismo hay una problemática energética y una teoría del
sentido. Pero Freud nunca se presentó como un sintetizador de la energía y del
sentido [...] ¡Nunca las separó una de otra! Esto es lo que importa para asumir una
identidad freudiana y sacar sus consecuencias. [...] Freud no se pasea del
naturalismo a la hermenéutica, como de una estación a otra: naturalismo y
hermenéutica están unidos en Freud como un solo y mismo lenguaje. Ésa es la
realidad epistémica freudiana que hay que pensar en su lugar propio" (Assoun, 1981/1982: 26).

Más recientemente, en la misma línea, Carlo Strenger ha planteado que "el psicoanálisis está inevitablemente atrapado en el campo de tensión entre la hermenéutica y la ciencia"529 (Strenger, 1991: 215). Ello se debe a que combina esas dos maneras de enfocar al hombre que, tempranamente, Bertrand Russel (1927) denominó desde adentro y desde afuera: como disciplina hermenéutica, se orienta a comprender al ser humano desde su propia perspectiva y realidad psíquica, la cual determina su manera de ser y actuar; como ciencia, se propone explicar al hombre a partir de hipótesis legaliformes que no necesariamente coinciden con la perspectiva de los sujetos abordados. Para desarrollarse como ciencia, sostiene Strenger, el psicoanálisis necesita urgentemente realizar investigación empírica, especialmente sobre cuáles son los factores terapéuticos que inciden en los procesos de cambio ${ }^{530}$. En este punto el planteo de Strenger tiene sus bemoles, ya que él considera que el trabajo del analista supone la combinación de varias facetas que se mueven

\footnotetext{
529 "Psychoanalysis is inevitably caught in the field of tension between hermeneutics and science"

${ }^{530}$ Strenger parece adherir a una concepción tradicional de la ciencia, que se evidencia en el uso que hace de la expresión investigación empírica, sin mayores aclaraciones: pareciera adoptar implícitamente el ideal del tipo de investigación hegemónica en las ciencias naturales experimentales. ¿Es ese el único tipo ideal de investigación al que se debe aspirar para poder definir al psicoanálisis como una ciencia?
} 
entre el descubrimiento y la creación de significado: ¿deja eso inexorablemente atrapado al psicoanálisis en el limbo de las disciplinas, entre la ciencia y la hermenéutica?

A nuestro modo de ver, sólo un punto de vista que trascienda la dicotomía causas-motivos permite ponderar de una manera más justa el significado de esa ambivalencia freudiana, ya no como una confusión epistemológica de sus supuestos sobre la filosofía de la acción sino como una postura en la que reposaba, en potencia, la idea de que las razones son causas de la acción. Uno de los filósofos que probablemente más ha contribuido a esta superación de la dicotomía es Donald Davidson ${ }^{531}$. Lo interesante es que el propio Davidson ha recuperado la propuesta freudiana para señalar que en ella

no existe un conflicto esencial entre las explicaciones fundadas en razones y las explicaciones causales. Puesto que las creencias y los deseos son causas de las acciones para las que son razones, las explicaciones fundadas en razones incluyen un elemento causal esencial (Davidson, 1981: 5)

Esta perspectiva resuelve algunas de las contradicciones que, prima facie, aparecen en el pensamiento de Freud sobre la causalidad de la acción. Veámoslo brevemente.

Davidson aborda el problema de la irracionalidad, que define (en base a la noción aristotélica de akrasia y tomando como ejemplo una acción del historial del Hombre de las ratas) como aquel caso "en el que el agente sabe qué está haciendo y por qué lo está haciendo y sabe que no es lo mejor y sabe por qué" 532 (ibíd. p. 17). Es decir que la irracionalidad aparece definida en términos de inconsistencia interna del agente, entre sus patrones de creencia, actitudes,

\footnotetext{
${ }^{531}$ Davidson (1963/1995) propuso un enfoque alternativo a las dicotomías que hasta la década del '60 habían comandado el tópico de la filosofía de las acciones humanas. Allí planteó considerar las razones como causas y a las explicaciones por razones como explicaciones causales, tratando por un lado de resaltar la importancia de la racionalización en la explicación de la acción (sin rechazar el poder causal de las razones, a los fines de explicar la acción) y, por otro lado, intentando destacar el carácter causal de las razones (sin ceder completamente al naturalismo, en tanto consideró que no puede haber leyes psicofísicas o psicológicas en sentido estricto).

${ }^{532}$ En otro de sus escritos, define a la conducta incontinente con la siguiente fórmula: "Al hacer $x$, un agente actúa de manera incontinente si y sólo si: (a) el agente hace $x$ intencionalmente; (b) el agente cree que hay una acción alternativa y que le es asequible; y (e) el agente juzga que, hechas todas las consideraciones, sería mejor hacer $y$ qué hacer $x^{\prime \prime}$ (Davidson. 38). Se trata de una definición de la irracionalidad, en tanto que el agente actúa contrariando su mejor juicio.
} 
emociones y acciones; emergiendo en un trasfondo de racionalidad. Seguido de ello, propone la siguiente tesis: "muchos ejemplos comunes de irracionalidad pueden caracterizarse por el hecho de que hay una causa mental que no es una razón [para la acción que ocasiona]" (Davidson, 1981: 10). Según Davidson, el mérito del psicoanálisis ha sido brindar una explicación fecunda de la conducta irracional mostrando aquellas "causas que no son razones" o señalando de qué modo ciertas partes del psiquismo causan ciertos eventos "sin ser razones para ello". Esto se comprende mejor si se tiene en cuenta el criterio de Davidson para definir el ser razón de: "una razón racionaliza una acción sólo cuando se conforman apropiadamente las descripciones, y cuando las descripciones apropiadas no son lógicamente independientes" (Davidson, 1963/1995: 30).

A nuestro modo de ver, la teorización freudiana ilustra bien el hecho de que "se puede decir que las razones constituyen causas precisamente cuando el sujeto puede ignorar las razones de su acción y, sin embargo, las reconoce como sus razones en un momento dado" (Cavell, 2000: 106). Además, la teorización freudiana tiene el mérito de enfocar la pluralidad de factores causales, nomológicos y teleológicos, que permiten explicar mejor la acción irracional (en el sentido de Davidson ${ }^{533}$ ).

Lo anterior contribuye a replantear el dualismo abierto por el enfoque causalista (defendido por algunos críticos naturalistas como Grünbaum) y las perspectivas intencionales (adoptadas por la mayoría de los analistas partidarios de los enfoques hermenéuticos), reconociendo el potencial de la propuesta freudiana para trascenderlo ${ }^{534}$.

En la actualidad, la filosofía de las ciencias sociales cuenta con argumentos promisorios para abogar por alternativas no dicotómicas al binomio causa-

\footnotetext{
${ }^{533}$ Para un análisis de la evolución del abordaje davidsoniano del problema de la racionalidadirracionalidad, cf. Álvarez Layna (2013) y para un análisis de las relaciones de estas tesis con el psicoanálisis, cf. Gardner (1993) y Mantilla (2007).

${ }^{534}$ Davidson llega a plantear el carácter necesario del psicoanálisis para un abordaje de este tópico filosófico: "Después de analizar el problema que subyace a explicar la racionalidad, concluyo que cualquier enfoque satisfactorio tiene que abarcar algunas de las tesis más importantes de Freud, y que cuando esas tesis se enuncian de manera suficientemente amplia, no hay en ellas confusión conceptual" (Davidson, 1981: 2). Lo que Davidson ha tratado de mostrar "es que los rasgos muy generales de la teoría psicoanalítica, que he enumerado como factores de perplejidad para los filósofos y otras personas, son rasgos que si estoy en lo cierto aparecerán en cualquier teoría que se proponga explicar la racionalidad" (ibíd. p. 16).
} 
motivo. Al interior del psicoanálisis es posible encontrar algunos pronunciamientos que intentan deshacer esa dicotomía (Holt, 1981; Eagle, 1984; Holzman, 1985; Hopkins, 1982, Wallerstein, 1986/1987; entre otros); pero, la mayoría de las veces, o bien las discusiones sobre este tópico continúan basándose en ese binomio reductor, o bien la trascendencia propuesta no está acompañada de la elucidación conceptual necesaria para fundamentarla.

Es interesante observar lo que ocurre en otros campos disciplinares, respecto al problema del causalismo y la teleología:

En la biología contemporánea no hay conflicto entre explicación causal y explicación teleológica. El darwinismo operó una naturalización de la teleología tal que esta se inserta perfectamente en un mundo de causas eficientes. [...] En la selección natural las causas eficientes actúan teleológicamente: actúan en virtud de las exigencias funcionales que los seres vivos deben atender para tener condición de existir; y así producen el diseño de los seres vivos. (Caponi, 2014: $35)$.

Para la filosofía de las ciencias sociales y, en particular para el psicoanálisis, esa articulación pareciera seguir siendo un problema incompletamente resuelto.

A nuestro modo de ver, el psicoanálisis puede asumir una perspectiva no dicotómica, en la que las razones o motivos humanos sean considerados un tipo causa, caracterizado por ser: a) contextual (no universal), b) inmaterial (por ende, no sensible) y c) predisponente (teleológica). Y que coexiste con otro tipo de factores causales en las explicaciones psicoanalíticas.

El modo en el que Freud sostuvo la tensión entre causalidad y teleología sin renunciar a ninguno de ambos extremos, constituye un elemento fructífero para reconsiderar las matrices explicativas que el psicoanálisis puede ofrecer. El escenario de las conceptualizaciones freudianas, de evidente multiplicidad causal, ha resultado confuso y problemático para aquellos que pretenden reducir a un solo tipo ontológico las relaciones de determinación de los fenómenos humanos (ya sean físicos o psíquicos), pero no debería ser un problema para aquellos que asuman, al interior de sus modelos conceptuales, múltiples vectores de causalidad, inmanentes a la compleja realidad que pretenden entender. Aquí coincidimos con André Green en que definir la noción 
de causalidad psíquica tiene algunas dificultades añadidas: "las fronteras de la causalidad psíquica no están netamente definidas y se extienden tanto hacia lo que nos enseña la ciencia del cerebro como, e incluso la biología en general, como hacia la antropología y la historia" (Green, 1995/2005: 258). Entre las dificultades de arribar a una definición de causalidad psíquica se encuentra el hecho de que debe lograrse por relación a otros tipos de causalidad con los que, no obstante, no sería legítimo confundirla: su especificidad hace que no se la pueda reducir ni a la causalidad biológica ni a la causalidad cultural, ni tampoco es un resultado de la simple mezcla de ambas (ibíd.). En virtud de estas consideraciones, tal y como hemos expuesto en la primera parte de esta tesis, para Green el psicoanálisis no puede definirse por reducción a una única orientación disciplinar:

En mi opinión, el psicoanálisis no es una ciencia ni una rama de la hermenéutica: es una práctica basada en el pensamiento clínico, que da origen a hipótesis teóricas. Recordemos la definición que dio de él Freud en 1922 para un artículo de una enciclopedia: un método, una cura y una teoría. No es un híbrido, aunque se alimenta de fuentes tanto naturales como culturales. Es el puente entre la naturaleza y la cultura (Green, 2005/2006: 664).

La perspectiva de Green de considerar al psicoanálisis como un pensamiento clínico ofrece una respuesta interesante a los dilemas tradicionales, fundamentalmente porque evita una definición reductiva de la identidad disciplinar y rescata lo específico de su racionalidad: el ámbito clínico. Ricardo Bernardi también concuerda con Green y sostiene que es a partir de esta base clínica que se puede "recurrir tanto a la tradición científica como a la hermenéutica para desarrollar al psicoanálisis en múltiples direcciones teóricas y prácticas. Para ello es necesario aceptar la tensión o polaridad que se genera entre estas tradiciones" (Bernardi, 2015: 842).

Volviendo al debate de Grünbaum con los hermenéuticos, el filósofo germano-estadounidense hace bien en concebir al motivo como un tipo de causa, en tanto que es algo causalmente relevante cuando determina un comportamiento diferencial en el agente ${ }^{535}$. Sin embargo, tal y como hemos

\footnotetext{
535 Postura con la que algunos analistas han acordado. Holzman, por ejemplo, plantea que "...las razones pueden ser causas cuando tales razones determinan una diferencia en cuanto a que se produzcan o no los hechos de los cuales son razones" (Holzman, 1985: 753).
} 
expresado antes, en virtud del carácter inobservable y del alcance singular de la referencia de los motivos, Grünbaum yerra al pretender cernirlos y evaluarlos mediante el formalismo del inductivismo eliminativo. Los hermeneutas, hemos dicho, se equivocan por igual al pretender homologar la teleología de los procesos inconscientes con la intencionalidad fenomenológica del yo consciente. En psicoanálisis, más que en ninguna otra disciplina, se conoce bien que las razones que da un agente para explicar su acción no coinciden necesaria o completamente con las causas de la misma. Al mismo tiempo, veremos en breve, no todas esas causas necesitan describirse en términos nomotéticos, como durante mucho tiempo se pensó.

\title{
c) ¿Sólo puede haber explicaciones causales por referencia a leyes en psicoanálisis?
}

\author{
"El espíritu científico puede descarriarse siguiendo dos \\ tendencias opuestas: la atracción de lo singular y la \\ atracción de lo universal”. (Bachelard, 1971: 160).
}

Recordemos que en la primera parte de esta tesis reseñamos cómo las perspectivas naturalistas en psicoanálisis han hecho hincapié en las formulaciones universales de la metapsicología y sus posibilidades de corroboración empírico-experimental, mientras que las posiciones apoyadas en la tradición hermenéutica han tendido a resaltar el valor de las formulaciones clínicas singulares y su validación interna (círculo hermenéutico).

Una de las preguntas que dejamos planteadas en el apartado anterior es si resulta necesario siempre acudir sólo a leyes para hablar de explicaciones causales. Aquí dejaremos de lado el debate sobre el grado de necesariedad de la metapsicología, entendida como el conjunto de hipótesis legaliformes de máximo nivel de universalidad, adoptado por cada orientación psicoanalítica particular (Assoun, 2000/2002). Si bien tales formulaciones metapsicológicas, freudianas o de cada escuela posterior, suelen expresarse en enunciados nómicos, lo cierto es que a nivel del trabajo clínico la mayor parte del tiempo esas leyes funcionan de manera meramente instrumental y orientativa, ya que el tipo de conexiones causales que se establecen en los historiales clínicos

["... reasons can be causes when such reasons make a difference to the occurrence of the event for which it is the reason."] 
supone la preponderancia de relaciones causales de eventos singulares que ordenan el material. En el trabajo clínico con los casos, aunque los enunciados legaliformes de la metapsicología de cada perspectiva teórica no resultan excluidos (porque subyacen a la observación y participan implícitamente en la construcción de los datos empíricos) lo cierto es que frecuentemente pasan a un segundo plano respecto de las características inherentes a cada sujeto. Así, la racionalidad explicativa de un fenómeno clínico supone principalmente la puesta en relación causal de eventos y procesos idiosincráticos, excediendo ampliamente las posibilidades de subsunción nómica (en la labor clínica) o de generalización universal (en la labor investigativa).

Es en virtud de lo anterior que se suele consensuar la centralidad del caso por caso en la racionalidad explicativa psicoanalítica. Sin embargo, a ello se le añade otro aspecto inferencial importante: se sabe que, desde el comienzo mismo de la actividad analítica, la escucha estuvo orientada al hallazgo de patrones idiosincráticos en los sentimientos, acciones y pensamientos del paciente, a los que se puede acceder sólo indirectamente (Edelson, 1984: 107; Strenger, 1991: 78). Esta búsqueda parece estar motivada por la suposición de que "el sujeto es no solo una singularidad, sino también un conjunto de repeticiones. Es decir, tiene una generalidad que es propia, personal o individual, además de sus características psíquicas generales..." (Epstein, 2010: 268; cursivas añadidas). En el capítulo siguiente, apoyándonos en la lógica abductiva, abordaremos el problema del surgimiento y validación de las hipótesis que refieren a tales regularidades. Pero ahora creemos oportuno plantear algunos interrogantes: ¿qué estatuto epistémico darle a estas regularidades no universalizables que cada funcionamiento psíquico evidencia?, ¿deberían elucidarse por relación a motivos o a causas?, ¿podría tratarse de la causación de fenómenos clínicos sin la intervención directa de leyes? Analizaremos algunas vías escasamente exploradas por el psicoanálisis, intentando delimitar algunos andariveles por los que podrían comenzar a buscarse algunas respuestas.

Hemos visto que los intentos de la tradición hermenéutica por revivir el distingo entre causas y motivos al interior del psicoanálisis, se basa en una lectura reductora del carácter híbrido del método freudiano. Nuestra intención ahora es repensar la noción de causalidad en torno a la oposición clásica entre 
universalidad y singularidad, apuntando a los aspectos intermedios que orientan el trabajo clínico y, muchas veces, también el trabajo investigativo.

Uno de los esbozos pioneros por deslindar la racionalidad de explicaciones causales sin apelar a leyes se debe, posiblemente, a Peter Winch. En un afán por ampliar los desarrollos weberianos y siguiendo las reflexiones finales de Wittgenstein, Winch (1958/1990) sostuvo que el comportamiento humano puede comprenderse por referencia a reglas inmanentes antes que a leyes universales. Reglas que, explícitas e implícitas, se distinguen de las leyes naturales porque pueden ser modificadas o desobedecidas por los actores que las utilizan y porque ese uso está en relación con una terceridad capaz de sancionar su adecuación o no (otros sujetos, instituciones, etc.). Las reglas no son pautas externas a las acciones sino su significación misma; y es por ello que comprender el sentido de la acción equivale a comprender la regla que se está siguiendo en un contexto determinado ${ }^{536}$.

A nuestro modo de ver la noción de reglas de Winch tiene plena vigencia y podría constituir un insumo importante para la elucidación del trabajo clínico del analista, en la medida en que permite conceptualizar mejor la noción de comprensión que allí se pone en juego y de algunos fenómenos centrales de la experiencia analítica, tales como la vivencia de repetición. La noción de regla permite captar el orden en aquellos modos de funcionamiento en los que lo universal de las teorías ya no permite explicar determinadas regularidades de la singularidad del caso. En ese sentido, es una noción que permite enfocar de otra manera el problema de la tensión irreductible entre la teoría y el caso: mientras que la teoría pretende exponer las relaciones entre variables con pretensión universal, la conceptualización del caso supone asumir relaciones idiosincráticas no alcanzadas por la teoría (no subsumibles). Éstas últimas relaciones no necesariamente están exentas de regularidad (aunque ella no

\footnotetext{
${ }^{536}$ Otra característica de las reglas, con implicancias epistemológicas para toda perspectiva falsacionista pero que no siempre han sido tenidas en cuenta, es la siguiente: una acción puede, en virtud de la regla a la que responde, ser correcta o incorrecta, sin que de ello se deriven mayores consecuencias para la regla en sí. En cambio, cuando un fenómeno predicho no se produce, esto constituye un problema para el sistema de datos: aparece un falsador potencial (en término popperianos) que contraría la ley que lo predice. Es decir: mientras que la predicción de acciones que no se cumplen no puede refutar una regla, la predicción de hechos que no siguen una ley, sí puede hacerlo (al menos para Popper y los de "temperamento revolucionario" respecto a la refutación).
} 
sea universal) y su captación puede obtenerse a partir de la elucidación de reglas singulares de funcionamiento. Las reglas son, entonces, una manera de referir a la lógica de lo singular que no puede ser discernida por contrastación con lo universal ni expuesta en explicaciones nomológicas ${ }^{537}$.

Para su aprovechamiento psicoanalítico la noción de regla debe ser distinguida de la noción de hábito. Actuar por hábito o costumbre supone que una pauta de acción previamente aprendida se repite mecánicamente, pero seguir una regla es poder aplicar un criterio para discernir lo que, en cada nueva situación, se encuentra en conformidad con la regla. Es decir: mientras que adoptar un hábito es lograr la capacidad de hacer lo mismo en cada circunstancia nueva que reproduzca las mismas condiciones iniciales, seguir una regla no supone repetir idénticamente lo mismo sino, justamente, poder distinguir en cada nueva situación aquellas formas de actuar en conformidad con la regla de las que no lo son. Esto último supone hacer cada vez algo distinto de lo que se ha mostrado originalmente, pero actuando todas las veces en conformidad con la regla ${ }^{538}$. Este aspecto de la noción de seguir una regla es crucial para su diferenciación con la noción de causación nomológica, tan común en las ciencias naturales: mientras que ésta última supone la idéntica subsunción de los fenómenos naturales en sus respectivas leyes causales (universales o estadísticas), la aplicación de una regla exige por parte del agente un discernimiento, en cada nueva ocasión, sobre lo que es y lo que no es adecuado. Además, en el planteo de Winch esta reflexividad no tiene necesariamente que ver con una formulación consciente de las reglas que se siguen, como si se tratase de la explicitación de principios axiomáticos para poder razonar. Se trata, por el contrario, de la capacidad de aplicación de un criterio que no necesita ser formulado; de ahí que su traslación al psicoanálisis resulte promisoria. A nuestro modo de ver, esta noción de reglas tiene enormes

\footnotetext{
${ }^{537}$ No se trata con ello, por lo tanto, del movimiento conceptual que algunos partidarios de la lógica dialéctica proponen para la indagación psicoanalítica, en tanto hallazgo de lo universal en lo particular (cf. Azaretto y Ros, 2014: 54 y ss). Se trata, más bien, de una aproximación a la racionalidad de la construcción de saber de lo singular sin necesariamente pasar, justamente, por lo universal.

538 "La historia humana no es precisamente un registro de hábitos variables, sino la historia de cómo los hombres trataron de trasladar lo que consideraban importante en sus modos de conducta a las nuevas situaciones que tenían que enfrentar" (Winch 1958/1990: 63).
} 
implicancias para la elucidación metateórica de la causalidad de los fenómenos clínicos, fundamentalmente de aquellos aspectos que implican formas de repetición en la diferencia.

La tesis wincheana de que las ciencias sociales deben explicar el sentido que tienen las acciones e instituciones por referencia a reglas, supone el rechazo de la posibilidad de explicaciones causales en este dominio. A nuestro modo de ver, esta postura encierra al menos dos malentendidos. El primero consiste en hacer ver como incompatibles a la noción de causación por leyes con la de seguimiento de reglas. El segundo consiste en asumir una equiparación clásica, pero que cada vez se vuelve más dudosa en la filosofía actual de las ciencias, entre causación y nomicidad. Veamos ambos malentendidos con mayor detalle.

1) No parece justificado creer que las virtudes de utilizar la noción de reglas deban necesariamente conllevar un abandono o reemplazo de la noción de nomicidad. El psicoanálisis no debería excluir, a priori, la posibilidad de una superestructura especulativa de aspiraciones universalizantes y, con ella, la posibilidad de arribar a explicaciones nomológico-deductivas. Ello no quita que, como ha sido señalado, en la racionalidad del trabajo clínico son los patrones idiosincráticos de funcionamiento psíquico, determinables por referencia a cada situación histórico-vivencial y no por subsunción nomológica a modelos teóricos universales, los que posiblemente gocen de la mayor relevancia explicativa. De lo que se trata no es de rechazar todo afán nomotético ${ }^{539}$ sino de brindar herramientas para la elucidación de aquellos aspectos imposibles de entender bajo la subsunción nomológica, ya que de ese modo se pierde la posibilidad de

\footnotetext{
${ }^{539}$ No podemos obviar la réplica que Alasdair Maclntyre hiciera del planteo de Winch, recurriendo a Marx y a Malinowsky para subrayar la existencia de acciones basadas en algo diferente que motivos, creencias o reglas. Maclntyre considera que esta distinción "nos da derecho a cuestionar con escepticismo la afirmación de Winch de que la comprensión en términos de seguimiento de una regla y en términos de explicaciones causales se excluyen mutuamente (Maclntyre, 1967/1976: 35). Para Maclntyre no sólo debemos considerar las acciones causadas en reglas aprendidas y que eventualmente el mismo agente podría explicitar conscientemente, sino que también necesitamos considerar las acciones causadas por mecanismos, estructuras o leyes de las que el agente no es generalmente consciente. Es decir que el punto de vista interno es insuficiente: se necesita además de un punto de vista externo que muestre la relación causal entre esos mecanismos sociales y el comportamiento del agente. Por ello, para Maclntyre la jerarquía epistémica de la explicación nomológica no puede ser reemplazada por la de la comprensión. A nuestro modo de ver, el psicoanálisis necesita de una complementariedad (de proporción variable según el contexto) entre ambos puntos de vista.
} 
explicar causalmente a partir de un entramado en el que también se incluyan regularidades singulares.

Ahora bien, así como el psicoanálisis difícilmente pueda prescindir de los enunciados nómicos de la metapsicología, también debería poder repensar la noción misma de causación. Actualmente, el campo de la filosofía de las ciencias no aporta respuestas contundentes y el asunto permanece alejado de los grandes consensos. Esto nos conduce al segundo malentendido.

2) Hoy en día es posible reconocer, a grandes rasgos, al menos dos formas de abordar el asunto de la causación: o bien se intenta dar cuenta de la causalidad apelando a leyes, regularidades y procesos físicos, o bien mediante el análisis de la dependencia contrafáctica entre eventos (Beebee, Hitchcock \& Menzies, 2009). La teoría contrafáctica de la causación, desarrollada por Lewis (1973), propone que entre dos eventos que ocurren, uno es causa del otro si es verdadero que de no haber ocurrido el primero, el otro no habría tenido lugar ${ }^{540}$.

Entre las ventajas de la teoría contrafáctica de la causación encontramos que no presupone la existencia o el conocimiento de algún mecanismo que lleve de la causa al efecto y que puede ser explicativa en contextos en los que no cabe hablar de leyes. Para Hernán Miguel es por esta última razón que los contrafácticos constituirían "un buen detector de causación aun en casos en que la relación nomológica es dudosa o desconocida, como en el caso de la causación mental"541 (Miguel, 2014: 31). Se sabe desde hace bastante tiempo que existen dominios cognitivos, por ejemplo algunos campos de la física o de la biología, en los que no parece haber leyes naturales (ni universales ni estadísticas) que conecten la presunta causa con el efecto, pese a lo cual no se duda en afirmar la presencia de causalidad en virtud de su relación de dependencia contrafáctica (Cartwright, 1983; Woodward, 2003).

Daniel Biebel es uno de los pocos que ha reflexionado sobre el valor que los enunciados contrafácticos podrían tener para la clínica psicoanalítica: "sea

\footnotetext{
${ }^{540}$ Así definida, toda relación causal queda asociada a la verdad de ciertos condicionales contrafácticos. Aunque no lo analizaremos aquí, debemos señalar que Lewis reformuló más tarde su teoría en términos de influencia (Lewis, 2000).

${ }^{541}$ No vamos a dedicarnos específicamente aquí al espinoso problema de la causación de lo mental. No obstante lo cual, cabe señalar que una teoría de la causación es algo diferente de las explicaciones que pragmáticamente puedan darse dentro de cada dominio explicativo (Pissinis, 2014).
} 
como fuere la constatación de la recurrencia del contrafáctico de tal o cual característica, nos puede dar una indicación del estilo de cada quien en cuanto a sus creencias básicas, al menos en cuanto esté bajo esa estructura o subestructura mental. Sería así un indicador, una pista." (Biebel, 2008: 13). Es decir, inspeccionando los mundos posibles en los que se realiza el antecedente del condicional contrafáctico $\mathrm{y}$, a su vez, estipulando la efectivización del consecuente, entonces podrían localizarse representaciones subjetivas con relevancia causal. Sin apelar, agreguemos, a relaciones nómicas. Jorge Ahumada también examina su valor en la clínica:

\begin{abstract}
Nuestros analizados respetan multitud de condicionales contrafácticos que desencadenan lo que Freud llamaba la ansiedad señal, poniendo en marcha las defensas para evitar las ansiedades catastróficas. El arte de la neutralidad del analista consiste justamente en proveer el marco que posibilite que se amplíe en sesión el ámbito de ostensividad sin que el analizado deba poner excesivamente a prueba sus condicionales contrafácticos inconscientes, sus vivencias inconscientes de quedar expuesto a ser atropellado por ansiedades masivas (Ahumada, 1999a: 53).
\end{abstract}

Consideramos imprescindible que el psicoanálisis contribuya a repensar la estructura de sus explicaciones clínicas, en tanto que explicaciones causales que no se identifican completamente con los modelos nomológicos. También necesitamos en nuestros dominios psicoanalíticos una noción que nos permita romper con el carácter necesario de la ligazón entre causalidad y nomicidad, embutida en el modelo hipotético-deductivo desde los trabajos de Popper y Hempel.

El psicoanalista que indaga sobre un caso clínico se orienta a la identificación de invariantes causales singulares, que están involucrados en los factores psíquicos de producción y mantenimiento de los fenómenos clínicos que importan, pero no se orienta por la subsunción de dichos fenómenos en leyes universales. Son esos invariantes los que le brindan su contenido causal a las explicaciones clínicas que se formulan. Una fantasía determinada, por ejemplo, puede describirse enunciativamente como una regularidad en el funcionamiento psíquico de un determinado sujeto en un período determinado de tiempo y puede servir para explicar fenómenos clínicos como, por ejemplo, una repetición en acto o un síntoma. Pese a que todos los neuróticos tienen 
fantasías inconscientes por ejemplo, éstas encierran algo imposible de universalizar. $\mathrm{O}$, mejor dicho, lo que nos importa de ellas en términos causales o explicativos en cada caso, no es universalizable. Por lo tanto, es necesario poder concebir que haya explicaciones causales genuinas que no sean explicaciones nomológicas.

Aunque la actividad analítica supone, como cualquier otra práctica interhumana, la comprensión de razones y motivos de la acción, lo específico de su metodología radica en la elucidación de la relevancia causal de determinados procesos psíquicos y de determinados eventos históricovivenciales, a partir de un proceder interpretativo dinámico y recursivo. En virtud de que en las explicaciones psicoanalíticas de casos clínicos los aspectos descriptivos del material se entrelazan con la identificación de significados contextuales, procesos y estructuras, resulta difícil disociar fases consecutivas de aspectos interpretativos y de aspectos inferenciales sobre mecanismos y procesos explicativos.

Entonces, la noción wincheana de reglas y la conceptualización contrafáctica de la causación, parecen ofrecer, por vías diferentes, la posibilidad de vincular la causación de fenómenos humanos sin necesidad de recurrir a leyes ni al modelo de cobertura legal. Considerando que gran parte de la labor clínica consiste en la elucidación de patrones idiosincráticos con relevancia explicativa, el psicoanálisis podría dialogar fructíferamente con esta clase de teorizaciones.

\section{Algunas conclusiones sobre la propuesta de hermeneutización del psicoanálisis}

En este capítulo hemos expuesto y revisado los argumentos generales de la propuesta de redefinir, total o parcialmente, la identidad epistemológica del psicoanálisis en términos hermenéuticos.

En primer lugar, hemos mostrado que aun siendo el método psicoanalítico de Freud esencialmente interpretativo, hay significativas razones que impiden identificarlo con la hermenéutica metódica, debido a que existen profundas 
divergencias no sólo en sus orígenes y objetivos, sino también a nivel de las suposiciones antropológico-lingüísticas y axiológicas explícita o implícitamente asumidas.

En segundo lugar, en virtud de que la hermenéutica metódica no constituye más que su punto de partida en el campo epistemológico, hemos abordado las transformaciones principales que han acontecido al interior de la tradición hermenéutica desde mediados del siglo XX, analizando diferencialmente los principales aportes ontológicos y metodológicos que algunos han pretendido desembarcar en el campo psicoanalítico. Cuatro aspectos han sido deslindados y específicamente analizados, arribándose a las siguientes conclusiones: A) algunos supuestos epistémicos del método freudiano conllevan una posibilidad de crítica a la concepción tradicional de la ciencia, por lo que no es necesario apelar al vocabulario de la tradición hermenéutica para argumentar en su contra. B) Hemos analizado además los aportes de la hermenéutica analógica, cuyos desarrollos recientes han venido a renovar la propuesta de redefinición hermenéutica del psicoanálisis. Aunque sus nociones centrales de analogía e iconicidad sintonizan bien con el espíritu epistémico del método psicoanalítico freudiano, la hermenéutica analógica conserva una serie de supuestos que resultan incompatibles con aquellos aspectos teórico-técnicos de la propuesta freudiana que exceden la dimensión narrativa. C) Analizando la propuesta de Laplanche de considerar al psicoanálisis como una antihermenéutica, así como su discusión con las ideas de Ricœur, concluimos que el rol diferencial otorgado a la intencionalidad, junto con otras diferencias en torno a la concepción del sentido y de la comprensión, constituye un límite no franqueado por los intentos de redefinición hermenéutica del psicoanálisis. D) Finalmente, hemos expuesto la tesis de Velasco Gomez sobre la hermeneutización de la filosofía de la ciencia, asumiendo que existe un conjunto de supuestos compartidos por las diversas formas contemporáneas de conocimiento científico. En función de ello, concluimos lo siguiente: si cabe hablar de un fundamento hermenéutico del psicoanálisis, éste se debe a que comparte, junto con el resto de las disciplinas que en la actualidad estudian al hombre, esa serie de supuestos generales sobre la producción, establecimiento y evolución del conocimiento, inherentes a tal hermeneutización. Sin embargo, ello no le impide al psicoanálisis argumentar en contra de determinados supuestos 
específicos (antropológicos, metodológicos y axiológicos) de la tradición hermenéutica, anteponiendo sus propias conjeturas de base a partir de la racionalidad inmanente a su campo de experiencia clínica. Así, el psicoanálisis es hermenéutico en un sentido amplio y al igual que cualquier otra disciplina científica ocupada de lo humano; pero no puede ser hermenéutico en sentido estricto, ya que no puede compatibilizar algunas de sus asunciones centrales con los fundamentos de esta tradición.

En tercer lugar, hemos abordado específicamente uno de los aspectos centrales de la controversia entre las perspectivas naturalistas y hermenéuticas en psicoanálisis: el tipo de entidades a las que se le otorga relevancia causal y su papel desempeñado en las explicaciones psicoanalíticas. Para facilitar la elucidación de algunas posturas contrapuestas, el análisis de sus argumentos y nuestro propio punto de vista, hemos dividido la exposición en tres partes interrelacionadas: A) recuperamos la crítica de Grünbaum a los primeros en proponer una reversión hermenéutica del psicoanálisis, pero enfocándonos en el problema de la distinción causas-razones para las explicaciones psicoanalíticas. Mostramos que Grünbaum acierta en sus objeciones a la utilización del silogismo práctico para la formalización de las explicaciones freudianas, pero también mostramos que fracasa en su reconstrucción de las mismas al pretender reducirlas al clásico modelo de cobertura legal. B) Luego argumentamos que la concepción freudiana de la causalidad es desconcertante sólo para aquellos que adoptan como punto de partida el binomio causa-razón, pero su racionalidad se hace viable cuando asumimos un punto de vista que lo trasciende. Recuperamos la noción freudiana de sentido para mostrar que, por un lado, supone la presencia de aspectos teleológicos que posibilitan explicaciones funcionales que no pueden reducirse al modelo nomológicodeductivo $\mathrm{y}$, por otro lado, que esa teleología tampoco se reduce a la intencionalidad fenomenológica del yo consciente, asumida comúnmente por los partidarios de la hermenéutica. Nuestra tesis aquí es que el modo en que el creador del psicoanálisis sostuvo la tensión entre causalidad y teleología, sin renunciar a ninguno de ambos extremos, constituye un elemento fructífero para reconsiderar las matrices explicativas que el psicoanálisis puede ofrecer. C) finalmente, decidimos explorar un aspecto contemporáneo que interseca algunos problemas del tópico de la explicación científica con el campo de los 
debates filosóficos sobre la causalidad. Asumiendo que las distintas metapsicologías contemplan formulaciones nomológicas, pero que gran parte de las explicaciones que se dan a nivel de los fenómenos clínicos no se realiza como una subsunción nomológica sino a partir de la elucidación de regularidades singulares presentes en el funcionamiento psíquico de cada sujeto, introdujimos la posibilidad de apelar a la noción wincheana de reglas (por oposición a las leyes) para reconstruir el estatuto epistémico de tales generalizaciones no universales. Por otro lado, recuperamos la propuesta de algunos autores, provenientes del campo de la filosofía general de las ciencias, de disociar el vínculo entre causación y nomicidad, naturalizado con el modelo nomológico-deductivo. Específicamente, recuperamos las ventajas de la teoría contrafáctica de la causación para explorar la posibilidad de concebir explicaciones genuinamente causales sobre fenómenos clínicos singulares. Así, la noción wincheana de reglas y la conceptualización contrafáctica de la causación parecen ofrecer, por vías diferentes, la posibilidad de vincular la causación de fenómenos humanos sin necesidad de recurrir a leyes ni al modelo de cobertura legal. Debido a que gran parte de la labor clínica consiste en la elucidación de patrones idiosincráticos con relevancia explicativa, consideramos que el psicoanálisis podría dialogar fructíferamente con esta clase de teorizaciones. Con ello no hemos pretendido una eliminación de las explicaciones nomológicas en psicoanálisis sino que, en virtud de la variedad de fenómenos a explicar hemos planteado la necesidad de complementar diversos tipos de explicaciones causales.

La convergencia de los argumentos expuestos en este capítulo de la tesis nos lleva a concluir que la propuesta de redefinir, total o parcialmente, la identidad epistemológica del psicoanálisis en términos hermenéuticos, no se sostiene. Como el lector podrá notar, la conclusión de este capítulo es la contracara de la que resulta en la parte destinada a la crítica de Grünbaum: mientras que allí mostramos, además de las falencias argumentativas de dicho filósofo, que el modelo del inductivismo eliminativo (concebido para la evaluación de leyes en física experimental) no puede ser utilizado en el dominio psicoanalítico para la evaluación de las hipótesis causales, en este capítulo hemos mostrado que el modelo hermenéutico (concebido para la interpretación 
textual o la comprensión de motivos) tampoco logra captar las complejidades de la racionalidad psicoanalítica sin cercenar varios de sus aspectos centrales.

En el capítulo siguiente intentaremos profundizar en algunos aspectos puntuales que hacen a la racionalidad psicoanalítica: el papel de las inferencias lógicas involucradas en la producción del saber clínico y las características del estudio de casos como metodología de investigación psicoanalítica. 


\title{
CAPÍTULO 10: Aspectos lógico-metodológicos de la elaboración teórica en psicoanálisis
}

\begin{abstract}
Lo que con pretensiones universalistas se enseña entre nosotros con el nombre de epistemología -la postura del empirismo estricto de Grünbaum y el falsacionismo de Poppersoslaya el contexto de descubrimiento para centrarse en la idea de la verificación de las teorías, siendo en ambos casos la estructura de la física clásica -construida sobre la base de las llamadas "variables de buen comportamiento" homogéneas y matematizables- el criterio de cientificidad a imitar en todo ámbito de las ciencias (Ahumada, 2014: 57).
\end{abstract}

n la segunda parte de esta tesis hemos analizado el modelo
deductivista de Popper y en la tercera parte hemos abordado el
modelo inductivista de Grünbaum. En esta parte analizaremos una serie de desarrollos en torno a un tercer tipo de inferencia básica: la abducción. Veremos que la orientación general que siguen los distintos desarrollos, pese a sus diferentes recorridos y bifurcaciones, es la de establecer una alternativa viable para abarcar aquello que excede los márgenes de los otros dos modelos inferenciales mencionados y para la forma de actividad cognitiva que de ellos se desprende.

Luego de exponer las limitaciones del falsacionismo popperiano, hemos visto los problemas del inductivismo eliminativo, analizando las limitaciones de los cánones de Mill y elucidando las dificultades que su pretendida aplicación conlleva en disciplinas como el psicoanálisis. Nuestra conclusión adversa respecto del inductivismo eliminativo como criterio de demarcación nos ha conducido a denegar también el rechazo de Grünbaum de la consiliencia freudiana y ha dejado abierta la puerta para considerar el papel de la abducción y de la inferencia a la mejor explicación en el proceder metodológico de Freud. En esta parte de la tesis nos ocuparemos especialmente de mostrar la superioridad que dichos modelos de la inferencia causal mantienen respecto de los de Popper y Grünbaum, esclareciendo cómo puede ser utilizada para 
reconstruir el corazón de las inferencias clínicas y contribuyendo a establecer la validación del proceder metodológico del psicoanálisis desde Freud hasta nuestros días.

Para ello, será necesario primero presentar brevemente la concepción de Peirce sobre la naturaleza de la abducción, así como el modo en que este conjunto complejo de inferencias puede ser subtipificado. Además, nos veremos obligados a adentrarnos en una serie de polémicas nacidas con la relectura que suele hacerse de la abducción en términos de inferencia a la mejor explicación. Luego podremos dedicarnos a mostrar una de las versiones de este tipo de inferencias que se opone explícitamente a los cánones de Mill y al falsacionismo popperiano.

En segundo lugar, indagaremos sobre lo que ha dado en llamarse paradigma indiciario y sobre cómo ha sido considerado el trabajo de Freud desde esa perspectiva. Eso nos permitirá adentrarnos luego en el proceder metodológico de Freud, elucidando la función que desempeñan las inferencias abductivas en torno a la producción y establecimiento de las hipótesis psicoanalíticas, tanto en el contexto clínico como extraclínico. Nos detendremos también en la peculiar relación que Freud estableció entre la práctica clínica y la investigación psicoanalítica, apuntando a dilucidar sus alcances y limitaciones.

Luego de precisar el rol desempeñado por las inferencias abductivas en los modos de producción de conocimiento en psicoanálisis, intentaremos elucidar cómo las conjeturas psicoanalíticas se ponen a prueba durante el trabajo clínico y en los procesos de investigación. Intentaremos, por último, establecer el valor que poseen los estudios de caso para la investigación en psicoanálisis, contraponiendo los argumentos centrales de las diversas opiniones existentes que hemos reseñado en la primera parte de la tesis. 


\title{
1. La abducción y la inferencia a la mejor explicación
}

\section{a) La abducción de Peirce: una lógica del descubrimiento}

Durante la primera mitad del siglo XX la postura filosófica hegemónica sobre la creación científica, mantenida por algunos como Reichenbach, Braithwaite y especialmente Popper, ha sido rechazar que haya una lógica del descubrimiento ${ }^{542}$. Desde esta visión clásica, la distinción adoptada entre contexto de descubrimiento y contexto de justificación denegaba el acceso del primero al ámbito de las consideraciones epistemológicas. Sin embargo, hacia mediados del siglo XX esta tendencia comenzó a revertirse por el resurgir del interés de algunos filósofos por la racionalidad de las creaciones científicas, abriendo las puertas nuevamente a la posibilidad de concebir una lógica del descubrimiento. Como ha señalado Lakatos: "la heurística infalibilista de deducir teorías de los hechos ciertamente ha fracasado, pero substituirla por la heurística popperiana de especulaciones y refutaciones es arrojar el bebé junto con el agua de la bañera" (Lakatos, 1981: 128). Norwood Hanson, un tiempo antes, había sido uno de los primeros en asumir el desafío:

\begin{abstract}
Todos los enfoques H-D [hipotético-deductivistas] coinciden en que las leyes físicas explican los datos, pero obscurecen la conexión inicial entre datos y leyes; en realidad, sugieren que la inferencia fundamental va desde las hipótesis de alto rango a los enunciados observacionales. Este puede ser el modo de exponer las razones que tiene uno para aceptar una hipótesis después de que ha sido propuesta, o para hacer una predicción, pero no es un modo de exponer las razones para proponer o para ensayar una hipótesis en un comienzo. Sin embargo, en la sugerencia inicial de una hipótesis es muy frecuente un asunto razonable. No viene afectada tan a menudo por la intuición, la penetración, las corazonadas u otros imponderables como sugieren muchos biógrafos o científicos. Los partidarios del enfoque H-D evitan la consideración del origen de una hipótesis porque piensan que sólo tiene un interés psicológico, o bien afirman que es solamente un fruto del genio y no de la lógica. Están equivocados. Si tiene una lógica establecer una hipótesis por sus predicciones, también la tiene la
\end{abstract}

\footnotetext{
${ }^{542}$ En la segunda parte de esta tesis hemos analizado la perspectiva de Popper, para quien "no existe, en absoluto, un método lógico de tener nuevas ideas, ni una reconstrucción lógica de este proceso" (Popper, 1934/1980: 31). También Hempel (1966: 33) se refiere a la invención libre de "conjeturas felices", ratificando así la propuesta popperiana de desestimar toda lógica del descubrimiento.
} 
concepción de una hipótesis. (Hanson, 1958/1977: 165; corchetes y cursivas añadidos).

Hanson, y luego otros autores, reconocen en Charles Peirce al hombre que abrió la puerta para estos planteamientos sobre la lógica del descubrimiento. En efecto, hacia finales del siglo XIX y principios del XX, desde una perspectiva pragmatista y a los fines de dar cuenta del problema del aumento del conocimiento científico, Peirce recuperó una noción ya presente en la obra de Aristóteles utilizando el término abducción ${ }^{543}$. Asumiendo que la garantía para alcanzar la verdad a largo plazo está en el método del conocer, Peirce propuso entender al método como un conjunto de inferencias relacionadas: abducción, deducción e inducción.

Peirce utilizó los términos de caso $(c)$, regla $(R)$ y resultado ( $r$ ) para exponer su conceptualización de los distintos tipos de inferencias. Así, definió a la deducción como aquel tipo de inferencia que se establece a partir de la afirmación de una regla y un caso de la misma, derivándose de allí el rasgo que la regla enuncia $(R+c \rightarrow r)$. La inducción, por el contrario, generaliza una regla a partir de ciertos rasgos que presentan los casos observados $(c+r \rightarrow R)$. Finalmente, la abducción consiste en interpretar los rasgos a partir de alguna regla que se propone para entenderlos como caso que se subsume a ella $(r+$ $R \rightarrow c)$. Peirce (1878a/1970) esquematizó estas diferencias con el conocido ejemplo de las judías o porotos:

\section{Deducción}

Regla Todos los porotos de este saco son blancos.

Caso Estos porotos son de este saco.

Resultado Estos porotos son blancos.

\section{Inducción}

Caso Estos porotos son de este saco.

Resultado Estos porotos son blancos.

Regla Todos los porotos de este saco son blancos.

${ }^{543}$ Este tipo de inferencia fue caracterizado por primera vez por Aristóteles (2006) en sus Primeros Analíticos. Peirce utilizó también otros términos para referirse a dicha inferencia, tales como hipótesis, retroducción o presuposición, que algunos intérpretes han intentado diferenciar de la abducción (Rescher, 1978; Laudan, 1981b). Aquí adherimos al planteo de que hay argumentos fuertes para considerarlos sinónimos (Velasco, 1998). Un estudio detallado que distingue tres etapas en la evolución de la noción de abducción puede hallarse en el clásico trabajo de Fann (1970). 


\section{Hipótesis}

Regla Todos los porotos de este saco son blancos.

Resultado Estos porotos son blancos.

Caso Estos porotos son de este saco.

La abducción (llamada hipótesis en esa época) es la menos certera de las tres, ya que simplemente sugiere que algo puede ser: el caso. Es decir que leer indicios mediante reglas para luego concluir el caso, es hacer uso de una inferencia abductiva. La conclusión es una conjetura que se ha obtenido mediante la invención (reconocimiento) de que un patrón o pauta observable es análogo a un patrón conocido (inteligible idealmente); y de ese modo se ha reducido el campo de indagación a un espacio humanamente manejable. Es decir que la abducción permite conectar el conocimiento previo con estructuras de datos, acotando significativamente los espacios de búsqueda.

Avanzada su obra Peirce considera a esos tres tipos de inferencia como tres etapas o momentos de un método para la indagación lógica, en donde la hipótesis, ahora denominada abducción, es la primera de ellas (Aliseda, 1998). Así, la abducción sugiere una hipótesis cuyas consecuencias se extraen mediante la deducción y se ponen a prueba a partir de la inducción. La noción de abducción se complejiza y deviene en "la operación de adoptar una hipótesis explicatoria" (Peirce, 1903a/1978), cuya estructura lógica se representa de la siguiente manera: "se observa un hecho sorprendente, C; pero si A fuera verdadera, C sería una cosa corriente. Por lo tanto, hay razón para sospechar que A es verdadera" (ibíd.).

Mientras que la deducción sólo desarrolla las consecuencias de una idea previamente asumida como verdadera y la inducción sólo se limita a comprobar si una extensión puede ser evidencia a favor o en contra de una teoría, la abducción es la única inferencia lógica que permite introducir alguna idea nueva; es, por lo tanto, la única inferencia verdaderamente ampliativa.

A lo largo de su obra, Peirce aborda de diferentes maneras el interrogante de por qué hacemos abducciones. Una de las suposiciones fuertes que adopta es que existe cierta concordancia estructural entre nuestro modo de pensar y las características del mundo pensado, que nos permite adivinar la verdad: 
enteramente desesperanzada, con tal que cada conjetura sea revisada comparándola con la observación. (Peirce, 1896/1997).

Sin embargo, esta capacidad adivinatoria ${ }^{544}$ encuentra en Peirce distintas razones de ser: a veces apela a un rasgo instintivo de la especie, esbozando una explicación naturalista de corte darwiniano; otras veces se apoya en las virtudes explicativas de las ideas abducidas $y$, en otros momentos, vemos justificaciones psicológicas ligadas al insight. Sin embargo, la racionalidad de la inferencia abductiva no se ve comprometida por la diversidad de lecturas peirceanas sobre cómo esta inferencia produce las ideas ${ }^{545}$. Gonzalo Génova resume las cuatro características que Maryann Ayim (1974) ha señalado de la abducción, afirmando porqué se trata de un proceso racional. La abducción es:

1) deliberada, puesto que se realiza con el objetivo definido de encontrar una explicación verdadera;

2) voluntaria, porque el científico decide libremente buscar la explicación del hecho sorprendente;

3) crítica, porque las conclusiones abductivas, que no pasan de ser meras sugerencias, se someten a la confrontación con la experiencia mediante la deducción y la inducción; y

4) controlada, puesto que mediante el ejercicio de la razón instintiva el científico cultiva y desarrolla su sensibilidad para encontrar hipótesis explicativas. (Génova, 1997: 73).

La propuesta de Peirce se inscribe en la tradición falibilista, que define como "la doctrina de que nuestro conocimiento nunca es absoluto, sino que siempre oscila como si estuviera en un continuum de incertidumbre e indeterminación" (Peirce, 1897/1997). De modo tal que la certidumbre que provee la abducción no excluye la posibilidad del error, inherente a todo proceso cognitivo ${ }^{546}$.

\footnotetext{
544 Freud parece haber tenido una opinión similar: “...nuestro aparato anímico, se ha desarrollado justamente en el empeño por escudriñar el mundo exterior, y por tanto tiene que haber realizado en su estructura alguna adecuación al fin" (Freud, 1927/2004: 54).

${ }^{545}$ Aunque Peirce apele al instinto para dar cuenta del origen de las nuevas ideas, él mismo se encarga de señalar que el asunto no puede reducirse a una explicación psicológica, porque eso no resolvería el problema lógico implicado (cf. Three Types of Reasoning, en Peirce, 1903d/1988).

546 “Peirce habla de estado de creencia y no de conocimiento. Así, la pareja 'duda-creencia' es en realidad un ciclo entre dos estados diametralmente opuestos; mientras que la creencia es un hábito, la duda es la privación del mismo. Sin embargo, la duda, escribe Peirce, no es un estado que se genere voluntariamente haciendo una pregunta, así como una oración no es
} 
Por otro lado, conviene recordar que para Peirce los tres tipos canónicos de inferencia aparecen siempre de manera entrelazada en un proceso cognitivo, ya sea del pensar cotidiano o relativo a la investigación sistemática ${ }^{547}$.

Es frecuente afirmar que la abducción se produce ante la necesidad de explicar hechos sorprendentes. Peirce se refirió a la sorpresa como aquello que se genera cuando un hábito se ve conmovido (Peirce, 1901/2001). Jaime Nubiola lo expresa de la siguiente manera:

\begin{abstract}
Nuestras creencias son hábitos y en cuanto tales fuerzan al hombre a creer hasta que algo sorprendente, alguna nueva experiencia externa o interna, rompe ese hábito. El fenómeno sorprendente requiere una racionalización, una regularización que haga desaparecer la sorpresa mediante la creación de un nuevo hábito. [...] La sorpresa produce una cierta irritación y demanda una hipótesis, una abducción, que haga normal, que haga razonable, el fenómeno sorprendente. (Nubiola, 2001).
\end{abstract}

Ahora bien, ¿es la sorpresa una condición necesaria para abducir? Considérese el siguiente ejemplo: veo en la mesa un poco de líquido verdoso y, a poca distancia, veo también un mate con una pava. Lo que cualquiera de nosotros concluiría, al menos en nuestras latitudes, es una conjetura casi automática; pero ello no reduce su carácter hipotético ni le otorga, a priori, mayor certeza. Peirce fue incluso más allá y se refirió a la abducción como subyaciendo a todo proceso perceptivo:

\begin{abstract}
Al mirar por mi ventana esta hermosa mañana de primavera -escribió Peirce en 1901- veo una azalea en plena floración. ¡No, no! No es eso lo que veo; aunque sea la única manera en que puedo describir lo que veo. Eso es una proposición, una frase, un hecho; pero lo que yo percibo no es una proposición, ni una frase, ni un hecho, sino sólo una imagen, que hago inteligible en parte mediante un enunciado de hecho. Este enunciado es abstracto, mientras que lo que veo es concreto. Realizo una abducción cada vez que expreso en una frase lo que veo. La verdad es que toda la fábrica de nuestro conocimiento es una tela entretejida de puras hipótesis confirmadas y refinadas por la inducción. No puede realizarse
\end{abstract}

interrogativa por el simple hecho de ponerle una marca especial, debe existir una duda real y auténtica [...] Peirce no sólo argumenta que para romper un hábito debe existir una duda auténtica, sino que la identifica con la sorpresa" (Aliseda, 1998: 128).

${ }^{547}$ Peirce intenta mostrar, en el segundo de sus dos ensayos anti-cartesianos de 1868 (Some Consequences of Four Incapacities), que no es posible efectuar ningún acto psíquico sin recurrir necesariamente a esas tres clases de inferencia: inducción, deducción y abducción (Peirce, 1868/1988). 
el menor avance en el conocimiento más allá de la mirada vacía, si no media una abducción en cada paso (Peirce, citado en Nubiola, 1998).

Pareciera ser que hay abducciones que, por su idéntica recurrencia, se realizan sin el mencionado efecto sorpresivo. Como dijimos, esto no les resta en nada su carácter hipotético, pero sí nos alerta sobre la omnipresencia y variedad de este tipo de inferencias. Cabría hablar, parece, de un abanico de procesos abductivos que irían desde los deliberados y conscientes, en los que el sujeto puede dar cuenta de cómo llego a su conjetura; hasta los automáticos y no conscientes, en los que el sujeto no se ha percatado del modo en que llegó a fijar su creencia abductivamente.

Esta omnipresencia de la abducción tiene, naturalmente, consecuencias para la lógica de la justificación científica: si asumimos que a) la identificación de un caso (ya sea una azalea, un lapsus o un microbio) siempre supone la presencia de inferencias abductivas; y que b) la abducción es una inferencia que no garantiza la conservación de la verdad entre premisas y conclusión; por lo tanto: c) la verificación y la refutación nunca pueden ser conclusivas ${ }^{548}$. Tal y como hemos expuesto en la segunda parte de esta tesis, a esa misma conclusión puede llegarse desde diferentes premisas.

Peirce reconoce el carácter falible de nuestras creencias, pese a lo cual esboza serias dudas para creer que nuestra capacidad de inventar hipótesis exitosas se deba al azar:

\begin{abstract}
Pensemos en los trillones de trillones de hipótesis que pueden hacerse de las cuales sólo una es verdadera; y, con todo, el físico, después de dos o tres conjeturas, o, todo lo más, de una docena, da muy cerca de la hipótesis correcta. Por azar no lo hubiese conseguido, probablemente ni en todo el tiempo transcurrido desde que la tierra se solidificó (Peirce, 1903/1988: 134).
\end{abstract}

\title{
I. Del azar y el instinto a la analogía
}

Juan Samaja (1993/2008), apoyándose en la tradición dialéctico-hegeliana, ha acentuado las relaciones que la inferencia abductiva guarda con la analogía.

\footnotetext{
${ }^{548}$ Así ejemplifica Roxana Ynoub este argumento: "si partimos de premisas que sostienen, por ejemplo, que 'toda histeria presenta síntomas conversivos' y, además, que 'la paciente Dora es una histérica', podemos entonces concluir deductivamente que 'Dora, presentará síntomas conversivos', pero para esto debimos antes 'identificar a Dora como histérica'. Esta identificación es la que compromete la inferencia abductiva" (Ynoub, 2015: 73).
} 
Para él, la abducción consiste en inferir una causa probable de un caso desconocido y a partir de la analogía con reglas aceptadas para otro tipo de casos ya conocidos. Así planteado, el movimiento abductivo consiste en un reconocimiento acertado del caso, cuya complejidad variable no modifica su naturaleza: desde cualquier juicio perceptual ordinario (como el de la azalea) hasta por ejemplo un diagnóstico, supone el mismo acto de proponer una regla conocida para elaborar una explicación plausible de los rasgos enigmáticos que, de ser acertada, confirmarían que el fenómeno es un caso de dicha regla. Sin embargo, no siempre disponemos de reglas conocidas para extrapolar el rasgo inicialmente enigmático que deseamos explicar, ¿qué pasa en estas situaciones? Según Samaja, este escenario podría formularse así:

$$
r+i R ? \rightarrow i ?
$$

Reconocemos los hechos (rasgos o resultados) pero no podemos identificar a qué tipo de caso corresponden, justamente porque no disponemos de ninguna regla que nos permita explicarlos. Se trata de la presencia de una anomalía. Como hemos visto, la respuesta que se ha sostenido durante mucho tiempo es que los científicos dan rienda suelta a su imaginación y prueban suerte: el proceso de inventar hipótesis explicativas no tiene lógica alguna, por lo que sólo cabría esperar un procedimiento generalizado de ensayo y error. Peirce puso en evidencia, incluso antes de que Popper la estableciera, lo absurdo de esta propuesta:

Un físico, en su laboratorio, da con algún fenómeno nuevo. ¿Cómo sabe que las conjunciones de los planetas no tienen nada que ver con ello, o que no es quizá porque a la emperatriz viuda de China se le haya ocurrido por la misma época, hace un año, pronunciar alguna palabra con poder místico, o porque se encuentra presente algún genio invisible? (Peirce, 1903/1988: 134).

Esto no contraría la idea de ensayo y error, sino que justamente introduce la idea de que evidentemente debe haber criterios previos que hagan posible seleccionar las hipótesis que van a ser puestas a prueba. Es en función de esta necesidad económica y también del éxito relativo que suele tener el hombre para acertar en poco tiempo, que Peirce rechaza de raíz la hipótesis de que la creación de conjeturas se pueda explicar por azar. Él supone que es la 
abducción lo que comanda la lógica del descubrimiento, tanto en el plano de la vida cotidiana como en la investigación científica. Aun así, como también mencionamos, Peirce sigue suponiendo que, en última instancia, el hombre posee una especie de facultad adivinatoria que le permite, mediante la abducción, dar en el calvo con relativa prontitud. Aunque Peirce no resuelve este misterioso problema, su intuición nos parece muy razonable:

\begin{abstract}
Sea como sea el modo cómo el hombre ha adquirido su facultad de adivinar las vías de la naturaleza, lo cierto es que no ha sido mediante una lógica autocontrolada y crítica. Ni siquiera ahora puede dar una razón exacta de sus mejores conjeturas. Me parece que el enunciado más claro que podemos hacer de la situación lógica -la más libre de toda mezcla incuestionable- es decir, que el hombre tiene un cierto discernimiento [insight] de la terceridad, de los elementos generales de la naturaleza, no lo bastante fuerte como para estar con más frecuencia acertado que equivocado, pero lo bastante como para no estar abrumadoramente con más frecuencia equivocado que acertado. Lo llamo discernimiento porque hay que referirlo a la misma clase general de operaciones a la que pertenecen los juicios perceptivos. Esta facultad participa a la vez de la naturaleza general del instinto, pareciéndose a los instintos de los animales en que supera con mucho los poderes generales de nuestra razón y en que nos dirige como si estuviéramos en posesión de hechos que se encuentran por completo más allá del alcance de nuestros sentidos. Se parece también al instinto en su pequeña predisposición al error; pues aunque yerra con más frecuencia que acierta, con todo la frecuencia relativa con la que acierta es en conjunto la cosa más maravillosa de nuestra constitución. (Peirce, 1903d/1988; cursivas y corchetes añadidos).
\end{abstract}

Samaja considera que esa intuición peirceana está bien encaminada, pero propone una alternativa que vale tanto para Peirce como para Popper en lo que a la creación de hipótesis respecta. Según el metodólogo argentino, no es la invención fortuita ni la capacidad adivinatoria lo que está a la base de la abducción creativa; sino que dicho proceso se pone en marcha a partir del establecimiento de una analogía:

La percepción de una semejanza con algo muy conocido nos empuja a derivar que nuestro rasgo se explica por una Regla como la que está empotrada en nuestro caso familiar [...] de manera que la abducción que pone la explicación al alcance de nuestra mente ha sido posible gracias a que la analogía ha reducido 
drásticamente el campo de búsqueda y le confiere el fundamento que emana de la eficacia de la propia praxis humana (Samaja, 2002: 187).

Captar una analogía es, al mismo tiempo, captar semejanzas y diferencias; por lo que la analogía sólo nos brinda un punto de partida (regla análoga) para la confección de una regla propia para nuestro rasgo enigmático. La analogía determina solamente las condiciones de posibilidad de la hipótesis, restringiendo el campo de búsqueda del investigador ${ }^{549}$. Es, por lo tanto, un proceso que tiene una lógica, aunque ésta no sea una lógica autocontrolada y crítica (ibíd. p. 189). La analogía desempeña un papel central, según Samaja, en aquellas abducciones que están en la base de los procesos más creativos:

La abducción de Peirce puede ponerse en marcha sin tener que presuponer la Regla Universal. Para ello, alcanza con poner en el lugar de la Regla propia del fenómeno que se quiere comprender, la regla de algún otro fenómeno que presenta una relación de analogía con aquel (Samaja, 1993/2008: 125, cursivas del original).

Podríamos reconstruir la secuencia que Samaja propone de la siguiente forma: 1) incertidumbre inicial ante unos rasgos enigmáticos que no pueden resolverse por la aplicación de una regla conocida, quedando el caso sin identificar. 2) Comparación de lo enigmático con otros casos o reglas conocidas, en búsqueda de analogías. 3) El hallazgo de una analogía permite la exploración de semejanzas y diferencias entre los rasgos enigmáticos y el caso/regla análogo. 4) Identificación progresiva de la regla propia, apoyándose en el modelo análogo y en los rasgos enigmáticos. 5) Establecimiento de la regla nueva que permite la identificación del caso y la naturalización de los rasgos enigmáticos.

A pesar de que Samaja lo sistematiza más allá de Peirce, ya encontramos en su pensamiento un vínculo entre abducción y analogía. De hecho, Mauricio Beuchot ha planteado recientemente que éste era un vínculo central:

...llama la atención lo vinculada que está la abducción de Peirce con la analogía.

Él mismo se queja de que muchos críticos suyos reducían la abducción al

${ }^{549}$ Este achicamiento del campo de búsqueda del científico era fundamental para Peirce: debido a que la puesta a prueba de hipótesis "es tan costosa en tiempo, energía y dinero", la "consideración principal en la abducción" es en todos los casos "la cuestión de la Economía Economía de dinero, tiempo, pensamiento y energía" (Peirce, 1903c/2003). 
argumento por analogía, dada la semejanza que los vinculaba. Peirce admite la cercanía de la abducción con la analogía, y con ello señala que a la base de la abducción está la analogía misma. El pensamiento abductivo es analógico, y éste es icónico. (Beuchot, 2014: 86).

A nuestro modo de ver, aunque aceptemos que la analogía es un mecanismo básico de toda abducción creativa, eso no nos dice nada respecto de la conjetura metafísica de Peirce sobre la capacidad adivinatoria del hombre. Por el contrario, uno podría relanzar la pregunta: ¿qué mueve al hombre a esbozar analogías que, luego de unos pocos intentos, se muestran acertadas? Aceptamos que la analogía funcione como una guía heurística para la resolución de enigmas $y$, en ese sentido, la propuesta de Samaja parece constituir un aporte a la elucidación de los aspectos cognitivos involucrados en la creación científica; pero también podemos admitir que el misterio indicado por Peirce sigue vigente.

\section{Tipos de abducción}

En virtud de las complejidades que parece suponer el asunto de la abducción, no resulta extraño encontrarnos con que existen diversos modos de clasificar los subtipos de este conjunto de inferencias. Intentaremos mencionar sintéticamente algunas de las propuestas para su clasificación, a los fines de munirnos con una taxonomía general que nos permita luego una lectura del papel que desempeñan en el campo psicoanalítico.

Recordemos que ya Peirce señaló que las conjeturas fruto de la abducción pueden ser de distinto tipo (Peirce, 1878a/1970), mencionando al menos tres: hipótesis acerca de entidades o hechos no observados en el momento de su formulación (pero que pueden ser observados en el futuro para contrastarla), hipótesis sobre entidades o hechos observados en el pasado pero imposibles de volver a observar $y$, finalmente, hipótesis acerca de entidades o hechos inobservables por estar más allá de lo sensible (constructos teóricos).

En su artículo To Guess or Not To Guess?, Bonfantini y Proni diferencian tres tipos de abducción según tres grados ascendentes de originalidad y creatividad:

Primer tipo de abducción: la ley mediadora a emplear para inferir el caso del resultado viene dada de una manera obligante y automática o semiautomática; 
Segundo tipo de abducción: la ley mediadora a emplear para inferir el caso del resultado se encuentra por selección en la enciclopedia disponible; Tercer tipo de abducción: la ley mediadora a emplear para inferir el caso del resultado es enunciada ex novo, inventada. En este tipo de abducción hay auténtica adivinación. (Bonfantini y Proni, 1989: 183).

Según estos autores, el primer tipo de abducciones aparece en la vida cotidiana todo el tiempo; mientras que el segundo tipo se correspondería con los periodos de ciencia normal kuhnianos y sólo el tercer tipo de abducciones daría lugar a las novedades, coincidiendo con los períodos de la ciencia revolucionaria kuhneana ${ }^{550}$.

También Guy Debrock traza una diferencia entre abducción débil y fuerte, apoyándose en la distinción kunheana:

\begin{abstract}
Una buena abducción débil no necesita nada más que: 1) Una analogía establecida empíricamente (semejanza de propiedades), y 2) la ausencia de indicaciones de lo contrario. Un ejemplo reciente de una hipótesis que al principio parecía muy plausible, pero que ahora debe ser descartada, es nuestra creencia de que el hombre de Neanderthal era un ancestro del homo sapiens. La hipótesis se estableció sobre la base de la analogía, pero ahora se dan fuertes indicios de que la analogía era superficial y, por tanto, engañosa.

Sin embargo, en el caso de la abducción en el sentido fuerte de la palabra, esos criterios fallan por la ausencia de analogía. El descubrimiento de Lavoisier del oxígeno es un buen ejemplo de esa abducción fuerte. La diferencia entre su hipótesis y la hipótesis de Priestley debería ser explicada en términos de ese misterioso 'flash de entendimiento'. (Debrock, 1998: 16).
\end{abstract}

Sólo las abducciones fuertes producen verdaderas hipótesis nuevas según Debrock, mientras que las abducciones débiles son propias de la ciencia normal en sentido kuhneano: "es importante distinguir entre inferencia abductiva débil tal como se encuentra en la 'ciencia ordinaria' donde la

550 En base a ello, Bonfantini y Proni exponen las diferencias existentes entre los procedimientos de Peirce y Holmes: "La cuestión está en elucidar si el tipo de abducción implicada en la investigación policial es idéntica, o similar, o diferente por completo del tipo de abducciones implicadas en la investigación teórica científica que, es de presumir, interesaba más a Peirce. Que puede haber cierta diferencia entre los dos tipos de abducción podía suponerse a priori, teniendo en cuenta la diferencia de objetivos de los dos tipos de investigación. En la investigación policial el objetivo es remontarse de un hecho particular a su causa particular, mientras que en la investigación científica el fin es encontrar una ley teórica fundamental de aplicación general, o bien (más a menudo) encajar un hecho anómalo en el campo de aplicación de una ley fundamental mediante la reordenación de las leyes «intermedias»". (Bonfantini y Proni, 1989: 173). 
inferencia es fuertemente analógica o disfrazadamente deductiva, e inferencia abductiva fuerte, característica de los pensamientos científicos revolucionarios" (Debrock, 1998: 23).

Umberto Eco también adopta la taxonomía de Bonfantini y Proni, nominando esos tres tipos y añadiendo un cuarto:

a) Abducción hipercodificada: la regla o ley viene dada de manera automática o semiautomática, por lo que se trata de una ley codificada.

b) Abducción hipocodificada: la regla o ley debe seleccionarse entre una serie de reglas equiprobables puestas a nuestra disposición por el conocimiento corriente del mundo.

c) Abducción creativa: la regla o ley tiene que ser inventada, lo cual nos lleva a realizar una meta-abducción.

d) Meta-abducción: consiste en decidir si el universo posible delineado por nuestras abducciones creativas equivale al universo de nuestra experiencia; es decir en poner a prueba la abducción creativa efectuada. Esto se debe a que, en éstas, la regla o ley inventada no está, a diferencia de lo que sucede con los dos primeros tipos de abducción, establecida o reconocida como válida. Por eso, cuando una hipótesis creativa resulta corroborada, da lugar a cambios revolucionarios. (Eco, 1989: 276-277).

Otra de las clasificaciones es la de Paul Thagard (1988: 54-63), quien diferencia cuatro tipos de abducción a partir del tipo de resultado obtenido:

a) Abducción simple: se conjetura sobre entidades individuales;

b) Abducción existencial: se postula la existencia de entidades previamente desconocidas;

c) Abducción formativa de reglas: se hacen hipótesis sobre alguna regla que explica otras reglas; $y$

d) Abducción analógica: que utiliza casos pasados similares para generar hipótesis que expliquen los hechos actuales.

Finalmente, Roxana Ynoub retoma tres criterios propuestos por Samaja para tipificar las abducciones:

Reglas de atribución: la conclusión abductiva consistirá en caracterizar o describir el caso, según sus rasgos y características específicas. 
Reglas de causación o procesualidad: la conclusión abductiva consistirá en explicar el caso, en función de factores etiológicos o productivos.

Reglas de significación: la conclusión abductiva consistirá en significar o interpretar el caso, adjudicando un sentido a los hechos, signos o indicios (Ynoub, 2015: 76; cursivas en el original).

Estas clasificaciones, que son apenas algunas de las disponibles en la bibliografía, nos permiten advertir que carecemos de univocidad en los criterios y en las clases para poder trazar una cartografía homogénea sobre la abducción. Esta situación, lejos de ayudar al esclarecimiento de la naturaleza de la abducción, complejiza el panorama y nuestras aspiraciones de utilizarla como herramienta conceptual para la elucidación de las inferencias psicoanalíticas. A ello debemos sumarle una dificultad añadida: la discusión, aún vigente, sobre las relaciones de la abducción con la denominada inferencia a la mejor explicación.

\section{b) Abducción e inferencia a la mejor explicación}

La expresión inferencia a la mejor explicación (IME de aquí en más) fue acuñada por Gilbert Harman para denominar el procedimiento ya conceptualizado por Aristóteles y al que Peirce se refirió como abduction. Antes de pasar a definirla mejor, conviene detenernos a distinguir algunas de las posturas principales sobre las relaciones de la IME con la abducción. Existe una lectura filosófica, sostenida en varias razones, que se empeña en utilizar de manera indistinta las nociones de abducción y de inferencia a la mejor explicación ${ }^{551}$, o al menos de concebirlas como estrechamente relacionadas (Harman, 1965; Josephson y Josephson, 1996; Magnani, 2001; Walton, 2004). La postura contraria, sostenida también por diversos autores, versa sobre la utilidad e incluso necesidad de mantener una distinción entre ambas nociones (Hintikka, 1998; Kapitan, 1992; Minnameier, 2004; Paavola, 2006; Niño, 2012; Iranzo, 2011; Campos, 2011). Existen también desarrollos que han intentado

${ }^{551}$ La entrada Abduction de la célebre Stanford Encyclopedia of Philosophy, efectuada por Douven (2011), inicia con este presupuesto: "Abducción, o como también es llamada frecuentemente, Inferencia a la Mejor Explicación...." [Abduction or, as it is also often called, Inference to the Best Explanation....]. 
conectar ambas nociones en un modelo integrador (Aliseda, 2006; Lipton, 2004; Lycan, 1988; Psillos, 2000; Schurz, 2008; Thagard, 1978).

Cuando Harman (1965) introdujo la noción de IME lo hizo para referirse a todos los razonamientos que no fueran deductivos, incluyendo tanto a la abducción como a la inducción ${ }^{552}$. Sin embargo, la IME ha devenido un modelo que pretende dar cuenta de otros aspectos distintos de los que da cuenta la abducción:

...mientras que $A B$ [la abducción] refiere al proceso por el que se obtienen soluciones potenciales -diversas hipótesis explicativas- para una evidencia dada, esto es, a un proceso de descubrimiento, IME se ocupa de los criterios de selección que deben aplicarse para determinar cuál de aquellas es la respuesta correcta, o sea, la explicación verdadera. Visto así, IME plantea un problema específico que no surge a propósito de $A B$, a saber, cuál es el valor epistémico de las virtudes explicativas, o dicho con otras palabras, por qué el hecho de que una hipótesis $h$ las posea ha de tomarse como indicio de que $h$ es verdadera. (Iranzo, 2011: 301; cursivas y negrita en el original).

En la propuesta de Harman, "a partir del hecho de que cierta hipótesis explicaría la evidencia se infiere la verdad de esa hipótesis" ${ }^{553}$ (Harman, 1965: 89). De manera un tanto inespecífica, Harman sostiene que se debe escoger la mejor de las hipótesis en competencia, en base a criterios como simplicidad, mayor explicatividad o menor carácter ad hoc (ibíd. p. 88); es decir aquella hipótesis que encaje mejor que sus competidoras con la evidencia disponible y que, por lo tanto, nos proporcione una mejor imagen del mundo (Harman, 1968: 530-532).

Paul Thagard sostuvo que Harman no fue del todo claro en delimitar criterios para distinguir cual es la mejor hipótesis y propuso tres criterios más específicos:

\footnotetext{
${ }^{552}$ Para Harman las inducciones serían inferencias implícitas a la mejor explicación: "su idea es que una conclusión como "todos los cuervos son negros», por ejemplo, es aceptada porque constituye la mejor explicación de la frecuencia observada (la explicación alternativa sería que la muestra está sesgada)." (Iranzo, 2011: 302).

553 "...from the fact that a certain hypothesis would explain the evidence, to the truth of that hypothesis."
} 
a) Consiliencia: una teoría es más consiliente que otra si explica más variedad (no cantidad) de hechos o de leyes en distintos dominios, unificando y sistematizando el conocimiento.

b) Simplicidad: entendida como la limitación más importante para la consiliencia, en la medida en que vuelve inaceptables a las hipótesis auxiliares que sólo expliquen una clase de hechos (hipótesis ad hoc). Así, puede decirse que una teoría es simple si tiene pocas hipótesis ad hoc (lo cual también puede verse en términos de economía ontológica, aunque en sí misma no es lo relevante para IME).

c) Analogía: consiste en concluir que si A y B comparten las propiedades $p$, $q, r, \mathrm{y}$ además, sabemos que $\mathrm{A}$ tiene la propiedad $\mathrm{s}$ y que $\mathrm{Z}$ explica por qué $A$ tiene todas esas propiedades, por lo tanto $Z$ es una conjetura promisoria para dar cuenta de las características de B y para esperar que s también sea una propiedad de $\mathrm{B}$. La analogía permite así conducir la investigación con cierto rumbo o dar apoyo a ciertas hipótesis ya existentes.

Thagard se propone mostrar que, con estos criterios, la IME es un modelo más adecuado que el hipotético-deductivo. Sostiene que el descubrimiento y la justificación de hipótesis no pueden concebirse como procesos cualitativamente diferentes o autónomos: "porque la analogía es un factor al elegir la mejor explicación, no hay una lógica del descubrimiento distinta de la lógica de la justificación" ${ }^{554}$ (Thagard, 1978: 90). Dicho de otra manera: las razones para sugerir una clase de hipótesis explicativa, no son de una índole diferente a las razones esgrimidas para aceptarla (Thagard, 1981: 251-259). Este argumento refuerza la idea de una continuidad esencial entre la abducción y la IME o, lo que es otra manera de decirlo, que las inferencias abductivas no sólo desempeñan un papel en la invención sino también en la validación. Esta lectura se apoya en algunas expresiones de Peirce, como la siguiente:

...con respecto a las consideraciones instintivas, ya he señalado que es una hipótesis primaria subyacente a todas las abducciones que la mente humana es

\footnotetext{
554 "Because analogy is a factor in choosing the best explanation, there is no logic of discovery distinct from the logic of justification."
} 
parecida a la verdad en el sentido que un número finito de conjeturas iluminará la hipótesis correcta. (Peirce, 1901/2001: 42).

Algunos suelen interpretar esa asunción de Peirce sobre la capacidad adivinatoria del hombre como una propuesta que tiende a indiferenciar los contextos de descubrimiento y justificación (Achinstein, 1987; Okasha, 2000). Como enseguida veremos, esa línea argumental parece desdibujar el falibilismo con el que Peirce entendía al proceso investigativo, representado por la fase final donde las hipótesis abducidas se ponen a prueba de manera inductiva. Antes de adentrarnos en la metodología peirceana, me parece oportuno señalar cuál es el modo más conveniente de leer estas cuestiones o, al menos, el que voy a adoptar aquí: no veo inconveniente alguno en separar las suposiciones metafísicas de Peirce sobre la capacidad del hombre de dar con la verdad, respecto de sus consideraciones metodológicas sobre el proceso investigativo ${ }^{555}$. Esta independencia relativa tiene implicancias importantes, ya que cualquier cuestionamiento sobre esas suposiciones metafísicas no afectará necesariamente a su caracterización de las etapas del proceder científico.

Analizando la necesidad que algunos plantean de distinguir entre las razones para proponer una hipótesis y las razones para aceptarla, Lorenzo Magnani retoma la idea de que "hay dos principales significados epistemológicos de la palabra abducción: 1) la abducción que solo genera hipótesis 'plausibles' (selectivas o creativas) y 2) la abducción considerada como inferencia a la mejor explicación, que también evalúa las hipótesis" 556 (Magnani, 2001: 19). Y más adelante agrega:

\footnotetext{
${ }^{555}$ Aclaro que esa separación es simplemente a los fines de centrarme en lo metodológico sin tener que ocuparme del aspecto metafísico. Pero no siento, como otros lectores, ninguna aversión especial ante esa suposición de Peirce. De hecho, en el capítulo siguiente veremos que esa idea guarda alguna similitud con las capacidades que Freud le atribuye al analista para colegir lo inconsciente del paciente. Me parece que aunque esa suposición pueda resultar innecesaria para algunos, en realidad es mucho más frecuente de lo que se suele creer. No parece exagerado decir que la mayoría de los partidarios del realismo científico de nuestros días, aunque probablemente "remisos a expresarse tan rotundamente como Pierce, [...] siguen sospechando que efectivamente los científicos tienen una suerte de talento que los guía en dirección a la verdad" (Gaeta, 2008: 194).

556 "There are two main epistemological meanings of the word abduction: 1) abduction that only generates 'plausible' hypotheses (selective or creative) and 2) abduction considered as inference to the best explanation, which also evaluates hypotheses."
} 
Es importante señalar que ya en la fase de generación muchas consideraciones evaluativas pueden estar presentes y entrelazadas [...] [por lo que] la abducción considerada como una manera de generar hipótesis es inmediatamente una generación de hipótesis "plausibles". Yo creo que este controvertido estatus de la abducción está relacionado con la confusión entre niveles epistemológicos y cognitivos... ${ }^{557}$ (ibíd. p. 26).

Coincido con lo que ya había manifestado Gonzalo Génova analizando estos aspectos: "Peirce no distingue explícitamente estos dos momentos. Para él la abducción es indistintamente selección y construcción de hipótesis" (Génova, 1997: 76). Para Marisa Velasco, el hecho de que en el propio Peirce encontremos, o bien en el mismo trabajo o bien en trabajos de la misma época, que la abducción es caracterizada como una inferencia generadora y como forma de seleccionar hipótesis: "constituye una sobrada prueba de que estas son dos facetas de la abducción, según nuestro autor, y no responden a dos formas diferentes de caracterizarlas" (Velasco, 2002: 118). Esto es así porque Peirce entiende que la creación de hipótesis no es por azar y que, por ende, quien así razona puede dar razones de la verosimilitud de su conjetura: "una hipótesis, entonces, que en sí misma sea probable y que haga probables a los hechos, ha de ser adoptada. Este paso de adoptar una hipótesis como siendo sugerida por los hechos, es lo que llamo abducción" (Peirce, 1901/2001: 2425). Entonces, como la abducción consiste en alcanzar una hipótesis explicativa para que pueda ser puesta a prueba, en la generación misma aparecen presupuestos los momentos peirceanos de la investigación. De este modo, construir una hipótesis equivale a seleccionarla; pero, esta selección no corresponde a su establecimiento: para ello primero debe ser sometida a prueba y, además, atravesar exitosamente esta instancia.

Por eso, para Génova, la denominada IME

...tiene el inconveniente de sugerir que la abducción proporciona siempre la hipótesis verdadera que da cuenta de los hechos ("la mejor explicación"), olvidando el carácter de extrema falibilidad que Peirce atribuye a las inferencias

\footnotetext{
557 "It is important to note that already at the generation phase many evaluation considerations can be present and intertwined [...] abduction considered as a way of generating hypotheses is immediately a generation of "plausible" hypotheses. I think this controversial status of abduction is related to a confusion between the epistemological and cognitive levels, and to a lack of explanation as to why people sometimes deviate from normative epistemological principles."
} 
abductivas, que siempre dependen de la confirmación inductiva. (Génova, 1997:

83).

A mi modo de ver, las dificultades para separar netamente los momentos de creación y elección de conjeturas, atentan contra la posibilidad de identificar la abducción con la IME: éste último constituye un modelo que contempla un momento inicial en el que se dispone de un conjunto establecido de hipótesis explicativas, omitiendo las características inherentes a la fase de su descubrimiento; y, por otro lado, al considerar la IME que la mejor explicación es la más próxima a la verdad, se minimiza el carácter falible de la abducción. Como sostiene Douglas Niño:

la IME harmaniana justifica la afirmación de su conclusión, mientras que en la abducción peirceana este no es el caso. En otras palabras, de acuerdo con los seguidores de IME, con IME obtenemos nuevo conocimiento, mientras que de acuerdo con Peirce, las abducciones científicas no proporcionan nuevo conocimiento y ello solamente pueden hacerlo las inducciones. (Niño, 2012: 79).

Por eso, para Niño, la abducción no es la inferencia a la mejor explicación sino una inferencia a la mejor hipótesis para ser puesta a prueba; ya que el papel de la abducción es ofrecer conjeturas que faciliten los propósitos de la investigación ${ }^{558}$.

Distinguir la formalización de las dos principales acepciones mencionadas nos permitirá captar mejor las diferencias que hemos mencionado. La representación de la inferencia abductiva ha sido inmejorablemente explicitada por Peirce:

Se observa el hecho sorprendente C.

Pero si A fuera cierto, C sería algo corriente,

por lo tanto, hay razón para sospechar que A es cierto. (Peirce, 1903a/1978).

Una representación cabal de la IME ha sido expuesta, entre otros, por Josephson y Tanner:

\footnotetext{
${ }^{558}$ Niño propone la hipótesis de que las diferencias entre la abducción y la IME "podrían tener sus raíces en sus respectivos trasfondos filosóficos, esto es, el empirismo y el pragmatismo" (ibíd. p. 86), es decir en una concepción diferencial de la experiencia, de las reglas metodológicas y de las características formales de esas inferencias.
} 
$D$ es un grupo de datos.

H explica D.

No existe otra hipótesis que explique $\mathrm{D}$ tan bien como lo hace $\mathrm{H}$.

Por lo tanto, $\mathrm{H}$ es probablemente cierto. ${ }^{559}$ (Josephson \& Tanner, 1996: 5).

Cuando se las utiliza con propósitos científicos, la diferencia entre ambos esquemas es enorme. Esto se comprende bien si nos adentramos brevemente en la conceptualización peirceana de la abducción y de la inducción.

1) En primer lugar, destaquemos que el papel de la sorpresa señala, para Peirce, cómo una investigación comienza con una duda efectiva que se desencadena por el encuentro con hechos extraordinarios; es decir que es algo del orden de la necesidad lo que da lugar a la abducción. Ahora bien, una vez que la abducción ha sido efectuada y contamos con una hipótesis (segunda premisa), estamos autorizados a arribar a una conclusión que, a menudo, ha sido malinterpretada: podemos sospechar que la hipótesis abducida es correcta, lo cual no quiere decir que tengamos derecho epistémico a creer en ella ${ }^{560}$. Para Peirce, la inferencia abductiva no es un método de fijar la creencia: el proceso científico en su conjunto sí lo es ${ }^{561}$. La abducción constituye apenas

559 " $D$ is a collection of data (facts, observations, givens).

H explains D (would, if true, explain D ).

No other hypothesis can explain $\mathrm{D}$ as well as $\mathrm{H}$ does.

Therefore, $\mathrm{H}$ is probably true."

${ }^{560}$ Nótese, además, que si la conclusión del razonamiento abductivo es asumida con certeza, la inferencia se transforma en una falacia de afirmación del consecuente.

561 En La fijación de la creencia Peirce (1877/1988) diferenció cuatro métodos para fijar creencias, que podemos sintetizar así: 1) el método de la tenacidad: implica adoptar una creencia a partir de mantener las propias asunciones, aun cuando la experiencia las contradiga, "aprendiendo a alejarnos con desprecio y aversión de todo lo que pueda perturbarla" (ibíd.). Esto es así porque yo lo digo, sería su expresión resumida. 2) El método de la autoridad: consiste en fijar una creencia por referencia a una opinión ajena pero jerarquizada: esto es así porque fulano lo dice, sería su expresión sintética. Desgraciadamente, si sustituimos fulano por Freud o Lacan, veremos cuán común y corriente es este método para fijar creencias en las argumentaciones psicoanalíticas de nuestro margen rioplatense. Peirce, adelantándose a lo que Freud propondría, p.ej. en Psicología de las masas, considera que "el método de la autoridad regirá siempre la masa de la humanidad"; y también que "la persecución no siempre procede de afuera; sino que un hombre se atormenta a sí mismo, llegando con frecuencia a angustiarse al máximo al descubrirse creyendo en proposiciones que la educación recibida le llevaba a considerar con aversión". 3) El método a priori: frecuente en 
el momento inicial de este proceso y luego serán las inferencias deductivas las encargadas de desarrollar la hipótesis abducida y, finalmente, las inferencias inductivas las que comandarán la puesta a prueba. Una vez que este proceso de testeo de sus resultados, estaremos en condiciones de justificar nuestra sospecha (pasando a un estado de creencia en el caso de que las consecuencias resulten confirmadas) o de desestimarla ${ }^{562}$.

2) Para Peirce, las inferencias inductivas tienen un estatuto epistémico mayor, en la medida en que constituyen el último momento del proceso investigativo. Así define Peirce a la inducción:

\begin{abstract}
La inferencia de que un carácter designado previamente tiene aproximadamente la misma frecuencia de ocurrencia en toda una clase que la que tiene en una muestra de esa clase tomada al azar, es inducción. Si el carácter no se designa previamente, entonces, una muestra en la que se encuentra que es prevalecedor puede servir solamente para sugerir que podría ser prevalecedor en toda la clase. Podemos considerar esta suposición como una inferencia si queremos -una inferencia de posibilidad; pero ha de sacarse una segunda muestra para evaluar la cuestión de si el carácter es realmente prevalecedor. (Peirce, 1878b/2001; cursivas del original).
\end{abstract}

Según Niño, las nociones allí expuestas de predesignación del carácter ("carácter designado previamente") y muestreo, son usualmente pasadas por alto por los epistemólogos. Su importancia puede ejemplificarse como sigue: imaginemos que hemos arribado a una hipótesis $\mathrm{W}$ tal que, además de explicar los hechos sorprendentes, presenta como consecuencias observacionales a los hechos $h, i, j$ y $k$, de tal manera que cuando vamos a efectuar las observaciones experimentales ya hemos predesignado a $h, i, j$ y $k$ como hechos que deberíamos encontrar (predicciones) si la hipótesis fuese

filósofos, consiste en suponer algunos principios fundamentales y derivar de ellos las características del mundo efectivo. Esto nos brinda "confortables conclusiones [...] hasta que los rudos hechos nos despiertan de nuestro placentero sueño. 4) El método de la ciencia: el único que no depende de los intereses de las personas que lo manejan y que nos permite confiar en que alcanzaremos la verdad, entendida como correspondencia con la realidad. Recién en 1898 Peirce llegará a caracterizar el método científico a partir de las tres etapas que hemos mencionado: abducción, deducción e inducción.

${ }^{562}$ En virtud de que algunos han confundido el proceso por el cual, según Peirce, se llega a obtener una conjetura plausible (pasible de ser sometida a testeo empírico) con el proceso que permite decidir si esa conjetura es la mejor entre otras posibles, Laudan (1981: cap. 11) propuso hablar de contexto de prosecusión para referirse a la región intermedia entre descubrimiento y justificación. 
verdadera. Pero supongamos ahora que hemos dado con la hipótesis $\mathrm{W}$ y que antes de haber podido extraer las consecuencias $h, i, j$ y $k$ ya nos hemos encontrado con ellas como hechos concomitantes que, en tanto que tales, los hemos registrado como parte de la evidencia disponible. En este caso $h, i, j$ y $k$ no han sido predesignados, por lo que no pueden contar como evidencia inductiva para $\mathrm{W}$ en el momento de efectuar las observaciones; puesto que aún estamos dentro del proceso abductivo. Por eso "la inducción sólo tiene toda su fuerza cuando el carácter al que concierne ha sido designado antes de examinar la muestra"563 (Peirce, 1878b/2001). La predesignación, por lo tanto, es la operación de establecer, antes de la observación (aunque no antes del muestre $\left.{ }^{564}\right)$, cuáles son los caracteres que vamos a poner a prueba. Nos indica qué y cómo debemos realizar la búsqueda ${ }^{565}$. (Niño, 2012: 74).

Entonces, para Peirce, si la abducción supone un encuentro con los hechos sorprendentes, la inducción implica una búsqueda deliberada de hechos que deben predecirse antes de ser observados; pues de lo contrario la inducción retrocede hasta la abducción. Por eso, Peirce sostiene que la conclusión de una inferencia abductiva debe tener el estatuto de una pregunta o, a lo sumo, de una sugerencia: "ha de presentarse expresamente como una cuestión a discutir" (Perice, 1878a/1970). Y sólo la conclusión de una inducción, que haya sido precedida de abducción y deducción, tiene las credenciales para fijar la

\footnotetext{
${ }^{563}$ Es muy interesante notar que, en el escrito citado y en base a este argumento, Peirce desestima cabalmente la concepción de la inducción sostenida por Mill y sus discípulos, fundamentalmente el supuesto sobre el que descansa: la uniformidad de la naturaleza.

${ }^{564}$ Esto es así, independientemente de las peculiaridades que asume el muestreo cuando la inducción es cuanti o cualitativa.

${ }^{565}$ Aunque Niño no lo ha notado, este requisito de Peirce ha sido reformulado por Popper como requisito de testabilidad independiente: "además de explicar todos los explicanda que la nueva teoría debe explicar, debe tener también nuevas consecuencias testables (preferiblemente, consecuencias de un nuevo tipo); debe conducir a la predicción de fenómenos hasta ahora no observados. Este requisito me parece indispensable porque sin él nuestra nueva teoría sería ad hoc; pues siempre es posible elaborar una teoría que se adapte a cualquier conjunto dado de explicanda". (Popper, 1963/1991: 295). La testabilidad y la testabilidad independiente son requisitos "formales" para Popper. Pero él señala, además un tercer requisito "material": el éxito empírico. Indica que sólo podemos decir algo sobre el valor de verdad de la hipótesis si ha sido testada empíricamente. Como puede notarse, Popper le otorga un mayor peso a la evidencia nueva que a la evidencia ya disponible; lo cual supone un contraste con la postura de IME. Worrall (1978) y Musgrave (1989), por ejemplo, han radicalizado este valor de la nueva evidencia en desmedro de la evidencia sobre la que nace la conjetura. Para otros, como Carnap (1950) y Hempel (1965/1996), es la forma lógica de la relación hipótesis-evidencia lo que cuenta, y no la temporalidad de la obtención de la evidencia.
} 
creencia de manera científica. De ello se desprende que abducción, deducción e inducción son cualitativamente distintas.

Como puede advertirse, las características con las que Peirce define al proceso de investigación y el lugar que otorga a los tres tipos de inferencias son aspectos que divergen respecto al modelo IME. A diferencia de lo que sucede con la conclusión de la abducción peirceana, que no provee conocimiento sino una sugerencia, la formalización citada de la IME muestra que la afirmación de la verdad de la conclusión aparece justificada. Como sostiene Niño, pareciera ser que para los partidarios de la IME el proceso de justificación de una creencia es algo gradual o cuantitativo: mientras una hipótesis tenga mayor evidencia que sus competidoras estará más firmemente apoyada. Pero esta apelación a la evidencia acumulada, en la medida en que no diferencia los hechos encontrados de los hechos buscados, constituye una desestimación de la predesignación y, por ende, de la diferencia que separa a la abducción de la inducción en el proceso de justificación de las creencias, tal y como Peirce lo entiende.

Posiblemente estas diferencias no se manifiestan cuando nuestros estándares de justificación no son elevados, como por ejemplo ocurre en contextos cotidianos de actividad cognitiva. Pero son cruciales cuando se trata del establecimiento de conjeturas en contextos científicos.

A mi modo de ver, las consideraciones anteriores pueden sintetizarse en tres criterios centrales que permiten separar la abducción de la IME:

a) El contexto al que pertenecen: mientras que la abducción pertenece al momento del proceso que sirve para dar lugar a conjeturas plausibles y no al momento dedicado a su contrastación, la IME comprende ambos momentos de manera integrada.

b) El tipo de evidencia que se tiene en cuenta para introducir una hipótesis: mientras que la abducción peirceana da lugar a la extracción de consecuencias observacionales que se buscará verificar inductivamente atendiendo a los caracteres predesignados, la IME considera suficiente la evidencia de base y algunos criterios añadidos (como los establecidos por Harman o Thagard) para seleccionar la mejor explicación.

c) El tipo de estado epistémico al que se llega con las hipótesis obtenidas: mientras que la abducción permite el arribo a una sugerencia plausible de ser 
evaluada, para la IME se obtiene una conjetura aceptada 0 , en términos peirceanos, una creencia fijada.

No ha sido mi objetivo reconstruir las múltiples interpretaciones que la abducción y la IME han recibido a lo largo de la historia de la filosofía de la ciencia, sino efectuar una caracterización, esbozar algunas de sus posibles relaciones y adoptar una opinión sobre lo que nos interesa de este debate. Todo ello a los fines de utilizar luego esas elucidaciones en el campo de la creación y asunción de conjeturas psicoanalíticas.

\section{c) Anteponiendo la IME a los cánones de Mill}

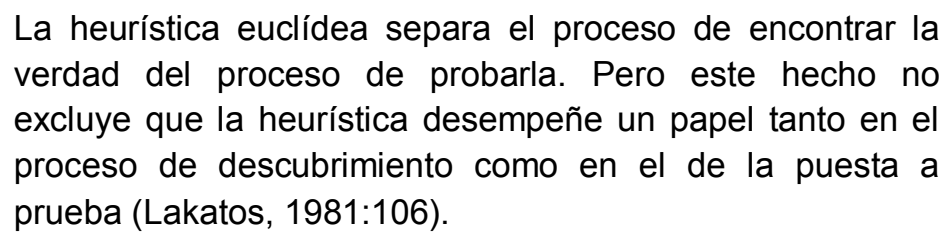

En la parte de la tesis en la que analizamos la crítica de Grünbaum, hemos mostrado por qué es inapropiado hacer depender la evaluación de las hipótesis causales del psicoanálisis de los cánones del inductivismo eliminativo derivado de Bacon y Mill. Antes de pasar a analizar el lugar que podemos darle a las inferencias abductivas en psicoanálisis, expondremos en este apartado las razones que han llevado a algunos a anteponer el modelo de IME al modelo del inductivismo eliminativo. Resulta propicio detenernos en ello más allá de las controversias antes señaladas sobre la naturaleza de la IME y sus relaciones con la abducción, debido a que las razones que enseguida analizaremos constituyen un argumento a favor de nuestra tesis, que ha sido esbozado independientemente del psicoanálisis. Los señalamientos que expondremos a continuación vienen así a complementar el análisis crítico que antes hiciéramos respecto de los cánones de Mill.

Posiblemente, uno de los argumentos más conocidos sobre la utilidad de la IME, contrariando la pretendida centralidad de los cánones del inductivismo, se deba a Peter Lipton (2004), quien sostiene que la IME es, en la mayoría de los casos, una mejor explicación del razonamiento causal utilizado en las ciencias. Lipton señala tres razones por las que es preferible una IME por sobre los cánones de Mill: 
En primer lugar, que los métodos de Mill "están de acuerdo en que todas las partes sean una descripción incompleta de la inferencia causal. Así Mill permite que sus métodos deban ser complementados por el Método de Hipótesis, que se parece mucho a un método de inferencia explicativa." 566 (ibíd. p. 126). Recordemos que para Grünbaum (1984: 189), a pesar de que el método psicoanalítico sea defectuoso, los métodos extraclínicos de validación podrían permitirnos apreciar cómo la "brillante imaginación intelectual de Freud" lo habría conducido a la verdad. A diferencia de este librarlos a la suerte o al genio individual, la IME ofrece un relato coherente de los principios de la creación de hipótesis: que es guiada por preocupaciones explicativas y que ello conecta el contexto de descubrimiento con el de justificación, ambos bajo el imperativo de asegurar la mejor explicación ${ }^{567}$.

En segundo lugar, el propio Mill reconoce que lo más importante del canon de la diferencia es algo idealizado: nunca hay una sola diferencia entre dos casos. Como ya señalamos antes, para saber qué diferencias son relevantes necesitamos conocimiento previo que fundamente nuestros principios de selección. Coincidimos con Lipton (p. 128) en que la IME, a diferencia del canon de la diferencia, sí proporciona buenas razones de los principios de selección y del fondo de conocimientos utilizado en los juicios de relevancia. Buscamos una diferencia que, si fuera causalmente relevante, podría proporcionar la mejor explicación de la evidencia que tenemos.

En tercer lugar, el canon de la diferencia no es capaz de dar cuenta de la inferencia de causas no observables o no observadas (ibíd. p. 127). Este canon sólo permite inferir que de algún efecto, uno de los antecedentes observados es una de las causas; pero no dice nada sobre el descubrimiento o la inferencia de una diferencia antecedente en los casos que están siendo analizados. Por el contrario, la IME permite inferir que hay una cierta diferencia de causalidad no

\footnotetext{
566 "....are agreed on all sides to be an incomplete account of inductive inference. Thus Mill allows that his methods must be supplemented by the Method of Hypothesis, which looks a great deal like a method of explanatory inference."

567 Este planteo se encuentra en las antípodas del binomio contexto de descubrimiento/contexto de justificación, tan difundido y defendido también por analistas. Así, para Thomä y Kächele, por ejemplo, "para la puesta a prueba de la teoría en cuestión no es relevante el modo en que las interpretaciones surgen en el psicoanalista." (Thomä y Kächele, 2002/2003). Abordaremos este asunto en el apartado siguiente.
} 
observada entre los casos, puesto que precisamente esto explicaría mejor por qué los casos resultan de manera diferente (como se observa). Planteado sintéticamente: mientras que el canon de la diferencia compara las historias conocidas de los dos casos para ver si hay una diferencia, la IME plantea la cuestión adicional de si, habiendo una diferencia, se habría explicado mejor la evidencia contrastante. De ser así, se infiere que la diferencia existe y es una causa.

Según Lipton, las explicaciones autoevidentes constituyen un buen ejemplo de la fecundidad de la IME. Considérese el caso de inferir el tránsito humano a partir de huellas en la nieve: tales huellas son la evidencia de lo que las explica (que una persona pasó por allí), al mismo tiempo que la hipótesis explicativa sólo puede ser ideada y tener sentido a partir de ese explanans (las huellas en la nieve). Esto introduce, evidentemente, una especie de circularidad $^{568}$ en la IME; pero, asegura Lipton, se trata de una circularidad virtuosa:

...no es simplemente que los fenómenos a ser explicados proveen razones para inferir tal explicación: inferimos las explicaciones precisamente porque ellas podrían, en caso de ser ciertas, explicar los fenómenos [...] Lejos de que la explicación sólo entre en escena después de que el trabajo inferencial ha sido realizado, la idea central de la Inferencia a la Mejor Explicación es que las consideraciones explicativas son una guía para la inferencia. ${ }^{569}$ (ibíd. p. 56).

En el caso del trabajo clínico del psicoanálisis, como enseguida veremos, esto es particularmente relevante; pues allí se trata de la inferencia de causas inobservables o inobservadas (estados mentales, mecanismos psíquicos, etc.) a partir de una evidencia que constituye, al mismo tiempo, la mejor prueba para hipostasiar tales hipótesis causales. Sin embargo, podemos aquí plantear un interrogante: ¿es suficiente ese tipo de evidencia para dar paso a la aceptación

\footnotetext{
568 Tal y como ya vimos en el apartado anterior, Peirce supo resolver esta circularidad separando la abducción de la puesta a prueba inductiva, prescribiendo para ésta última la necesidad de estipular caracteres predesignados.

569 "...it is not simply that the phenomena to be explained provide reasons for inferring the explanations: we infer the explanations precisely because they would, if true, explain the phenomena. [...] Far from explanation only coming on the scene after the inferential work is done, the core idea of Inference to the Best Explanation is that explanatory considerations are a guide to inference."
} 
de una conjetura así abducida o se necesita de una puesta a prueba a partir de la búsqueda de los caracteres predesignados (en sentido peirceano)?

Además de lo anterior, la IME mantiene una ventaja fundamental (no analizada por Lipton) respecto de los cánones del inductivismo eliminativo. Mill deja bien en claro que sus cánones son procedimientos tendientes a encontrar y justificar leyes causales, pero ¿qué sucede cuando no tratamos con enunciados legaliformes que designen factores causales universales, tales como, por ejemplo, motivos o reglas? Como hemos afirmado, los cánones de Mill nada tienen que decir respecto de los factores causales idiosincráticos. La IME, por el contrario, es lo suficientemente flexible como para hacer frente a este tipo de demandas de factores causales singulares: podemos buscar y brindar una buena respuesta a ¿por qué sucedió $x$ ? sin tener que referirnos necesariamente a todos los casos de $\mathrm{x}$, o porque $\mathrm{x}$ se explica mejor por su singularidad que por lo que comparte con otros de su clase (el sentido de un lapsus determinado, por ejemplo). Resulta, por lo tanto, innecesario el mandato del inductivismo eliminativo de, por ejemplo, comparar las instancias en las que $x$ ocurre con aquellas en las que no ocurre, etc.

Hemos mostrado ya, contrariando lo que Grünbaum cree, las insalvables deficiencias que los cánones de Mill mantienen para una evaluación coherente de las hipótesis causales en psicoanálisis, y también hemos visto que no podemos adjudicarle a Freud una adhesión a tales cánones del inductivismo eliminativo, como nuestro filósofo también supone. En virtud de la superioridad que muestra la IME para evaluar, en los contextos de descubrimiento y justificación al mismo tiempo, factores causales no observacionales y no necesariamente legaliformes, es necesario preguntarnos si el proceder de Freud no puede elucidarse mejor como una variante de IME. A ello nos dedicaremos en el capítulo que sigue.

Coincidimos con la idea, anteriormente expuesta, de que la caracterización de la IME muchas veces constituye un rechazo implícito del doble carácter que tiene, para Peirce, la inferencia abductiva: como inferencia generadora y como modo de seleccionar el material para ser testeado. Además, IME desestima el papel del momento inductivo que Peirce prescribe como coronando el proceso científico de fijar creencias. Pese a ello, hemos decidido presentar la versión que da Lipton de IME porque despliega algunas objeciones diferentes a las que 
ya hemos señalado respecto del inductivismo eliminativo. Más allá de las diferencias que hemos señalado, aquí coincidimos en el beneficio de asumir el valor de este tipo de inferencias por sobre el inductivismo eliminativo.

En la segunda parte de este capítulo nos abocaremos a explorar la utilidad de estas herramientas inferenciales para representar el modo en que se construyen y establecen las hipótesis psicoanalíticas.

\title{
2. La lógica abductiva en psicoanálisis
}

\section{a) Freud y el paradigma indiciario}

Carlo Ginzburg, el italiano fundador de la vertiente cultural de la microhistoria, publicó en 1978 un artículo que ha devenido clásico ${ }^{570}$ y en el que sostuvo una importante hipótesis:

\begin{abstract}
...a finales del siglo diecinueve, surgió silenciosamente, en el ámbito de las ciencias sociales, un modelo epistemológico (o, si se prefiere, un paradigma). El examen de este paradigma, que todavía no ha recibido la atención que merece y que ha venido utilizándose sin que ni siquiera se haya formulado su teoría de manera explícita, puede quizás ayudarnos a superar la estéril oposición entre «racionalismo» e «irracionalismo». (Ginzburg, 1989: 116)
\end{abstract}

Para dar apoyo a su hipótesis, Ginzburg se dedica a elucidar y entrelazar el modo en que Giovanni Morelli, Arthur Conan Doyle (vía su célebre personaje Sherlok Holmes) y Sigmund Freud representan inmejorablemente este paradigma emergente. Según Ginzburg, el modo de producir conocimiento a partir de indicios se remonta hasta los cazadores primitivos, luego pasa por las prácticas jurídicas mesopotámicas y la semiología médica, hasta alcanzar la práctica detectivesca, la crítica de la pintura y el psicoanálisis. En primer lugar expondremos sintéticamente los aspectos similares que Ginzburg halló en la metodología de indagación de esos tres autores.

\footnotetext{
${ }^{570}$ El artículo, que lleva por título original: Spie. Radici di un paradigma scientifico, ha sido sumamente difundido y traducido a diversos idiomas. La versión castellana que aquí manejamos apareció en un libro compilado por Umberto Eco y Thomas Sebeok bajo el título Morelli, Freud y Sherlock Holmes: indicios y método científico (Ginzburg, 1989).
} 
El aporte fundamental de Giovanni Morelli al arte vino dado por su invención de una metodología que permitía la atribución correcta de la autoría a las pinturas de los viejos maestros, distinguiendo de ese modo los originales de las falsificaciones y las copias. El célebre historiador del arte Edgar Wind caracterizó claramente la genialidad de Morelli:

Explicaba Morelli que para reconocer la mano de un maestro en un cuadro determinado es necesario suspender, incluso invertir, la reacción estética normal. Al contemplar un cuadro, nuestro impulso natural es entregarnos primero a la impresión general y luego concentrarnos en los rasgos particulares artísticamente importantes: composición, proporción, color, expresión, gesto. Ninguna de estas cosas, dice Morelli, nos revelará con certeza la mano de un pintor concreto, porque son técnicas de estudio que los pintores aprenden unos de otros. [...] Para identificar la mano del maestro y distinguirla de la de un copista, hemos de basarnos en pequeñas idiosincrasias que no parecen esenciales, rasgos subordinados de aspecto tan nimio que no llamarían la atención de ningún imitador, restaurador o falsificador: la forma de la uña o el lóbulo de la oreja. Como estas son partes menos expresivas de una figura, el artista mismo, no menos que su imitador, no se molesta probablemente tanto en la ejecución; son los puntos en que se abandona y obra con espontaneidad, y por esa razón le revelan inconfundiblemente. Este es en esencia el argumento de Morelli: el instinto personal de un artista para la forma aparecerá en su máxima pureza en las partes menos significativas de su obra, porque estas son las menos elaboradas" (Wind, 1963/1986: 53-54).

Se trata de una captación de los detalles que escapan al control consciente del artista pero que son efecto de su propia personalidad creadora. En virtud de este proceder, no parece exagerado afirmar que el método de Morelli se vincula al proceder freudiano mucho más de lo pensado incluso por Ginzburg, ya que "el método Morelli desemboca en la reconstitución minuciosa, no de las idiosincrasias poco relucientes del artista, sino en lo que no duda en llamar su alma, reconstituida a partir de las elecciones éticas que debió haber hecho en la representación de su propia mirada, es decir, de su deseo" (Sauvagnat, 1998: 47).

La analogía metodológica se refuerza aún más si tenemos en cuenta que, como señala Ginzburg, Freud había leído y citado a Morelli en El Moisés de Miguel Ángel: 
Mucho antes de que pudiera enterarme de la existencia del psicoanálisis, supe que un conocedor ruso en materia de arte, Ivan Lermolieff,'* había provocado una revolución en los museos de Europa revisando la autoría de muchos cuadros, enseñando a distinguir con seguridad las copias de los originales y especulando sobre la individualidad de nuevos artistas, creadores de las obras cuya supuesta autoría demostró ser falsa. Consiguió todo eso tras indicar que debía prescindirse de la impresión global y de los grandes rasgos de una pintura, y destacar el valor característico de los detalles subordinados, pequeñeces como la forma de las uñas, lóbulos de las orejas, la aureola de los santos y otros detalles inadvertidos cuya imitación el copista omitía y que sin embargo cada artista ejecuta de una manera singular. Luego me interesó mucho saber que bajo ese seudónimo ruso se ocultaba un médico italiano de apellido Morelli. Falleció en 1891 siendo senador del Reino de Italia. Creo que su procedimiento está muy emparentado con la técnica del psicoanálisis médico. También este suele colegir lo secreto y escondido desde unos rasgos menospreciados o no advertidos, desde la escoria — rrefuse»— de la observación. (Freud, 1914c/2004: 227; cursivas añadidas).

En ese escrito Freud se esfuerza en realizar una serie de observaciones sobre los detalles de la escultura del Moisés esculpida por Miguel Ángel, analizando, de un modo morelliano, la posición de los dedos de la mano, el gesto, las ondulaciones de la barba, el modo en que sostiene las tablas de la ley, etc., para inferir aspectos subjetivos del personaje. Por su parte, Ginzburg analiza minuciosamente la posible cronología de los encuentros de Freud con la lectura de Morelli, concluyendo algo con lo que es difícil no estar de acuerdo: nos encontramos ante un elemento que contribuyó a la cristalización del psicoanálisis de manera directa, puesto que Morelli pareciera haberle aportado a Freud "la propuesta de un método interpretativo que se basaba en considerar los detalles marginales e irrelevantes como indicios reveladores" (Ginzburg, 1989: 123).

Además de analizar el método morelliano-freudiano, Ginzburg retoma una analogía que se había establecido entre ese proceder con el método detectivesco que Artur Conan Doyle le hacía practicar a su personaje Sherlock Holmes: "ambos se dedican a descubrir, a partir de indicios no observados por nadie más, el autor de un delito, en un caso, y de una pintura, en el otro" (ibíd. p. 119). Como es bien sabido, las habilidades de Holmes pasaban por utilizar el eclecticismo de sus saberes con una potente observación de los detalles y con una contundente capacidad de realizar inferencias: 
...apenas divisada una persona cualquiera, resulta hacedero inferir su historia completa, así como su oficio o profesión. Parece un ejercicio pueril, y sin embargo afina la capacidad de observación, descubriendo los puntos más importantes y el modo como encontrarles respuesta. Las uñas de un individuo, las mangas de su chaqueta, sus botas, la rodillera de los pantalones, la callosidad de los dedos pulgar e índice, la expresión facial, los puños de su camisa, todos estos detalles, en fin, son prendas personales por donde claramente se revela la profesión del hombre observado. (Doyle, 1887/2004: 29).

Holmes resuelve así los escenarios más misteriosos. Vale la pena citar, ejemplificando su despliegue, el momento en que Holmes conoce a Watson, sorprendiéndolo de entrada:

- Por lo que veo, ha estado usted en tierras afganas.

- ¿Cómo diablos ha podido adivinarlo? (ibíd. p. 14)

Pero Holmes se reserva la explicitación de sus inferencias hasta haberle expuesto a Watson su "Ciencia de la Deducción y el Análisis":

Me constaba esa procedencia suya de Afganistán. El hábito bien afirmado imprime a los pensamientos una tan rápida y fluida continuidad, que me vi abocado a la conclusión sin que llegaran a hacérseme siquiera manifiestos los pasos intermedios. Éstos, sin embargo, tuvieron su debido lugar. Helos aquí puestos en orden: "Hay delante de mí un individuo con aspecto de médico y militar a un tiempo. Luego se trata de un médico militar. Acaba de llegar del trópico, porque la tez de su cara es oscura y ése no es el color suyo natural, como se ve por la piel de sus muñecas. Según lo pregona su macilento rostro ha experimentado sufrimientos y enfermedades. Le han herido en el brazo izquierdo. Lo mantiene rígido y de manera forzada... ¿en qué lugar del trópico es posible que haya sufrido un médico militar semejantes contrariedades, recibiendo, además, una herida en el brazo? Evidentemente, en Afganistán". Esta concatenación de pensamientos no duró el espacio de un segundo. Observé entonces que venía de la región afgana, y usted se quedó con la boca abierta. (ibíd. p. 31; cursivas añadidas).

No puede dejar de sorprendernos el hecho de que Doyle le haga reconocer a Holmes el carácter no consciente de su proceder inferencial. Hacia el final de la novela, Holmes señala otros importantes rasgos de su método:

Casi todo el mundo, ante una sucesión de hechos, acertará a colegir qué se sigue de ellos... Los distintos acontecimientos son percibidos por la inteligencia. en la que, ya organizados, apuntan aun resultado. A partir de éste, sin embargo, pocas 
gentes saben recorrer el camino contrario, es decir, el de los pasos cuya sucesión condujo al punto final. A semejante virtud deductiva llamo razonar hacia atrás o analíticamente (ibíd. p. 178).

Veremos enseguida que el método freudiano guarda enormes similitudes con este razonar hacia atrás ${ }^{571}$.

Ginzburg sostiene que hay una suerte de común denominador entre Morelli, Sherlock Holmes y Freud: "En los tres casos, unos detalles minúsculos proporcionan la clave para acceder a una realidad más profunda, inaccesible por otros métodos. Para Freud, estos detalles son síntomas, para Holmes, pistas, indicios, y para Morelli, rasgos pictóricos"572 (Ginzburg, 1989: 124). Además sostiene que, si bien este enfoque semiótico basado en la interpretación de indicios o paradigma indiciario había llegado a tener una gran influencia entre 1870 y 1880 en el campo de las ciencias humanas, sus raíces eran mucho más antiguas: se remontan al desciframiento de huellas, con finalidad de dar caza, como actividad humana primordial. Según Ginzburg, este paradigma indiciario habría sido eclipsado en la antigüedad por el avance del platonismo y, más tarde, por el galileanismo de las ciencias naturales hegemónicas desde la modernidad:

\footnotetext{
${ }^{571}$ En la novela de Nicholas Meyer, Elemental, doctor Freud, llevada a la pantalla grande por Herbert Ross en 1976, se plantea un encuentro entre ambos personajes. Se plantea allí un intercambio cuando Freud tiene la oportunidad de exponerle a Holmes su modo de investigar; a lo que el célebre detective contesta: "Esto es notable. ¿Sabe lo que ha hecho? Ha tomado mis métodos -observación e inferencia-y los ha aplicado al interior de la cabeza de un hombre. Freud sonrió por un instante. -De cualquier manera sus métodos, como usted los llama, no están protegidos por una patente de propiedad intelectual, supongo." (Meyer, 1975: 103). Estas coincidencias ficcionales no dejan de ser interesantes, sobre todo si pensamos que Freud sí había leído a Conan Doyle y que encontramos, en una carta a Jung y refiriéndose a una paciente que éste le había derivado, una específica analogía de sí mismo con Holmes: "Fräulein Spielrein ha admitido en su segunda carta que el asunto que la preocupa tiene que ver con usted; aparte de eso, ella no revela sus intenciones. Mi respuesta fue de lo más sabia y perspicaz; hice parecer que la más tenue de las pistas me había permitido, como si fuera Sherlock Holmes, adivinar la situación [...] y le sugerí un procedimiento más adecuado, algo endopsíquico, por así decir..." (Freud, 1909/1974: 113). [Fräulein Spielrein has admitted in her second letter that her business has to do with you; apart from that, she has not disclosed her intentions. My reply was ever so wise and penetrating; I made it appear as though the most tenuous of clues had enabled me Sherlock Holmes-like to guess the situation (which of course was none too difficult after your communication) and suggested a more appropriate procedure, something endopsychic. as it were....].
}

572 Una caracterización de los aspectos comunes entre los métodos de Holmes y de Freud puede hallarse en el primer capítulo del libro de Pulice, Manson y Zelis (2000), cuyas coincidencias con el libro de Eco y Sebeok (1989) son formidables; y una lectura comparativa y minuciosa de las biografías de estos tres autores (Morelli, Doyle y Freud) puede hallarse en el capítulo uno del libro de Gallo y Helkin Ramírez (2012). 
Cuanto más pertinentes resultaran las características en lo individual, más difícil era elaborar un corpus de conocimiento rigurosamente científico. Por supuesto, la decisión indispensable para adoptar el modelo galileano de descartar las características individuales no era en sí una garantía de que los métodos de las matemáticas y de la física fueran a apocarse, pero, al menos, no excluía por completo esta aplicación. (Ginzburg, 1989: 137).

Se desarrollaron así, según Ginzburg, dos enfoques posibles: sacrificar la comprensión del elemento individual para alcanzar un nivel relativamente riguroso de generalización y matematización del saber o, por el contrario, centrarse en la producción de conocimiento basado en distinciones individualizadoras. Pero, pese a su hegemonía, no todas las disciplinas pudieron desarrollar en su seno la racionalidad galileana: "cuando las causas no son reproducibles, no cabe más alternativa que inferirlas de sus efectos" (ibíd. p. 138). Ginzburg concluye, luego de un recorrido sumamente erudito, que existió desde siempre "un modelo epistemológico común, articulado en disciplinas diversas, vinculadas a menudo entre sí por métodos o palabras clave tomadas de préstamo" (ibíd. p. 145).

En la parte final del ensayo, Ginzburg se pregunta algo que nos parece fundamental: “¿Es el rigor compatible con el paradigma indiciario?”, y responde, entre otras cosas, lo siguiente:

Nos asalta la duda, sin embargo, de que este tipo de rigor sea quizás inalcanzable, e incluso indeseable, para las formas de conocimiento más ligadas a nuestra experiencia cotidiana, o, para ser más precisos, más ligadas a todo contexto donde el carácter único e irreemplazable de los datos sea decisivo para quienes están implicados. (ibíd. p. 153).

Pero, entonces, la duda aparece ahora de nuestro lado: ¿de qué racionalidad se trata, en el caso freudiano y su apelación a lo indiciario, si debemos excluir la racionalidad galileana de la subsunción nomológica o de la formalización matemática? Para responder a ello debemos ahora volver sobre la lógica abductiva de este tipo de inferencias, con la que Ginzburg coquetea continuamente pero sin avanzar, al menos en el ensayo citado, a su encuentro efectivo. 


\section{b) Colegir: alcances de la lógica abductiva en el método freudiano}

Sobre el carácter forzoso de estas inferencias reposa la certeza relativa de nuestra ciencia psíquica. Quien profundice en este trabajo hallará que nuestra técnica resiste cualquier crítica. (Freud, 1940/2004: 157).

Al iniciar una alocución en 1930, a propósito del recibimiento de un premio que lo emparentaba con su poeta más admirado, Freud caracteriza sintéticamente su trabajo de una manera que nos resulta reveladora:

El trabajo de mi vida tendió a una sola meta. Observé las más sutiles perturbaciones de la operación anímica en sanos y enfermos, y a partir de tales indicios quise descubrir -o, si ustedes lo prefieren, colegir- cómo está construido el aparato que sirve a esas operaciones, así como las fuerzas que en él producen efectos conjugados o contrarios. (Freud, 1930b/2004: 208).

Si nos detenemos en lo que aquí Freud modestamente resume como el trabajo de su vida, podemos delimitar al menos dos etapas: en primer lugar, se trata de la observación de indicios: sutiles perturbaciones de la operación anímica. No se trata de lo evidente ni de lo global, sino de lo sutil y fragmentario. El segundo paso consiste en una doble maniobra a partir de esos indicios: por un lado, descubrir cómo está construido el aparato que, se supone, produce tales operaciones; es decir modelizar el edificio anímico. Por otro lado, descubrir las fuerzas que producen efectos en su funcionamiento. Se trata de teorizar sobre la estructura y funcionamiento del psiquismo en general (arribando a lo que dio en llamar metapsicología) y de cada caso en particular.

Analizando este importante pasaje, Carlos Escars se detiene en el sinónimo de descubrir que Freud le proporciona allí a su audiencia: colegir. En virtud de que el vocablo erraten, traducido siempre como colegir por Etcheverry, aparece innumerables veces en los textos freudianos, Escars sostiene que la utilización explícita de ese sinónimo no podría tratarse de una especie de concesión a la audiencia profana, a los fines de darse a entender más sencillamente. Se trata, por el contrario, de un empleo deliberado de este atípico verbo alemán y cuyo significado puede traducirse como encontrar la solución, la respuesta, acertar, adivinar. Aunque el verbo que elige Etcheverry (colegir) tiene varias acepciones que parecieran solapadas, es mejor que el seleccionado por López Ballesteros 
(adivinar), en la medida en que esa traducción parece reducir injustificadamente al azar la operación que Freud estaba queriendo significar (Escars, 2011b).

Escars ha sido el primero en analizar los usos y alcances del colegir freudiano, destacando el llamativo hecho de que esta expresión no haya merecido comentarios ni desarrollos por parte de los analistas, ya que su frecuencia y coherencia en los escritos del creador del psicoanálisis lo constituyen en un "concepto clave en un abordaje de lo que podría denominarse una 'epistemología freudiana', es decir para pensar cómo concibe Freud la forma singular en que se produce el trabajo analítico" (Escars, 2011a: 20). Escars concluye que "el interés de Freud en el término no es solamente epistemológico, sino clínico. No se trata sólo de un modo de conocimiento, sino de un modo de operar, de intervenir" (Escars, 2011b: 113). Veamos cómo funciona entonces, según Freud, esta operación en ambos contextos psicoanalíticos.

\section{Colegir, interpretar y construir: lógica de la indagación clínica}

Lo que Freud tempranamente conceptualiza como interpretación de los sueños consiste en una operación que nace de aspectos indiciarios:

\footnotetext{
...el primer paso en la aplicación de este procedimiento enseña que no debe tomarse como objeto de la atención todo el sueño, sino los fragmentos singulares de su contenido. Si yo pregunto al paciente todavía no ejercitado: «¿Qué se le ocurre acerca de este sueño?», por regla general no atinará a capturar nada en su campo de visión mental. Debo presentarle el sueño en fragmentos, y entonces él me ofrecerá para cada trozo una serie de ocurrencias que pueden definirse como los «segundos pensamientos» de esa parte del sueño. (Freud, 1900a/2004: 125; cursivas añadidas).
}

La interpretación comprende, entonces, el señalamiento de un detalle que dará lugar a una nueva cadena asociativa. Este abordaje de los elementos puede resultar extraño para el paciente, puesto que "toda fragmentariedad inhibe o demora la formación de un convencimiento" (Freud, 1923b/2004: 117), sin embargo se justifica porque "lo reprimido se trasluce sólo fragmentariamente" (ibíd.). La interpretación de lo fragmentario, entonces, es solidaria de una demora en el convencimiento del paciente; y es el trabajo de éste último el que 
permitirá alcanzar esa convicción sobre las relaciones entre lo fragmentario. El trabajo interpretativo parece, visto de esta manera, como otro modo de fijar creencias: no por autoridad, reflexión o tenacidad, sino por medio de la eficacia explicativa que conllevan los hallazgos a partir de lo fragmentario y por vía abductiva (cf. Peirce, 1877/1988).

Por otro lado, lo que hacia el final de su obra designa con el término construcción, también parece estar vinculado a esta pesquisa de indicios:

\begin{abstract}
Todos sabemos que el analizado debe ser movido a recordar algo vivenciado y reprimido por él, y las condiciones dinámicas de este proceso son tan interesantes que la otra pieza del trabajo, la operación del analista, pasa en cambio a un segundo plano. El analista no ha vivenciado ni reprimido nada de lo que interesa; su tarea no puede ser recordar algo. ¿En qué consiste, pues, su tarea? Tiene que colegir lo olvidado desde los indicios que esto ha dejado tras sí; mejor dicho: tiene que construirlo. (Freud, 1937/2004: 260).
\end{abstract}

Notamos, en primer lugar, un contrapunto de la labor del analista con la labor propia del paciente. Además, a pesar de la distinción freudiana entre interpretación y construcción (no siempre tan nítida en sus escritos, pero sí alentada y sostenida posteriormente) ambas operaciones se basan en indicios. Si la interpretación implica la devolución de un elemento discursivo y la construcción supone la presentación al paciente de una pieza de su prehistoria olvidada, como intento de restituir un trozo de su biografía, no obstante ambas se realizan siempre a partir de un trabajo basado en los detalles, en la escoria de la observación. Así, la delimitación de aquellos fenómenos que dio en llamar retoños de lo psíquico inconciente es correlativa de sus esfuerzos por colegir los procesos causales que permiten explicarlos. A esta altura, Freud es capaz de especificar cuáles son esos indicios sobre los que el analista deberá apoyar su trabajo inferencial:

Son de muy diversa índole: jirones de esos recuerdos en sus sueños, en sí de incomparable valor, pero por regla general asaz desfigurados por todos los factores que participan en la formación del sueño; ocurrencias que él produce cuando se entrega a la «asociación libre», de las que podemos nosotros entresacar unas alusiones a las vivencias reprimidas, retoños de las mociones de afecto sofocadas, así como de las reacciones contra estas; por último, indicios de repeticiones de los afectos pertenecientes a lo reprimido en las acciones más 
importantes o ínfimas del paciente, tanto dentro de la situación analítica como fuera de ella. Hemos hecho la experiencia de que la relación trasferencial que se establece respecto del analista es particularmente apta para favorecer el retorno de tales vínculos afectivos. Con esta materia prima — por así llamarla—, debemos nosotros producir lo deseado. (ibíd. p. 259).

Ahora bien, desde mucho antes de poder explicitar estas diferencias conceptuales lo vemos esforzarse por delimitar con precisión cierto contraste que deben tener ambas acciones:

\begin{abstract}
En vista del carácter incompleto de mis resultados analíticos, no me queda otra opción que seguir el ejemplo de aquellos exploradores que, tras largas excavaciones, tienen la dicha de sacar a luz los inapreciables aunque mutilados restos de la antigüedad. He completado lo incompleto de acuerdo con los mejores modelos que me eran familiares por otros análisis, pero, tal como lo haría un arqueólogo concienzudo, en ningún caso he omitido señalar dónde $m i$ construcción se yuxtapone a lo auténtico. (Freud, 1905b/2004: 11; cursivas añadidas).
\end{abstract}

Completar lo incompleto con los mejores modelos familiares es hacer uso de inferencias abductivas y analógicas; y, por otro lado, distinguir la construcción propia de lo auténtico implica un esfuerzo por diferenciar claramente el fenómeno que demanda una explicación de la explicación misma. Esto último es necesario para Freud en la medida en que "tan pronto uno empieza a distanciarse del material del que debe nutrirse, corre el riesgo de embriagarse con sus propias aseveraciones" (Freud, 1918/2004: 47).

El colegir freudiano no equivale a adivinar o escoger al azar una entre varias opciones, sino que se trata de reunir indicios a partir de relaciones significativas en el material empírico (Freud, 1915a/2004: 113), lo que constituye una condición necesaria (pero no suficiente) para la actividad analítica:

Si comunicamos a un paciente una representación que él reprimió en su tiempo y hemos logrado colegir, ello al principio en nada modifica su estado psíquico. Sobre todo, no cancela la represión ni, como quizá podría esperarse, hace que sus consecuencias cedan por el hecho de que la representación antes inconciente ahora devenga conciente. (Freud, 1915b/2004: 171).

El colegir es, por lo tanto, un paso previo al establecimiento de un cambio efectivo producido por la fijación de un nueva creencia; ¿qué otra cosa se 
necesita para producirlo? Pues bien, las operaciones del analista comúnmente conceptualizadas por Freud (interpretación y construcción) tienen como condición de posibilidad la instalación de ese terreno de combate en el que el paciente reactualiza sus conflictos: la transferencia. Freud se encargó de señalar que el momento del colegir no coincide con el de la comunicación de lo colegido, sino que éste último depende de la instalación de la transferencia y de las características de cada caso en particular: "la brusca comunicación, en su primera visita al consultorio, de los secretos que el médico le ha colegido es reprobable técnicamente" (Freud, 1910b/2004: 226). Como veremos luego, esta dimensión, específica del campo analítico, implica serias consideraciones respecto de la validación de las conjeturas del analista en su labor clínica.

Es oportuno retomar uno de los argumentos de Peirce sobre la capacidad adivinatoria del hombre:

\footnotetext{
Infiero en primer lugar que el hombre adivina algo de los principios secretos del universo porque su mente se ha desarrollado como una parte del universo y bajo la influencia de esos mismos principios secretos; y en segundo lugar, que a menudo derivamos de la observación fuertes indicaciones de la verdad sin ser capaces de especificar cuáles eran las circunstancias que habíamos observado que proporcionaban esas indicaciones. (Peirce, 1907/2012: 282).
}

Ambas cuestiones se relacionan con el proceder freudiano, pues la atención flotante, consistente en relajar la atención selectiva propia del proceso secundario, sin concentrarse especialmente en nada, parte de una suposición similar: la percepción de los indicios reveladores escapa a la conciencia del interpretante, encontrándose con "... relaciones que se cree colegir aun antes que se las pueda conocer y demostrar" (Freud, 1915a/2004: 113). Esta operación de colegir introduce la idea de "una lectura de indicios que no obedece sólo al plano de la conciencia sino que incluye la dimensión de la trama textual inconsciente y transferencial" (De Battista, 2015: 22). Si el funcionamiento de cualquier proceso cognitivo supone la interacción constante de observaciones e inferencias, el trabajo clínico del analista se caracteriza por 
prestar atención a una serie especial de datos e intervenir en consecuencia. Sin embargo, esa atención es de un tipo especial ${ }^{573}$, pues el analista no debe

\begin{abstract}
sustituir por una censura propia la selección que el enfermo resignó; dicho en una fórmula: debe volver hacia el inconciente emisor del enfermo su propio inconciente como órgano receptor, acomodarse al analizado como el auricular del teléfono se acomoda al micrófono. De la misma manera en que el receptor vuelve a mudar en ondas sonoras las oscilaciones eléctricas de la línea incitadas por ondas sonoras, lo inconciente del médico se habilita para restablecer, desde los retoños a él comunicados de lo inconciente, esto inconciente mismo que ha determinado las ocurrencias del enfermo. (Freud, 1912a/2004: 115).
\end{abstract}

También Peirce se refiere a un peculiar estado de la mente, que denomina musement, mediante el cual se propicia el advenimiento de las conjeturas nuevas. Se trata de un estado de la mente que se caracteriza como no siguiendo ninguna regla ni atendiendo a ninguna cosa en especial, sino que supone una especie de especulación o juego imaginativo "que no envuelve otro propósito que el de dejar a un lado todo propósito serio":

Sube al bote del musement, empújalo en el lago del pensamiento y deja que la brisa del cielo empuje tu navegación. Con tus ojos abiertos, despierta a lo que está a tu alrededor o dentro de ti, y entabla conversación contigo mismo, para eso es toda meditación. Sin embargo, no es una conversación sólo con palabras, sino ilustrada con diagramas y experimentos como una conferencia (Peirce, 1908/1996: 39).

Aunque el musement no equivale a la atención flotante, sí podemos trazar una similitud: en ambos casos se trata de lograr un peculiar estado de receptividad indiscriminada como antesala del insight y de la creación de hipótesis.

Repasando las transformaciones de la técnica analítica, Freud recuerda que una vez abandonada la sugestión hipnótica "pasó a primer plano la tarea de colegir desde las ocurrencias libres del analizado aquello que él denegaba recordar" (Freud, 1914a/2004: 149). Ahora bien, el material que produce la asociación libre del paciente "no aportaba lo olvidado mismo, pero sí indicaciones tan ricas y claras que el médico podía colegirlo (reconstruirlo)

${ }^{573}$ La atención flotante del analista es uno de los elementos que permite diferenciar su actividad de la faceta interpretativa de la psicosis paranoica, gobernada por una "atención constante" (De Battista, 2011: 231). 
desde ellas mediante ciertos completamientos e interpretaciones" (Freud, 1924/2004: 208). Lo que complementa esta producción de material por parte del analizado, es la escucha de indicios que habilitan al analista a efectuar un salto creativo:

La experiencia mostró pronto que la conducta más adecuada para el médico que debía realizar el análisis era que él mismo se entregase, con una atención parejamente flotante, a su propia actividad mental inconciente, evitase en lo posible la reflexión y la formación de expectativas concientes, y no pretendiese fijar particularmente en su memoria nada de lo escuchado; así capturaría lo inconciente del paciente con su propio inconciente. Entonces pudo notarse, cuando las circunstancias no eran demasiado desfavorables, que las ocurrencias del paciente eran en cierta medida como unas alusiones arrojadas al tanteo hacia un determinado tema, y sólo hizo falta atreverse a dar otro paso para colegir eso que le era oculto y poder comunicárselo. Por cierto, este trabajo de interpretación no podía encuadrarse en reglas rigurosas y dejaba un amplio campo al tacto y a la destreza del médico (Freud, 1923a/2004: 235).

Es decir que a partir de la atención flotante el analista puede percibir, en base a indicios, la alusión de las asociaciones y, luego, atreverse a colegir. El carácter aventurado de esta operación radica en su basamento lógico: no se trata de deducciones, en las que la conclusión estaría garantizada; sino de un movimiento abductivo que arriesga una conjetura.

Freud era consciente de las limitaciones probatorias que implica inferir hipótesis retroductivamente:

...aquí advertimos un estado de cosas que nos sale al paso también en muchos otros ejemplos de esclarecimiento psicoanalítico de un proceso anímico. Durante todo el tiempo en que perseguimos el desarrollo desde su resultado final hacia atrás, se nos depara un entramado sin lagunas, y consideramos nuestra intelección acabadamente satisfactoria, y quizás exhaustiva. Pero si emprendemos el camino inverso, si partimos de las premisas descubiertas por el análisis y procuramos perseguirlas hasta el resultado, se nos disipa por completo la impresión de un encadenamiento necesario, que no pudiera determinarse de ningún otro modo. Reparamos enseguida en que podría haber resultado también algo diverso, y que a este otro resultado lo habríamos podido comprender y esclarecer igualmente bien. La síntesis no es, por tanto, tan satisfactoria como el análisis; en otras palabras: no estaríamos en condiciones de prever, conociendo las premisas, la naturaleza del resultado (Freud, 1920b/2004: 160). 
Además de que constituye otra muestra de su falibilismo epistémico, este argumento muestra claramente que Freud no mantenía un pensamiento etiológico determinista y que contemplaba el papel del azar en los procesos que decantan en fenómenos clínicos. El límite que Freud antepone a la posibilidad de las retrodicciones psicoanalíticas puede ser expresado en estos términos: puede colegirse el acontecer causal de las condiciones suficientes de un fenómeno determinado, pero no puede arribarse a un conocimiento certero de las condiciones necesarias para su causación. Por eso señaló que el desarrollo, en el caso que él allí analiza, no necesariamente hubiera tenido que desembocar en una homosexualidad femenina. Esta argumentación de Freud afirma la importancia central de la explicación por sobre la predicción, constituyendo una postura clara respecto del alcance de la teoría psicoanalítica.

En virtud de lo anterior resulta bastante evidente que el trabajo del analista implica un esfuerzo de teorización: creación de hipótesis para explicar los efectos que produce. Esto parece en sintonía con lo aseverado por Jacques Lacan: "el analista, para tener efectos, es el analista que, a esos efectos, los teoriza"574 (Lacan, 1974-75). Esto pareciera querer decir que no sólo es necesario plantear dos fases, la de quien analiza y la de quien teoriza los efectos; sino que para tener efectos analíticos es necesario teorizarlos. Esto se comprende mejor si advertimos que el trabajo clínico del analista supone una serie de operaciones cognitivas en las que la lógica abductiva parece insoslayable; $\mathrm{y}$, como se ha expuesto, ésta es una lógica de la producción teórica. Sin embargo, aquí es necesario hacer una distinción que, hasta donde sabemos, no ha sido cabalmente trazada: lo propio de la clínica psicoanalítica no es el uso de la abducción hipercodificada, al modo del detective o del diagnosticador. Piénsese en las inferencias de descubrimiento que hace todo el tiempo Sherlock Holmes; o, para utilizar otra referencia conocida y

\footnotetext{
${ }^{574}$ Como es sabido, la expresión pronunciada por Lacan ha sido registrada de dos modos distintos: además de la citada encontramos la versión de Jacques Alain Miller, quien aprovecha la homofonía entre los vocablos franceses et - est ("y" - "es") para transcribir esa expresión de un modo que parece acentuar la distinción entre aquel que analiza y aquel que teoriza. Más allá del problema de traducción/traición, lo importante en nuestro contexto de discusión es, me parece, considerar qué entendemos, entre otras cosas, por teorizar. La preciosa conjunción freudiana adquiere, como veremos, diversos matices según qué respondamos.
} 
contemporánea, el Dr. Gregory House ${ }^{575}$ en la conocida serie televisiva: ante rasgos sorprendentes, House apela a la abducción para reconocer la regla que, de aceptarse, permite explicar el caso por subsunción. ¿En qué se diferencia esta práctica de la práctica del psicoanalista? Digámoslo nuevamente: el analista no tiene, en su haber, un conocimiento enciclopédico del cual extraer la regla para que el caso (paciente) resulte cubierto y sus rasgos enigmáticos (síntomas) tipificados. Cuando Freud advierte que cada caso debe tratarse como si fuera el primero, se refiere justamente a esto: respecto de lo que verdaderamente importa para un sujeto, no hay saber universal que pueda ser extrapolado desde casos anteriores. El conocimiento relevante que se construye en torno a cada paciente es singular, es decir que en cada trabajo analítico se inventan reglas idiosincráticas para dar cuenta de los fenómenos sorprendentes ${ }^{576}$ que allí acontecen. En este punto podríamos incluso hablar de una relación de proporcionalidad entre relevancia e idiosincrasia: el grado de relevancia causal del conocimiento que se obtiene mediante un análisis es directamente proporcional a su nivel de singularidad. Esa singularidad, como hemos planteado en el capítulo anterior, no equivale a una ausencia de regularidad: por el contrario, la regularidad es compatible con la singularidad, y los fenómenos ligados a la repetición constituyen un claro ejemplo de ello ${ }^{577}$. Si esto es así, el tipo de abducción que utilizamos para arribar a un conocimiento de las reglas singulares de funcionamiento psíquico, se mueve entre las

\footnotetext{
575 Esta serie televisiva duró ocho temporadas, desde el 2004 hasta el 2012, y tuvo por protagonista a un médico que parece recrear diversos aspectos del mítico personaje de Doyle. Esta inspiración en el armado del personaje ha sido reconocida por el propio guionista de la serie (David Shore). Para un análisis de las diversas similitudes entre Holmes y House, incluyendo su uso de las inferencias abductivas, cf. el artículo de Peláez Paz (2013).

${ }^{576}$ El factor sorpresa al que se refiere Peirce, por ejemplo en la primera premisa de su enunciado canónico, da cuenta de una necesidad: no hay verdadera indagación posible si no se parte de una duda genuina. Esto se condice enteramente con la labor de indagación clínica: los momentos iniciales del análisis suponen una conmoción (si es que aún no la hay) de las certezas del sujeto, para poner en movimiento, justamente, el motor de la duda sobre aquello que no marcha.
}

${ }^{577}$ Aunque no siempre se lo ha advertido, hay además razones formales que impiden excluir, basándonos en la preeminencia de los elementos singulares (propia del modelo indiciario), todo tipo de referencia a regularidades: en virtud de que la abducción es el tipo de inferencia predilecta para dicho modelo, las regularidades no pueden ser soslayadas porque su naturaleza supone indefectiblemente la presencia de reglas, ya sean éstas conocidas o inventadas. Me parece que apelar conjuntamente a la singularidad extrema y a lo indiciario/abductivo, es una curiosa contradicción en la que algunos psicoanalistas han incurrido sin notarlo. 
abducciones hipocodificadas y las abducciones creativas (recuérdese la tipología de Eco); o, mejor dicho, comienza con abducciones hipocodificadas y se desliza, necesariamente, al nivel de las abducciones creativas. Por el contrario, las abducciones detectivescas o del diagnosticador se mueven sólo entre lo hipercodificado y lo hipocodificado, sin pasar a la abducción creativa ${ }^{578}$.

Ahora bien, ¿quiere eso decir que todas las abducciones inherentes al trabajo clínico son de tipo hipocodificado o creativo? Evidentemente que no, pues varios de los fenómenos clínicos con los que el analista se encuentra son, inmediatamente o no, identificados como casos en base a alguna regla conocida. Por ejemplo, en el momento inicial de la clínica de la neurosis, cuando se logra el establecimiento de la transferencia y la delimitación de un síntoma, el analista ya ha reconocido estos fenómenos en base a ciertas reglas (provenientes de la metapsicología y teoría clínica que adopta). Así, puede reconocer, por ejemplo, que un síntoma neurótico implica una solución de compromiso entre fuerzas en pugna, una satisfacción substitutiva, etc.; y ha podido identificar la instalación de un vínculo con ciertas propiedades generales, como la presencia de una demanda, la suposición de un saber, etc. Ahora bien, este es el punto destacable: esas reglas generales no nos permiten explicar los rasgos enigmáticos que se nos presentan, puesto que tales rasgos no son subsumibles bajo ninguna regla universal. Éstas últimas funcionan inicialmente y sólo como orientación para abducir el caso (tipo de fenómeno clínico e incluso de cuadro clínico, etc.) pero no alcanza a referir a las propiedades del fenómeno que sí resultarán pertinentes (causalmente relevantes) a posteriori para explicarlo ${ }^{579}$. Por eso sostengo que las abducciones propias del trabajo clínico son las que se mueven desde lo hipocodificado a lo creativo. Sólo cuando las abducciones creativas han hecho su trabajo, se abre la posibilidad de representación de la singularidad del caso

\footnotetext{
${ }^{578}$ Esta generalización tiene sus excepciones. En algunas ocasiones podemos ver a Holmes adivinando el curso de los pensamientos de Watson, lo cual constituye una clara mostración de abducciones creativas (Eco, 1989: 288). Más allá de esta excepción literaria, la tarea detectivesca consiste generalmente en descubrir la regla conocida que mejor explique el caso con sus rasgos misteriosos.

579 Si acentuamos la vertiente explicativa, debemos reconocer que Carl Hempel se acercó bastante a estas limitaciones del modelo nomológico en el ámbito psicoanalítico cuando se refirió a la parcialidad como rasgo distintivo de muchas de sus explicaciones.
} 
psicoanalítico. Las abducciones del analista difícilmente podrían, por lo tanto, identificarse completamente con uno de los tipos discriminados.

Si asumimos la necesidad que se presenta en el trabajo clínico de arribar a conjeturas causales tendientes a explicar ciertas regularidades idiosincráticas, sin apelar exclusivamente a la subsunción nomológica ni a la indeterminación de los motivos, entonces podemos plantear que allí también opera la invención abductiva y que la racionalidad del tratamiento inferencial del material clínico con objetivos idiosincráticos puede ser estipulada. De asumirse este argumento, se le estaría otorgando otra razonabilidad al lema psicoanalítico de que las explicaciones clínicas son caso por caso; en virtud de la noción de regla que expusimos y utilizamos con referencia a Winch. En la medida en que ella pone a jugar una forma de determinación no universal que nosotros podemos vincular con aquellas regularidades idiosincráticas que cada paciente despliega en transferencia, ahora podemos notar que esas reglas son efecto de un trabajo de abducción (fundamentalmente creativa) que se despliega en el dispositivo.

En virtud de que la construcción del saber singular que la clínica psicoanalítica propicia puede entenderse a partir de un movimiento combinado de abducciones hipocodificadas y creativas, la conjunción preciosa freudiana alcanza, de este modo, su justa razón de ser. Esto no significa, como veremos más adelante, que la investigación en psicoanálisis deba identificarse completamente con la indagación clínica. Aunque estamos acentuando los aspectos abductivos, tal y como ya se dijo, la analogía, la inducción, la deducción y la abducción, constituyen un sistema de inferencias que se comporta como un todo orgánico; y no podríamos suponer que eso fuera de otro modo en la labor clínica o investigativa del analista.

\section{Colegir y teorizar: la abducción en el contexto de producción metapsicológica}

En su Logik der Forschung, diferenciándose de los empiristas lógicos respecto al valor que poseen los presupuestos metafísicos, Popper sostiene:

...si miramos el asunto desde un ángulo psicológico, me siento inclinado a pensar que la investigación científica es imposible sin fe en algunas ideas de una índole puramente especulativa ( $y$, a veces, sumamente brumosas): fe desprovista 
enteramente de garantías desde el punto de vista de la ciencia, y que —en esta misma medida- es «metafísica». (Popper, 1934/1980: 38).

Freud también reparó en diversas oportunidades sobre el valor de introducir conjeturas haciendo uso de la imaginación: "sin un especular y un teorizar metapsicológicos - a punto estuve de decir: fantasear- no se da aquí un solo paso adelante" (Freud, 1925a/2004: 228). El phantasieren freudiano puede verse como una apelación necesaria a esos elementos irracionales que están a la base de la creación científica y que tiene por fundamento lógico a la abducción.

Como es bien sabido, importantes creaciones y descubrimientos científicos han sido efecto de procesos no conscientes ${ }^{580}$ y Freud supo expedirse sobre ello:

...tenemos pruebas de que hasta un trabajo intelectual sutil y difícil, como el que suele exigir una empeñosa reflexión, puede realizarse también preconcientemente, sin alcanzar la conciencia. Estos casos son indubitables; se producen, por ejemplo, en el estado del dormir, y se exteriorizan en el hecho de que una persona, inmediatamente tras el despertar, sabe la solución de un difícil problema matemático o de otra índole que en vano se afanaba por resolver el día anterior (Freud, 1923c/2004: 28).

En una carta a Ferenczi, Freud le comenta una impresión suya sobre el teorizar: "considero que no hay que elaborar teorías -éstas deben caer de improviso en la casa, como huéspedes a los que no se había invitado, mientras está uno ocupado en los detalles" (Freud y Ferenczi, 2001: 121). Podría considerarse que esta actitud de ocuparse de los detalles es tan esperable para el clínico como para el investigador en psicoanálisis (off-line, digamos). Pareciera que para Freud dedicarse a los detalles posibilita un encuentro sorpresivo con lo pretendidamente universal. De hecho, en lo que a la producción teórica respecta, cabe recordar que el vienés se topó varias veces con algo que no pudo dejar de abordar.

\footnotetext{
${ }^{580}$ Podemos mencionar dos ejemplos que me parecen significativos porque en sus heurísticas intervienen procesos oníricos: August Kekulé descubrió la estructura circular del átomo del benceno, luego de soñar con una serpiente que se mordía la cola; e Isaac Merrit Singer inventó la máquina de coser luego de soñar que lo perseguía un caballero cuya lanza tenía un ojal.
} 
Atocha Aliseda, analizando la propuesta de Peirce a propósito de su relación con los estados mentales de creencia y de duda, pone de relieve el valor que tiene la sorpresa (bajo la forma de la novedad o la anomalía) en tanto que motor de toda indagación:

El proceso cognitivo que integra a la inferencia abductiva con el proceso epistémico puede describirse como sigue: una experiencia novedosa o anómala da lugar a un hecho sorprendente, el cual genera un estado de duda que rompe un hábito de creencia, y así dispara al razonamiento abductivo. Este consiste justamente en explicar el hecho sorprendente y así "apaciguar" el estado de duda (Aliseda, 2003: 266).

En lo que a Freud respecta, quizás el caso de los sueños sea el más emblemático de este encuentro con lo sorpresivo que detona la abducción:

En el curso de esos estudios psicoanalíticos di con la interpretación de los sueños. Mis pacientes, a quienes yo había comprometido a comunicarme todas las ocurrencias y pensamientos que acudiesen a ellos sobre un tema determinado, me contaron sus sueños y así me enseñaron que un sueño puede insertarse en el encadenamiento psíquico que ha de perseguirse retrocediendo en el recuerdo a partir de una idea patológica (Freud, 1900a/2004: 122).

Se trata de un hallazgo inesperado, pues no fue sino ante la demanda de lo que más adelante será definido como asociación libre que los pacientes también incluían sus sueños; situación que lo condujo a interrogarse por el modo en que debía abordar este tipo de asociaciones. En el prólogo a la tercera edición inglesa de La interpretación de los sueños, publicada en 1931, Freud dice que ha sido "el más valioso de los descubrimientos que tuve la fortuna de hacer" y añade: "un insight como éste no nos cabe en suerte sino una sola vez en la vida" (Freud, 1900a/2004: 27).

A pesar de que la teorización sobre los sueños resulta emblemática respecto de su hallazgo, las sorpresas con las que Freud supo toparse tenían ya una larga data. Otro de los ejemplos célebres lo constituye la reformulación de la teoría de la seducción, que hemos analizado en detalle en nuestra parte dedicada a la crítica de Popper. En la destacada esquela de 1897 Freud expresa el carácter inesperado de la contravidencia empírica: 
...la sorpresa de que en todos los casos el padre debiera ser inculpado corno perverso sin excluir al mío propio, la comprobación de la inesperada frecuencia de la histeria para la cual debería repetirse esta misma condición cuando es poco probable que la perversión en perjuicio de niños esté tan difundida... (Freud, 1985/1986: 283).

Es la sensación de perplejidad, efecto de lo inesperado, lo que conduce a Freud a responder la pregunta directora del pensamiento abductivo: “¿de qué premisas puede mostrarse que se sigue esta anomalía?" (Hanson, 1958/1977: 53). También el fenómeno de la transferencia, "regular en cada caso nuevo" lo llevó a sospechar de algo más que "una contingencia perturbadora", hasta producir una conjetura que, por considerarse acertada, le devolvía al fenómeno su naturalidad y razón de ser, pues eso enigmático pasaba a ser considerado algo que "está en la más íntima relación con la naturaleza de la enfermedad misma" (Freud, 1917b/2004: 401). El recorrido freudiano parece seguir la misma secuencia lógica que Peirce describió en la séptima de sus Lecciones sobre el pragmatismo: "se observa el hecho sorprendente C; pero si A fuese verdadero, C sería una cosa corriente, luego hay razones para sospechar que A es verdadero." (Peirce 1903a/1978). Vale la pena detenernos también en otra exposición, que podríamos caracterizar de informal, que hace Peirce de ese camino:

Tenemos ante nosotros una masa de hechos. Los revisamos. Los examinamos. Los encontramos una maraña confusa, una jungla impenetrable. Somos incapaces de sostenerlos en nuestras mentes. Nos esforzamos para ponerlos por escrito, pero parecen ser tan diversamente intrincados que no podemos estar satisfechos de que lo que hemos escrito represente los hechos, ni podemos obtener ninguna idea clara de qué es lo que hemos puesto por escrito. Pero de repente, mientras estamos repasando nuestro resumen de los hechos y tratando de ponerlos en orden, nos damos cuenta de que si supusiéramos como verdadero algo que no sabemos que sea verdadero, estos hechos se ordenarían luminosamente. Eso es la abducción... (Peirce, 1903b: §n. 348; cursivas añadidas).

Notamos que el hecho sorprendente es una especie de incapacidad por volver inteligible lo que acontece y que, además, esto sorprendente no necesariamente se trata de un hecho aislado o individual: bien puede tratarse de un conjunto de hechos. ¿No es acaso un conjunto de hechos sorprendentes lo que el analista, en el trabajo intrasesión, procura volver inteligible 
reordenándolo bajo una nueva hipótesis interpretativa?, ¿no fue también ése el itinerario del trabajo investigativo de Freud al reunir un conjunto de fenómenos sorprendentes rechazados por la ciencia?

Otro aspecto merece nuestra consideración aquí, en función de las relaciones que han sido estipuladas entre la abducción y la analogía, es el modo en que Freud plasma ese vínculo en determinados momentos de elaboración teórica. Veamos unos pocos ejemplos.

En el marco de la mencionada teoría temprana del trauma (ST), el vienés establece una analogía entre la etiología de las psiconeurosis y la etiología de la tuberculosis. Como hemos expuesto en la segunda parte de la tesis, en La etiología de la histeria Freud analiza una serie de objeciones que parece haber recibido (desde el hereditarismo) luego de su conferencia en la Sociedad de Psiquiatría y Neurología de Viena. Una de tales objeciones fue que las vivencias sexuales que él invocaba eran demasiado frecuentes "como para atribuirles un significado etiológico a su comprobación" y que seguramente habría "personas que recuerdan escenas de seducción sexual y de abusos sexuales en su niñez, a pesar de lo cual nunca han sido histéricas" (Freud, 1896a/2004: 205). El vienés utiliza la mencionada analogía para abducir creativamente algunos aspectos del modelo teórico que está postulando y, además, para responder fenomenalmente a esa acusación recibida:

\footnotetext{
...la enorme frecuencia de un factor etiológico no podría utilizarse como argumento para desestimar su significado etiológico. ¿Acaso el bacilo de la tuberculosis no es omnipresente y no lo contraen muchos más hombres de los que se muestran enfermos de tuberculosis? ¿E importa menoscabo para su significación etiológica el hecho de que, evidentemente, ha menester de la cooperación de otros factores para producir su efecto específico, la tuberculosis? Para ser apreciado como etiología específica basta que la tuberculosis no sea posible sin su cooperación. Y lo mismo vale para nuestro problema. (Ibíd. p. 208).
}

El tipo de causa específica que Freud postula es, análogamente a la etiología de la tuberculosis, esa que no puede estar ausente siempre que se produzca el efecto. Sólo si hallamos un efecto en el que no se haya producido esa causa abducida, el modelo puede ser objetado. La analogía muestra, además, el préstamo implícito de supuestos ontológicos en la invención del nuevo modelo: son factores externos los que determinan el proceso patológico. 
Una vez modificada esa teoría (lo que hemos elucidado, en la segunda parte, como el tránsito ST-FT), Freud comienza a elaborar su modelo de la dinámica libidinal. Utiliza, para dilucidar el modo en que acontecen algunos procesos libidinales, una analogía con ciertos procesos hidrológicos. Así, en sus Tres ensayos de teoría sexual sostiene que la neurosis se contrae después de la pubertad "cuando se frustran las vías normales de satisfacción de la libido [...] la libido se comporta como una corriente cuyo cauce principal queda cortado; Ilena entonces las vías colaterales que hasta entonces quizás habían permanecido vacías" (1905d/2004: 155). Freud crea un modelo que combina, al igual que el desagote hídrico de una crecida, factores internos y externos que explican el resultado. En el historial de Dora, sostiene que "las corrientes de agua que tropiezan con un obstáculo en su cauce se volcarán a un cauce antiguo que parecía destinado a permanecer seco" (Freud, 1905b/2004). En 1920 añadirá, en nota al pie a sus Tres ensayos, que "los diversos caminos por los que migra la libido se comportan desde el comienzo entre sí como vasos comunicantes ${ }^{581}$, y es preciso tener en cuenta el fenómeno de la corriente colateral" (ibíd. p. 137).

Las anteriores son algunas de las múltiples analogías freudianas que están a la base de sus modelos teóricos, sirviendo para la abducción creativa de hipótesis explicativas ${ }^{582}$. Además de utilizarlas, Freud parece haber reflexionado explícitamente sobre su papel en la invención cognitiva. Uno de los tópicos que centran esta reflexión es el de la originalidad. Freud manifiesta que "el costado subjetivo de la originalidad es digno de estudio" y señala algunos aspectos dignos de consideración:

\begin{abstract}
Un trabajador científico acaso se pregunte alguna vez de dónde le vienen las ideas que le son peculiares, que él ha aportado a su material. Entonces hallará, para una parte de ellas, sin necesidad de reflexionar mucho, las incitaciones a que se remontan, los indicios de otros autores que él ha recogido, modificado y
\end{abstract}

\footnotetext{
${ }^{581}$ Varios años más tarde seguirá manteniendo esta analogía: "las mociones pulsionales de carácter sexual [...] se comportan entre sí como una red de vasos comunicantes" (Freud, 1917j/2004: 314).

${ }^{582}$ Bajo la tesis de que la física que Freud utiliza no es más que una heurística, mientras que la biología le sirve de base para elaborar una ontología, Leticia Minhot (2003: 57-142) analiza minuciosamente varias de las analogías que el vienés trazó en la construcción de sus modelos metapsicológicos, apelando a ciertos compromisos metateóricos inherentes al siglo XIX.
} 
desarrollado en sus consecuencias. Pero acerca de otra parte de sus ideas no puede confesar nada semejante; tiene que suponer que esos pensamientos y puntos de vista se han engendrado - no sabe cómo- en su propia actividad de pensamiento, y en ellos afirma su reclamo de originalidad. No obstante, una indagación psicológica cuidadosa restringirá todavía más ese reclamo. Ella descubre fuentes ocultas, hace tiempo olvidadas, de las que emanó la incitación de las ideas en apariencia originales, y así la presunta creación nueva resulta ser una reanimación de lo olvidado, que se aplicó a otro material. No hay nada que lamentar en ello; es que no había derecho alguno a esperar que lo "original» fuese algo no derivable, carente de todo determinismo. (Freud, 1923d/2004: 281).

Más allá de la implícita referencia al fenómeno de la criptomnesia, la operación de aplicar a otro material las ideas que se pretenden originales ${ }^{583}$ se vincula con lo que hemos venido conceptualizando, pues constituye un tipo de inferencia abductiva en el que se hace evidente la utilización de la analogía como recurso creativo. En virtud de los entrecruzamientos anteriores, coincidimos con Ariel Viguera cuando sostiene que el intercambio entre el campo de las inferencias abductivas y el campo de la investigación psicoanalítica es doblemente fecundo: el psicoanálisis puede ayudar a esclarecer los procesos mentales que intervienen en la abducción de hipótesis $y$, a su vez, la noción de inferencias abductivas puede devenir en un aporte significativo para la investigación y clínica psicoanalíticas (Viguera, 2010).

Finalmente, debemos mencionar que el papel desempeñado por las inferencias abductivas no sólo es central en la labor clínica del analista con cada paciente y en el trabajo de investigación teórica, sino que Freud también parece basarse en esta lógica de indagación cuando dirige su método a producciones artísticas o literarias. Como ya adelantamos, el Moisés de Miguel Ángel es analizado por Freud ${ }^{584}$ del mismo modo: luego de discutir con algunas

\footnotetext{
${ }^{583}$ Freud consideraba que buena parte de sus "originales" ideas habían estado determinadas, de un modo u otro, por ideas ajenas que él conocía. Su conjetura de la etiología sexual de las neurosis fue considerada una brillante idea propia, hasta que “...un día se agolparon en mí ciertos recuerdos que me estorbaron esa satisfacción y me abrieron una buena perspectiva sobre los procesos de nuestra actividad creadora y la naturaleza de nuestro saber. Esa idea, por la que se me había hecho responsable, en modo alguno se había engendrado en mí" (1914b/2004: 12). Breuer, Charcot y Chrobak le "habían trasmitido una intelección que, en todo rigor, ellos mismos no poseían" (ibíd.). Para un interesante análisis de este fenómeno en otros episodios de la vida de Freud, cf. Viguera, (2006).

${ }^{584}$ Hay distintas lecturas acerca de lo que llevó a Freud a producir esta interpretación basada en una figura de la cual, como es sabido, se ocupará pormenorizadamente más tarde. Para un análisis comparativo de algunas de esas lecturas, cf. el capítulo VI de Cancina (2008).
} 
de las principales interpretaciones que se habían dado de la escultura, el vienés introduce la mencionada referencia a Morelli y prosigue a elucidar la intencionalidad del autor al plasmar su obra. Se detiene en detalles que rápidamente dan lugar a inferencias abductivas y habilitan el planteamiento de nuevos interrogantes; así, por ejemplo, luego de la observación y análisis de la barba y la mano derecha, sostiene:

\begin{abstract}
la presión del índice de la mano derecha recae principalmente sobre cordones de pelo de la mitad izquierda de la barba, y en virtud de la trasgresión que él opera la barba es impedida de acompañar el giro de la cabeza y de la mirada hacia el lado izquierdo. Es lícito preguntar, entonces, qué significado tendría ese ordenamiento y a qué motivos debe su existencia. [...] Continuemos bajo la premisa de que también estos detalles poseen un significado [...] quizás esto se pueda comprender como el resto de una relación mucho más íntima, en un momento anterior al figurado, entre esa mano y aquella mitad de la barba. Acaso la mano derecha había tomado la barba más enérgicamente, avanzando hasta el costado izquierdo, y al retirarse a la postura que ahora vemos en la estatua le siguiera una parte de la barba y diera testimonio del movimiento que ahí acababa de trascurrir. La guirnalda de la barba sería la huella que esa mano dejó en su trayectoria. (Freud, 1914c/2004: 229).
\end{abstract}

Freud continúa analizando algunos otros detalles, como la postura invertida de las Tablas, para complejizar su inferencia abductiva postulando tres estadios previos a la postura de Moisés que, de haber existido, explicarían bien los rasgos de la postura que Miguel Ángel esculpió en la estatua:

\footnotetext{
Lo que en él vemos no es el introito a una acción violenta, sino el resto de un movimiento trascurrido. En un ataque de cólera, quiso levantarse de golpe y cobrar venganza olvidado de las Tablas. Pero superó la tentación: ahora permanecerá sentado con furia domeñada, con una mezcla de dolor y desprecio. (ibíd. p. 234).
}

Hacia el final del artículo, Freud manifiesta explícitamente que este tipo de inferencias bien podría resultar incorrecto, por estar basadas en "pistas falsas". Pero en un apéndice agregado en 1927, Freud cuenta de su encuentro con el trabajo de un crítico de arte, que describe una estatuilla de bronce de un conocido artista del siglo XII, quien había representado un Moisés que coincidía con "el momento anterior" a la escena representada en el Moisés de Miguel Ángel. Freud lo interpreta a su favor: "creo que el hallazgo aquí comunicado 
eleva la verosimilitud de la interpretación que ensayé en mi trabajo de 1914" (ibíd. p. 242). Esto constituye una clara muestra del esfuerzo freudiano por validar sus inferencias abductivas (en sintonía con lo que Peirce propugnaba); en este caso contrastándolas con otras interpretaciones. Nos ocuparemos de este aspecto en la tercera parte del presente capítulo.

Además del Moisés de Miguel Ángel, Freud utiliza el mismo tipo de inferencias abductivas para explicar algunas características de, por ejemplo, la personalidad de Leonardo Da Vinci y las peculiaridades del delirio y los sueños de Hanold, el personaje de la "Gradiva" de Jensen. Respecto de éste último, Freud comenta el modo en que el personaje de Zoe-Gradiva "cura" al joven Hanold: "el tratamiento consiste en devolverle desde afuera los recuerdos reprimidos que él no puede libertar desde adentro" (Freud, 1907/2004: 73); y luego señala la diferencia que este procedimiento mantiene con el psicoanalítico, en el cual

\footnotetext{
el médico, que no cala de antemano a sus enfermos y no lleva en su interior como recuerdo conciente aquello que en estos trabaja inconcientemente, se ve precisado a valerse de una técnica compleja a fin de compensar esa desventaja. Tiene que aprender a inferir con gran certeza, desde las ocurrencias y comunicaciones concientes del enfermo, lo reprimido en él, colegir lo inconciente donde se trasluce tras las exteriorizaciones y acciones concientes del enfermo. (ibíd. p. 74; cursivas añadidas).
}

Como habrá podido notarse a esta altura, si bien existe un común denominador abductivo en las inferencias que el analista efectúa en los diversos ámbitos en los que se propone indagar, esto no autoriza desdeñar las diferencias que persisten en las diversas formas de indagación psicoanalítica. Adentrarnos en este asunto supone abordar uno de los problemas que más desacuerdos ha producido en las conceptualizaciones de la investigación en psicoanálisis: la identificación, propiciada por Freud, entre el método de tratamiento con el método de investigación.

\section{c) Vicisitudes de la preciosa conjunción para la investigación clínica}

En la primera parte de la tesis hemos visto que no hay una sola forma de clasificar el campo de la investigación en psicoanálisis y que las discusiones 
sobre la necesidad y posibilidad de basar la investigación en el método clínico o en otros métodos, persiste. En este apartado me voy a referir a lo que se ha venido conceptualizando como investigación clínica (Leuzinger-Bohleber, 2015) para intentar contribuir a un aspecto que pareciera seguir dando lugar a confusiones. Para ello, primero considero necesario establecer una diferencia terminológica entre indagación clínica e investigación científica basada en la clínica $^{585}$. Esto responde a la existencia de criterios que pueden explicitarse para su diferenciación al interior del campo de la investigación clínica, bajo la suposición de que no hacerlo ha contribuido a confundir dos actividades diversas; a veces identificándolas. Es decir, esa distinción terminológica no es más que la nominación de una diferencia semántica previamente existente que, por no ser claramente establecida, ha dado lugar a malentendidos prácticos.

Tempranamente Freud comenta, a propósito de Breuer, la relación descubierta entre investigación y curación: "con su primera paciente él hizo esta experiencia: el intento de averiguar el ocasionamiento de un síntoma es al mismo tiempo una maniobra terapéutica" (Freud, 1893b/2004: 36). La conceptualización final que reciben esas ideas iniciales se resume así:

En el psicoanálisis existió desde el comienzo mismo una unión entre curar e investigar; el conocimiento aportaba el éxito, y no era posible tratar sin enterarse de algo nuevo, ni se ganaba un esclarecimiento sin vivenciar su benéfico efecto. Nuestro procedimiento analítico es el único en que se conserva esta preciosa conjunción. Sólo cuando cultivamos la cura analítica de almas ahondamos en la intelección de la vida anímica del ser humano, cuyos destellos acabábamos de entrever. Esta perspectiva de ganancia científica fue el rasgo más preclaro y promisorio del trabajo analítico; ¿deberíamos sacrificarlo a unas consideraciones prácticas? (Freud, 1926b/2004: 240).

Por lo tanto, desde el inicio "investigación científica y empeño terapéutico coinciden" (Freud, 1923a/2004: 232). Sin embargo, Freud señaló también que

\footnotetext{
${ }^{585}$ Sé del pavor que para muchos representa, aún hoy en día, la palabra ciencia al lado de la palabra psicoanálisis en nuestro margen rioplatense. Además de que cada vez es más problemática la univocidad del término psicoanálisis, el problema ha sido y sigue siendo, a qué llamar ciencia y con qué criterios. Si se asume alguna versión anacrónica de la ciencia natural o de la concepción tradicional de la metodología o las teorías, entonces seguramente ese adjetivo no pueda ser aplicado al tipo de investigación clínica que se hace a partir del método y experiencia psicoanalíticos. Pero si asumimos una concepción distinta, no veo problema epistémico alguno (aunque sí los beneficios y los desafíos) para definir al psicoanálisis como una ciencia y a sus formas de investigación clínica como métodos científicos.
} 
el tiempo del trabajo de investigación en psicoanálisis no puede coincidir con el tiempo de trabajo clínico:

Mientras el tratamiento de un caso no esté cerrado, no es bueno elaborarlo científicamente: componer su edificio, pretender colegir su marcha, establecer de tiempo en tiempo supuestos sobre su estado presente, como lo exigiría el interés científico [...] la conducta correcta consistirá en pasar de una actitud psíquica a la otra al compás de sus necesidades; en no especular ni cavilar mientras analiza, y en someter el material adquirido al trabajo sintético del pensar sólo después de concluido el análisis (Freud, 1912a/2004: 114).

El trabajo analítico implica que el analista se deje llevar espontáneamente por el material (atención flotante), dejándose sorprender y absteniéndose de teorizar a partir de él. Aquí es necesaria una aclaración: en tanto que la labor clínica consiste en una serie de operaciones cognitivas, la conceptualización paulatina del caso es ineludible. Pero esta teorización es relativa al caso en cuestión y debe distinguirse de la que se efectúa con afanes de generalización o modelización. Respecto de ésta última forma de teorización, el analista que investiga (basado en la experiencia clínica) sólo debe proceder una vez finalizado el análisis, sometiendo el material obtenido al trabajo sintético del pensar: "durante el análisis de un caso clínico no se puede obtener una impresión intuible sobre la estructura y el desarrollo de la neurosis. Ello incumbe a un trabajo de síntesis que se debe emprender después" (Freud, 1909a/2004: 106).

Por lo tanto, hay razones (antepuestas por el propio Freud) que nos obligan a separar ambas acciones y a pensar el modo en que podemos concebir esa conducta correcta de pasar de una actitud psíquica a la otra. Para Azaretto et. al. "la identificación directa entre uno y otro obstaculiza la discriminación de los niveles así como la distinción precisa del modo en que las coordenadas del dispositivo clínico, por ejemplo la transferencia, participan de la lógica de investigación" (Azaretto y Ros, 2014: 24). A nuestro modo de ver, la indagación clínica y la investigación científica basada en la clínica tienen varios puntos en común pero deben ser diferenciadas en base a criterios específicos. Esbozamos, a continuación, algunos que consideramos posibles:

a) Los objetivos. Mientras que la indagación clínica apunta a la producción de un saber-hacer singular que le permita al paciente arreglárselas mejor con 
su sufrimiento, la investigación científica parte de otro planteamiento de los problemas y se plantea, por ende, otros objetivos; tales como la elucidación de factores intervinientes en el desarrollo de un fenómeno o proceso psíquico que ha sido delimitado, el discernimiento del rol del vínculo transferencial en los distintos momentos del tratamiento, la revisión de alguna conjetura etiológica o la dilucidación de formas de validación empírica para determinadas hipótesis metapsicológicas, etc. ${ }^{586}$

b) La posición del investigador. Mientras que en el proceso de indagación clínica el analista debe soportar la transferencia y los tiempos del caso, siguiendo las reglas técnicas y axiológicas de la comunidad analítica de la que forma parte; en la investigación científica el analista desempeña un rol de investigador que lo vincula con una lógica de indagación diferente ${ }^{587}$. Además, las obligaciones deontológicas y responsabilidades éticas son divergentes según se asuma una u otra posición.

c) Actitud procedimental. Aunque los defensores de la investigación clínica han venido desestimando la utilización de otros procedimientos de recolección o análisis de datos para investigar, no puede obviarse el hecho de que los

\footnotetext{
${ }^{586}$ Vale la pena señalar que el problema de articular el afán nomotético con la prioridad de lo idiográfico en la construcción del conocimiento psicoanalítico, que nos propusimos abordar desde el capítulo anterior, ha constituido una suerte de impasse para algunos analistas que han intentado conceptualizar la investigación en psicoanálisis. Pulice y otros, por ejemplo, sólo llegan a plantearse el interrogante sin brindar una respuesta: "¿es posible atravesar esta dificultad, y conciliar en un trabajo de investigación científica lo universal y lo singular? Este es un interrogante que dejaremos planteado" (Pulice et al, 2000: 122-123). Por su parte, Gallo y Ramírez se preguntan lo mismo, para dar lugar a una respuesta que no parece hacernos avanzar en una propuesta concreta: "Nos queda la pregunta: ¿cómo articular en una investigación con el psicoanálisis lo singular y lo estructural? Lo singular requiere que el investigador esté dispuesto a mantener abierto el abordaje metódico de lo imprevisto y de lo real no codificado, mientras que lo estructural hace referencia a lo constante. Entre lo real siempre por establecer en su singularidad y lo estructural que invoca lo universal, ha de mantenerse la investigación psicoanalítica tanto en lo clínico como en lo social" (Gallo y Ramírez, 2012: 95). A mi modo de ver, lo Real lacaniano no necesariamente vaya a encontrarse sólo a nivel de lo singular; y, además, no resulta claro cómo la investigación psicoanalítica podría conducirse en ese espacio entre ambos planos. Por mi parte, considero que la propuesta del capítulo anterior de apelar a la noción de reglas y a la posibilidad de explicaciones causales sin subsunción nómica, junto con la elucidación que aquí intentamos del tipo de inferencias inherentes al proceder clínico, nos permitirán echar luz sobre algunos aspectos concretos y de una manera plausible. Va de suyo que esto está muy lejos de disolver el problema y que constituye apenas una propuesta para ulteriores líneas de indagación.

${ }^{587}$ Por ejemplo, por muy ansioso que pueda estar un analista investigador por dar respuesta a un problema que en su comunidad de pertenencia se ha vuelto necesario abordar imperiosamente, su posición no podría equivaler a la que adopta ante la indagación a partir del encuentro con un otro sufriente en el campo clínico. De esa posición diferencial se siguen diversos ritmos y formas de abordar los problemas.
} 
procedimientos cognitivos que un analista-investigador utiliza para abordar un problema de investigación difieren de los que pone en juego mediante la indagación clínica con el método psicoanalítico en funcionamiento ${ }^{588}$. Por empezar, mientras que en la indagación clínica se pone el acento en una escucha abierta y flotante desde los propios procesos primarios del analista, hasta dar sorpresivamente con algo no buscado; por el contrario, en la investigación científica se privilegia la búsqueda orientada por interrogantes precisos y hacia dominios concretos de variables circunscriptas. Esto no impide, por supuesto, que en determinados momentos el analista no pueda buscar y que el investigador no se deje sorprender; pero me parece que el acento diferencial sobre una actitud y otra los diferencia en la mayor parte del proceso. Aunque me estoy refiriendo fundamentalmente a la investigación clínica, me parece que este criterio es independiente del hecho de dar prioridad al método clínico o a otros procedimientos (extra-clínicos) en la investigación psicoanalítica.

Estos criterios no excluyen otras particularidades que puedan darse en nuestra disciplina. Por ejemplo, Roger Perron ha destacado una especie de dificultad añadida a la investigación en nuestro campo: "el abordaje psicoanalítico tiene un rasgo epistemológico único: el sujeto y el método de estudio son idénticos; el aparato psíquico es descubierto por medio del aparato psíquico"589 (Perrón, 1999: 6). Esto pareciera dar al trabajo investigativo en psicoanálisis unas características propias. Julieta De Battista considera que

\begin{abstract}
Si bien el procedimiento del que el analista se vale en la escucha no es aquel que utiliza para investigar, no por eso puede elidirse el hecho de que el analista ha sido primero un analizante, es decir, ha llevado su análisis lo suficientemente lejos como para convertirse en un analizado. [...] A diferencia de otros abordajes metodológicos en investigación, que pretenden eliminar la incidencia de las variables subjetivas del investigador en la recolección de datos, la investigación en
\end{abstract}

\footnotetext{
${ }^{588}$ Esto es lo suficientemente inespecífico como para resultar independiente de lo que cada quien entienda por método psicoanalítico y por metodología de investigación. Así, el evidente pluralismo de ambos campos no debería afectar la diferencia a la que me estoy refiriendo.

589 "The psychoanalytic approach has a unique epistemological feature: the subject and the method of study are identical, the psychic apparatus is discovered by means of the psychic apparatus."
} 
psicoanálisis propone que el material mismo está condicionado por la posición de quien lo lee (De Battista, 2015: 21 y 22).

Sin lugar a dudas, el analista lee y, además, incide en la reescritura que el paciente hace de sí mismo. En ese sentido, tanto para la indagación clínica como para la investigación científica, la posibilidad de contar con un saber sobre el propio inconsciente no puede constituir sino un privilegio para el analista-investigador.

Ahora bien, respecto de la investigación clínica y quizás en función de su insoslayable relación con el método psicoanalítico, todavía persisten algunas opiniones que conviene revisar. El hecho de que la indagación clínica habitual consista en una permanente pesquisa de indicios, caso por caso y sin aspiración alguna de generalización universal, ha dado lugar a profundos malentendidos respecto de: a) las posibilidades de generalización o subsunción nómica, y b) de los alcances de la investigación en psicoanálisis. Respecto de lo primero, como ya hemos señalado en el capítulo anterior, la singularidad de cada caso implica regularidades inherentes, de manera tal que las operaciones lógicas de generalización-subsunción aparecen involucradas en la escucha del analista y en la co-construcción del saber-hacer que se gesta en cada recorrido. En segundo lugar, en virtud de que los aspectos con mayor relevancia causal que el psicoanalista recorta no son aspectos subsumibles en enunciados nómicos sino que constituyen elementos idiosincráticos del funcionamiento psíquico de cada paciente, el proceso de indagación clínica dista mucho del reconocimiento clasificatorio que suele operar en otras disciplinas (como la semiología médica o psiquiátrica) y demanda constantemente el hacer camino al andar, aventurándose constantemente en la averiguación mediante abducciones creativas. Pero esto no debería implicar, necesariamente, que ese modo de indagación clínico agote completamente las posibilidades de investigación de un psicoanalista. Tal y como hemos reseñado en la primera parte de la tesis, las formas de investigar en la disciplina muestran un crecimiento y una diversificación considerable.

En síntesis, la implementación de algunos criterios (tales como los objetivos, la posición del investigador y su actitud procedimental) permite distinguir la indagación clínica de la investigación científica basada en la clínica, sin por ello rechazar la suposición freudiana de la preciosa conjunción: al contrario, 
contribuye a elucidar el modo de investigación clásico en psicoanálisis, entendiéndolo como inherente e insoslayable a nuestro campo disciplinar. Lo cual no significa que sea el único posible.

\section{Aspectos de la contrastación clínica de hipótesis abducidas}

Considerando el pluralismo existente en el campo psicoanalítico que hemos reseñado en la primera parte de la tesis, resulta difícil extraer algún común denominador respecto a cómo entienden los representantes de las distintas orientaciones teóricas que deberían definirse cuestiones como la naturaleza y forma de las intervenciones del analista, el valor de la interpretación como factor de cambio, su función en torno a la dinámica transferencial, etc. Nuestro propósito en esta parte de la tesis, desprendido del objetivo general, es más modesto: elucidar los aspectos centrales de la racionalidad freudiana, en base a las herramientas de las que nos hemos venido apropiando y a los fines de contribuir a mostrar la inviabilidad de las críticas nacidas con los enfoques de Popper y Grünbaum a la legitimidad del conocimiento clínico.

A menudo se olvida, entre los analistas que intentan vincular la lógica peirceana con el proceder freudiano, que la abducción constituye sólo el momento inicial de un proceso de investigación. Momento muy importante por cierto, ya que permite iluminar la lógica de la creación de hipótesis y revertir la desestimación popperiana de incluirla como objeto digno de consideración epistemológica. Sin embargo, así y todo la abducción sólo nos permite elucidar el modo en que se introducen nuevas ideas, es decir el aspecto creativo de la invención cognitiva. Para Peirce la abducción por sí sola resulta insuficiente para una cabal caracterización del proceso investigativo, que también debe hacer uso de la deducción, utilizándola para extraer las consecuencias necesarias y corroborables de la hipótesis abducida y, finalmente, también de la inducción, en tanto permite representar el momento de confirmación o refutación experiencial de esas consecuencias, evaluando así la hipótesis abducida. Al menos para Peirce, estos tres tipos de inferencia funcionan de 
manera integral y sinérgica en el proceder científico. ¿Cómo podemos concebir, entonces, el momento de la puesta a prueba de las conjeturas psicoanalíticas en los distintos dominios en los que el analista se dispone a abducir? Pretendemos aquí saldar una deuda que habíamos dejado planteada en la parte dedicada al análisis de Popper: allí pudimos mostrar, además de su inviable postura y su omisión histórica, que Freud adhería a una forma de falsacionismo sofisticado. Pero por el modo en que decidimos exponer allí nuestra idea, centrándonos en la racionalidad de algunos cambios teóricos del programa freudiano, el contexto de la labor clínica se mantuvo al margen de nuestro análisis. Es momento de incluirlo.

\section{a) ¿Impide la materialidad significante, por su condición de tal, su evaluación empírica?}

A mi modo de ver, ha existido y quizás siga persistiendo entre muchos analistas, un sorprendente malentendido sobre la contrastabilidad empírica en nuestro campo, que conviene aclarar de entrada para evitar que entorpezca la lectura que voy a llevar a cabo. Roger Dorey, en la introducción de El inconciente y la ciencia, encarna cabalmente dicho malentendido:

\footnotetext{
El dominio del análisis, en efecto, es el de la significación, la que es propia del inconsciente como radicalmente otro; es en otra escena donde se juega la partida, en otro terreno que no es aquel en que se despliega la investigación científica (Dorey, 1991: 13).
}

Es la suposición de que el psicoanálisis, por operar desde y sobre fenómenos de significación, no puede ser visto ni entendido como una disciplina científica. En virtud de esta suposición y de otras (como la de adherir, mediante su oposición, a la concepción tradicional de la ciencia) Dorey le da la razón a Popper en su crítica del psicoanálisis. Tal y como espero haber mostrado, los analistas partidarios de la tradición hermenéutica han sostenido, de un modo u otro, ambas suposiciones.

Una forma sencilla de exponer porqué esto es un malentendido es a partir de un artículo de Dagfinn Føllesdal, quien supo argumentar a favor de un enfoque interesante sobre la dicotomía metodológica tradicional, afirmando que "el método hermenéutico es el método hipotético-deductivo aplicado a materiales 
significativos" (Føllesdal, 1979: 320). Aunque Føllesdal parece estar refiriéndose a la noción de comprensión inherente a la hermenéutica romántica y aunque por momentos parezca asumir una versión simplificada de la contrastación, vale la pena retomarlo porque contribuye bien a eliminar el malentendido.

Como argumento central para su idea, Føllesdal utiliza un ejemplo extraído de la literatura y muestra cómo la forma de resolución del problema (la interpretación de lo que representa uno de los personajes del texto) procede hipotético-deductivamente: se plantean conjeturas y se contrastan sus consecuencias lógicas con el resto del material contenido en la obra y con otro material adicional que se tiene (datos del autor, contexto histórico, etc.). La obra que le sirve de ejemplo es Peer Gynt, de Henrik Ibsen; y el problema que retoma es el del papel que juega el personaje "el extraño". Føllesdal examina cinco interpretaciones que se han dado sobre lo que representa ese personaje, así como algunos de los principales argumentos a favor y en contra de las mismas (obtenidos mediante contrastaciones de sus consecuencias). Obsérvese que las interpretaciones sobre lo que representa el personaje "el extraño", son hipótesis contrastables y, además, no se trata de hipótesis universales sino restringidas al contexto de la obra Peer Gryn. Con lo cual, de su tesis se sigue que los procedimientos hermenéuticos no necesitan adoptar el modelo explicativo de cobertura legal, puesto que bien puede haber conjeturas y refutaciones de interpretaciones particulares. A nuestro modo de ver, este ejemplo debería ilustrar lo suficientemente bien tres cosas: 1) el hecho de que el psicoanálisis se ocupe de significaciones no impide que se puedan hacer conjeturas sobre las mismas y evaluarlas utilizando criterios consensuados disciplinarmente; 2) adoptar esta estrategia general no implica que su realización sea por la vía de la experimentación o de la correlación estadística; y 3) se pueden evaluar conjeturas interpretativas a partir de sus consecuencias derivadas sin que éstas tengan una formulación nómica; lo cual supone una separación de esta estrategia metodológica respecto de los modelos explicativos utilizados (p. ej. el de cobertura legal). Estas consecuencias que podemos extraer de la tesis de Føllesdal vienen a empalmar, aunque por la vía inversa, con el movimiento de hermeneutización de la filosofía contemporánea de la ciencia que hemos descripto en el capítulo 
anterior. Aportan, me parece, a una concepción de la hermenéutica en sentido amplio y de la que el psicoanálisis es deudor.

Como hemos visto, en el trabajo clínico e investigativo de Freud puede atisbarse su espíritu falibilista. Hacia el final de su obra supo expresar la necesidad de testear las enunciaciones del analista en el contexto clínico: "a cada construcción la consideramos apenas una conjetura, que aguarda ser examinada, confirmada o desestimada" (Freud, 1937/2004: 266). Como las hipótesis interpretativas del analista se contrastan con la realidad psíquica del analizado, Freud es taxativo respecto de las conjeturas que no coinciden con esa realidad: "es preciso retirarlas y sustituirlas por algo más correcto" (Freud, 1917/2002: 412). Adentrémonos, entonces, en las dificultades que supone esta empresa con el objetivo de atisbar su racionalidad.

\section{b) La interpretación clínica como conjetura evaluable: interrogantes al enfoque clásico}

En virtud de la pluralidad actual del psicoanálisis, es evidente que la estructura y contenido de las interpretaciones varíe en grado significativo respecto de la matriz teórica a la que adhiera el analista que la efectúa. En este sentido, quizás ya no sea posible generalizar propiedades relevantes sobre el uso de la herramienta interpretativa sin singularizar al paciente, al analista ${ }^{590}$ y sus referentes teóricos (Ungar, 2015). Podría aseverarse, en sintonía con lo que hemos venido considerando, que el background de modelos metapsicológicos y clínicos del analista no constituye, en virtud de los aspectos abductivos involucrados, una variable menor para la génesis de hipótesis interpretativas. Además de todo ello, debemos tener en cuenta que a pesar de la centralidad que ha tenido la interpretación en psicoanálisis, hoy sólo constituye una entre diversas herramientas técnicas y no es aplicable a todos los pacientes ${ }^{591}$. Sin perder de vista estas consideraciones, en este apartado

\footnotetext{
590 Ya Freud supo reconocer el carácter idiosincrático que define a los elementos de la técnica: "he decantado las reglas técnicas que propongo aquí de mi experiencia de años [...] pero estoy obligado a decir expresamente que esta técnica ha resultado la única adecuada para mi individualidad" (Freud, 1912a/2004: 111).

591 Aunque no hay unanimidad sobre este aspecto sí hay algunos consensos, relativos a la manera en que cada corriente teórica concibe aspectos como la técnica y la tipología clínica, a
} 
avanzaré analizando brevemente algunos referentes locales clásicos, a los fines de exponer luego una lectura propia sobre ciertos interrogantes específicos relativos al problema de la evaluación clínica de las interpretaciones.

Asumiendo que la interpretación es una herramienta o recurso Prínceps del analista, gran parte de los debates epistemológicos sobre el psicoanálisis han cuestionado la forma en la que éstas se validan en el contexto clínico. Comencemos por definir validez como el hecho de que una afirmación sea aceptada o creída, actuándose en consecuencia. Por otro lado, validación puede pensarse como el proceso mediante el cual una proposición adquiere validez (Jimenez, 2004). Atendiendo a los interrogantes sobre estos asuntos en nuestro campo, diversos autores han planteado que la interpretación psicoanalítica es una proposición científica susceptible de validación empírica (Wisdom, 1967/1969; Glymour, 1974; Edelson, 1984; Klimovsky, 1986/2009; Alvarez Lince, 1996; Etchegoyen, 2001). Estamos de acuerdo con ello: en la medida en que una interpretación refiere a un estado o proceso de la realidad psíquica del paciente en un momento dado, constituye una conjetura que puede ser contrastada y evaluada en el contexto mismo de su emergencia. Aquí se hace necesaria una aclaración de lo que voy a entender por interpretación. Entre los diversos usos que el vocablo interpretación ha adquirido en la bibliografía psicoanalítica, podemos notar al menos dos que conviene explicitar:

a) Primero, el uso referido a una modalidad de intervención característica de la teoría psicoanalítica, tal como la define Freud (1937/2004) y como aparece en el diccionario de Laplanche y Pontalis (1968/1993).

b) Segundo, un uso referido al efecto interpretativo, susceptible de producirse por cualquier acción del analista, partiendo de su simple presencia, e independientemente de que éste se lo proponga. De esta forma, toda acción llevada adelante puede orientarse, más allá de su formato, a la búsqueda del fenómeno interpretativo (Roussos et. al., 2009).

partir de los cuales la interpretación no se considera operativa o no es viable en un grado suficiente para determinados pacientes (p. ej. psicosis, personalidades narcisistas, etc.). 
A los fines de cercar lo más posible nuestro problema, sólo abordaremos algunos aspectos de la primera acepción de dicho vocablo, en virtud de la cual existe, de por sí, profusa bibliografía y diversos enfoques de análisis. En nuestro ámbito rioplatense se destaca una postura clásica sobre el tema, que voy a citar e intentar revisar a continuación, para terminar afinando algunos interrogantes que me permitirán exponer lo que sigue.

Horacio Etchegoyen define a la interpretación psicoanalítica como "una hipótesis que el analista ofrece a su analizado sobre lo que está operando en ese momento en su inconciente, sin otro fin que el de informarlo y para que él decida sobre su contenido de verdad" (Etchegoyen, 1999: 24). Para Etchegoyen es conveniente separar metodológicamente el estudio de la situación psicoanalítica, entendida como la sesión sincrónica y puntual; del proceso psicoanalítico, es decir el acontecer diacrónico de un tratamiento, con sus complejidades añadidas. $Y$ agrega: "que no podamos trazar una divisoria neta entre una y otro no autoriza, sin embargo, a confundirlos" (Etchegoyen, 2001: 40). La decisión de separarlos es metodológica, pero Etchegoyen reconoce que sólo uniéndolos estratégicamente podremos arribar a un reforzamiento de la validez.

El planteo de Etchegoyen se apoya, como él mismo explicita, en los desarrollos de Klimovsky sobre el asunto de la validación. Klimovsky ha analizado, en un artículo clásico que se incluyó en el monumental libro de Etchegoyen (1986/2009) sobre la técnica, el problema de la naturaleza lógica de la interpretación en psicoanálisis, diferenciando tres aspectos que conducen a tres conjunto de problemáticas: el explicativo, el semiótico y el instrumental.

1) Aspecto explicativo: se refiere a la dimensión gnoseológica de la interpretación, que permite verla como una hipótesis que involucra la existencia y funcionamiento de entidades inobservables que permiten explicar lo fenoménico. Klimovsky distingue dos tipos de interpretaciones, que parecen derivar de su adherencia a la clásica distinción entre lo observable directa e indirectamente.

a) Interpretación-lectura: aquella donde el material latente es leído a través del material manifiesto y en virtud de las reglas de correspondencia que vinculan los fenómenos observacionales con las entidades teóricas de cada metapsicología. Así como es necesaria una teoría para observar por el 
microscopio y por el telescopio lo que no podemos percibir mediante los sentidos de manera directa, también el analista necesita de modelos y teorías para leer el material empírico que se le presenta. Debido a que la forma lógica de esas reglas de correspondencia tiene, según Klimovsky, la estructura de un condicional en cuyo antecedente se representan los elementos observacionales y en el consecuente los caracteres hipotéticos, siempre que nos topemos con la presencia de tales elementos observacionales estaremos efectuando una lectura: "la teoría nos permite ver lo que sin ella no podríamos ver: tiene, realmente, el mismo efecto que un lente de aumento. No por repetida, la metáfora deja de ser exacta" (klimovsky, 1986/2009: 540).

b) Interpretación-explicación: la interpretación constituye una hipótesis acerca de lo que ocurre en lo inconsciente. El caso típico de interpretación psicoanalítica, según Klimovsky, es un enunciado cuya estructura lógica es la inversa del condicional anterior: "el contenido manifiesto es la condición necesaria y el contenido latente la condición suficiente" (ibíd. p. 541). De este modo, lo observacional clínico queda representado por el consecuente y el antecedente por la hipótesis que lo explica; pero, en virtud de que el consecuente podría seguirse de cualquier otro antecedente y de que constituye una falacia extraer la verdad de la teoría a partir de sus consecuencias observacionales, Klimovsky sostiene que esta forma de interpretación no pude ser una lectura. El autor considera que el modelo de cobertura legal permite dar cuenta de las interpretaciones de hechos clínicos particulares por subsunción nómica a los enunciados teóricos. No es esta la perspectiva que aquí he adoptado, en virtud de que los fenómenos del sentido en el campo subjetivo no se pueden reconducir completamente a leyes universales, quedando un margen de aspectos causales (motivos, reglas, etc.) que no tienen alcance universal y que, por ende, no se adecúan bien al clásico modelo de HempelPopper. Además, en virtud de su adherencia a la concepción clásica, Klimovsky no toca el tema de la lógica del descubrimiento.

2) Aspecto semiótico: la interpretación, en base a la función semiótica del paciente, aspira a los significados de su actividad psíquica. Aquí Klimovsky señala diversas formas de relación entre un significante y un significado (naturales, de isomorfismos culturales y convencionales), pero reconoce la capacidad de cada sujeto para transformar objetos en símbolos de otra cosa. 
Seguido de lo cual, señala, aunque sin desarrollarlo, que aquí "el psicoanálisis se encuentra ante un terreno epistemológico muy serio, porque tiene que hacer dos cosas: primero advertir el código ad hoc que en un momento determinado ha adoptado el paciente y luego reconocerlo en el devenir del proceso analítico" (ibíd. p. 551). Este aspecto es el que en el capítulo anterior hemos destacado como fundamental en la formalización de las explicaciones psicoanalíticas de casos: en virtud de que los enunciados explanantes fundamentales no son leyes, sino que refieren a acontecimientos y a regularidades idiosincráticas, la posibilidad de subsunción nómica se ve coartada en disciplinas como el psicoanálisis. No resulta casualidad que Klimovsky, cuyas afinidades al hipotético-deductivismo y al modelo de cobertura legal son notorias, no haya explorado más pormenorizadamente esta vía.

3) Aspecto instrumental y terapéutico: en virtud de que la interpretación es una acción con finalidad, su análisis no puede dejar de lado los problemas axiológicos que le son inherentes: la finalidad del análisis, la concepción de cura, de patología, etc. Esta carga valorativa no impide que el psicoanálisis siga defendiendo una neutralidad cognoscitiva en su labor ni vuelve a sus principales teorizaciones algo dependiente de los sistemas valorativos que se asuman.

Pese a la utilidad de esta conceptualización, a mi modo de ver ella supone dejar por fuera algunos aspectos que resultan cruciales para elucidar la racionalidad clínica del psicoanálisis y para hacer frente a las críticas que hemos venido analizando. Entre los aspectos que esta conceptualización desatiende, aquí voy a recuperar sólo dos y a los fines de nuestros objetivos.

En primer lugar, aunque en esa concepción clásica se asume que una interpretación es una conjetura, las vicisitudes relativas a su génesis no son contempladas. Esta escisión de los procedimientos de evaluación respecto de los de invención constituye, en función de lo que hemos examinado, una imagen bastante empobrecida del proceso en su conjunto. Podemos preguntarnos, por ejemplo, de qué modo podemos representar ese proceso continuo de génesis y testeo, atendiendo al acontecer natural e inherente al devenir del proceso analítico. Hay en esto algunos aspectos que no parecieran estar suficientemente saldados. Por ejemplo, ¿alcanza con utilizar el mismo 
conjunto de evidencias para generar que para contrastar las conjeturas interpretativas? Tal y como hemos visto, asumir el modelo de IME o asumir un marco como el peirceano constituyen dos opciones que resultan ser mutuamente excluyentes frente a este asunto. En el apartado siguiente intentaré abordar estos problemas y esbozar alguna respuesta que resulte pertinente para el contexto clínico.

En segundo lugar, vimos que la concepción clásica define a la interpretación como una hipótesis que es verbalizada al paciente de manera tal que él pueda expedirse y reaccionar, consciente e inconscientemente, sobre su plausibilidad. Sin embargo, aquí convendría detenernos para plantear otro interrogante, ¿es necesario que el analista formule su hipótesis interpretativa tal y cómo él se la representa conscientemente para que ésta pueda ser testeada? Veremos que no necesariamente y analizaremos un ejemplo de cómo una conjetura, cuya generación abductiva podremos reconstruir, puede ser contrastada sin ser completamente enunciada. Además intentaremos mostrar, apartándonos del modelo nomológico-deductivo y a partir del ejemplo seleccionado, que el grado de relevancia causal del conocimiento que se obtiene mediante un análisis es directamente proporcional a su nivel de singularidad; por lo que el valor de los enunciados nómicos se reduce a medida que el conocimiento clínico de un caso se hace más significativo, otorgando paulatinamente un lugar mayor a enunciados idiosincráticos. Veremos también por qué el tipo de abducciones que hace el analista para interpretar los aspectos singulares se ubica entre lo hipocodificado y lo creativo (siguiendo la mencionada clasificación de Eco) y por qué sólo pueden evaluarse por sus consecuencias en ese mismo suelo contrastacional.

\section{c) El valor de los caracteres predesignados en la lógica práctica del analista}

\footnotetext{
El psicoanálisis se apoya en una lógica práctica de descubrimientos y refutaciones, en una indagación tentativa en múltiples niveles de evidencias de discordancia y analogía. (Ahumada, 1997b/1999: 409).
}

Comenzaré exponiendo la reciente objeción que Edward Erwin (2015), epistemólogo afín a los planteos de Grünbaum, realiza al modelo de IME. 
Aunque no estoy de acuerdo con Erwin en su visión general del psicoanálisis, sí me parece que su manera de exponer esta crítica es más consistente que la presentación que hace Grünbaum y que hemos visto en la parte anterior de la tesis. Intentaré mostrar, luego de su argumento, cómo el problema que él señala puede ser neutralizado apelando a las recomendaciones de Peirce y sin necesidad de pretender una validación extra-clínica, tal y como Erwin, siguiendo a Grünbaum, propone.

Según Erwin, utilizar IME para sostener una hipótesis causal $H$ no prueba que ella sea verdadera. Supongamos que $H$ exprese que $C$ es la causa de $E$. Por lo tanto $H$ explica $E$. Pero ¿qué quiere decir que $H$ explica $E$ ? Según Erwin, podemos tomar la expresión explica en dos sentidos: o bien se asume que $H$ es verdadera en virtud de alguna evidencia independiente que la posiciona mejor que sus competidoras, lo cual conduce a afirmar que IME es algo derivado; o bien se asume que $H$ es potencialmente verdadera, lo cual conduce a elegir una entre varias explicaciones potenciales, sin que de esto tampoco se siga que $H$ es verdadera. Por lo tanto:

\begin{abstract}
...si "explica" se toma literalmente, entonces IME no tiene ninguna utilidad. Se necesitaría evidencia de que $\mathrm{H}$ es verdadera antes de aplicar la regla; y si "explica" se interpreta en el sentido de "explicaría sólo si fuese verdadera", entonces el hecho de que "H explica E", en este sentido potencial, mejor que sus competidores conocidos, nunca es evidencia de que $\mathrm{H}$ es verdadera. ${ }^{592}$ (Erwin, 2015: 49).
\end{abstract}

Erwin considera que los "filósofos y psicoanalistas de mentalidad hermenéutica" ${ }^{593}$ defienden lo que él denomina teoría del indicador, pues sin negar completamente que las hipótesis psicoanalíticas sean a menudo causales, estos autores sostienen que "las conexiones de sentido, a veces llamadas 'afinidad temática', usualmente son indicadores de conexiones causales y así proporcionan pruebas de hipótesis causales" ${ }^{594}$ (ibíd.). Esto es

\footnotetext{
592 "The upshot of all of this is that if "explains" is taken literally, then IBE is of no use. We would need evidence that $\mathrm{H}$ is true before we apply the rule; and if "explains" is interpreted to mean "would explain if only it were true", then the fact that $H$ "explains $E$ " in this potential sense better than its known competitors is never evidence that $\mathrm{H}$ is true."

593 “...hermeneutically minded philosophers and psychoanalysts..."

594 "...meaning connections, sometimes called "thematic affinities", are often indicators of causal connections and so provide evidence for causal hypotheses."
} 
algo injustificado según Erwin, ya que la IME nunca brinda "evidencia per se". El razonamiento de Erwin es una derivación de la opinión de Grünbaum sobre la que ya me expedí; por lo que no tengo más para agregar que lo ya estipulado antes. Sin embargo, lo que Erwin objeta respecto de IME nos permite trazar un contrapunto respecto de la abducción peirceana (que él no considera) y, como intentaré mostrar, respecto del modo freudiano de evaluación de hipótesis clínicas relativas a un caso. Voy a defender, por lo tanto, la idea de que el proceder clínico del analista debería seguir el modelo abductivo antes que el modelo IME.

Difícilmente podría haber predicciones significativas sobre un caso clínico, tal y como Freud lo asevera. Sin embargo, también hemos planteado que, para Peirce, la evaluación inductiva de hipótesis supone la predesignación de caracteres, es decir el establecimiento de consecuencias observacionales independientes de las que dieron originalmente apoyo al surgimiento de la hipótesis. Esta predesignación es, por lo tanto, una predicción necesaria para la puesta a prueba. ¿Debemos renunciar a este requisito en psicoanálisis y conformarnos con alguna variante de IME? A nuestro modo de ver, en la labor clínica responsable este requisito resulta incluido en la lógica práctica del analista. Antes de ver cómo, es necesaria una pequeña digresión. Veamos cómo compara Feyerabend el proceder del científico con el proceder del filósofo:

Un científico opera a partir de un conjunto de materiales compuesto por diversos y conflictivos ingredientes. Las teorias formuladas con el más alto grado de rigor coexisten lado a lado con aproximaciones infundadas y groseras, hay ciertos hechos 'sólidos', leyes locales basadas en dichos hechos, hay principios heurísticos, formulaciones tentativas de nuevos puntos de vista que en parte coinciden y en parte desentonan con los hechos aceptados, hay vagas ideas filosóficas, estándares de racionalidad y de procedimiento en conflicto con ellas. Al ser imposible que tal material se acomode a ideas simples de orden y consistencia, el científico generalmente desarrolla una lógica práctica que le permite obtener resultados en medio del caos y la incoherencia. La mayoría de las reglas y estándares se conciben ad hoc; sirven para resolver una dificultad particular y no es posible convertirlas en un órganon de la investigación [...] El camino del filósofo es muy diferente; no podría haber un mayor contraste. Hay algunas ideas generales y estándares articulados en detalle, y están los principios 
de la lógica elegida. No hay casi ninguna otra $\operatorname{cosa}^{595}$. (Feyerabend, 1981b: 8384).

Como podemos notar, el método de un científico se define por una lógica práctica que debe ser diferenciada de las reconstrucciones racionales a las que apunta el filósofo. Volviendo a nuestro asunto, diré que la lógica práctica del analista en su labor también debe ser diferenciada respecto de la labor epistemológica de reconstrucción de su proceder; o, mejor aún, que una reconstrucción racional debería dejar cierto margen para que esa lógica práctica se vea representada. Entonces, en lo que a la evaluación de sus conjeturas conlleva, el analista necesariamente opera en un complejo y heterogéneo campo de variables y factores; lo cual no necesariamente entorpece la permanente corrección de sus conjeturas y representaciones sobre la realidad psíquica del analizado, pero sí constituye un obstáculo para su aprehensión y reconstrucción racional cuando se pretende algo más que conceptualizar parámetros generales de su accionar. Freud considera que el trabajo de colegir indicios y arribar a una interpretación no puede "encuadrarse en reglas rigurosas" y que deja "un amplio campo al tacto y a la destreza del médico" (Freud, 1923a/2004: 235). Pues bien, la puesta a prueba clínica de las conjeturas abducidas tampoco puede considerarse un procedimiento rígido ni supeditado a reglas rigurosas, sino que debemos entenderlo como un proceso natural de corrección y refinamiento progresivo de las hipótesis del analista. Así y todo, esa lógica práctica contempla los requisitos antes mencionados. Nos queda remitirnos a ejemplos concretos para ilustrarlo.

Un ejemplo clínico de lo que queremos mostrar puede ser extraído de Fragmento de análisis de un caso de histeria:

Cierto día [Dora] se quejó de un supuesto nuevo síntoma, unos lacerantes dolores de estómago, y yo di en lo justo preguntándole: «¿A quién copia usted en eso?».

\footnotetext{
595 "A scientist starts with a bulk of material consisting of diverse and conflicting ingredients. There are theories formulated in accordance with the highest standards of rigour and precision side by side with unfounded and sloppy approximations, there arc 'solid' facts, local laws based on some of these facts, there arc heuristic principles, tentative formulations of new points of view which partly agree, partly conflict with the accepted facts, there are vague philosophical ideas, standards of rationality and procedures that conflict with these. [...] The way of the philosopher is very different; there could not be a greater contrast. There are some general ideas and standards which are spelled out in detail and there are the principles of the logic chosen. There is hardly anything else."
} 
El día anterior había visitado a sus primas, las hijas de la tía fallecida. La más joven había formalizado noviazgo, y con esa ocasión la mayor contrajo unos dolores de estómago y debió ser llevada a Semmering. Dora creía que en la mayor no era sino envidia, pues siempre enfermaba cuando quería obtener algo y, justamente, lo que ahora quería era alejarse de la casa para no asistir a la dicha de su hermana. Pero sus propios dolores de estómago decían que ella se identificaba con su prima, así declarada simuladora, ya fuera porque también le envidiaba a la más dichosa su amor, o porque veía representado su propio destino en el de la hermana mayor, que poco antes había tenido una relación amorosa de final desdichado. (Freud, 1905b/2004: 35; cursivas añadidas).

La secuencia investigativa de este pequeño fragmento de la historia de Dora podría ser descripta en una serie de pasos: a) abducción, b) retrodicción, c) contrastación, d) corroboración.

a) Desde su conocimiento de la paciente y ante el hecho sorprendente (la queja ante la aparición de un nuevo malestar), Freud elabora una hipótesis: ese dolor de estómago podría tener, entre sus factores causales, una identificación.

b) Esa hipótesis refiere a un hecho (identificación) que potencialmente ha acontecido o que aún persiste, pero cuyo inicio habría sucedido en un tiempo anterior. Por lo tanto, parece sensato derivar una consecuencia que refiera al pasado; Freud hace, entonces, una retrodicción: si (a) Dora se hubiera identificado con alguien, entonces (b) debería tener alguna representación mnémica referida a otra persona con una dolencia similar.

c) La interpretación, bajo el modo interrogativo, parece signada por el sello de la convicción que le habría aportado su plausible abducción: no interviene preguntando ¿sería acaso posible que usted quizás haya copiado en algún momento a alguien...? No. La formulación interrogativa es sólo retórica, pues el mensaje es asertivo: usted ha copiado a alguien en esto. Ésta es la hipótesis que busca su contraste con el material y según los criterios del procedimiento:

...en la técnica del psicoanálisis vale como regla que una conexión interna, pero todavía oculta, se da a conocer por la contigüidad, por la vecindad temporal de las ocurrencias, exactamente como en la escritura una a y una b puestas una al lado de la otra significan que ha querido formarse con ellas la sílaba ab. (Ibíd.).

Podemos notar, debido a la intervención misma, la búsqueda de caracteres designados previamente que no han sido incluidos como evidencia para la 
génesis de la hipótesis. Por un lado tenemos el malestar que relata Dora como algo encontrado (no buscado) y que ha funcionado como detonador abductivo para la génesis de una hipótesis plausible (Dora se ha identificado con alguien), pero no podría contar como evidencia para la evaluación de esa misma hipótesis; tal como señala Erwin. Por otro lado, entonces, la intervención de Freud es correlativa de una búsqueda (que trasciende la pasividad del encuentro) de evidencia independiente de la que ya dispone; es decir una búsqueda basada en los caracteres designados con anterioridad a su hallazgo, que podrían formularse así: si la conjetura es acertada, Dora probablemente asocie algún recuerdo sobre dolencias similares vistas en otra persona. Este enunciado constituye una consecuencia observacional desconocida, bajo la forma de una retrodicción, que permite cumplimentar el requisito del momento inductivo de Peirce o el de la testabilidad independiente de Popper.

d) Mal que le pese a Grünbaum (y a Erwin), Freud apoya la evaluación de su conjetura sobre las ocurrencias próximas a su intervención: Dora relata la visita del día anterior a la casa de sus primas y el dolor de estómago, junto con la envidia, de la mayor. Aunque puede notárselo, explicitemos el valor de la abducción en esa conjetura de Freud: "pensemos en los trillones de trillones de hipótesis que pueden hacerse" respecto de ese dolor de estómago y en las posibilidades de adivinar, por azar, una situación como la de la prima mayor, vivenciada el día anterior por parte de Dora. Si se lo analiza en términos de probabilidad relativa y de azar, esa conjetura no podría haber dado en el clavo "ni en todo el tiempo transcurrido desde que la tierra se solidificó" (Peirce, 1903/1988: 134). El valor del recuerdo asociativo es el de una corroboración y el procedimiento analítico continúa su rumbo habiendo fijado la creencia de esa identificación.

Algunas páginas más adelante Freud explicita claramente lo que aquí he reconstruido como el momento de la contrastación, exponiéndonos formidablemente su particular manera de introducir los caracteres predesignados que Peirce solicitaba buscar en el momento de la evaluación inductiva:

Estoy habituado a ver en tales ocurrencias \{Einfall\}, que presentan algo acorde con el contenido de lo que yo he aseverado \{al paciente\}, una confirmación que 
viene del inconciente. Ninguna otra clase de «sí» se escucha desde el inconciente; un «no» inconciente no existe en absoluto. (ibíd. p. 51).

Ahora bien, ese algo acorde que Freud decididamente espera encontrar es lo suficientemente inespecífico como para no caer bajo la sospecha de la sugestión y, a la vez, constituir un elemento de corroboración. En virtud de sus características, nos parece que su valor es inestimable: no sólo se trata de la predesignación de algunos caracteres que van a ser buscados (aquí, por ejemplo, la representación de un síntoma similar en otra persona con la cual Dora se habría identificado) sino de que las asociaciones, cuando son corroborativas, traen también algo sorpresivo: un material que no sólo es acorde sino que también es ampliativo. A ello me referí antes como hallazgos clínicos sorprendentes (cf. tercera parte, capítulo 7, punto c). En el ejemplo que estamos viendo, el proceder de Freud le permite efectuar no sólo una corroboración sino el hallazgo sorprendente de la envidia de la situación amorosa y todo lo que comienza a abrirse desde allí. Es decir, la fuerza que este modo de evaluar conjeturas tiene, no sólo radica en la posible corroboración sino en su potencial heurístico para relanzar el proceso clínico a partir de hallar algo inespecífico y añadido que no se estaba buscando. La dinámica del hallazgo sorpresivo y la búsqueda deliberada parecen inmiscuirse en la lógica práctica del analista de un modo mucho más complejo de lo que cualquier reconstrucción podría permitirnos representar.

\section{d) Alfredo Reik: ¿es una intervención necesariamente una formulación de la conjetura del analista?}

\footnotetext{
Es probable que la verdadera diferencia entre las abducciones de hechos a leyes y las abducciones de hechos a hechos resida en la flexibilidad meta-abductiva, es decir, en la osadía de desafiar $\sin$ verificaciones ulteriores el falibilismo fundamental que rige el conocimiento humano. Por esa razón, en la vida «real» los detectives cometen errores más frecuentes (o más frecuentemente visibles) que los científicos. La sociedad recompensa a los detectives por el descaro con que apuestan por sus meta-abducciones, mientras que a los científicos se les recompensa socialmente por la paciencia con que verifican sus abducciones. (Eco, 1989: 293).
} 
Es necesario diferenciar las conjeturas que el analista se forma de los recursos enunciativos que utiliza para intervenir. Respecto de las primeras, si asumimos que su origen es abductivo, podemos suponer que caen como un rayo en la mente del analista y que no siempre alcanzan una formulación consciente acabada. Se trataría de tentativas fragmentarias que orientan al analista en su labor, que va modificando a medida que las contrasta con el nuevo material, fundamentalmente con los efectos de sus intervenciones. Tales intervenciones no necesariamente constituyen una formulación proposicional de su conjetura, pese a lo cual ella puede ser puesta a prueba. Un ejemplo clínico de Freud, aunque no de los más típicamente referenciados, nos permitirá mostrar inmejorablemente esta idea ${ }^{596}$.

En el capítulo sexto de su libro Confesiones de un psicoanalista, Theodor Reik relata una anécdota de su análisis con Freud. Agobiado por una serie de dolencias y después de realizar algunas consultas médicas sin éxito ${ }^{597}$, Reik mantiene una esporádica conversación con Freud en la que se convence de que su padecimiento no es de índole orgánica. Reik cuenta cómo al verano siguiente, "siendo ya un analista con muchos años de experiencia", se reencontró con el diván analítico como paciente de Freud:

De pronto caí enfermo. Tenía accesos de mareos, vómitos y diarrea. El comienzo de esos ataques era inesperado. Recuerdo que la primera sensación de este tipo me sorprendió cierto día al abandonar el sanatorio, después de visitar a mi esposa [...] Durante las semanas y meses que siguieron esos ataques se repitieron, empeoraron, o cuando asistía a una representación teatral, en el club de bridge o en mi casa, mientras analizaba a un paciente [...] Su comienzo estaba acompañado por una abrumadora sensación de que el fin se aproximaba, por la

\footnotetext{
${ }^{596}$ Entre los aspectos destacables que este ejemplo presenta quisiera subrayar el hecho de que, a partir del relato del paciente, podemos trascender la dimensión sintáctico-semántica de la interpretación y adentrarnos en su funcionalidad pragmático-comunicativa; lo cual hace de éste, en virtud de los aspectos de la lógica práctica que venimos considerando, un ejemplo significativo.

597 "Al principio, los médicos pensaron en una afección cardíaca, luego en una intoxicación por nicotina. Dejé de fumar, seguí las instrucciones de los médicos, pero mi salud no mejoró. Entonces, algunos especialistas pensaron que los ataques, acompañados de una súbita pérdida del equilibrio y violentos mareos y vómitos, indicaban la enfermedad del oído conocida como enfermedad de Meniére. Me examinaron varias veces y me trataron de distintas maneras, pero los ataques persistieron y su carácter tormentoso aumentó en lugar de disminuir. Me di inyecciones de calcio, pero tampoco sirvieron para nada." (Reik, 1949/1965: 213).
} 
ansiedad de que la aniquilación estaba cercana, como en los espasmos de la angina de pecho [...] Había experimentado el temor a la muerte con bastante frecuencia bajo el fuego de artillería, durante la primera guerra mundial, pero nunca había sentido nada similar al abrumador terror que me sobrecogía durante esos ataques [...] Esta dolencia se había prolongado durante unos cuantos meses antes de que la mencionara casualmente a Freud. Me dijo que no creía que mis malestares tuvieran que ver con una angina de pecho porque era demasiado joven para padecer esa enfermedad. Solicité su ayuda. (Reik, 1949/1965: 207).

Lo que Reik describe pareciera corresponder a lo que Freud había descripto hacia 1895 como neurosis de angustia, y que hoy ha sido reabsorbido por el DSM-V como ataque de pánico. Así relata Reik la transcurrencia de esas seis sesiones:

...acostado en el diván, dejé que mis asociaciones surgieran libremente y en ellas, desde luego, la enfermedad, de mi mujer y mi relación con ella desempeñaban un papel importante. Le hablé a Freud sobre mis temores con respecto a los peligros de la relación sexual con Ella, sobre la tremenda impresión producida por sus dificultades respiratorias durante el acto sexual — todo eso había ocurrido algunos años antes- y le describí el conflicto en que me había encontrado más adelante. Había conocido a una muchacha que, muchos años menor que yo, me atraía de múltiples maneras, no sólo sexualmente. Le confesé que a veces se me había ocurrido la idea de divorciarme de mi esposa y casarme con esa joven, pero agregué que sabía, desde luego, que ello era imposible: uno no puede divorciarse de una mujer que está seriamente enferma. Además, sabía también que seguía queriendo a mi mujer y sintiéndome cerca de ella, aunque experimentaba la creciente atracción de esa muchacha joven a quien yo parecía importarle [...] Hablé de éstas y otras cosas, pero cada tanto volvía a describir aquellos ataques de mareos acompañados por el pánico a la muerte que habían obstaculizado mi trabajo (ibíd. p. 215).

Reik destaca dos aspectos de la posición de Freud en esas sesiones: su escucha silenciosa y una única interpretación que lo sorprende completamente, justo en la última sesión y antes de su retorno a Berlín:

...Freud no había dicho casi nada durante esa sesión. Había escuchado en silencio las descripciones de mis malestares, mis dudas, acusaciones y remordimientos, la mezcla confusa de mis emociones y el choque de pensamientos que reflejaban las múltiples contradicciones existentes en mí. Casi al final de esa última sesión, escuché por primera vez su voz baja pero firme. Dijo 
sólo unas pocas palabras. Se trataba de una sencilla pregunta, pero su eco resonó en mí durante mucho tiempo. La pregunta llegó después de mi repetida descripción de esos ataques de mareo y constituyó una sorpresa completa. Cuando la hizo no pude comprender qué relación tenía su contenido con mi comunicación o la cadena de mis asociaciones. No logré captar su conexión con lo que había dicho durante esa hora. Aguardé como si esperara una explicación, pero no hubo ninguna. Sólo silencio. (Reik, 1949/1965: 211).

La sorprendente pregunta de Freud fue: "¿recuerda usted la novela El asesino de Schnitzler?". Luego de experimentar un súbito y leve mareo, Reik asevera que se oyó a sí mismo decir: "ah, ¿es eso?" (ibíd.). La pregunta, como señala el propio destinatario, no estaba hecha para ser respondida, porque la respuesta era obvia: Reik había escrito algunos años antes un libro titulado Arthur Schnitzler como psicólogo, en donde analizaba psicoanalíticamente las obras de ese escritor vienés; dedicándole además el libro a Freud. Notamos, entonces, que algo del orden de la ironía aparece contenido en esa pregunta $^{598}$.

No podemos saber cómo habría de formularse, en caso de que ello efectivamente se pudiese, la conjetura que Freud manejaba en el momento en que efectuó la intervención a Reik. Pero podemos advertir, por el saber que éste último elabora a partir de ella y por el efecto mismo que tuvo, la marca de una inferencia abductiva del vienés. Para notarlo, detengámonos brevemente en el argumento de la novela de Schnitzler: Alfredo, el protagonista, cuya mujer está gravemente enferma, conoce y se enamora de la joven Adela. La escena que aquí parece ser medular es aquella en la cual Alfredo decide matar a su mujer, Elisa, luego de reponerse de una sensación de mareo: la envenena para poder consumar su encuentro amoroso con Adela. Conociendo bien esta trama y en base a la sagaz interpretación de Freud, Reik pudo atisbar a dónde apuntaba ese decir:

\footnotetext{
598 Lacan hizo hincapié varias veces sobre esa dimensión chistosa de la interpretación: "es sin embargo en la medida en que una interpretación justa extingue un síntoma que la verdad se especifica por ser poética. No es del lado de la lógica articulada, aunque en este caso me deslizo en ella, no es del lado de la lógica articulada que hay que sentir el alcance de nuestro decir [...] la primera cosa sería extinguir la noción de lo bello. No tenemos nada bello que decir. Es de otra resonancia que se trata de fundar sobre el chiste. Un chiste no es bello, no se sostiene sino de un equívoco o como dice Freud de una economía" (Lacan, 1977/2008: 16970). En términos lacanianos, esa interpretación de Freud parece ajustarse bien a ese entre la cita y el enigma (Lacan, 1969/2008), dejando a Reik en la necesidad de descifrar por sí mismo el inquietante mensaje que contraría la univocidad aparente de esa formulación interrogativa.
} 
Los motivos inconscientes del protagonista de esa novela y los míos eran de carácter similar. La única diferencia radicaba en que Alfredo cometió el crimen y yo sólo había pensado en él. Asimismo, la reacción emocional de Alfredo y la mía propia frente al pensamiento cuando éste surgió por primera vez de lo reprimido sólo diferían en cuanto a su intensidad. Mientras que él se vio abrumado por mareos y sentimientos de ansiedad durante sólo unos pocos segundos, mis ataques duraban a menudo varias horas. (ibíd. p. 224, cursivas añadidas).

En base a ello, podemos suponer que Freud apeló a la analogía para cernir algo del orden de la conflictiva inconsciente que atravesaba a Reik en ese momento. Se trata de una abducción que debemos ubicar en el trayecto de lo hipocodificado hacia lo creativo: el vienés seleccionó una lectura posible para el material, transportando una regla que proviene de una situación que presenta un drama análogo. Sin embargo, no hay razones para suponer que Freud se haya representado coherentemente gran parte de la conflictiva de Reik en ese momento, sino que nos basta con suponer que, mínimamente, captó cierta lógica mediante esa analogía. Es decir que quizás haya tenido una intuición que supo hacer madurar: pudo afinarla, desechando o confirmando sus rasgos específicos a medida que las asociaciones de Reik lo posibilitaban, sesión tras sesión. El propio Reik sostiene esta idea: "éste [Freud] debe haber sabido desde mucho tiempo antes de la última sesión cuál era el significado inconsciente de mis ataques. Yo le proporcioné sin duda suficiente material inconsciente como para llegar a una conclusión psicológica que estaba tan alejada de mí mismo" 599 (ibíd. p. 223). Es decir que el vienés ya había podido atreverse a colegir y, cuando resultó oportuno, comunicárselo. Ahora bien, si la intervención estuviera motivada por una abducción hipocodificada, deberíamos pensar que Freud se podría haber representado conscientemente su conjetura así: él quiere y no quiere que su esposa enferma muera para poder casarse

\footnotetext{
${ }^{599}$ Reik se pregunta por qué razón, entonces, Freud no le proporcionó antes esa interpretación, a lo que se responde: "sólo el psicoanalista inexperto, el novato en nuestro arte, cederá a la tentación de informar al paciente inmediatamente sobre lo que él, el analista, ha adivinado y entendido acerca de los motivos inconscientes y los orígenes de su neurosis. La experiencia analítica recomienda más bien esperar hasta que el paciente esté psicológicamente preparado para la interpretación que el analista debe hacerle. En la mayoría de los casos, significa aguardar hasta que el paciente parece necesitar sólo unos pocos pasos para llegar por su propia cuenta a la explicación. Resulta difícil definir cuándo llega ese momento. Ciertos signos inconscientes, percibidos por el analista, indican que el paciente está psicológicamente preparado o dispuesto a recibir y absorber la explicación" (ibíd. 223). Esta es una idea que el propio Reik había desarrollado en su libro Listening With the Third Ear (Reik, 1948).
} 
con esa otra joven ${ }^{600}$. Evidentemente, aunque podemos suponer la preexistencia lógica de una conjetura como ésta, también debemos reconocer que ella sería acertada sólo en términos generales, mientras que los específicos rasgos sintomáticos (enigmáticos) del caso Reik, no se explican bajo esa sola regla importada. Por empezar, Reik solo parece haber fantaseado eso que Alfredo sí había consumado. De manera tal que esa primera abducción sólo permite la apertura de un proceso que, indudablemente, conduce a la creación abductiva de una legalidad inherente e intransferible, en la que aparecen involucrados procesos y entidades no analogables. Algo de este saber singular, imposible de extraer de Schnitzler, es elaborado más tarde por el propio Reik:

Yo negaría enfáticamente que él haya elegido esa forma conscientemente, que la haya elaborado, determinado mediante el razonamiento consciente. Creo que fue su respuesta inconsciente a mi relato. Mientras me escuchaba con el "tercer oído", sus pensamientos, estimulados por la similitud emocional de las situaciones, deben haberlo llevado a la comparación con la novela de Schnitzler. [...] El lector que comprende la forma en que trabaja el psicoanálisis apreciará que la técnica de Freud en este caso fue un toque genial. Resulta aún más notable si se considera que Freud no trató el problema en forma mecánica, prescripta por una conducta técnica rígida, sino como un soberano que sigue su intuición [...] no me dio una explicación analítica directa e inmediata, sino que hizo que yo la encontrara solo. No me acompañó todo el camino hasta la meta, sino que me llevó hasta cierto punto, a partir del cual yo podía seguir por mi propia cuenta. (ibíd. p. 224-225).

Luego de la última sesión, los ataques de angustia cesaron y "nunca se repitieron" (ibíd. p. 225). Ese toque genial que refiere Reik, nacido con una intuición (abductiva), evidencia que la conjetura de Freud estaba bien encaminada. De haber sido una conjetura equivocada, la intervención de Freud habría dejado al paciente como no tocado (Freud, 1937/2004: 263). Me pregunto: ¿qué tipo de ad-hocidad tendría que invocar Grünbaum para incorporar esta inmejorable exposición clínica, a modo de contraevidencia, a

\footnotetext{
${ }^{600}$ El aparato conceptual freudiano está montado sobre la necesidad de resolver este tipo de aporías. Mucho antes de postular que en lo inconsciente no existe la contradicción, tuvo que acuñar un neologismo para poder hablar de estos aparentes absurdos: contravoluntad «Gegenwillen» (Freud, 1892b/2004). Para Octave Mannoni este término supone, aunque luego fuera reemplazado por el de conflicto psíquico e integrado en la metapsicología, el verdadero bautismo conceptual del psicoanálisis (Mannoni, 1986/1987: 157).
} 
eso que él ha conceptuado (y rechazado) como argumento de la coincidencia? ¿Podría acaso objetarse semejante grado de coincidencia azarosa entre lo colegido por Freud y lo representado por Reik?, ¿dónde quedaría el argumento de la inevitable sugestionabilidad en un ejemplo como este, en el cual el contenido de la interpretación se reduce apenas a una perspicaz insinuación retórica, seguida de una remisión casi espontánea del síntoma? 


\section{CONCLUSIONES}

"La naturaleza misma de la deliberación y de la argumentación se opone a la necesidad y a la evidencia, pues uno no delibera allí donde la solución es necesaria, ni argumenta contra la evidencia" (Chaim Perelman \& Lucie Olbrechts-Tyteca, Tratado de la argumentación, p. 30).

\section{Retrospectiva general}

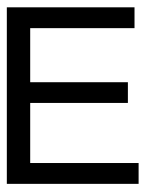

$\mathrm{n}$ virtud de la estructura convergente que presentan los desarrollos argumentativos de esta tesis, quisiera exponer las conclusiones de manera paulatina y esquemática, recogiendo lo central de cada capítulo. Luego de ello, quisiera finalizar con unos pocos comentarios generales sobre la utilidad esperada de esta tesis y sobre algunos potenciales decursos de investigación que se podrían transitar.

La PRIMERA PARTE de la tesis está destinada a mostrar un estado de la cuestión del contexto y de la interrelación de los problemas que nos hemos propuesto indagar. El proceso de cartografiado que allí hemos desplegado no ha pretendido ser, como adelantamos en la presentación, exhaustivo sino operativo. Por eso, apoyándome en el ordenamiento que algunos historiadores han efectuado del campo, intenté trazar allí los principales contornos del territorio sobre el que pudimos luego aventurarnos. Bajo el supuesto de que los debates epistemológicos sobre el psicoanálisis se presentan profundamente vinculados con el desarrollo histórico de sus principales tradiciones de investigación, el primer capítulo inaugura la tesis reseñando las principales objeciones del positivismo lógico, del racionalismo crítico y del inductivismo eliminativo, a la vez que caracterizando dos grandes posicionamientos contestatarios, que hemos nominado retirada hermenéutica y concesión naturalista. De esa presentación se desprenden tres aspectos significativos: 1) en primer lugar, que las discusiones sobre la identidad epistémica del psicoanálisis no pueden separarse de los debates filosóficos que históricamente se han venido efectuando sobre su legitimidad; 2) por otro lado, 
que no hay consenso respecto de la pertinencia de las principales críticas epistemológicas recibidas, lo cual en cierto modo justifica (o al menos habilita) una revisión pormenorizada de las mismas; y 3) finalmente, que la manera de recepcionar tales críticas epistemológicas se vincula no sólo con el modo de concebir la identidad epistémica de la disciplina sino también con el modo de entender la naturaleza de su metodología de investigación.

En el segundo capítulo se expusieron algunas controversias inherentes a la investigación en psicoanálisis: se presentaron las principales maneras de tipificar el campo de la investigación, destacando las principales razones que han llevado a un sector de la comunidad psicoanalítica a propender al desarrollo de investigaciones extra-clínicas (empírico sistemáticas, experimentales, interdisciplinarias, etc.), así como los argumentos centrales que esboza otra parte de nuestra comunidad que pretende privilegiar la investigación clínica basada en el método tradicional de estudio de casos. Seguido de ello, se expusieron las posturas a favor y en contra de estas tendencias, apelando a la encarnadura que ellas encuentran, en los últimos años, en determinados actores reconocidos. Se concluye subrayando un rasgo interesante de este paisaje histórico: mientras que inicialmente las controversias epistemológicas y metodológicas aparecen protagonizadas por actores y argumentos foráneos, en las últimas décadas este tipo de debates es sostenido y promovido sistemáticamente por los propios analistas al interior de sus comunidades psicoanalíticas de referencia. Así, quienes asumen que el psicoanálisis no es una ciencia o le confieren una identidad hermenéutica, han resistido la intromisión de otras metodologías y el desarrollo naturalista de técnicas y procesos de indagación que vayan más allá de lo que el método clínico permite; mientras que aquellos que asumen una identidad científica en el psicoanálisis o rechazan su redefinición hermenéutica, han patrocinado tanto la testabilidad extra-clínica en búsqueda de evidencias empíricas aprovechables, como el desarrollo de nuevas metodologías de investigación para continuar ampliando el campo de nuestro saber en estrecha relación con otros dominios cognitivos pretendidamente ineludibles. En este escenario, mientras que la crítica temprana de Popper ha funcionado como una estigmatización originaria para el estatuto identitario de la disciplina, las 
objeciones de Grünbaum han contribuido a justificar la necesidad de llevar la investigación psicoanalítica más allá de lo que Freud hubiera imaginado.

La SEGUNDA PARTE de la tesis estuvo dedicada a evaluar cuidadosamente la postura del fundador del racionalismo crítico sobre el psicoanálisis. En el tercer capítulo se sistematizaron los aspectos centrales de la epistemología de Popper, destacando el contexto filosófico de su surgimiento y sus propuestas principales. Allí también se expuso la caracterización que nuestro autor hizo del psicoanálisis freudiano como una pseudociencia, cuyas inconsistencias se advierten ya desde su planteamiento inicial.

Luego nos dedicamos a exponer una serie de dificultades que el racionalismo crítico ha presentado con el correr del siglo $\mathrm{xx}$, tales como el problema de la carga teórica de la observación, del comportamiento efectivo de los científicos, del papel de las hipótesis auxiliares en la contrastación, la consecuencias de la fallida teoría de la verosimilitud y el irresoluble problema de la inducción. En base a estas limitaciones intentamos comprender la figura de Popper a partir de su carácter transitivo en la historia de la filosofía contemporánea de la ciencia. Hemos podido mostrar por qué Popper fracasó en el hallazgo de un método mecánico de elección de teorías, basado en una supuesta racionalidad algorítmica: contrariamente a lo que él creyó, la imposibilidad lógica de verificar un enunciado teórico y la imposibilidad lógica de refutarlo, constituyen un binomio proporcionado; lo cual reintroduce la inexorable centralidad de nuestras decisiones en la justificación racional. Todo esto constituye de por sí, un serio problema para la filosofía de Popper y sus pretensiones ecuménicas.

En el cuarto capítulo intentamos mostrar que Freud perteneció a una tradición crítica y falibilista. Defendimos la posibilidad de elucidar el surgimiento y evolución de sus ideas psicoanalíticas como un programa de investigación lakatosiano y, a partir de esto, propusimos una reconstrucción de dos episodios de cambio teórico. Esta reconstrucción nos permitió mostrar, ya en el quinto capítulo, que la sentencia de pseudociencia dictada por Popper al psicoanálisis es inviable y que sólo puede basarse en una omisión deliberada de la metodología efectivamente utilizada por su creador. Además, a partir de tales reconstrucciones, hemos podido caracterizar el falsacionismo freudiano como sofisticado, por estar en sintonía con la propuesta de Lakatos. Eso nos 
llevó a mostrar que la refutabilidad empírica ocupa, al igual que en cualquier otro PIC, un lugar mucho menos preponderante que el supuesto por la filosofía de Popper. Finalmente, nuestro exhaustivo análisis del segundo episodio de cambio intra-teórico nos permitió mostrar que, además de los factores epistémicos en la investigación clínica, la reconstrucción racional de este tipo de modificaciones debe tener en cuenta factores no epistémicos (en contra de lo que el canon popperiano prescribe).

En síntesis, a partir del itinerario efectuado en esta segunda parte esperamos haber dado suficientes razones para sostener las siguientes conjeturas:

a) La epistemología de Popper no está exenta de dificultades que vuelven problemática su aplicación directa en todo campo de saber.

b) El rótulo de pseudociencia dado por Popper al psicoanálisis no se apoya en datos fehacientes ni se acerca al proceder efectivo de Freud.

c) La omisión popperiana parece más una maniobra ad-hoc para proteger su criterio de demarcación, que una crítica reflexiva y justificada.

d) Entre los factores que incidieron en las modificaciones de la teoría por parte de Freud, las contra-evidencias empíricas tienen un papel importante. Ello no nos autoriza a desdeñar otros factores no epistémicos en la determinación de los cambios intra-teóricos, así como tampoco nos permite erguirlos como único blasón explicativo.

e) La crítica de Popper pareciera haber constituido un antecedente inevitable para todas las posteriores; al punto que siempre aparece citada, ya sea para acordar con ella, para moderarla o para rechazarla.

La idea de que la teoría freudiana es pseudocientífica es un mito deslegitimador que Popper inventó y contribuyó a desarrollar sobre la base de esa omisión. Su negligente maniobra ha funcionado, por diversas razones históricas, como una especie de estigmatización originaria, retomada en grado variable por diversas voces, cuyos ecos resuenan en la actualidad.

En la TERCERA PARTE se han analizado críticamente los complejos argumentos que Grünbaum esgrime para considerar que los fundamentos del psicoanálisis son epistemológicamente defectuosos, lo cual impediría establecer su legitimidad como ciencia empírica. El sexto capítulo presentó las principales características de la propuesta de este filósofo germano-americano. 
Primero pudimos exponer y revisar la caracterización de "exégesis mítica" que Grünbaum efectuó respecto de los promotores de la redefinición de las bases epistemológicas y metodológicas del psicoanálisis a partir de la tradición hermenéutica. En virtud de que este abordaje, a pesar de ser sumamente complejo, no parece más que una argumentación "satelital" respecto de sus objeciones centrales, decidimos presentarlo y reservar un abordaje pormenorizado para al anteúltimo capítulo de la tesis. En el sexto capítulo, además de indagar las razones por las que este filósofo rechaza el falsacionismo popperiano como criterio de demarcación, también pudimos desglosar los rasgos centrales del inductivismo eliminativo proveniente de la tradición metodológica de Francis Bacon y John Stuart Mill, propuesto por Grünbaum como criterio de demarcación y como parámetro para desestimar las inferencias causales que brindan evidencia probatoria al psicoanálisis. Vimos que, para Grünbaum, Freud intentó establecer inferencias causales sobre una base exclusiva de datos clínicos; lo cual dejaría a la teoría psicoanalítica a merced de tres objeciones principales que conducen a nuestro filósofo a la conclusión de que su metodología sería inviable: a) el malogrado argumento de la coincidencia habría dejado sin justificación epistemológica a la metodología de Freud; b) fracaso que haría retornar la vieja sospecha de contaminación sugestiva de los datos clínicos validatorios; y c) además, el modo inferencial que subyace a la construcción teórica de Freud constituiría una extrapolación indebida de la argumentación general de la neurosis, por carecer del equivalente corroborativo del éxito terapéutico y por incurrir en falacias causales argumentativas en la explicación con casos clínicos (como post hoc ergo propter hoc), todo ello en desmedro de los resguardos de la tradición inductivista para prestar apoyo y credibilidad a este tipo de inferencias. Lo cual le ha hecho concluir a Grünbaum que la situación analítica no puede arrojar datos que acrediten las principales hipótesis psicoanalíticas y que la única posibilidad de lograr reunir evidencia probatoria deberá provenir de investigaciones extraclínicas que asuman los cánones del inductivismo eliminativo.

Contrariando algunas tendencias frecuentes (como la recepción acrítica y la desestimación irreflexiva), en el séptimo capítulo se elucidan uno por uno los principales argumentos de Grünbaum, arribando a una serie de conclusiones 
que resumí en el apartado final de la tercera parte de la tesis, y que aquí recupero de manera sucinta: a) el denominado argumento de la coincidencia no tiene en psicoanálisis el valor central que nuestro filósofo crítico pretende y sólo puede sostenérselo omitiendo considerar buena parte de los aportes freudianos sobre la fundamentación del conocimiento; b) la desestimación del procedimiento de la asociación libre es efecto de una preconcepción filosófica de la causalidad típicamentemente experimentalista, en la que se omiten las particularidades ontológicas y epistémicas del dominio cognitivo al que la estructura argumental freudiana refiere; c) el supuesto carácter parasitario que Grünbaum adjudica a lapsus y sueños en la expansión del modelo causal freudiano, encuentra su racionalidad en la progresividad del propio programa y cuya heurística puede elucidarse en base a una lógica abductiva de integración fecunda de datos provenientes de diversas fuentes. Esto último vuelve inviables dos asunciones de Grünbaum: la pretendida subordinación de la validación general del corpus psicoanalítico al contexto específico de sus fundamentos clínicos $y$, fundamentalmente, el pretendido vínculo entre validación empírica y éxito terapéutico. Además, d) el inductivismo eliminativo no constituye una metodología universalmente válida para evaluar la credibilidad del conocimiento causal en las ciencias empíricas en general ni en el ámbito psicoanalítico en particular, en virtud de la discrepancia de supuestos ontológicos, epistemológicos y axiológicos que mantienen los dominios cognitivos de la física experimental y de los fenómenos mentales. El octavo capítulo finaliza nuestro análisis crítico sosteniendo que el problema de la contaminación epistémica vía sugestión no constituye un obstáculo mayor en el camino de validación psicoanalítica a partir de los datos obtenidos clínicamente: hemos mostrado que las críticas de circularidad y de petitio principii que Grünbaum imputa al razonamiento freudiano, o bien son equivocadas o bien se sostienen a condición de mantener un escepticismo gnoseológico paralizante; y, además, que es posible redefinir el fenómeno de la sugestión en la situación clínica como una forma de influencia de las expectativas del analista (separándolo además del sesgo de confirmación) que puede ser neutralizada mediante hallazgos confirmatorios compartidos y hallazgos clínicos sorprendentes. Esto nos llevó a rechazar tanto la sentencia de Grünbaum sobre la irremediable contaminación probatoria de los datos 
clínicos, como también su insistencia derivada en la necesidad de que las conjeturas psicoanalíticas sean testeadas extra-clínicamente (situación que consideramos posible pero prescindible). Si se acepta esto último, aquellos partidarios de la tradición naturalista que se han apoyado cómodamente en las críticas de Grünbaum para abogar por la necesidad de investigaciones extraclínicas en psicoanálisis, deberían apelar a otros justificativos.

La conclusión general a la que he llegado en esta parte de la tesis es que si bien la crítica epistemológica de Grünbaum ha contribuido a la discusión racional sobre los fundamentos psicoanalíticos como pocas veces se ha visto, manteniéndose en el centro de tales discusiones desde hace décadas, resulta inviable; debido a tres aspectos fundamentales: a) su análisis y reconstrucción de los argumentos freudianos oscila entre la agudeza y la exageración, adoleciendo de significativos defectos parciales o siendo, en algunos aspectos, completamente equivocada; b) su argumentación general resulta sesgada por una serie de fundamentos filosóficos indebidamente explicitados y de aspiración injustamente universal; c) sus pretensiones metodológicas soportan la carga de limitaciones y defectos que les son inherentes, pero que se acrecientan exponencialmente en su intento de extrapolación a disciplinas como el psicoanálisis.

La CUARTA PARTE de la tesis se enfocó, desde diversos ángulos y con una profundidad variable, en algunos aspectos de la racionalidad clínica freudiana. Apoyándome en lo expuesto en la primera y la tercera parte, en el noveno capítulo examiné críticamente los argumentos generales de la propuesta de redefinir, total o parcialmente, la identidad epistemológica del psicoanálisis en términos hermenéuticos. Primero, procuré mostrar que aun siendo el método psicoanalítico de Freud esencialmente interpretativo, hay significativas razones que impiden identificarlo con la hermenéutica metódica, debido a que existen profundas divergencias no sólo en sus orígenes y objetivos, sino también a nivel de las suposiciones antropológico-lingüísticas y axiológicas, explícitas o implícitamente asumidas. Segundo, en virtud de que la hermenéutica metódica no constituye más que su punto de partida en el campo epistemológico, hemos abordado las transformaciones principales que han acontecido al interior de la tradición hermenéutica desde mediados del siglo $\mathrm{XX}$, analizando diferencialmente los principales aportes ontológicos y metodológicos que 
algunos han pretendido desembarcar en el campo psicoanalítico. Cuatro aspectos han sido deslindados y específicamente analizados, arribándose a las siguientes conclusiones: A) desde supuestos epistémicos del método freudiano se desprenden objeciones a la concepción tradicional de la ciencia, por lo que no es necesario apelar al vocabulario de la tradición hermenéutica para argumentar en su contra. B) Los principales aportes de la hermenéutica analógica, cuyos desarrollos recientes han venido a renovar la propuesta de redefinición hermenéutica del psicoanálisis, dejan una serie de problemas fundamentales sin resolver. Aunque sus nociones centrales de analogía e iconicidad sintonizan bien con el espíritu epistémico del método psicoanalítico freudiano, la hermenéutica analógica conserva una serie de asunciones que resultan incompatibles con aquellos aspectos teórico-técnicos de la propuesta freudiana que exceden la dimensión narrativa. C) En base al examen efectuado de la tesis de Laplanche de considerar al psicoanálisis como una antihermenéutica y de su discusión con las ideas de Ricœur, concluimos que el rol diferencial otorgado a la intencionalidad, junto con otras diferencias en torno a la concepción del sentido y de la comprensión, constituye un límite no franqueado por los intentos de redefinición hermenéutica del psicoanálisis. D) Finalmente, la inclusión a nuestro análisis de la tesis de la hermeneutización de la filosofía de la ciencia, nos permite concluir lo siguiente: si cabe hablar de un fundamento hermenéutico del psicoanálisis, éste se debe a que comparte, junto con el resto de las disciplinas que en la actualidad estudian al hombre, una serie de supuestos generales sobre la producción, establecimiento y evolución del conocimiento, inherentes a tal hermeneutización. Sin embargo, ello no impide al psicoanálisis argumentar en contra de determinados supuestos específicos (antropológicos, metodológicos y axiológicos) de la tradición hermenéutica, anteponiendo sus propias conjeturas de base a partir de la racionalidad inmanente a su campo de experiencia clínica. He sintetizado estas consideraciones en la siguiente afirmación: el psicoanálisis es hermenéutico en un sentido amplio y al igual que cualquier otra disciplina científica ocupada de lo humano; pero no puede ser hermenéutico en sentido estricto, ya que no puede compatibilizar algunas de sus asunciones centrales con los fundamentos de esta tradición. 
En la tercera parte del capítulo, abordé específicamente uno de los aspectos centrales de la controversia entre las perspectivas naturalistas y hermenéuticas en psicoanálisis: el tipo de entidades a las que se le otorga relevancia causal y su papel desempeñado en las explicaciones psicoanalíticas. Para facilitar la elucidación de algunas posturas contrapuestas, el análisis de sus argumentos y nuestro propio punto de vista, se dividió la exposición en tres partes interrelacionadas: A) recuperamos la crítica de Grünbaum a los precursores de la reversión hermenéutica del psicoanálisis, pero enfocándonos en el problema del binomio causas-razones y su incidencia en las explicaciones psicoanalíticas. Mostramos que Grünbaum acierta en sus objeciones a la utilización del silogismo práctico para la formalización de las explicaciones freudianas, pero también mostramos que fracasa en su reconstrucción de las mismas al pretender reducirlas al clásico modelo de cobertura legal; B) Luego argumentamos que la concepción freudiana de la causalidad es desconcertante sólo para aquellos que adoptan como punto de partida el binomio causa-razón, pero su racionalidad se hace viable cuando asumimos un punto de vista que lo trasciende. Recuperamos la noción freudiana de sentido para mostrar que, por un lado, supone la presencia de aspectos teleológicos que posibilitan explicaciones funcionales que no pueden reducirse al modelo nomológicodeductivo $\mathrm{y}$, por otro lado, que esa teleología tampoco se reduce a la intencionalidad fenomenológica del yo consciente, asumida comúnmente por los partidarios de la hermenéutica. Nuestra hipótesis aquí es que el modo en que el creador del psicoanálisis sostuvo la tensión entre causalidad y teleología, sin renunciar a ninguno de ambos extremos, constituye un elemento fructífero para reconsiderar las matrices explicativas que el psicoanálisis puede ofrecer. Finalmente, C) decidimos explorar un aspecto contemporáneo que entrevera algunos problemas del tópico de la explicación científica con el campo de los debates filosóficos sobre la causalidad. Asumiendo que las distintas metapsicologías contemplan formulaciones nómicas, pero que gran parte de las explicaciones que se dan a nivel de los fenómenos clínicos no se realiza como una subsunción nomológica sino a partir de la elucidación de regularidades singulares presentes en el funcionamiento psíquico de cada sujeto, introdujimos la posibilidad de apelar a la noción wincheana de reglas (por oposición a las leyes) para reconstruir el estatuto epistémico de tales 
generalizaciones no universales. Por otro lado, recuperamos la propuesta de algunos autores, provenientes del campo de la filosofía general de las ciencias, de disociar el vínculo entre causación y nomicidad, naturalizado con el modelo nomológico-deductivo. Específicamente, recuperamos las ventajas de la teoría contrafáctica de la causación para explorar la posibilidad de concebir explicaciones genuinamente causales sobre fenómenos clínicos singulares. Nuestra conjetura aquí es que la noción de reglas y la conceptualización contrafáctica de la causación podrían ofrecerle a las explicaciones psicoanalíticas, por vías diferentes, la posibilidad de vincular la causación de fenómenos humanos sin necesidad de recurrir a leyes ni al modelo de cobertura legal. Debido a que gran parte de la labor clínica consiste en la elucidación de patrones idiosincráticos con relevancia explicativa, consideramos que el psicoanálisis podría dialogar fructíferamente con esta clase de teorizaciones. Con ello no hemos pretendido una eliminación de las explicaciones nomológicas en psicoanálisis sino que, en virtud de la variedad de fenómenos a explicar, hemos planteado la necesidad de complementar diversos tipos de explicaciones causales. Aunque esta vía necesitará de nuevos desarrollos para mostrar su plausibilidad, el punto alcanzado nos basta para concluir que es posible rechazar las ilícitas pretensiones nomológicodeductivas de Popper y los afanes experimentalistas de Grünbaum, sin quedar a la deriva de posturas posmodernistas.

La convergencia de los argumentos expuestos en este capítulo de la tesis nos lleva a concluir que la propuesta de redelinear la identidad epistemológica del psicoanálisis en términos hermenéuticos, no se sostiene. Como el lector podrá notar, la conclusión de este capítulo es la contracara de la que resulta en la parte destinada a la crítica de Grünbaum: mientras que allí mostramos, además de las falencias argumentativas de dicho filósofo, que el modelo del inductivismo eliminativo (concebido para la evaluación de leyes en física experimental) no puede ser utilizado en el dominio psicoanalítico para la evaluación de las hipótesis causales, en este capítulo hemos mostrado que el modelo hermenéutico (concebido para la interpretación textual o la comprensión de motivos) tampoco logra captar las complejidades de la racionalidad psicoanalítica sin cercenar varios de sus aspectos fundamentales. 
El décimo capítulo constituye el final de nuestro recorrido en esta tesis. Allí se han analizado una serie de desarrollos en torno a las inferencias abductivas, a los fines de localizar un camino viable para abordar aquello que de la racionalidad freudiana excede los márgenes de los otros dos modelos inferenciales previamente abordados (deductivismo e inductivismo) y del narrativismo hermenéutico.

En primer lugar, se presentó la concepción de Peirce sobre la naturaleza de la abducción y su papel en la génesis de hipótesis científicas creativas. Seguido de ello, la aspiración de utilizar el conjunto de las inferencias abductivas como herramienta conceptual para la elucidación de la producción de conocimiento psicoanalítico, se topó rápidamente con dos obstáculos: la heterogeneidad de criterios y taxones propuestos para ordenar dicho conjunto de manera homogénea $y$, además, las discusiones, aún vigentes, sobre el vínculo que mantiene la abducción con la denominada inferencia a la mejor explicación. A mi modo de ver, ambos modelos pueden separarse en base a tres criterios centrales: el contexto al que pertenecen, el tipo de evidencia del que se sirven en la validación y el tipo de estado epistémico al que se llega con las hipótesis obtenidas. Sin dejar de reconocer que el modelo de la IME muestra una superioridad evidente respecto de los cánones de Mill, decidí adoptar la concepción peirceana de la abducción y del proceso científico general para efectuar una lectura de lo que sucede en psicoanálisis, en virtud de que éste representa mejor el acontecer inferencial de la labor clínica.

En la segunda parte del capítulo hemos vinculado la lógica abductiva de Peirce con las caracterizaciones pioneras que hiciera Carlo Ginzburg respecto del modelo indiciario de Freud, a los fines de elucidar la función que desempeñan las inferencias abductivas en torno a la producción y establecimiento de las hipótesis psicoanalíticas, tanto en el contexto clínico como extra-clínico.

1) Respecto del contexto clínico, hemos examinado el modo en que las operaciones clínicas del analista están atravesadas por la actividad del colegir indicios, que puede verse como una manera de hablar de la abducción. Me he apoyado en Freud para mostrar que la indagación clínica supone un esfuerzo de teorización ineludible basado en la lógica abductiva. He arribado además a la siguientes conjeturas: a) asumiendo que el grado de relevancia causal del 
conocimiento que se obtiene mediante un análisis es directamente proporcional a su nivel de singularidad, podemos afirmar que lo propio de la clínica psicoanalítica no es el uso de la abducción hipercodificada, al modo del detective o del diagnosticador: para la captura de lo singular el analista no dispone de un saber enciclopédico del cual extraer la regla, sino que debe contribuir a su invención. b) Además, asumiendo que la singularidad no equivale a una ausencia de regularidad sino que es compatible con ella, propongo que el tipo de abducción que utilizamos para inventar un saber de las reglas singulares de funcionamiento psíquico, comienza con abducciones hipocodificadas y se desliza, necesariamente, al nivel de las abducciones creativas (en la tipología de Eco). Esto no excluye que en diversos momentos el analista haga uso de otros tipos de abducción ni de cualquier otra inferencia. Pero en función de que lo causalmente relevante en la explicación de un caso psicoanalítico es del orden de lo singular, no es lícito apelar a la relación de subsunción nómica para explicar. Sólo mediante abducciones creativas se abre la posibilidad de representación de la singularidad del caso psicoanalítico.

2) Respecto del contexto de teorización metapsicológica, el phantasieren freudiano puede verse como una apelación necesaria a esos elementos involuntarios que están a la base de la creación científica y que parcialmente podemos elucidar como inferencias abductivas. Hay varios ejemplos en la producción teórica de Freud que dan cuenta de un esfuerzo de teorización a partir del hallazgo sorpresivo, inesperado, que detona el proceso abductivo; y, además, varios que muestran cómo las analogías están a la base de la abducción creativa en sus múltiples variantes: tanto hipótesis explicativas metapsicológicas como conjeturas interpretativas sobre obras artísticas o históricas.

Por otro lado, analizando el problema de la conjunción entre investigar y curar, hemos propuesto reparar en algunos criterios como los objetivos, la posición del investigador y el método, para contribuir a la distinción de las actividades inherentes a la indagación clínica y a la investigación científica basada en la clínica. Ello no supone rechazar la suposición freudiana de la preciosa conjunción: al contrario, contribuye a elucidar el modo de investigación clásico en psicoanálisis, entendiéndolo como inherente e insoslayable a nuestro campo disciplinar, pero sin suponer que sea el único posible. 
En el tercer punto del capítulo, hemos retomado el problema de la validación de las conjeturas interpretativas que el analista abduce en el contexto clínico, complementando así el análisis del falibilismo freudiano que efectuamos en la segunda parte de la tesis. En primer lugar, apuntamos a despejar una serie de malentendidos sobre la contrastabilidad empírica en nuestro campo, concluyendo, en sintonía con la tesis de la hermeneutización de la filosofía de la ciencia contemporánea, que 1) el hecho de que el psicoanálisis se ocupe de significaciones no impide que se puedan hacer conjeturas sobre las mismas y evaluarlas utilizando criterios consensuados disciplinarmente; 2) adoptar esta estrategia general no implica que su realización sea por la vía de la experimentación o de la correlación estadística; y 3) se pueden evaluar conjeturas interpretativas a partir de sus consecuencias derivadas sin que éstas tengan una formulación nómica; lo cual supone una separación de esta estrategia metodológica respecto de los modelos explicativos utilizados ( $p$. ej. el de cobertura legal). Seguido de ello y a partir de examinar la postura de algunos referentes locales clásicos sobre el asunto de la puesta a prueba de la interpretación, hemos efectuado una lectura propia sobre ciertos aspectos específicos que tales autores, cuyas notorias afinidades al hipotéticodeductivismo y al modelo de cobertura legal, habían dejado sin explorar: el origen abductivo de las conjeturas interpretativas y la posibilidad de separar la puesta a prueba de su enunciación efectiva. Para ello, hemos mostrado cómo, a diferencia del modelo de IME, la lógica peirceana de evaluación de hipótesis (basada en la predesignación de caracteres) escapa a ciertas críticas usuales, permitiendo elucidar aquella parte de la lógica práctica del analista en la que se evalúan las hipótesis clínicas relativas a un caso. Por referencia a dos ejemplos concretos, hemos podido elucidar una serie de pasos (abducción, retrodicción, contrastación, corroboración/refutación) en la génesis y evaluación freudiana de una hipótesis interpretativa. Hemos visto cómo las dinámicas del hallazgo sorpresivo y de la búsqueda deliberada parecen inmiscuirse en la lógica práctica del analista y también por qué es necesario diferenciar las conjeturas que el analista se forma de los recursos enunciativos que utiliza para intervenir. Finalmente, a partir de los ejemplos seleccionados también he podido ilustrar mejor dos conclusiones anteriores: por un lado, la relación proporcional postulada entre el grado de relevancia causal y su nivel de singularidad; y, por 
otro lado, la posibilidad de evaluar las abducciones que hace el analista para interpretar los aspectos singulares (entre lo hipocodificado y lo creativo) mediante sus consecuencias clínicas.

\title{
Palabras finales
}

\begin{abstract}
"si no se puede afrontar el desafío de las críticas de Popper / Grünbaum, el psicoanálisis será ubicado en la posición de una psicología pastoral de la que la filosofía hermenéutica no puede salvarlo"601 (Hanly, 1994: 15).
\end{abstract}

Creo que esta reflexión, proveniente de un ex presidente de la International Psychoanalytical Association (2011-2013), armoniza bien con el espíritu general de esta tesis. Sin embargo, a mi modo de ver, "afrontar el desafío de las críticas" dista mucho de cualquier intento deferente por adecuar la práctica clínica e investigativa del psicoanálisis a unos cánones prescriptos desde afuera o que constituyen el ideal regulatorio de otras disciplinas. Y es por ello que, desde el principio, me he dedicado a analizar sistemáticamente los principales argumentos de Popper y Grünbaum, así como aquellos inherentes al movimiento hermenéutico en psicoanálisis, intentando ponderar su pertinencia y viabilidad. Considero que el itinerario argumental efectuado aporta suficientes razones para afirmar que la racionalidad clínica inaugurada por Freud resiste los embates de las críticas epistemológicas de Popper y Grünbaum y, al mismo tiempo, se resiste a ser redefinida en términos hermenéuticos.

En el recorrido de la tesis intenté mostrar por qué los problemas epistemológicos y metodológicos abordados constituyen un conjunto entramado de debates, que difícilmente podría ser justipreciado sin tener en cuenta la interdependencia de su devenir diacrónico. El lector habrá advertido que la tesis no recorre en clave histórica, ni mucho menos sociológica, el terreno deslindado; sino que se apoya en diversos aspectos para efectuar un

\footnotetext{
601 "If it cannot meet the challenge of the Popper/Grünbaum critiques, psychoanalysis will be left in the position of a pastoral psychology from which hermeneutic philosophy cannot save it..."
} 
análisis epistemológico. Pese a ello, me he encontrado en la situación de reflexionar, de manera subsidiaria y sin proponérmelo, sobre algunas suposiciones sociohistóricas relativas al acontecer de tales debates en el psicoanálisis argentino. Hoy estoy sumamente persuadido del impacto indirecto e insidioso que han tenido, en nuestra manera local de concebir la disciplina, los problemas epistemológicos y metodológicos que he examinado en esta tesis. Me refiero concretamente a las consecuencias que han acarreado, aunque más no sea por su omisión en la agenda de problemas, sobre la autopercepción que los analistas mismos mantienen sobre el estatuto epistemológico del trabajo que realizan y sobre el modo en que entienden el lugar del psicoanálisis en la cultura.

Como escoger un camino significa abandonar otros, vale la pena dejar en claro lo siguiente. A diferencia de lo que explícitamente se afirma o de lo que implícitamente sucede en algunas perspectivas psicoanalíticas, adhiero a dos premisas irrenunciables de Freud: el psicoanálisis debe buscarse un lugar entre las ciencias y no debe ser una concepción del mundo. En ese sentido, desconozco el valor que una tesis como ésta podrá tener para aquellos que, acobardados, hayan desistido de preguntarse por los fundamentos de la racionalidad clínica freudiana; pero, sobre todo, desconozco qué podrían encontrar aquí aquellos que viven dispuestos a evadir toda interrogación proveniente de la reflexión epistemológica, porque ya cuentan con las respuestas suficientes.

Si he intentado defender la racionalidad freudiana es porque estimo la vigencia de sus aspectos centrales y porque me parece que hay vías legítimas para continuar desarrollándolos. Frente a los embates del hipotéticodeductivismo y del inductivismo eliminativo, la retirada hermenéutica y la concesión naturalista conducen o bien a callejones epistémicos sin salida, o bien a una extenuación onerosa del programa freudiano. He pretendido recorrer algunas sendas no del todo exploradas del territorio de las inferencias abductivas que, junto con las herramientas provenientes de la lógica de la explicación causal, podrían llevarnos a otros ámbitos desde los que elucidar críticamente nuestras teorías, métodos y prácticas. No estoy seguro de hasta dónde exactamente podría llevarnos esta vía, pero he querido mostrar que ella es plausible y transitable. 
Asumiendo que la experiencia clínica es un soporte ineludible, tanto para la evaluación específica de las conjeturas psicoanalíticas como para el desarrollo general de la investigación en el campo, el análisis crítico de sus principales atolladeros epistemológicos constituye una tarea que amerita cada vez más profundos abordajes desde el interior mismo de nuestra disciplina. Tarea que puede contribuir a dejar al psicoanálisis en mejores condiciones de posicionarse en los diálogos culturales en los que le toque participar.

Más allá del lugar del psicoanálisis en la cultura, mi objetivo principal en esta tesis ha apuntado a las controversias acaecidas en el interior de la disciplina y ha sido el de contribuir a la discusión epistemológica sobre la racionalidad del conocimiento psicoanalítico, entablando un diálogo frontal con algunas de sus principales líneas de interlocución crítica. El devenir histórico de esta conversación metateórica nos enseña cómo sus repercusiones llegan hasta las disputas actuales sobre la identidad de la disciplina y sobre sus metodologías de investigación. Creo que, afortunadamente, sigue siendo responsabilidad de los analistas decidir qué hacer con la pluralidad existente en nuestro campo a propósito de tales asuntos. Fructificar el intercambio o promover una babel no han sido ni serán opciones sin consecuencias. 


\section{REFERENCIAS BIBLIOGRÁFICAS}

Achinstein, P. (1963). Theoretical Terms and Partial Interpretation. The British Journal for the Philosophy of Science, 54, 89-105.

Achinstein, P. (1983). The nature of explanation. Oxford: Oxford University Press.

Achinstein, P. (1987). Scientific Discovery and Maxwell's Kinetic Theory. Philosophy of Science, 54 (3), 409-434.

Aguillaume, R. (2016). Epistemology and psychoanalysis: One psychoanalysis or two? International Forum of Psychoanalysis, 25 (3), 149.

Ahumada, J. L. (1997a/1999). "Hacia una epistemología del psicoanálisis clínico". En: Descubrimientos y refutaciones. La lógica de la indagación psicoanalítica (pp. 311337). Madrid: biblioteca nueva.

Ahumada, J. L. (1997b/1999). "Descubrimientos y refutaciones: el psicoanálisis clínico como lógica de la indagación". En: Descubrimientos y refutaciones. La lógica de la indagación psicoanalítica (pp. 409-430). Madrid: biblioteca nueva.

Ahumada, J. L. (1999a). "Las lógicas y la epistemología del psicoanálisis". En: Descubrimientos y refutaciones. La lógica de la indagación psicoanalítica (pp. 43-59). Madrid: biblioteca nueva.

Ahumada, J. L. (1999b). "Interpretación y creacionismo". En: Descubrimientos y refutaciones. La lógica de la indagación psicoanalítica (pp. 219-241). Madrid: biblioteca nueva.

Ahumada, J. L. (2006). Contexto y texto en los descubrimientos freudianos. Revista de Psicoanálisis, 63 (2), 237-253.

Ahumada, J. L. (2014). "La clínica psicoanalítica, las teorías clínicas y las metapsicologías". En: A. Vertzner Marucco (comp.), Metapsicología. Una clínica con fundamentos (pp.49-62). Buenos Aires: APA editorial.

Aliseda, A. (1998). La abducción como cambio epistémico: CS Peirce y las teorías epistémicas en inteligencia artificial. Analogía Filosófica, 12(1), 125-144.

Aliseda, A. (2003). "Abducción y Pragmati(ci)smo en Charles S. Peirce”. En: S. Cabanchik, F. Penelas, V. Tozzi, et al. (Eds.). El giro pragmático de la filosofía (pp. 261-272). Barcelona: Gedisa.

Aliseda, A. (2006). Abductive Reasoning. Logical Investigations into Discovery and Explanation. Dordrecht: Springer.

Álvarez Layna, J. R. (2013). Lo irracional en Donald Davidson. Pensamiento. Revista de Investigación e Información Filosófica, 69(261), 963-977. 
Alvarez Lince, B. (1996), La Interpretación Psicoanalítica. Método y Creación. Santafé de Bogotá: Grijalbo.

American Psychological Association (2010). Manual de estilo de publicaciones de la APA. Tercera edición en español de la sexta en inglés. México: Manual Moderno.

Anderson, E. (2004). Uses of value judgments in science: a general argument, with lessons from a case study of feminist research on divorce. Hypatia 19(1), 1-24.

Antiseri, D. (2000/2001). La Viena de Popper. Madrid: Unión.

Apel, K. O. (1973/1985). "El desarrollo de la «filosofía analítica» del lenguaje y el problema de las «ciencias del espíritu»". En: La transformación de la filosofía, tomo II, (pp. 27-90). Madrid: Taurus.

Argañaráz J. (2007). Psicopatología y psicoanálisis. Una perspectiva desde Lakatos. Córdoba: Brujas.

Argañaráz, J. (2012). Ruptura y continuidad de Lacan con Freud (desde Lakatos). Córdoba: Universidad Nacional de Córdoba.

Aristóteles (2006). "Analíticos Primeros". En: Tratados de lógica (Organon) II. Madrid: Gredos.

Arrivé, M. (1994/2004). Lenguaje y psicoanálisis, lingüística e inconciente. Freud, Saussure, Pichon, Lacan. Buenos Aires: Siglo XXI.

Asociación Ernst Mach (1929/2002) La concepción científica del mundo: el Círculo de Viena. Traducción de Lorenzano Pablo, en revista Redes $n^{\circ}$ 18, vol. 9, Universidad Nacional de Quilmes, pp. 103-149.

Assoun, P. L. (1976/1982). Freud. La filosofía y los filósofos. Buenos Aires: Paidós.

Assoun, P. L. (1981/1982). Introducción a la epistemología freudiana. México: Siglo XXI.

Assoun, P. L. (1993/2003). Freud y las ciencias sociales. Psicoanálisis y teoría de la cultura. Barcelona: Ediciones del Serbal.

Assoun, P. L. (2000/2002). La metapsicología. Buenos Aires: Siglo XXI.

Ávila Espada, A. \& García de la Hoz, A. (2014). "Historia, núcleo conceptual y controversias epistemológicas del modelo psicodinámico". En: A. Ávila Espada, B. Rojí Menchaca \& L. Á. Saúl Gutiérrez (Coord.), Introducción a los tratamientos psicodinámicos (pp. 6398). Madrid: UNED.

Ávila-Espada, A. \& Mitjavila, M. (2003). El método del plan de acción latente del terapeuta (TLAP). Un nuevo método para predecir la contribución cualitativa del terapeuta al resultado de tratamiento. Subjetividad y Procesos Cognitivos, 3, 9-36.

Ayim, M. (1974). Retroduction: The rational instinct. Transactions of the Charles S. Peirce Society, 10 (1), 34-43.

Azaretto, C. y Ros, C. (2014). Investigar en psicoanálisis. Buenos Aires: JCE. 
Azcona M. (2013a). Epistemología y Psicoanálisis: una lectura sobre la concepción freudiana de la realidad. Revista de Psicología - Segunda Época, 13, 13-32.

Azcona, M. (2013b). Algunos aspectos de reduccionismo freudiano. En Actas del $4^{\circ}$ Congreso Internacional de Investigación de la Facultad de Psicología de la Universidad Nacional de La Plata (pp- 58-67). La Plata: UNLP.

Azcona, M. (2014) "Problemas ontológicos y epistemológicos en la enseñanza de la metodología: el debate 'realismo - antirrealismo' en la filosofía de las ciencias". En Sánchez Vazquez, M.J. (coord). La Enseñanza de la Metodología de la Investigación en Psicología. Un acercamiento crítico a sus fundamentos y problemas. La Plata: Edulp.

Azcona, M. (2015). "Hipermodernidad y teorización en psicoanálisis". En: C. J. Escars (comp.). Declinaciones del padre. Lecturas psicoanalíticas de la época, (pp. 19-36). Buenos Aires: Letra Viva.

Bachelard, G. (1948/2000) La formación del espíritu científico. Contribución a un psicoanálisis del conocimiento objetivo. Buenos Aires: Siglo XXI.

Bacon, F. (1620/1984). Novum Organum. Madrid: Sarpe.

Bar-Hillel, Y. (1970). "Neorealism vs. Neopositivism. A Neo-Pseudo Issue". In: Aspects of Language, (pp. 263-272). Jerusalem: The Magnes Press.

Barreira, I. (2009). Schopenhauer y Freud. Buenos Aires: Del signo.

Beebee, H., Hitchcock, C., \& Menzies, P. (2009). The Oxford handbook of causation. Oxford: Oxford University Press.

Bercherie, P. (1983/1988). Génesis de los conceptos freudianos. Buenos Aires: Paidós.

Bernardi, R. (1994/1995). Sobre el determinismo psíquico. Revista uruguaya de Psicoanálisis, 81, 65-88.

Bernardi, R. (2009). ¿Qué Metapsicología necesitamos? Vigencia de J. Bleger. Revista Uruguaya de Psicoanálisis, 108, 223-248.

Bernardi, R. (2015). Investigación clínica e investigación empírica sistemática: ¿qué nos enseñan las controversias actuales? International Journal of Psycho-Analysis en Español, 1(3), 836-866.

Beuchot, M. (1997/2009). “La hermenéutica y la epistemología del psicoanálisis”. En: Tratado de hermenéutica analógica. Hacia un nuevo modelo de interpretación, (pp. 153-166). México: Itaca.

Beuchot, M. (2003). Hermenéutica analógica y del umbral. Salamanca: San Esteban.

Beuchot, M. (2004). Hermenéutica, analogía y símbolo. México: Herder.

Beuchot, M. (2014). “Objetividad y certeza en la interpretación”. En: M. Beuchot y J. L. Jerez, Dar con la realidad. Hermenéutica analógica, realismo y epistemología (pp. 73-94). Neuquén: Círculo Hermenéutico. 
Bick, E. (1964). Notes on infant observation in psycho-analytic training. The International Journal of Psycho-analysis, 45, 558-566.

Bick, E. (1968). Experience of the skin in early object relations. International Journal of Psychoanalysis, XLIX, 484-486.

Bick, E. (1986). Further considerations on the function of the skin in early object relations. British journal of psychotherapy, 2(4), 292-299.

Biebel, D. (2008). ¿Y si hubiera ocurrido otra cosa? Imaginación y condicionales contrafácticos en la clínica psicoanalítica. Aperturas psicoanalíticas: Revista de psicoanálisis, 28, 5 .

Birch, J. A. (2000). Una revisión de la teoría psicoanalítica a la luz de la ciencia moderna. México: Plaza y Valdés.

Blatt, S.J. \& Auerbach, J.S. (2003). Psychodynamic measures of therapeutic change. Psychoanalytic Inquiry 23, 268-307.

Bleichmar, N. \& Leiberman, C. (1997). "Problemas epistemológicos en la teoría psicoanalítica”. En: El psicoanálisis después de Freud: teoría y clínica (477-496). Buenos Aires: Paidós.

Bleichmar, S. (1993). La fundación de lo inconciente. Destinos de pulsión, destinos del sujeto. Buenos Aires: Amorrortu.

Bleichmar, S. (1994). Repetición y temporalidad: una historia bifronte. En: S. Bleichmar (comp.), Temporalidad, determinación, azar, lo reversible y lo irreversible (pp. 45-75). Buenos Aires: Paidós.

Bleichmar, S. (2004/2005). "Límites y excesos del concepto de subjetividad en psicoanálisis". En: La subjetividad en riesgo, (pp. 79-85). Buenos Aires: Topía.

Blight, J. G. (1981). Must Psychoanalysis Retreat to Hermeneutics?: Psychoanalytic Theory in the Light of Popper's Evolutionary Epistemology. Psychoanalysis and Contemporary Thought, 4(2), 147-205.

Bonfantini, M. y Proni, G. (1989). "To Guess or Not to Guess?" En: U. Eco y T. Sebeok (eds.), El signo de los tres. Dupin, Holmes, Peirce (pp. 164-184). Barcelona: Lumen.

Borch-Jacobsen, M. (1996). Neurotica: Freud and the Seduction Theory. October, 76, 15-42.

Borges, J. L. (1960/1984). "Del rigor en la ciencia”. En: Jorge Luis Borges. Obras Completas 1923-1972. El Hacedor (pp. 847). Buenos Aires: Emecé.

Bornstein, R. \& Masling, J. (eds.) (1998a). Empirical Perspectives on the Psychoanalytic Unconscious. Washington DC: American Psychological Association.

Bornstein, R. \& Masling, J. (eds.) (1998b). Empirical studies of the therapeutic hour. Washington DC: American Psychological Association.

Bornstein, R. (2001). The impending death of psychoanalysis. Psychoanalytic Psychology, 18, 3-20. 
Bornstein, R. (2005). Reconnecting psychoanalysis to mainstream psychology. Challenges and opportunities. Psychoanalytic Psychology 22(3), 323-340.

Bornstein, R. (2001). The impending death of psychoanalysis. Psychoanalytic Psychology 18, 3-20.

Bowlby, J. (1969/1990). El vínculo afectivo. Buenos Aires: Paidós.

Braithwaite, R. (1960). Scientific explanation. New York: Harper.

Brakel, L. (2015). Critique of Grünbaum's “Critique of psychoanalysis”. In: S. Boag, L. Brakel \& V. Talvitie (Eds.), Philosophy, Science, and Psychoanalysis, pp. 59-72. London: Karnac Books.

Braudel, F. (1985/1989). "Mediterráneo". En: El Mediterráneo. El espacio y la historia (pp. 711). México: Fondo de Cultura Económica.

Brenner. C. (1982). The Mind in Conflict. New York: International Universities.

Buzzoni, M. (2001). The Operationalistic and Hermeneutic Status of Psychoanalysis. Journal for General Philosophy of Science, 32, 131-165.

Brown, H. I. (1977/1983). La nueva filosofía de la ciencia. Madrid, Tecnos.

Bunge, M. (1977/1980). Epistemología. Buenos Aires: Sudamericana.

Bunge, M. (1985). Seudociencia e ideología. Madrid: Alianza.

Bunge, M. (2001). Crisis y reconstrucción de la filosofía. Madrid: Gedisa.

Bunge, M. (2006). "Psicoanálisis a un siglo de distancia", en 100 Ideas. El libro para pensar y discutir en el café. Buenos Aires: Sudamericana.

Bunge, M. (2010). Las pseudociencias ;vaya timo! España: Laetoli.

Campos, D. G. (2011). "On the distinction between Peirce's abduction and Lipton's Inference to the best explanation". Synthese, 180, 419-442.

Cancina, P. H. (2008). La investigación en psicoanálisis. Rosario: Homo Sapiens.

Canguilhem, G. (1956/1994). ¿Qué es la psicología? Dpto. Publicaciones, Facultad de Psicología, UBA, 1994. [Traducción de: “Qu'est-ce que la psychologie?”, Revue de Mètaphysique et de Moral, 63, No 1, 1956, pp. 12-25.]

Caper, R. (2009). Building out into the dark: Theory and observation in science and psychoanalysis. New York: Routledge.

Caponi, G. (2014). Leyes sin causa y causas sin ley en la explicación biológica. Bogotá: Universidad Nacional de Colombia.

Carnap, R. (1950). Logical Foundations of Probability. Chicago: University of Chicago Press.

Cartwright, N. (1983). How the laws of Physics lie. Oxford: Oxford University Press.

Cassirer, E. (1942/1973). Las ciencias de la cultura. México: Fondo de Cultura Económica.

Cavell, M. (2000). La mente psicoanalítica. De Freud a la Filosofía. Barcelona: Paidós.

Chalmers, A. F. (1976/1990) ¿Qué es esa cosa llamada ciencia? Una valoración de la naturaleza y el estatuto de la ciencia y sus métodos. México: Siglo veintiuno. 
Cioffi, F. (1970) "Freud y la idea de pseudociencia", en R. Borger \& F. Cioffi (eds.), La explicación en las ciencias de la conducta (pp. 327-359). Madrid: Alianza.

Coderch, J. (1989). "El desafío científico al psicoanálisis". En: J. Poch (ed.), Psicología dinámica (pp. 13-17). Barcelona: Herder.

Coderch, J. (2006). Pluralidad y diálogo en psicoanálisis. Barcelona: Herder.

Cohen, M., \& Nagel, E. (1961/1990). Introducción a la lógica y al método científico. Vol. II: lógica aplicada y método científico. Buenos Aires: Amorrortu.

Cohen, R. S. (1983). Adolf Grünbaum: A Memoir. In R. S. Cohen \& L. Laudan (eds.), Physics, Philosophy and Psychoanalysis: Essays in Honor of Adolf Grünbaum, pp. ix-xviii. Dordrecht: Reidel.

Collingwood, R. (1946/1952). Idea de la historia. México: Fondo de Cultura Económica.

Copi, I. \& Cohen, C. (2013). Introducción a la lógica. México: Limusa.

Crombie, A. (1959/1987). Historia de la ciencia: de San Agustín a Galileo (tomo 2). Madrid: Alianza.

Dahl, H. (1998). "The Voyage of el Rubaiyat to the Discovery of FRAMES". In: R. F. Bornstein y J. M. Masling (Eds.), Empirical Studies of the Therapeutic Hour (pp. 179-227). Washington DC: American Psychological Association.

Dahl. H. (1988). "Frames of mind”. In: H. Dahl, H. Kächele, \& H. Thomä (eds.), Psychoanalytic Process Research Strategies (pp. 51-66). Berlin: Springer-Verlag.

Dalbiez, R. (1936/1948). El método psicoanalítico y la doctrina freudiana. Buenos Aires: Desclée.

Davidson, D. (1963/1995). “Acciones, razones y causas”. En: Ensayos sobre acciones y sucesos, (pp. 17-36). México: Crítica.

Davidson, D. (1981). Las paradojas de la irracionalidad. Análisis filosófico, 1(2), 1-18.

De Battista, J. (2011). "Posición paranoica, posición del analista". En: C. J. Escars (comp.), La trama de la interpretación. Lógica y condición de las operaciones del analista (pp.115-123). Buenos Aires: Letra Viva.

De Battista, J. (2015). El deseo en las psicosis. Buenos Aires: Letra Viva.

Debrock, G. (1998). El ingenioso enigma de la abducción. Analogía Filosófica XII (1), 21-40. Recuperado de: http://www.unav.es/gep/AN/Debrock.html

Diez, J. \& Lorenzano, P. (2002). "La concepción estructuralista en el concepto de la filosofía de la ciencia del siglo XX"; en J., Diez \& P., Lorenzano (eds.). Desarrollos actuales de la metateoría estructuralista: problemas y discusiones, (pp. 13-78). Bernal: Universidad Nacional de Quilmes.

Diez, J. A. (1998). "Popper y Kuhn sobre la falsación y la ciencia normal”; en Solís Santos, C. (comp.). Alta tensión: Historia, filosofía y sociología de la ciencia. Ensayos en memoria de Thomas Kuhn. Buenos Aires: Paidós. 
Diez, J. A. y Moulines, U. C. (1997). Fundamentos de filosofía de la ciencia. Barcelona: Ariel. Dilthey, W. (1883/1949). Introducción a las ciencias del espíritu. En la que se trata de fundamentar el estudio de la sociedad y de la historia. Buenos Aires: Fondo de Cultura Económica.

Dorey, R. (1991) "Introducción. El sujeto de la ciencia y el sujeto del inconciente". En: R. Dorey; C. Castoriadis; E. Enriquez; R. Thom; J. Ménéchal; W.-H. Fridman; G. Berquez; A. Green, El inconciente y la ciencia (pp. 11-20). Buenos Aires: Amorrortu.

Douven, I. (2011). Abduction. In: E. N. Zalta (ed.), The Stanford Encyclopedia of Philosophy. Recuperado de: http://plato.stanford.edu/entries/abduction/

Doyle, A. C. (1887/2004). Estudio en Escarlata. Córdoba: Ediciones del Sur.

Dreher, A. (2000). Foundations for Conceptual Research. London, Karnac Books.

Dreher, A. (2005). "Conceptual research". In Person, E.S., Cooper, A.M. and Gabbard, G.O. (eds). Textbook of Psychoanalysis. Arlington, VA: American Psychiatric Publishing, Inc.

Duhem, P. (1914/2003). La teoría física. Su objeto y su estructura. Barcelona: Herder.

Eagle, M. \& Wakefield, J. (2004). "How NOT to escape from the Grünbaum Syndrome: A critique of the "new view" of psychoanalysis." In: Ann Casement (ed), Who owns psychoanalysis? (pp. 343-361). London: Karnac.

Eagle, M. (1984). Recent Developments in Psychoanalysis: A Critical Evaluation. New York: McGraw-Hill.

Eagle, M., \& Wolitzky, D. (2011). Systematic empirical research versus clinical case studies: a valid antagonism? Journal of the American Psychoanalytic Association, 59 (4), 791 818.

Earman, J. (1992). Bayes or bust? A critical examination of Bayesian confirmation theory. Cambridge: MIT.

Echeverría, J. (1995). Filosofía de la ciencia. Madrid: Akal.

Echevarría, R. (2013). Las telarañas del psicoanálisis. Falsación, validez y consenso en la investigación psicoanalítica. Temas de Psicoanálisis, 6, 1-45.

Eco, U. (1968/1986). La estructura ausente. Introducción a la semiótica. Barcelona: Lumen.

Eco, U. (1989). "Cuernos, cascos, zapatos: algunas hipótesis sobre tres tipos de abducción”. En: U. Eco y T. Sebeok (eds.), El signo de los tres. Dupin, Holmes, Peirce (pp. 265294). Barcelona: Lumen.

Eco, U. (1992). Los límites de la interpretación. Barcelona: Lumen

Edelson, M. (1984). Hypothesis and Evidence in Psychoanalysis. Chicago: The University of Chicago Press.

Edelson, M. (1988). Psychoanalysis: A Theory in Crisis. Chicago: University of Chicago Press. 
Eidelsztein, A. (2015). Otro Lacan: Estudio crítico sobre los fundamentos del psicoanálisis lacaniano. Buenos Aires: Letra Viva.

Epstein, R. (2010). "Psicoanálisis y epistemología: aportes a un encuentro demorado". En C. Hidalgo \& V. Tozzi (comp.). Filosofía para la ciencia y la sociedad. Indagaciones en honor a Félix Gustavo Schuster, (pp. 265-280). Buenos Aires: Facultad de Filosofía y Letras de la UBA.

Erwin, E. (1993). "Philosophers on Freudianism: An examination of replies to Grünbaum's Foundations". In: J., Earman (ed.), Philosophical Problems of the Internal and External Worlds: Essays on the Philosophy of Adolf Grünbaum. Pittsburgh: University of Pittsburgh Press.

Erwin, E. (1996). A final accounting: Philosophical and empirical issues in Freudian psychology. Massachusetts: Mit Press.

Erwin, E. (2015). "Psychoanalysis and philosophy of science: basic evidence". In: S. Boag, L. Brakel \& V. Talvitie (Eds.), Philosophy, Science, and Psychoanalysis. A critical meeting, (pp. 37-58). London: Karnac.

Escars, C. (2006). Historia y función de las traducciones freudianas. Revista Universitaria de Psicoanálisis, 6, 135-151.

Escars, C. J. (2011a). "La interpretación y sus tradiciones". En: C. J. Escars (comp.), La trama de la interpretación. Lógica y condición de las operaciones del analista (pp. 1320). Buenos Aires: Letra Viva.

Escars, C. J. (2011b). “Si ustedes lo prefieren...”. En: C. J. Escars (comp.), La trama de la interpretación. Lógica y condición de las operaciones del analista (pp. 107-113). Buenos Aires: Letra Viva.

Esterson, A. (1993). Seductive mirage. An exploration of the Work of Sigmund Freud. Illinois: Open Court.

Esterson, A. (2005/2007). La teoría de la seducción: un mito para nuestro tiempo. En: Mayer, C. (Ed.). El libro negro del psicoanálisis. Vivir, pensar y sentirse mejor sin Freud. Buenos Aires: Sudamericana.

Etchegoyen, R. H. (1986/2009). Los fundamentos de la técnica psicoanalítica. Buenos Aires: Amorrortu.

Etchegoyen, R. H. (1999). Un ensayo sobre la interpretación psicoanalítica. Buenos Aires: Polemos.

Etchegoyen, R. H. (2001). Algo más sobre el testeo del proceso clínico. Subjetividad y procesos cognitivos, $1,34-59$.

Evans, J. \& Over, D. (1996). Rationality and Reasoning. East Sussex: Psychology Press. 
Eysenck, H. J. (1985/2004). Decadencia y caída del imperio freudiano. Buenos Aires: La editorial virtual. (Disponible en http://www.laeditorialvirtual.com.ar/pages/ Eysenck/ Eysenck Freud_01.htm)

Fann, K. T. (1970). Peirce's Theory of Abduction. La Haya: Nijhoff.

Ferenczi, S. (1911/1984). "Sobre la historia del movimiento psicoanalítico". En Obras Completas. Tomo I, 1908-1912. Madrid: Espasa-Calpe.

Ferenczi, S. (1928/1984). "Elasticidad de la técnica psicoanalítica". En Obras completas de Sándor Ferenczi, Tomo III. Madrid: Espasa-Calpe.

Ferrater Mora, J. (1965). Diccionario de filosofía. Tomo II. Buenos Aires: Sudamericana.

Feyerabend, P. (1970/1975). “Consuelos para el especialista”. En Lakatos, I. \& Musgrave, A. (eds.). La crítica y el desarrollo del conocimiento. Barcelona: Grijalbo.

Feyerabend, P. (1975/1986). Tratado contra el método. Esquema de una teoría anarquista del conocimiento. Madrid: Taurus.

Feyerabend, P. (1981a). "An Attempt at a Realistic Interpretation of Expenence". In: Realism, Rationalism and Scientific Method (pp. 17-36). New York: Cambridge University Press.

Feyerabend, P. (1981b). "Philosophy of science versus scientific practice: observation on Mach, his followers and his opponents". In: Problems of Empiricism. Philosophical Papers, Volume 2. (pp. 80-88). New York: Cambridge University Press.

Fisher, S. \& Greenberg, R. (1996). Freud scientifically reappraised: Testing the theories and therapy. New York: Wiley \& Sons.

Flew, A. (1949). Psychoanalytic explanation. Analysis, 10, 8-15.

Føllesdal, D. (1979). Hermeneutics and the hypothetico - deductive method. Dialéctica, 33(34), 319-336.

Fonagy, P. (1982). The integration of psychoanalysis and experimental science: a review. International Review of Psycho-Analysis, 9, 125-145.

Fonagy, P. (1999). Reflections on psychoanalytic research problems - an anglosaxon view. In: An Open door review of outcome studies in psychoanalysis (pp. 10-27). Londres, IPA Report.

Fonagy, P. (2000). Grasping the nettle: Or why psychoanalytic research is such an irritant. The British Psycho-Analytical Society, 36, 28-36.

Fonagy, P. (2003). Genética, psicopatología evolutiva y teoría psicoanalítica: el argumento para terminar con nuestro (no tan) espléndido aislamiento. Aperturas psicoanalíticas: Revista de psicoanálisis, (15)2.

Fonagy, P. (2015). La eficacia de las psicoterapias psicodinámicas: una actualización. World Psychiatry (en español), 14, 137-150.

Freud, S. \& Breuer, J. (1895/2004). "Estudios sobre la histeria". En Obras Completas, tomo II. Buenos Aires: Amorrortu. 
Freud, S. \& Ferenczi, S. (2001). Correspondencia completa. Madrid: Síntesis.

Freud, S. \& Pfister, O. (1966). Correspondencia 1909-1939. México: Fondo de Cultura Económica.

Freud, S. (1888a/2004). "Histeria". En Obras Completas, tomo I. Buenos Aires: Amorrortu.

Freud, S. (1888b/2004). "Prólogo a la traducción de H. Bernheim, De la suggestion". En Obras Completas, tomo I. Buenos Aires: Amorrortu.

Freud, S. (1892a/2004). "Prólogo y notas de la traducción de J.-M. Charcot, Leçons du mardi à la Salpêtrière". En Obras Completas, tomo I. Buenos Aires: Amorrortu.

Freud, S. (1892b/2004). "Un caso de curación por hipnosis. Con algunas puntualizaciones sobre la génesis de síntomas histéricos por obra de la «voluntad contraria»". En Obras Completas, tomo I. Buenos Aires: Amorrortu.

Freud, S. (1893a/2004). "Algunas consideraciones con miras a un estudio comparativo de las parálisis motrices orgánicas e histéricas." En Obras Completas, tomo I. Buenos Aires: Amorrortu.

Freud, S. (1893b/2004). "Sobre el mecanismo psíquico de fenómenos histéricos". En Obras Completas, tomo III. Buenos Aires: Amorrortu.

Freud, S. (1894/2004). "Las neuropsicosis de defensa. (Ensayo de una teoría de la histeria adquirida, de muchas fobias y representaciones obsesivas y de ciertas psicosis alucinatorias)". En Obras Completas, tomo III. Buenos Aires: Amorrortu.

Freud, S. (1895/2004). "A propósito de las críticas a la «neurosis de angustia»". En Obras Completas, tomo III. Buenos Aires: Amorrortu.

Freud, S. (1896a/2004). "La herencia y la etiología de las neurosis". En Obras Completas, tomo III. Buenos Aires: Amorrortu.

Freud, S. (1896b/2004). "Nuevas puntualizaciones sobre las neuropsicosis de defensa". En Obras Completas, tomo III. Buenos Aires: Amorrortu.

Freud, S. (1896c/2004). "La etiología de la histeria". En Obras Completas, tomo III. Buenos Aires: Amorrortu.

Freud, S. (1900a/2004). "La interpretación de los sueños (primera parte)". En Obras Completas, tomo IV. Buenos Aires: Amorrortu.

Freud, S. (1900b/2004). "La interpretación de los sueños (segunda parte)". En Obras Completas, tomo IV. Buenos Aires: Amorrortu.

Freud, S. (1901/2004). "Psicopatología de la vida cotidiana. (Sobre el olvido, los deslices en el habla, el trastrocar las cosas confundido, la superstición y el error)". En Obras Completas, tomo VI. Buenos Aires: Amorrortu.

Freud, S. (1905a/2004). "Sobre psicoterapia". En Obras Completas, tomo VII. Buenos Aires: Amorrortu. 
Freud, S. (1905b/2004). "Fragmento de análisis de un caso de histeria". En Obras Completas, tomo VII. Buenos Aires: Amorrortu.

Freud, S. (1905c/2004). "El chiste y su relación con lo inconciente". En Obras Completas, tomo VIII. Buenos Aires: Amorrortu.

Freud, S. (1905d/2004). "Tres ensayos de teoría sexual". En Obras Completas, tomo VII. Buenos Aires: Amorrortu.

Freud, S. (1906/2004). "Mis tesis sobre el papel de la sexualidad en la etiología de las neurosis". En Obras Completas, tomo VII. Buenos Aires: Amorrortu.

Freud, S. (1907/2004). "El delirio y los sueños en la «Gradiva» de W. Jensen". En Obras Completas, tomo IX. Buenos Aires: Amorrortu.

Freud, S. (1908/2004). "Prólogo a Wilhelm Stekel, Nervöse Angstzustande und ihre Behandlung". En Obras Completas, tomo IX. Buenos Aires: Amorrortu.

Freud, S. (1909/1974) "Carta del 18 de junio de 1909". In: W. McGuire (ed.), The Freud-Jung Letters: The Correspondence Between Sigmund Freud and CG Jung. Princeton: Princeton University Press.

Freud, S. (1909a/2004). "Análisis de la fobia de un niño de cinco años". En Obras Completas, tomo X. Buenos Aires: Amorrortu.

Freud, S. (1909b/2004). "A propósito de un caso de neurosis obsesiva". En Obras Completas, tomo X. Buenos Aires: Amorrortu.

Freud, S. (1910a/2004). "Cinco conferencias sobre psicoanálisis". En Obras Completas, tomo XI. Buenos Aires: Amorrortu.

Freud, S. (1910b/2004). "Sobre el psicoanálisis «silvestre»". En Obras Completas, tomo XI. Buenos Aires: Amorrortu.

Freud, S. (1911/2004). "El uso de la interpretación de los sueños en el psicoanálisis". En Obras Completas, tomo XII. Buenos Aires: Amorrortu.

Freud, S. (1912a/2004). "Consejos al médico sobre el tratamiento psicoanalítico". En Obras Completas, tomo XII. Buenos Aires: Amorrortu.

Freud, S. (1912b/2004). "Sobre la dinámica de la transferencia". En Obras Completas, tomo XII. Buenos Aires: Amorrortu.

Freud, S. (1913a/2004). "Sobre la iniciación del tratamiento (Nuevos consejos sobre la técnica del psicoanálisis, I). En Obras Completas, tomo XII. Buenos Aires: Amorrortu.

Freud, S. (1913b/2004). "Sobre psicoanálisis". En Obras Completas, tomo XII. Buenos Aires: Amorrortu.

Freud, S. (1913c/2004). "El interés por el psicoanálisis". En Obras Completas, tomo XIII. Buenos Aires: Amorrortu. 
Freud, S. (1913d/2004). "Tótem y tabú. Algunas concordancias en la vida anímica de los salvajes y de los neuróticos". En Obras Completas, tomo XIII. Buenos Aires: Amorrortu.

Freud, S. (1914a/2004). "Recordar, repetir y reelaborar (Nuevos consejos sobre la técnica del psicoanálisis, II)". En Obras Completas, tomo XII. Buenos Aires: Amorrortu.

Freud, S. (1914b/2004). "Contribución a la historia del movimiento psicoanalítico". En Obras Completas, tomo XIV. Buenos Aires: Amorrortu.

Freud, S. (1914c/2004). "El Moisés de Miguel Ángel". En Obras Completas, tomo XIII. Buenos Aires: Amorrortu.

Freud, S. (1915a/ 2004). "Pulsiones y destinos de pulsión". En Obras Completas, tomo XIV. Buenos Aires: Amorrortu.

Freud, S. (1915b/2004). "Lo inconciente". En Obras Completas, tomo XIV. Buenos Aires: Amorrortu.

Freud, S. (1915c/2004). "Puntualizaciones sobre el amor de trasferencia (Nuevos consejos sobre la técnica del psicoanálisis, III)". En Obras Completas, tomo XII. Buenos Aires: Amorrortu.

Freud, S. (1915d/2004). "Un caso de paranoia que contradice la teoría psicoanalítica". En Obras Completas, tomo XIV. Buenos Aires: Amorrortu.

Freud, S. (1917/1970). "Carta a Georg Groddeck del 5 de junio de 1917". En: Epistolario (Trad. De J. Merino Pérez). Barcelona: Plaza y Janes.

Freud, S. (1917a/2004). "Conferencias de introducción al psicoanálisis. $16^{\circ}$ conferencia. Psicoanálisis y psiquiatría". En Obras Completas, tomo XVI. Buenos Aires: Amorrortu.

Freud, S. (1917b/2004). "Conferencias de introducción al psicoanálisis. $27^{\circ}$ Conferencia. La trasferencia". En Obras Completas, tomo XVI. Buenos Aires: Amorrortu.

Freud, S. (1917c/2004). "Conferencias de introducción al psicoanálisis. $28^{\circ}$ conferencia. La terapia analítica". En Obras Completas, tomo XVI. Buenos Aires: Amorrortu.

Freud, S. (1917d/2004). "Conferencias de introducción al psicoanálisis. 10 conferencia. El simbolismo en el sueño". En Obras Completas, tomo XV. Buenos Aires: Amorrortu.

Freud, S. (1917e/2004). "Conferencias de introducción al psicoanálisis. $6^{\circ}$ conferencia. Premisas y técnica de la interpretación." En Obras Completas, tomo XV. Buenos Aires: Amorrortu.

Freud, S. (1917f/2004). "Conferencias de introducción al psicoanálisis. $3^{\circ}$ conferencia. Los actos fallidos (continuación)". En Obras Completas, tomo XV. Buenos Aires: Amorrortu.

Freud, S. (1917g/2004). "Conferencias de introducción al psicoanálisis. 24 conferencia. El estado neurótico común". En Obras Completas, tomo XVI. Buenos Aires: Amorrortu. 
Freud, S. (1917h/2004). "Conferencias de introducción al psicoanálisis. 23 conferencia. Los caminos de la formación de síntoma”. En Obras Completas, tomo XVI. Buenos Aires: Amorrortu.

Freud, S. (1917i/2004). "Conferencias de introducción al psicoanálisis. $17^{\circ}$ conferencia. El sentido de los síntomas". En Obras Completas, tomo XVI. Buenos Aires: Amorrortu.

Freud, S. (1917j/2004). "Conferencias de introducción al psicoanálisis. $22^{\circ}$ conferencia. Algunas perspectivas sobre el desarrollo y la regresión. Etiología". En Obras Completas, tomo XVI. Buenos Aires: Amorrortu.

Freud, S. (1918/2004). "De la historia de una neurosis infantil". En Obras Completas, tomo XVII. Buenos Aires: Amorrortu.

Freud, S. (1919a/2004). "Lo ominoso". En Obras Completas, tomo XVII. Buenos Aires: Amorrortu.

Freud, S. (1919b/2004). "Nuevos caminos de la terapia psicoanalítica". En Obras Completas, tomo XVII. Buenos Aires: Amorrortu.

Freud, S. (1920a/2004). "Más allá del principio de placer". En Obras Completas, tomo XVIII. Buenos Aires: Amorrortu.

Freud, S. (1920b/2004). "Sobre la psicogénesis de un caso de homosexualidad femenina". En Obras Completas, tomo XVIII. Buenos Aires: Amorrortu.

Freud, S. (1921a/2004). "Psicoanálisis y telepatía". En Obras Completas, tomo XVIII. Buenos Aires: Amorrortu.

Freud, S. (1921b/2004). "Psicología de las masas y análisis del yo". En Obras Completas, tomo XVIII. Buenos Aires: Amorrortu.

Freud, S. (1923a/2004). "Dos artículos de enciclopedia: «Psicoanálisis» y «Teoría de la libido»". En Obras Completas, tomo XVIII. Buenos Aires: Amorrortu.

Freud, S. (1923b/2004). "Observaciones sobre la teoría y la práctica de la interpretación de los sueños". En Obras Completas, tomo XIX. Buenos Aires: Amorrortu.

Freud, S. (1923c/2004). "El yo y el ello". En Obras Completas, tomo XIX. Buenos Aires: Amorrortu.

Freud, S. (1923d/2004). “Josef Popper-Lynkeus y la teoría del sueño". En Obras Completas, tomo XIX. Buenos Aires: Amorrortu.

Freud, S. (1924/2004). "Breve informe sobre el psicoanálisis". En Obras Completas, tomo XIX. Buenos Aires: Amorrortu.

Freud, S. (1925a/2004). "Las resistencias contra el psicoanálisis". En Obras Completas, tomo XIX. Buenos Aires: Amorrortu.

Freud, S. (1925b/2004). "Presentación autobiográfica". En Obras Completas, tomo XX. Buenos Aires: Amorrortu. 
Freud, S. (1926a/2004). "Alocución ante los miembros de la Sociedad B'nai B'rith". En Obras Completas, tomo XX. Buenos Aires: Amorrortu.

Freud, S. (1926b/2004). “¿Pueden los legos ejercer el análisis? Diálogos con un juez imparcial". En Obras Completas, tomo XX. Buenos Aires: Amorrortu.

Freud, S. (1926c/2004). "Inhibición, síntoma y angustia". En Obras Completas, tomo XX. Buenos Aires: Amorrortu.

Freud, S. (1926d/2004). "Psicoanálisis". En Obras Completas, tomo XX. Buenos Aires: Amorrortu.

Freud, S. (1927/2004). "El porvenir de una ilusión". En Obras Completas, tomo XXI. Buenos Aires: Amorrortu.

Freud, S. (1930a/2004). "EI malestar en la cultura", en Obras Completas, tomo XXI. Buenos Aires: Amorrortu.

Freud, S. (1930b/2004). "Premio Goethe". En Obras Completas, tomo XXI. Buenos Aires: Amorrortu.

Freud, S. (1932/2004). "Mi contacto con Josef Popper-Lynkeus”, en Obras Completas, tomo XXII. Buenos Aires: Amorrortu.

Freud, S. (1933a/2004). "Nuevas conferencias de introducción al psicoanálisis. 33 conferencia. La feminidad". En Obras Completas, tomo XXII. Buenos Aires: Amorrortu.

Freud, S. (1933b/2004). "Nuevas conferencias de introducción al psicoanálisis. $34^{\circ}$ conferencia. Esclarecimientos, aplicaciones, orientaciones". En Obras Completas, tomo XXII. Buenos Aires: Amorrortu.

Freud, S. (1933c/2004). "Nuevas conferencias de introducción al psicoanálisis. 35 conferencia. En torno de una cosmovisión”. En Obras Completas, tomo XXII. Buenos Aires: Amorrortu.

Freud, S. (1933d/2004). "Nuevas conferencias de introducción al psicoanálisis. 31 conferencia. La descomposición de la personalidad psíquica”. En. Obras Completas, tomo XXII. Buenos Aires: Amorrortu.

Freud, S. (1937/2004). "Construcciones en el análisis". En Obras Completas, tomo XXIII. Buenos Aires: Amorrortu.

Freud, S. (1939/2004). "Moisés y la religión monoteísta". En Obras Completas, tomo XXIII. Buenos Aires: Amorrortu.

Freud, S. (1940/2004). "Esquema del psicoanálisis". En Obras Completas, tomo XXIII. Buenos Aires: Amorrortu.

Freud, S. (1968). Correspondencia Sigmund Freud/Lou Andreas-Salomé. Comp. de Ernst Pfeiffer, trad. de Carlos Gerhard. México: Siglo XXI.

Freud, S. (1985/1986). Cartas a Wilhelm Fließ. 1887-1904. Editadas por Jeffrey Moussaieff Masson. Buenos Aires: Amorrortu. 
Fusella, P. (2014). Hermeneutics versus science in psychoanalysis: a resolution to the controversy over the scientific status of psychoanalysis. Psychoanalytic review, 101(6), 871-894.

Gadamer, H. G. (1960/1999). Verdad y Método I. Salamanca: Sígueme.

Gadamer, H. G. (1977/1998). “Autopresentación de Hans-Georg Gadamer”. En: Verdad y Método II, (pp. 375-402). Salamanca: Sígueme.

Gadamer, H. G. (1985/1998). "Entre fenomenología y dialéctica. Intento de una autocrítica". En: Verdad y Método II, (pp. 11-32). Salamanca: Sígueme.

Gaeta, R. (2008). Descubrimiento, justificación e inferencia a la mejor explicación. Principia, 12(2), 193-202.

Gaeta, R. (2012). El fantasma del positivismo en las ciencias sociales. Filosofía Unisinos, 13(2-suppl.), 225-249.

Gallo, H., \& Ramírez, M. E. (2012). El psicoanálisis y la investigación en la universidad. Buenos Aires: Grama.

Gardner, S. (1993). Irrationality and the Philosophy of Psychoanalysis. Cambridge: Cambridge University Press.

Gauchet, M. \& Swain, G. (1997/2000). El verdadero Charcot. Los caminos imprevistos del inconsciente. Buenos Aires: Nueva Visión.

Gentile, A. M. (2008). La terminología del discurso del psicoanálisis francés/español: Un estudio sobre la noción de "funcionamiento polinómico». Hermeneus: Revista de la Facultad de Traducción e Interpretación de Soria, 10, 83-108.

Gill, M. (1976). "Metapsychology is not psychology". In: M. Gill \& P. Holzman (dirs.), Psychology versus metapsychology. Psychoanalytic essays in memory of George S. Klein (pp. 71-105). Nueva York: Basic Books.

Gill, M. (1983). The point of view of psychoanalysis: Energy discharge or person? Psychoanalysis \& Contemporary Thought, 6, 523-552.

Ginzburg, C. (1989). "Morelli, Freud y Sherlock Holmes: indicios y método científico". En U. Eco y T. Sebeok (eds.), El signo de los tres. Dupin, Holmes, Peirce (pp. 116-163). Barcelona: Lumen.

Glover, E. (1931/1970). El efecto terapéutico de la interpretación inexacta. Revista de Psicoanálisis, 27(4), 827-844.

Glymour, C. (1974). "Freud, Kepler, and the clinical evidence". In: R. Wollheim (ed.), Freud: A Collection of Critical Essays, 285-304. New York: Doubleday.

Glymour, C. (1980). Theory and Evidence. Princeton: Princeton University Press.

Glymour, C. (1982). "Afterword to Freud, Kepler, and the clinical evidence". In: R. Wollheim \& J. Hopkins (eds.) Philosophical essays on Freud, pp. 12-31. London: Cambridge University Press. 
Glymour, C. (1983). "The Theory of Your Dreams". In: R. S. Cohen \& L. Laudan (eds.), Physics, philosophy, and psychoanalysis. Essays in Honor of Adolf Grünbaum (pp. 5772). Dordrecht: Reidel.

Goldberg, A. (1984). The tension between realism and relativism in psychoanalysis. Psychoanalysis \& Contemporary Thought, 7:367-386.

Gomez, L. (2005). The Freud Wars. An introduction to the philosophy of psychoanalysis. London: Routledge.

Gómez, R. J. (1995). Neoliberalismo y seudociencia. Buenos Aires: Lugar.

Gómez, R. J. (2004). La polémica Mach-Planck: ¿ni vencedores ni vencidos? Análisis Filosófico, XXIV(1), 5-27.

Gómez, R. J. (2014). "Hacia una filosofía política del conocimiento científico". En: M. C. Di Gregori, L. Rueda y L. Mattarollo (coord.). El conocimiento como práctica. Investigación, valoración, ciencia y difusión, (pp. 149-168). La Plata: Facultad de Humanidades y Ciencias de la Educación Universidad Nacional de La Plata

Gould, S. J. (2003/2004). Érase una vez el zorro y el erizo: Las humanidades y la ciencia en el tercer milenio. Barcelona: Crítica.

Green, A. (1991/1993). "Desconocimiento del inconciente (ciencia y psicoanálisis)". En: R. Dorey, C. Castoriadis, E. Enriquez, R. Thom, J. Ménéchal, W. Fridman, G. Berquez y A. Green, El inconciente y la ciencia, pp. 167-257. Buenos Aires: Amorrortu.

Green, A. (1995/2005). La causalidad psíquica. Entre naturaleza y cultura. Buenos Aires: Amorrortu.

Green, A. (2000/2010). El pensamiento clínico. Buenos Aires, Amorrortu.

Green, A. (2000a). "Science and science fiction in infant research". In: J., Sandler; A.-M., Sandler; R., Davies (eds.). Clinical and observational psychoanalytic research: Roots of a controversy. André Green \& Daniel Stern (41-72). London: Karnac.

Green, A. (2000b). "What kind of research for psychoanalysis?" In: J., Sandler; A.-M., Sandler; R., Davies (eds.). Clinical and observational psychoanalytic research: Roots of a controversy. André Green \& Daniel Stern (pp. 21-26). London: Karnac.

Green, A. (2000c). "Response to Robert S. Wallerstein". In: J., Sandler; A.-M., Sandler; R., Davies (eds.). Clinical and observational psychoanalytic research: Roots of a controversy. André Green \& Daniel Stern. (pp. 32-37). London and New York: Karnac.

Green, A. (2001/2015). "El pensamiento clínico. Renovar los fundamentos de la técnica: el encuadre externo y el encuadre interno". En Green, A. \& Urribarri, F. Del pensamiento clínico al paradigma contemporáneo. Conversaciones, (pp. 73-91). Buenos Aires: Amorrortu.

Green, A. (2003/2011). El pluralismo de las ciencias y el pensamiento psicoanalítico. Revista de Psicoanálisis, 2-3, 283-301. 
Green, A. (2005/2006). La ilusión del terreno común y el pluralismo mítico. Psicoanálisis, 28 (3), 657-665.

Grondin, J. (1991/1999). Introducción a la hermenéutica filosófica. Barcelona: Herder.

Grünbaum, A. (1976a). Is falsifiability the touchstone of scientific rationality? Karl Popper versus inductivism. In: R. S. Cohen, P. K. Feyerabend, M. W. Wartofsky (Eds.), Essays in Memory of Imre Lakatos (pp. 213-252). Netherlands: Reidel.

Grünbaum, A. (1976b). Can a Theory Answer more Questions than one of its Rivals? British Journal for the Philosophy of Science, 1-23.

Grünbaum, A. (1976c). Is the method of bold conjectures and attempted refutations justifiably the method of science?. The British Journal for the Philosophy of Science, 27(2), 105136.

Grünbaum, A. (1976d). Ad hoc auxiliary hypotheses and falsificationism. The British Journal for the Philosophy of Science, 27(4), 329-362.

Grünbaum, A. (1977a). How scientific is psychoanalysis? In R. Stern, L.S. Horowitz, and J. Lynes (eds.), Science and Psychotherapy, pp. 219-254. New York: Haven Publishing.

Grünbaum, A. (1977b). Is Psychoanalysis a Pseudo-Science? Karl Popper versus Sigmund Freud. Part I. Zeitschrift für philosophische Forschung, 31 (3) 333-353.

Grünbaum, A. (1978a). Is Psychoanalysis a Pseudo-Science? Karl Popper versus Sigmund Freud. Part II. Zeitschrift für philosophische Forschung, 32 (1) 49-69.

Grünbaum, A. (1978b). "Popper vs Inductivism". In: G. Radnitzky \& G. Andersson (eds.), Progress and Rationality in Science, pp. 117-142. Dordrecht: Reidel.

Grünbaum, A. (1979a). Is Freudian psychoanalytic theory pseudo-scientific by Karl Popper's criterion of demarcation?. American Philosophical Quarterly, 16 (2), 131-141.

Grünbaum, A. (1979b). Epistemological Liabilities of the Clinical Appraisal of Psychoanalytic Theory. Psychoanalysis and Contemporary Thought, 2, 451-526.

Grünbaum, A. (1980). Epistemological liabilities of the clinical appraisal of psychoanalytic theory. Noûs, 14, 307-385.

Grünbaum, A. (1981). The placebo concept. Behaviour research and therapy, 19 (2), 157167.

Grünbaum, A. (1982). Can Psychoanalytic Theory be Cogently Tested on the Couch? Psychoanalysis \& Contemporary Thought, 5(2), 155-255 (parte 1) y 311-436 (parte 2).

Grünbaum, A. (1983a). Logical foundations of psychoanalytic theory. Erkenntnis, 19, 109152.

Grünbaum, A. (1983b). Retrospective versus Prospective Testing of Aetiological Hypotheses in Freudian Theory. In J. Earman (ed.), Testing Scientific Theories. Minnesota Studies in the Philosophy of Science, vol. X, (315-348). Minneapolis: University of Minnesota Press. 
Grünbaum, A. (1983c). Is object-relations theory better founded than orthodox psychoanalysis? A reply to Jane Flax. The Journal of Philosophy, 80, 46-51.

Grünbaum, A. (1983d). "Freud's Theory: The Perspective of a Philosopher of Science", Presidential Address to the American Philosophical Association (Eastern Division, December 1982). Proceedings \& Addresses of The American Philosophical Association 57 (1), 5-31.

Grünbaum, A. (1984). The Foundations of Psychoanalysis: A Philosophical Critique. California: University of California Press.

Grünbaum, A. (1986a). Précis of The Foundations of Psychoanalysis: A Philosophical Critique. Behavioral and Brain Sciences, 9 (2), 217-228.

Grünbaum, A. (1986b). The validity of hidden motives in psychoanalytic theory. Conferencia pronunciada en la Universidad Johns Hopkins, Baltimore, April 9 de 1986.

Grünbaum, A. (1988). The Role of the Case Study Method in the Foundations of Psychoanalysis. Canadian Journal of Philosophy, 18 (4), 623-658.

Grünbaum, A. (1990). "Meaning" Connections and Causal Connections in the Human Sciences: The Poverty of Hermeneutic Philosophy. Journal of the American Psychoanalytical Association, 38, 559-577.

Grünbaum, A. (1993). Validation in the clinical theory of psychoanalysis: $A$ study in the philosophy of psychoanalysis. Madison: International Universities Press.

Grünbaum, A. (1994a). Freud's Permanent Revolution: An Exchange. The New York Review of Books, 41(14), 54-55.

Grünbaum, A. (1994b). Reply to Louis Berger's Review of Validation in the Clinical Theory of Psychoanalysis. Psychoanalytic Books, 5(1), 154-167.

Grünbaum, A. (2002/2015). "Critique of Psychoanalysis". In: S. Boag, L. Brakel \& V. Talvitie (Eds.), Philosophy, Science, and Psychoanalysis. A critical meeting, (pp. 1-36). London: Karnac.

Grünbaum, A. (2006). Is Sigmund Freud's psychoanalytic edifice relevant to the 21st century? Psychoanalytic Psychology, 23(4), 257-284.

Grünbaum, A. (2007). The reception of my Freud-critique in the psychoanalytic literature. Psychoanalytic Psychology, 24(3), 545-576.

Grünbaum, A. (2008). An autobiographical-philosophical narrative. In: A. Jokić (Ed.), Philosophy of religion, physics and psychology: essays in honor of Adolf Grünbaum. Amherst, NY: Prometheus Books.

Grünbaum, A. (2009). Popper's Fundamental Misdiagnosis of the Scientific Defects of Freudian Psychoanalysis. In: Z. Parusniková \& R. S. Cohen (Eds.), Rethinking Popper. Netherlands: Springer. 
Gunderson, J.G., \& Gabbard, G.O. (1998). Making the case for psychoanalytic therapies in the current psychiatric environment. Journal of the American Psychoanalytic Association, 47, 679-704.

Habermas, J. (1968/1990). Conocimiento e interés. Buenos Aires: Taurus.

Habermas, J. (1969/1973). "Contra un racionalismo menguado de modo positivista". En: T. Adorno, K. Popper, R. Dahrendorf, J. Habermas, H. Albert y H. Pilot, La disputa del positivismo en la sociología alemana, (pp. 221-250). Barcelona: Grijalbo.

Habermas, J. (1982/1988). La lógica de las ciencias sociales. Madrid: Tecnos.

Hacking, I. (1981/1985). “La Filosofía de la Ciencia según Lakatos”. En Hacking, lan (Ed.). Revoluciones Científicas. México: Fondo de Cultura Económica.

Hacking, I. (1983/1996). Representar e intervenir. México: Paidós.

Hanly, C. (1988). Book Review of A. Grünbaum's The foundations of psychoanalysis. Journal of the American Psychoanalytic Association, 36(2), 521-528.

Hanly, C. (1994). Popper and Grünbaum on Psychoanalytic Knowledge: A Response to J. A. O'Neil. Canadian Journal of Psychoanalysis, 2, 65-73.

Hanson, N. R. (1958/1977). Patrones de descubrimiento. Observación y explicación. Madrid: Alianza.

Harman, G. (1965). The Inference to the Best Explanation. The Philosophical Review, 74 (1), 88-95.

Harman, G. (1968). Enumerative Induction as Inference to the Best Explanation. The Journal of Philosophy, 65 (18), 529-533.

Hartmann, H. (1927). Die Grundlagen der Psychoanalyse. Leipzig: Thieme.

Heidegger, M. (1927/1998). Ser y tiempo. Santiago de Chile: Edición electrónica de la Escuela de Filosofía de la Universidad ARCIS; disponible en www.philosophia.cl

Hempel, C. G. (1943). A Purely Syntactical Definition of Confirmation, The Journal of Symbolic Logic, 8, 127-143.

Hempel, C. G. (1945). Studies in the Logic of Confirmation, Mind, 54, 1-26 y 97-121.

Hempel, C. G. (1965/1996). La explicación científica. Estudios sobre la filosofía de la ciencia. Buenos Aires: Paidós.

Hempel, C. G. (1966/1999). Filosofía de la Ciencia Natural. Madrid: Alianza.

Henry W., Strupp H., Schacht T. y Gaston L. (1994). Psychodynamic Approaches. In: Bergin \& Garfield, Handbook of Psychotherapy and Behavior Change (pp. 467-508). New York: Wiley.

Hintikka, J. (1998). "What is Abduction? The Fundamental Problem of Contemporary Epistemology". Transactions of the Charles S. Peirce Society, XXIV (3), 503-533. 
Hoffman, I. Z. (2009). Doublethinking our way to "scientific" legitimacy: The desiccation of human experience. Journal of the American Psychoanalytic Association, 57(5), 10431069.

Hoffman, I. Z. (2012). Response to Eagle and Wolitzky. Journal of the American Psychoanalytic Association, 60(1), 105-120.

Hofmann S. G. (2016). Psychodynamic therapy: a poorly defined concept with questionable evidence. Evidence Based Mental Health, 19: 63.

Holt, R. R. (1981). The death and transfiguration of metapsychology. International Review of Psychoanalysis, 8,129-143.

Holt, R. R. (1984). The current status of psychoanalytic theory. Psychoanalytic Psychology, 2(4), 289-315.

Holt, R. R. (1989). Freud reappraised: a fresh look at psychoanalytic theory. New York: Guilford.

Holzman, P. S. (1985). Psychoanalysis: is the therapy destroying the science? Journal of the American Psychoanalytic Association, 33(4), 725-770.

Home, H. J. (1966). The concept of mind. International Journal of Psychoanalysis, 47, 42-49.

Hook, S. (1959/1964). "Science and Mythology in Psychoanalysis". In: S. Hook (Ed.) Psychoanalysis, Scientific Method, and Philosophy (pp. 212-224). New York: New York University Press.

Hopkins, J. (1982). "Introduction: Philosophy and Psychoanalysis". In: R. Wollheim \& J. Hopkins (eds.), Philosophical Essays on Freud, pp. vii-xlv. Cambridge: Cambridge University Press.

Hopkins, J. (1988). "Epistemology and Depth Psychology: Critical Notes on The Foundations of Psychoanalysis". In: Clarke \& Wright (eds), Mind, Psychoanalysis and Science, pp. 33-60. Oxford: Blackwell.

Hopkins, J. (1993/1996). "La interpretación de los sueños". En, J. Neu. (comp.), Guía de Freud, pp. 102-162. Cambridge: Cambridge University Press.

Hume, D. (1739/2001). Tratado sobre la naturaleza humana. Ensayo para introducir el método del razonamiento experimental en los asuntos morales. Albacete: Servicio de Publicaciones Electrónicas.

Hume, D. (1748/2004). Investigaciones sobre el entendimiento humano; Madrid: Istmo.

Iranzo, L. (2011). “Inferencia a la mejor explicación”. En: L. Vega Reñón y P. Olmos Gómez (Eds.), Compendio de lógica, argumentación y retórica (pp. 301-303). Madrid: Trotta.

Israëls, H (2005/2007). La teoría de la seducción: una idea que no funcionó. En: Mayer, C. (Ed.). El libro negro del psicoanálisis. Vivir, pensar y sentirse mejor sin Freud. Buenos Aires: Sudamericana.

Israëls, H. \& Schatzman, M. (1993). The seduction theory. History of Psychiatry, 4, 23-59. 
Izenberg, G. N. (1991/1996). "Seducidos y abandonados: auge y ocaso de la teoría freudiana de la seducción". Neu, Jerome (comp.). Guía de Freud. Cambridge: Universidad de Cambridge.

Jauss, H. R. (1979/1981). Estética de la recepción y comunicación literaria. Punto de Vista, 12, 34-40.

Jimenez, J. P. (2004). Validez y validación del método psicoanalítico (alegato sobre la necesidad del pluralismo metodológico y pragmático en psicoanálisis). Revista Aperturas Psicoanalíticas, 18.

Jones, E. (1953/1981). Vida y obra de Sigmund Freud. Tomo II. Barcelona: Anagrama.

Josephson, J. \& Tanner, M. (1996). "Conceptual analysis of abduction”. In: J. R. Josephson \& S. G. Josephson (Eds.), Abductive Inference: Computation, Philosophy, Technology. Cambridge: Cambridge University Press.

Juri, L. J. (1999). El psicoanalista neutral ¿un mito? Psicoanálisis y paradigmas. Rosario: Homo Sapiens.

Kächele, H. (1992). Investigación psicoanalítica: 1930-1990. Revista Chilena de Psicoanálisis, 9(1), 55-68.

Kächele, H.; Schachter, J. \& Thomä, H. (2011). From psychoanalytic narrative to empirical single case research: Implications for psychoanalytic practice. New York: Routledge.

Kandel, E. R. (1998) A new intellectual framework for psychiatry. American Journal of Psychiatry, 155, 457-469.

Kandel, E. R. (1999). Biology and the future of psychoanalysis: A new intellectual framework for psychiatry revisited. American Journal of Psychiatry, 156, 505-524.

Kapitan, T. (1992). Peirce and the Autonomy of Abductive Reasoning. Erkenntnis, 37, 1-26.

Kaplan-Solms, K., \& Solms, M. (2000/2005). Estudios clínicos en neuropsicoanálisis: introducción a la neuropsicología profunda. Colombia: Fondo de Cultura Económica.

Kernberg, O. (2006) Research anxiety: A reply to Roger Perron's comments, International Journal of Psychoanalysis, 8, 933-937.

Kitcher, P. (1995). The Advancement of Science. Science without Legend, Objectivity without Illusions. Oxford: Oxford University Press.

Klappenbach, H. (1994). Diferentes problemas y tradiciones en la psicología del siglo XIX. Idea, 14, 63-80.

Klauber, J. (1968). On the dual use of historical and scientific method in psychoanalysis. The International journal of psycho-analysis, 49, 80-88.

Klein, D. B. (1985). Jewish Origins of the Psychoanalytic Movement. Chicago: The University of Chicago Press. 
Klein, G. S. (1976b). Freud's two theories of sexuality. En: M. Gill \& P. Holzman (eds.), Psychology versus Metapsychology. Nueva York: Int. Univ. Press.

Klein, G.S. (1976a) Psychoanalytic Theory. An Exploration of Essential. New York: Int. Univ. Press.

Klimovsky, G. \& Hidalgo, C. (1998/2012). La inexplicable sociedad. Cuestiones de epistemología de las ciencias sociales. Buenos Aires: A-Z.

Klimovsky, G. (1981/2009). "Problemas metodológicos del psicoanálisis", en Epistemología y Psicoanálisis. Vol. 2, Análisis del Psicoanálisis. Buenos Aires: Ediciones Biebel.

Klimovsky, G. (1986/2009). Aspectos epistemológicos de la interpretación psicoanalítica. En: $\mathrm{H}$. Etchegoyen, Los fundamentos de la técnica psicoanalítica (pp. 533-557). Buenos Aires: Amorrortu.

Klimovsky, G. (1987/2009). “Acerca del carácter científico del psicoanálisis". En: Epistemología y Psicoanálisis. Vol. 2: análisis del psicoanálisis, pp. 20-27. Buenos Aires: Biebel.

Klimovsky, G. (1994/2005). Las desventuras del conocimiento científico. Una introducción a la epistemología. Buenos Aires: AZ.

Kline, P. (1972/2014). Fact and fantasy in freudian theory. New York: Routledge.

Kohut, H. (1959/2009). Introspección, empatía y psicoanálisis. Un examen de la relación entre el modo de obsenación y la teoría. Revista de Psicoanálisis, 66(1), 17-40. Originalmente publicado en: Journal of the American Psychoanalytic Association (1959), 7, págs. 459-483.

Kohut, H. (1977). The Restoration of the Self. New York: International University Press.

Kohut, H. (1971/1996). Análisis del self: el tratamiento psicoanalítico de los trastornos narcisistas de la personalidad. Buenos Aires: Amorrortu.

Kolteniuk Krauze, M. (1976). En torno al carácter científico del psicoanálisis. México: Fondo de Cultura Económica.

Korzybski, A. (1994/1933). Science and Sanity: An Introduction to Non-Aristotelian Systems and General Semantics. USA: Institute of General Semantics.

Koyré, A. (1973/1978). Estudios de historia del pensamiento científico. Madrid: Siglo veintiuno.

Kris, E. (1950/1973). "Estudio preliminar", introducción a Los Orígenes del Psicoanálisis. En Freud, S; Obras Completas de Sigmund Freud. Tomo III (3433-3656). Madrid: Biblioteca Nueva.

Krüll, M. (1979/1986). Freud and his father. New York: WW Norton.

Kuhn, T. (1962/2004). La estructura de las revoluciones científicas. México: Fondo de Cultura Económica. 
Kuhn, T. (1970/1977). “Lógica del descubrimiento o psicología de la investigación”; en La tensión esencial. Estudios selectos sobre la tradición y el cambio en el ámbito de la ciencia. Madrid: Fondo de Cultura Económica.

Kuhn, T. (1970/2002). "Consideraciones en torno a mis críticos"; en Conant, J. \& Haugeland, J. (comp.). Thomas S. Kuhn. El camino desde la estructura. Ensayos filosóficos 19701993, con una entrevista biográfica. Barcelona: Paidós.

Kuhn, T. (1971/1987). "Notas sobre Lakatos". En Lakatos, I (comp). Historia de la ciencia y sus reconstrucciones racionales, pp. 79-95. Madrid: Tecnos.

Kuhn, T. (1977/1993). La tensión esencial. Estudios selectos sobre la tradición y el cambio en el ámbito de la ciencia. Madrid: Fondo de cultura económica.

Labastida, J. (2007). El edificio de la razón. El sujeto científico. México: Siglo XXI.

Lacan, J. (1954/2010). El Seminario de Jacques Lacan. Libro 1. Los escritos técnicos de Freud. Buenos Aires: Paidós.

Lacan, J. (1955/1995). El Seminario de Jacques Lacan. Libro 3. Las psicosis. Buenos Aires: Paidós.

Lacan, J. (1964/1987). El Seminario de Jacques Lacan. Libro 11. Los cuatro conceptos fundamentales del psicoanálisis. Buenos Aires: Paidós.

Lacan, J. (1966/1992). Del sujeto por fin cuestionado. En Escritos I, pp. 223-224. Buenos Aires: Siglo XXI.

Lacan, J. (1966/2012). "Respuestas a estudiantes de filosofía". En Otros escritos, (pp. 221229). Buenos Aires: Paidós.

Lacan, J. (1967). Breve discurso a los psiquiatras. Conferencia inédita, obtenida de http://www.teebuenosaires.com.ar/biblioteca/trad_07.pdf

Lacan, J. (1969/2008). El Seminario de Jacques Lacan. Libro 17. El reverso del psicoanálisis. Buenos Aires: Paidós.

Lacan, J. (1974-1975). Seminario 22. R.S.I. Inédito. Versión crítica de Ricardo E. Rodríguez Ponte.

Lacan, J. (1977/2008). El fracaso del Un-desliz es el amor. A la manera del seminario oral de Jacques Lacan 1976-1977. México: Ortega y Ortiz.

Lacan, J. (1977/1978). Seminario 25. El momento de concluir. Inédito. Disponible en http://ecole-lacanienne.net/wp-content/uploads/2016/04/1977.11.15.pdf

Lacewing, M. (2013). The problem of suggestion in psychoanalysis: An analysis and solution. Philosophical Psychology, 26(5), 718-743.

Lakatos, I. (1968/1981). "Cambios en el problema de la lógica inductiva”. En Matemáticas, ciencia y epistemología. Madrid: Alianza.

Lakatos, I. (1971/1987). Historia de la ciencia y sus reconstrucciones racionales. Madrid: Tecnos. 
Lakatos, I. (1976/1978). Pruebas y refutaciones. La lógica del descubrimiento matemático. Madrid: Alianza.

Lakatos, I. (1978/1989). La metodología de los programas de investigación científica. Madrid: Alianza.

Lakatos, I. (1981). Matemáticas, ciencia y epistemología. Escritos Filosóficos, 2. Madrid: Alianza.

Lancelle, G. (1997). El psicoanálisis y la investigación en escorzo desde una perspectiva clínica. Investigación en Psicoanálisis. Revista de la Asociación Psicoanalítica de Buenos Aires, 19(1-2), 119-156.

Laplanche, J. \& Pontalis, J.-B. (1968/1993). Diccionario de psicoanálisis. Buenos Aires: Labor.

Laplanche, J. (1981/1987). El inconsciente y el ello. Problemáticas IV. Buenos Aires: Amorrortu.

Laplanche, J. (1987). La cubeta. Transcendencia de la transferencia. Problemáticas V. Buenos Aires: Amorrortu.

Laplanche, J. (1987/1989). Nuevos fundamentos para el psicoanálisis. La seducción originaria. Buenos Aires: Amorrortu.

Laplanche, J. (1993/2001). "Breve tratado del inconsciente". En: Entre seducción e inspiración: el hombre, (pp.61-98). Buenos Aires: Amorrortu.

Laplanche, J. (1995/2001). "El psicoanálisis como anti-hermenéutica”. En: Entre seducción e inspiración: el hombre, (pp.199-212). Buenos Aires: Amorrortu.

Laplanche, J. (1996). La prioridad del otro en psicoanálisis. Buenos Aires: Amorrortu.

Laplanche, J. (1997/1998). Conversaciones (II) con Jean Laplanche. Conferencia dictada el 25 de octubre 1997 en el Hospital de Niños R. Gutiérrez, La Plata, Argentina como invitado al Seminario de Silvia Bleichmar. Texto establecido por Ariel Viguera. Acheronta, 8. Disponible en: http://www.acheronta.org/acheronta8/laplanche-02.htm

Laplanche, J. (1997/2001). "El psicoanálisis: mitos y teoría”. En: Entre seducción e inspiración: el hombre, (pp.213-236). Buenos Aires: Amorrortu.

Laplanche, J. (1999/2001). Entre seducción e inspiración: el hombre. Buenos Aires: Amorrortu.

Laudan, L. (1977/1986). El progreso y sus problemas: hacia una teoría del crecimiento científico. Madrid: Alianza.

Laudan, L. (1981/1984). “A confutation of convergent realism”, en Leplin, J. (ed.). Scientific Realism. Berkeley: University of California Press. (Publicado previamente en Philososphy of Science, Vol. 48, No. 1, 1981:19-49).

Laudan, L. (1981a). Science and hypothesis. Historical Essays on Scientific Methodology. Dordrecht: Springer. 
Laudan, L. (1981b). "Peirce and the Trivialization of the Self-Corrective Thesis". In: Science and hypothesis. Historical Essays on Scientific Methodology, (pp. 226-252). Dordrecht: Springer.

Laudan, L.; Laudan, R. \& Donovan, A. (1992). Testing Theories of Scientific Change. In: A. Donovan; L. Laudan \& R. Laudan (eds.), Scrutinizing Science: Empirical studies of scientific change (pp. 3-46). Dordrecht: Kluwer Academic Publishers.

Lavin, M. (2011). “On behalf of free association”. In: M. A. Holowchak (ed.). Radical claims in Freudian psychoanalysis: point/counterpoint, (pp. 153-166). New York: Jason Aronson.

Leichsenring, F.; Abbass, A.; Gottdiener, W.; Hilsenroth, M.; Keefe, J. R.; Luyten, P.; Rabung, S. \& Steinert, C. (2016). Psychodynamic therapy: a well-defined concept with increasing evidence. Evidence Based Mental Health, 19(2), 64.

Leichsenring, F.; Luyten, P.; Hilsenroth, M. J.; Abbass, A.; Barber, J. P.; Keefe, J. R.; Leweke, F.; Rabung, S. \& Steinert, C. (2015). Psychodynamic therapy meets evidence-based medicine: a systematic review using updated criteria. The Lancet Psychiatry, 2(7), 648-660.

Lemlij, M. (2013). La investigación en la API: Reflexiones de un ex tesorero. Calibán: Revista Latinoamericana de Psicoanálisis, 11(2), 150-152.

Leuzinger-Bohleber, M. \& Kächele, H. (eds.) (2015). An open door review of outcome and process studies in psychoanalysis. Third Edition. Londres: International Psychoanalytical Association.

Leuzinger-Bohleber, M. (2015). Psychoanalysis as a "science of the unconscious" and its dialogue with the neurosciences and embodied cognitive science: some historical and epistemological remarks. In: Finding the Body in the Mind: Psychoanalysis, Neurosciences, Embodied Cognitive Science in Dialogue. (pp. 1-18) London: Karnac.

Leuzinger-Bohleber, M., \& Bürgin, D. (2003). Pluralism and unity in psycho-analytic research: Some introductory remarks. In M. Leuzinger-Bohleber, A.U. Dreher, \& J. Canestri (eds), Pluralism and Unity? Methods of Research in Psychoanalysis, pp. 1-25. London: International Psychoanalytical Association.

Levy, S. \& Inderbitzin, L. (2000). Suggestion and psychoanalytic technique. Journal of the American Psychoanalytic Association, 48(3), 739-758.

Lewis, D. (1973). Counterfactuals. Oxford: Blackwell.

Lewis, D. (1986). "Causal Explanation". In: D. Lewis, Philosophical Papers II, pp. 214-240. Oxford: Oxford U. P.

Lewis, D. (2000). "Causation as Influence”. Journal of Philosophy, 97, 182-197.

Liberman, D. (1970). Lingüística, interacción comunicativa y proceso psicoanalítico. Buenos Aires: Nueva Visión.

Lichtenberg G.C. (1989). Aforismos. México: Fondo de Cultura Económica. 
Lipton, P. (2004). Inference to the Best Explanation (2nd ed.). London: Routledge.

Loftus, E. (1980). Memory. Reading, Mass: Addison-Wesley.

Lorenzano, C. J. (1988/2012). La estructura del conocimiento científico. Buenos Aires: UNTREF.

Lorenzano, C. J. (1993). "Hipotético-deductivismo". En Moulines, C. U. (ed.). La ciencia. Estructura y desarrollo. Madrid: Trotta. Pp. 31-56.

Lorenzer, A. (1970/1977). El lenguaje destruido y la reconstrucción psicoanalítica. Trabajos preliminares para una metateoría del psicoanálisis. Buenos Aires: Amorrortu.

Losee, J. (1972/1981). Introducción histórica a la filosofía de la ciencia. Madrid: Alianza.

Lothane, Z. (1998). El eterno Freud: el método frente al mito y la malicia de los detractores de Freud. Revista de la Asociación Española de Neuropsiquiatría, 18(66), 269-292.

Luyten, P., Blatt, S. J., \& Corveleyn, J. (2006). Salvando la distancia entre el positivismo y la hermenéutica en la investigación psicoanalítica. Aperturas psicoanalíticas. Revista de psicoanálisis, 24.

Lycan, W. G. (1988). Judgement and Justification. Cambridge: Cambridge University Press.

Mach, E. (1883/1974). The Science of Mechanics. La Salle IL: Open Court.

Mach, E. (1886/1987). El análisis de las sensaciones. Barcelona: Alta Fulla.

MacIntyre, A. (1958/2004). The Unconscious A Conceptual Analysis. New York: Routledge.

MacIntyre, A. (1967/1976). "La idea de una ciencia social". En: A. Ryan (comp.), La filosofía de la explicación social, (pp. 27-53). México: FCE.

Magnani, L. (2001). Abduction, Reason and Science. Processes of Discovery and Explanation. New York: Kluwer Academic / Plenum Publishers.

Makari, G. (1998). The seductions of history: sexual trauma in Freud's theory and historiography. The International Journal of Psycho-Analysis, 79 (5) 857-869.

Maldavsky, D., \& Liberman, D. (2004). La investigación psicoanalítica del lenguaje: algoritmo David Liberman. Buenos Aires: Lugar.

Mannoni, O. (1986/1987). "El psicoanálisis y la ciencia”. En: M. Augé, M. David-Ménard, W. Granoff, J.-L. Lang y O. Mannoni, El objeto en psicoanálisis. El fetiche, el cuerpo, el niño, la ciencia (pp. 155-173). Buenos Aires: Gedisa.

Mantilla, C. (2007). Davidson y la subjetividad: alcances y limitaciones para la comprensión del sujeto psicoanalítico. Revista de Psicoanálisis, 26.

Marcuse, H., Popper, K. R., \& Horkheimer, M. (1971/1989). A la búsqueda del sentido. Salamanca: Sígueme.

Mardones, J. M., \& Ursúa, N. (1982). "Filosofía de las ciencias humanas y sociales. Nota histórica de una polémica incesante". En: Filosofía de las ciencias sociales y humanas (pp. 15-33). Barcelona: Fontamara. 
Marmor, J. (1962). Psychoanalytic therapy as an educational process. In: J. Messerman (Ed.), Psychoanalytic Education Science Series (pp. 286-299). New York: Grune \& Stratton.

Martínez Solano, J. F. (2005). El problema de la verdad en K. R. Popper: reconstrucción histórico-sistemática. España: Netbiblo.

Masling, J.M., \& Bornstein, R.F, (eds.) (1996). Psychoanalytic Perspectives on Developmental Psychology. Washington: American Psychological Association.

Masson, J. M. (1984/1985). El asalto a la verdad. La renuncia de Freud a la teoría de la seducción. Barcelona: Seix Barral

Maxwell, G. (1962) “The Ontological Status of Theoretical Entities”. In: H. Feigl \& G. Maxwell (eds.), Minnesota Studies in the Philosophy of Science, vol. III, (pp. 3-27). Minneapolis: University of Minnesota Press.

Mayer, C. (Ed.). El libro negro del psicoanálisis. Vivir, pensar y sentirse mejor sin Freud. Buenos Aires: Sudamericana.

McDougall, W. (1908/2001). An Introduction to Social Psychology. Kitchener: Batoche Books.

Merton, R. (1949/2002). Teoría y estructura sociales. México: Fondo de Cultura Económica.

Meyer, N. (1975). Elemental, Dr. Freud... Buenos Aires: Emecé.

Miguel, H. (2014). “¿De qué puede estar hecha la relación causal?”. En: H. Miguel (coord.), Causación, explicación y contrafácticos, (pp. 21-40). Buenos Aires: Prometeo.

Mill, J. S. (1843). A System Of Logic, Ratiocinative And Inductive, Being a Connected view of the Principles of evidence, and the Methods of Scientific Investigation. 8th ed. [ebook] New York: Harper \& Brothers. Disponible en: www.gutenberg.org [consultado 3 Abr. 2016].

Mill, J. S. (1873/2010). La lógica de las ciencias morales. Madrid: Consejo Superior de Investigaciones Científicas.

Miller, D. W. (1974). Popper's qualitative theory of verisimilitude. British Journal for the Philosophy of Science, 25 (2), 166-177.

Miller, D. W. (2004). "Falsabilidad - ¿Más que una Convención?”. Conferencia dictada en Congreso Filosófico Internacional: Karl Popper: vigencia y transformación de su pensamiento. Facultad de Humanidades y Artes (UNR). Rosario, Argentina, 3-5 de junio de 2004. Versión electrónica disponible en http://www2.warwick.ac.uk/fac/soc/philosophy/people/associates/miller/falsabilidad1.pd $f$

Miller, D. W. (2006). Out of error: Further essays on critical rationalism. Aldershot: Ashgate Publishing.

Minhot, L. (2003). La mirada psicoanalítica. Un análisis kuhniano del psicoanálisis de Freud. Córdoba: Brujas. 
Minnameier, G. (2004). "Peirce-suit of Truth - Why Inference to the Best Explanation and Abduction Ought not to be Confused". Erkenntnis, 60, 75-105.

Mitchell, S. A. (1993a). Conceptos relacionales en psicoanálisis: una integración. México D. F.: Siglo XXI.

Mitchell, S. A. (1993b). Hope and Dread in Psychoanalysis. Nueva York: Basic Books.

Mitchell, S. A. (1998). The analyst's knowledge and authority. Psychoanalytic Quarterly, 67, 1-31.

Mitchell, S. A. (2000). Relationality: From Attachment to Intersubjectivity. Nueva Jersey: The Analytic Press.

Mondolfo, R. (1980). Figuras e ideas de la filosofía del Renacimiento. Barcelona: ICARIA.

Moreira, D. (2001). Sobre la investigación en psicoanálisis. Subjetividad y procesos cognitivos, 1, 159-180.

Moser, U. (1989/1992). "On-Line and Off-Line, Practice and Research: A Balance". In: M. Leuzinger-Bohleber, H. Schneider, \& R. Pfeifer (eds.), Two Butterflies on My Head... Psychoanalysis in the Interdisciplinary Scientific Dialogue (pp. 181-196). New York: Springer. Originalmente publicado en Psyche - Zeitschrift für Psychoanalyse, 45, 31534.

Moulines, C. U. (2008/2011). El desarrollo moderno de la filosofía de la ciencia (1890-2000). México: UNAM, Instituto de Investigaciones Filosóficas.

Moulines, U. (1995). La filosofía de la ciencia como disciplina hermenéutica. Isegoría, 12, 110-118.

Moya Espí, C. (1985). "Prólogo y traducción”. En: W. Dilthey, Crítica de la razón histórica. Barcelona: Península.

Musgrave, A. (1989). "Deductive Heuristics". In K. Gavroglu; Y. Gondaroulis \& P. Nicolacopoulos (eds.), Imre Lakatos and Theories of Scientific Change (pp. 15-31). Reidel: Dordrecht.

Nagel, E. (1959/1964). Methodological issues in psychoanalytic theory. In: S. Hook (Ed.) Psychoanalysis, Scientific Method, and Philosophy (pp. 38-56). New York: New York University Press.

Nagel, E. (1961/2006). La estructura de la ciencia. Problemas de la lógica de la investigación científica. Buenos Aires: Paidós.

Nasio, J. D. (2001). ¿Qué es un caso?. En J.D. Nasio (ed.), Los más famosos casos de psicosis (pp. 15-37). Buenos Aires: Paidós.

Neurath, O. (1932/1965). "Proposiciones protocolares". En: A. J. Ayer (comp.), El Positivismo Lógico, (pp. 205-214). México: Fondo de Cultura Económica.

Newton-Smith, W. H. (1981/1987). La racionalidad de la ciencia. Buenos Aires: Paidós. 
Nickerson, R. (1998). Confirmation bias: a ubiquitous phenomenon in many guises. Review of General Psychology, 2(2), 175-220.

Niño, D. (2012). Abducción y pragmatismo peirceano versus inferencia a la mejor explicación y empirismo: un comentario crítico. Cuadernos de sistemática peirceana, 4, 71-92.

Nubiola, J. (1998). Walker Percy y Charles S. Peirce: abducción y lenguaje. En: C. S. Peirce y la abducción, Analogía Filosófica XII/1, 3-8. Disponible en: http://www.unav.es/ gep/AN/Nubiola.html

Nubiola, J. (2001). La abducción o lógica de la sorpresa. Razón y palabra, 21. Recuperado de: https://www.razonypalabra.org.mx/anteriores/n21/21_jnubiola.html

Nudler, O. (2004). Hacia un modelo de cambio conceptual: espacios controversiales y refocalización. Revista de Filosofía, 29(2), 7-19.

O’Neil, J. A. (1993). Popper, Grünbaum, and induction. Canadian Journal of Psychoanalysis, 1(2), 105-130.

Okasha, S. (2000). Van Fraassen's Critique of Inference to Best Explanation. Studies in History and Philosophy of Science, 31(4), 691-710.

Onfray, M. (2010/2011). Freud: El crepúsculo de un ídolo. Madrid: Taurus.

Orange, D. (2011/2013). El desconocido que sufre: Hermenéutica para la práctica clínica cotidiana. Santiago: Cuatro Vientos.

Orwell, G. (1948/1980). 1984. Madrid: Salvat.

Paavola, S. (2006) "Hansonian and Harmanian Abduction as Models of Discovery". International Studies in the Philosophy of Science, 20 (1), 93-108.

Paniagua, C. (2009). Técnica en la psicología del yo contemporánea. Revista de Psicoanálisis, 66 (1), 79-95.

Peirce, C. S. (1868/1988). "Algunas consecuencias de cuatro incapacidades". En: Charles S. Peirce. El hombre, un signo (El pragmatismo de Peirce), Trad. de José Vericat (pp. 88122). Barcelona: Crítica.

Peirce, C. S. (1877/1988). "La fijación de la creencia". En: Charles S. Peirce. El hombre, un signo (El pragmatismo de Peirce), Trad. de José Vericat (pp. 175-199). Barcelona: Crítica.

Peirce, C. S. (1878a/1970). "Deducción, inducción e hipótesis". Trad. de Juan Martín RuizWerner. Disponible en: http://www.unav.es/gep/DeduclnducHipotesis.html

Peirce, C. S. (1878b/2001). "El orden de la naturaleza". Trad. de Juan Marrodán. Disponible en: http://www.unav.es/gep/OrderNature.html

Peirce, C. S. (1896/1997). "Lecciones de la historia de la ciencia". Trad. de Fernando C. Vevia. Disponible en: http://www.unav.es/gep/LessonsHistory Science.html\#nota1

Peirce, C. S. (1897/1997). "Falibilismo, continuidad y evolucion". Trad. de Fernando C. Vevia. Disponible en: http://www.unav.es/gep/FalContEvol.html 
Peirce, C. S. (1901/2001). "Sobre la lógica de la extracción de la historia a partir de documentos antiguos, especialmente de testimonios". Trad. de Douglas Niño. Disponible en: http://www.unav.es/gep/Peirce-esp.html

Peirce, C. S. (1903a/1978). "Lección VII: pragmatismo y abducción”. En: Lecciones de Harvard sobre el pragmatismo. Trad. de Dalmacio Negro Pavón. Recuperado de: http://www.unav.es/gep/HarvardLecturesPragmatism/HarvardLecturesPragmatism7.ht $\mathrm{ml}$

Peirce, C. S. (1903b/1978). "Conferencias en Harvard sobre el pragmatismo. El pragmatismo como lógica de la abducción". En: Obra filosófica reunida. Tomo II (1893-1913). México: Fondo de Cultura Económica.

Peirce, C. S. (1903c/2003). "Cómo teorizar (sobre la selección de hipótesis)". Trad. de Sara Barrena. Recuperado de: http://www.unav.es/gep/ComoTeorizar.html

Peirce, C. S. (1903d/1988). "Lección VI: Tres tipos de razonamiento". En: Lecciones de Harvard sobre el pragmatismo. Trad. de José Vericat. Recuperado de: http://www.unav.es/gep/OnThreeTypesReasoning.html\#nota21

Peirce, C. S. (1907/2012). "Adivinar". Trad. de Sara Barrena. Recuperado de: http://www.unav.es/gep/Adivinar.html

Peirce, C. S. (1908/1996). Un argumento olvidado en favor de la realidad de Dios. Cuadernos de Anuario Filosófico, 34, 69-94.

Peirce, C. S. (1994). The Collected Papers of Charles Sanders Peirce, vol. 1-6. C. Hartshorne, \& P. Weiss (Eds.). Cambridge: Harvard University Press.

Peláez Paz, A. (2013). Doctor House y Mr. Holmes: enigma, muerte y verdad en un héroe de la posmodernidad. Área abierta, 34(2), 45-69.

Perelman, Ch. \& Olbrechts-Tyteca, L. (1958/1989). Tratado de la argumentación. La nueva retórica. Madrid: Gredos.

Perrés, J. (1989a). "La problemática de la realidad en la obra de Freud: sus repercusiones teóricas y epistemológicas (aportes para una epistemología freudiana)". En: A. Suarez (comp.), Psicoanálisis y realidad, pp. 111-153. Buenos Aires: Paidós.

Perrés, J. (1989b/2000). Proceso de constitución del método psicoanalítico. Xochimilco: Universidad Autónoma Metropolitana.

Perron, R. (1999). Reflections on psychoanalytic research problems - the French-speaking view. In: An Open door review of outcome studies in psychoanalysis (pp. 3-9). Londres: IPA Report.

Peters, R. S. (1949). Cause, cure and motive. Analysis, 10, 103-109.

Pissinis, G. (2014). "Pragmática de la explicación vs. metafísica de la causación: ¿una tensión inconciliable?". En: A. M. Talak (coord.), Las explicaciones en psicología, (pp. 197-216). Buenos Aires: Prometeo. 
Politzer, G. (1928/1964). Crítica de los fundamentos de la psicología: el psicoanálisis. Buenos Aires: Davalos-Hernandez.

Popper, K. (1961/2008). "La lógica de las ciencias sociales”, en Popper, Adorno, Dahrendorf, Habermas. La lógica de las ciencias sociales (pp. 11-40). Madrid: Colofón.

Popper, K. R. (1976/1985). Búsqueda sin término. Una autobiografía intelectual. Madrid: Tecnos.

Popper, K. R. (1934/1980). La lógica de la investigación científica. Madrid: Técnos.

Popper, K. R. (1945/1991). La sociedad abierta y sus enemigos. Barcelona: Paidós.

Popper, K. R. (1956/2011). Realismo y el objetivo de la ciencia. Post Scriptum a la Lógica de la Investigación Científica. Madrid: Técnos.

Popper, K. R. (1961/1973). La miseria del historicismo. Madrid: Taurus.

Popper, K. R. (1963/1991). Conjeturas y refutaciones. El desarrollo del conocimiento científico. Buenos Aires: Paidós.

Popper, K. R. (1968/1970). Ensayos de filosofía de la ciencia: en torno a la obra de Sir Karl R. Popper (simposio de Burgos). Madrid: Tecnos.

Popper, K. R. (1969/1973). "La lógica de las ciencias sociales". En: T. Adorno, K. Popper, R. Dahrendorf, J. Habermas, H. Albert y H. Pilot, La disputa del positivismo en la sociología alemana, (pp. 101-120). Barcelona: Grijalbo.

Popper, K. R. (1970/1975). La ciencia normal y sus peligros; en Lakatos, I. \& Musgrave, A. (eds.). La crítica y el desarrollo del conocimiento. Madrid: Grijalbo.

Popper, K. R. (1972/1974). Conocimiento objetivo. Un enfoque evolucionista. Madrid: Tecnos.

Popper, K. R. (1974). "Replies to my critics". In: Paul Arthur Schilpp (Ed.), The philosophy of Karl Popper (Vol. 2, pp. 961-1197). LaSalle, IL: Open Court.

Popper, K. R. (1974/1995). “El problema de la demarcación”. En: Miller, D. Popper, Escritos Selectos (pp. 131-142). México: Fondo de Cultura Económica.

Popper, K. R. (1975/1983). "La racionalidad de las revoluciones científicas". Teorema: Revista internacional de filosofía, 13(1), 109-140.

Popper, K. R. (1975/1985). "La racionalidad de las revoluciones científicas". En Hacking, I. (comp.) Revoluciones científicas. México: Fondo de Cultura Económica.

Popper, K. R. (1977/1995). “El yo”, en Miller, D. Popper, Escritos Selectos. México: Fondo de Cultura Económica, pp. 293 - 306.

Popper, K. R. (1982/1985). Realismo y el objetivo de la ciencia. Post Scriptum a La lógica de la investigación científica, Vol. 1. Madrid: Tecnos.

Popper, K. R. (1984). Sociedad abierta, universo abierto. Conversación con Franz Kreuzer. Madrid: Tecnos.

Popper, K. R. (1986). Predicting overt behavior versus predicting hidden states. Behavioral and Brain Sciences, 9(2), 254-255. 
Popper, K. R. (1986). Predicting overt behavior versus predicting hidden states. Behavioral and Brain Sciences, 9(2), 254-255.

Popper, K. R. (1993/1999). El mundo de Parménides. Ensayos sobre la ilustración presocrática. Barcelona: Paidós.

Popper, K. R. (1994/1996). En busca de un mundo mejor. Barcelona: Paidós.

Popper, K. R. (1994/1997). El mito del marco común. Barcelona: Paidós.

Porchia, A. (1974). Voces. Buenos Aires: Hachette.

Potter, E. (2006). Feminism and Philosophy of Science. An Introduction. London and New York: Routledge.

Psillos, S. (2000). "Abduction: Between Conceptual Richness and Computational Complexity". In: P. A. Flach \& A. C. Kakas (Eds.), Abduction and Induction. Essays on their Relation and Integration (pp. 59-74). Dordrecht: Kluwer Academic Publishers.

Pulice, G., Manson, F. y Zelis, O. (2000). Investigación y Psicoanálisis. Buenos Aires: Letra Viva.

Putnam, H. (1962) "What theories are not". In: E. Nagel, P. Suppes \& A. Tarski (eds.), Logic, Methodology and Philosophy of Science: Proccedings of the 1960 International Congress (pp. 240-252). Stanford: Stanford University Press.

Quine, W. V. O. (1953/2002). Desde un punto de vista lógico. Barcelona: Paidós.

Quine, W. V. O. (1975/2001). "Sobre los sistemas del mundo empíricamente equivalentes". En: Acerca del conocimiento científico y otros dogmas (55-74). Barcelona: Paidós.

Rapaport, D. (1960/1967). La estructura de la teoría psicoanalítica: un intento de sistematización. Buenos Aires: Paidós.

Reichenbach, H. (1938/1957). Experience and prediction: An analysis of the foundations and the 9structure of knowledge. Chicago: University of Chicago Press.

Reik, T. (1948). Listening with the third ear. The inner experience of a psychoanalyst. England: Farrar, Straus \& Co.

Reik, T. (1949/1965). Confesiones de un psicoanalista. Buenos Aires: Hormé.

Rescher, N. (1978). Peirce's Philosophy of Science. Notre Dame: University of Notre Dame Press.

Rickert, H. (1899/1943). Ciencia cultural y ciencia natural. Buenos Aires: Espasa-Calpe.

Ryle, G. (1949/2005). El concepto de lo mental. Buenos Aires: Paidós.

Ricœur P (1977/2009). "La cuestión de la prueba en psicoanálisis". En: Escritos y conferencias alrededor del psicoanálisis, (pp.17-55). Buenos Aires: Siglo XXI.

Ricœur, P. (1965/2007). Freud: una interpretación de la cultura. Buenos Aires: Siglo XXI.

Ricœur, P. (1969/2006). El conflicto de las interpretaciones. Ensayos de hermenéutica. Buenos Aires: Fondo de Cultura Económica. 
Ricœur, P. (1976/2006). Teoría de la interpretación. Discurso y excedente de sentido. México: Siglo XXI.

Ricœur, P. (1981). Hermeneutics and the human sciences: Essays on language, action and interpretation. Cambridge: Cambridge University Press.

Ricœur, P. (1985/2004). Tiempo y narración I. Configuración del tiempo en el relato histórico. Buenos Aires: Siglo XXI.

Ricœur, P. (1986a/2002). "La tarea de la hermenéutica: desde Schleiermacher y desde Dilthey". En: Del texto a la acción. Ensayos de hermenéutica II, (pp. 71-94). México: Fondo de Cultura Económica.

Ricœur, P. (1986b/2002). "Explicar y comprender". En: Del texto a la acción. Ensayos de hermenéutica II, (pp. 149-163). México: Fondo de Cultura Económica.

Rivadulla, A. (1991). Probabilidad e inferencia científica. Barcelona: Anthropos.

Rivadulla, A. (1993). "Inducción y verosimilitud". En Moulines, C. U. (ed.) (1993).

Robinson, P. (1993). Freud and His Critics. Berkeley: University of California Press.

Rodríguez Sutil, C. \& García de la Hoz, A. (2001). Desarrollos sobre formación y práctica del psicoterapeuta psicoanalítico. Intersubjetivo, 1(3), 67-76.

Roque, G. (2007). “'Sensación' alrededor de 1880: una nueva representación de la percepción visual en el arte y la ciencia”. En Suárez Díaz, E. (comp.). Variedad infinita. Ciencia y representación. Un enfoque histórico y filosófico. pp. 131-152. México: Limusa.

Rosenthal, R. \& Rosnow, R. L. (2009). Artifacts in Behavioral Research: Robert Rosenthal and Ralph L. Rosnow's Classic Books. Oxford: Oxford University Press.

Rosenthal, R. (1966). Experimenter effects in behavior research. Nueva York: AppletonCentury-Crofts.

Rosenthal, R. (1967). Covert communication in the psychological experiment. Psychological Bulletin, 67, 356-367.

Rosenthal, R. (1969). Interpersonal expectations: Effects of the Experimenter's Hypothesis. In: R. Rosenthal y R. L. Rosnow (Eds.), Artifacts in behavioral research. Nueva York: Academic Press.

Rosenthal, R. (2000). “Expectancy effects”. In: A.E. Kazdin (Ed.). Encyclopedia of Psychology (pp. 294-6). Washington, D.C.: American Psychological Association.

Roudinesco, É. (1999/2000). ¿Por qué el psicoanálisis? Buenos Aires: Paidós.

Roussos, A., Etchebarne, I., \& Waizmann, V. (2009). La interpretación psicoanalítica y su relación en el estilo lingüístico del paciente: Un estudio de caso único. Anuario de investigaciones, 15, 95-102.

Rubistein, A. (2007) ¿Cómo se investiga hoy en psicoanálisis? En: Memorias de las XIV Jornadas de Investigación y Tercer Encuentro de Investigadores en Psicología del 
MERCOSUR: Vol. III (pp. 244-246) Buenos Aires: Facultad de Psicología de la Universidad de Buenos Aires.

Rubistein, A. y Trotta, L. (2004). La eficacia del psicoanálisis: importancia y estado actual del tema. En: Memorias de las XI Jornadas de Investigación. Buenos Aires: Facultad de Psicología de la Universidad de Buenos Aires.

Rycroft, C. (1966). "Causes and Meanings". In: C. Rycroft (comp), Psychoanalysis Observed (pp. 7-22). London: Constable.

Sachs, D. (1993/1996). "En justicia a Freud: una reseña crítica de The Foundations of Psychoanalysis, de Adolf Grünbaum”. En, J. Neu. (comp.), Guía de Freud, (pp. 370406). Cambridge: Cambridge University Press.

Safran, J. D. (2001). When worlds collide: Psychoanalysis and the empirically supported treatment movement. Psychoanalytic dialogues, 11(4), 659-681

Safran, J. D. (2010). Discussion by Jeremy D. Safran. Panel discussion on "Clinical and Empirical Issues: Disagreements and Agreements". Paper presented at the Annual Meeting of the Rapaport-Klein Study Group, Austen Riggs Center.

Safran, J. D. (2012). Doublethinking or dialectical thinking: A critical appreciation of Hoffman's "Doublethinking" critique. Psychoanalytic Dialogues, 22(6), 710-720.

Salmon, W. (1971). Statistical Explanation and Statistical Relevance. Pittsburgh: University of Pittsburgh Press.

Salmon, W. (1984). Scientific explanation and the causal structure of the world. Princeton: Princeton University Press.

Samaja, J. (1993/2008). Epistemología y metodología de la investigación. Buenos Aires: Eudeba.

Samaja, J. (2002). “Aspectos lógico-epistemológicos”. En: H. D. Dei (ed.), Pensar y hacer en investigación. Tomo I. Buenos Aires: Docencia.

Sandler, J.; Sandler, A.-M. \& Davies, R. (Eds.) (2000). Clinical and Observational Psychoanalytic Research: Roots of a Controversy (Vol. 5). London: Karnac.

Sarnoff, I. (1971). Testing Freudian concepts: An experimental social approach. New York: Springer.

Sauvagnat, F. (1998). G. Morelli: de l'indice au désir de l'artiste. La Cause Freudienne, Revista de l'École de la cause freudienne, 39, 46-48.

Schafer, R. (1976). A New Language for Psychoanalysis. New Haven: Yale University Press.

Schafer, R. (1976). A New Language for Psychoanalysis. New Haven: Yale University Press.

Schimek, J. (1987). Fact and Fantasy in the Seduction Theory: A Historical Review. Journal of the American Psychoanalytic Association, 35, 4, 937-965

Schleiermacher, F. (1813/2000). Sobre los diferentes métodos de traducir. Madrid: Gredos. 
Schröter, M., \& Hermanns, L. M. (1992). Felix Gattel (1870-1904): Freud's first pupil. I. International Review of Psycho-analysis, 19(1), 91-104.

Schurz, G. (2008). Patterns of abduction. Synthese, 164, 201-234.

Schuster, F. L. (2002). "Del naturalismo al escenario postempirista"; en Schuster, F. L. (comp.) Filosofía y métodos de las ciencias sociales. Buenos Aires: Manantial.

Schütz, A. (1952/1974). "Formación de conceptos y teorías en ciencias sociales". En: El problema de la realidad social. Buenos Aires: Amorrortu.

Sellars, W. (1956/1967). "Empirismo y filosofía de la mente". En: H. Feigl \& M. Scriven (eds.), Los fundamentos de la ciencia y los conceptos de la psicología y del psicoanálisis, (pp. 285-364). Santiago: Editorial Universitaria.

Shapiro, T. \& Emde, R. (1995). Research in Psychoanalysis: process, development, outcome. Madison, CT: International Universities Press.

Shedler, J. (2002). A new language for psychoanalytic diagnosis. Journal of American Psychoanalytic Association, 50 (2), 429-456.

Shedler, J. (2002). A new language for psychoanalytic diagnosis. Journal of the American Psychoanalytic Association, 50: 429-456.

Sherwood, M. (1969). The logic of explanation in psychoanalysis. New York and London: Academic Press.

Shevrin, H., \& Fritzler, D. E. (1968). Visual evoked response correlates of unconscious mental processes. Science, 161(3838), 295-298.

Shevrin, H.; Bond J.; Brakel, L. A. W.; Hertel, R.; \& Williams, W. (1996). Conscious and Unconscious Processes: Psychodynamic, Cognitive, and Neurophysiologic Convergences. New York: Guilford Press.

Shevrin, H.; Bond, J.; Hertel, R.; Marshall, R.; Williams, W.; \& Brakel, L. A. W. (1992). Event-related potential indicators of the dynamic unconscious. Consciousness and Cognition, 1: 340-366.

Shevrin, H.; Snodgrass, M.; Brakel, L. A.; Kushwaha, R.; Kalaida, N. L.; \& Bazan, A. (2013). Subliminal unconscious conflict alpha power inhibits supraliminal conscious symptom experience. Frontiers in Human Neuroscience, 7, 544.

Skinner, B. F. (1956/1967). Crítica de los conceptos y teorías psicoanalíticos. En: H. Feigl \& M. Scriven, Los fundamentos de la ciencia y los conceptos de la psicología y del psicoanálisis, pp. 94-104. Santiago: Editorial Universitaria.

Sneed, J. (1971). The Lexical Structure of Mathematical Physics. Dordrecht: Reidel.

Soler, C. (1988/2007). Finales de análisis. Buenos Aires: Manantial.

Solms, M. (2001). The interpretation of dreams and the neurosciences. Psychoanalysis and History, 3, 79-91.

Solms, M. (2013). The Conscious Id. Neuropsychoanalysis, 15, 5-19. 
Solms, M., \& Turnbull, O. H. (2011). What is neuropsychoanalysis?. Neuropsychoanalysis, 13(2), 133-145.

Spence, D. P. (1984). Narrative truth and historical truth: Meaning and interpretation in psychoanalysis. New York: WW Norton \& Company.

Starobinski, J. (1971/1996). Las palabras bajo las palabras. La teoría de los anagramas de Ferdinand de Saussure. Barcelona: Gedisa.

Steiner, R. (2000). Introduction. In Sandler, J., Sandler, A-M., Davies, R. (eds.). Clinical and observational psychoanalytic research: Roots of a controversy. André Green \& Daniel Stern (pp. 1-17). London: Karnac.

Stern, D. N. (2000). The relevance of empirical infant research to psychoanalytic theory and practice. In: Sandler, J., Sandler, A-M., Davies, R. (eds.). Clinical and observational psychoanalytic research: Roots of a controversy. André Green \& Daniel Stern (73-90). London: Karnac.

Storolow, R. \& Atwood G. (2004). Los contextos del ser. Las bases intersubjetivas de la vida psíquica. Barcelona: Herder.

Strenger, C. (1991). Between hermeneutics and science: An essay on the epistemology of psychoanalysis. Madison: International Universities Press.

Strenger, C. (2013). Why Psychoanalysis Must not Discard Science and Human Nature. Psychoanalytic Dialogues, 23, 197-210.

Sulloway, F. J. (1979/1992). Freud, Biologist of the Mind: Beyond the Psychoanalytic Legend. Harvard: Harvard University Press.

Suppe, F. (1972). What's wrong with the Received-View on the Structure of Scientific Theories? Philosophy of Science, 39, 1-19.

Suppe, F. (1979). La estructura de las teorías científicas. Madrid: Editora Nacional.

Swales, P. J. (1982). Freud, Minna Bernays, and the Conquest of Rome. The New American Review, 1, 1-23.

Thagard, P. (1978). The Best Explanation: Criteria for Theory Choice. The Journal of Philosophy, 75 (2), 76-92.

Thagard, P. (1981). "The Autonomy of a Logic of Discovery". In: L. W. Sumner et al. (Eds.). Pragmatism and Purpose: Essays in Honor to Thomas A. Goudge (pp. 248-260). Toronto: Toronto University Press.

Thagard, P. (1988). Computational Philosophy of Science. London: The MIT Press.

Thomä, H. y Kächele, H. (1999/2000). Memorándum sobre la reforma de la formación psicoanalítica. Intersubjetivo, 2(1), 101-114. Originalmente publicado en: IPA Newsletters, 8, 33-35.

Thomä. H.; Kächele, H. (2002/2003). Teoría y práctica del psicoanálisis. 3 Investigación. Barcelona: Herder. 
Thomä. H.; Kächele. H. (1985/1989). Teoría y práctica del psicoanálisis. 1 fundamentos. Barcelona: Herder.

Thomä. H.; Kächele. H. (1988/1990). Teoría y práctica del psicoanálisis. 2 Estudios clínicos. Barcelona: Herder.

Thompson, S. (2011). La sugestión analítica. Construcción de un concepto freudiano. Buenos Aires: Letra Viva.

Tichý, P. (1974). On Popper's definitions of verisimilitude. British Journal for the Philosophy of Science, 25 (2), 155-160.

Tim, J. (2011/2013). En busca de las fuentes del Nilo. Barcelona: Crítica.

Timpanaro, S. (1974/1977). El lapsus freudiano. Psicoanálisis y crítica textual. Barcelona: Crítica.

Tizón, J. L. (1995). ¿Existen las ciencias interpretativas?: una reflexión acerca de los límites epistemológicos del conocimiento psicoanalítico. Anuario de Psicología, 67, 51-74.

Toulmin, S. (1949). The logical status of psychoanalysis. Analysis, 9, 23-29.

Toulmin, S. (1961). Foresight and understanding: An enquiry into the aims of science. Bloomington: Indiana University Press.

Triplett, H. (2004). The Misnomer of Freud's "Seduction Theory". Journal of the History of Ideas, 65 (4), 647-655.

Tubert-Oklander, J. \& Beuchot Puente, M. (2008). Ciencia mestiza: Psicoanálisis y hermenéutica analógica. Mexico D. F.: Torres.

Tubert-Oklander, J. (2013). "Hermes en el diván. El encuentro del psicoanálisis y la hermenéutica analógica”. En: J. R. Coca (ed.), Impacto de la hermenéutica analógica en las ciencias humanas y sociales, (pp. 283-298). España: Hergué.

Umérez, O. (2007). Metodología psicoanalítica. Buenos Aires: JCE.

Ungar, V. (2015). El oficio del analista y su caja de herramientas: la interpretación revisitada. International Journal of Psycho-Analysis en Espanol, 1(3), 663-682.

Vallejo, M. (2008). Los miércoles por la noche, alrededor de Freud. La construcción del discurso psicoanalítico a la luz de las Actas de la Sociedad Psicoanalítica de Viena. Buenos Aires: Letra Viva.

Vallejo, M. (2012). La seducción freudiana (1895-1897). Un ensayo de genética textual. Buenos Aires: Letra Viva.

Van Fraassen, B. C. (1980/1996). La imagen científica. México: Paidós.

Van Rillaer, J. (1980/1985). Las ilusiones del psicoanálisis. Barcelona: Ariel.

Vassalli, G. (2001). The birth of psychoanalysis from the spirit of technique. The International Journal of Psychoanalysis, 82(1), 3-25.

Velasco Gómez, A. (1995). La hermeneutización de la filosofía de la ciencia contemporánea. Diánoia, 41, 53-64. 
Velasco Gómez, A. (2000). Tradiciones naturalistas y hermenéuticas en la filosofía de las ciencias sociales. México: Universidad Nacional Autónoma de México.

Velasco, M. (1998). "La inducción en Peirce". En: H. Faas y L. Salvático (eds.), Epistemología e Historia de la Ciencia. COMPLETAR VIII Jornadas de Epistemología e Historia de la Ciencia, Facultad de Filosofía y Humanidades, Universidad Nacional de Córdoba.

Velasco, M. (2002). "La abducción: sus aspectos lógicos y metodológicos". En: P. Lorenzano y F. Tula Molina (comp.), Filosofía e Historia de la Ciencia en el Cono Sur, (pp. 115123). Buenos Aires: Universidad Nacional de Quilmes.

Vezzetti, H. (1998) Las psicologías del fin de siglo a la luz de su historia. Revista de Psicología General y Aplicada, 51(1), 105-114.

Viguera, A. (2006). Originalidad, imaginación y criptomnesia en Freud. En J. Ahumada; M. Pantalone, y V. Rodríguez (eds), Epistemología e historia de la ciencia. Selección de trabajos de las XVI jornadas, 12, 570-577. Córdoba: Centro de Investigaciones en Filosofía e Historia de la Ciencia de la Universidad Nacional de Córdoba.

Viguera, A. (2010). La representación y la génesis de hipótesis: una lectura psicoanalítica. Revista de Psicología - Segunda Época, 11, 27-45.

Viguera, A. (2012). Tres tesis acerca del inconciente en el Coloquio de Bonneval de 1960: Lacan, Laplanche, Politzer. Revista de Psicología - Segunda Época, 12, 41-53.

Von Wright, G. (1971/1979). Explicación y comprensión. Madrid: Alianza.

Waelder, R. (1962). Psychoanalysis, scientific method, and philosophy. Journal of the American Psychoanalytic Association, 10(3), 617-637.

Wallerstein, R. S. \& Sampson, H. (1971). Issues in research in the psychoanalytic process. International Journal of Psychoanalysis, 52, 11-50.

Wallerstein, R. S. (1986). Forty-two lives in treatment: A study of psychoanalysis and psychotherapy. New York: Guilford.

Wallerstein, R. S. (1986/1987). El psicoanálisis como ciencia: una respuesta a las nuevas críticas. Revista de Psicoanálisis, 44 (1), 9-40.

Wallerstein, R. S. (1993). Investigación psicoanalítica. Informativo de la API, Psicoanálisis Internacional, verano de 1993.

Wallerstein, R. S. (2000). "Psychoanalytic research: Where do we disagree?" In: J. Sandler, A. M. Sandler, \& R. Davies (eds.), Clinical and Observational Research: Roots of a Controversy (pp. 27-31). London: Karnac,

Wallerstein, R. S. (2001). The generations of psychotherapy research: An overview. Psychoanalytic Psychology, 18(2), 243-267.

Wallerstein, R. S. (2005/2006a). ¿Será el pluralismo psicoanalítico un estado duradero de nuestra disciplina? Psicoanálisis, 28 (3), 649-655. (Original publicado en: International Journal of Psychoanalysis, 86, 623-626) 
Wallerstein, R. S. (2005/2006b). ¿Diálogo o ilusión? ¿Y cómo seguimos a partir de aquí? Respuesta a André Green. Psicoanálisis, 28 (3), 667-675. (Original publicado en: International Journal of Psychoanalysis, 86, 633-638).

Wallerstein, R. S. (2006). Psychoanalytic therapy research: Its history, its present status, and its projected future. PDM Task Force. Psychodynamic diagnostic manual. Silver Spring, MD: Alliance of Psychoanalytic Organizations, 511-535.

Walton, D. N. (1994). Begging the question as a pragmatic fallacy. Synthese, 100(1), 95-131.

Walton, D. N. (2004). Abductive Reasoning. Alabama: The University of Alabama Press.

Wason, P. C. (1966). "Reasoning". In: B., Foss. New horizons in psychology. Middlesex: Penguin.

Westen, D. (1998). The scientific legacy of Sigmund Freud: Toward a psycho-dynamically informed psychological science. Psychological Bulletin, 124, 333-371.

Westen, D. (1999). The scientific status of unconscious processes: is Freud really dead? Journal of the American Psychoanalytic Association, 47(4), 1061-1106.

Westen, D. (2002). El lenguaje del discurso psicoanalítico. Aperturas psicoanalíticas: Revista de psicoanálisis, 14.

Whewell, W. (1840/1967). Aphorisms concerning science. In: The Philosophy of the Inductive Sciences: Founded Upon Their History, Volumen 2. London: Cambridge.

Winch, P. (1958/1990). Ciencia social y filosofía. Buenos Aires: Amorrortu.

Wind, E. (1963/1986). Arte y anarquía. Madrid: Taurus.

Wisdom, J. (1967/1969). Puesta a prueba de una interpretación en el curso de una sesión. Revista de psicoanálisis, 26 (2), 403-423.

Wittgenstein, L. (1966/1992). Lecciones y conversaciones sobre estética, psicología y creencia religiosa. Barcelona: Paidós.

Wolff, P. H. (1996). The irrelevance of infant observations for psycho-analysis. Journal of the American Psychoanalytic Association, 44, 369-392.

Woodward, J. (2003). Making things happen: a theory of causal explanation. Oxford: Oxford University Press.

Worrall, J. (1978). "The Ways in Which the Methodology of Scientific Research Programmes Improves Upon Popper's Methodology". In: G. Radnitzky \& G. Andersson (eds.), Progress and Rationality in Science (pp. 45-70). Dordrecht: Reidel.

Wurmser, L. (1989). "Either-or": Some comments on professor Grünbaum's critique of psychoanalysis. Psychoanalytic Inquiry, 9(2), 220-248.

Ynoub, R. (2015). Cuestión de método. Aportes para una metodología crítica. Tomo I. México: Cengage Learning. 
Yovell, Y., Solms, M., \& Fotopoulou, A. (2015). Argumento a favor del neuropsicoanálisis: por qué el diálogo con la neurociencia es necesario pero no suficiente para el psicoanálisis. International Journal of Psycho-Analysis en Espanol, 1, 1782-1833.

Zamora Bonilla, J. P. (1996). Mentiras a medias. Unas investigaciones sobre el programa de la verosimilitud. Madrid: Universidad Autónoma de Madrid.

Zanotti, G. (2003). Hacia una hermenéutica realista. Buenos Aires: Austral.

Zanotti, G. (2010). El contexto de descubrimiento en Peirce: un adelantado a su tiempo. En IV Jornadas GEP "Peirce en Argentina”, Argentina, 26-27 agosto de 2010. Disponible en: http://www.unav.es/gep/IVPeirceArgentinaZanotti.html

Zukerfeld, R. (2001). Alianza terapéutica y encuadre analítico. VERTEX Revista Argentina de Psiquiatría, 12, 211-20. 